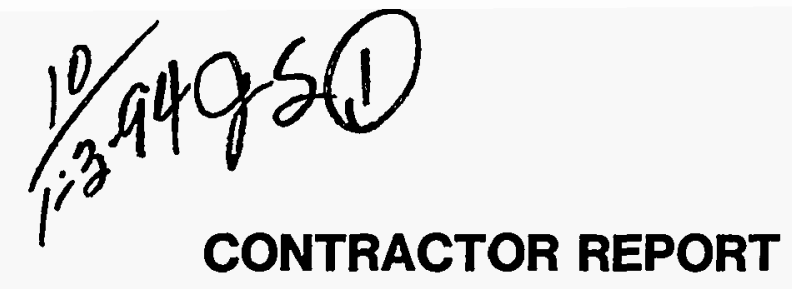

SAND93-7098

Unlimited Release

$\mathrm{UC}-237$

\title{
Performance of the Southern California Edison Company Stirling Dish
}

Charles W. Lopez, Kenneth W. Stone,

Mako Enterprises

Southern California Edison Company

PO Box 800

Rosemead, California 91770

Prepared by Sandia National Laboratories Albuquerque, New Mexico 87185 and Livermore, California 94550 for the United States Department of Energy under Contract DE-AC04-94AL85000

Printed October 1993 
Issued by Sandia National Laboratories, operated for the United States Department of Energy by Sandia Corporation.

NOTICE: This report was prepared as an account of work sponsored by an agency of the United States Government. Neither the United States Government nor any agency thereof, nor any of their employees, nor any of their contractors, subcontractors, or their employees, makes any warranty, express or implied, or assumes any legal liability or responsibility for the accuracy, completeness, or usefulness of any information, apparatus, product, or process disclosed, or represents that its use would not infringe privately owned rights. Reference herein to any specific commercial product, process, or service by trade name, trademark, manufacturer, or otherwise, does not necessarily constitute or imply its endorsement, recommendation, or favoring by the United States Government, any agency thereof or any of their contractors or subcontractors. The views and opinions expressed herein do not necessarily state or reflect those of the United States Government, any agency thereof or any of their contractors.

Printed in the United States of America. This report has been reproduced directly from the best available copy.

Available to DOE and DOE contractors from Office of Scientific and Technical Information

PO Box 62

Oak Ridge, TN 37831

Prices available from (615) 576-8401, FTS 626-8401

Available to the public from

National Technical Information Service

US Department of Commerce

5285 Port Royal Rd

Springfield, VA 22161

NTIS price codes

Printed copy: A06

Microfiche copy: A01 


\section{DISCLAIMER}

Portions of this document may be illegible electronic image products. Images are produced from the best available original document. 
Distribution

Category UC-237

SAND93-7098

Unlimited Release

Printed October 1993

\title{
PERFORMANCE OF THE SOUTHERN CALIFORNIA EDISON COMPANY STIRLING DISH
}

\author{
Charles W. Lopez \\ Southern California Edison Company \\ Kenneth W. Stone \\ Mako Enterprises
}

\begin{abstract}
McDonnell Douglas and United Stirling AB of Sweden (USAB) formed a joint venture in 1982 to develop and produce a Stirling dish solar generating system. In this report, the six year development and testing program continued by the Southern California Edison Company are described. Test data is presented and used to estimate the performance of a commercial system.
\end{abstract}




\section{Foreword}

The Stirling dish solar electric power system owned by the Southern California Edison Company (SCE) underwent an extensive test program during a joint venture program initiated by McDonnell Douglas Astronautics Company (MDAC) and United Stirling $A B$ of Sweden (USAB), in 1982 and completed by the SCE in September 1988. Each Stirling dish module consists of a sun tracking dish concentrator developed by the MDAC and a Stirling engine driven power conversion unit (PCU) developed by the USAB. The Stirling dish system demonstrated twice the peak and daily solar-to-electric conversion efficiency of any other system then under development. This system continues to set the performance standard for solar to electric systems being developed in the early 1990's.

USAB designed the only available commercial Stirling engines in the late 1970's and early 1980's. These are the fossil-fuel-fired 4-295 engines used in submarine service, the V-160 engines licensed to Stirling Power Systems for auxiliary power units, and the 4-95 engines licensed to Mechanical Technologies, Inc., for automotive application and to MDAC and subsequently to Southern California Edison for solar or solar hybrid application. USAB supplied the 4-95 engine for three successful Stirling dish test programs: Jet Propulsion Laboratory for test at Edwards Air Force Base, California, Advanco for test at Rancho Mirage, California, and the joint venture program initiated by MDAC and USAB and completed by SCE. The Jet Propulsion Laboratory and Advanco programs were sponsored by the U.S. government.

The Stirling dish joint venture program initiated by USAB and MDAC was intended to commercialize the technology during a period of high fuel prices $(\$ 47 / \mathrm{barrel}$ of oil). The Stirling engine and the dish were designed for mass production while maintaining system performance. The MDAC/USAB/SCE program demonstration that the system with comparatively minor revisions would have been cost competitive at the prevailing fuel price level. However, due to the sharp drop in fuel prices and lack of evidence that the fuel prices would return to their previous level in the near term, USAB, MDAC and then SCE discontinued their participation in this Stirling dish commercialization effort. This report summarizes the MDAC/USAB/SCE test program and test results. The authors conclude that Stirling dish system development should continue. 1985 
production cost estimates for the first 1000 units indicated the units could be installed at less than $\$ 2000 / \mathrm{kW}$, thus producing electrical energy at a cost of less than $\$ 0.10 / \mathrm{kWhr}$. Current estimates indicate that the units could be installed at a cost of $\$ 1500$ to $\$ 2000 / \mathrm{kW}$ at production rates as low as 10,000 units per year. The Stirling dish system did not encounter any technical barriers that would prevent commercialization of the technology. The absence of technical barriers and the system modularity will reduce the development expenditures required to refine the technology for commercial application.

This report was sponsored by SCE and the original draft was completed in 1988. The report was originally prepared to respond to the many inquiries received by SCE regarding the successful test program. The report was edited in the subsequent four years and the intermediate revisions were disseminated in response to continuing requests for information on MDAC/USAB/SCE demonstration program. This final edition was prepared at the request of Sandia National Laboratories and its contents are intended to supersede all previous report drafts. 


\section{CONTENTS}

Section No. I. Title

Page No.

INTRODUCTION $1-1$

Background of Stirling Engine Development $1-4$ SCE/MDAC/USAB Stirling Dish Program

II.

DESCRIPTION OF STIRLING DISH SYSTEM 2-1

Solar Concentrator 2-2

Power Conversion Unit 2-13

Data Acquisition System $2-22$

III.

POWER PERFORMANCE $3-1$

Power Output Performance 3-1

Power Efficiency 3-4

Peak Power Efficiency 3-5

Available Insolation 3-6

Reflectivity 3-6

Intercept 3-9

Receiver Conduction and Reflectivity Losses 3-10

Receiver Temperature Difference 3-10

Power Conversion Unit Engine 3-11

Generator 3-11

Parasitic Power

IV. ENERGY PERFORMANCE 4-1

Daily Energy Performance 4-2

Energy Component Performance 4-5

Available Insolation 4-7

Reflectivity 4-7

Intercept 4-7

Receiver 4-7

Power Conversion Unit Engine 4-7 Generator 4-8

Parasitic $4-8$ 


\section{CONTENTS (continued - 2)}

Section No. Title

Page No.

V.

POWER AND ENERGY COMPARISON WITH $5-1$ OTHER SOLAR SYSTEMS

Solar One $5-1$

The Vanguard Unit 5-3

Intersol Photovoltaic Concentrator . 5-5

Solar Electric Generation System (SEGS) 5-9

VI.

SYSTEM AVAILABILITY 6-1

Availability of SCE Unit at the Solar One Test Site $6-8$

Expected Barstow System Availability 6-11

Availability of Georgia Unit 6-12

Availability of MDAC Units $6-13$

Estimate of Availability of Commercial Unit 6-15

VII. OPERATION OF THE STIRLING DISH $7-1$

Concentrator $7-1$

Power Conversion Unit 7-7

VIII. SYSTEM PERFORMANCE OF THE STIRLING DISH 8-1

IX LESSONS LEARNED AND RECOMMENDATIONS FOR A 9-1 CONTINUING TEST PROGRAM

CONCLUSION $10-1$

REFERENCES

APPENDIXES 


\section{LIST OF FIGURES}

Figure No. Title Page No.

Figure 1-1. Stirling Dish Operating at the SCE Test Site with Solar $1-2$ Onein the Background

Figure 1-2. Development of the USAB 4-95 Mark I and Mark II Stirling .... 1-5 Engine

Figure I-3. MDAC/USAB Test Program ……............................................... 1-5

Figure 1-4. First Stirling Dish Operated in November $1984 \ldots \ldots \ldots \ldots \ldots . . . . . . . . . .1-8$

Figure 1-5. View of the MDAC Solar Test Facility .......................................... 1-8

Figure II-1. Stirling Dish Principal of Operation ........................................... 2-1

Figure II-2. Stirling Dish Main Components ............................................. 2-2

Figure II-3. Aim Points on the Receiver of Concentrator Individual ............ 2-3 Mirror Modules

Figure II-4. Receiver Flux Measured with the DIR System ............................ 2-3

Figure II-5. Stirling Dish Subassemblies ..................................................... 2-4

Figure II-6. Assembly of the Reflector and PCU Support Structure ........... 2-5

Figure II-7. Field Assembly of the Concentrator ............................................ 2-7

Figure II-8. Stirling Dish Control System Configuration ................................ 2-9

Figure II-9. Comparison of Track Accuracy Without and With Track .......... 2-12 Alignment Parameters

Figure II-10. Stirling Engine Thermal Cycle ...................................................... 2-13

Figure II-11. Description of USAB 4-95 Stirling Engine Operation .............. 2-14

Figure II-12. Main Component of the Mark II Stirling ........................................ 2-15

Figure II-13. Side View of the USAB Mark II Power Conversion Unit .......... 2-16

Figure II-14. Startup Sequence ................................................................. 2-16

Figure II-15. Cold Startup Current Transient .................................................. 2-17 


\section{LIST OF FIGURES (continued - 2)}

Figure No. Title

Page No.

Figure II-16. Maximum Working Gas Temperature Differential 2-18

Figure II-17. Working Gas Temperature Differences $2-18$

Figure II-18. Test Site Data Acquisition System $2-23$

Figure III-1. Typical Power Performance of the System as a Function 3-2 Time

Figure III-2. Power Performance as a Function of the Sun Irradiance 3-2 Level

Figure III-3. Typical Response of the Stirling Dish System on a Cloudy .... 3-3 Day

Figure III-4. Peak Net Power and Efficiency Performance 3-5

Figure III-5. Peak Power and Peak Power Efficiency at the SCE Test Site 3-6

Figure III-6. System and Subsystem Peak Power Efficiency 3-6

Figure III-7. Mirror Reflectivity History for MDAC Test Site .......................... 3-8

Figure III-8. Variation in Soiling Rate at the MDAC Test Site ....................... 3-9

Figure III-9. Average Soiling Rate at the MDAC Solar Test Site ................. 3-9

Figure III-10. Sensitivity of Receiver Spillage to Intercept Losses ................ 3-10

Figure III-11. Engine Efficiency as Function of Gas Temperature ................. 3-11 Difference

Figure III-12. Generator Efficiency …......................................................... 3-12

Figure III-13. Energy Consumed for Different Operating Modes .................... 3-13

Figure IV-1. Total Net Energy Generated for the Three Test Sites .............. 4-1

Figure IV-2. Energy Performance Test Data From MDAC Test Site, Pad 2 4-2

Figure IV-3. Energy Performance Test Data From the Georgia Test Site ... 4-3 


\section{LIST OF FIGURES (continued - 3)}

Figure No. Title

Page No.

Figure IV-4. Energy Performance Test Data From the SCE Test Site ......... 4-3

Figure IV-5. Daily Net Energy at the SCE Test Site from June 88 to 4-5 Sept 88

Figure IV-6. Daily Energy Waterfall 4-6

Figure IV-7. Stirling Engine Efficiency over the Day ....................................... 4-7

Figure V-1. Power Comparison of Stirling Dish with Solar One, ............... 5-2 Intersol PV and SEGS Trough

Figure V-2. Daily Energy Performance of Stirling Dish Compared with .... 5-3 Solar One, Intersol PV, SEGS 3 and Vanguard Program

Figure V-3. Daily Energy Performance of Solar One ................................... 5-5

Figure V-4. Daily Energy of the Vanguard Stirling Dish .............................. 5-7

Figure V-5. Intersol PV Concentrator Key Components ............................... 5-8

Figure V-6. Intersol PV Module Design ........................................................... 5-8

Figure V-7. Daily Energy Performance of Intersol PV System ..................... 5-9

Figure V-8. Daily Energy Performance of SEGS .......................................... 5-10

Figure V-9. Modified Daily Energy Performance for the SEGS Plant ........ 5-11

Figure V-10 Typical Efficiency Chain for SEGS III-V ........................................ 5-12

Figure VI-1. System Availability is the Ratio of Track Time to Time ............. 6-4 of Operating Day

Figure VI-2. The Number of Days of Continued Operation at the SCE ...... 6-10 Test Site

Figure VII-1 Stamped Facet has Maintained Performance for Over Eight.. 7-6 Years

Figure VIII-1. Stirling Dish Annual Performance Simulation 


\section{LIST OF FIGURES (continued - 4)}

Figure No. Title

Page No.

Figure VIII-2. Sun Energy Model Distribution Function for SCE Test Site ... 8-3

Figure VIII-3. SCE Test Site Annual Wind Speed Density Function ............ 8-3

Figure VIII-4. Example of Simulation Accumulated Generated Energy ........ 8-5

Figure VIII-5. Example of Simulation Daily Energy Performance .................. 8-6

Figure VIII-6. Installed cost of the Stirling dish system ................................... 8-8

Figure VIII-7 Estimate of Levelized Energy Cost ............................................ 8-9

Figure VIII-8 Estimate of System O\&M Cost ..................................................... 8-10 


\section{LIST OF TABLES}

Table No. Title

Page No.

Table 1-1. . Stirling Dish Design Characteristics ............................................ 1-3

Table 1-2. Development of the USAB Stirling Engines .............................. 1-6

Table II-1. Stirling Dish Operating Modes ....................................................... 2-10

Table II-2. Changes Made from Mark I to Mark II ............................................... 2-20

Table II-3. Comparison of the Original and Commercial Mark II ................... 2-21 Components

Table II-4. Parameters Recorded During Testing ........................................... 2-24

Table III-1. Concentrator Reflective Area ......................................................... 3-4

Table III-2. Power Losses _.................................................................................... 3-7

Table III-3. Reflectivity Before and After Washing .......................................... 3-8

Table III-4. Stirling Dish Parasitic Power ............................................................ 3-13

Table IV-1. Energy Performance of the Stirling Dish Test Unit ...................... 4-6

Table IV-2 Estimate of 24 hour parasitic energy .............................................. 4-8

Table V-1. Cosine, Blocking, and Shadowing at Solar One ....................... 5-4

Table V-2. Comparison of MDAC/USAB and Vanguard Stirling .................. 5-6 Dish System

Table VI-1. Test Program System Availability .................................................. 6-2

Table VI-2. Estimate of a Commercial Plant Availability ................................. 6-2

Table VI-3. Availability of SCE Unit ................................................................... 6-9

Table VI-4. Most Frequent Cause of Outage at the SCE Test Site ................ 6-10

Table VI-5. Availability Analysis of the SCE Unit at Solar One ...................... 6-11

Table VI-6. Availability of Georgia Unit ............................................................. 6-13 


\section{LIST OF TABLES (continued - 2)}

Table No. Title

Page No.

Table VI-7. Availability of MDAC Units 6-14

Table VII-1. Summary of Concentrator Status as of August 1992 $7-2$

Table VII-2. Concentrator Problems 7-3

Table VII-3. Summary of Mark I Engine Operation 7-7

Table VII-4. Summary of Mark II Engine Operation 7-8

Table VII-5. Stirling Engine Problems 7-9

Table VIII-1. Example of simulation data base 8-5

Table VIII-2. Annual Energy Performance 8-7

Table VIII-3. Estimate of Average Annual Cost Per Concentrator Over 8-10 a 30 Year Period

Table VIIl-4. Estimate of Required Manload Per Concentrator Per Year 


\section{INTRODUCTION}

The Stirling dish solar electric power system owned by the Southern California Edison Company (SCE) consists of a sun tracking parabolic dish concentrator developed by the McDonnell Douglas Astronautics Corp. (MDAC) and a Stirling engine power conversion unit (PCU) developed by the United Stirling $A B$, Sweden (USAB). The dish concentrates the sun's energy on the PCU heater elements contained in the receiver enclosure mounted near the concentrator's focal point. The power conversion unit converts the solar radiant energy into electrical energy. The PCU utilizes a directly illuminated receiver, Stirling cycle engine with hydrogen as the working fluid, and standard generator to transduce the energy. A photograph of the unit at the SCE Test Site with the Solar One Central Receiver in the background is shown in Figure 1-1. Previous Stirling dish programs indicated that the Stirling dish systems have a good commercialization potential. The results of the USAB/MDAC/SCE program confirmed this conclusion. A brief summary of the test program results is:

- Demonstrated net peak power efficiency of $30 \%$ at $1000 \mathrm{~W} / \mathrm{m}^{2}$ insolation

- Demonstrated net daily energy efficiency of $27 \%$ at $10 \mathrm{kWh} / \mathrm{m}^{2}$ insolation

- On-sun power-generating time of over 13,852 hours

- Generated over $118 \mathrm{MWh}$ of energy

- Sun insolation for sustained operation of 200 to $300 \mathrm{~W} / \mathrm{m}^{2}$

- No receiver operating problems

- Uniform flux distribution maintained

- Low heater head temperature difference maintained

- No receiver failures

- Low hydrogen gas consumption

- Gas leaks not a problem

- Low refill frequency

- High mirror performance maintained over 8 years

- No change in reflectivity $(91 \%)$

- No change in radius of curvature or surface waviness

- Some stress cracks where experienced, they did not affect performance

- Mirror alignment maintained over 8 years

- Concentrators disassembled and transported around the world without effecting mirror alignment

- DIR provides an accurate low cost method of mirror alignment

- Demonstrated potentially high system availability

- Test program availability of $87-90 \%$, limited by MDAC \& USAB divestiture

- Estimate commercial system availability could be better than $95 \%$ to $99 \%$ 


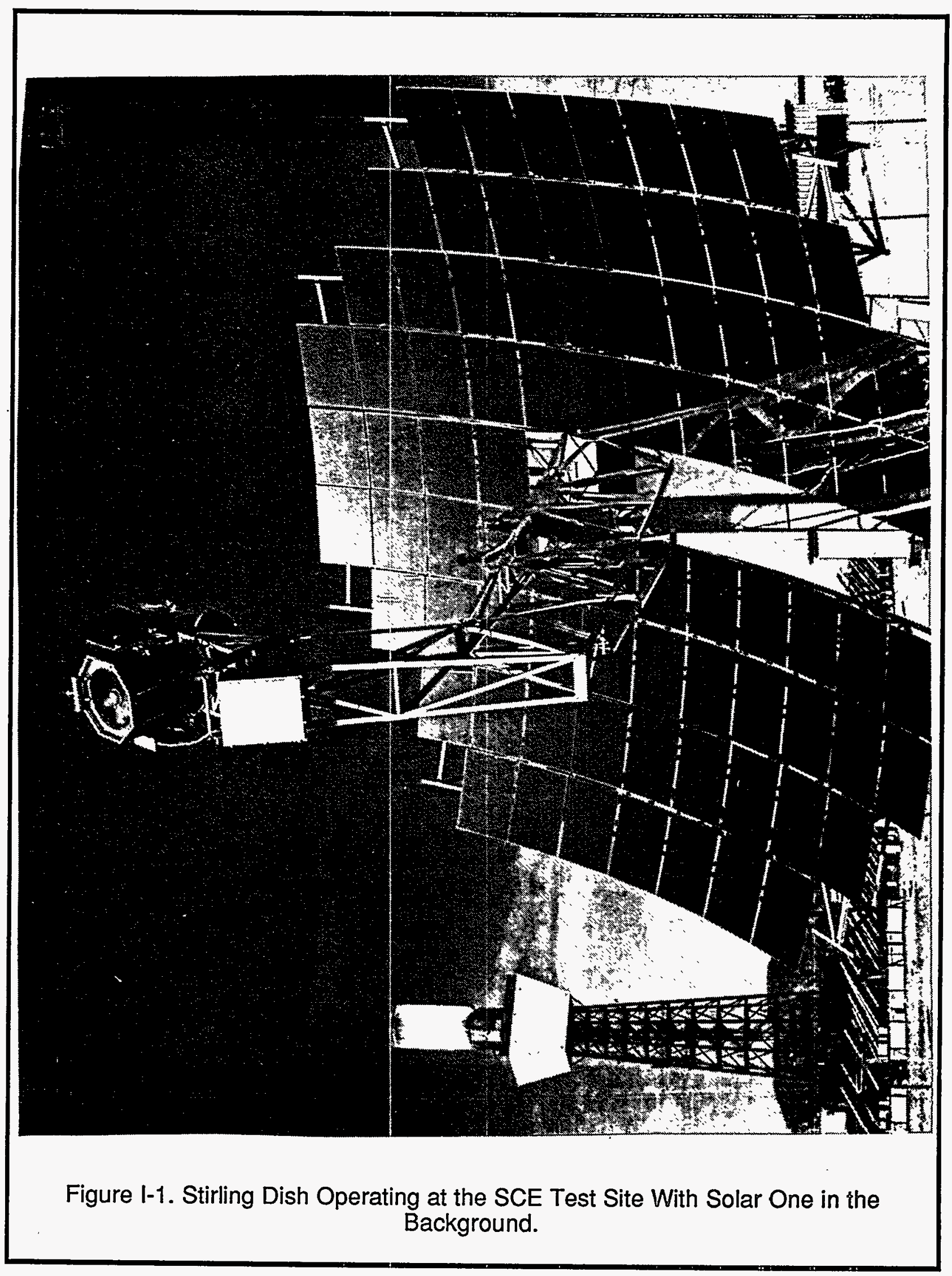


The design characteristics of the concentrator and the Stirling engine are summarized in Table 1-1. Eight concentrators were manufactured by McDonnell Douglas Astronautics Corp. in 1984 and 1985. Six of the units were installed and tested for various periods of time. This section discusses the background in the development of the MDAC/USAB/SCE Stirling dish program. The remainder of this report discusses the results of the test program. In order to preserve as much of the actual test data as possible, a summary is presented in Appendixes A, B, and C. Section 8 uses the test results of previous sections to estimate the annual energy performance of the system and combines this information with the MDAC cost data to estimate the levelized energy cost of a power plant.

Table 1-1. Stirling Dish Design Characteristics.

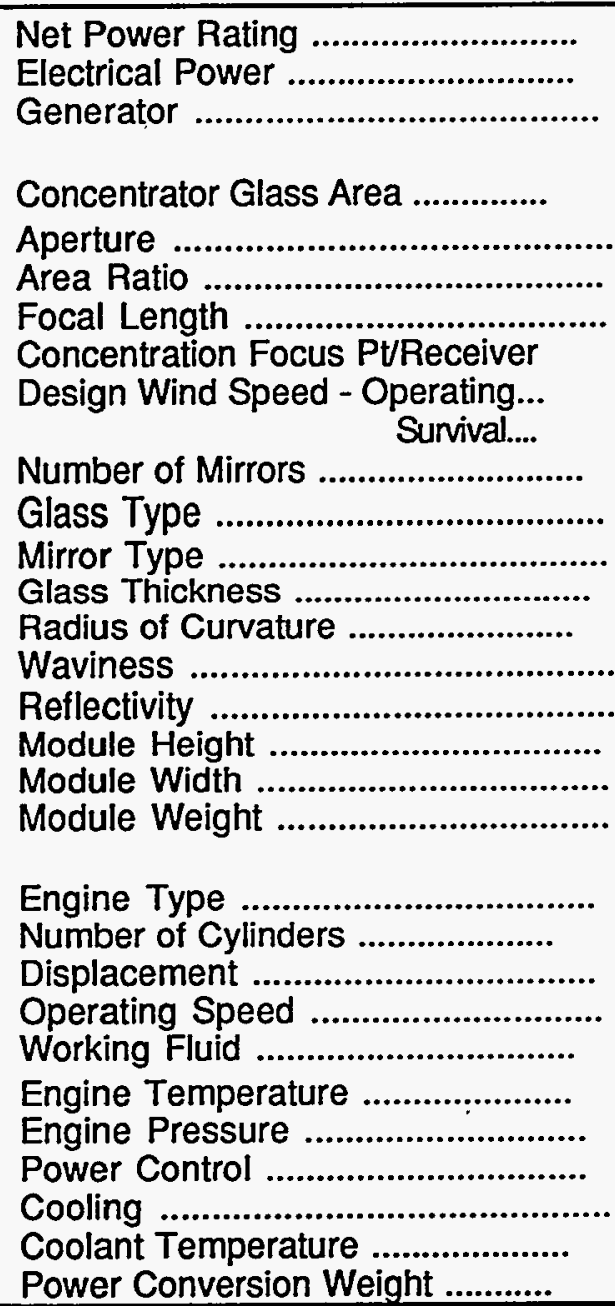

Net Power Rating

Electrical Power

Concentrator Glass Area

Aperture

Focal Length

Concentration Focus Pt/Receiver

Survival....

Number of Mirrors

Mirror Type

Glass Thickness

Radius of Curvature

Module Height

Module Width

Engine Type

Number of Cylinders

Operating Speed

Working Fluid

Power Control

Coolant Temperature

Power Conversion Weight ............
$25 \mathrm{~kW}$ at $1000 \mathrm{~W} / \mathrm{m}^{2}$ insolation

$480 \mathrm{~V}, 60 \mathrm{~Hz}, 3$ Phase

$1800 \mathrm{rpm}$ Induction

$91.01 \mathrm{~m}^{2}\left(979.72 \mathrm{ft}^{2}\right) @ 82$ mirrors

$87.67 \mathrm{~m}^{2}$ (943.76 ft $)$ @ 82 mirrors

0.963

$7.45 \mathrm{~m}(24.44 \mathrm{ft})$

7500 Suns $/ 780$ Suns

$30 \mathrm{mph}$

$90 \mathrm{mph}$

82 to 88 ( 82 for this test program)

Commercial Grade Float

Silvered Glass

$0.7 \mathrm{~mm}$

$599,616,640,667$, and 698 inches

$<0.6$ milliradians

$>91 \%$

$11.89 \mathrm{~m}$ (39 ft)

$11.28 \mathrm{~m}(37 \mathrm{ft})$

$14,900 \mathrm{lbs}$

Kinematic Stirling

Four Double-Acting Pistons

Each Piston at $95 \mathrm{cc}$

$1800 \mathrm{rpm}$

Hydrogen

$720^{\circ} \mathrm{C}\left(1328^{\circ} \mathrm{F}\right)$

$20 \mathrm{MPa}$

Variable Pressure

Water/Air Radiator

$50^{\circ} \mathrm{C}\left(122^{\circ} \mathrm{F}\right)$

$<1500$ lbs 


\section{Background of Stirling Engine Development}

The Stirling engine principle was invented in 1816 by Robert Stirling. NV Philips initiated a comprehensive research program to develop the Stirling engine in Sweden in 1938. Thirty years later, in 1968, USAB was licensed by Philips to continue research on a Stirling engine. United Stirling began the design and development of the 4-95 Mark I Stirling engine in 1975, based on a revised concept. In this design, the engine had a " $U$ " configuration that simplified its design and manufacture. This configuration allowed the engine's power to be controlled through variable pressure operation. The engine design allowed for conversion to variable-displacement power should variable pressure power operation prove unacceptable.

USAB initially was contacted by Jet Propulsion Laboratory (JPL) in 1978 regarding installation of a Stirling engine on a solar concentrator. United Stirling was selected to participate in the U.S. Department of Energy's (DOE) sponsored JPL Solar Dish Electric Program in 1979. During this test program, the first solar designed USAB Mark I engine demonstrated 29 percent peak power efficiency (Reference 1). Because of the success of this program and continued interest by the U.S. Department of Energy, USAB developed a second generation 4-95 engine in 1981-83 designated as the 4-95 Mark I PCU. This engine provided for mounting all energy devices (receiver, engine, generator, controls) above the solar concentrator focal point. USAB then continued with the development of the 4-95 Mark II PCU in 1982 and completed it in 1985. The engine design goal was to retain the performance level of the Mark I, while improving reliability and reducing the production cost. USAB supplied a Mark II PCU for DOE's Vanguard program (Reference $2 \& 3$ ). A summary of the development and testing of the USAB 4-95 Mark I and Mark II engines for these two programs is shown in Figure 1-2. USAB has developed and tested many Stirling engines for different applications, as summarized in Table 1-2.

MDAC was contacted by USAB in 1982 regarding joint participation in developing a Stirling dish system, MDAC's market analysis indicated a large market for Stirling dishes existed in the United States based on 1982 and expected future fuel prices. United Stirling joined with MDAC to develop, manufacture, and market worldwide the Stirling dish electric system. The first phase of the commercialization plan for the 


\begin{tabular}{|c|c|c|c|c|c|c|c|}
\hline Event & 1979 & 1980 & 1981 & 1982 & 1983 & 1984 & 1985 \\
\hline DOE / NASA Solar Stitin & & & & & & & \\
\hline Devalopment Testing of & & & & & & & \\
\hline Enghe \& Recolver Revis & & & & & & & \\
\hline Rebuliding 2 Engines \& B & & & & & & & \\
\hline Solar only Recoivex Test & & & & & & & \\
\hline JPL Test Program al Ed & & & & & & & \\
\hline Final Design of $4.95 \mathrm{Mk}$ & & & & & & & \\
\hline Vanguard Test Program & & & & & & & \\
\hline
\end{tabular}

Figure 1-2. Development of the USAB 4-95 Mark I and Mark II Stirling Engine.

Stirling dish was to design a concentrator for the USAB 4-95 engine, build eight units, involve four US utilities with testing the systems at utility test sites, and locate one unit at an international location. The significant events of this program are shown in Figure 1-3.

\section{SCE/MDAC/USAB Stirling Dish Program}

The first MDAC Stirling dish module shown in Figure 1-4 began operation in November 1984 at the MDAC test facility in Huntington Beach, California. At least one

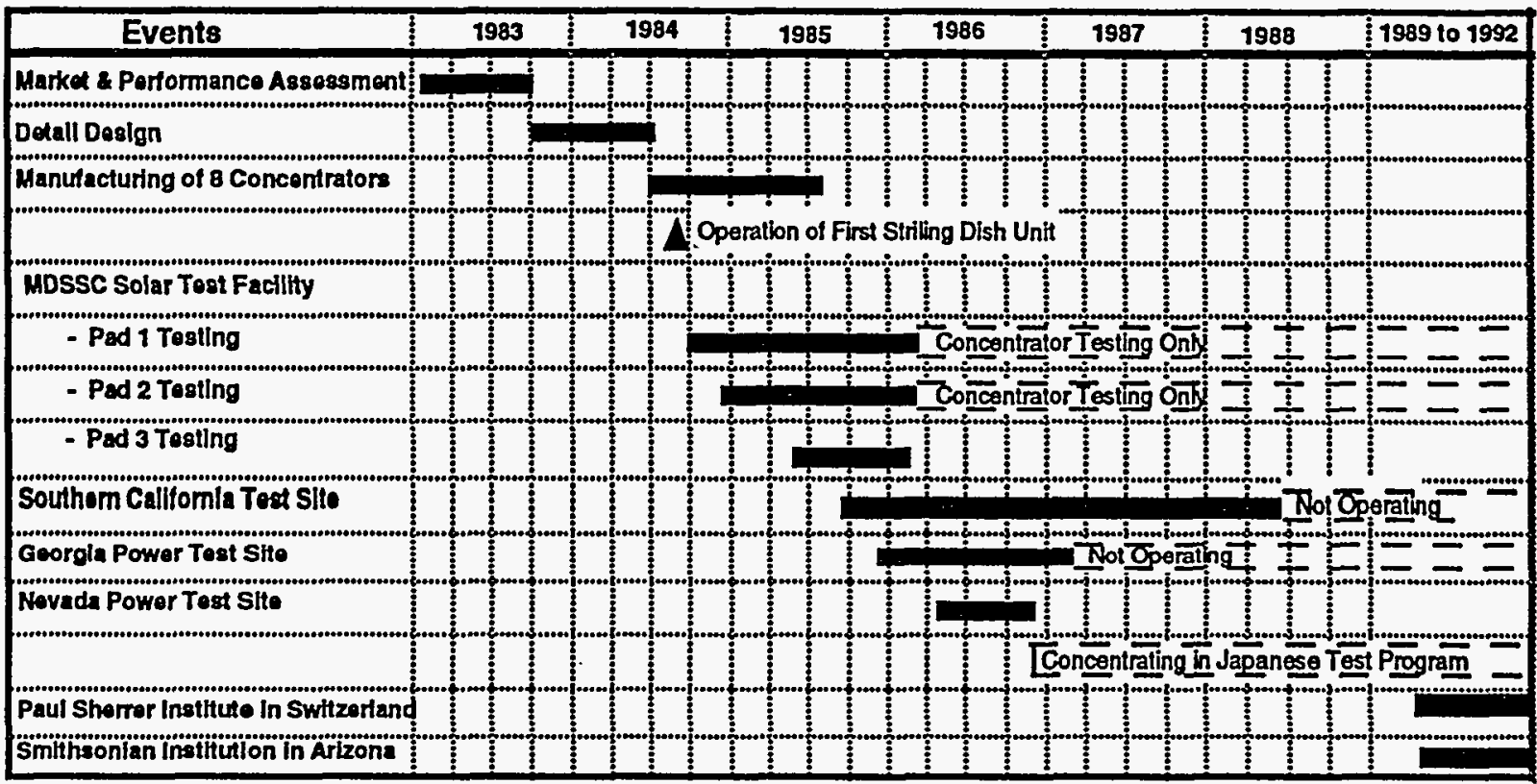

Figure 1-3. MDAC/USAB Test Program. 


\begin{tabular}{|c|c|c|c|c|c|c|c|c|c|}
\hline $\begin{array}{l}\text { Engine } \\
\text { Type }\end{array}$ & $\begin{array}{l}\text { Years in } \\
\text { Operation }\end{array}$ & $\begin{array}{l}\text { No. of } \\
\text { Engines } \\
\text { Prod. }\end{array}$ & $\begin{array}{l}\text { Accum. } \\
\text { Operating } \\
\text { Time (hrs) }\end{array}$ & $\begin{array}{l}\text { Type of } \\
\text { Drive } \\
\text { Mechanism }\end{array}$ & Application & $\begin{array}{l}\text { Number of } \\
\text { Cylinders/ } \\
\text { Swept } \\
\text { Volume } \\
\text { cc/Cylin. }\end{array}$ & $\begin{array}{l}\text { Max. } \\
\text { Power } \\
\text { (kW) }\end{array}$ & $\begin{array}{l}\text { Maximum } \\
\text { Efficiency } \\
(\%)\end{array}$ & Field Test \\
\hline $1-96$ & $1970-1976$ & 3 & 6,200 & Rhombic & Auxiliary Power Unit & $1-98$ & 7 & 25 & $\begin{array}{l}\text { Pleasure boat, Auxiliary } \\
\text { Power Unit }\end{array}$ \\
\hline $4-615$ & 1971-1973 & 4 & 650 & Rhombic & Truck and Underwater & $4-615$ & 147 & 31 & \\
\hline V $4 \mathrm{X}$ & 1971-1976 & 6 & 2,600 & V4 & Passenger Car & 4-90 & 35 & 27 & Ford Pinto, Ford Taurus \\
\hline 4-189 & 1972-1977 & 5 & 800 & $V_{4}$ & $\begin{array}{l}\text { Truck and Auxiliary Power } \\
\text { Unit }\end{array}$ & $4-189$ & 75 & 32 & Volvo 405 \\
\hline$V-160$ & 1973 & 95 & 150,000 & V2 & Auxiliary Power Unit & $1-160$ & 10 & 30 & $\begin{array}{l}\text { Twenty auxiliary power } \\
\text { units }\end{array}$ \\
\hline $4-95$ & 1976- & 25 & 60,000 & $\mathrm{U}_{4}$ & $\begin{array}{l}\text { Development Test, Auxiliary } \\
\text { Power Unit Underwater, } \\
\text { Solar, and Passenger Car }\end{array}$ & & & & $\begin{array}{l}\text { Open R, AMC Concord, } \\
\text { Mercedes Van, two } \\
\text { Auxiliary Power Units, three } \\
\text { Solar, and Underwater }\end{array}$ \\
\hline $4-275$ & 1978 & 9 & 16,000 & $\mathrm{U}_{4}$ & $\begin{array}{l}\text { Truck Auxiliary Power Unit, } \\
\text { and Solar }\end{array}$ & $4-275$ & 110 & 42 & $\begin{array}{l}\text { Auxiliary Power Unit and } \\
\text { Solar }\end{array}$ \\
\hline MOD1 & $1961-$ & 8 & 6,000 & $\mathrm{U}_{4}$ & Passenger Car & $4-123$ & 55 & 37 & AMC Lerma \\
\hline $\begin{array}{l}\text { V4- } \\
\text { 275R }\end{array}$ & 1984 & 2 & 500 & V4 & Underwater & $4-275$ & 120 & 42 & - \\
\hline
\end{tabular}

Solar Engine Operation:

Simulated Solar \#7 Units @ 39,000 hrs.

Actual Solar \#4 units @ 3,400 hrs. 
Stirling dish operated every day from November 1984 until September 1988. MDAC built eight parabolic solar concentrators during 1984 and early 1985. Three of the units were installed in the MDAC test facility shown in Figure I-5. In this figure, one unit is operating with a Stirling engine, a second unit is operating with a flux measurement system and the third unit in the distance is in a night stow position. These three units operated until June of 1986. Only the first two units operated with an engine. The third concentrator completed functional checkout testing and flux mapping. An engine was mounted on this unit but it was never operated. In 1985, MDAC signed a cooperative agreement with the SCE, Georgia Power Company, and Nevada Power Company under which a Stirling dish was installed at each utility. MDAC agreed to help operate and test the units for 33-months. A unit was installed at SCE's Test Site which was located at the Solar One Central Receiver Test Site near Barstow, California, in August 1985. Another unit was installed at Georgia Power's Shenandoah facility in November 1985, and a third unit was installed at Nevada Power in April 1986. In June 1986, MDAC decided to divest itself of this and other energy ventures. Southern California Edison acquired the rights to the Stirling dish technology from MDAC by year's end, and in January 1987, SCE also acquired the Stirling dish hardware owned or held by MDAC.

Southern California Edison continued testing and improving the performance of the system at the SCE Test Site. One unit remains at Shenandoah, Georgia. It was operated occasionally through 1988 but has not operated since that time. The third unit, originally installed at a Nevada Power site, was removed in the spring of 1987, and the concentrator was shipped to Aisin Seiki Company, Japan. This concentrator is being used to test the Aisin Seiki Stirling engine. As of early 1993, two of the concentrators are still operating without PCUs at McDonnell Douglas, Huntington Beach, as a part of a space power test lab. One of the concentrators was sold to the Smithsonian Institution (Fred Lawrence Wipple Observatory) and is being used as part of a space telescope in Amado, Arizona. A third concentrator was sold to the Paul Scherrer Institute in Switzerland and is being used as a solar furnace. 


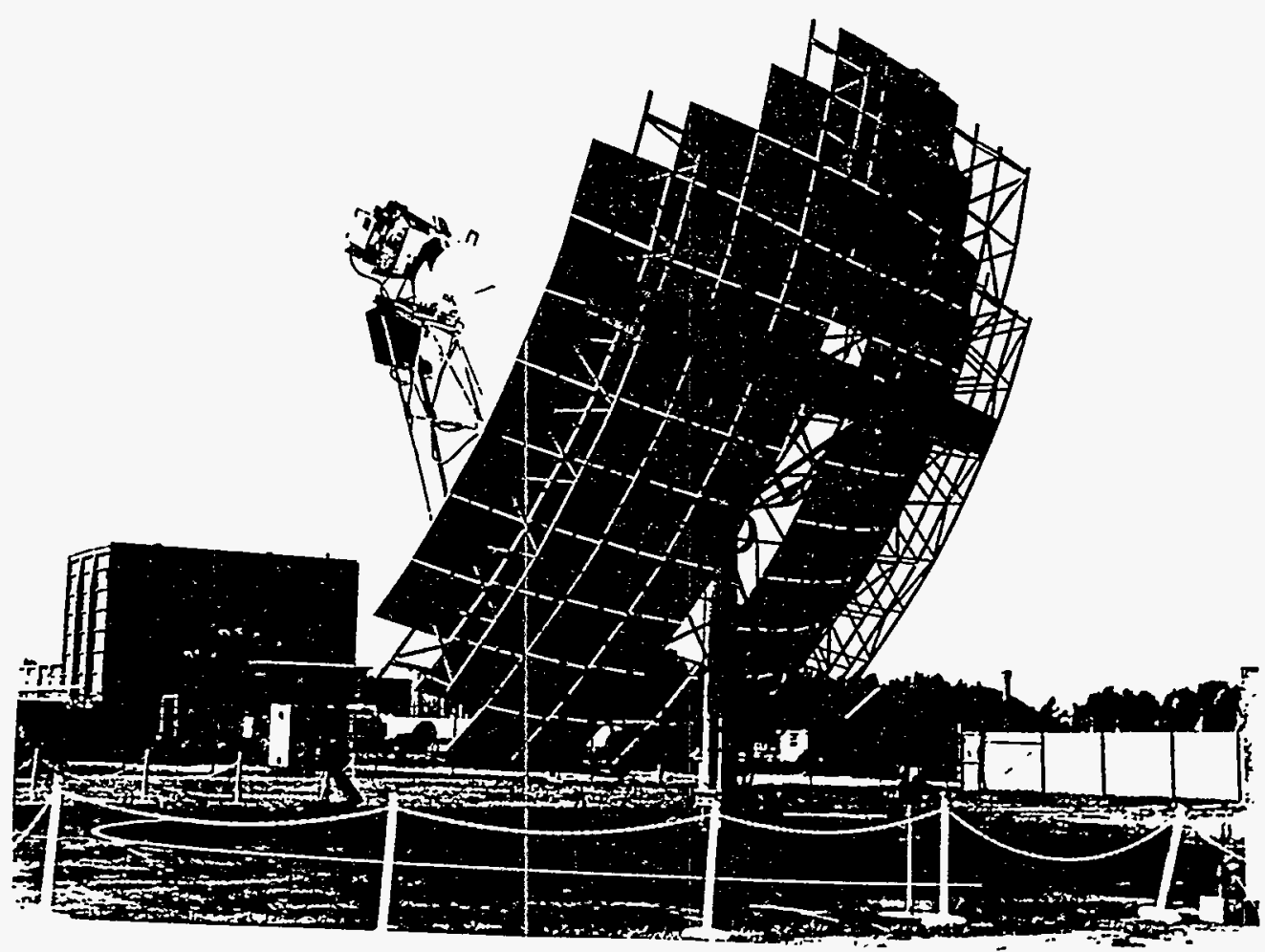

Figure 1-4. First Stirling Dish operated in November 1984.

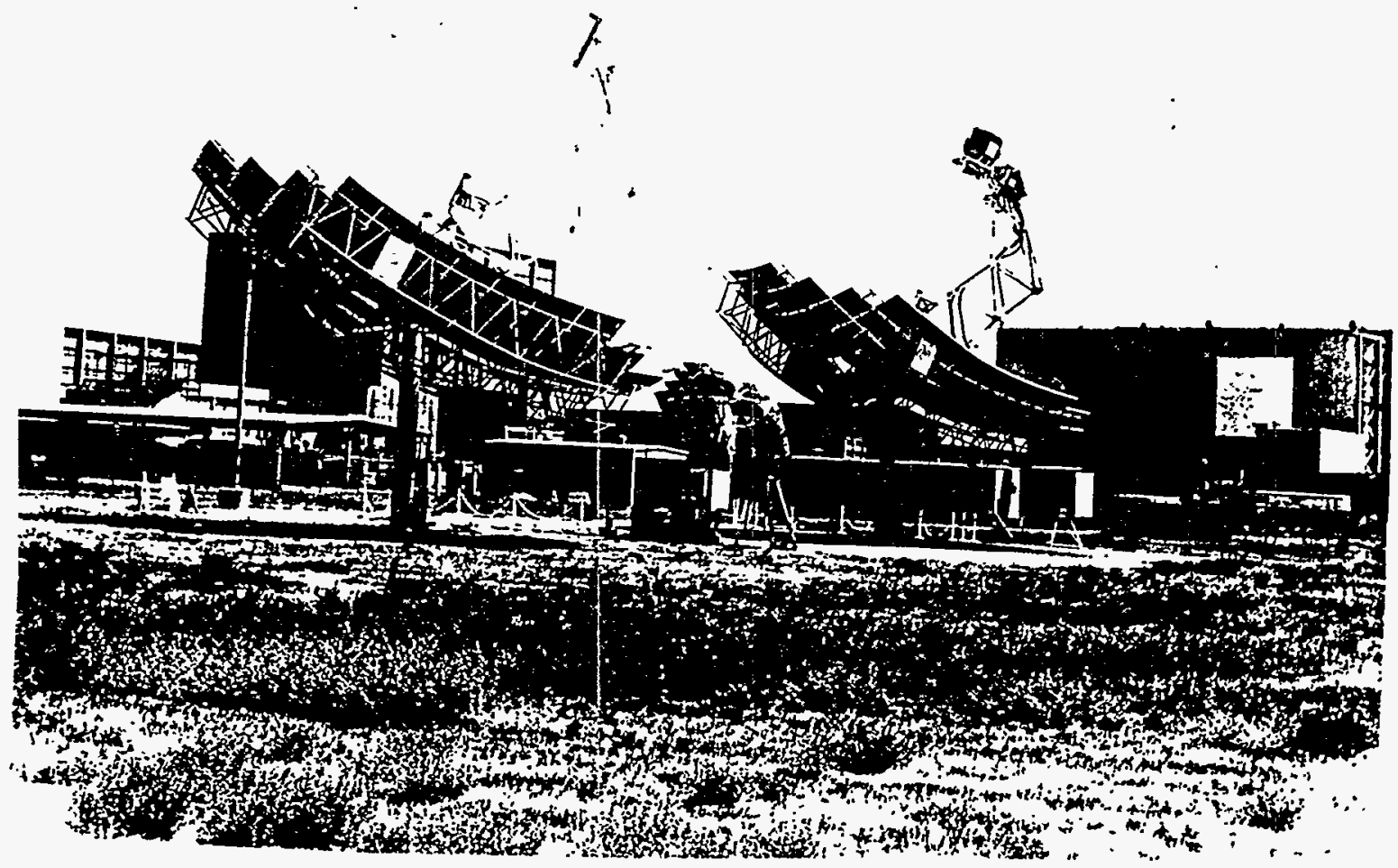

Figure 1-5. View of the MDAC Solar Test Facility. 


\section{DESCRIPTION OF STIRLING DISH SYSTEM}

- System consists of two components - concentrator and power conversation unit

- Concentrator facet alignment can be done very accurately at a low cost

- High open loop tracking accuracy can be obtained at a low cost

- Concentrator maintains uniform PCU flux distribution

The principle of operation of the Stirling dish is shown in Figure II-1. The Stirling dish tracks the sun daily by rotating about two axes: azimuth and elevation. The azimuth axis is the local vertical and the elevation axis is perpendicular to the local vertical axis. The curved mirrors reflect and focus the sun's energy onto the PCU's receiver. The concentrated solar energy is absorbed by hydrogen gas going through the receiver heater head. As the hydrogen gas expands, it pushes a piston which turns a crankshaft. The linear mechanical energy is converted to rotational mechanical energy by the Stirling engine. The engine crankshaft rotates an induction generator, which converts this mechanical energy to 480V, 3-phase, 60 hertz AC electrical energy.

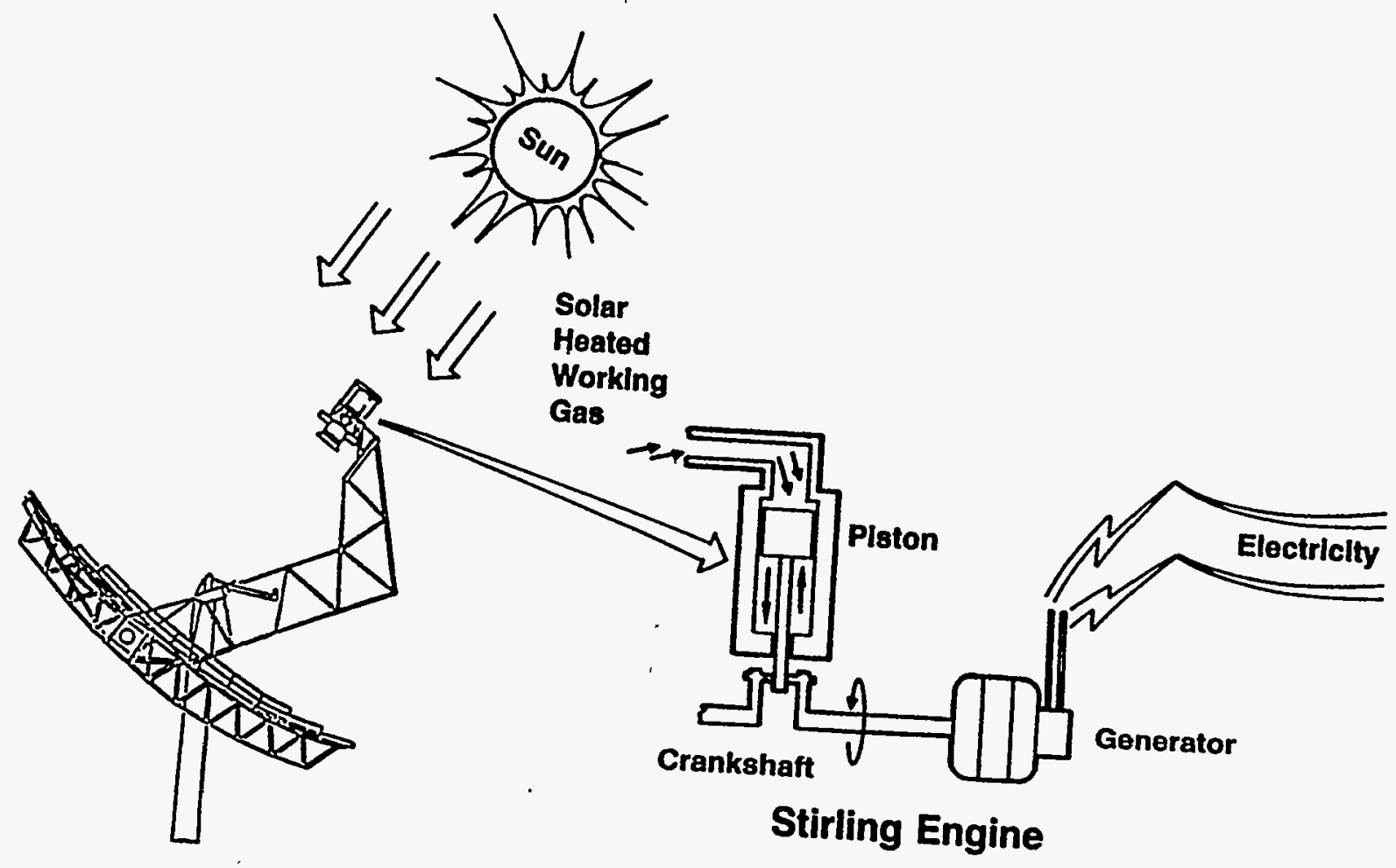

Figure II-1. Stirling Dish Principle of Operation. 


\section{Solar Concentrator}

The dish consists of curved glass-mirrored facets, a mirror support or truss structure, a pedestal, a PCU support structure and an elevation support/drive system as shown in Figure II-2. Eighty-two curved facets give a total reflective area of $91 \mathrm{~m}^{2}\left(980 \mathrm{ft}^{2}\right)$. Locations are provided for the installation of six additional mirror facets, which would increase the total area to $97 \mathrm{~m}^{2}\left(1040 \mathrm{ft}^{2}\right)$. Each mirror measures $3 \mathrm{ft}$ by $4 \mathrm{ft}$ and is curved in two directions. There are five different nominal curvature radii: 599,616 , 640,667 , and 698 inches. Each mirror is aimed at a different point on the receiver (Figure II-3) to provide an uniform flux on the receiver surface. The resulting flux (Figure 11-4) was measured using the Digital Image Radiometer (DIR) flux mapper (Reference 4 \& 5). The DIR flux mapper consists of a high temperature target that rotates through the reflected beam. When the target is perpendicular to the concentrator centerline, a camera mounted on the axes of the dish takes an image of the flux contours.

In order to create the desired flux distribution, each mirror facet on the concentrator was aligned using a DIR mirror-alignment system developed by MDAC. The DIR mirror-alignment system is composed of a camera, digitizer, computer, and a panel of lights. The accuracy of the DIR alignment system was verified to be less than $0.2 \mathrm{mr}$,

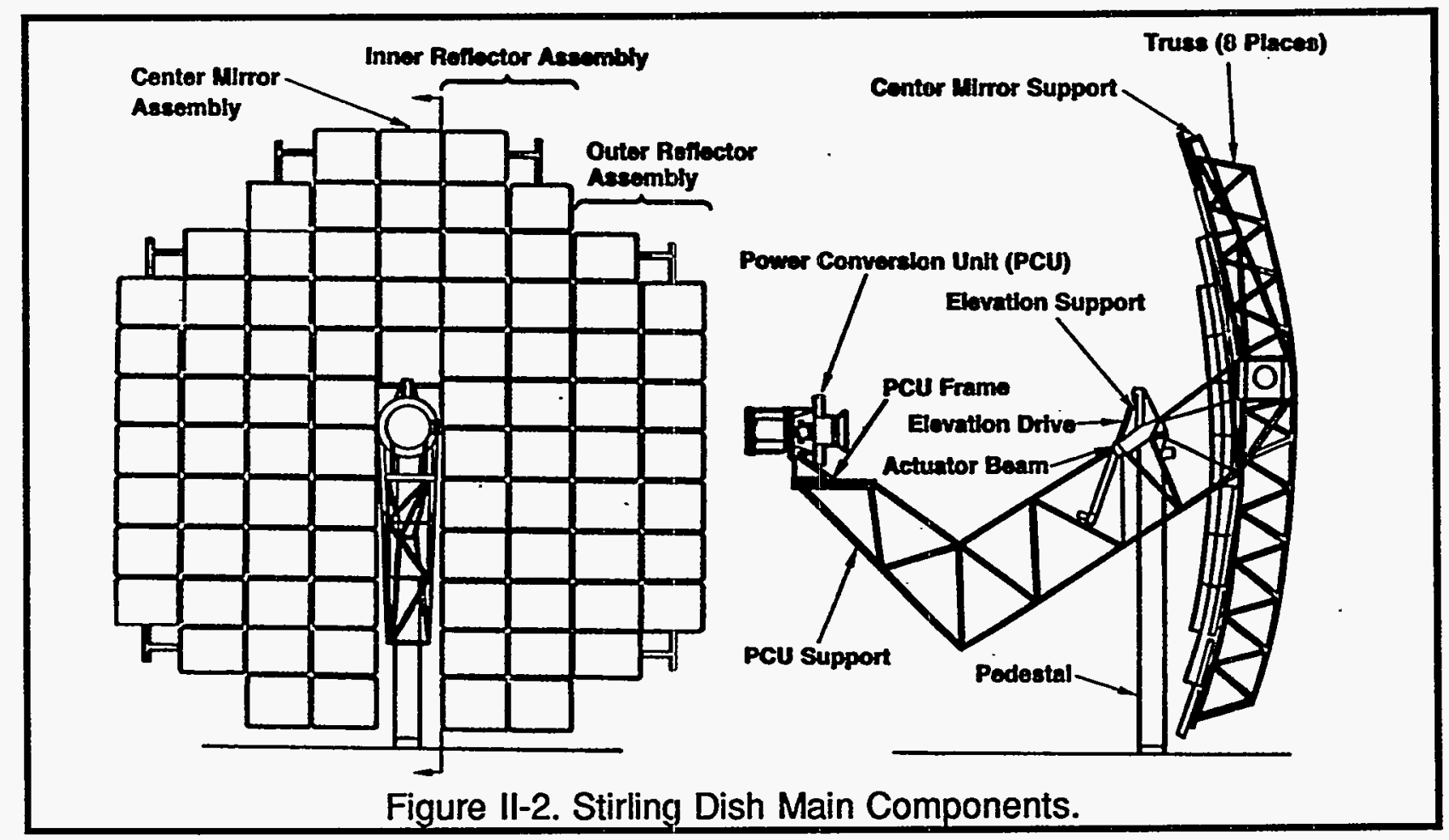



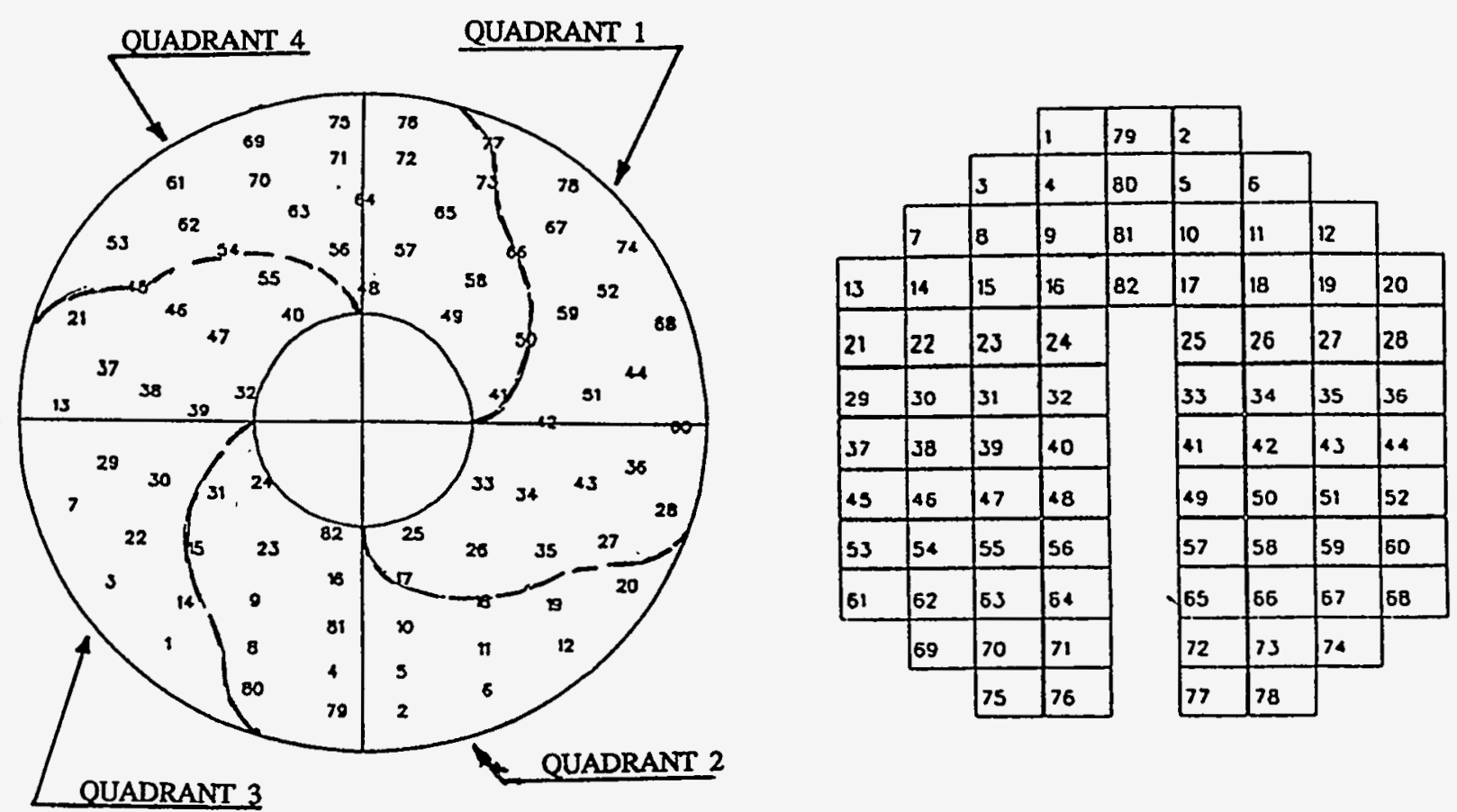

Figure II-3. Aim Points on the Receiver of Concentrator Individual Mirror Modules.

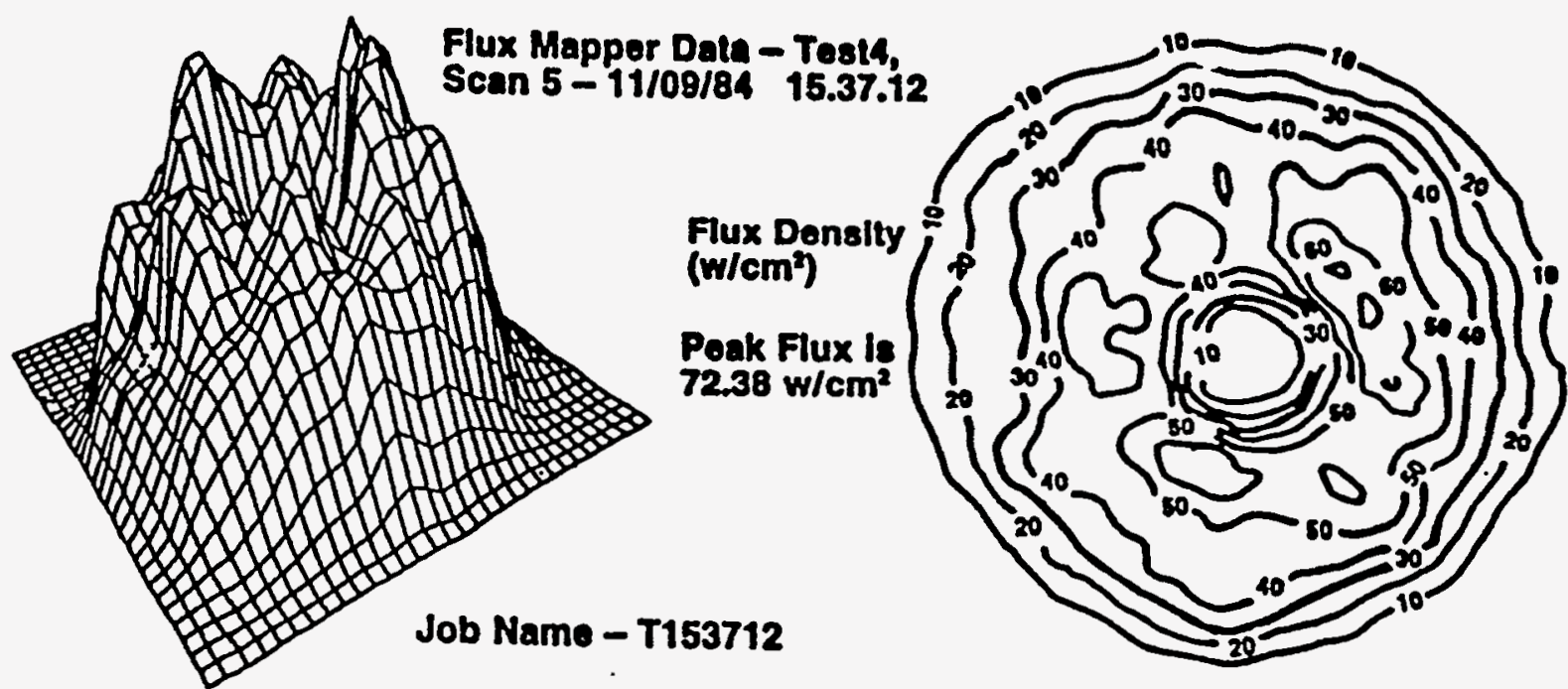

Figure II-4. Receiver Flux Measured with the DIR System. 
and it took 4 to 8 man-hours to take the alignment data, adjust the position of the mirrors, and take a final measurement to verify the alignment. With the newer equipment now available, it is possible that the concentrator could be aligned nearly as quickly as the mirror facets could be mounted and bolted to the structure.

The dish is manufactured in six subassemblies (Figure II-5). The six subassemblies were the two outer reflector assemblies, the two inner reflector assemblies, the center mirror assembly, and the tracking assembly consisting of the pedestal, azimuth support drive, elevation drive and PCU support structure. The assembling of the reflector support structure and PCU structure for one of the units is shown in Figure II6. Each of these subassemblies can be transported by a regular size semi truck, thereby reducing transportation costs. A final assembly plant would be used for assembling Stirling dishes for large solar power plants located a long distance from the main concentrator factory to reduce transportation costs. In this scenario, all of the components, truss assemblies, cross braces, etc. are made at the main factory and shipped to the field factory. In this way, several concentrators could be shipped on one truck. At the field factory, the reflector structure would be assembled, the inner and outer assemblies would be joined to the PCU structure, mirrors mounted and aligned, and the completely assembled concentrator and PCU carried as a single unit into the field and set on the pedestal.

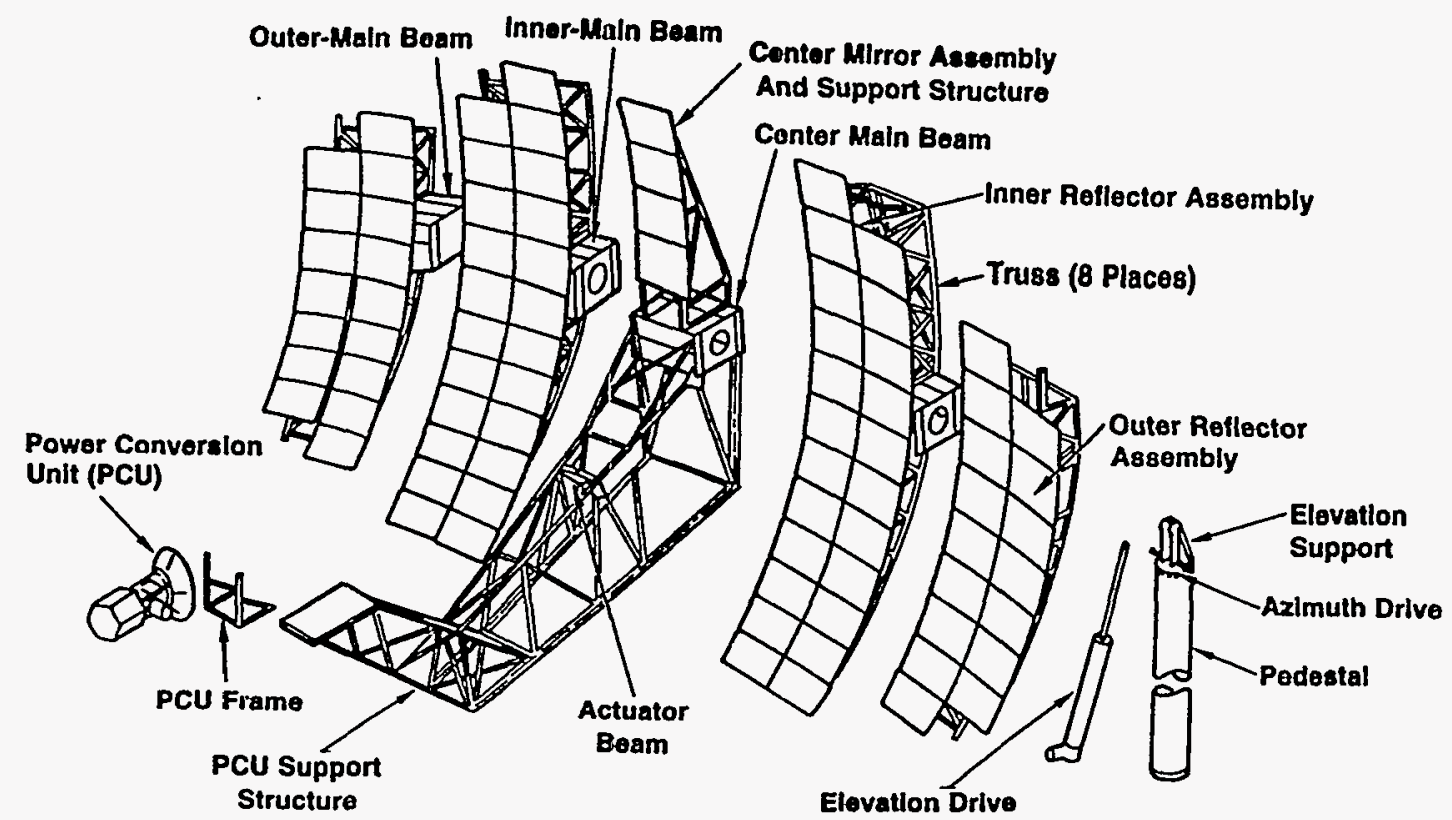

Figure II-5. Stirling Dish Subassemblies. 


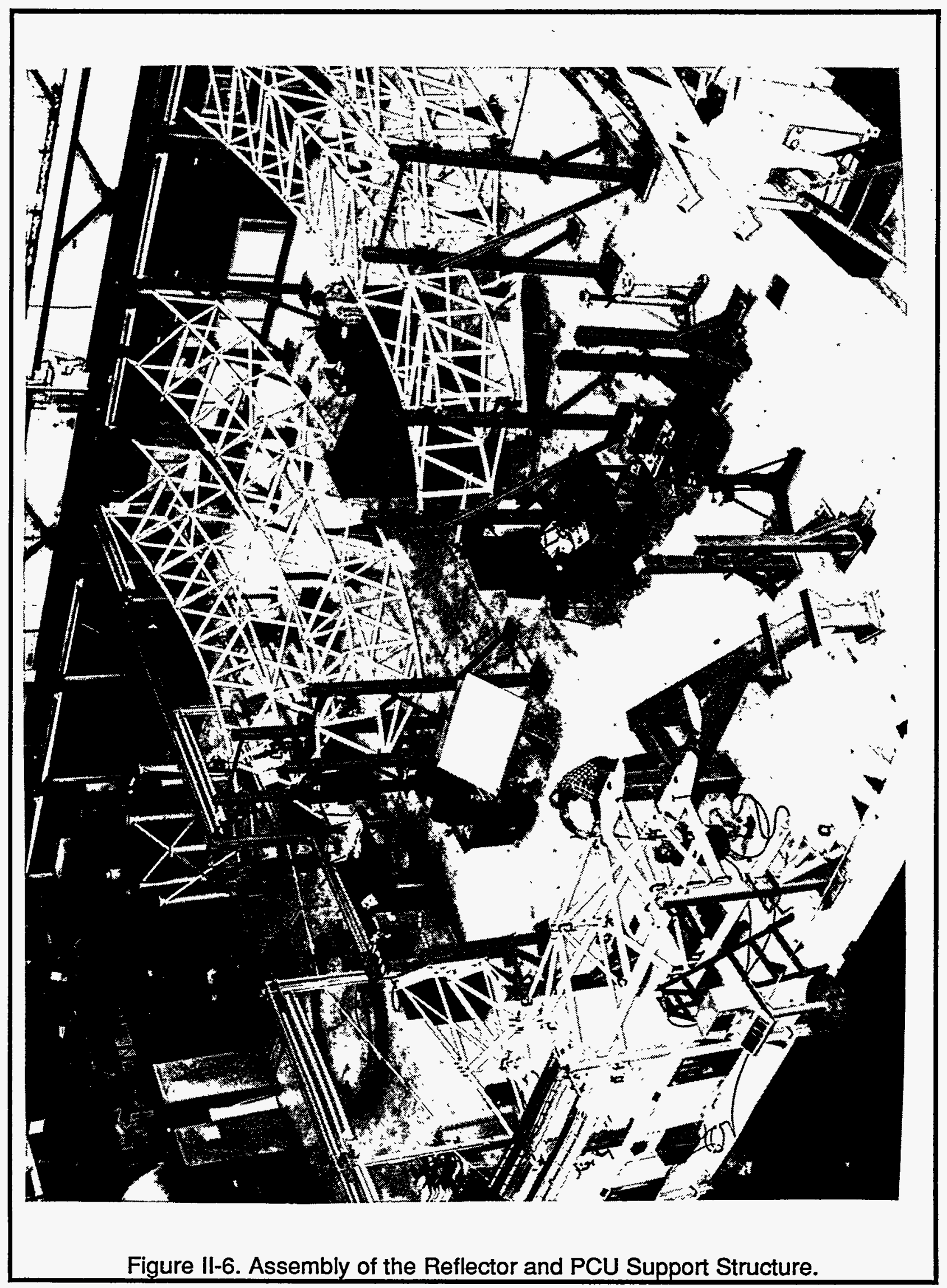


Field installation of the six subassemblies at each site was accomplished in four to six hours using standard lift equipment available at the sites. It is estimated that in mass production, the units could be installed in two hours, employing three or four people and special lift equipment. First, a 12-16 ft deep concrete foundation with a tapered steel cone that extends approximately four feet above the ground, and the field wiring were installed prior to the actual concentrator installation. Next, the pedestal and PCU support structure were placed, as illustrated in Figure II-7, onto the tapered cone. Two hydraulic jacks pulled the concentrator pedestal down onto the tapered cone. Then the PCU was mounted and the assembly was rotated to a vertical position with the PCU directly above the pedestal. The reflector structure was assembled by mounting the center mirror assembly, the first inner reflector assembly, the second reflector assembly, the first outer reflector assembly, and then the second outer reflector assembly. Special slings were used to lift the reflector assemblies into place. Each reflector assembly had alignment pins that made the mating of each assembly very easy. After the assembly was aligned on the pins, it was bolted into place.

In the MDAC/USAB/SCE program the mirror support structure was assembled in the MDAC factory, then the mirrors were mounted and aligned. Following this, each unit was disassembled and transported to a test site, where they were installed. Even though the concentrators were transported in subassemblies, the structural design of the concentrator maintained the required optical performance by the use of two alignment pins in each of the mirror subassemblies box beams. One of the concentrators was assembled, aligned, disassembled, transported to and from Barstow, and reassembled in the factory. The alignment was re-checked and it was still within the accuracy requirement.

The slot in the concentrator mirror assembly avoids interference between the concentrator mirror assembly and the pedestal. This allows the PCU to be lowered for installation, inspection, repair, and replacement without costly motorized lifts. A ballscrew jack changes the elevation, and a 10-inch-diameter harmonic drive changes the azimuth angles of the concentrator. Because of the low wind-load capability of the harmonic drive, a Sumitomo azimuth gear drive was developed during the program replace the harmonic gear drive. One of the Sumitomo drives has been in operation on a concentrator at MDAC since 1989. 


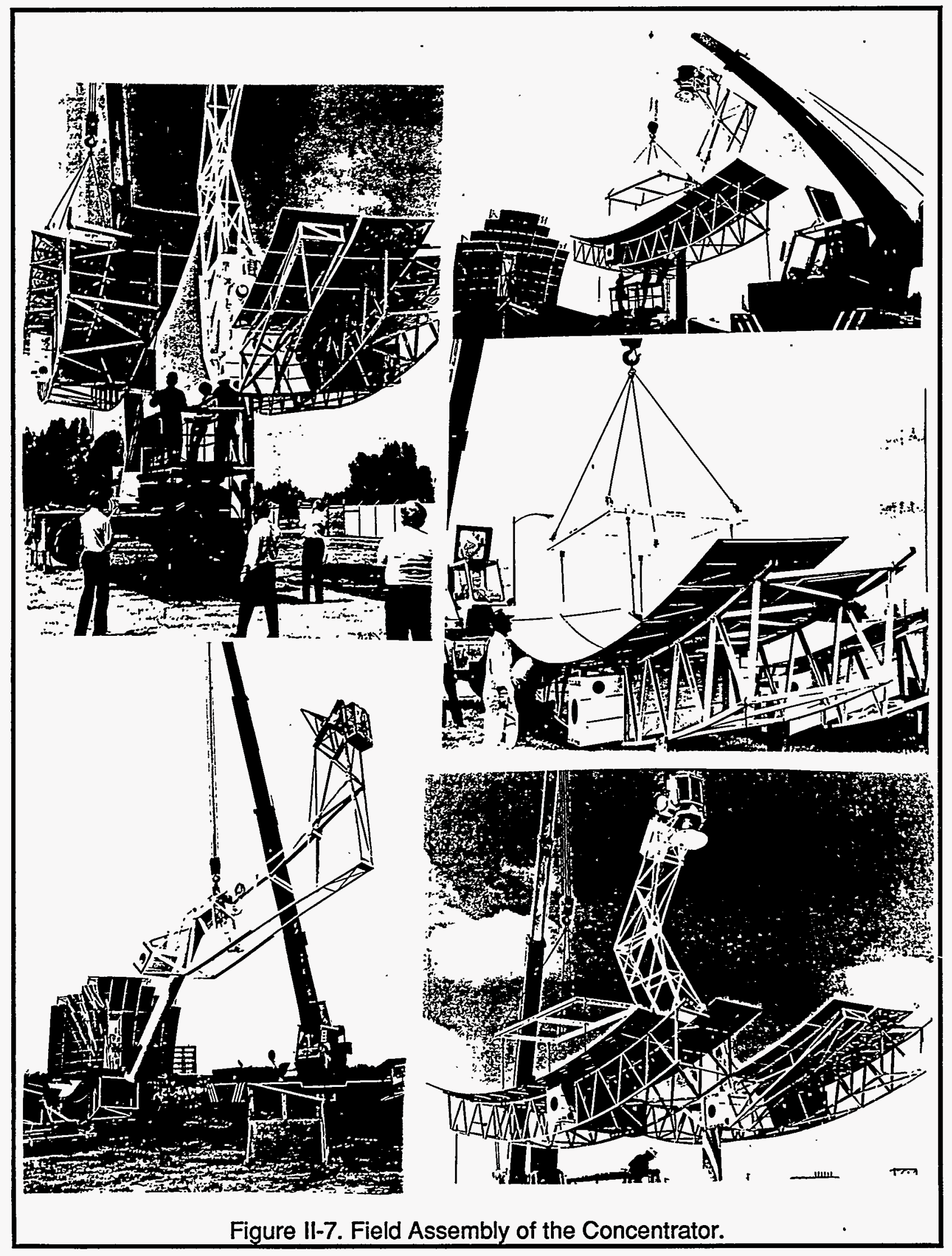


The Stirling dish control system illustrated in Figure II-8 is composed of a concentrator controller (CC) located in the pedestal, a system controller (SC) and data logger located in the remote control room, and a weather station. The concentrator controller was a specially designed microprocessor controller that performed all local operations of the concentrator as directed by the system controller. The system controller was a DEC PDP 11/23. The system controller displayed all concentrator operating information, executed operator commands; gathered operating information from the concentrator controller, the PCU, and weather station; and calculated operating positions for the concentrator. Although the operator interface with the system controller was for a single concentrator, the DEC operating software and hardware was designed to control a large field of concentrators.

The Stirling dish system could operate both automatically or manually. In the automatic state, the concentrator would unstow in the morning when the sun reached a defined elevation angle and then move to a standby point. From standby, when the average sun insolation was above a threshold value, it would go to a sun-tracking position, track the sun all day, and move to the night-stow position when the sun position was lower than a defined elevation. If a problem occurred during the day, the controller would move the concentrator to the night-stow position. This was performed automatically without operator intervention. In the manual state, each of the operating steps had to be performed by the operator, except for an automatic detrack when a PCU problem was detected or the wind stow when the measured wind speed exceeded the safe limit.

Because of the high energy concentration, the movement of the concentrator from one position to another position had to be performed in a controlled manner to prevent energy spillage and damage to electrical wiring, mechanical equipment, or structures. This was accomplished by defining a set of operating modes and the dish movement trajectory required to safely change operating modes. The different operating modes are defined in Table II-1. The controlled movements required to change from a nightstow mode to a tracking mode illustrates the process. First the concentrator would rotate in elevation from the night stow position of $-32^{\circ}$ to $0^{\circ}$, then rotate about the azimuth axis to an angle $90^{\circ}$ from the sun, rotate in elevation to an angle approximately $10^{\circ}$ above the sun's elevation, then rotate about the azimuth axis to align with the sun's azimuth position. This was the standby position. When the system was ready to generate power, the concentrator would rotate down in 


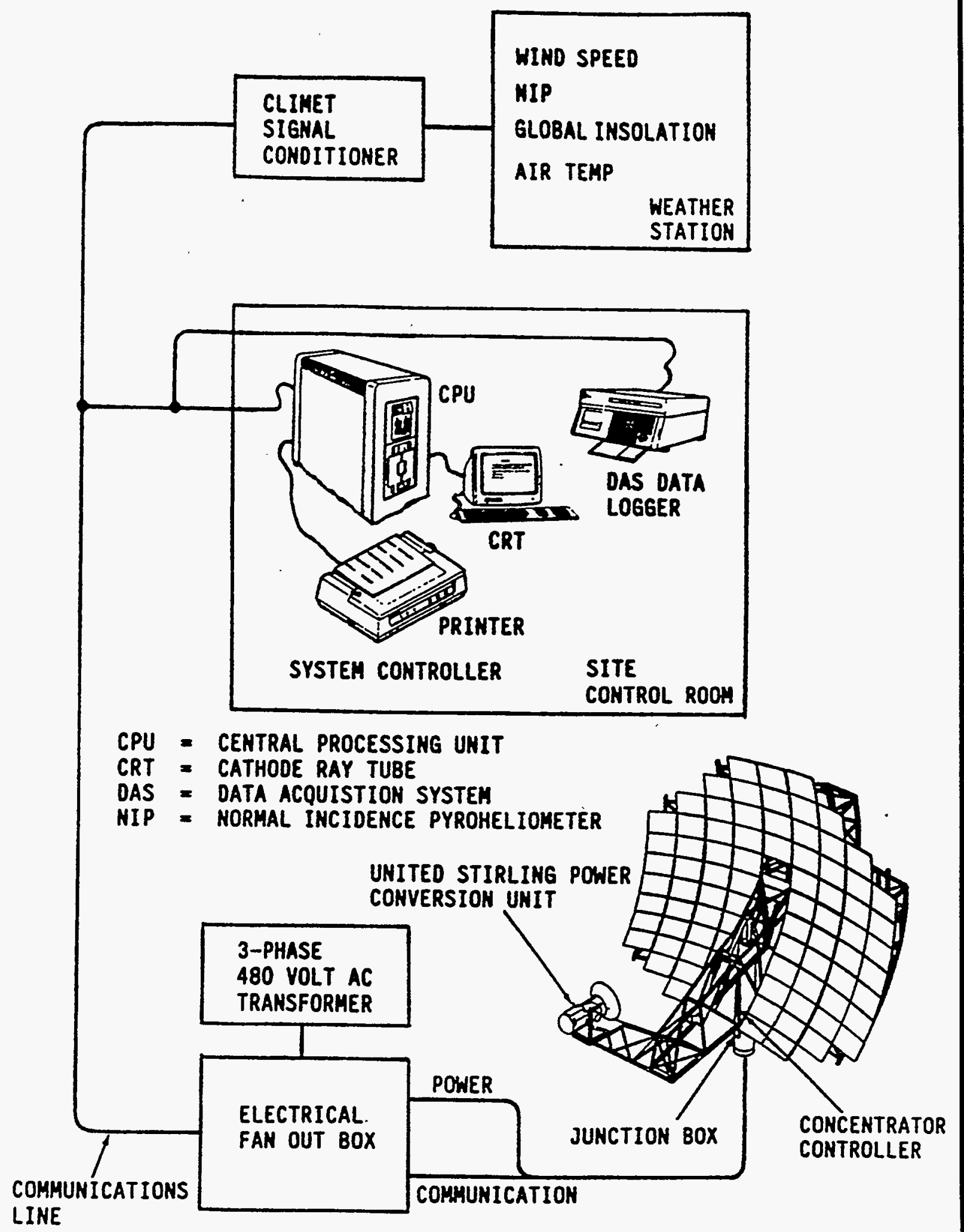

Figure II-8. Stirling Dish Control System Configuration. 


\begin{tabular}{|c|c|}
\hline \multicolumn{2}{|c|}{ Table II-1. Stirling Dish Operating Modes. } \\
\hline Mode & Description \\
\hline Night Stow & $\begin{array}{l}\text { A static position at an azimuth angle facing North } \\
\text { and an elevation angle of }-32^{\circ} \text { relative to local } \\
\text { horizontal. }\end{array}$ \\
\hline Standby & $\begin{array}{l}\text { A sun tracking position with the elevation of the } \\
\text { concentrator centerline } 10^{\circ} \text { above the sun. }\end{array}$ \\
\hline Track & $\begin{array}{l}\text { A sun tracking position with the concentrator } \\
\text { pointing at the center of the sun. }\end{array}$ \\
\hline Faceup Stow & $\begin{array}{l}\text { A static position at an azimuth angle point South } \\
\text { and an elevation angle of } 90^{\circ} \text {, centerline of } \\
\text { concentrator line in a vertical direction. }\end{array}$ \\
\hline Maintenance & $\begin{array}{l}\text { A static data base position.position. Used for } \\
\text { washing, engine oil/water check, etc. }\end{array}$ \\
\hline Gimbal & A static position at angles entered by the operator. \\
\hline Reference Update & $\begin{array}{l}\text { A procedure used to find the reference position } \\
\text { after a power loss. }\end{array}$ \\
\hline Detrack & $\begin{array}{l}\text { A transition from track to a standby position when a } \\
\text { problem occurs with the PCU }\end{array}$ \\
\hline Emergency Detrack & $\begin{array}{l}\text { A transition from any azimuth position to an } \\
\text { elevation angle of } 90^{\circ} \text { in the event of grid loss or } \\
\text { similar conditions. }\end{array}$ \\
\hline
\end{tabular}

elevation, concentrating the solar energy in the receiver's cavity. This movement provided the maximum aberration of the sun's image as it crossed the PCU support structure.

The concentrator sun tracking control system is an open-loop tracking system. The system calculates the position of the sun and commands the concentrator to move to the position where it will be pointing at the sun. Although a sun sensor was added during the test phase to gather tracking error data, it is not required for the unit's operation. The open-loop tracking error for the unit is less than $0.01 \mathrm{deg}(0.2$ milliradians) rms over the day. Achieving this accuracy did not place stringent requirements upon the structure, mechanical, or installation requirements. It was achieved through a track alignment method. Development of this track alignment method was started and patented (Reference 6) by MDAC in the 1980's for improving solar central receiver heliostat tracking accuracy while decreasing costly requirements on the structure, mechanical components, and installation procedures. Early heliostat testing showed that this method could be used to reduce the tracking error caused by 
pedestal tilt, elevation nonorthogonality, gravity bending, atmospheric refraction, etc. In this method of track alignment, an error model of the system is developed and the algorithms are derived which will correct for the errors. Track data from a sun sensor, PCU power point tracking or DIR tracking system are used to calculate the alignment error parameters of the model. The alignment parameters are used in the open-loop control algorithms to correct for these errors. A comparison of the tracking accuracy with and without this track alignment method for a heliostat was obtained by Sandia (Reference 7). A comparison of the track accuracy of the Stirling dish system with and without this track alignment system is shown in Figure II-9. When fully implemented, this alignment process would be fully automatic like the system used at Solar One. Therefore, obtaining this high tracking accuracy does not result in costly requirements upon the structure and mechanical systems or upon the installation procedure. Since it can be completely automated, it does not require significant manpower to perform open loop track alignment.

The interface between the concentrator controller and the PCU controller was a single high/low signal A high signal indicated that the PCU was operational and ready to produce power and a low signal indicated that the PCU was not ready to produce power. If the unit was on-sun, the low signal would cause the concentrator controller to move the concentrator to a standby position (normal detrack). The normal detrack was for such things as high receiver temperature difference, too many engine starts, cooling fan fault, high cooling fluid temperature, etc. There was also an emergency system (fast slew) that detracked the unit in the event of a grid power loss or a PCU emergency signal (emergency detrack). The fast slew system was independent of the concentrator control system and consisted of a battery, control electronics, and a dc motor connected to the normal elevation drive system. The fast slew system, which could only rotate the concentrator in an up elevation direction, would move the concentrator from the present position to a faceup position. Because of the high speed of the dc motor, the sun's energy was removed form the receiver faster than the normal concentrator tracking control system. Therefore, the emergency detrack was for such things as having no oil pressure, loss of hydrogen gas in the receiver or engine, gas control valve problem, etc.

Each site also had a weather station and data acquisition systems, discussed later. The weather station consisted of six measurement devices: two wind-speed measuring elements, one wind direction, a normal incidence pyroheliometer, 

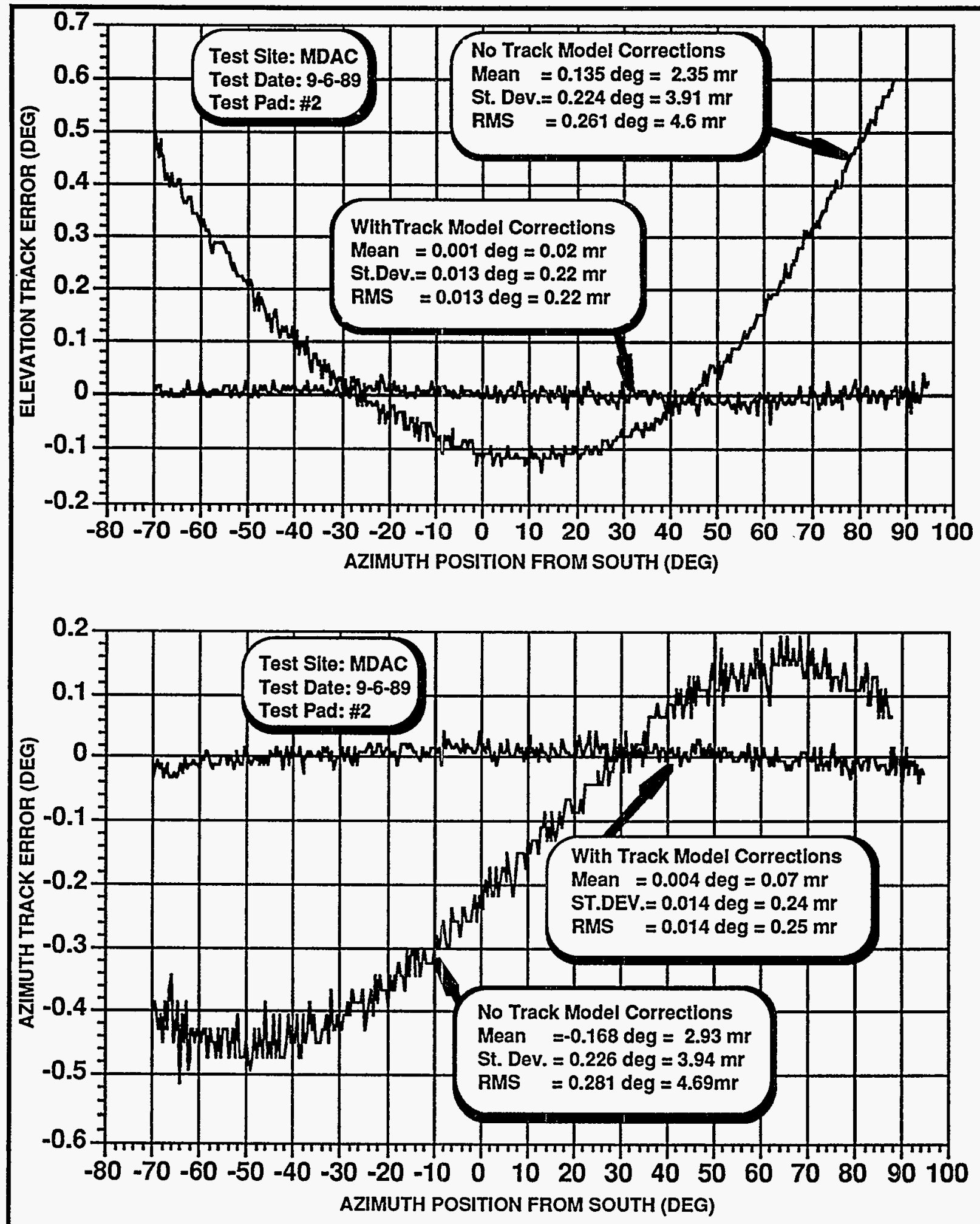

Figure II-9. Comparison of Track accuracy Without and With Track Alignment Parameters. 
a global insolation, and air temperature.

\section{Power Conversion Unit}

The Stirling engine thermal cycle is shown in Figure II-10. Ideally, the thermodynamic cycle consists of two isothermal and two constant-volume processes: isothermal compression, constant-volume heat addition, isothermal expansion, and constantvolume heat rejection. The actual cycle, with crankshafts and sinusoidal motion of pistons, can only approach the thermodynamic efficiency of the ideal cycle. The difference in the areas inside the ideal and the actual pressure-volume (P-V) curves represents inefficiencies introduced by the hardware.

The Stirling engine hydrogen-gas system is shown in Figure II-11. When insolation is incident upon the receiver, hydrogen gas passes back and forth through the receiver, absorbing the energy. As the gas passes through the receiver on the way to piston $A$, energy is absorbed which heats the gas. It then expands and pushes the piston down. When the piston reaches the bottom of the stroke, it starts moving up,

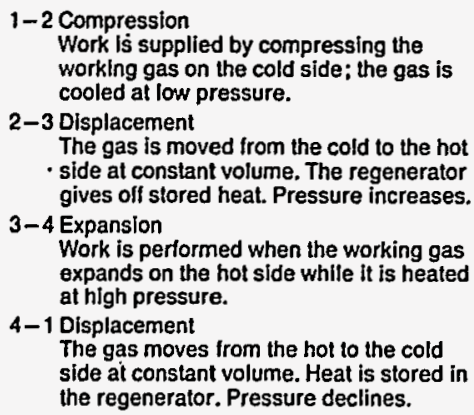

The gas is moved from the cold to the hot - side at constant volume. The regenerator gives olf stored heat. Pressure increases. 3-4 Expansion

Work is performed when the working gas expands on the hot side while it is heated athigh pressure.

4-1 Displacement

The gas moves from the hot to the cold side at constant volume. Heat is stored in the regenerator. Pressure declines.

The total volume of the space between the cylinders is thus reduced (compression) when most of the gas is on the cold side and the pressure is low. And the volume increases (expansion) when most of the gas is on the hot side and pressure is high. Theoretically, the Stirling process

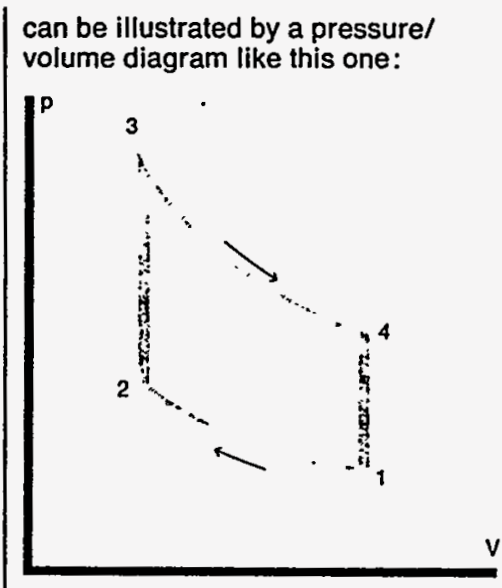

Theoretical pressure/volume curve

In reality, the curve has a somewhat different shape because the process entails continuous piston movements and continuous heating and cooling.

$P^{p}$

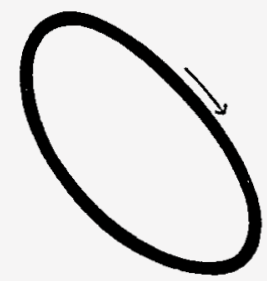

v

Actual pressure/volume curve

v

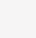




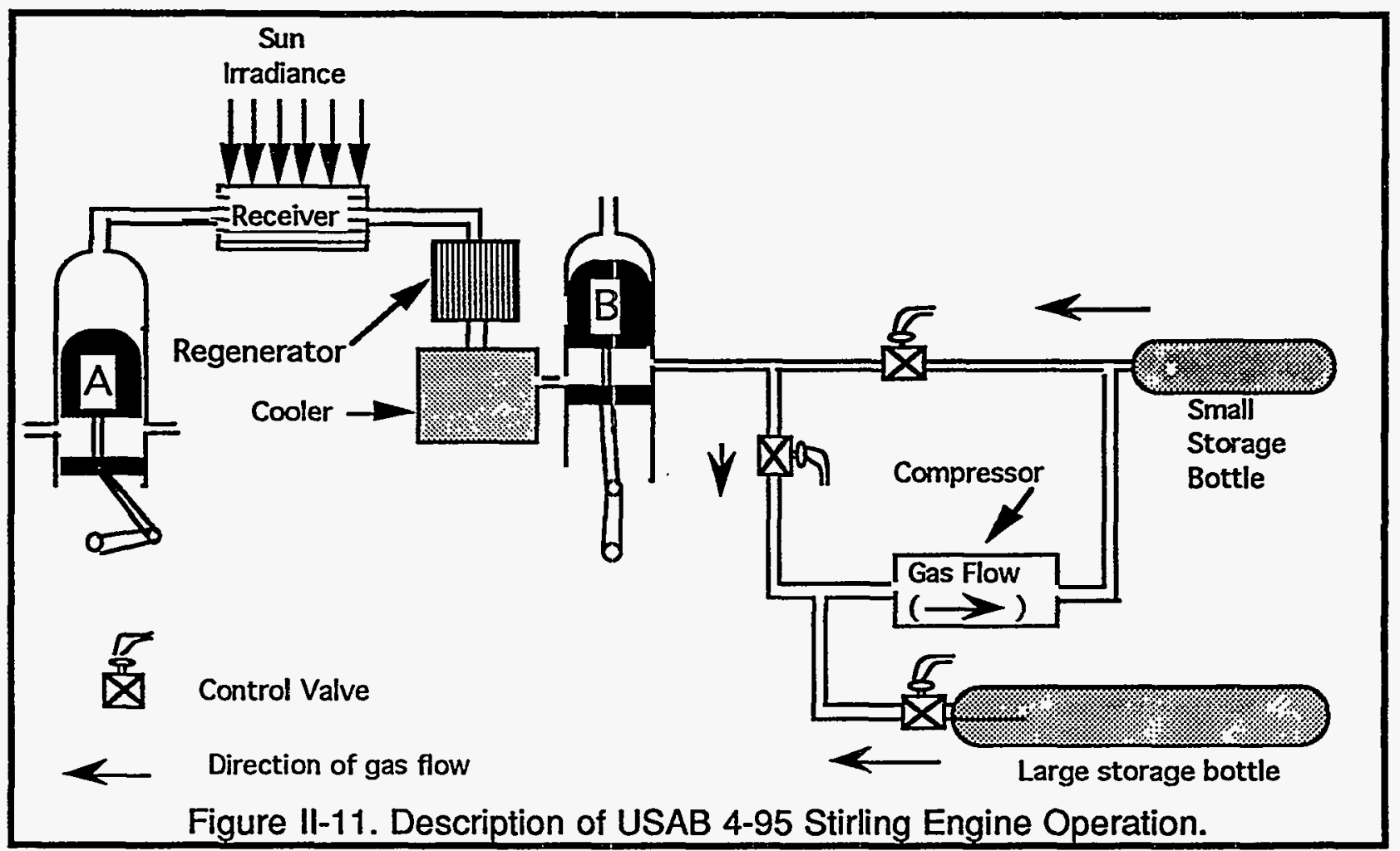

forcing the gas back through the receiver where additional energy is added. After the hydrogen gas passes through the receiver, it enters the regenerator where it gives up energy to the regenerator, thereby cooling the gas. From the regenerator, the gas enters the cooler where it is further cooled. The reduction in gas pressure due to cooling allows piston B to move down. As piston B moves down, the gas is forced back through the cooler. The gas temperature does not change much since it has already been cooled. After having flowed through the cooler, the gas enters the regenerator, where the energy that was taken out is now reintroduced. Then the gas enters the receiver, where more energy is added. This completes the cycle. Four cylinders, configured similar to Figure $\mathrm{II}-11$, are connected together in what is called the Siemens arrangement.

Hydrogen gas is added to or removed from the cold section to maintain a constant hot gas temperature, which is inferred from the highest receiver tube temperature. As the controlling tube temperature increases due to an increase in incident power, gas is added to the cycle from the storage bottle, which increases the coolant flow through the receiver and brings the tube temperature back to the set-point value. When the tube temperature drops due to a reduction in incident power, gas is removed from the 
cycle, compressed, and returned to the high-pressure storage bottle, which reduces coolant flow through the receiver and increases the working gas temperature.

The main components and functions of the PCU are:

- Receiver

Converts incident sun energy to thermal energy and transfers the heat to the hydrogen gas flowing through the tubes.

- Engine

Converts heat energy stored in the hydrogen gas into rotational mechanical energy.

- Generator

Converts rotational mechanical energy to electrical energy.

- Cooling system Collects waste heat from the engine and rejects it to the air.

- Control system Controls the engine operating temperature, maintains status of operation, detracks system, connects the system to the grid line, etc.

A Mark II Stirling engine cross section is shown in Figure II-12 and a photograph of the $\mathrm{PCU}$ is shown in Figure II-13.

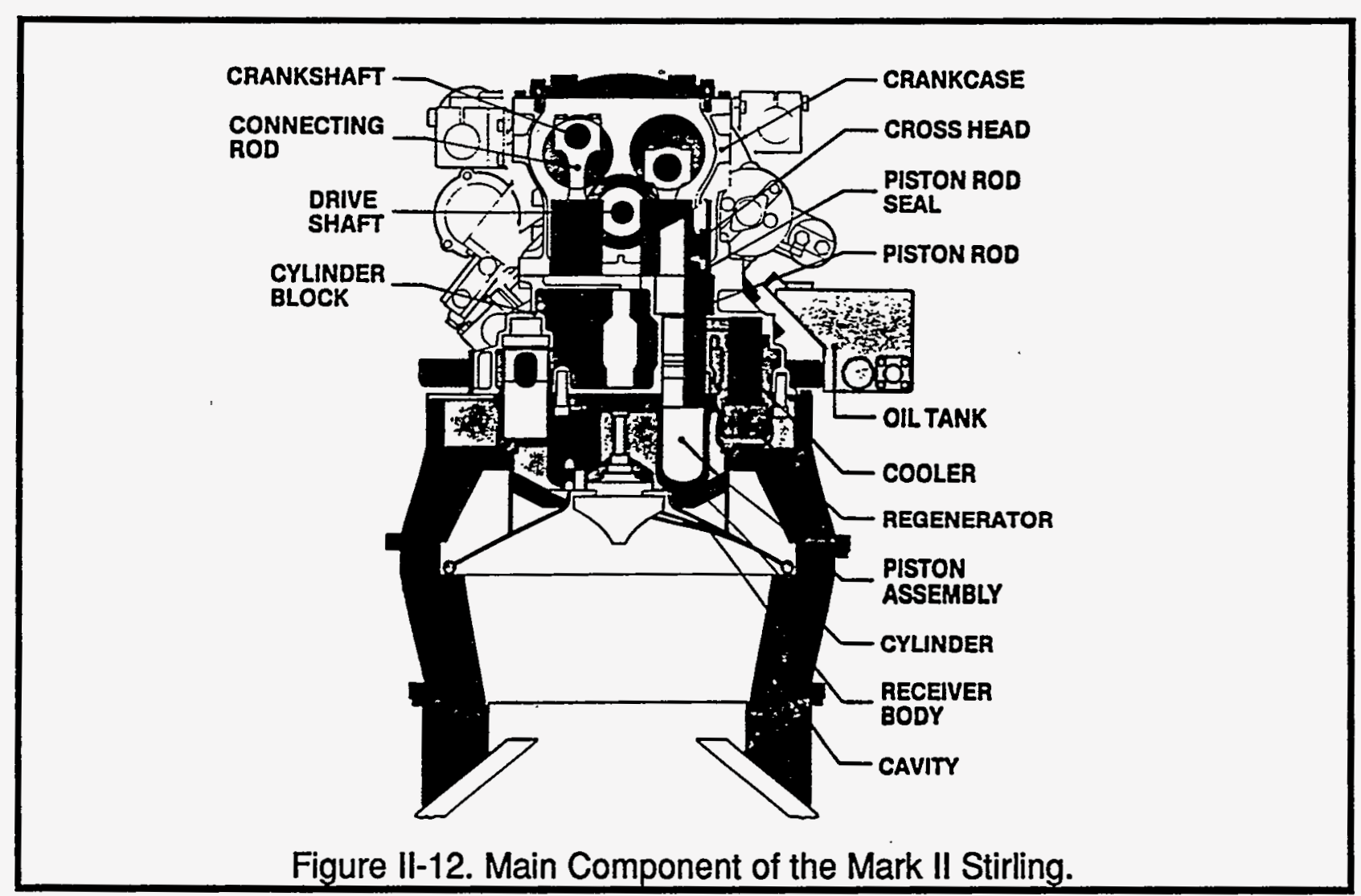




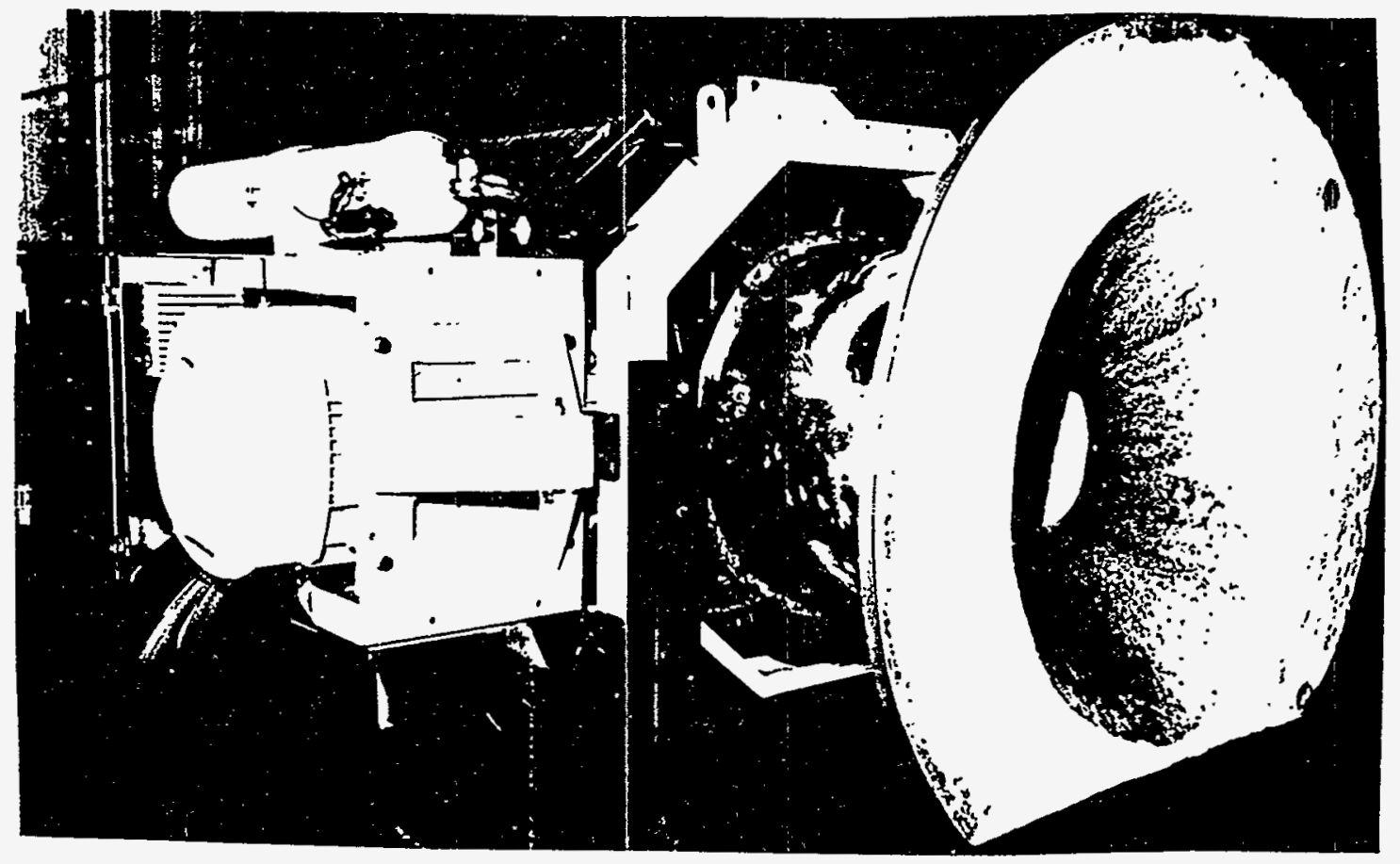

Figure II-13. Side view of the USAB Mark II Power Conversion Unit.

The normal morning startup sequence for the PCU shown in Figure II-14 is:

-The concentrator moves to a track position focusing the sun's radiant energy on the PCU receiver.

- The gas temperature rises to $720^{\circ} \mathrm{C}$ and the grid relay is closed, connecting the generator to the grid line. The startup current transient is shown in Figure II15.

-The generator acts as a starter motor and spins the Stirling engine up to $1800 \mathrm{rpm}$.

-The grid relay opens and the engine speed decreases to match the thermal level on the receiver.As the thermal energy in the receiver increases, the speed of the engine increases

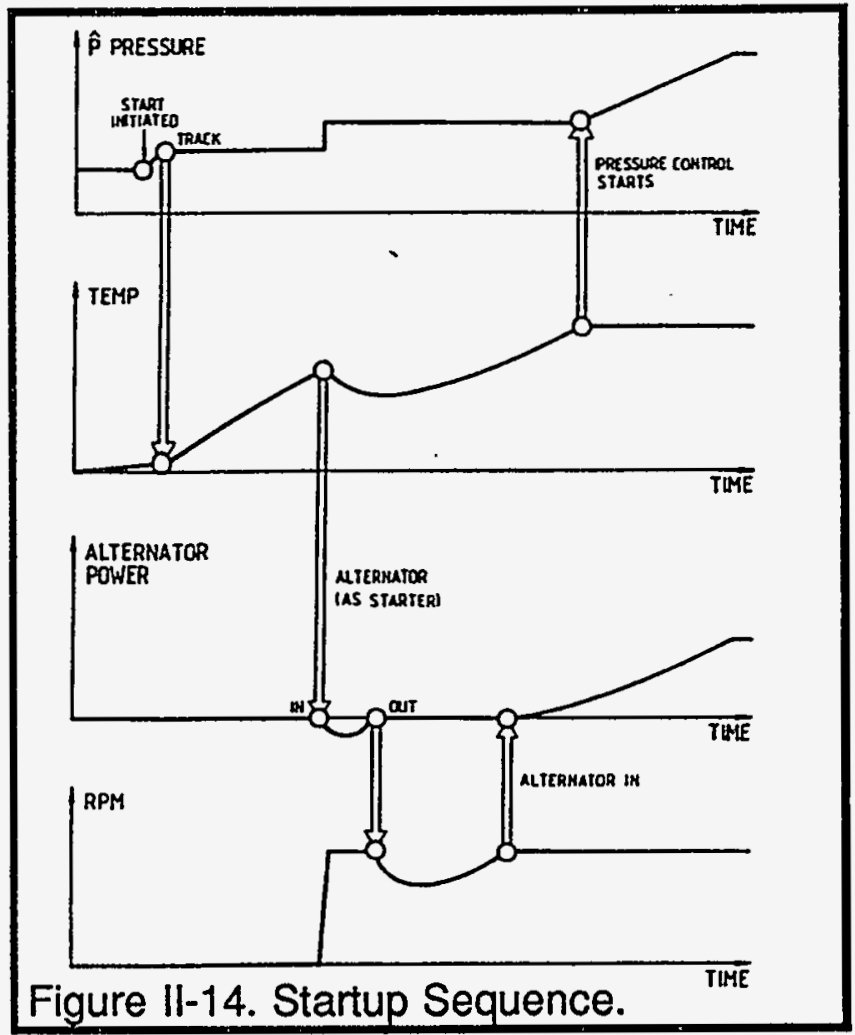




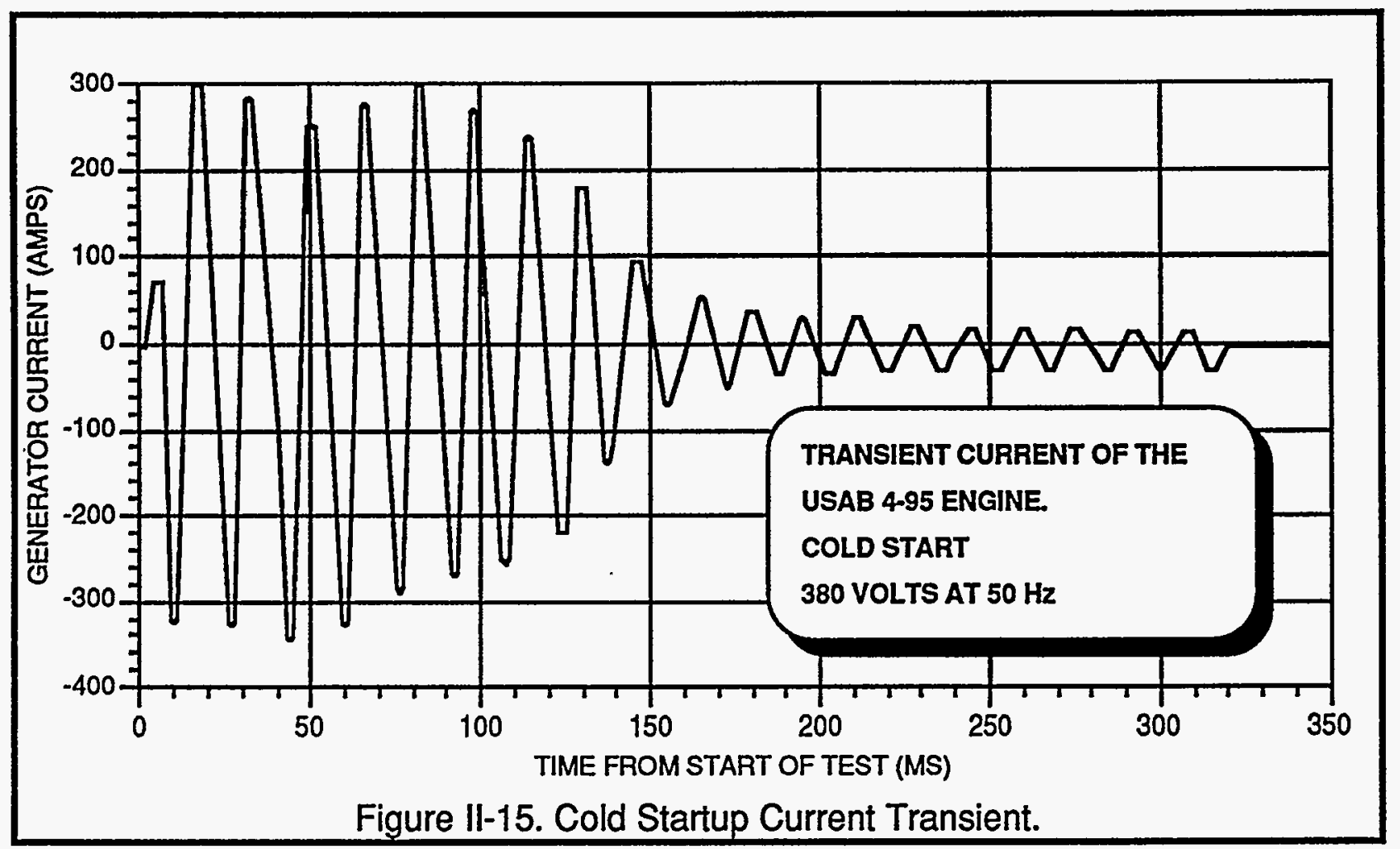

- When the speed reaches $1800 \mathrm{rpm}$, the grid relay closes and the generator is now supplying power to the grid line.

The difference in the working gas temperature between the four receiver quadrants affects the system's performance. Because all four pistons are connected through a common crankshaft, a lower temperature in one quadrant takes energy away from the other three. As discussed earlier in the system description, each mirror was aimed at a different point on the receiver to provide an even flux over the receiver (Figure II-4). An example of the working gas temperature of the four different quadrants is shown in Figures $\|-16$ and the maximum temperature difference between the four quadrants is shown in Figure II-17. Under most operating conditions, the maximum difference in the working gas temperature ranged between $30^{\circ}$ and $60^{\circ} \mathrm{C}$. Temperature differences as high as $100^{\circ}$ to $130^{\circ} \mathrm{C}$ were observed during the test period. These were usually the result of clouds, uneven dirty mirrors, winds, etc. but were not found to be a problem. When the mirrors were so dirty that there was a large temperature difference, the amount of power lost due to the lower reflectivity made it cost effective to wash the concentrator. 


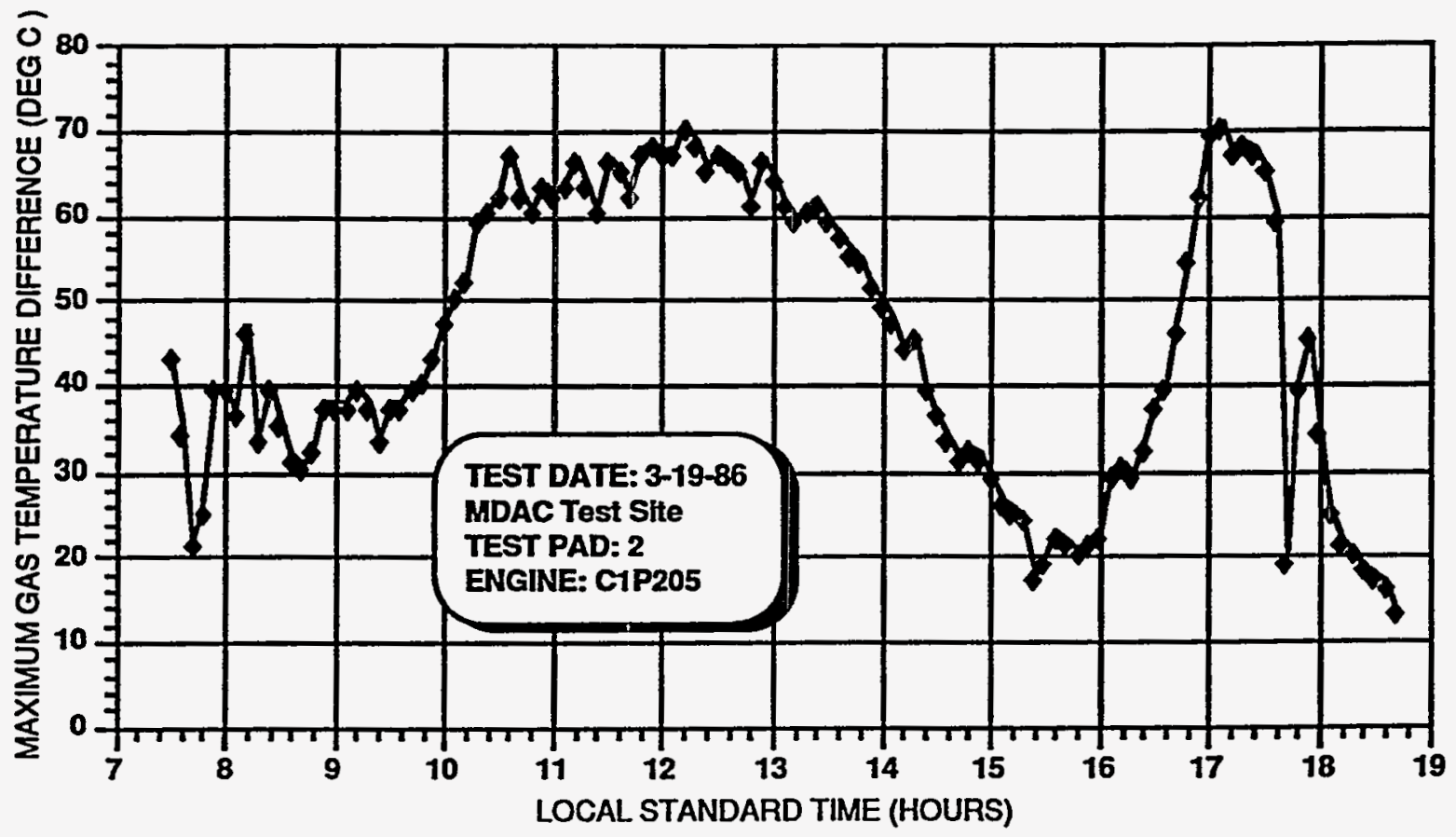

Figure II-16. Maximum Working Gas Temperature Differential.

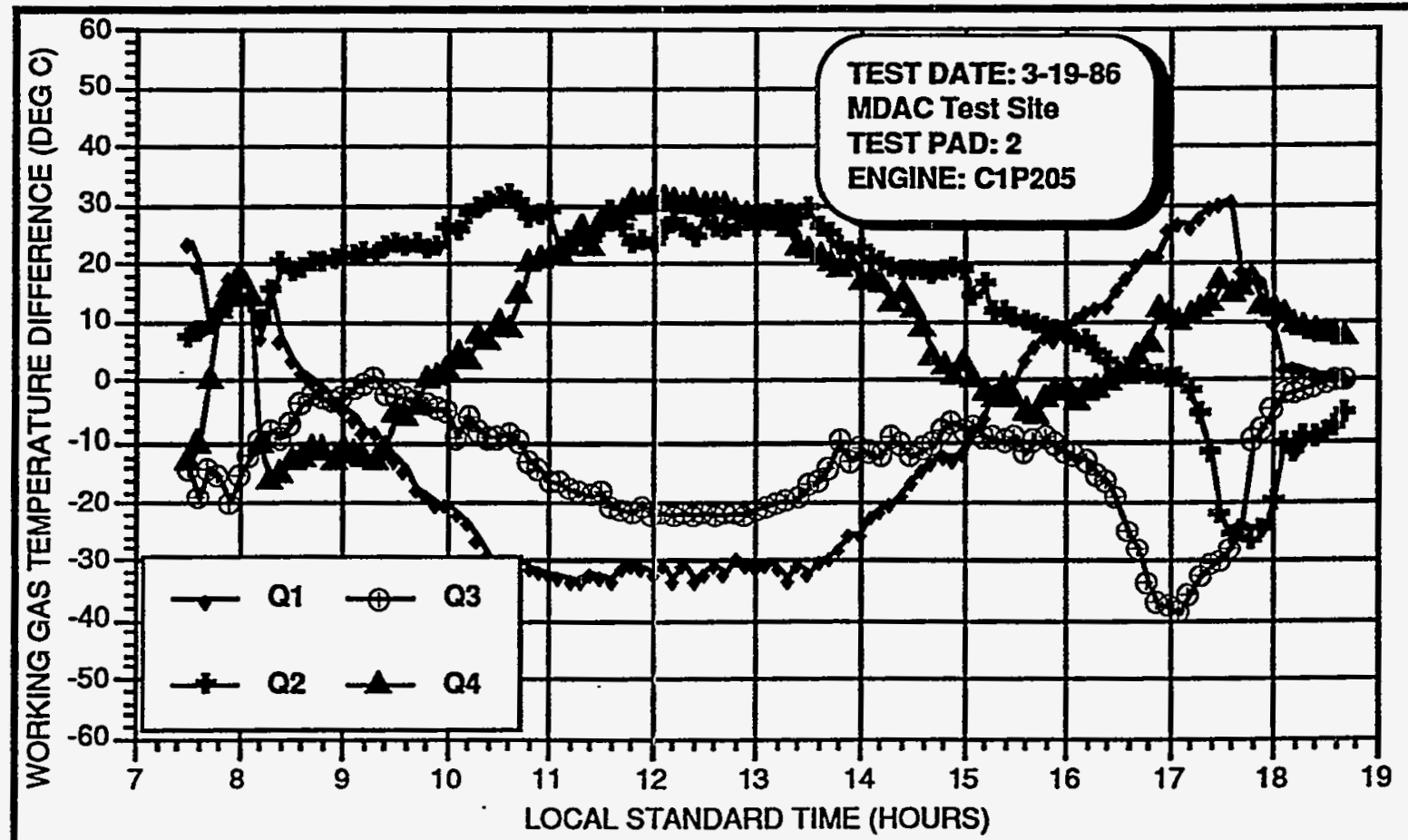

Figure II-17. Working Gas Temperature Differences. 
The program included testing of two different versions of the USAB 4-95 engine, the Mark I and Mark II power conversion units (PCU). The Mark I unit was tested at Edward's Air Force Base, and the refined Mark II design was first tested at Rancho Mirage, California. In the joint venture with MDAC, USAB upgraded and modified the Mark II PCU for installation on the MDAC solar concentrator. Mark I engines were used at the start of the MDAC/USAB/SCE program while the Mark II upgrades and modifications were being performed.

The original objectives of the Mark II were to reduce production cost, retain the high power performance level, and increase the system reliability. The Mark II production cost was estimated to be less than for the Mark I and the test program showed that the power performance level of the Mark II was the same as the Mark I. Because the program was not completed, there was not sufficient test time to verify that improved reliability was obtained.

The requirement to integrate a USAB PCU to a MDAC solar concentrator and to further refine the performance of the Mark II resulted in the prototype commercial Mark II PCU. The revised unit had the following design refinements:

- Optimized receiver

- Gas compressor integration to the engine

- New oil pump

- Gas refill system for extended operation

- PCU frame for installation on the solar concentrator

- Integral PCU control system

- Solar concentrator interface logic

- Combined generator/starter motor (the generator is motored to start the engine)

The differences in the Mark I, the original Mark II, and the MDAC version are described in "Design Summary of USAB 4-95 Stirling Power Conversion Unit," United Stirling $A B$, January 1986. As noted earlier, the MDAC/USAB joint venture tested the Mark I and the commercialized Mark II PCUs. A summary of the comparisons between the Mark I and Mark II is shown in Table II-2. Table II-3 compares the original and commercial Mark II. 


\begin{tabular}{|l|l|}
\hline \multicolumn{2}{|c|}{ TABLE II-2. Changes Made From Mark I to Mark II. } \\
\hline Receiver & $\begin{array}{l}\text { Heater element was redesigned to integrate solar } \\
\text { concentrator and PCU requirements. }\end{array}$ \\
\hline Regenerator & $\begin{array}{l}\text { A smaller size and new design were selected, } \\
\text { improving the cost. The design of the regenerator } \\
\text { housing was improved by eliminating the regenerator } \\
\text { housing manifolds, which were required for hybrid } \\
\text { operation. The regenerator matrix enclosure was } \\
\text { eliminated. The matrix was installed directly in the } \\
\text { receiver. The new design meant a one-time assembly } \\
\text { af receiver, including regenerators. The } \\
\text { regenerators could not be removed without destroying } \\
\text { them. }\end{array}$ \\
\hline Cylinder Liner/System & $\begin{array}{l}\text { The cylinder and cross head liner were combined into } \\
\text { a single piece, which improved the alignment of seal } \\
\text { and piston rings. }\end{array}$ \\
\hline Oil System & $\begin{array}{l}\text { The location of the oil tank was altered to improve the } \\
\text { return oil flow to the oil tank. }\end{array}$ \\
\hline Drive System & $\begin{array}{l}\text { The Mark I engine has an output shaft connected to the } \\
\text { generator via a gear system. The Mark II engine } \\
\text { crankshaft gears are connected directly to a generator } \\
\text { gear. Because the oil system lubricates this gear, the } \\
\text { generator shaft provided an oil seal. In this } \\
\text { arrangement, a fly wheel and a separate flange } \\
\text { between engine and alternator are not needed. }\end{array}$ \\
\hline $\begin{array}{l}\text { Components were integrated into modular blocks to } \\
\text { minimize the number of connections. A simplified } \\
\text { control system based in the experience gained on } \\
\text { previous tests was utilized. The reduction in } \\
\text { connections minimized gas leakage from the system. }\end{array}$ \\
\hline
\end{tabular}


TABLE III-3. Comparison of the Original and Commercial Mark II Components.

\begin{tabular}{|c|c|}
\hline Aperture Cone Cavity & $\begin{array}{l}\text { The aperture was designed specifically for the MDAC } \\
\text { solar concentrator and flux distribution. A new cavity } \\
\text { was made of two cast pieces rather than a large stack } \\
\text { of ceramic pieces. }\end{array}$ \\
\hline Gas Compressor & $\begin{array}{l}\text { The compressor was connected directly to the PCU } \\
\text { crankshaft. Previous design provided for a ground- } \\
\text { mounted unit to service multiple engines. }\end{array}$ \\
\hline Oil System & $\begin{array}{l}\text { Because of the dedicated gas compressor noted } \\
\text { above, a new pump was used that required relocation }\end{array}$ \\
\hline Gas Refill System & $\begin{array}{l}\text { In addition to the } 10 \text {-liter }\left(0.3 \mathrm{ft}^{3}\right) \text { gas bottle, a large } \\
\text { gas bottle with a capacity of } 11,330 \text { liters }\left(400 \mathrm{ft}^{3}\right) \text { was } \\
\text { added to the concentrator structure. The engine } \\
\text { compressor was used to pump gas from the large } \\
\text { bottle to the small bottle. This allowed the unit to } \\
\text { operate for extended periods between refills. }\end{array}$ \\
\hline Electrical & $\begin{array}{l}\text { All PCU electrical and control equipment were } \\
\text { mounted on the PCU. }\end{array}$ \\
\hline Control System & $\begin{array}{l}\text { Control logic was modified for integration with the } \\
\text { MDAC solar concentrator. }\end{array}$ \\
\hline Generator & $\begin{array}{l}\text { The generator was replaced with a unit that allowed } \\
\text { installation of a shaft gear and could be used as the } \\
\text { engine starter motor. The generator was replaced } \\
\text { with a unit capable of both } 50 \text { and } 60 \mathrm{~Hz} \text { operation. }\end{array}$ \\
\hline Frame Structure & $\begin{array}{l}\text { Because of flux patterns of the MDAC solar } \\
\text { concentrator and the noted revisions, the PCU support } \\
\text { design was revised. }\end{array}$ \\
\hline
\end{tabular}




\section{Data Acquisition System}

The configuration of the data acquisition system is shown in Figure Il-18. Except for a couple of minor differences, this data logging configuration was identical at the Huntington Beach Test Site, SCE Test Site and Georgia Power Test Site. The only major difference, as far as data analysis were concerned, was at Barstow and Georgia Power. The weather station at these sites operated on the same power lines as the lines furnishing power to the concentrator. Therefore, the daily power and energy usage recorded for the Stirling dish were biased by the power and energy consumed by this equipment. The amount of power/energy consumed by the weather station equipment is small, approximately 110 watts and $2.6 \mathrm{kWh}$ per day. Also note that at the SCE test site an Intersol PV system was installed on the same power lines as the Stirling Dish system. This system operated during the last two years of the test program. There was a meter to measure the generated power by the PV system which was subtracted from the Stirling Dish system. There was no meter to measure the power consumed by the PV system. The PV system parasitic power could not be measured separately from the power consumed by the Stirling dish. The parasitic power was estimated to be less than $1 \mathrm{kWh}$ per day. Attempts were made to measure the parasitic energy of these components when the concentrator was not operating but because of the granularity of the utility's metering, the measurements were not that accurate. It is estimated that the daily energy for the Georgia Power unit is low by 2 to $3 \mathrm{kWh}$ per day and the SCE unit is low by 3 to $4 \mathrm{kWh}$ per day. The data presented in this report have not been corrected for these factors.

The data that was recorded by the Fluke data logger as a function of time are shown in Table II-4. This data were transferred to cassettes from the Fluke and an IBM program was used to analyze the data. The IBM program produced a hard copy report and stored the data on floppy diskettes. There were eight monthly reports made for the SCE Test Site unit and six monthly reports made for the Georgia Power unit. These reports are listed in Reference 8. 


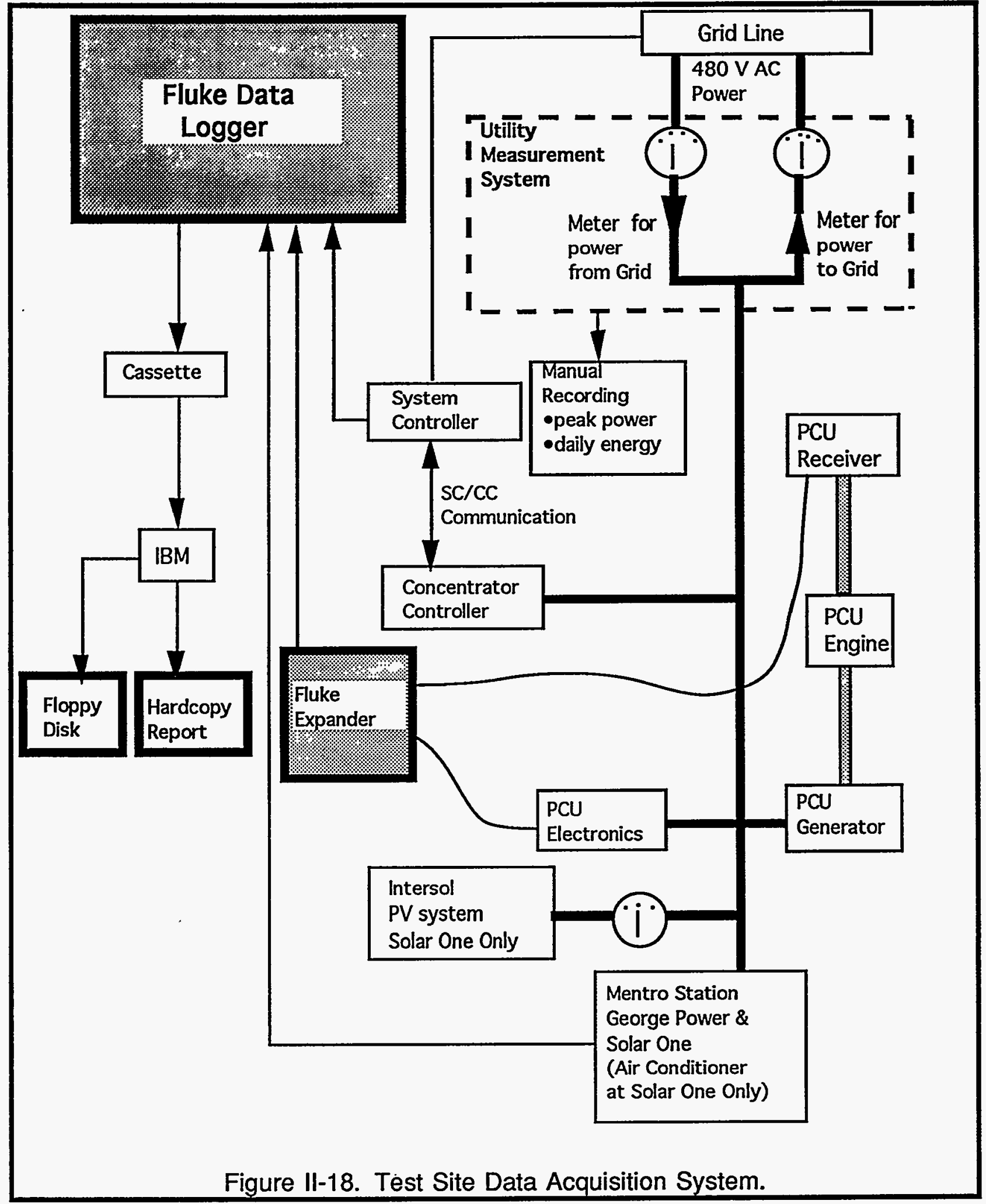


Table II-4. Parameters Recorded During Testing

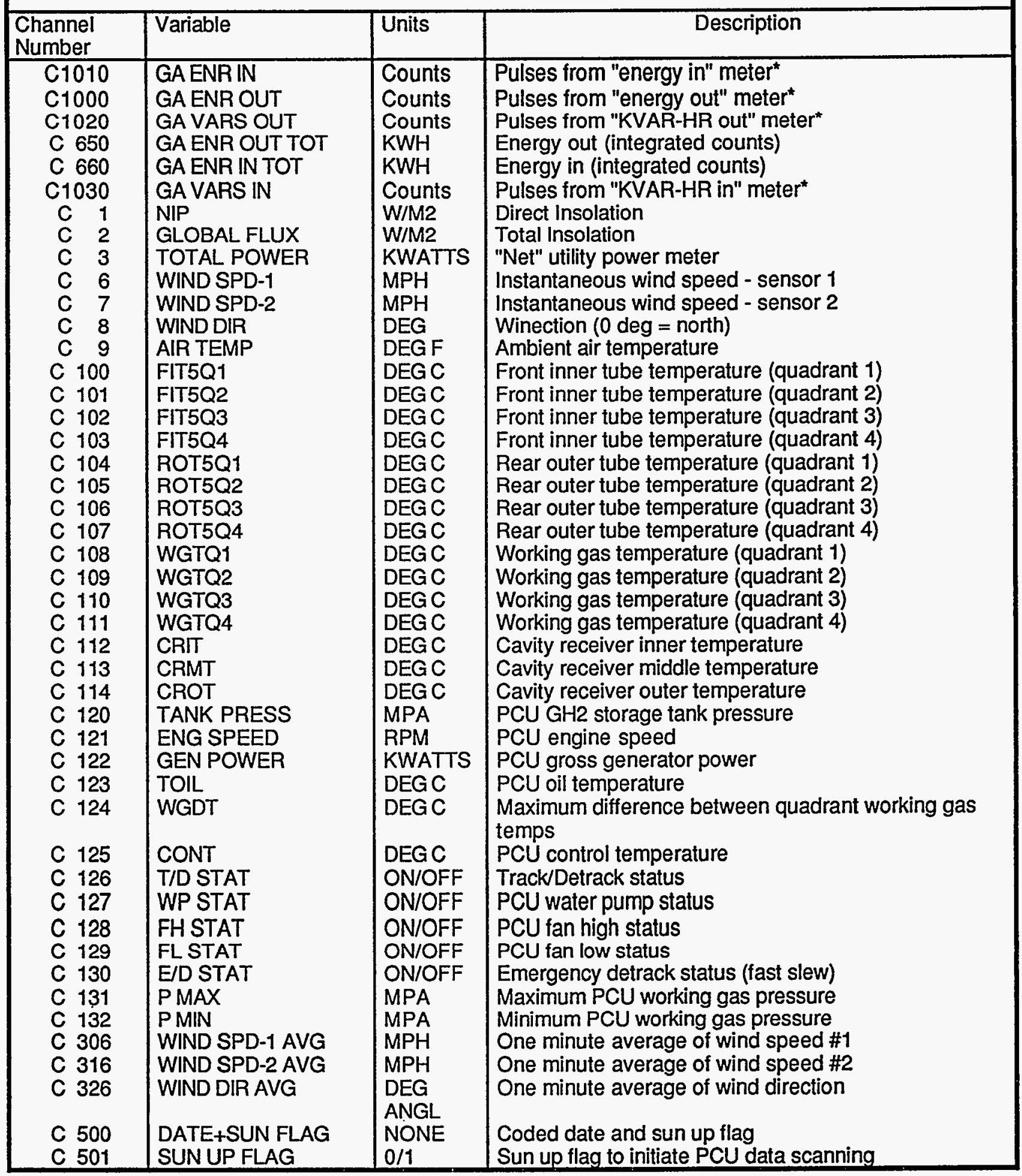


Table I1-4. Parameters Recorded During Testing

\begin{tabular}{|c|l|l|l|}
\hline $\begin{array}{l}\text { Channel } \\
\text { Number }\end{array}$ & Variable & \\
\hline C 502 & DATE & Description \\
C 510 & TIME & N2SEC & Current date (coded) \\
C 520 & AZ MOTOR TURNS & COUNTS & Coded GMT time \\
C 530 & EL MOTOR TURNS & COUNTS & Coded elevation motor turns \\
C 540 & SUN INTEN+CMODE & NONE & Coded insolation level \& CC operating mode \\
C 550 & SUN AZ+EL ERROR & NONE & Coded azimuth/elevation sun sensor error \\
C 560 & WGTM & DEGC & PCU working gas mean temperature \\
C 4 & TOTAL VARS & KVARS & Net utility KVAR meter \\
C 670 & GA VARS OUT TOT & KVARS & KVAR-HR out (integrated counts) \\
C 680 & GA VARS IN TOT & KVARS & KVAR-HR in (integrated counts) \\
\hline
\end{tabular}




\section{POWER PERFORMANCE}

- Peak power efficiency of $30 \%$ at $1000 \mathrm{~W} / \mathrm{m}^{2}$ sun irradiance

- Operation at low sun irradiance levels as low as $200 \mathrm{~W} / \mathrm{m}^{2}$ sun irradiance

- Fast response to changes in sun irradiance caused by clouds

The power design performance goal for the Stirling dish set by MDAC/USAB at the beginning of the program was that the system generate positive power at sun's irradiance levels between $300 \mathrm{~W} / \mathrm{m}^{2}$ and $1000 \mathrm{w} / \mathrm{m}^{2}$ and $25 \mathrm{~kW}$ net power at 1000 $\mathrm{W} / \mathrm{m}^{2}$. This section presents the peak power performance and estimates the power performance of each component. The performance measurement techniques and information supporting the performance estimates are also presented. A summary of the daily test data is contained in Appendix A for the MDAC test site, Appendix B for the Georgia Power test site, and Appendix $C$ for the Solar One test site.

\section{Power Output Performance}

Operation of the Stirling dish generally started very early in the morning after sunrise when the sun's irradiance level was very low and power performance would increase throughout the morning as the sun's irradiance level increased. In the afternoon, the power level would decrease as the sun began to set and the sun's irradiance level decreased. A typical example of this power profile is shown in Figure III- 1 by the direct normal sun's irradiance and instantaneous net-power output versus time on a clear day at the Huntington Beach test site. The small variations in the net output power during the day are caused by a small variation in the sun's irradiance level and the on/off operation of the PCU cooling fan. The same data are plotted in Figure III-2 as a function of the direct normal sun irradiance level. As shown in this figure, the Stirling engine will start producing positive net power by the time the sun's irradiance level reaches $300 \mathrm{~W} / \mathrm{m}^{2}$. However, the engine will produce power in the evening at sun's irradiance levels as low as $200 \mathrm{~W} / \mathrm{m}^{2}$, as shown in this figure. This difference was caused by the thermal mass of the receiver. In the morning, the engine reached the operating temperature at a sun's irradiance level of $200 \mathrm{~W} / \mathrm{m}^{2}$ to $250 \mathrm{~W} / \mathrm{m}^{2}$ and the engine started rotating, but because the receiver started cold, it took a few minutes for the receiver to fully heat up and the engine to obtain the required speed to connect to the grid line. By this time, the irradiance level had risen to approximately $300 \mathrm{~W} / \mathrm{m}^{2}$. 


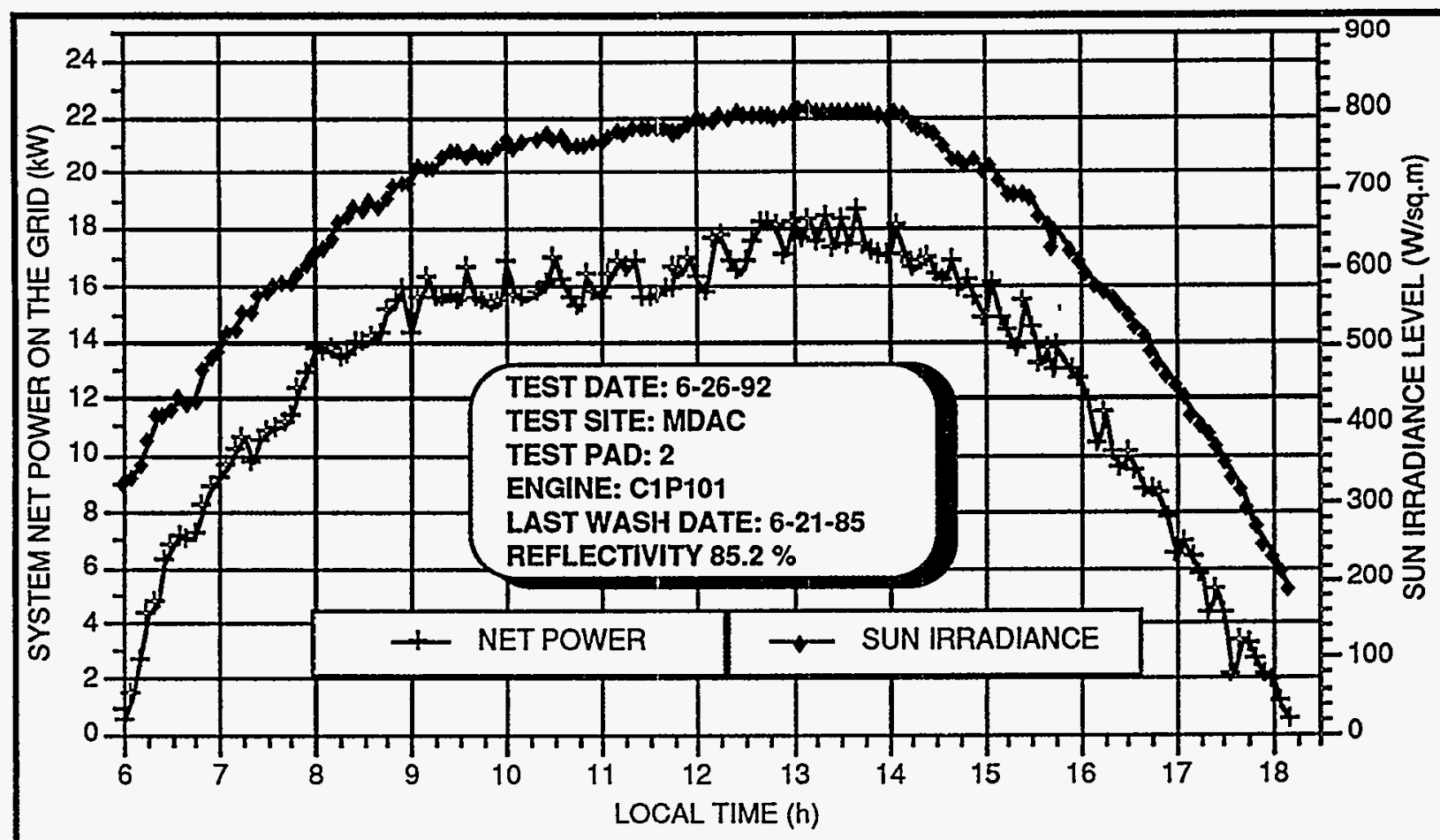

Figure III-1. Typical Power Performance of the System as a Function of Time.

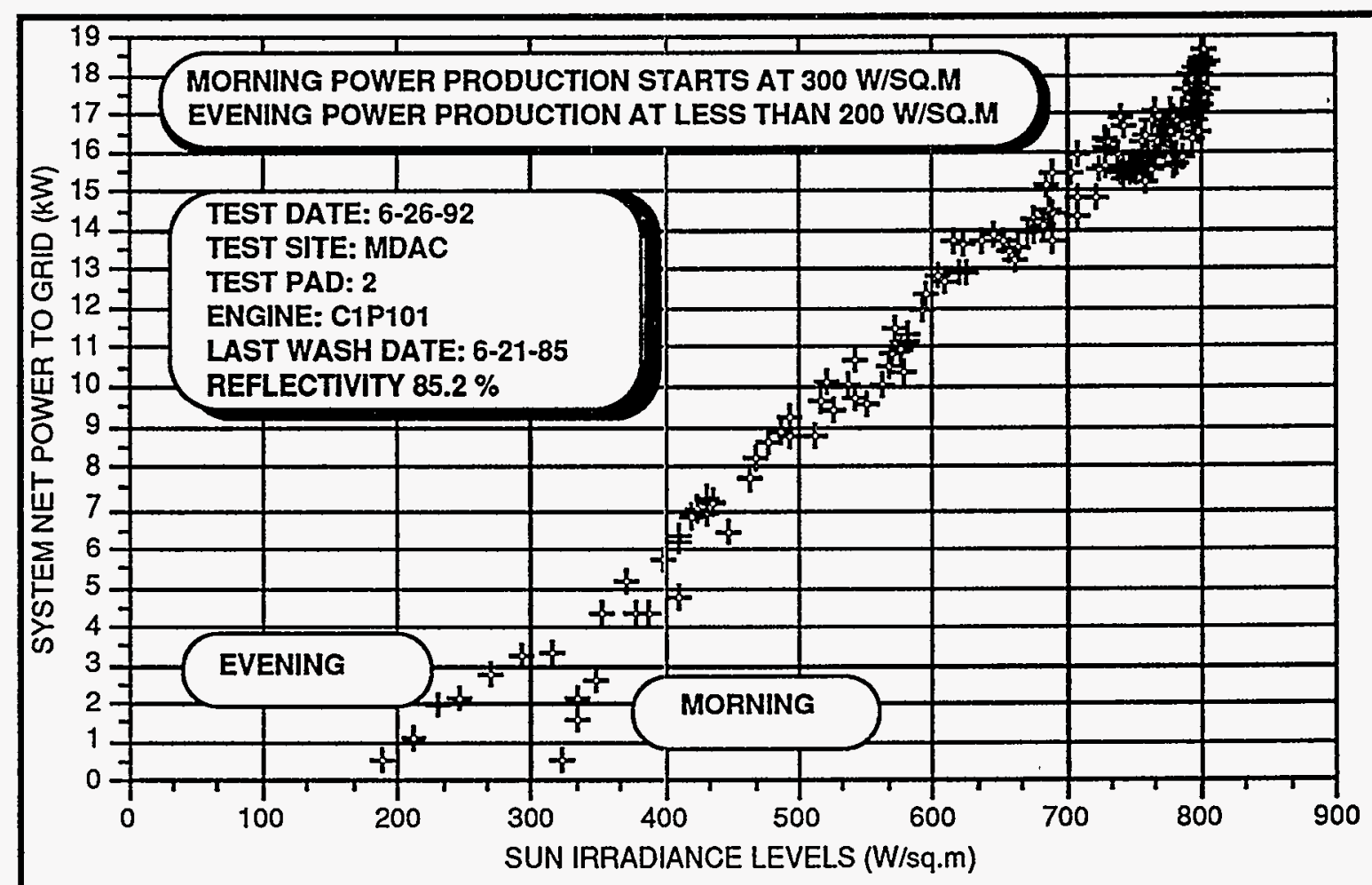

Figure III-2. Power Performance as a Function of the Sun Irradiance Level. 
As shown in these plots, the Stirling dish has a very low operating threshold and it responds very quickly to changes in the sun's irradiance level. This is an advantage for a solar conversion system because the sun's irradiance level can rise and fall significantly from clouds passing over. When the sun's irradiance level recovers to $300 \mathrm{~W} / \mathrm{m}^{2}$, the PCU produced electrical power within 20 seconds. This rapid response to changes is illustrated in Figure III-3 by the power transient response to the sun's irradiance level on a cloudy day at Huntington Beach. There is enough thermal mass in the receiver to carry the PCU through very short periods of low solar insolation. The data in this figure shows, even when the sun's irradiance level falls below $200 \mathrm{w} / \mathrm{m}^{2}$ for several minutes, the system will still generate positive power.

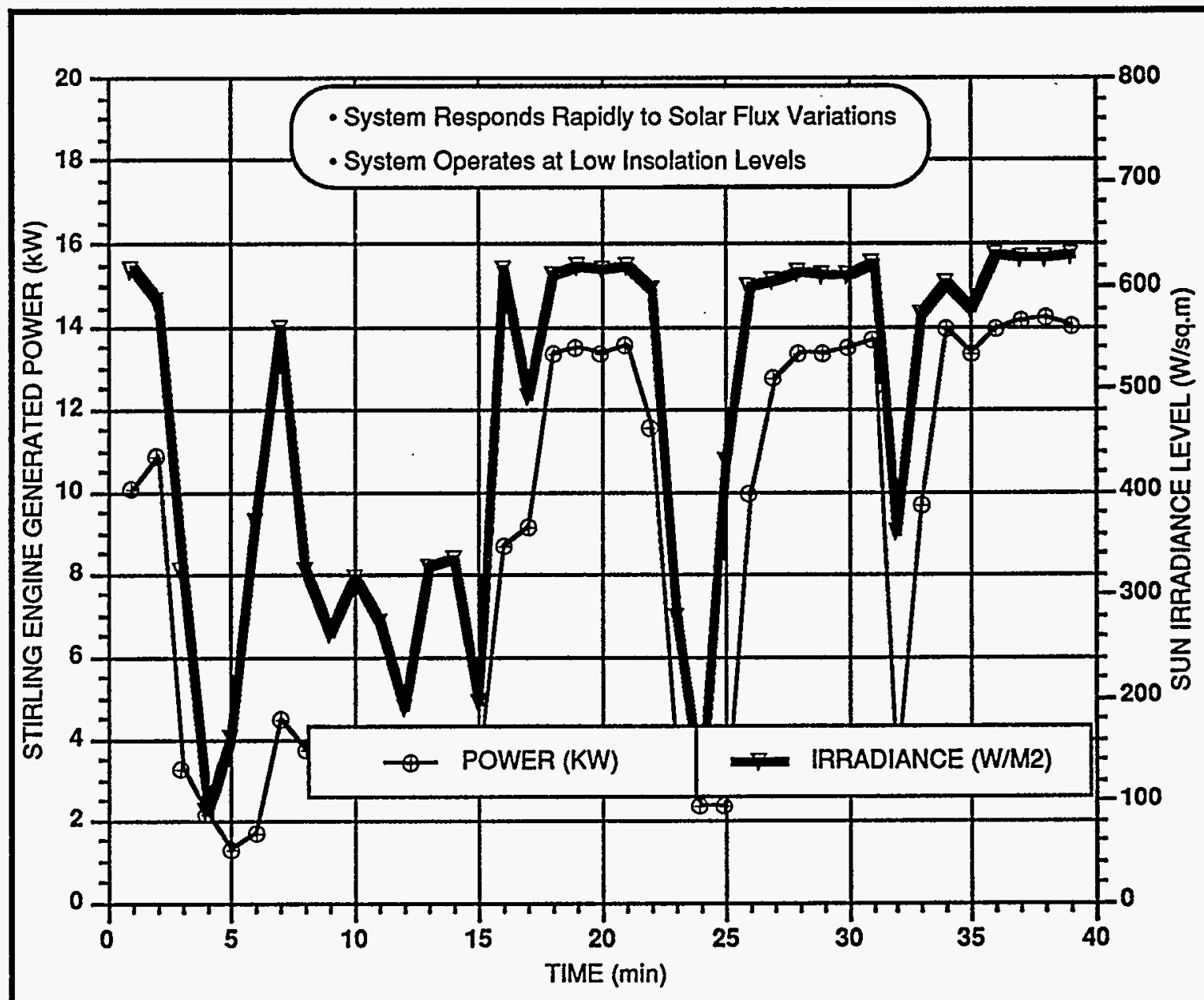

Figure III-3. Typical Response of the Stirling Dish System on a Cloudy Day. 


\section{Power Efficiency}

One measure of system performance is the power efficiency. The power efficiency of the Stirling dish is defined as:

Power Efficiency $=$ Instantaneous Net Power

(Sun Irradiance) (Dish Sun Aperture Area)

The dish aperture area or sun-normal reflective area is $87.67 \mathrm{~m}^{2}$. This was found by taking the individual mirror area of $1.11 \mathrm{~m}^{2}$ and projecting it on a plane perpendicular to the sun. The resulting sun-normal reflective area for each mirror is shown in Table III-1. The total glass surface area is $91.01 \mathrm{~m}^{2}$. The net power level and power efficiency are shown in Figure III-4 as a function of the sun's irradiance level for the MDAC test site. These data shows that the system produces net power at irradiance levels of approximately $200 \mathrm{~W} / \mathrm{m}^{2}$. The power output is greater than the design performance requirement between $200 \mathrm{~W} / \mathrm{m}^{2}$ and $1000 \mathrm{~W} / \mathrm{m}^{2}$. Since the sun's

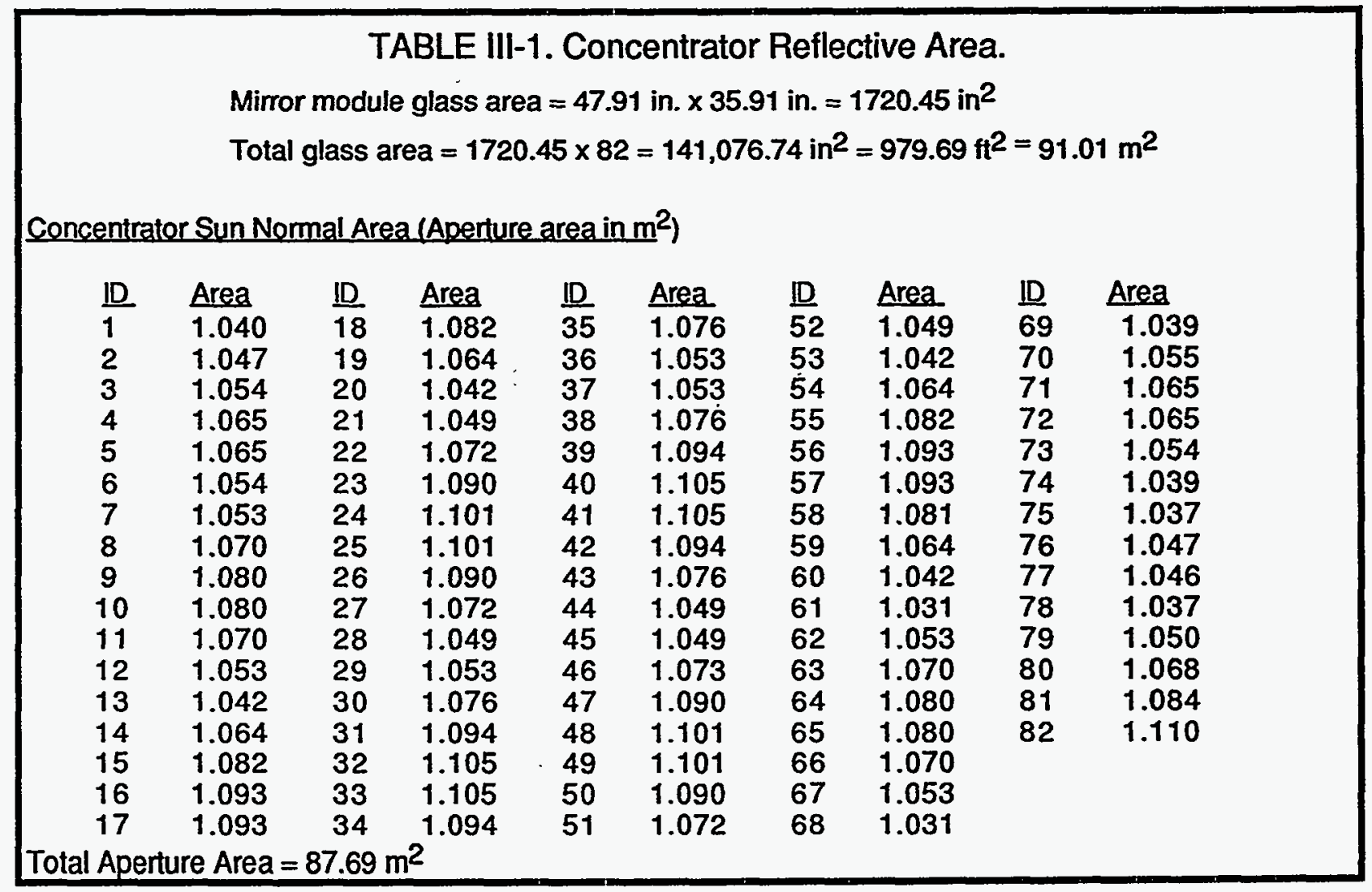




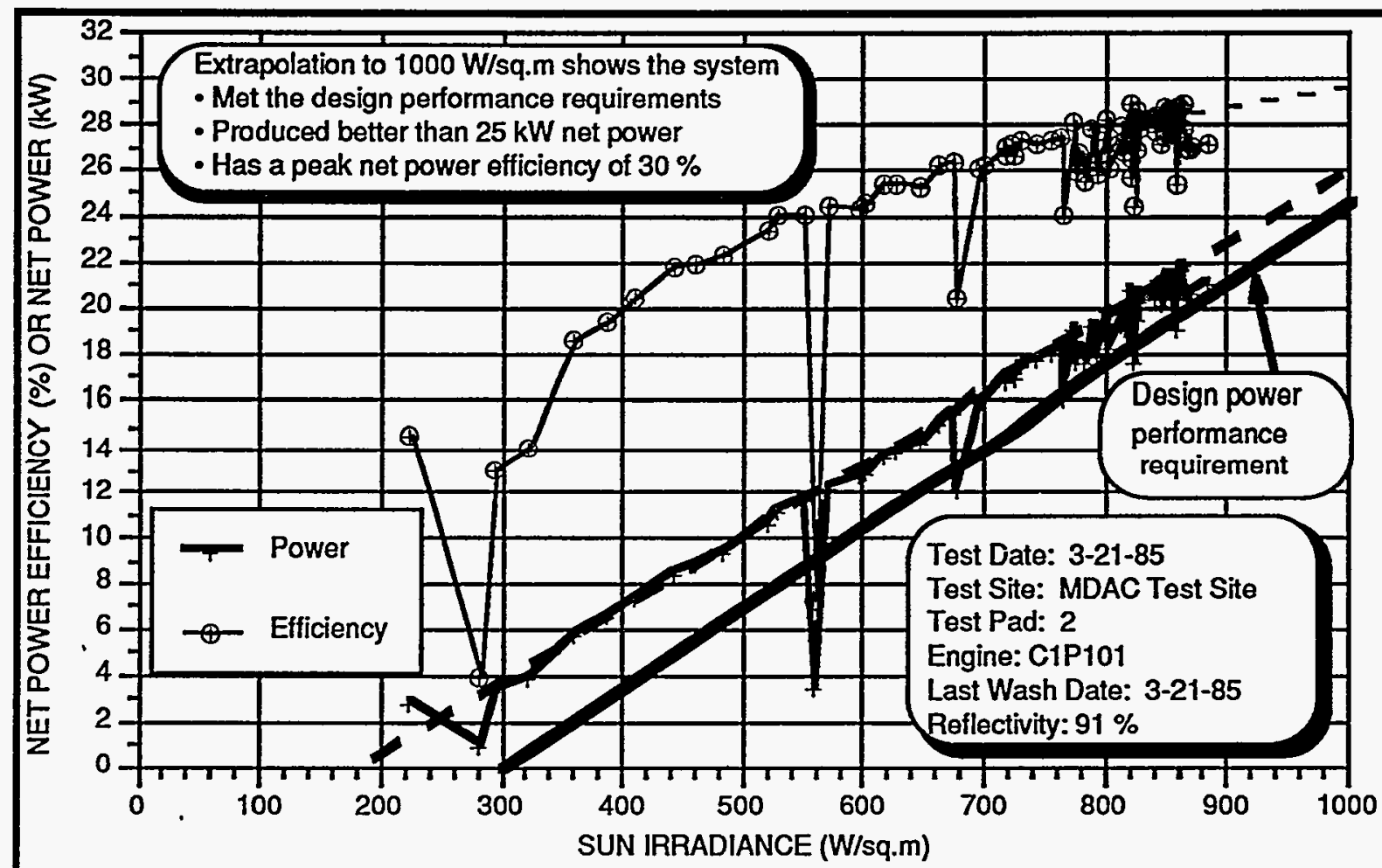

Figure III-4. Peak Net Power and Efficiency Performance.

irradiance level very seldom gets above $900 \mathrm{~W} / \mathrm{m}^{2}$ at Huntington Beach, the estimated upper power level is determined by extrapolating the net power data to a sun's irradiance level of $1000 \mathrm{~W} / \mathrm{m}^{2}$. Again by extrapolating to $1000 \mathrm{~W} / \mathrm{m}^{2}$, the power efficiency data in this figure shows that the system had a peak power efficiency of approximately $30 \%$ at a sun's irradiance level of $1000 \mathrm{~W} / \mathrm{m}^{2}$. Another example is the set of data shown in Figure III-5 for March 19, 1986 at the SCE One Test Site. In this case the sun irradiance level was higher than $990 \mathrm{~W} / \mathrm{m}^{2}$. The system produced a peak of $26 \mathrm{~kW}$ of power with a net efficiency of a little over $30 \%$. The mirror reflectivity for this day was unknown and the log does not indicate when the unit was last washed. The data logs also shows that the Georgia Power Test Site exceeded $26 \mathrm{~kW}$ several times when the irradiance level reached $1000 \mathrm{~W} / \mathrm{m}^{2}$.

\section{Peak Power Efficiency}

The peak power efficiencies of the subsystems are shown in Figure III-6. This section analyzes the system's peak power efficiency and discusses supporting test and collaborating data. The major sources of power loss are listed in Table III-2. The Peak 


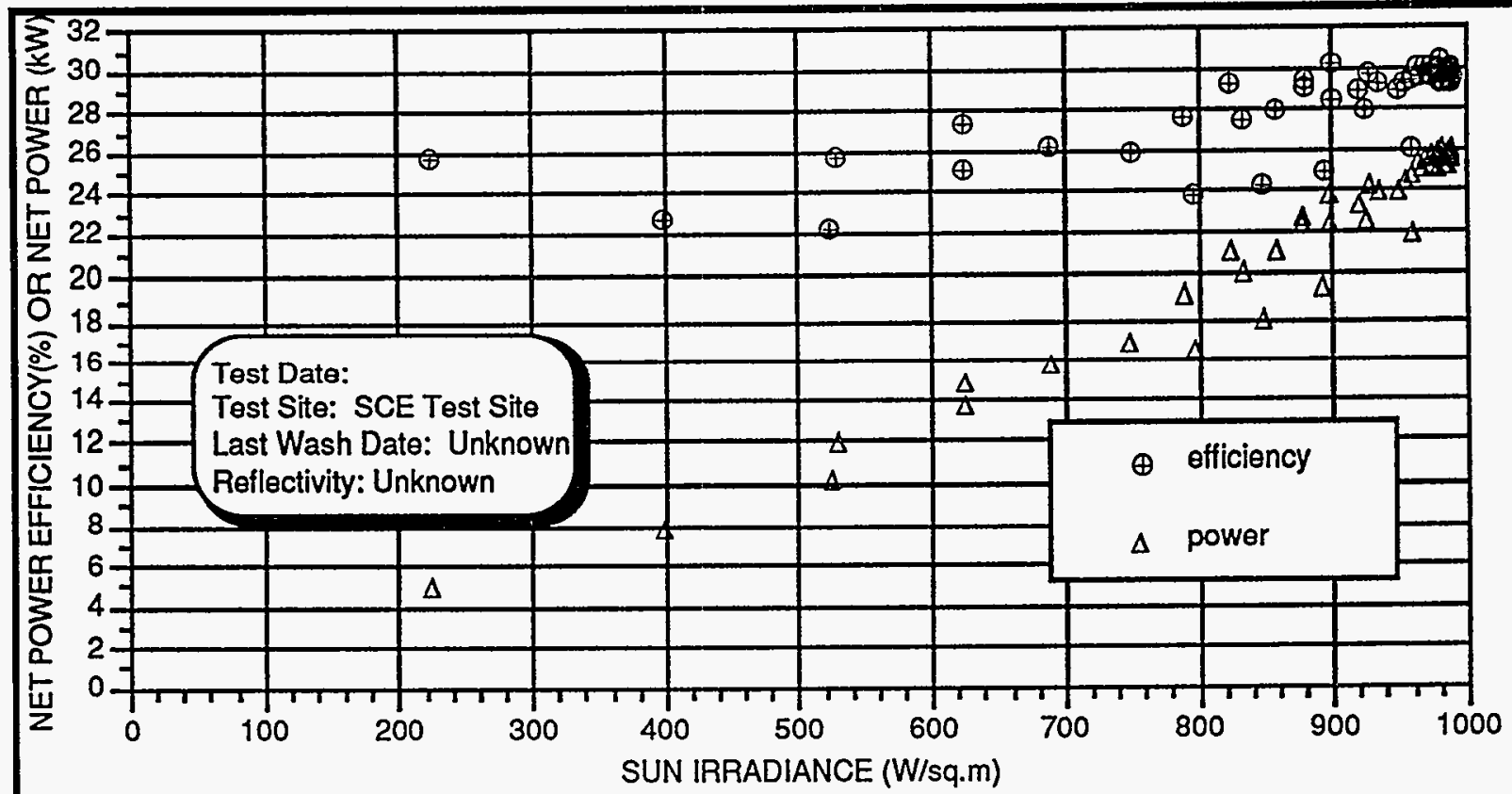

Figure III-5. Peak Power and Peak Power Efficiency at the SCE Test Site.

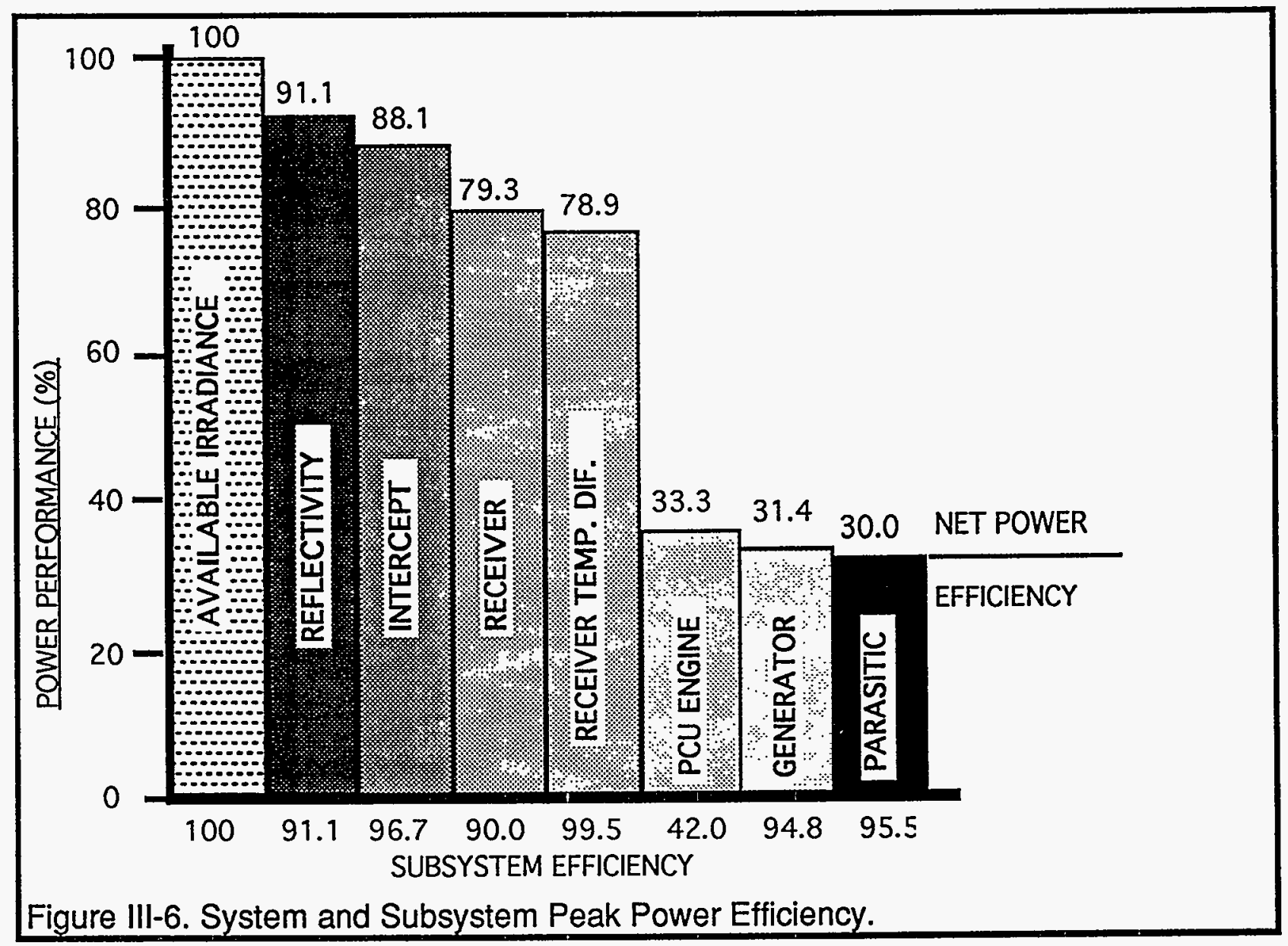


Table III-2. Power Losses.

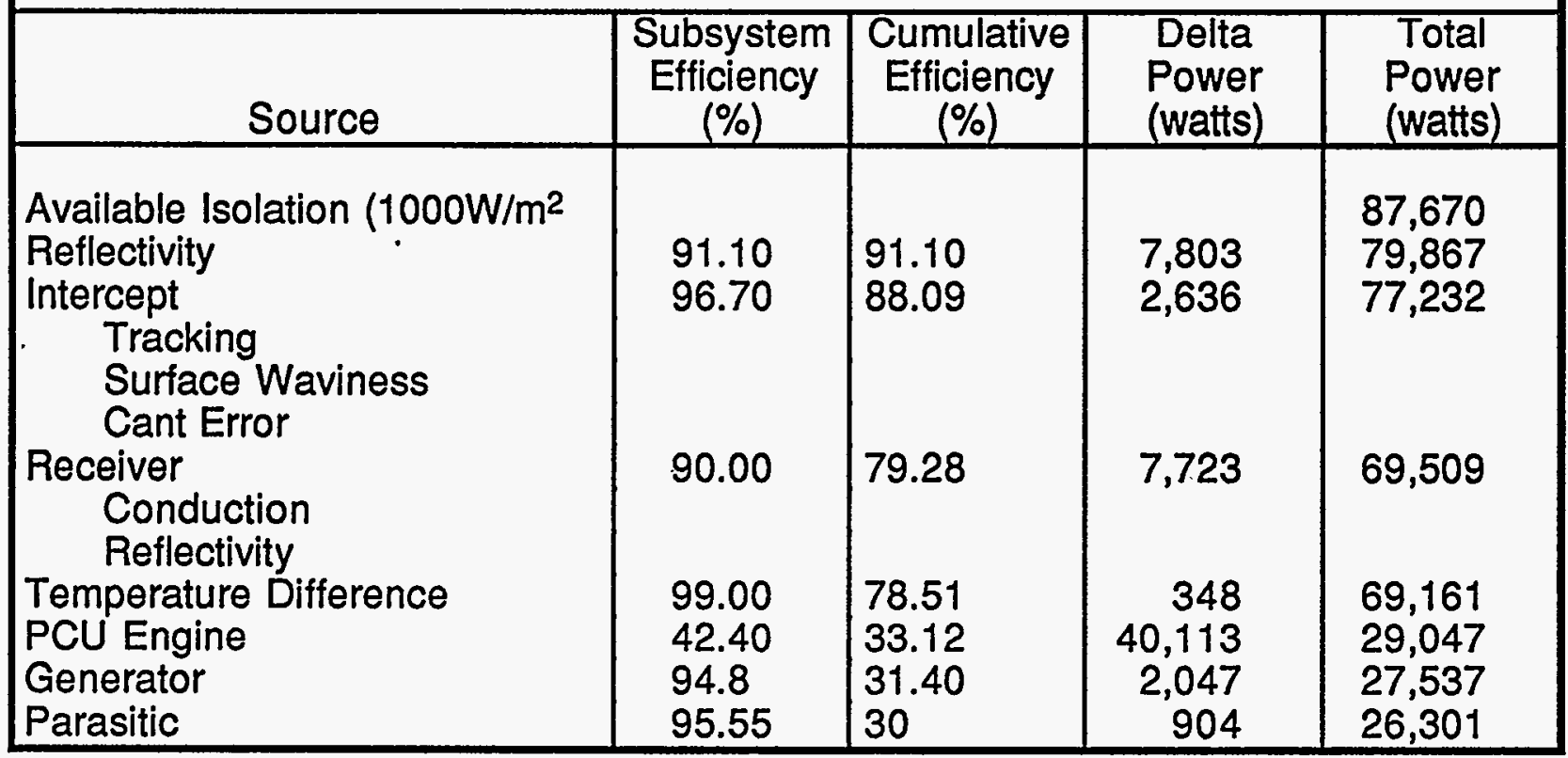

power efficiencies were obtained from the data presented in Figure III-4 and Figure III5. The subsystem efficiency was obtained by direct measurement, analytical analysis, or manufacture specifications. The method for determining subsystem efficiencies are discussed in the following sections.

\section{AVAILABLE INSOLATION}

The available insolation is assumed to be $1000 \mathrm{~W} / \mathrm{m}^{2}$ over a sun-normal reflective area of $87.67 \mathrm{~m}^{2}$. The total available power is 87,670 watts.

\section{REFLECTIVITY}

The peak power efficiency will vary directly with the reflectivity of the mirrors. Soiling of the mirrors not only causes a loss in power because of lower reflectivity, but because the lower mirrors soil more quickly, resulting in uneven flux on the receiver. The reflectivity for the dish on pad \#2 at the MDAC test site is shown in Figure III-7 for a little over one year of the testing period. The reflectivity measurement is an average of six measurements per facet for four different facet locations. The data in Table III-3 shows the reflectivity before and after washing. 


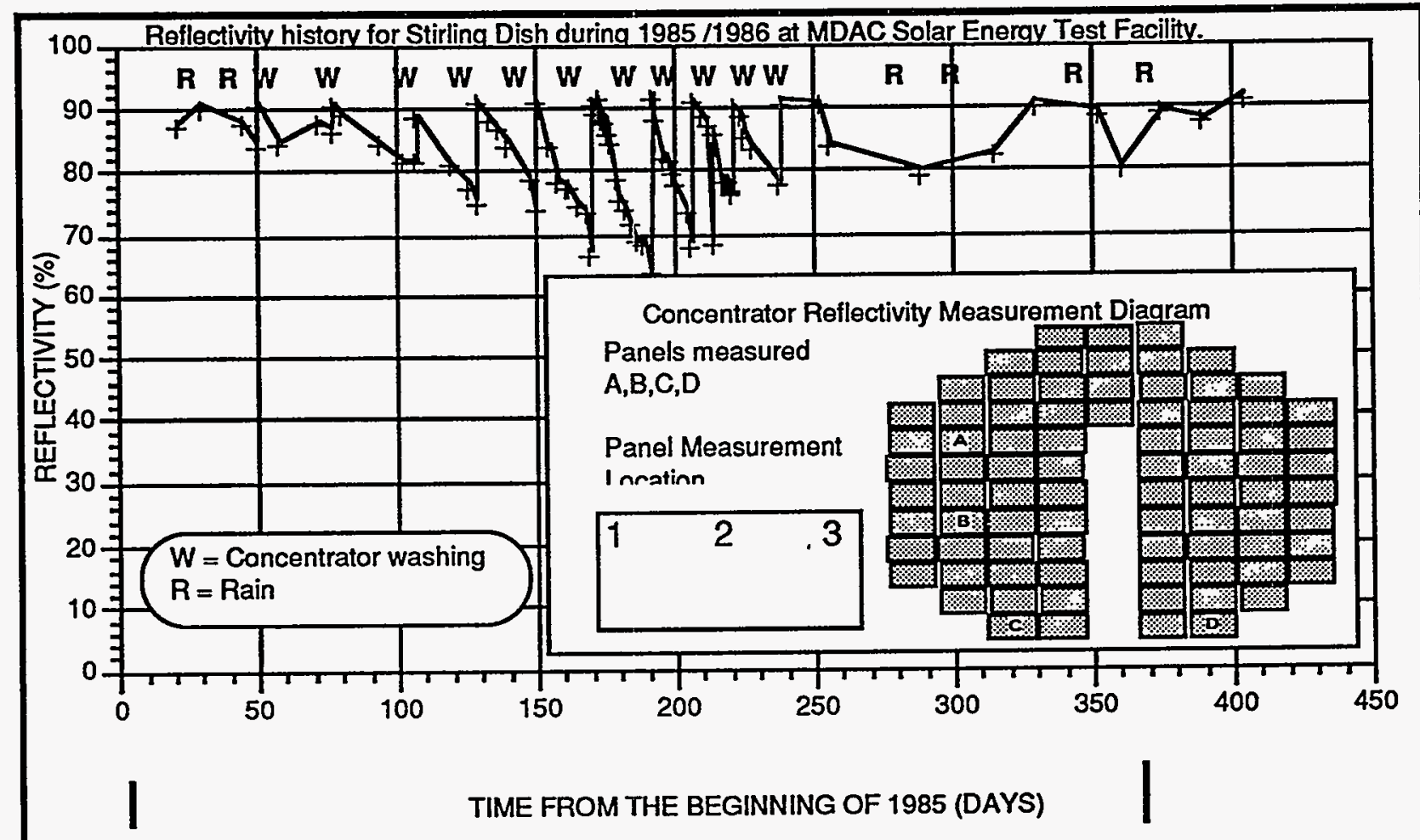

Figure III-7. Mirror Reflectivity History for MDAC Test Site.

\begin{tabular}{|c|c|c|}
\hline \multicolumn{3}{|c|}{ Table III-3. Reflectivity Before and After Washing. } \\
\hline Date & Before Washing & Reflectivity (\%) \\
\hline & & After Washing \\
$6 / 18 / 85$ & 67.7 & 91.4 \\
$6 / 21 / 85$ & 90.0 & 92.0 \\
$7 / 11 / 85$ & 64.3 & 92.2 \\
$7 / 25 / 85$ & 68.9 & 91.7 \\
$8 / 02 / 85$ & 69.1 & 86.6 \\
$8 / 09 / 85$ & 77.1 & 90.7 \\
& & Mean $=91.1$ \\
& & Standard Dev. $=1.63$ \\
\hline
\end{tabular}

This data shows that a mean reflectivity of $91.1 \%$ was obtained after washing. The washing technique is a non-contact spraying method developed by MDAC which takes about 10 to 15 minutes per dish. Because of the difficulty in taking the measurements on the higher mirrors, some of the data are an average of the readings 
from mirrors $C$ and $D$ only. The reflectivity data from other test sites were not recorded regularly.

The variation in the rate of soiling is shown in Figure III- 8 as a function of the number of days since washing. The mean soiling rate for the MDAC test site is shown in Figure III-9. This rate of soiling is considered to be higher than normal because land excavation was going on nearby during several months covered by the test period.

\section{INTERCEPT}

Intercept losses are defined as energy spillage caused by tracking errors, mirror module cant error, mirror surface waviness, aperture size, variation in the radius of curvature of the mirror, position error resulting from winds, etc. No measurements were made to determine the magnitude of intercept losses, but measurements were made to determine the magnitude of some of the contributors such as tracking, waviness, and cant error. An analytical program was used to estimate the magnitude of the intercept losses. The calculated sensitivity curves for different error sources are given in Figure III-10. These curves show spillage out of the receiver aperture as a

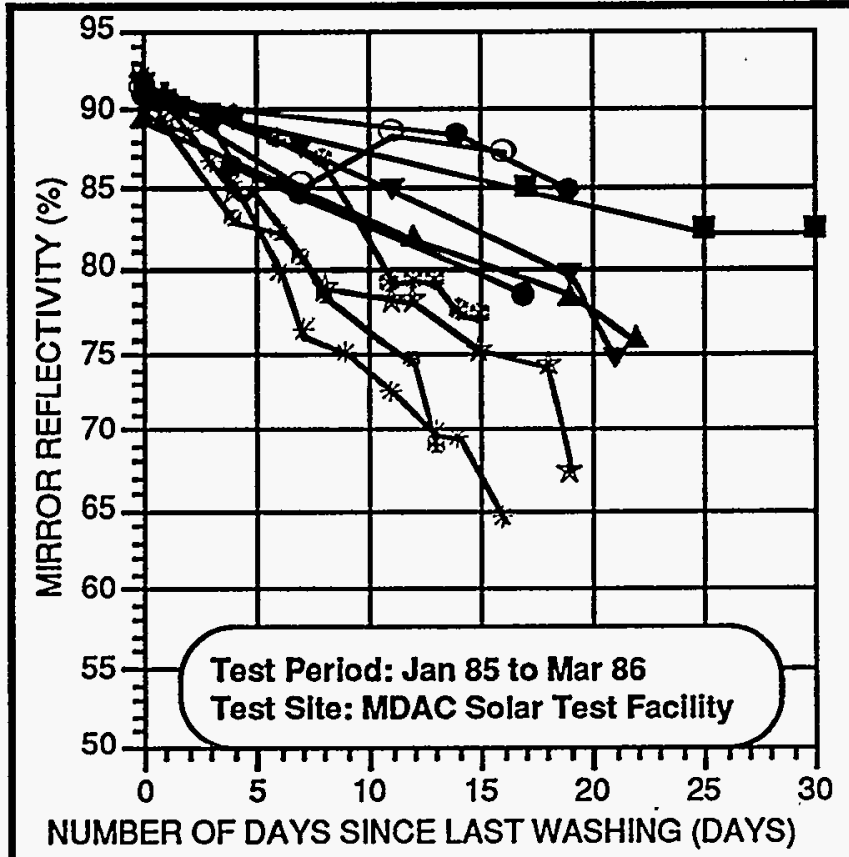

Figure III-8. Variation in Soiling Rate at the MDAC Solar Test Site.

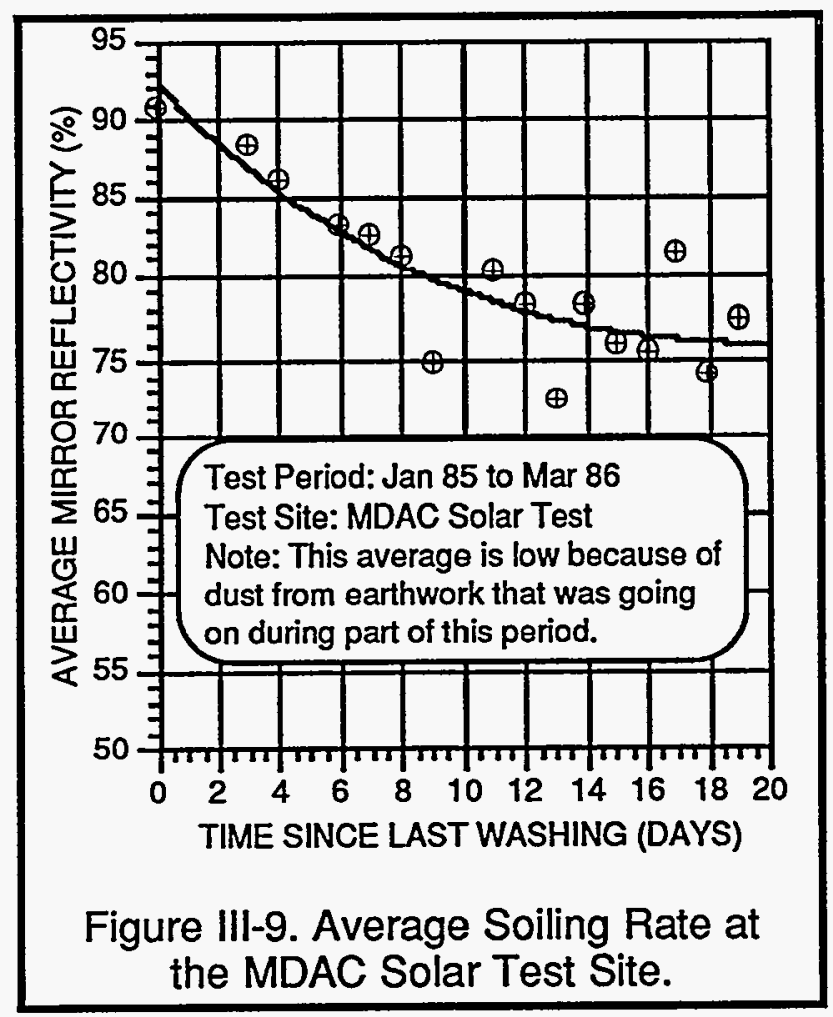




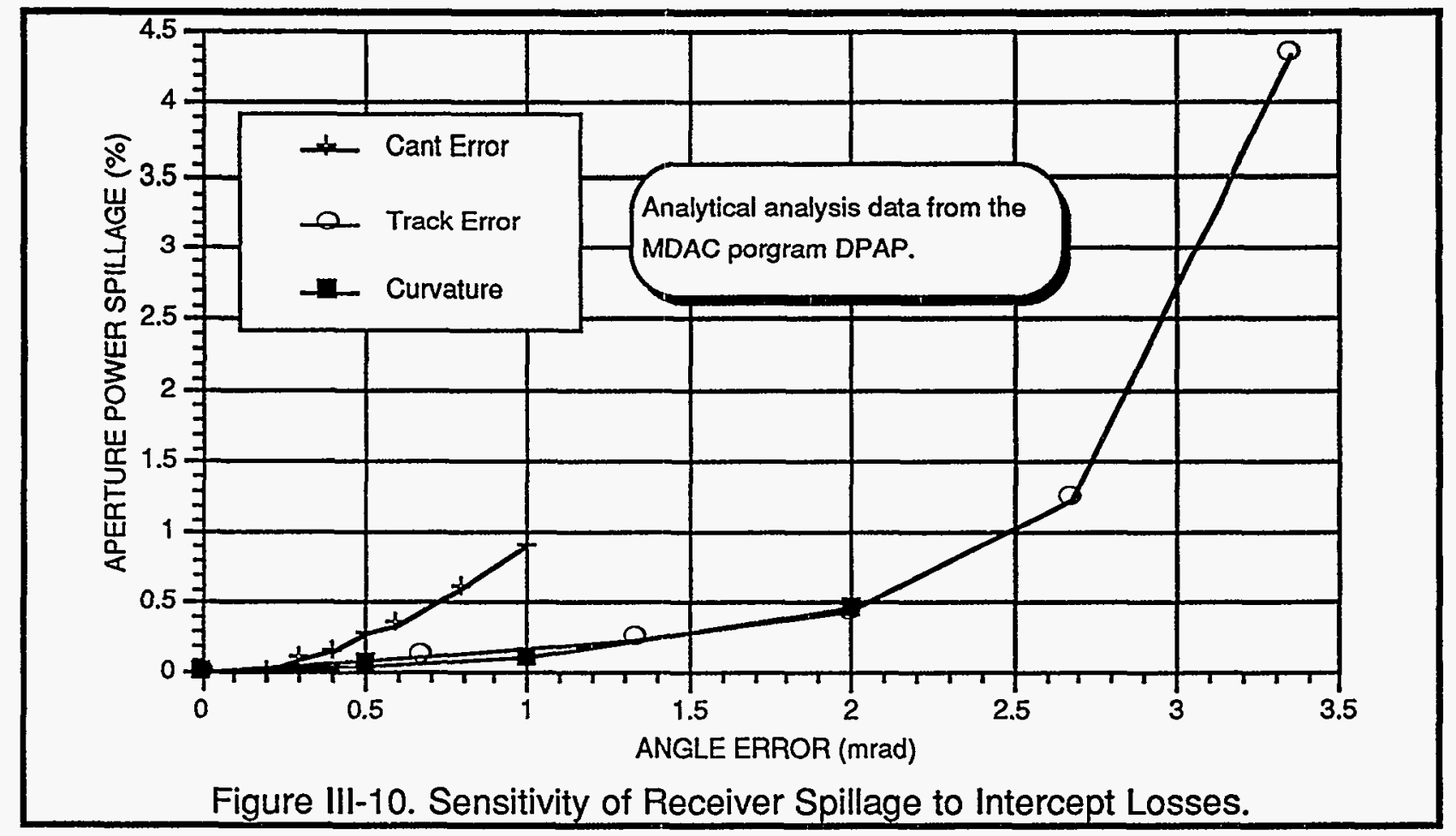

function of angular slope error. As discussed in Section II, the tracking error was less than $0.5 \mathrm{mrad}$ rms over the day, and the DIR system is capable of aligning the mirrors to less than $0.3 \mathrm{mr}$, and the DIR can measure the radius of curvature to less than 10 inches. Based upon the curves in Figure III-10, the total power spillage is estimated to be less than $0.5 \%$. A value of $2.8 \%$ has been allocated for the remaining errors. In the past, it was assumed that the spillage energy was lost from the system, but non qualitative experience and observation have raised doubt about this hypothesis. For instance, the tracking errors show very little sensitivity to errors of less than $1 \mathrm{mr}$, but experience has shown the quadrant temperature is fairly sensitive to tracking errors larger than $1.0 \mathrm{mr}$. Temperature differentials results in a lower system efficiency, but the relationship has not been measured. Therefore, a tracking error results in lost energy from spillage and also lower engine efficiency because of the quadrant temperature differential.

\section{RECEIVER CONDUCTION AND REFLECTIVITY LOSSES}

This is the power that is not absorbed by the receiver tubes and is radiated back out of the cavity to the atmosphere. The number used for receiver losses is estimated from 
design data provided by USAB. This data was derived from analytical programs and receiver test data.

\section{RECEIVER TEMPERATURE DIFFERENCE}

This efficiency was determined by a statistical analysis of the Huntington Beach test data. Efficiencies were calculated for over 2000 data points. The normalized efficiency was plotted as a function of the mean gas temperature difference. The mean efficiency shown in Figure III-11 was calculated as a function of the mean gas temperature difference Except for cloudy conditions, high winds, or uneven mirror soiling, the mean gas temperature difference was generally maintained at less that $80^{\circ} \mathrm{C}$ which means less than $1.0 \%$.

\section{POWER CONVERSION UNIT ENGINE}

This is the power not converted to mechanical power that is dissipated as waste heat by the cooling system. Because the total efficiency was measured and a reasonable estimate or measurement was known for each of the other losses, the number for engine loss was calculated to make the total efficiency agree.

\section{GENERATOR}

The generator efficiency (Figure III-12) was obtained from a curve believed to originate

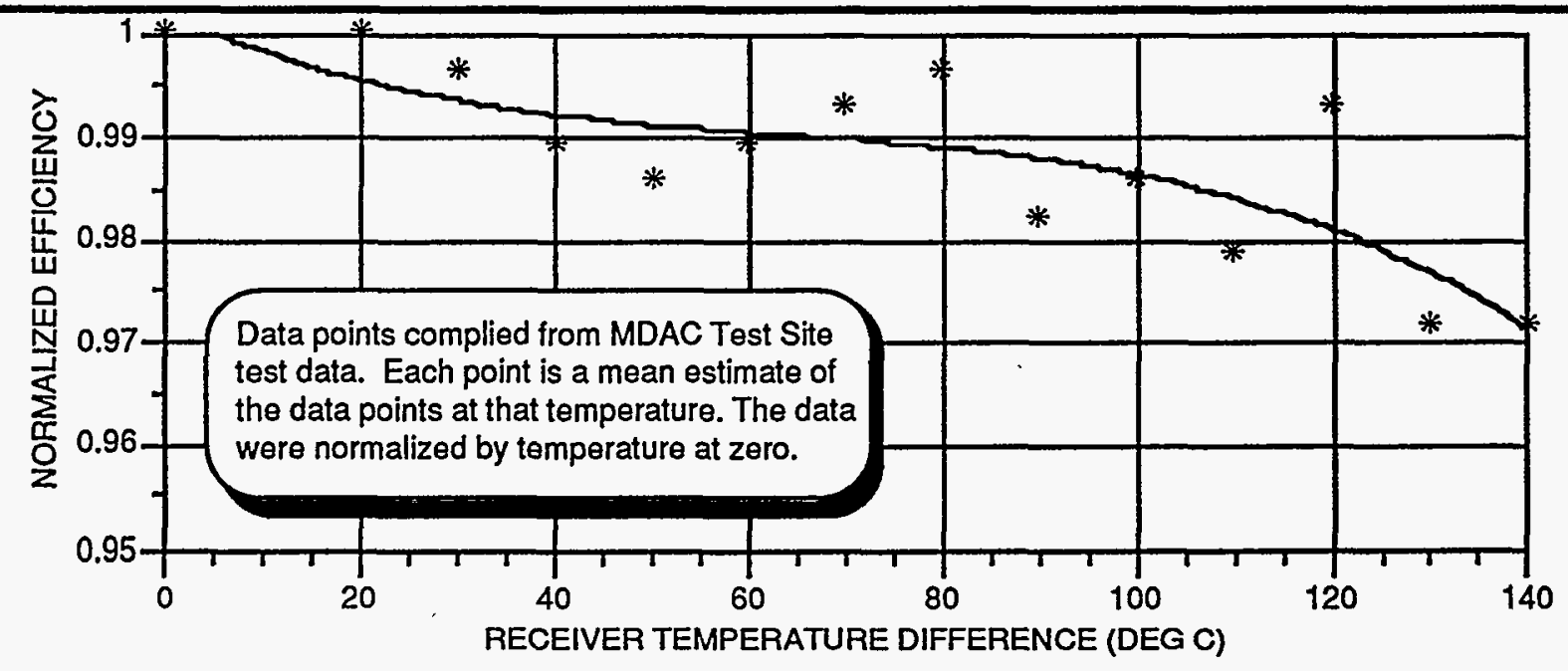

Figure III-11. Engine Efficiency as Function of Gas Temperature Difference. 


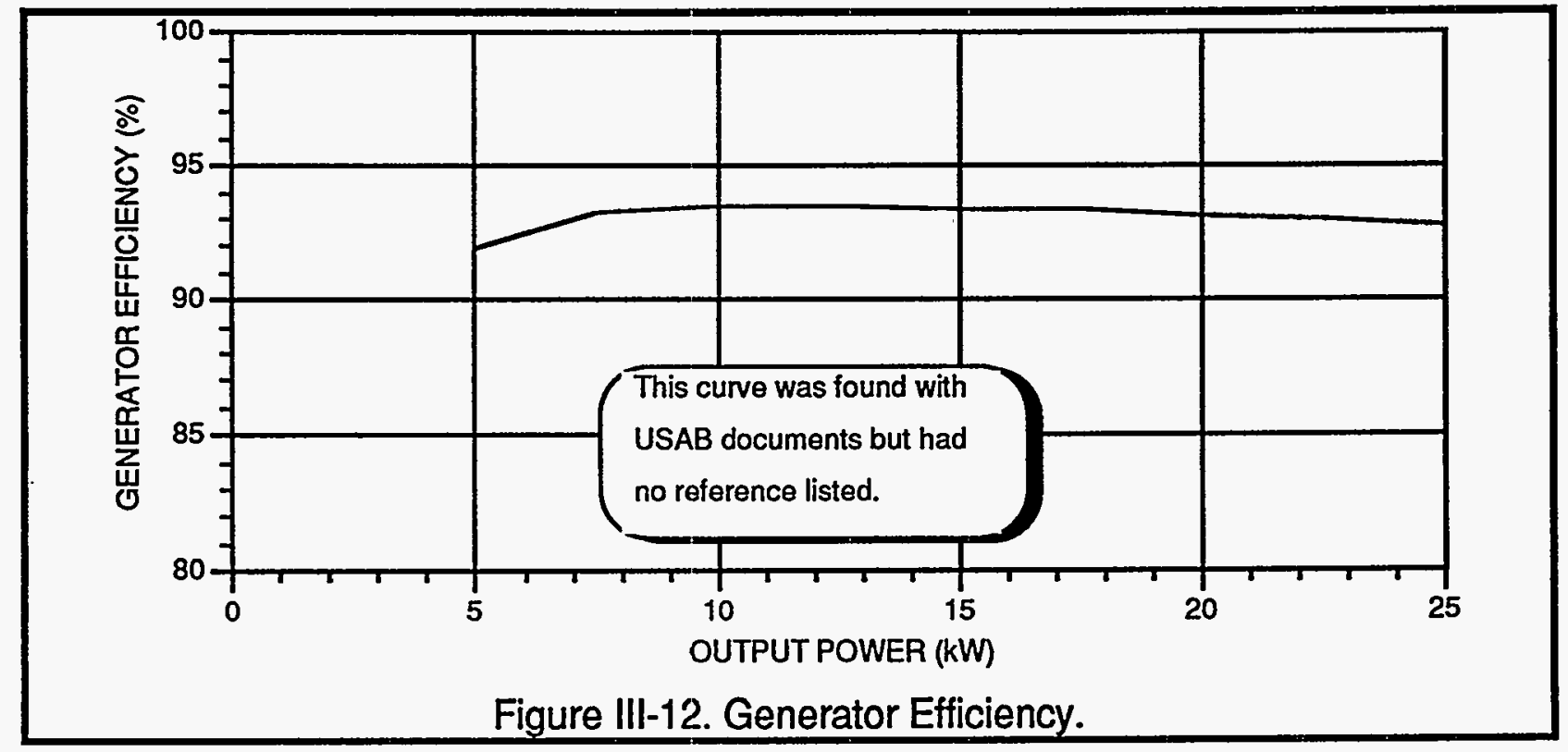

with the manufacturer, but it is not known whether it is estimated or is based upon test data.

\section{PARASITIC POWER}

Throughout the program, a number of tests were performed to determine the parasitic power used by the system. The results of an electrical energy consumption test that was conducted in June of 1985 are shown in Figure III-13. In this test, energy consumption was measured while the system was commanded to change operating modes. A list of the electrical components that were operating during the different modes of operation are shown in the same figure. From this data, the power requirements can be calculated. From this data the power required for the different electrical components on the concentrator and PCU can be estimated, as shown in Table III-4. The values in this table represent a mean estimate for the stowing and tracking operation. The actual values will vary depending upon the time of day and time of year. During the tracking period, depending on the ambient temperature, the PCU cooling fan could be off or on at either its low or high-speed setting. The power range shown represents the variation that might be expected under these conditions. It should be noted that during high ambient temperature conditions the cooling fan normally cycled between its low-speed setting and off. The fan operated at high speed infrequently at the test sites. An estimate of the parasitic power consumed during the 


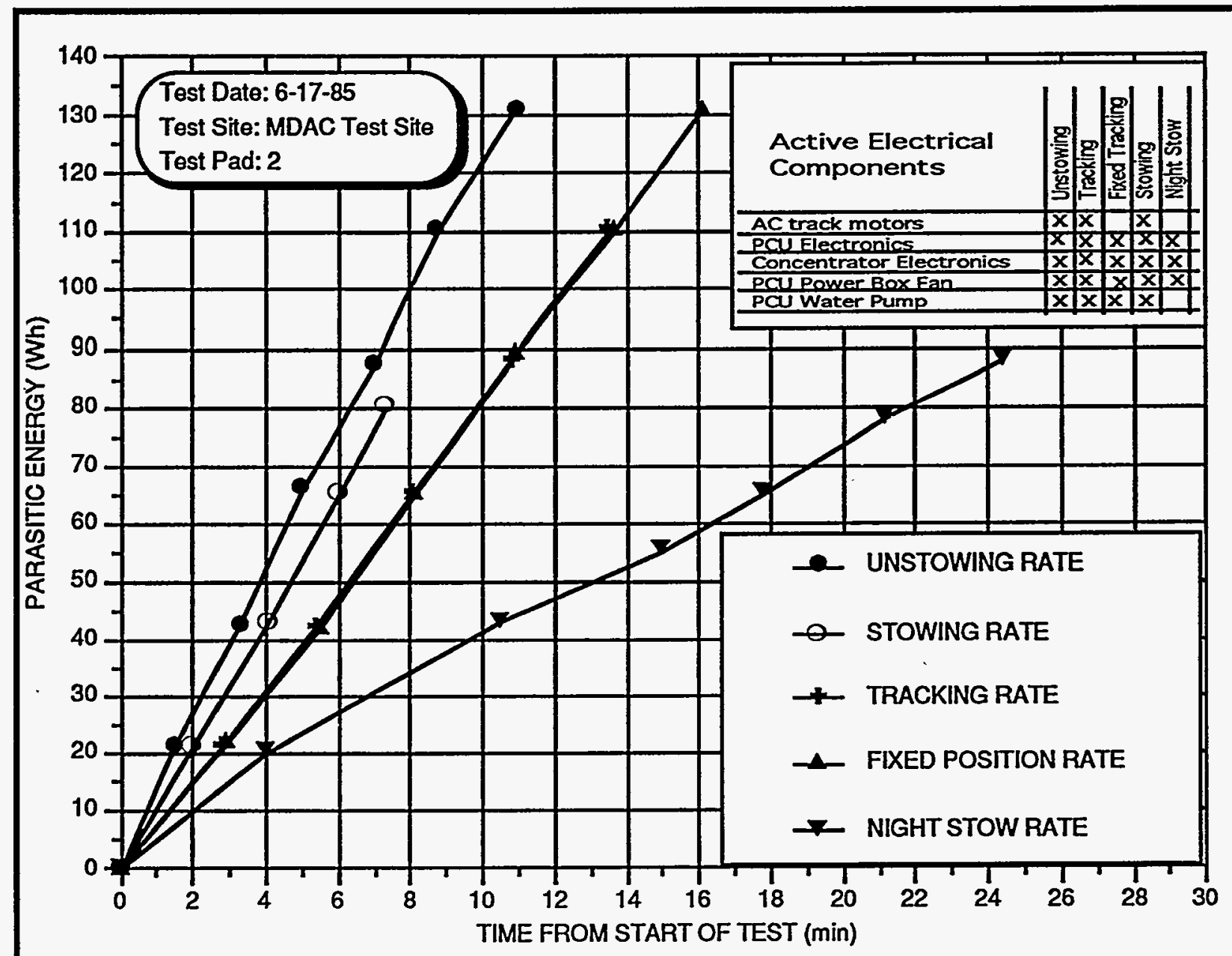

Figure III-13. Energy Consumed for Different Operating Modes.

\begin{tabular}{|l|c|c|c|}
\hline \multicolumn{4}{|c|}{ Table III-4. Stirling Dish Parasitic Power. } \\
\hline Electronic Component & $\begin{array}{c}\text { Night Stow } \\
\text { (watts) }\end{array}$ & $\begin{array}{c}\text { Tracking } \\
\text { (watts) }\end{array}$ & $\begin{array}{c}\text { Stowing } \\
\text { (watts) }\end{array}$ \\
\hline Dish & & & \\
Control Electronics & 40 & 40 & 40 \\
AC Motors & 0 & 20 & 154 \\
PCU Control Electronics & 180 & 180 & 180 \\
Water Pump & 0 & 264 & 264 \\
Cooling Fan & 0 & 800 & 0 \\
Low Speed & 0 & 1200 & 0 \\
High Speed & 220 & $1304-1704$ & 638 \\
\hline \multicolumn{2}{|c|}{ TOTAL } & & \\
\hline
\end{tabular}


operating mode is 904 watts. This was reached by assuming the fan is on low speed half the time. This is believed to be a conservative assumption.

In future parasitic measurements, caution needs to be taken because electronic components in both the solar concentrator and the PCU are single-phase low voltage, such as power for the microprocessors, sensors, valves, contactors, etc. The power for these components is obtained from one phase of the $480 \mathrm{~V}$ to neutral in the case of the PCU and from phase to phase for the dish controller, which is located in the pedestal. In either case, this unbalances the three-phase circuit. The metering was set up for a balanced circuit and therefore will not give accurate measurement in this situation. Depending upon how the metering was connected, the parasitic could range from a factor of 1.3 too high to only a fraction of the measured value. Also the power for the south weather station at the Solar One test site was taken from the Stirling dish power line. This equipment not only consumed power but further unbalanced the load. In the future, it is recommenced these components be measured using an oscilloscope to measure the voltage, current and phase angle.

It should be noted that the above parasitic power numbers may not necessarily agree with the data shown in the appendix for the system at SCE Test Site. This is because the Intersol 2.5-kW photovoltaic concentrator was added to the Stirling dish circuit. A power generating meter was added, but a power consumption meter was not. Therefore, all of the power/energy readings for the dish include the Intersol electronic and drive-motor power consumption. Also, the south meteorological station was on this line which increased the parasitic power for the Stirling dish system even more. Because this equipment was single phase, the power load was further unbalanced. Several attempts were made to determine the power level by turning off the Stirling dish electrical power overnight, but the lower power level could not be measured because of the unbalanced load and coarse scale on the power meter. For these reasons the SCE Test Site parasitic power shown in Appendix $C$ is higher than normal for the Stirling dish system. 


\section{ENERGY PERFORMANCE}

- Over $118 \mathrm{MWh}$ of energy was generated during the test program.

- Produces power at daily sun irradiance energy lower than $1 \mathrm{kWh} / \mathrm{m}^{2} /$ day

- Daily net energy efficiencies higher than $27 \%$ on a good solar day

The energy performance of the Stirling dish is analyzed in this section using the test data recorded during the test program. Using this data, an estimate of the efficiency of the major system components is presented. Following this section, the results of this analysis will be used to estimate the annual energy performance. The total net energy generated by all units during the test program is shown for each test site in Figure IV-1. A summary of the test data is given for the Stirling dish in Appendix $A$ for the MDAC Test Site, Appendix B for the Georgia Power Test Site and Appendix C for the SCE Test Site.

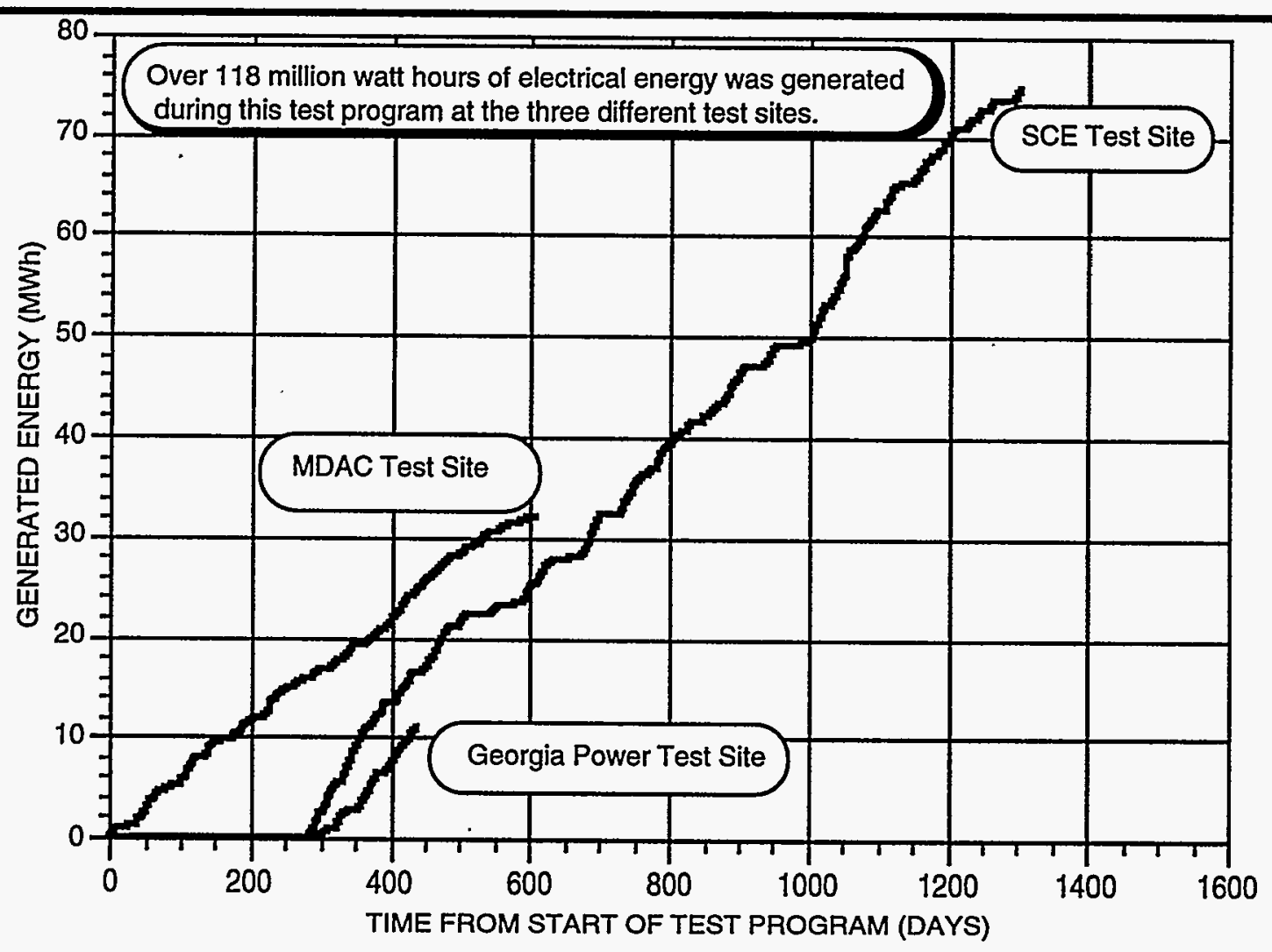

Figure IV-1. Total Net Energy Generated for the Three Test Sites. 


\section{Daily Energy Performance}

The daily energy performance of the Stirling dish can be illustrated by dividing the total daily net electrical energy generated by the reflective normal area of the dish $\left(87.69 \mathrm{~m}^{2}\right)$ and plotting this as a function of total daily solar irradiance energy received per square meter. The energy performance for test pad 2 at the Huntington Beach Test Site is shown in Figure IV-2, for the Georgia Test Site in Figure IV-3 and for the SCE Test Site in Figure IV-4. The data points were calculated from manual readings of the utility site meters. The sun's daily irradiance energy was obtained from the Solar One weather station or by integrating the output of the normal incidence pyroheliometer (NIP). The diagonal line drawn along the top of the data point envelope represents the performance line or system peak performance as a function of the sun's irradiance energy. This line represents the line of best performance under ideal conditions, i.e., clean mirrors, little winds, low tracking error, etc. The performance line shows that the Stirling dish can produce a positive net energy at daily sun irradiance levels of $1 \mathrm{kWh} / \mathrm{m}^{2}$. The system can obtain a peak energy

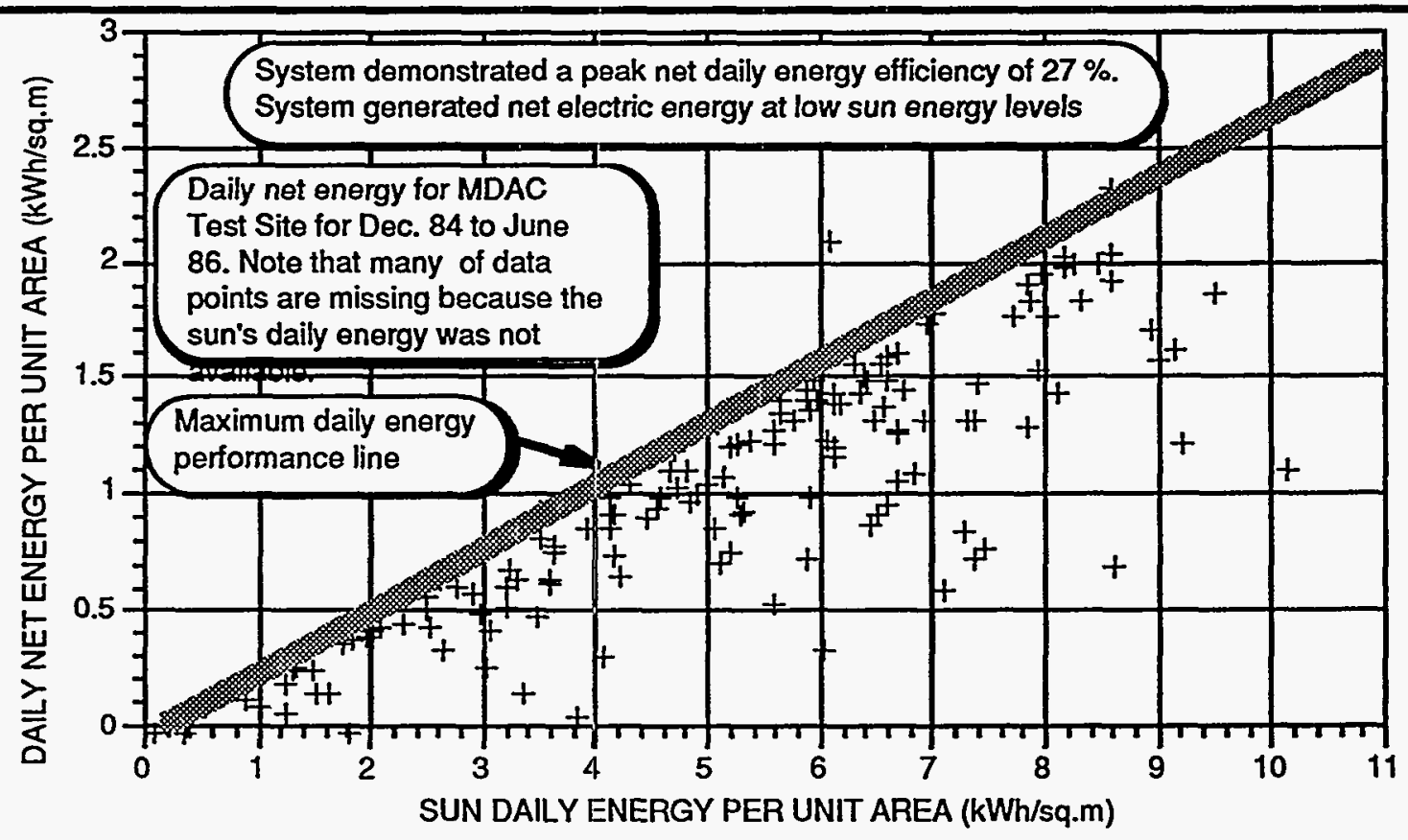

Figure IV-2. Energy Performance Test Data From MDAC Test Site, Pad 2. 


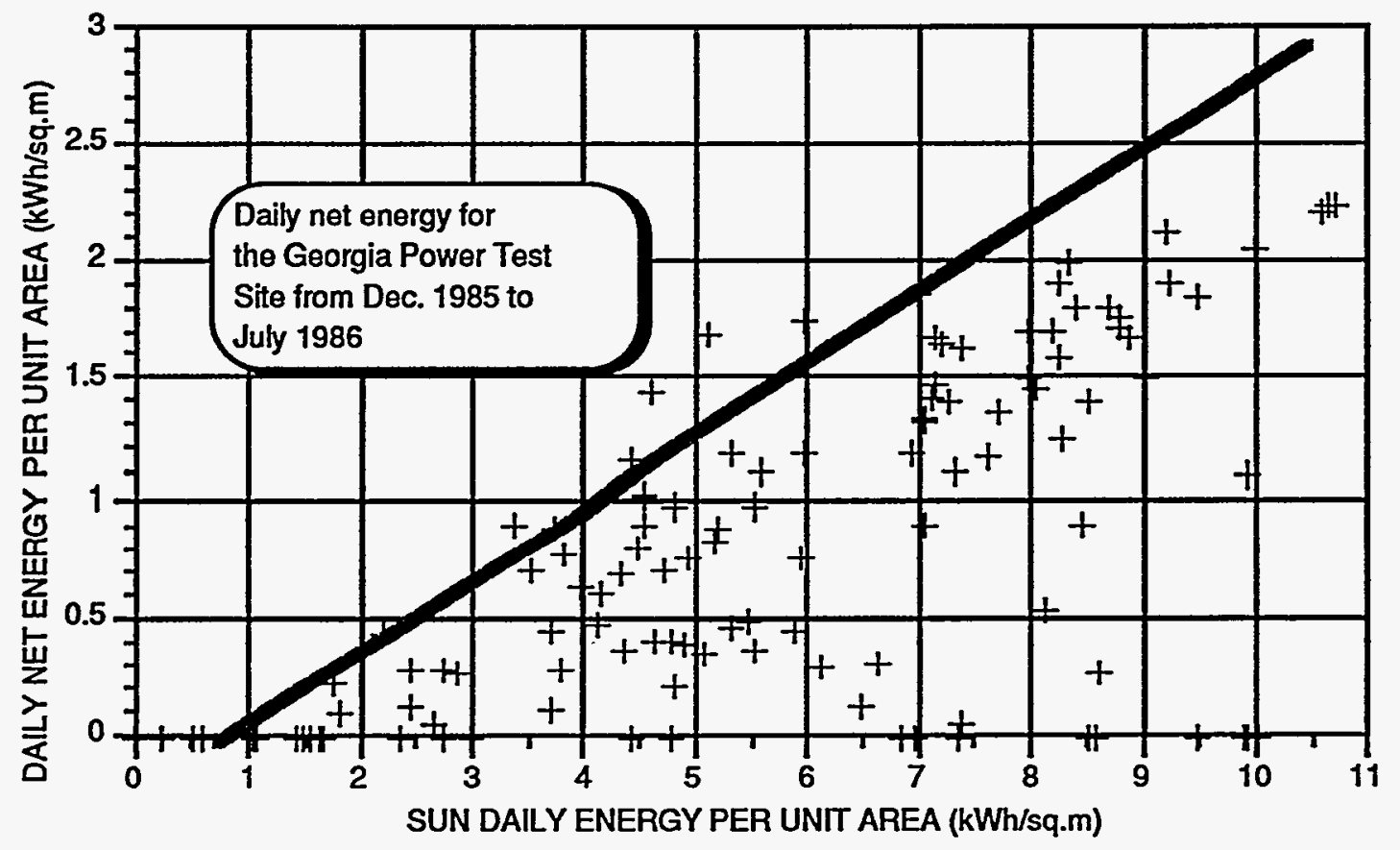

Figure IV-3. Energy Performance Test Data From the Georgia Test Site.

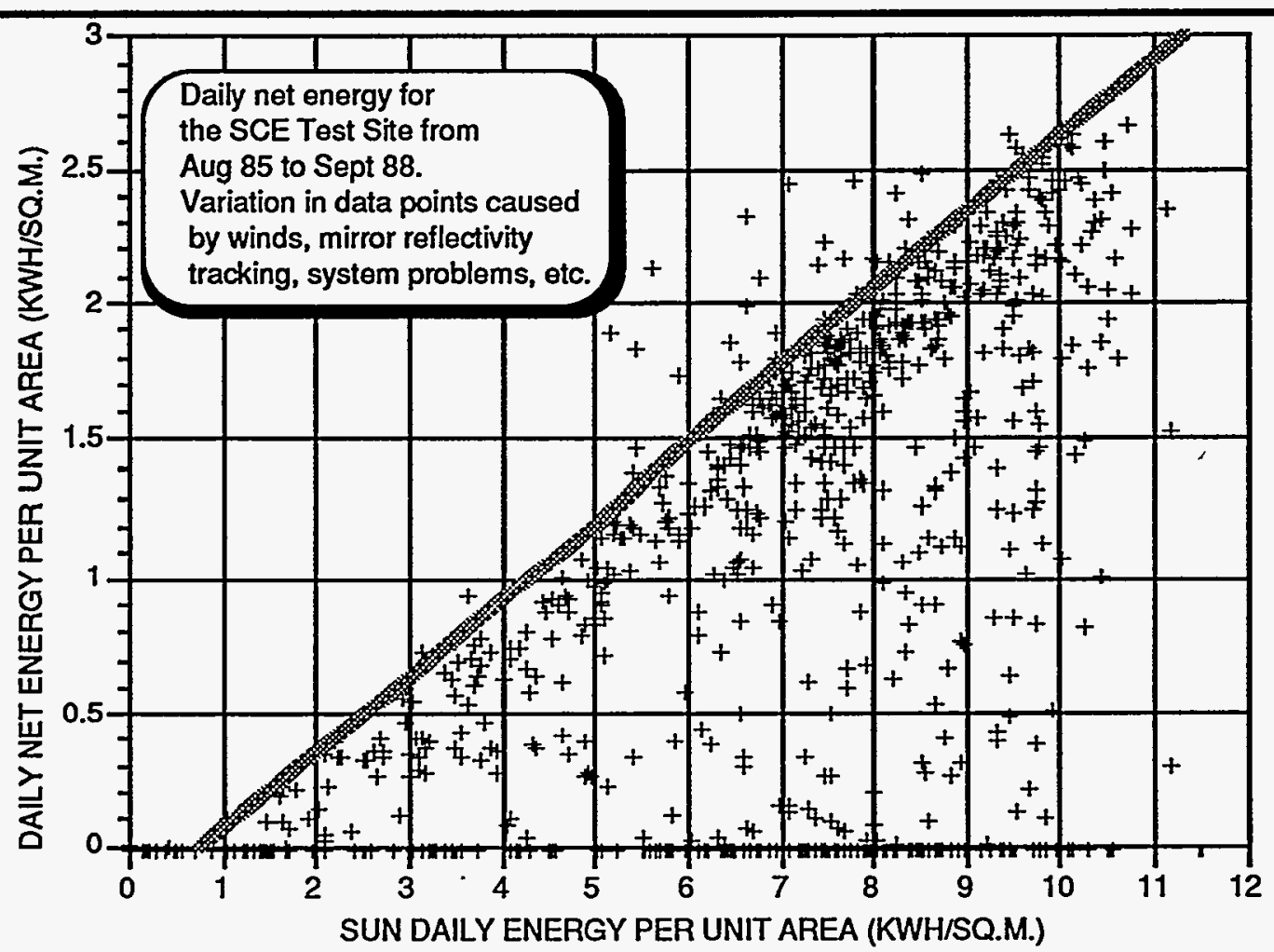

Figure IV-4. Energy Performance Test Data From the SCE Test Site. 
efficiency of greater than $27 \%$ at a daily sun energy level of $10 \mathrm{kWh} / \mathrm{m}^{2}$.

The data points that lie above the performance line are considered to be in error. These points could have been recorded in error since the utility meters were dial scale meters and were read manually. Also at times the NIP would become dirty or tracking drift errors would occur which made the sun energy appear lower than the actual level. Cleaning and adjusting the NIP tracking was part of the weekly operating procedure.

The wide spread of points below the performance line is the result of a number of factors. These can be summarized as:

1.0 Soiling of the mirrors reduced the mirror reflectivity and the daily generated energy.

2.0 Winds blowing across the receiver increased the heat loss from the receiver.

3.0 Winds caused movement of the receiver and reflective structure and increased receiver spillage.

4.0 High winds resulted in the concentrator going to high wind stow even though there was a good sun irradiance level.

5.0 The units at the Huntington Beach Test Site were frequently taken off line in order to conduct a specific development test.

6.0 The majority of the days that the SCE unit did not operate was due to delays in receiving spare parts. This was a result of the USAB and MDAC divestiture discussed later.

7.0 System operating problems interrupted the operation of the system.

8.0 The units were taken off line during the day to wash the mirrors, add gas to the system, system tests or for special demonstrations such as picture taking.

The wide spread of data points shown in Figure IV-4 at the SCE Test Site was a result of the USAB and MDAC divestiture. This divestiture resulted in a lack of spare parts and trained support personnel to repair the problems. During the mid part of 1988 (May and June) a new engine was mounted on the SCE Test Site 


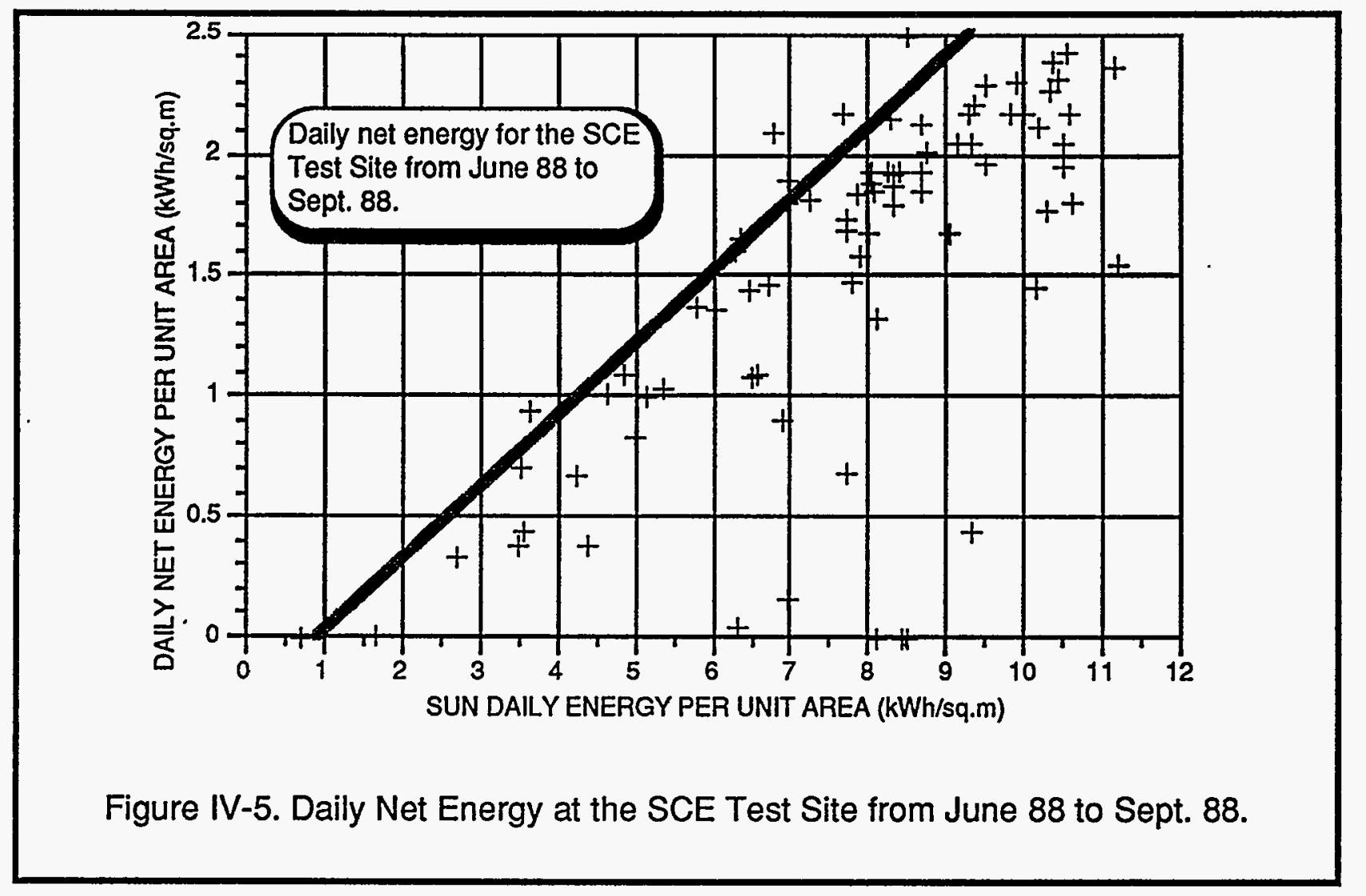

concentrator and a number of changes and modifications were made in order to fix some of the more frequently experienced problems. The data from testing this unit is shown in Figure IV-5 for the period from mid-June to early September 1988. During this time, the unit operated nearly every day.

\section{Energy Component Performance}

The energy performance of the test units is analyzed here to identify the sources of energy losses and quantify the amount of energy lost from each source. This analysis is performed for a daily energy level of $10 \mathrm{kWh} / \mathrm{m}^{2}$. The resulting component efficiencies are given in Table IV-1 and illustrated in the energy waterfall diagram shown in Figure IV-6. The losses are discussed in the following section. 


\begin{tabular}{|c|c|c|c|c|}
\hline \multirow[b]{2}{*}{ Source } & \multicolumn{2}{|c|}{ Efficiency $(\%)$} & \multicolumn{2}{|c|}{ Energy (kWh) } \\
\hline & Component & Cumulative & Delta & $\begin{array}{c}\text { Total } \\
\text { Available } \\
\end{array}$ \\
\hline Daily Energy & & & & 876.9 \\
\hline Reflectivity Losses & 91.00 & 91.00 & 78.92 & 797.98 \\
\hline $\begin{array}{l}\text { Intercept Losses } \\
\text { Tracking } \\
\text { Surface Waviness } \\
\text { Cant Error }\end{array}$ & 96.70 & 88.00 & 26.33 & 771.65 \\
\hline $\begin{array}{l}\text { Receiver } \\
\text { Conduction } \\
\text { Reflectivity }\end{array}$ & 90.00 & 79.20 & 77.16 & 694.49 \\
\hline Temperature Difference & 99.5 & 78.80 & 3.47 & 691.02 \\
\hline PCU Engine Losses & 38.78 & 30.56 & 423.01 & 268.00 \\
\hline Generator Losses & 93.00 & 28.42 & 18.76 & 249.24 \\
\hline Parasitic Losses & 94.88 & 26.97 & 12.76 & 236.48 \\
\hline
\end{tabular}

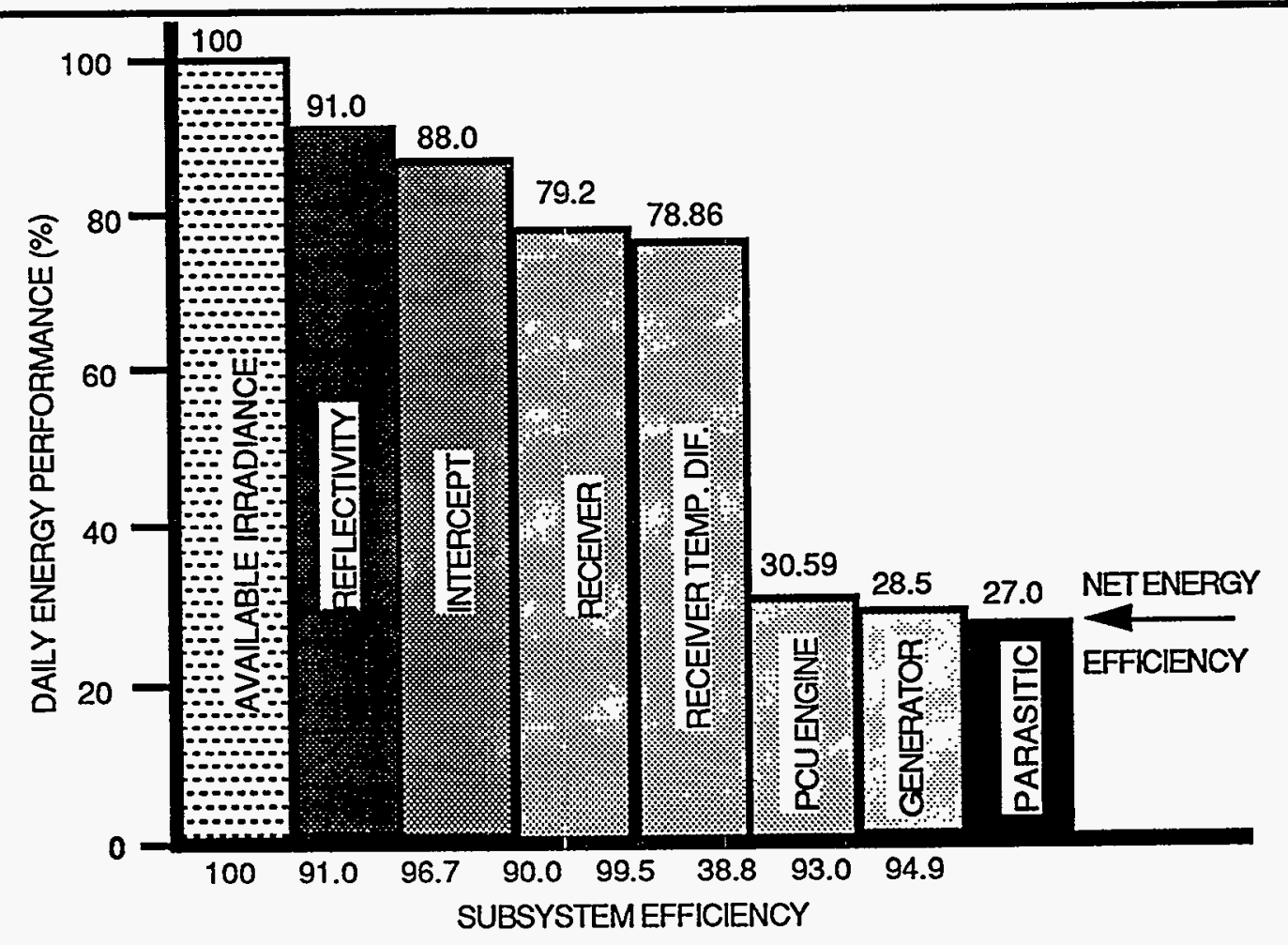

Figure IV-6. Daily Energy Waterfall. 
AVAILABLE INSOLATION -- For this analysis, the available daily solar energy is assumed to be $10 \mathrm{kWh} / \mathrm{m}^{2}$, which would result in $876.9 \mathrm{kWh}$ solar energy falling daily on the concentrator.

REFLECTIVITY -- This analysis identifies the subcomponent efficiency at the peak energy operating point with a clean mirror reflectivity of $91 \%$.

INTERCEPT -- The same percentage loss was used for this source as was used in the power-loss calculation in Section 3.

RECEIVER -- The same percentage loss was used for this source as was used in the power-loss calculation in Section 3.

POWER CONVERSION UNIT ENGINE -- The peak power efficiency analysis implies that the Stirling engine has a thermal efficiency of $42 \%$. As shown in Figure IV7 , the engine efficiency varies over the day as the sun irradiance level varies. This curve was calculated by dividing the efficiency at each time point by the maximum efficiency for the day. The second curve in this figure shows a density function for the normalized efficiency. The average efficiency factor over a day is 0.92344 . The average Stirling engine efficiency is obtained by multiplying 0.92344 by $42 \%$ to get $38.78 \%$.
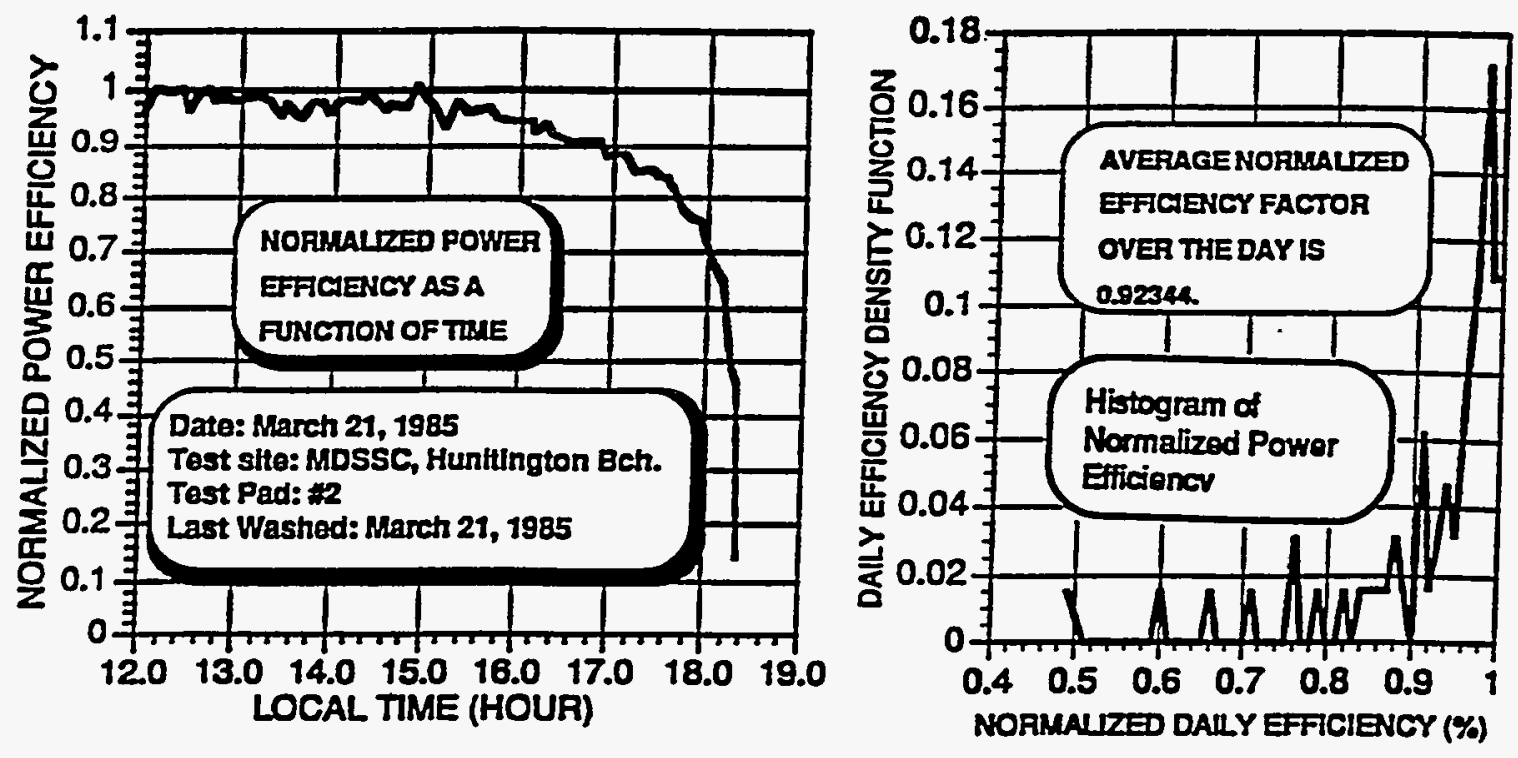

Figure IV-7. Stirling engine efficiency over the day. 
GENERATOR -- The generator efficiency given in the last section shows that the generating efficiency is constant for a given speed. Since the system operates at a constant speed, the daily energy efficiency was assumed to be the same as for power, $93 \%$.

PARASITIC -- The daily parasitic energy varies with the time of day and time of year, but from the data presented in the Power Performance Section, an estimate can be made of an average value for the daily 24-hour parasitic energy required. This estimate is shown in Table IV-2.

In the present control logic, the water pump is on while the dish is tracking. It shuts off when the dish detracks and the PCU has cooled to ambient. The estimate of fan time was based upon a ratio of fan on-time to total generating time shown in the summaries of the Mark I and Mark II Operation.

\begin{tabular}{|l|r|c|c|}
\hline \multicolumn{4}{|c|}{ Table IV-2. Estimate of 24 Hour Parasitic Energy. } \\
\hline Component & Time & Required Power & Energy \\
\hline Electronics & & & \\
Concentrator & $22 \mathrm{~h}$. & $40 \mathrm{w}$ & $0.96 \mathrm{kWh}$ \\
PCU & $24 \mathrm{~h}$. & $180 \mathrm{w}$ & $4.32 \mathrm{kWh}$ \\
Concentrator Motors & & & \\
Stowing & $0.7 \mathrm{~h}$ & $154 \mathrm{w}$ & $0.1 \mathrm{kWh}$ \\
Tracking & $10 \mathrm{~h}$ & $20 \mathrm{w}$ & $0.2 \mathrm{kWh}$ \\
PCU Water Pump & $12 \mathrm{~h}$ & $264 \mathrm{w}$ & $3.2 \mathrm{kWh}$ \\
PCU Cooling Fan & $5 \mathrm{~h}$ & $800 \mathrm{w}$ & $4.0 \mathrm{kWh}$ \\
\hline \multicolumn{4}{|c|}{ Total Parasitic Energy $=$} \\
\multicolumn{4}{|c|}{$12.78 \mathrm{kWh}$} \\
\hline
\end{tabular}




\section{POWER AND ENERGY COMPARISON WITH OTHER SOLAR SYSTEMS}

- Produces 2 to 5 times more power per aperture area than other solar systems

- Produces 1.5 to 2.5 times as much daily energy per area than other solar systems

- A previous program also verified the high performance of the Stirling Dish

The SCE Test Site offered a unique opportunity to compare four different solar systems. The $10 \mathrm{MW}$ Solar One Central Receiver Plant, an Intersol photovoltaic concentrator, the Solar Electric Generation Station (SEGS), and the Stirling dish were all located in the same general Mojave Desert area. The side-by-side energy performance of these systems will be compared in this section. In addition, the energy performance of the Vanguard Stirling dish unit, which used a similar Stirling engine, but a different concentrator design, will be compared to the MDAC/USAB/SCE system.

The normalized power performances of the four solar systems are shown in Figure $V-1$ for summer solstice and for spring equinox of 1986 as a function of time. The SEGS 1 power curve lags the others because the early morning energy is used to charge the thermal storage system which is then used to produce power after sundown. These data shows that the Stirling dish produced 2 to 5 times as much power as the other systems. The average daily energy performance of the MDAC/USAB/SCE system, Vanguard system, Intersol PV system, SEGS 3, and the Solar One Plant is shown in Figure, $\mathrm{V}-2$. This data shows that the Stirling dish produces 1.5 to 3 times the energy per unit aperture area as the other systems. The Stirling dish system not only produces more energy on clear days, but also is capable of producing energy on cloudy days when the other systems did not produce any energy. As might be expected, the MDAC/USAB/SCE Stirling dish and the Vanguard Stirling dish demonstrated comparable energy performance. These two programs substantiate the improved performance predicted for Stirling dish system.

\section{Solar One}

A considerable amount of performance data is available on the energy performance of the Solar One Central Receiver. There are a total of 1,818 heliostats at Solar One, 

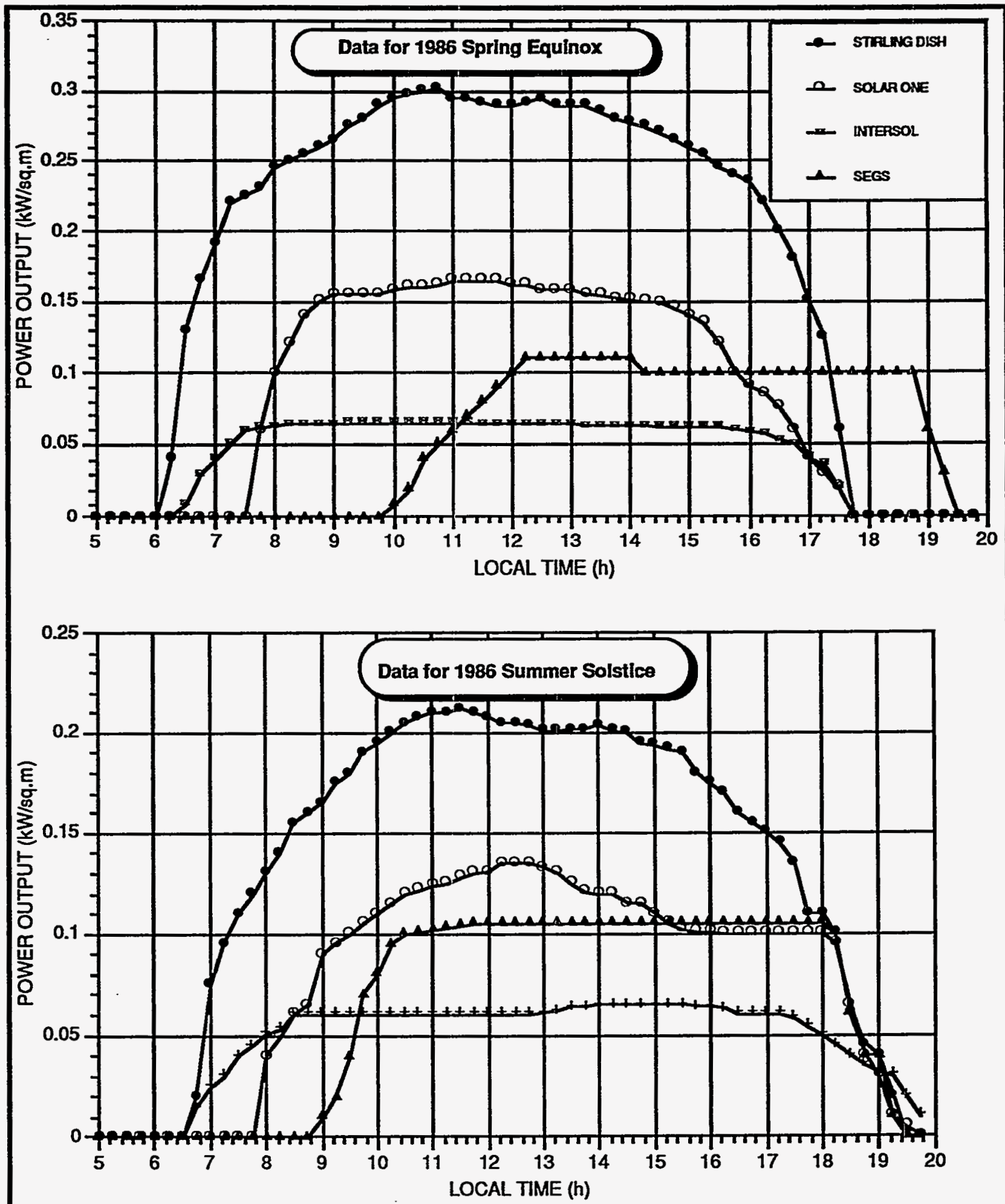

Figure V-1. Power Comparison of the Stirling Dish, Solar One, Intersol PV and SEGS 3. 


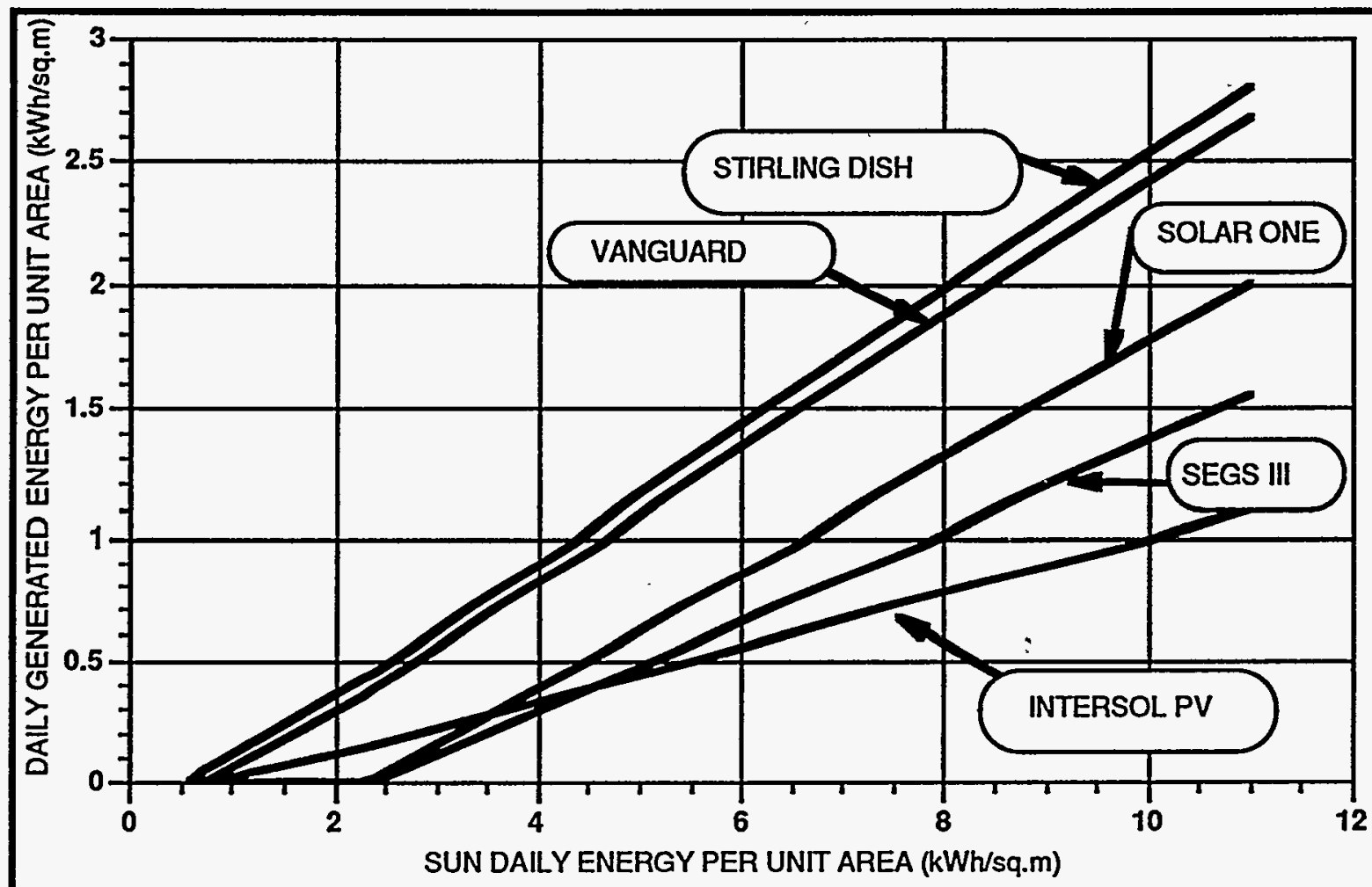

Figure V-2. Daily Energy Performance of Stirling Dish Compared with Solar One, Intersol PV, SEGS Trough and Vanguard Program

and each one has a total glass area of $423 \mathrm{ft}^{2}$. It is assumed that an average of eight heliostats are out of service. The total glass area would be $71,122 \mathrm{~m}^{2}\left(765,630 \mathrm{ft}^{2}\right)$. The effective glass area was calculated by multiplying the total area by an average cosine angle, an average blocking factor and an average shading factor. All of these factors were obtained from Reference 9. These data were plotted as a function of time, with the factor incremented at half-hour intervals (Table $V-1$ ). The average value was calculated by summing the values over the day and the year as shown in this table. A plot of the Solar One daily energy performance is shown in Figure V-3 using the total effective aperture reflective area. These data cover only the last two years of perforrfance, 1987 and 1988.

\section{The Vanguard Unit}

The Vanguard program demonstrated a Stirling dish system similar to the MDAC/USAB/SCE program. The information in the section was obtained from 


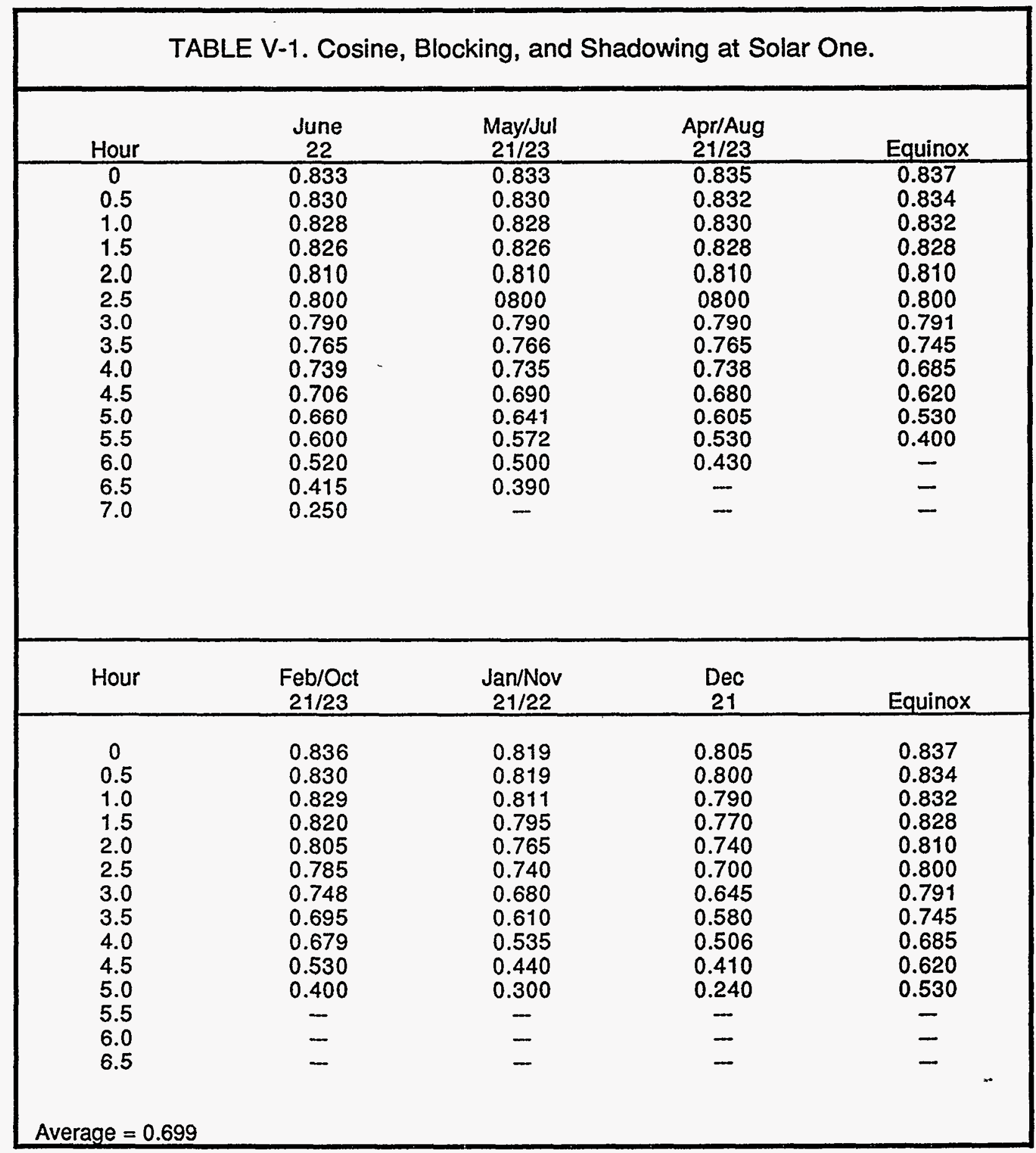




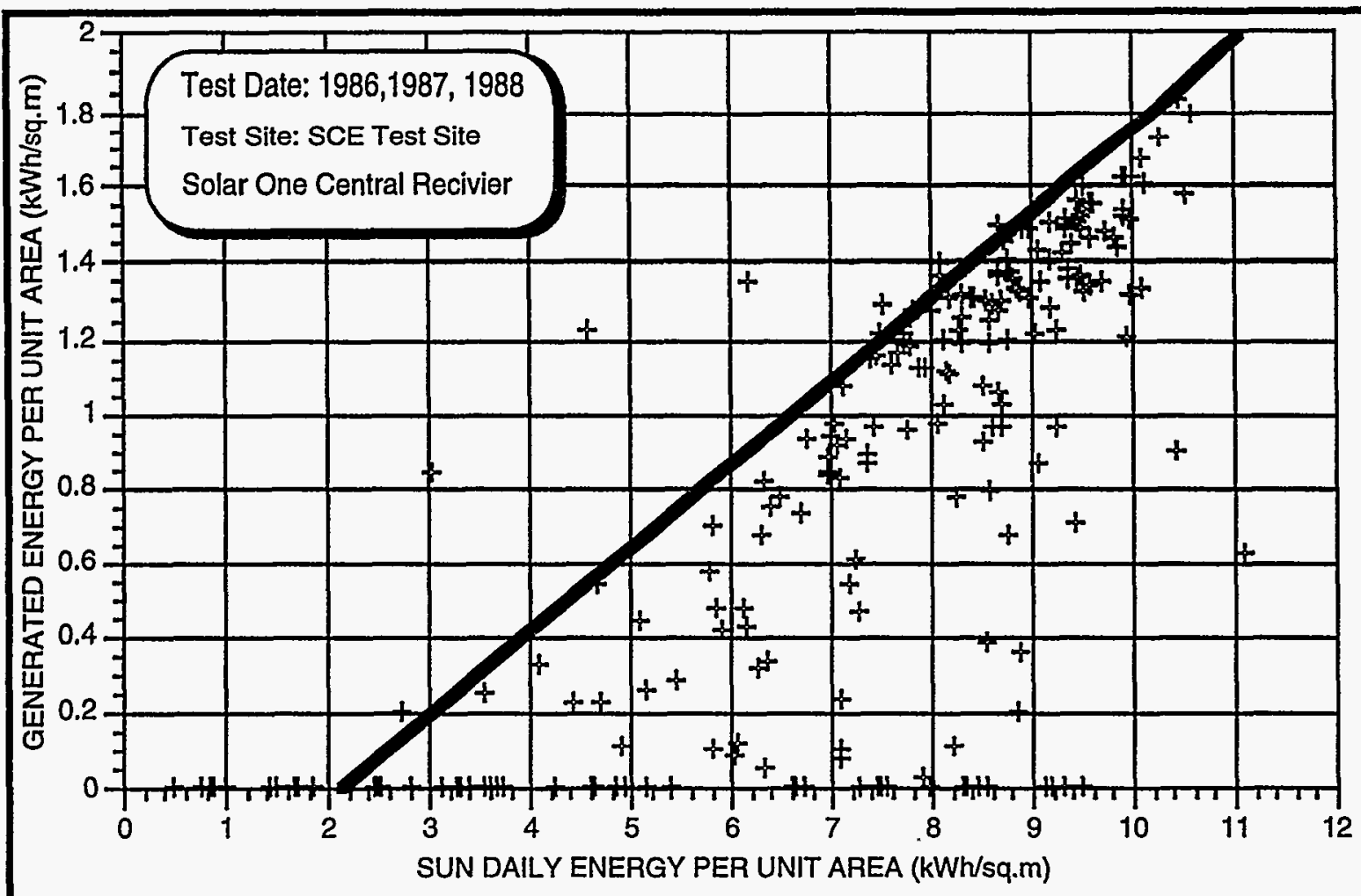

Figure V-3. Daily Energy Performance of Solar One.

References 2 \& 3. A comparison of the characteristics of the two units is summarized in Table V-2. The daily energy performance for the Vanguard unit shown in Figure V4, was taken from Reference 2. The data shown were not equivalent to the MDAC/USAB Stirling dish data presented previously because of the method that was used to calculate the total insolation. If the Vanguard unit only operated for part of a day, then only the sun's energy while it was operating was recorded. The MDAC/USAB Stirling dish data used the total daily insolation whether or not the system operated all day. The Vanguard data showed a higher efficiency for part-day operation and much less scattering of data points than the MDAC data. This difference in data gathering methods did not affect the peak performance line.

\section{Intersol Photovoltảic Concentrator}

An Intersol photovoltaic (PV) concentrator was installed at Solar One in 1987. The unit was originally designed by the Martin Marietta Corporation for mounting 60 
Table V-2. Comparison of MDAC/USAB and Vanguard Stirling Dish System.

\begin{tabular}{|c|c|c|}
\hline Characteristics & MDAC/USAB & Vanguard \\
\hline Number of facets & 82 & 336 \\
\hline Total Mirror Area & $91.0 \mathrm{~m}^{2}\left(979.7 \mathrm{ft}^{2}\right)$ & $91.4 \mathrm{~m}^{2}$ \\
\hline Aperture Area & $87.7 \mathrm{~m}^{2}\left(943.7 \mathrm{ft}^{2}\right)$ & $86.7 m^{2}$ \\
\hline Ratio Aperture/Total & 0.963 & 0.949 \\
\hline Facet Size & $\begin{array}{l}0.91 \mathrm{~m} \times 1.22 \mathrm{~m}(3 \mathrm{ft} X \\
4 \mathrm{ft})\end{array}$ & $\begin{array}{l}0.451 \mathrm{~m} \times 0.603 \mathrm{~m}(1.5 \mathrm{ft} X \\
1.98 \mathrm{ft})\end{array}$ \\
\hline Reflectivity (clean) & $91-92 \%$ & $93 \%$ \\
\hline $\begin{array}{l}\text { Weight (excluding PCU \& } \\
\text { foundation) }\end{array}$ & $6,803 \mathrm{~kg}(15,000 \mathrm{lbs})$ & $10,400 \mathrm{~kg}(22,927 \mathrm{lbs})$ \\
\hline Sun Tracking & Open Loop & Closed Loop \\
\hline $\begin{array}{l}\text { Energy at focal plane } \\
\left(850 \mathrm{~W} / \mathrm{m}^{2}\right)\end{array}$ & $68.4 \mathrm{kWt}$ & $63.1 \mathrm{kWt}$ \\
\hline $\begin{array}{l}\text { Structure blocking \& } \\
\text { shadowing }\end{array}$ & 0.998 & 0.92 \\
\hline Gimbal & Azimuth/Elevation & Exocentric \\
\hline
\end{tabular}




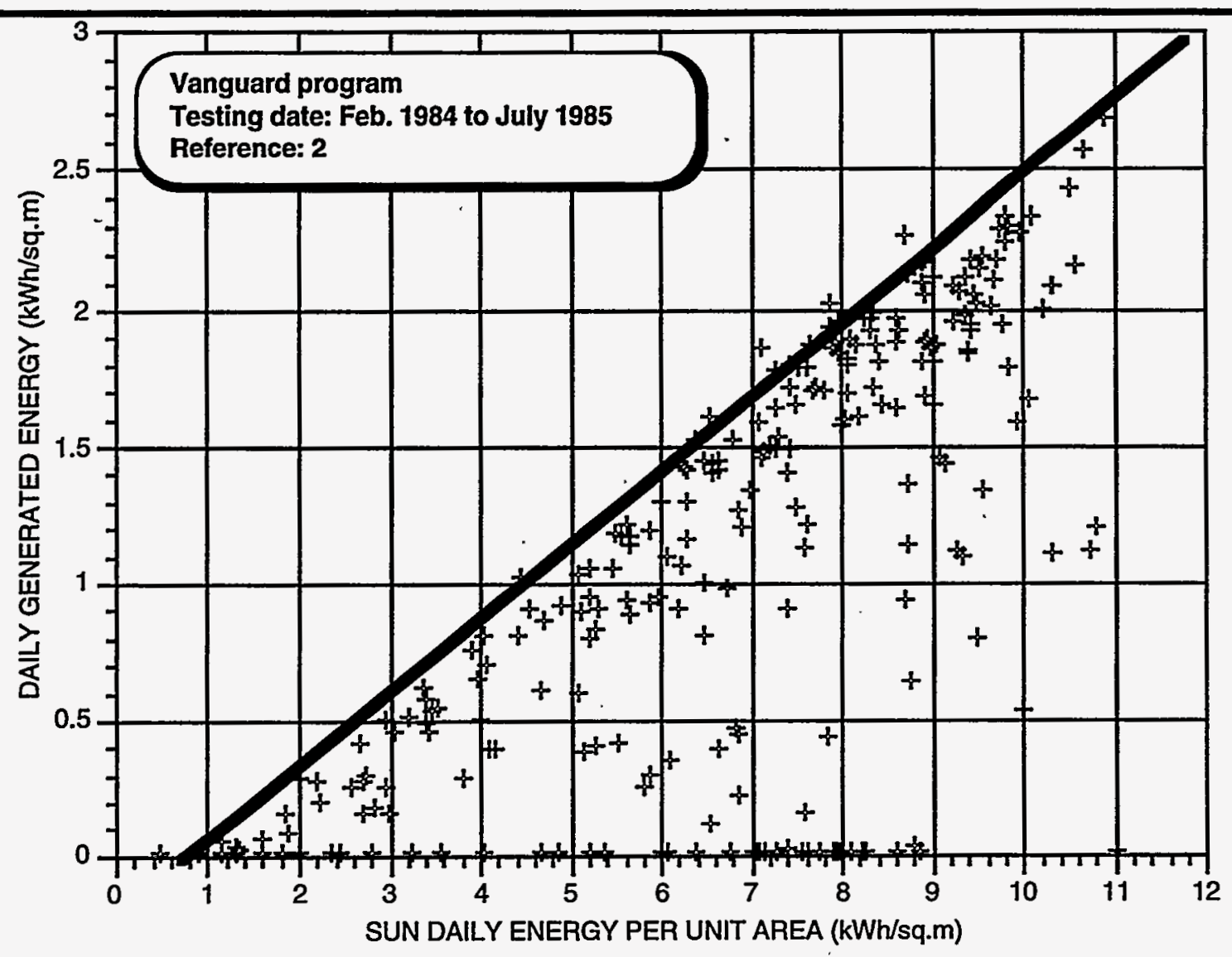

Figure V-4. Daily Energy of the Vanguard Stirling Dish.

photovoltaic modules. This unit uses the Martin Marietta tracker but is equipped with 32 concentrating photovoltaic modules supplied by the Intersol Company. The modules consist of 14 photovoltaic cells contained in a weatherproof enclosure. Each cell is provided with a Fresnel lens, which concentrates the solar flux density incident on.the cell by a factor of 70 .

The unit's rated electrical output is $2.5 \mathrm{~kW} @$ a solar insolation level of $1,000 \mathrm{~W} / \mathrm{m}^{2}$ and an ambient air temperature of $28^{\circ} \mathrm{C}\left(83^{\circ} \mathrm{F}\right)$. The unit operates unattended and has had an extremely low operating and maintenance cost since its installation in early 1987. Refer to Figures $V-5$ and $V-6$ for structural details. The energy produced per $m^{2}$ by the photovoltaic unit is presented in Figure V-7. 


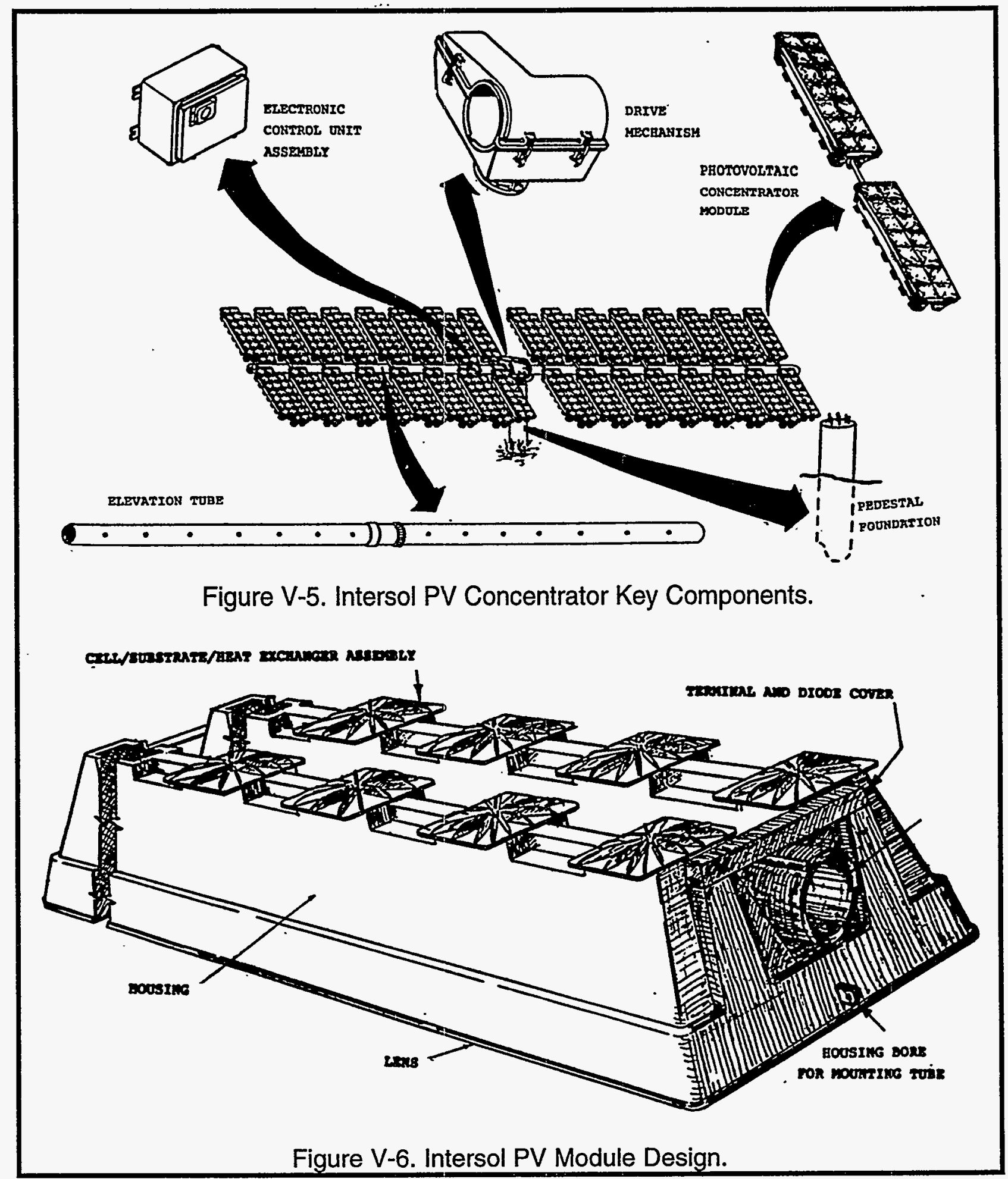




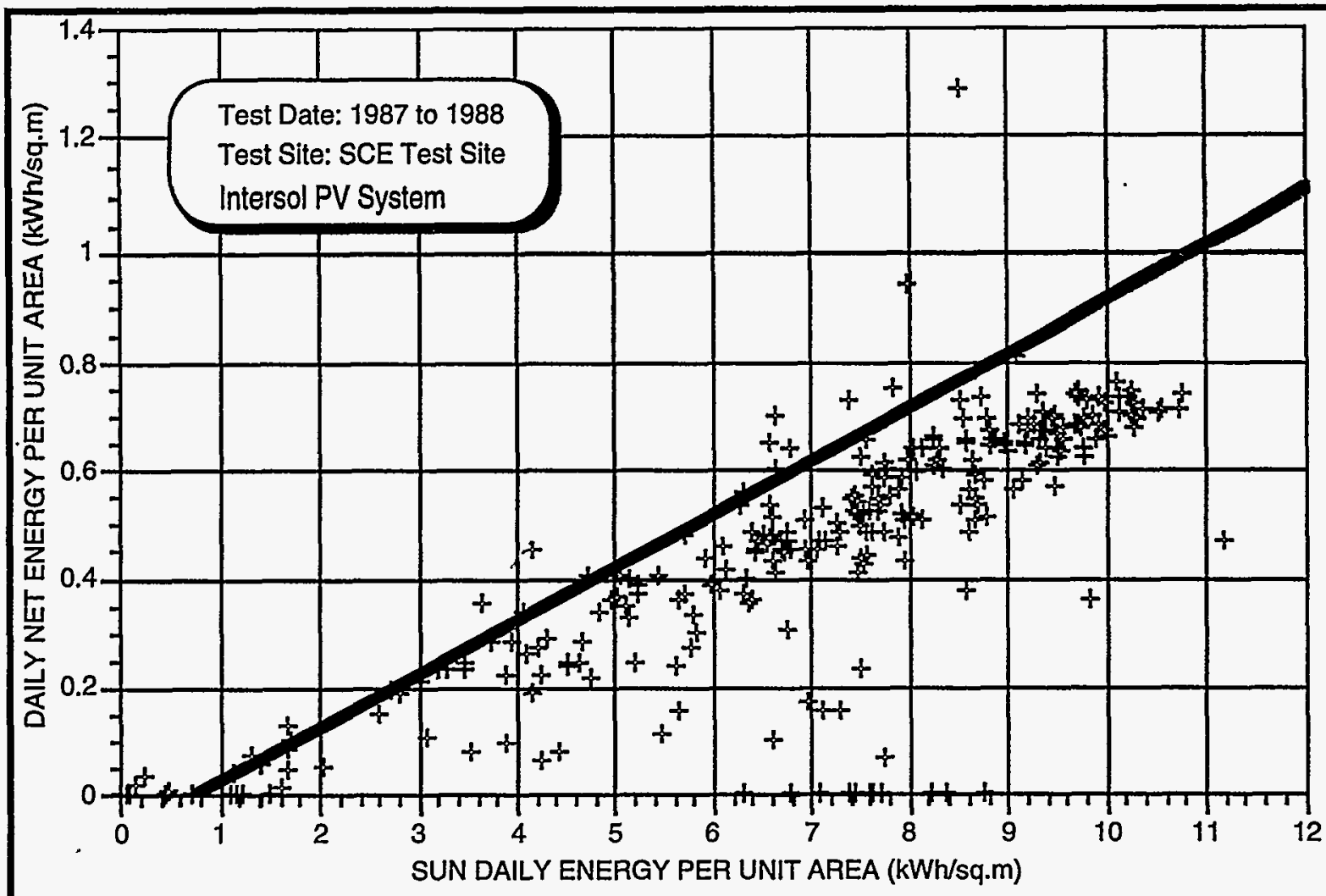

Figure V-7. Daily Energy Performance of Intersol PV System.

Operationally, the Stirling dish and the photovoltaic unit share the attributes of operating unattended and of modularity with respect to future growth. Based on the current operating experience, the Stirling dish has the advantage of high efficiency and the disadvantage of requiring routine operating intervention and higher maintenance cost. During the operation of the Stirling dish, it was demonstrated that its required operating intervention could be significantly reduced primarily by PCU software revisions and minor equipment modifications.

\section{Solar Electric Generation System (SEGS)}

The SEGS plants are located next to the Solar One plant at Barstow. SEGS-1 generates 13.8 megawatts and SEGS-2 produces 30 megawatts. SEGSs $3,4,5,6$ and 7 are 30 megawatt plants near Kramer Junction, 40 miles west of Barstow. SEGS $8 \& 9$ are $80 \mathrm{MW}$ plants located approximately 15 miles northwest of Barstow. These facilities are the largest commercial solar electrical generating plants in the world. The plants consist of a field of parabolic trough collectors which heat oil going through a 
receiver tube at the focus line of the troughs. The oil serves as the thermal transfer fluid and is pumped from a cold storage tank, held at approximately $465^{\circ} \mathrm{F}$ through the solar collector to absorb the sun's energy. The hot oil coming directly from the field or the hot storage tank is used to convert water into superheated steam. The superheated steam is used to power a turbine generator. Further information on the SEGS plants is in Reference 10 \& 11 .

The gross daily energy performance of the SEGS plant is shown in Figure V-8 (data furnished to Southern California Edison by Luz Engineering). Note that this data are gross daily energy and the daily sun energy was multiplied by a cosine

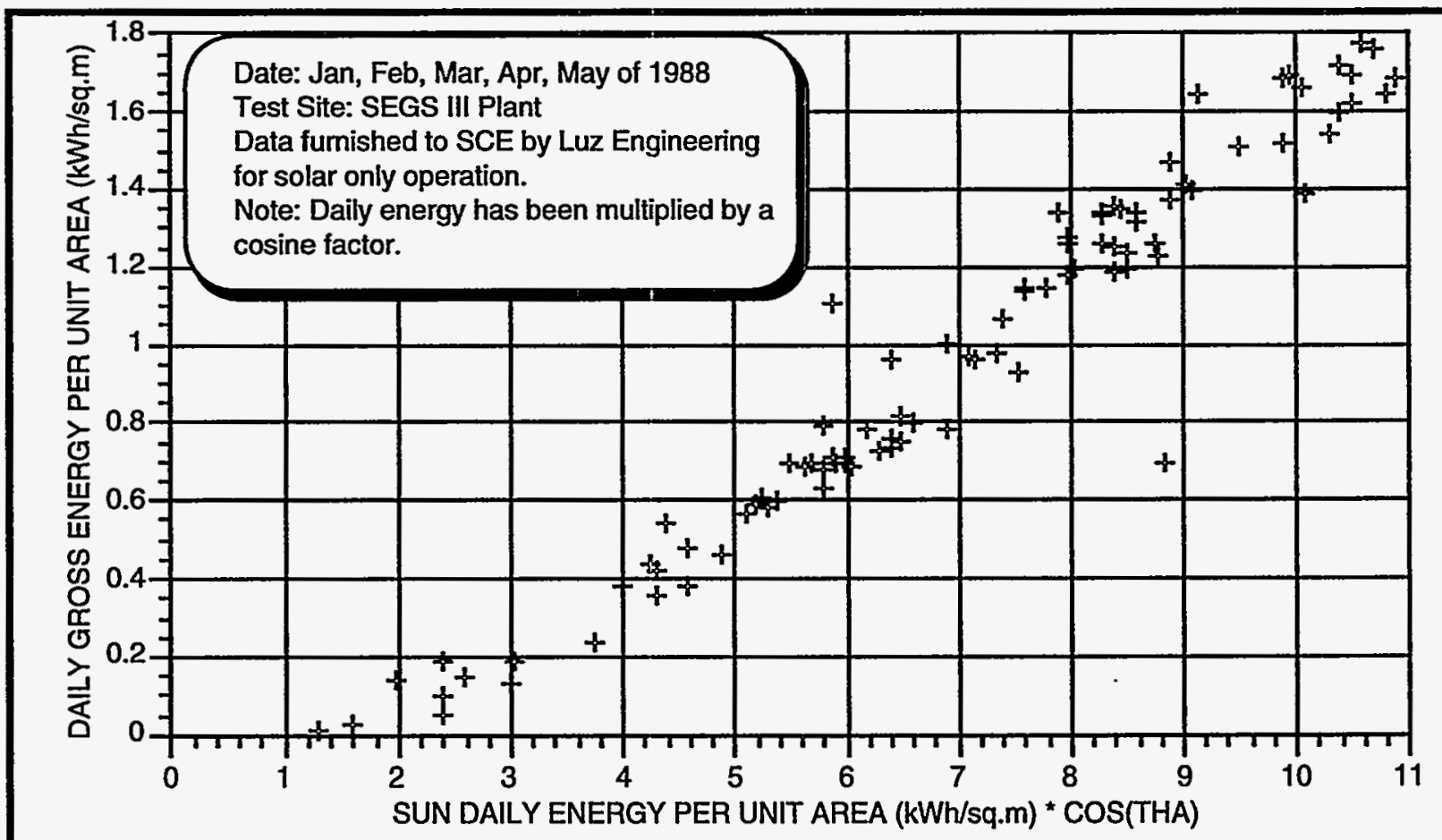

Figure V-8. Daily Energy Performance of SEGS.

factor (cosine(THA)). Therefore, this data are not directly comparable as furnished by Luz Engineering to the data of the previous system. This data were collected on days when gas was not used and, therefore, is for solar-only operation. Based upon estimates of parasitic system energy consumption obtained from Luz Engineering, the generated daily energy was modified to obtain the net energy. Each month of daily sun energy was divided by the cosine factor in order to obtain information comparable with the data from the other systems. The component power efficiency for the system is shown in Figure V-10. This data were furnished to SCE by Luz Engineering. 


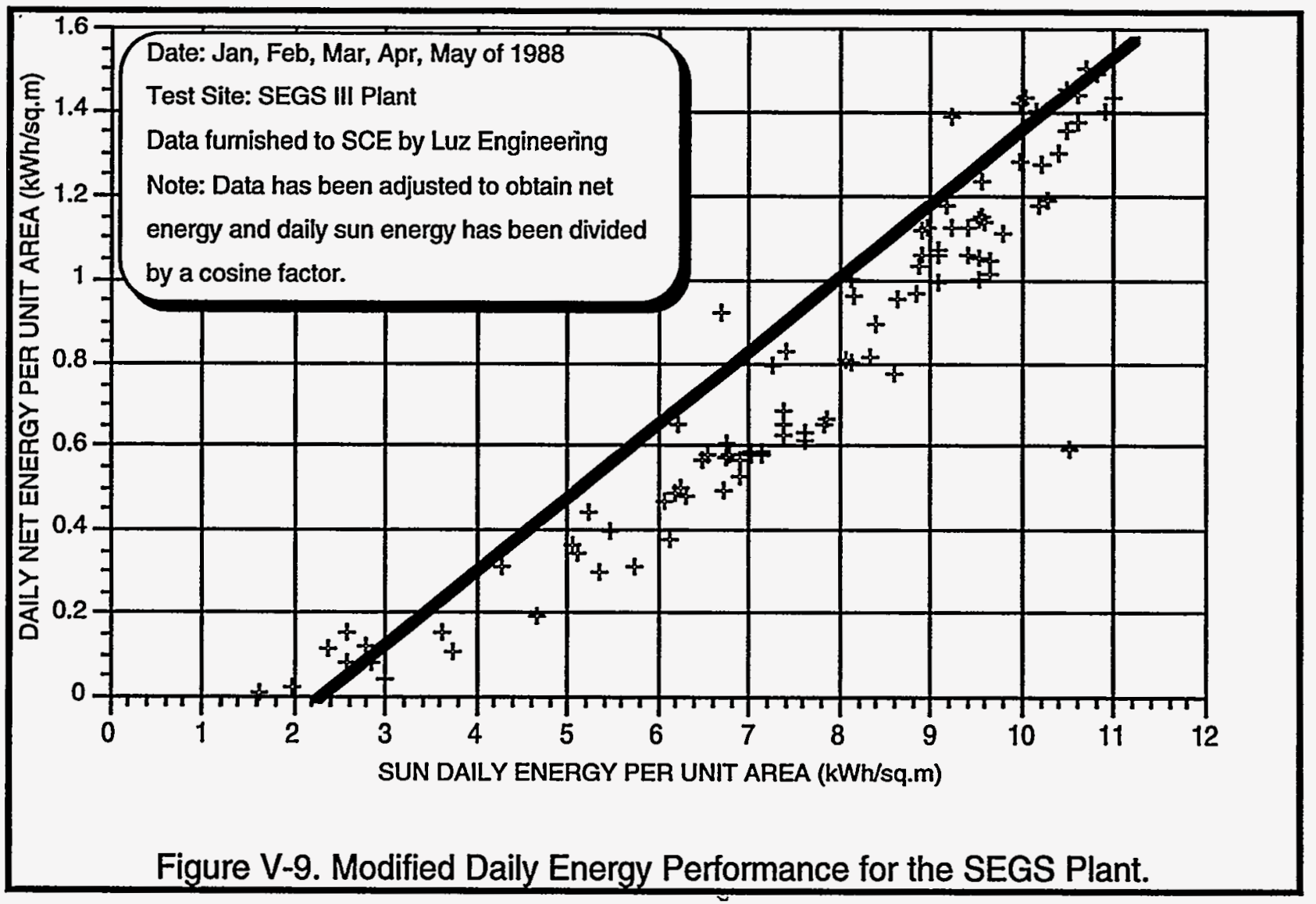




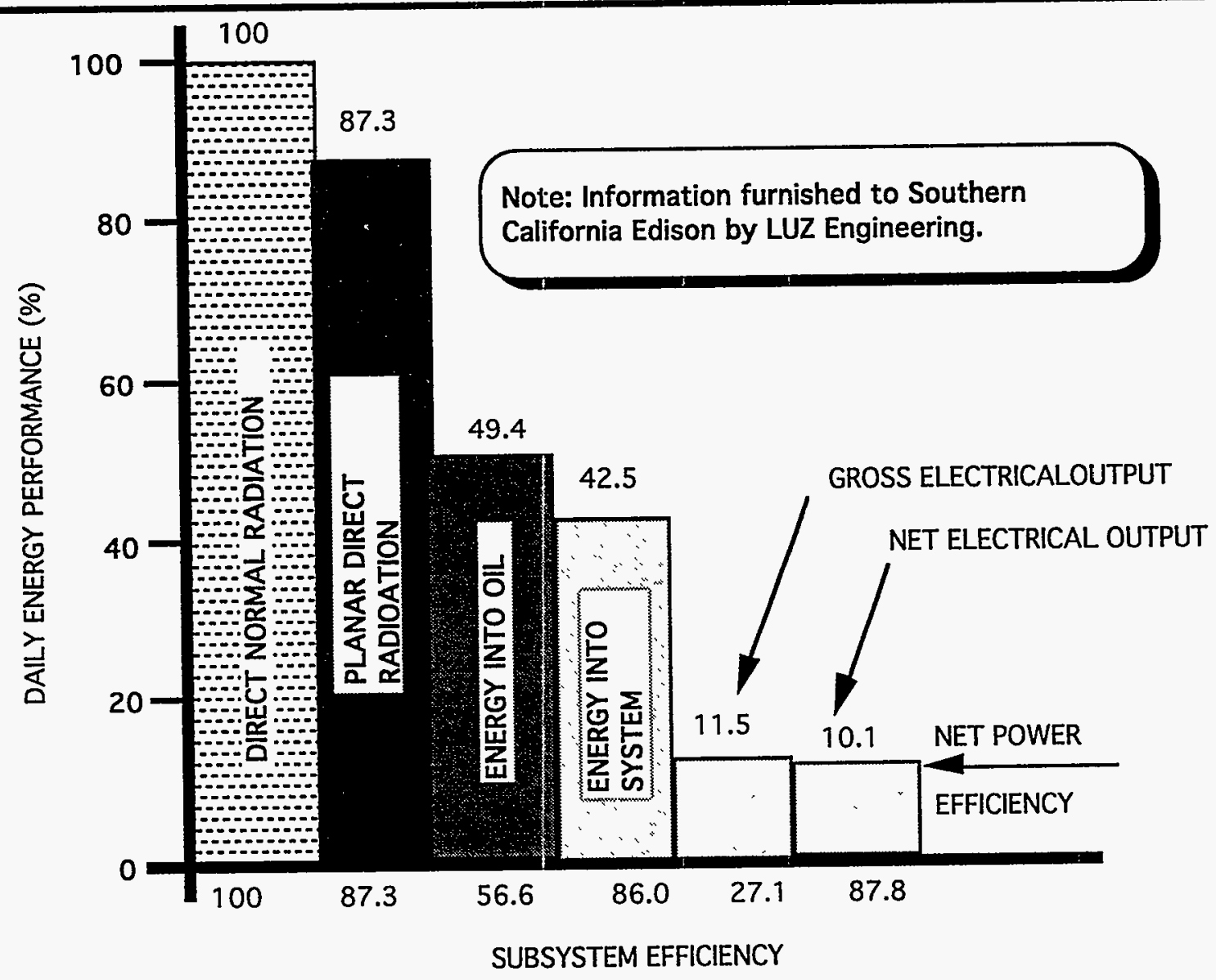

Figure V-10. Typical Efficiency Chain for SEGS III-V. 


\section{SYSTEM AVAILABILITY}

- Test program achieved a system availability of greater than $86 \%$
- Demonstrated that commercial plant availability could be better than $90 \%$
- Divestiture of USAB followed by MDAC detracked from true system avallabillty

This section uses the operating performance data from the test sites to calculate the system availability during the demonstration program. The results are then extrapolated to estimate the system availability for generating power in a commercial power plant consisting of multiple Stirling dishes. This analysis is derived from the event log at each test site, the monthly reports (Reference 6 ), and first-hand interviews with personnel involved with the program. A summary of the major operating events is given in Appendix A for the MDAC Test Site and in Appendix $B$ for the Georgia Power Test Site.

A summary of the system availability (defined later) is shown in Table VI-1. During the test program, a system availability of 86 to $90 \%$ was demonstrated. An analysis of the test program and lessons learned about how a commercial system should operate, indicated that a commercial system could have a system availability higher than $96 \%$ as shown in Table VI-2. It is conceivable, a system availability of $96 \%$ to $99 \%$ could be achievable with current state-of-the-art technology. Since the end of this Stirling Dish demonstration program in September 1988, simple concentrator modifications have been identified which would significantly increase the concentrator availability.

Although the system availability and the mean time between failures (MTBF) are of major interest, it is difficult to reduce the test data from this program to numbers that reflect the performance of commercial systems or that can be compared with other systems. Some of the reasons that make this task difficult are as follows:

1. The MDAC Test Site was used as a test bed where the PCU was operated for the first time on solar energy. Therefore, down time occurred because of first time PCU start-up problems and longer times were required for check-out. After a unit was operating satisfactorily, it was removed, and a new unit replaced it. As part of the test program, the units would be shut down for routine inspections even though they were operating satisfactorily. 
Table VI-I. Test Program System Availability.

\begin{tabular}{|c|c|}
\hline Test Site & System 'Availability \\
\hline $\begin{array}{l}\text { 1. MDAC Test Site } \\
\text { - Including first } 4 \text { months of startup problems } \\
\text { - After first } 4 \text { months of operation }\end{array}$ & $\begin{array}{l}89 \% \\
90 \%\end{array}$ \\
\hline $\begin{array}{l}\text { 2. Georgia Power Test Site } \\
\begin{aligned} \text { - Total Program } \\
\text { - Before MDAC/USAB Divestiture }\end{aligned}\end{array}$ & $\begin{array}{l}72 \% \\
86 \%\end{array}$ \\
\hline $\begin{array}{l}\text { 3. SCE Test Site } \\
\text { - Total Program } \\
\text { - From June } 1988 \text { to September } 1988 \\
\text { - Estimate with spare parts, manuals, trained } \\
\text { personnel, etc. }\end{array}$ & $\begin{array}{c}50 \% \\
87 \% \\
87-88 \%\end{array}$ \\
\hline
\end{tabular}

Table VI-2. Estimate of a Commercial Plant Availability.

\begin{tabular}{|ll|l|l|}
\hline \multicolumn{2}{|c|}{ Reason for Outage } & Outage \% & \multicolumn{1}{|c|}{$\begin{array}{c}\text { Total System } \\
\text { Outages }\end{array}$} \\
\hline 1. & Washing Concentrator & $0.05-0.2$ & $0.05-0.2$ \\
2. & Availability of Personnel & $0.1-0.4$ & $0.15-0.6$ \\
3. & Grid Power Loss & $0.05-0.2$ & $0.2-0.8$ \\
4. & General Maintenance & $0.1-0.2$ & $0.3-1.0$ \\
5. & Fill Hydrogen System & $0.05-0.1$ & $0.35-1.1$ \\
6. & Wind Stow & $0.2-0.4$ & $0.55-1.5$ \\
7. & Dish Trouble-Shooting, Repair, and Testing & $0.2-0.6$ & $0.75-2.1$ \\
8. & PCU Trouble-Shooting, Repair, and Testing & $0.4-1.2$ & $1.15-3.3$ \\
\hline \multicolumn{2}{|c|}{ System Availability $=96.7 \%-98.85 \%$} \\
\hline
\end{tabular}


2. The PCU control system was not a production-quality unit designed for a desert environment. In addition, implementing permanent fixes were not cost- effective, considering the remaining program duration. This resulted in reduced power generation time from problems that would have been corrected before producing a commercial system.

3. Although there was a vast amount of performance data compiled during the demonstration program, it was fragmented because of DAS software problems, instrumentation calibration, insufficient operator logs of maintenance and operating times at the different sites. This fragmentation made it difficult to determine the system test availability.

4. The program became the victim of circumstances when first USAB and then MDAC divested themselves of the program. The divestiture resulted in the loss of personnel trained to maintain the units. Consequent to the year long negotiations for the sale of the technology and subsequently sale of the remaining hardware, the availability of spare parts, manuals, and technical assistance to SCE, the purchaser, was limited. The divesting of USAB and MDAC from the program made it nearly impossible to determine and make permanent solutions to problems encountered in the SCE phase of the test program. Therefore, certain problems recurred throughout the remainder of the test program.

5. Plans were made during the SCE test program to correct some frequently occurring problems, but they were not completed before SCE decided to discontinue the Stirling dish development program. These improvements were limited to those provided by the authors and Lenoard Lundstrom, Intersol. A major portion of the time was spent during the SCE phase of the program repairing the old parts, searching for replacement parts, completing system manuals and drawings, etc.

6. Lack of operating personnel on the weekends often led to shut-down of the units even though the units did not have a problem and automatic operation was possible. During the last year of operation at the SCE's Solar One Test Site, the office building where the PCU monitor was located was locked on the weekends. If one of the erroneous detracks occurred, the unit had to wait until Monday when an operator had access to the office building to reset the monitor before operation 
could resume. Accordingly, it would be out of service for one or two days pending this reset action.

The data are summarized for each site with as few assumptions as possible. At the end of this section, the test data are used to estimate the availability of a commercial plant. After reviewing the available information, the availability of the unit to generate power on a nominally clear day (Figure VI-1) was determined to be the most meaningful compilation of the data. The availability or the fraction of the day that the dish was available to track the sun and produce power is the track time $\left(t_{1}+t_{2}\right)$ divided by the time of the operating day. The length of the operating day is defined as the length of time during which the insolation exceeds $300 \mathrm{~W} / \mathrm{m}^{2}$ in a "clear" environment. This is the time during the day when the PCU could operate and should be available to generate power (revenue generating time). Even if power could not have been produced because there was low sun irradiance during the outage, it was still counted as system down time. System outage time is divided into four main categories, with a number of subcategories. These categories are:

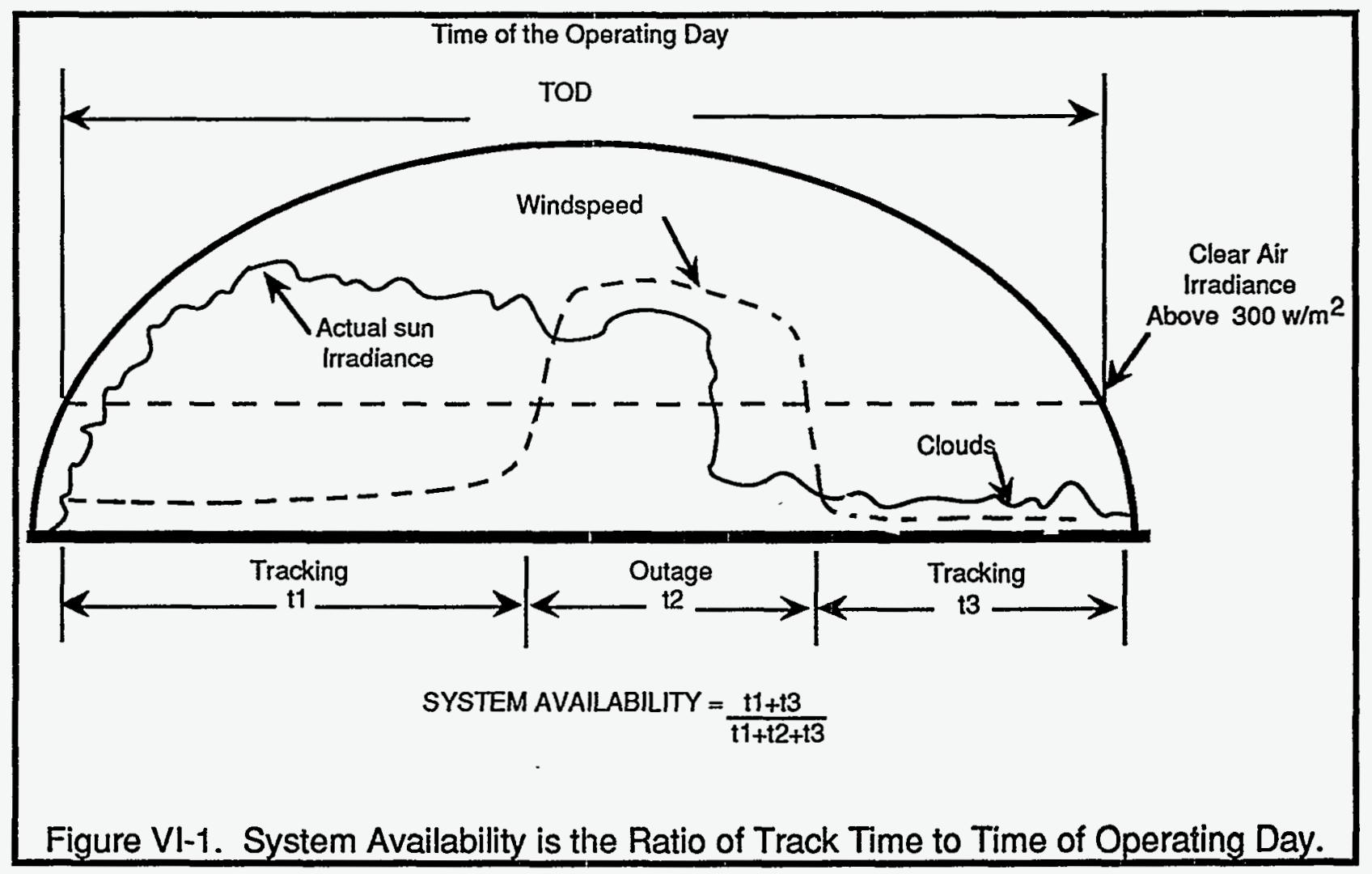


A. GENERAL OPERATION - The first outage category was general plant operation, which includes:

1. Washing the concentrator - The time to wash the dish, to initialize the system, and to put it back in a track position.

2. Availability of personnel - The operation and maintenance personnel at both SCE and Georgia Power Test Site had other responsibilities. The main function of the operators and maintenance personnel at the SCE Test Site was to keep Solar One operating, therefore, personnel were not always available to provide timely troubleshooting and repair. Lost time is the time that between problem detection and personnel availability to service the system.

3. Grid power loss - The grid line feeding the dish and/or control room lost power. Lost time includes the time power was off, time to reset, time to initialize the system, and time to go back to a track position.

4. General maintenance - Lost time was when general maintenance was performed, such as maintenance inspection, checking oil and water, etc.

5. Fill hydrogen system - Lost time to add hydrogen to the bottle or add a new bottle plus time to return the system back in service.

6. System Controller (SC) preventive maintenance - Lost time the DEC computer was down for general preventive maintenance, plus the time to return the system to service. There was no backup SC, so the system was down during this SC outage time.

B. DISH PROBLEMS - The second outage category, problems with the dish, included problems specific to solar concentrators such as:

1. Wind stow - The system outage time while the dish was in a wind-stow position due to high winds. Also, the time to go to and return from this wind-protected mode was included in the wind-stow outage time. This outage time was considered a dish problem because the azimuth drive did not meet its performance requirement and the wind stow limit was lowered to $25 \mathrm{mph}$. 
2. Waiting for parts and service - The lost time spent waiting for a spare part or for a technical service person to arrive at the site and investigate the problem. Lack of updated service manuals, incomplete training, and lack of available spare parts at MDAC during the transition of the technology to SCE.

3. Repairing and troubleshooting - This included the time needed to determine the problem, and the time to repair, test, and return the unit to service.

4. Fast Slew Repair - Time to service, troubleshoot, modify, and test this emergency system.

C. PCU PROBLEMS - The third outage category included all problems specific to the PCU.

1. Lightning protection stow - The PCU electronics were found to be very sensitive to lightning. The PCU electronics (which were really a development prototype and not a production unit) were not designed for this type of environment. Some "band-aid" modifications were made during 1988 that demonstrated the problem could be resolved. Since the concentrator electronics which were in the same environment, never had a problem, this also indicates the problem could be resolved. The SCE unit was put into a lightning-stow protection condition when lightning was in the area or if a lightning storm was anticipated. This consisted of disconnecting the PCU monitor cable at the PCU and the control room monitor and placing the dish in a face-up stow position. This included the time to disconnect, travel to face-up stow, time at wind stow, time to reconnect the cables, and return the system to service.

2. Waiting for parts and service - The time spent waiting for spare parts before the system could be repaired. Most of this time was the result of USAB's departure from the program and completion of the system sale to SCE. During this time, available spare parts could not be obtained.

3. Troubleshooting - This time included the travel time for a specialist to travel to the site and diagnose the problem, or time for O\&M personnel to work with the service person over the phone to diagnose the problem. 
4. Repairing and testing - This included time to repair the problem, test the system, and return the system to service.

5. Detracks - A number of false detracks occurred where the subsequent investigation did not find a problem. The PCU control system had a number of diagnostic tests which stopped the system when there wasn't a real problem, such as "oil pressure but not running". A high oil pressure indication occurred on cool mornings with hazy sun. The engine started and then stopped because of low sun irradiance. Because the oil was cold, the engine oil pressure stayed high longer than normal, causing the alarm. "Too many starts" is a second example of a frequent detrack outage. This occurred on partly cloudy days. This outage included the time it took to clear the alarm and put the system back in service. At the SCE site, the operator had to go to the dish control room from the Solar One control room to clear the alarm. If the alarm was the result of a valid problem, then the time to fix the problem was charged to one of the other categories. During the last year and a half, the SCE dish control room was locked, so the operator would have to wait until Monday before the unit could be put back into service. This was counted as down time.

6. PCU monitor problems - The monitor is not required to operate the PCU except to clear a detrack or to investigate a PCU problem. The time included in this category represents the time the system was down and could not be cleared because of a monitor problem.

7. Insolation too high - At high insolation levels, above $1,000 \mathrm{~W} / \mathrm{m}^{2}$, the engine could not remove heat from the receiver fast enough to maintain the receiver temperature at the setpoint temperature. The system would detrack and stay at standby until the insolation dropped and an operator commanded the system to return to track. This situation would be resolved in the next generation system.

D. MISCELLANEOUS - The fourth outage category was for events that did not fall into the above three categories. This category included the initial installation and checkout, and problems with the Fluke DAS. Although this system was not required for the operation of the Stirling dish, the dish had to be shut down several times for repair of the DAS. 


\section{Availability of SCE Unit at the SCE Test Site}

Analysis of the SCE test site data in Table VI-3 shows that over the period of the test program, the SCE unit was available $50.8 \%$ of the solar operating day. Fractions of the day during which the dish was not available to generate power are also shown in this table. This unacceptably low availability was not a result of low-hardware reliability but was primarily due to the absence of spare parts (see Items B-2 and C-2 in Table VI-3). This problem was caused by the USAB and MDAC divestiture and the time required to transfer the remaining hardware and spare parts to SCE. During this period the inventory of spare parts was not available to SCE. The divestiture occurred before the SCE maintenance personnel were trained and before manuals could be updated. Therefore, trained personnel were unavailable for this portion of the test program. This accounts for a major portion of the repair and troubleshooting outage time. The number of days of continuous operation is presented for the SCE system in Figure VI-2. An estimate of the mean time between outages was five days. Some of the more common reasons for the outages and the frequency are listed in Table VI-4. The mean time between outages caused by the dish was 48.5 days and for the PCU was 11.1 days. The majority of these outages were for short periods of time as a result of PCU false detracks. No problem could be found and the operator would clear the detrack and put the system back in operation. The false detracks will be discussed more in the next section.

The two most significant problems that occurred during the test period were the failure of the concentrator azimuth drive and PCU rod/bearing problems. Both of these problems are also discussed in detail in the following section.

\section{Expected Barstow System Availability}

The low availability of the SCE unit was not a result of hardware reliability, but was more the result of the divestiture of the program by MDAC and USAB. Due to the circumstances, it is felt that $50.4 \%$ is not representative of the true system availability. The predicted Barstow system availability, adjusted for the divestiture consequences, is given in Table VI-5. 


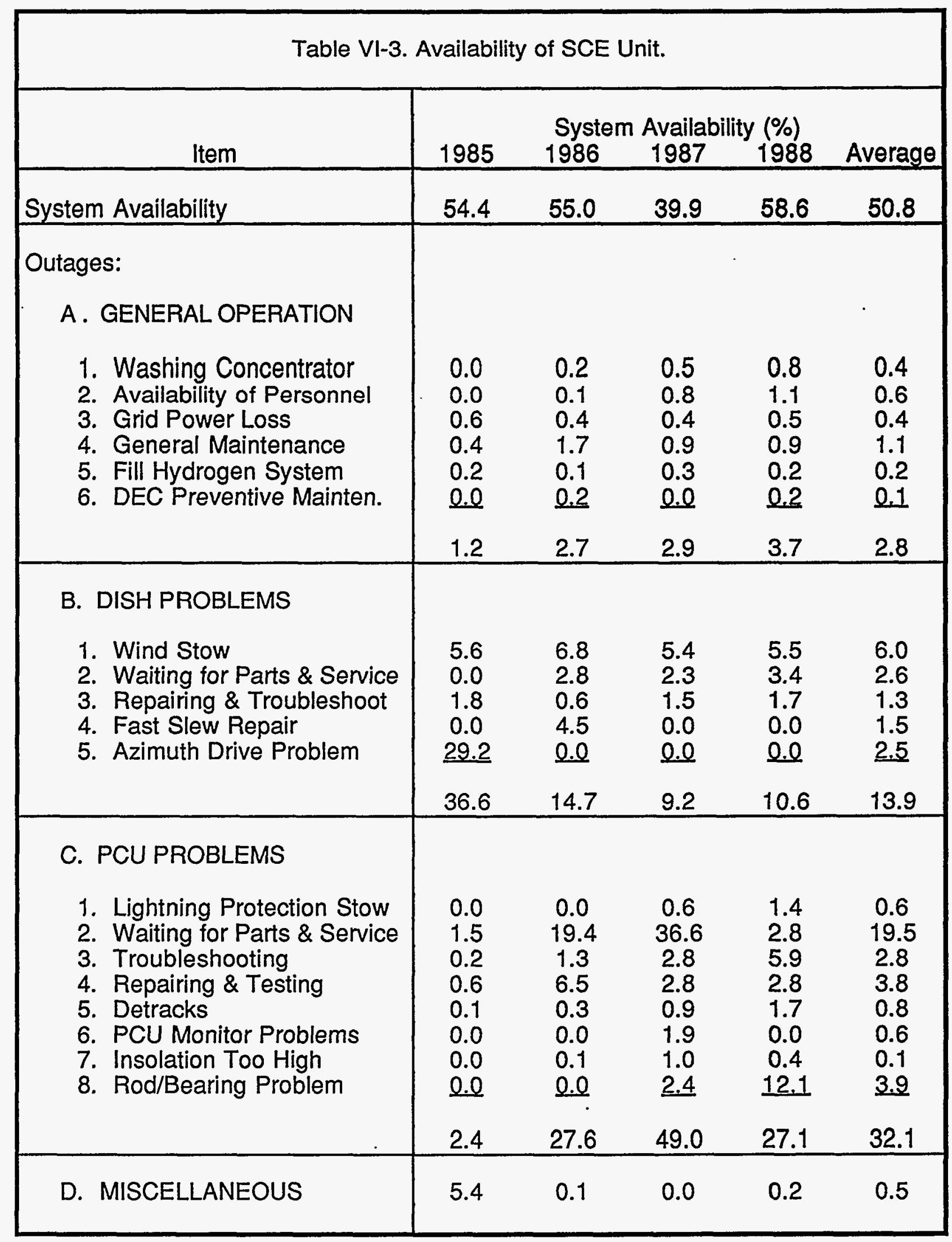




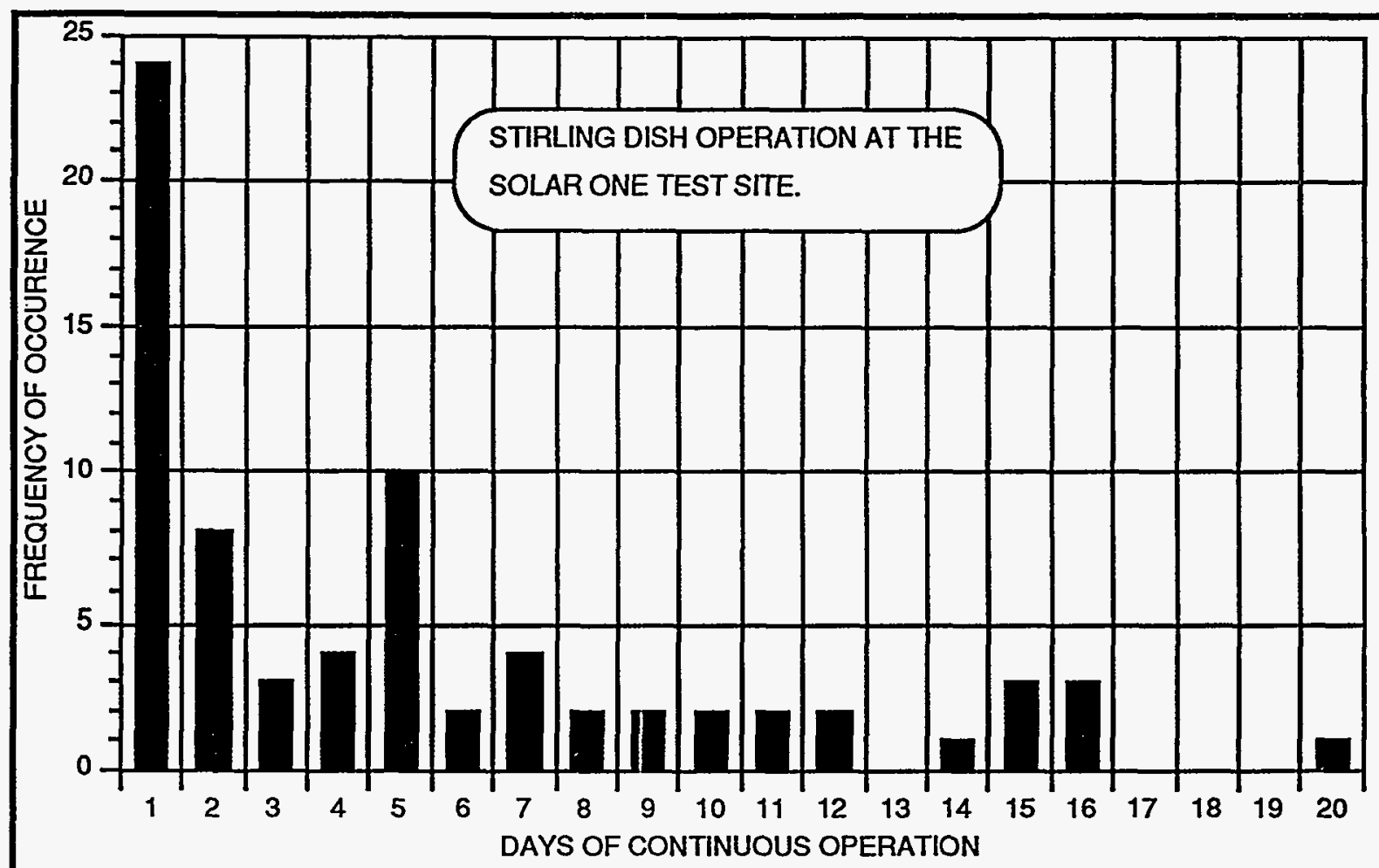

Figure VI-2. The Number of Days of Continued Operation at the SCE Test Site.

Table VI-4. Most Frequent Cause of Outage at the SCE Test Site.

\begin{tabular}{|c|c|c|c|}
\hline $\begin{array}{c}\text { System Outages } \\
\text { Wash } \\
\text { Grid Outages } \\
\text { Inspection } \\
\text { Hydrogen } \\
\text { Concentrator Outages } \\
\text { Fast Slew } \\
\text { Ref. Sensor } \\
\text { Azimuth Drive } \\
\text { Encoder }\end{array}$ & $\begin{array}{r}18 \\
10 \\
6 \\
5 \\
5 \\
2 \\
1 \\
1\end{array}$ & $\begin{array}{l}\text { PCU Outages } \\
\text { False Detracks } \\
\text { Lightning Induced } \\
\text { Valves/Nuts } \\
\text { Cone Insolation } \\
\text { Speed Sensor (Adj.) } \\
\text { Thermocouple } \\
\text { Rod/Bearing } \\
\text { Monitor } \\
\text { Water Level Sensor } \\
\text { Power Supply } \\
\text { Cooler } \\
\text { Oil Pressure Sensor } \\
\text { Compressor } \\
\text { Relay }\end{array}$ & $\begin{array}{r}25 \\
6 \\
5 \\
4 \\
3 \\
3 \\
2 \\
2 \\
2 \\
1 \\
1 \\
1 \\
1 \\
1\end{array}$ \\
\hline
\end{tabular}


Table VI-5. Availability Analysis of the SCE Unit at Solar One.

\begin{tabular}{|c|c|c|c|}
\hline Availability Component & $\begin{array}{c}\text { Test } \\
\text { Value } \\
(\%)\end{array}$ & $\begin{array}{l}\text { Adjusted } \\
\text { Value (\%) }\end{array}$ & $\begin{array}{c}\text { Adjusted } \\
\text { Availability } \\
(\%)\end{array}$ \\
\hline $\begin{array}{l}\text { Average System Availability } \\
\text { A. Waiting for Spare Parts } \\
\text { PCU Spare Parts } \\
\text { Dish Spare Parts } \\
\text { B. Dish Azimuth Drive } \\
\text { Azimuth Drive Problem Changeout } \\
\text { Wind Stow } \\
\text { C. PCU Rod/Bearing Problem . } \\
\text { D. PCU Monitor Problems } \\
\text { E. PCU Problems } \\
\text { Troubleshooting } \\
\text { Repair and Testing } \\
\text { F. Detracks } \\
\text { G. Dish Problems } \\
\text { Troubleshooting } \\
\text { Fast Slew Report }\end{array}$ & $\begin{array}{l}50.8 \\
19.5 \\
19.5 \\
2.6 \\
2.5 \\
6.0 \\
3.9 \\
0.6 \\
2.8 \\
3.8 \\
0.8 \\
1.3 \\
1.5\end{array}$ & $\begin{array}{c}-- \\
0 \\
0 \\
0 \\
0 \\
1.2 \\
0.0 \\
0.0 \\
1.8 \\
2.5 \\
0.5 \\
1.0 \\
0.5 \\
\end{array}$ & $\begin{array}{l}50.8 \\
70.3 \\
70.3 \\
72.9 \\
75.4 \\
80.2 \\
84.1 \\
84.7 \\
85.7 \\
87.0 \\
87.3 \\
87.6 \\
88.6\end{array}$ \\
\hline Actual System & $\begin{array}{l}\text { Estima } \\
\text { from }\end{array}$ & $\begin{array}{l}\text { Availability } \\
188-9 / 20 / 88\end{array}$ & $\begin{array}{l}88.6 \\
86.5\end{array}$ \\
\hline
\end{tabular}

Examples of the assumptions that were made to develop the adjusted values are listed below. A.) Spare parts would be available in an actual power plant, thus there will be no waiting for spare parts (2.6\% for the dish and $19.5 \%$ for the PCU); B.) The dish azimuth drive failure decreased availability as a result of having to wait for the new drive and the low wind stow limit that was used to prevent another failure. There would have been no waiting $(2.5 \%)$ in an actual plant, a spare drive would have been available. The new dish azimuth drive exceeds the wind load requirement, therefore the wind stow limit would be increased back to $35 \mathrm{mph}$ and the loss of operating time would be greatly reduced $(6.0 \%)$; C.) The long outage of the PCU due to the rod/bearing problem resulted from a combination of a shortage of personnel to analyze the problem and make a decision as to what action to take. In a utility power plant, the PCU would have been replaced immediately with a spare (3.9\%); D.) The PCU monitor would not be required in commercial production, therefore this outage would not occur; E.) Up-to-date PCU manuals and readily available test equipment would have greatly reduced the PCU trouble shooting time $(2.8 \%)$ and the repair and 
testing time (3.8\%); F.) Changing the PCU detract software logic would greatly reduce or eliminate the false detracks. An estimate of the detrack loss is $(0.5 \%)$; G.) Updating the dish manuals, development of ground test equipment and design modifications to the fast slew system would decrease the outage time for dish troubleshooting and repair (1.3\%) and the fast slew system (1.5\%). During the last few months of the SCE test program, a number of temporary fixes were made to the system and the system was available $86.5 \%$ of the time. The availability could also be improved by making limited design changes to correct frequent operating and maintenance problems, such as removing unused components and upgrading the hardware.

\section{Availability of Georgia Unit}

Even though this unit was installed in October of 1985 and was operated for demonstration purposes, through 1988, only operational data from its installation in November 1985 to July 1986 were considered for this analysis. After that time, technical support and spare parts were not available to resolve operating and maintenance problems. Since it was operated only for demonstration purposes after July 1986, the operational data are not applicable for an availability analysis.

The results of the analysis (Table VI-6) for the initial nine-month period shows the system had an availability of $72.3 \%$. Waiting for spare parts and technical service for the dish $(6.4 \%)$ and the PCU $(11.4 \%)$ was the major reason for the system's unavailability $(17.8 \%)$. If spare parts had been available, system availability would have been $90.1 \%$. Even though both USAB and MDAC were active in the test program during this test period, a large amount of time transpired trying to work out the problems over the phone, mailing parts back and forth, waiting for parts to come from Sweden, and/or waiting for the technician to fly from California to Georgia.

If one outage period, from late May to the end of June is removed from the analysis, the availability of the Georgia unit was better than $85 \%$. This outages began with a PCU control problem coupled with a fast slew design problem, which led to drivemotor damage and burned wires. While the system was down, the Mark II PCU replaced the original Mark I PCU and an additional hydrogen bottle was added. USAB and MDAC personnel were not available to complete the check-out, so it was delayed. Only $1.7 \%$ of the Georgia outage time is associated with general operation versus $3.2 \%$ for SCE. This difference is partly due to the test-log level of detail. The 


\begin{tabular}{|c|c|c|c|c|c|c|c|c|c|c|}
\hline Table & VI-6. & Aval & ability & of $\mathbf{G}$ & orgia & Unit & & & & \\
\hline It e m & Nov & Dec & $\mathbf{J}$ a $\mathbf{n}$ & Fe b & $\mathbf{M a r}$ & A p r & $\mathbf{M} \mathbf{a} \mathbf{y}$ & J u n & $\mathbf{J} \mathbf{u} \mathbf{l}$ & $\begin{array}{c}\text { Aver } \\
\text { age }\end{array}$ \\
\hline System Availability & 97.5 & 82.4 & 79.4 & 94.0 & 68.8 & 92.8 & 58.2 & 25.0 & 79.8 & 72.3 \\
\hline \multirow[t]{2}{*}{$\begin{array}{l}\text { Outages } \\
\text { A. GENERAL OPERATION } \\
\text { 1. Washing Concentrator } \\
\text { 2. Grid Power Loss } \\
\text { 3. General Maintenance } \\
\text { 4. Fill Hydrogen }\end{array}$} & $\begin{array}{l}0.0 \\
0.0 \\
0.4 \\
0.2 \\
\end{array}$ & $\begin{array}{l}0.5 \\
0.0 \\
0.8 \\
0.2 \\
\end{array}$ & $\begin{array}{l}0.0 \\
2.1 \\
0.5 \\
0.3\end{array}$ & $\begin{array}{l}0.3 \\
0.0 \\
0.4 \\
0.2 \\
\end{array}$ & $\begin{array}{l}0.3 \\
2.8 \\
0.3 \\
0.2 \\
\end{array}$ & $\begin{array}{l}0.3 \\
0.0 \\
0.3 \\
0.2 \\
\end{array}$ & $\begin{array}{l}0.2 \\
0.0 \\
0.3 \\
0.1\end{array}$ & $\begin{array}{l}0.0 \\
0.0 \\
0.0 \\
0.0\end{array}$ & $\begin{array}{l}0.3 \\
0.0 \\
0.2 \\
0.2 \\
\end{array}$ & $\begin{array}{l}0.2 \\
0.7 \\
0.2 \\
0.2 \\
\end{array}$ \\
\hline & 0.6 & 1.0 & 2.9 & 0.6 & 3.3 & 0.5 & 0.4 & 0.0 & 0.5 & 1.6 \\
\hline \multirow[t]{2}{*}{$\begin{array}{l}\text { B. DISH PROBLEMS } \\
\text { 1. Waiting for Parts and Service } \\
\text { 2. Repairing and Troubleshooting } \\
\text { 3. Fast Slew Repair }\end{array}$} & $\begin{array}{l}0.0 \\
0.0 \\
0.0 \\
\end{array}$ & $\begin{array}{l}0.0 \\
1.8 \\
3.2 \\
\end{array}$ & $\begin{array}{l}0.5 \\
2.9 \\
0.0 \\
\end{array}$ & $\begin{array}{l}0.0 \\
0.7 \\
0.0 \\
\end{array}$ & $\begin{array}{l}0.0 \\
0.7 \\
0.0 \\
\end{array}$ & $\begin{array}{l}0.6 \\
1.2 \\
0.0 \\
\end{array}$ & $\begin{array}{r}10.2 \\
10.9 \\
0.0 \\
\end{array}$ & $\begin{array}{r}30.6 \\
4.2 \\
3.2 \\
\end{array}$ & $\begin{array}{l}1.9 \\
1.1 \\
0.0 \\
\end{array}$ & $\begin{array}{l}6.4 \\
3.0 \\
0.7 \\
\end{array}$ \\
\hline & 0.0 & 5.0 & 3.4 & 0.7 & 0.7 & 1.8 & 21.1 & 38.0 & $3.0^{\circ}$ & 10.1 \\
\hline \multirow[t]{2}{*}{$\begin{array}{l}\text { C. PCU PROBLEMS } \\
\text { 1. Waiting for Parts and Service } \\
\text { 2. Troubleshooting } \\
\text { 3. Repairing/Testing } \\
\text { 4. Detracks }\end{array}$} & $\begin{array}{l}0.8 \\
0.0 \\
1.7 \\
0.0\end{array}$ & $\begin{array}{l}5.2 \\
0.0 \\
6.7 \\
0.5\end{array}$ & $\begin{array}{l}4.3 \\
4.9 \\
5.4 \\
1.2\end{array}$ & $\begin{array}{l}0.9 \\
0.9 \\
3.5 \\
0.0 \\
\end{array}$ & $\begin{array}{r}23.6 \\
0.7 \\
3.1 \\
0.7 \\
\end{array}$ & $\begin{array}{l}1.3 \\
0.0 \\
2.2 \\
0.0 \\
\end{array}$ & $\begin{array}{r}10.2 \\
10.2 \\
5.2 \\
0.1 \\
\end{array}$ & $\begin{array}{r}32.0 \\
3.0 \\
1.6 \\
0.1 \\
\end{array}$ & $\begin{array}{l}9.9 \\
2.9 \\
4.3 \\
0.0 \\
\end{array}$ & $\begin{array}{r}11.4 \\
1.7 \\
2.8 \\
0.1 \\
\end{array}$ \\
\hline & 2.5 & 12.4 & 15.8 & 5.3 & 28.1 & 3.5 & 25.7 & 36.7 & 17.1 & 16.0 \\
\hline
\end{tabular}


Georgia Power log time for such things as technicians and operators not being available, etc. was included in other outage categories, such as, repair.

\section{Availability of MDAC Units}

The availability of the MDAC units is shown in Table V1-7 for the month of December, 1984 and three six-month time periods starting in January 1985 and ending in June 1986. Although the first unit ran at the MDAC Test Site in late November 1984, the test plan did not actually begin until January 1985. Most of December was devoted to development tests, for holidays, and vacations. At the beginning of the test period, the unit was not operated on weekends because operators were not available. Later in the test program, if the unit operated on Friday with no problems it would be allowed to run in automatic mode during the weekend. Weekend time was only included in the

\begin{tabular}{|c|c|c|c|c|c|}
\hline \multicolumn{6}{|c|}{ Table VI-7. Availability of MDAC Units. } \\
\hline Item & Dec 84 & $\begin{array}{l}\text { Jan } 85- \\
\text { Jun } 85\end{array}$ & $\begin{array}{l}\text { Jul 85- } \\
\text { Dec 85 }\end{array}$ & $\begin{array}{l}\text { Jan 86- } \\
\text { Jun } 86\end{array}$ & Average \\
\hline $\begin{array}{l}\text { SYSTEM AVAILABILITY } \\
\text { A. Power Generating } \\
\text { B. Development Testing }\end{array}$ & $\begin{array}{l}59.2 \\
18.9 \\
78.1\end{array}$ & $\begin{array}{l}85.1 \\
\frac{8.1}{93.2}\end{array}$ & $\begin{array}{l}82.7 \\
\frac{2.4}{85.1}\end{array}$ & $\begin{array}{l}84.7 \\
\frac{6.3}{91.0}\end{array}$ & $\begin{array}{l}83.5 \\
35.6 \\
89.1\end{array}$ \\
\hline $\begin{array}{l}\text { OUTAGES } \\
\text { A. General Operation } \\
\text { 1. Washing Concentrator } \\
\text { 3. Grid Power Loss } \\
\text { 4. Fill Hydrogen System }\end{array}$ & $\begin{array}{l}0.2 \\
0.0 \\
0.3 \\
0.5 \\
\end{array}$ & $\begin{array}{l}0.4 \\
0.0 \\
0.3 \\
0.7 \\
\end{array}$ & $\begin{array}{l}0.3 \\
0.7 \\
0.2 \\
1.2 \\
\end{array}$ & $\begin{array}{l}0.2 \\
0.4 \\
0.2 \\
0.8 \\
\end{array}$ & $\begin{array}{l}0.3 \\
0.5 \\
0.2 \\
1.0 \\
\end{array}$ \\
\hline $\begin{array}{l}\text { B. Dish Problems } \\
\text { 1. Wind Stow } \\
\text { 3. Repairing } \\
\text { 4. Fast Slew Repair }\end{array}$ & $\begin{array}{l}0.0 \\
3.3 \\
0.0 \\
3.3\end{array}$ & $\begin{array}{l}0.1 \\
1.7 \\
0.0 \\
1.8\end{array}$ & $\begin{array}{l}0.2 \\
0.8 \\
1.0 \\
2.0\end{array}$ & $\begin{array}{l}0.2 \\
0.6 \\
0.2 \\
1.0\end{array}$ & $\begin{array}{l}0.2 \\
0.9 \\
0.4 \\
1.5\end{array}$ \\
\hline $\begin{array}{l}\text { C. PCU Problems } \\
\text { 3. Troubleshooting } \\
\text { 4. Repairing and Testing } \\
\text { 5. Detracks }\end{array}$ & $\begin{array}{l}1.2 \\
16.3 \\
0.6 \\
18.1\end{array}$ & $\begin{array}{l}1.1 \\
3.0 \\
0.2 \\
4.3\end{array}$ & $\begin{array}{l}2.8 \\
8.6 \\
0.3 \\
11.7\end{array}$ & $\begin{array}{l}2.2 \\
4.9 \\
0.1 \\
7.2\end{array}$ & $\begin{array}{l}2.1 \\
6.1 \\
0.2 \\
8.4\end{array}$ \\
\hline
\end{tabular}


availability calculations when the unit was left to operate automatically or an operator came in on the weekend to operate the unit. Weekends, when the unit was not put into automatic operation or it was not operational and no one was available to work on it were not included in the availability calculations.

As discussed previously, the MDAC units were used as a test bed. The time that the units were used for development testing was included in the availability calculations (special category B in Table VI-7).

The system availability for the MDAC unit was $86.9 \%$. Examination of the availability percentages reveals that the main reason for the higher availability at the MDAC Test Site is because trained personnel and spare parts were available. The PCU repair time is higher than might be expected because PCUs were replaced frequently as part of the development test program and not as a consequence of PCU failure. The new PCUs required considerably more outage time to allow complete prestart test of each PCU.

\section{Estimate of Availability of Commercial Unit}

This was a developmental test program and, as such, the units were not operated as a commercial plant: Different maintenance procedures, additional test hardware that caused outages, no redundancy, minimal spare parts and trained personnel, data logging equipment, etc. The following analysis presents a rationale why each of the previous outage categories would require less outage time at a commercial plant and estimates the outage time for a commercial plant. These numbers are estimates based upon the experience gained in the test program. The actual numbers can only be determined through a longer test program and more units and designed to emulate a commercial plant operation. An estimate of what a commercial plant could achieve is shown in Table VI-2. The basis for these estimates is as follows:

1. Concentrator Washing - The washing outage times were $0.4 \%$ for SCE, $0.2 \%$ for Georgia, and $0.3 \%$ for MDAC, for an average of $0.3 \%$. The washing equipment furnished to each test site was a prototype of what was envisioned for a commercial plant but required more manual labor. The washing process proved very effective and if mechanized similar to the final Solar One process, the outage time should be 
reduced by at least $50 \%$. The outage time because of washing for a commercial plant was estimated to be $0.05 \%$ to $0.2 \%$

2. Personnel Availability - Only the SCE test log had sufficient detail to estimate the amount of time that was required for operating and maintenance personnel to respond to a problem with the unit. SCE personnel were mainly responsible for the operation of the Solar One plant and not the Stirling dish. Although a Stirling dish plant would have devoted personnel, there will still be times when operating personnel will be involved in other tasks and will not be able to respond immediately when there is a problem with a unit. Some of the SCE outage time $(0.6 \%)$ was due to test related equipment that would not be part of a commercial plant, such as the PCU monitor. An estimate of the outage for a commercial plant is $0.1 \%-0.4 \%$

3. Grid Loss - Grid power loss accounted for an average of $0.6 \%$ of the outage time for the three sites. An outage this high is probably due to the fact that these units were an add on to the existing grid. This outage would be greatly reduced in a commercial plant connected to a grid line with backup grid connection. An estimate of this outage time is $0.05 \%-0.2 \%$.

4. General Maintenance - General maintenance time for the MDAC test site was lower than for the other two sites because the operating personnel would either stay late or come in early and perform the tasks outside the power generating period. Therefore, only the SCE and Georgia site data will be used for this time determination. Part of this outage time was involved with test equipment that would not be part of a commercial system. At the SCE test site, inspection and special testing were conducted routinely due to developmental problems. This testing would not have been done in commercial plant. The Georgia test data are felt to be more representative of a commercial plant $(0.1 \%-0.2 \%)$.

5. Hydrogen Fill - The hydrogen fill time at all three sites was $0.2 \%$. The majority of the hydrogen was lost as result of maintenance on the engine. When the engine developmental problems have been resolved, it is estimated that this outage time would be than $0.05 \%-0.1 \%$. 
6. Wind Stow - No significant wind-stow outage time was recorded at the MDAC and Georgia sites because the wind-stow limit was higher at these sites during the test period. The SCE limit was set at $25 \mathrm{mph}$ throughout most of the test program. The new azimuth drive would allow the SCE limit to be increased to $35 \mathrm{mph}$. Using statistical wind data, an estimated outage time for a commercial plant is $0.2 \%-0.4 \%$.

7. Concentrator Maintenance - The maintenance estimate for a commercial plant would be similar to the MDAC site data since spare parts and trained maintenance personnel would be available. Therefore, the time lost waiting for spare parts and technical service should not be considered for a commercial plant. The troubleshooting and repair time was 5.4\% for SCE, 3.7\% for Georgia, and $1.3 \%$ for MDAC, which reflects the availability of trained personnel at the MDAC Test Site. The MDAC number can be reduced by implementing some design changes and following a field replacement policy instead of trouble-shooting in the field. Based upon the component performance since the end of the testing by SCE in 1988 and following a replacement policy instead of in field repair, it is estimated that the outage time could be as low as $0.2 \%-0.6 \%$.

8. PCU Maintenance - The same reasoning applies to the PCU maintenance time. The repair time was longer at MDAC than at the other sites, because MDAC was used as a testbed to operate engines for the first time. The troubleshooting and repair for the other sites would be a better upper basis, although still very conservative $(5.6 \%$ and $4.5 \%)$. If design changes were implemented and a replacement policy were followed, these numbers would be reduced by more than a factor of 2. The outage resulting from the PCU monitor, monitor cable, and lightning would be eliminated because these components were only test components and would not be part of a commercial plant. The PCU is more complex than the concentrator, therefore it is estimated that the PCU outage time could be higher than the concentrator's $(0.4 \%-1.2 \%)$. 


\section{OPERATION OF THE STIRLING DISH}

- Over 13,852 hours of on-sun generating time

- Expected PCU hydrogen seal and piston ring problems did not occur, more testing required to confirm life expectancy

- No PCU heater head problems, more testing required to confirm life expectancy

- No major system design changes are required in the system

- Concentrator modifications have been made and under test, MTBF has increased

The previous section on system availability indicated a number of problems, which are discussed here in more detail. Of the eight dishes built, six were installed and operated for the periods shown in Table VII-1. Three concentrators were installed at the MDAC Test Site, where they were used to obtain performance data and to accumulate time on PCU engines before the engines were shipped to Barstow, Georgia, or Las Vegas.

\section{Concentrator}

A summary of the concentrator status and current location is given in Table VII-1. The operating times are estimates based upon the test logs at the different sites of how many operational cycles (unstow, track, and stow) were accomplished during the testing period. The time for the dishes at Huntington Beach include life-cycle testing at night and on cloudy days in which the units would unstow, track for 15 minutes, and then stow.

A summary of the problems at all sites since the start of the testing is given in Table VII2. The comment column describes the temporary fix to continue the testing and/or a possible permanent solution to the problem. The most significant problem during this time was the failure of the azimuth drive and the elevation drive helicon gear for reasons unclear at this time. The drives were designed to operate in wind speeds up to $35 \mathrm{mph}$ at the worst angle of attack, but it is estimated that the azimuth harmonic drive gear jumped a tooth at a wind speed around $30 \mathrm{mph}$. Although the drive will operate after this occurs, the wind load capability is greatly reduced. The drive used in the load test also jumped a gear tooth, but at a wind speed of $37 \mathrm{mph}$. There were a number of other units during the test program that continued operating at or higher than $35 \mathrm{mph}$. Concentrator \#1 at Huntington Beach, before the above problem was 
Table VII-1. Summary Of Concentrator Status As Of August 1992.

\begin{tabular}{|c|c|c|c|}
\hline $\begin{array}{l}\text { Present } \\
\text { Location }\end{array}$ & Period & $\begin{array}{c}\text { Operating } \\
\text { Time }\end{array}$ & Comments \\
\hline Huntington Beach & 11/84-Present & $7.0 \mathrm{yr}(1)$ & $\begin{array}{l}1 \text { MDAC Space Lab. Operated until } \\
\text { June of } 1986 \text { with a Stirling engine. } \\
\text { Operated as a solar furnace in the } \\
\text { MDAC Space Power Lab. }\end{array}$ \\
\hline Huntington Beach & 5/85-Present & $5.0 \mathrm{yr}(1)$ & $\begin{array}{l}\text { Operated until June of } 1986 \text { with a } \\
\text { Stirling engine. Operated as a solar } \\
\text { furnace in the MDAC Space Power } \\
\text { Lab }\end{array}$ \\
\hline Switzerland & $6 / 85-10 / 86$ & $1.5 \mathrm{yr}$ & $\begin{array}{l}\text { Moved from MDAC to SCE } \\
\text { Alhambra in 1987. Moved to Paul } \\
\text { Sherrer Institute, Switzerland in } \\
\text { 1989. Used as a solar furnace. }\end{array}$ \\
\hline SCE Test Site & $8 / 85-10 / 88$ & $3.2 \mathrm{yr}$ & $\begin{array}{l}\text { Operated at SCE Test Site until } \\
\text { September of } 1988 \text {. Only moved } \\
\text { twice since that time. }\end{array}$ \\
\hline Georgia & $11 / 85-6 / 88$ & $1.0 \mathrm{yr}$ & $\begin{array}{l}\text { Operated through July of } 1986 . \\
\text { Limited operation through } 1988 . \\
\text { Not operated since that time. }\end{array}$ \\
\hline Japan & $\begin{array}{l}\text { 4/86-6/87 } \\
\text { 6/87-Present }\end{array}$ & $\begin{array}{l}0.2 \mathrm{yr} \\
\text { Unknown }\end{array}$ & $\begin{array}{l}\text { Operated at Las Vegas, Nevada } \\
\text { test site. Sold to Aisin Seiki Stirling } \\
\text { in Japan. Testing with a Japanese } \\
\text { Stirling engine. }\end{array}$ \\
\hline SCE Test Site & Not Installed & None & $\begin{array}{l}\text { Never installed. Stored at SCE } \\
\text { Test Site. One outer and inner } \\
\text { assemblies were damaged when } \\
\text { high winds overturned assembly. } \\
\text { Support structure bent and mirrors } \\
\text { broken. All damage has been } \\
\text { repaired. }\end{array}$ \\
\hline Arizona/Spain & 1990 - Present & $1.5 \mathrm{yr}$ & $\begin{array}{l}\text { Stored at SCE Test Site until } 1989 . \\
\text { Structure drive and controls sold to } \\
\text { Smithsonian Institution to be used } \\
\text { as a space telescope. Mirrors sold } \\
\text { to Spain. for use in a solar furnace. }\end{array}$ \\
\hline
\end{tabular}


Table VII-2. Concentrator Problems.

\begin{tabular}{|c|c|c|}
\hline Problem & Description & Comment \\
\hline \multirow[t]{2}{*}{ Azimuth } & $\begin{array}{l}\text { Harmonic gear drive on } \\
\text { Barstow unit stripped at } \\
\text { approximately } 30 \mathrm{mph} \text { wind } \\
\text { speed while going to wind } \\
\text { stow position. }\end{array}$ & $\begin{array}{l}\text { Could have been an assembly or } \\
\text { manufacturer problem because several } \\
\text { drives have operated in } 35 \text { to } 45 \mathrm{mph} \\
\text { winds with no problem. } \\
\text { The wind speed was lowered to } 25 \mathrm{mph} \\
\text { for the test program. } \\
\text { New drive developed by Sumitomo } \\
\text { should have greater than } 35 \mathrm{mph} \\
\text { capability and cost less. }\end{array}$ \\
\hline & $\begin{array}{l}\text { On } 10 / 12 / 88 \text {, the azimuth } \\
\text { helicon of Huntington Beach } \\
\text { gear unit stripped. }\end{array}$ & $\begin{array}{l}\text { It appears that the harmonic gear } \\
\text { jammed, which resulted in stripping of } \\
\text { the helicon gear. It has not been taken } \\
\text { apart so the cause and extent of damage } \\
\text { has not been identified. }\end{array}$ \\
\hline \multirow[t]{2}{*}{ Elevation Jack } & $\begin{array}{l}\text { On } 11 / 20 / 88 \text {, the elevation } \\
\text { helicon gear on the Georgia } \\
\text { Power unit stripped. }\end{array}$ & $\begin{array}{l}\text { The gear teeth wore down to } \\
\text { approximately } 1 / 2 \text { the normal size. This } \\
\text { could have been caused by water in the } \\
\text { grease or damage that was done in June } \\
1986 \text { when the system was driven into } \\
\text { the pedestal because of a PCU failure } \\
\text { coupled with two control design } \\
\text { problems. At that time, it was observed } \\
\text { that many small grains of the Helicon } \\
\text { gear were in the grease. It was decided } \\
\text { not to change the gear. }\end{array}$ \\
\hline & $\begin{array}{l}\text { In February 1989, jack rod } \\
\text { broke on pad \#2 at } \\
\text { Huntington Beach. }\end{array}$ & $\begin{array}{l}\text { A crack was found in the jack rod. It was } \\
\text { determined that crack occurred during } \\
\text { manufacturing because plating was in } \\
\text { crack. Believed to be a one-of-a-kind } \\
\text { problem; no action being taken. }\end{array}$ \\
\hline \multirow[t]{2}{*}{ Fast Slew } & $\begin{array}{l}\text { Bushing in motor failed } \\
\text { because of side loading at the } \\
\text { SCE Test Site. }\end{array}$ & $\begin{array}{l}\text { Caused by tightening the drive belt too } \\
\text { tight, replacing motor with one that has } \\
\text { ball bearings or different drive } \\
\text { mechanisms. }\end{array}$ \\
\hline & $\begin{array}{l}\text { Pulley came off because it } \\
\text { was not installed properly at } \\
\text { the SCE Test Site. }\end{array}$ & $\begin{array}{l}\text { Replace present compression pulley } \\
\text { system with a key way pulley system. }\end{array}$ \\
\hline
\end{tabular}


Table VII-2. Concentrator Problems (Continued).

\begin{tabular}{|c|c|c|}
\hline Problem & Description & Comment \\
\hline Fast Slew (cont.) & $\begin{array}{l}\text { System would not disarm } \\
\text { under certain operating } \\
\text { conditions. }\end{array}$ & $\begin{array}{l}\text { Modified electronic logic to correct } \\
\text { problem. }\end{array}$ \\
\hline Dish Controller & $\begin{array}{l}\text { Heat fatigue of coils after long } \\
\text { periods of operation in hot } \\
\text { weather at the SCE Test Site. }\end{array}$ & $\begin{array}{l}\text { Vent controller in pedestal and add heat } \\
\text { sinks to contactors. } \\
\text { Replace contactors with solid state } \\
\text { relays. } \\
\text { Use a latching-type contactor. }\end{array}$ \\
\hline Center Mirror Section & $\begin{array}{l}\text { Upon assembling the SCE } \\
\text { unit, center four mirrors were } \\
\text { out of alignment. }\end{array}$ & $\begin{array}{l}\text { Only two } 1 / 4 \text { in. alignment bolts were } \\
\text { used. Added two more bolts and } \\
\text { increased bolt size to } 1 / 2 \text { in. }\end{array}$ \\
\hline Cables & $\begin{array}{l}\text { Data and PCU cables hanging } \\
\text { down the outside of the } \\
\text { pedestal would catch on the } \\
\text { jack screw at the SCE Test } \\
\text { Site. }\end{array}$ & $\begin{array}{l}\text { Found that the cables could be routed } \\
\text { down the center of the pedestal. Did } \\
\text { not cause problems after the } \\
\text { modification. }\end{array}$ \\
\hline Sun Sensor & $\begin{array}{l}\text { Erratic levels at the Georgia } \\
\text { Power and SCE Test Sites. }\end{array}$ & $\begin{array}{l}\text { Caused by condensation in the } \\
\text { chamber. Fixed by venting chamber to } \\
\text { ambient air. Note: sun sensor for } \\
\text { development testing only and would } \\
\text { only be used during the alignment of a } \\
\text { production unit. }\end{array}$ \\
\hline Reference Sensor & $\begin{array}{l}\text { Performance of sensor at } \\
\text { SCE and MDAC Test Sites. }\end{array}$ & $\begin{array}{l}\text { Appears that the strength of the } \\
\text { magnets degrades with time. Modify } \\
\text { brackets so that sensor is within } 1 / 4 \text { in. } \\
\text { of magnet. }\end{array}$ \\
\hline & $\begin{array}{l}\text { In three out of six units the } \\
\text { elevation helicon sensor did } \\
\text { not work at installation. }\end{array}$ & $\begin{array}{l}\text { The sensor face was even with the drive } \\
\text { casting, and the magnet was moved } \\
\text { closer to the sensor. Design should be } \\
\text { changed so that the sensor extends } \\
\text { beyond the drive casting. }\end{array}$ \\
\hline
\end{tabular}

known to be a limitation, operated routinely in winds of $45 \mathrm{mph}$ and at a wide range of angles of attack with no problems. The Georgia unit operated in winds of up to $35 \mathrm{mph}$ with no problems. A number of reasons could account for the failures:

A. The drives were not assembled correctly. A new crew did the assembly for the Barstow unit. It is possible the crew did not follow the correct procedure in shimming the drive to get the required gear clearance. 
B. The dynamics of having a 1500-lb PCU at the end of a long lever arm, coupled with pulsating wind loads, exceeded the load capability of the drive.

C. The manufacturer had several machines that had different tolerances. The manufacturing tolerances on the various components may have resulted in lower load capabilities. This could account for units operating in winds up to $45 \mathrm{mph}$ with no problem while one unit failed at $30 \mathrm{mph}$.

There were two different mirror designs developed by MDAC during the program. The first one was referred to as the eggcráte design. It had very good optical qualities but was considered to be too expensive to manufacture commercially. Therefore, a second design shown in Figure VII-1 was developed. Two concentrators were manufactured with the eggcrate design and six concentrators were manufactured with the second design referred to as the stamped facet design. Both of these designs met the required optical performance and have maintained this performance for over eight years. A number of the mirrors have stress cracks. A stress crack is a crack that have a circular pattern as a result of the high stress created by the double curving of the mirror combine with thermal forces. Most of the damaged mirrors can be related to incidents during testing such as the following:

A. Two receivers (one at the MDAC and one at the SCE Test Site) were destroyed because of problems with the safety system. Pieces of the hot receiver tubes hit the mirrors and caused stress cracks and pitting of the mirrors.

B. The flux mapper at Huntington Beach broke while in operation, and the tiles got so hot that they exploded. Hot pieces of tile hit the mirrors and caused stress cracks and pitting of the mirrors.

C. Mirror covers were left on the unit for several months while special tests were being done. When the covers were taken off, many mirrors had stress cracks. This is believed to be caused by the wind blowing on the covers and putting high loads on the mirrors. 


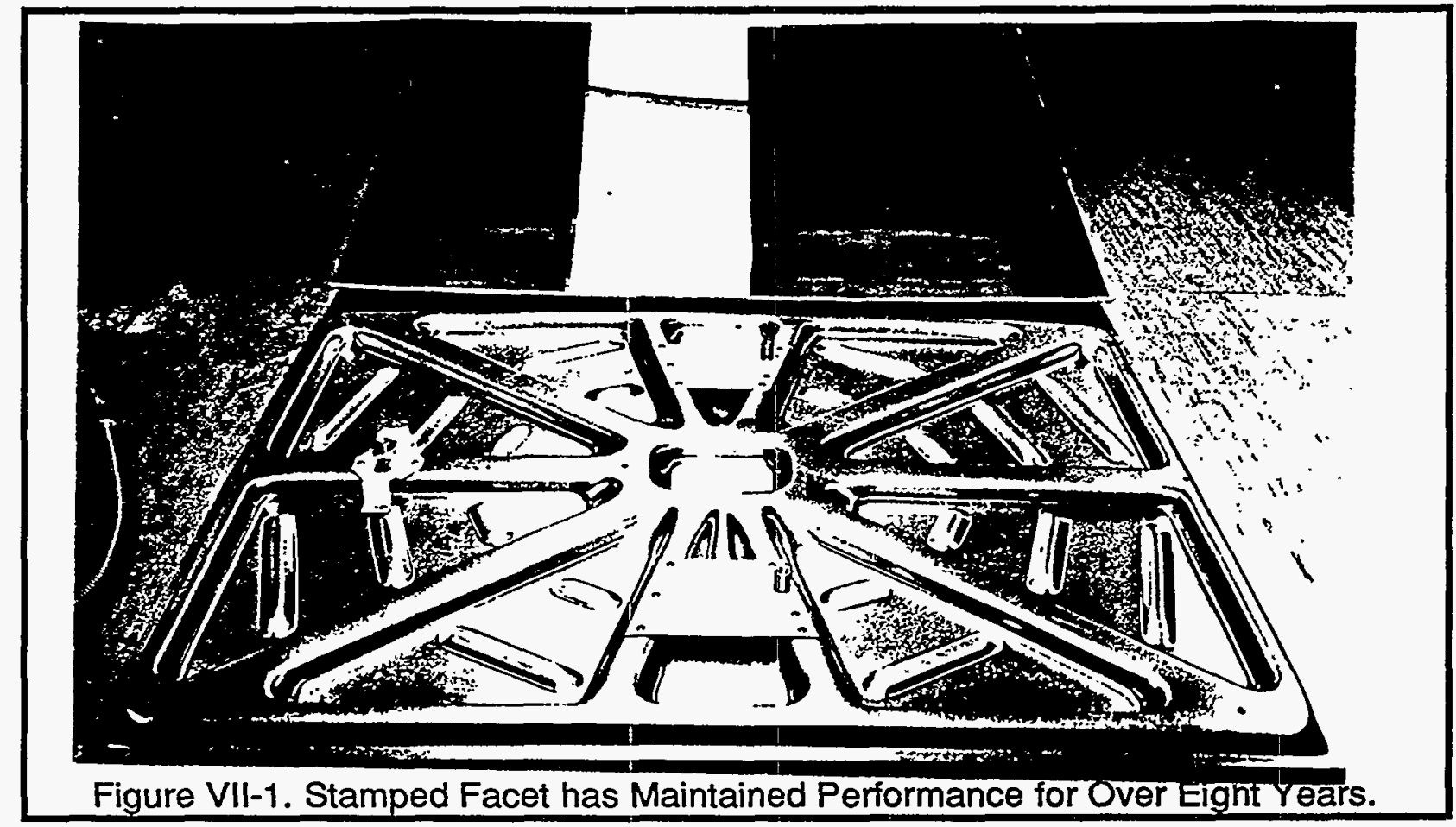

D. Tools were dropped on the mirrors while performing maintenance on the units.

E. Personnel, such as visitors pulled on the mirrors to see the beam move on the receiver or to see how much the concentrator would move.

The majority of the cracks have occurred on the eggcrate design at Huntington Beach, mostly for the above reasons. A much lower number of the stamped facets have had any cracks appear over this operating period. Five stamped facet mirrors developed cracks at the Georgia Power Test Site during the first six months of operation. One of them occurred when a tool was dropped on it. After seven additional years, no new cracks have occurred. There are eight stamped facets at the SCE Test Site that have developed cracks. Several of these occurred when the safety system malfunctioned which resulted in the receiver melting and hitting the mirrors. Although the cracked mirrors are discerning, tests at Huntington Beach could not detect any power loss. Because of the construction of the mirror, the surface slope across the crack does not change and the design prevents moisture from entering and corroding the reflective coating. Since the surface slope does not change, little if any energy is lost. Because moisture is restricted from reaching the silver, little corrosion has occurred along the cracks. In that the above does not account for all of the cracked mirrors, the other 
reasons need to be investigated and resolved before mass production begins. Several of the mirrors have been tested after eight years in the field, and their reflectivity is the same as the day they were manufactured. The radius of curvature and surface waviness were also measured and found to be the same as the day the mirror was manufactured.

\section{Power Conversion Unit}

A summary of the operating time, current condition, and location is given for the Mark I (Table VII-3) and for Mark II engines (Table VII-4). A summary of the problems with the Stirling engines since the start of the test program is also given (Table VII-5). Again the comment column describes the temporary fix made to allow the test to continue or contains a possible permanent solution to the problem.

\begin{tabular}{|c|c|c|c|c|c|c|}
\hline \multicolumn{7}{|c|}{ Table VII-3. Summary Of Mark I Engine Operation. } \\
\hline \multirow[b]{2}{*}{ PCU\# } & \multicolumn{4}{|c|}{ Operating Hours. } & \multirow[b]{2}{*}{ Description } & \multirow[b]{2}{*}{ Comments } \\
\hline & En & Pump & Fan $\mathrm{H}$ & Fan L & & \\
\hline 103 & 1,384 & 1.326 & 1 & 979 & $\begin{array}{l}\text { Controls destroyed in } \\
\text { shipping. Parts taken }\end{array}$ & $\begin{array}{l}\text { Need new control } \\
\text { electronics, valves, }\end{array}$ \\
\hline 101 & 1,575 & 2,563 & 2 & 974 & $\begin{array}{l}\text { Sensors used on other } \\
\text { units. }\end{array}$ & $\begin{array}{l}\text { Need to check the } \\
\text { system out before } \\
\text { operation. }\end{array}$ \\
\hline 110 & 308 & 471 & 1 & 523 & $\begin{array}{l}\text { Sensors used on other } \\
\text { units. }\end{array}$ & $\begin{array}{l}\text { Need to check the } \\
\text { system out before } \\
\text { operation. }\end{array}$ \\
\hline 102 & 2,923 & 2,171 & 1 & 729 & $\begin{array}{l}\text { Electronic cards lying } \\
\text { loose in the cabinet. }\end{array}$ & $\begin{array}{l}\text { Need to check the } \\
\text { system out before } \\
\text { operation. }\end{array}$ \\
\hline
\end{tabular}

The most significant malfunction during the test period was a rod bearing problem in the two Mark II engines. This is significant because a permanent solution requires major design changes. Other problems were solved (or could be solved) with relatively less effort (see Table VII-5).

The two Mark II engines were not disassembled to determine the cause of the bearing failures. Stirling Power Systems (SPS) thinks the bearings were too small to withstand the loads caused by repeated starting for a solar application. This is possible, but the factors described below should be considered: 


\begin{tabular}{|c|c|c|c|c|c|c|}
\hline \multicolumn{7}{|c|}{ Table VII-4. Summary Of Mark II Engine Operation. } \\
\hline & \multicolumn{4}{|c|}{ Operating Hours. } & \multirow[b]{2}{*}{ Description } & \multirow[b]{2}{*}{ Comments } \\
\hline PCU\# & Gen. & Pump & Fan $\mathrm{H}$ & Fan L & & \\
\hline 208 & 1,556 & 2,572 & 331 & 1,304 & $\begin{array}{l}\text { Operated at Barstow } \\
\text { until } 9 / 21 / 88 . \\
\text { Connecting rod crank } \\
\text { shaft bearing failure. }\end{array}$ & $\begin{array}{l}\text { Needs overhaul before } \\
\text { operating again }\end{array}$ \\
\hline 205 & 1,602 & 2,938 & 886 & 0 & $\begin{array}{l}\text { Parts taken for use on } \\
\text { other units. }\end{array}$ & $\begin{array}{l}\text { An intermediate Mark II. } \\
\text { Suspect high and low } \\
\text { fan meters were } \\
\text { reversed. }\end{array}$ \\
\hline 209 & 915 & 960 & 0 & 623 & $\begin{array}{l}\text { Mounted on dish at } \\
\text { Georgia Power. }\end{array}$ & $\begin{array}{l}\text { Has not operated since } \\
1987 \text {, requires service } \\
\text { before operating. }\end{array}$ \\
\hline 207 & 980 & 1,581 & 0 & & Bad receiver & $\begin{array}{l}\text { No other problem with } \\
\text { PCU. }\end{array}$ \\
\hline 211 & 1,912 & 661 & 13 & 1,380 & $\begin{array}{l}\text { Bad connecting rod } \\
\text { crank shaft bearing. }\end{array}$ & Requires overhaul. \\
\hline $\begin{array}{l}206 \\
210,213 \\
211,212 \\
214,215\end{array}$ & 697 & 1370 & 0 & 355 & $\begin{array}{l}\text { Test operated only } \\
\text { Never shipped from } \\
\text { USAB }\end{array}$ & \\
\hline
\end{tabular}

A. Logic circuitry was added to the system controller after the first failure. If the fiveminute average solar insolation went below $280 \mathrm{~W} / \mathrm{m}^{2}$, the concentrator would be pointed at a standby point until the average insolation was above $320 \mathrm{~W} / \mathrm{m}^{2}$ for a few minutes. Although no data were recorded, it is estimated that this reduced the number of starts by around a factor of 10 over the first failure. The number of cold starts would also be reduced, but by a much lesser amount, perhaps 10 to $25 \%$ fewer starts.

Note: There were no bearing failures on the Mark I engines that operated in the same start/stop environment before the logic change in $A$ above was made. One of these Mark I engines had 30 to $50 \%$ more running time than either of the two failed Mark II engines, and another had about the same running time as the Mark II or I.

B. The second failed Mark Il engine could have had an oil pressure problem. A month before the failure, detracks caused by low oil pressure were experienced. After checking the oil level, the operating personnel concluded that the problem was a continuation of the oil sensor problem experienced with other engines. This engine was returned to service following these incidents without any apparent difficulty. One of the differences between the Mark I and Mark II is the way the engine interfaces with the generator. This difference may be a contributing factor. 
Table VII-5. Stirling PCU Problems.

\begin{tabular}{|c|c|c|}
\hline Problem & Description & Comment \\
\hline Detrack & $\begin{array}{l}\text { Numerous detracks } \\
\text { occurred when no } \\
\text { operating problem } \\
\text { existed, such as cloud } \\
\text { transients, that the } \\
\text { software does not } \\
\text { accommodate. }\end{array}$ & $\begin{array}{l}\text { Ignored the alarm and reset system. } \\
\text { Added logic board in concentrator controller to go to stand- } \\
\text { by when average insolation was below a threshold value. } \\
\text { Software test in PCU controller needs to be modified or } \\
\text { removed. }\end{array}$ \\
\hline Radiator Leak & $\begin{array}{l}\text { When the PCU was } \\
\text { shipped, the radiator } \\
\text { leaked. }\end{array}$ & $\begin{array}{l}\text { Remove radiator or constrain radiator from vibrating during } \\
\text { shipment }\end{array}$ \\
\hline Oil Leak & $\begin{array}{l}\text { Small amount of oil } \\
\text { leaked around the } \\
\text { generator shaft on the } \\
\text { Mark II. Did not require } \\
\text { adding oil, but resulted } \\
\text { in a mirror soiling } \\
\text { problem. }\end{array}$ & Design better oil seal. \\
\hline Oil Sensor & $\begin{array}{l}\text { Several oil sensors } \\
\text { failed. }\end{array}$ & $\begin{array}{l}\text { Replaced sensor. } \\
\text { Replace with more reliable sensor. }\end{array}$ \\
\hline Lightning & $\begin{array}{l}\text { Lightning caused } \\
\text { numerous failures of } \\
\text { electronic components. }\end{array}$ & $\begin{array}{l}\text { Field wiring grounds not installed correctly. } \\
\text { PCU electronics need to be repackaged. Lightning } \\
\text { considerations to include twisted pair data wiring, cable } \\
\text { shield grounding outside enclosure, etc. }\end{array}$ \\
\hline $\begin{array}{l}\text { Water Level } \\
\text { Sensor }\end{array}$ & $\begin{array}{l}\text { Problem with ambient } \\
\text { light leaking into the } \\
\text { sensor housing }\end{array}$ & $\begin{array}{l}\text { Wrapped with tape. } \\
\text { Replace with better quality sensor. }\end{array}$ \\
\hline Gas Valve & $\begin{array}{l}\text { Several gas valves had } \\
\text { problems due to } \\
\text { manufacturing defect. }\end{array}$ & $\begin{array}{l}\text { Leaking normally occurs when engine has not operated for } \\
\text { two or more days. } \\
\text { Many problems thought to be valve related were in fact a } \\
\text { different problem. }\end{array}$ \\
\hline & $\begin{array}{l}\text { Several times solenoid } \\
\text { retaining nuts fell off. }\end{array}$ & $\begin{array}{l}\text { May have to use lock nuts. } \\
\text { New valve will not be required. }\end{array}$ \\
\hline Insolation & $\begin{array}{l}\text { When insolation goes } \\
\text { too high }\left(>1,000 \mathrm{~W} / \mathrm{m}^{2}\right) \text {, } \\
\text { PCU usually detracks } \\
\text { because it cannot utilize } \\
\text { all the power. }\end{array}$ & $\begin{array}{l}\text { Need design change so that system does not have to } \\
\text { detrack,; e.g., a few adjustable mirrors, blowing air into the } \\
\text { receiver, change engine temperature set point, several } \\
\text { defocusing mirrors, etc. }\end{array}$ \\
\hline
\end{tabular}


Table VII-5. Stirling PCU Problems (concluded).

\begin{tabular}{|c|c|c|}
\hline Problem & Description & Comment \\
\hline Cavity & $\begin{array}{l}\text { Insulation around the } \\
\text { cavity entrance falls off } \\
\text { with time and moisture. }\end{array}$ & Use ceramic tile, a high-temperature adhesive, etc. \\
\hline $\begin{array}{l}\text { Wrong Alarm } \\
\text { Messages }\end{array}$ & $\begin{array}{l}\text { There are errors in the } \\
\text { displayed alarms. One } \\
\text { message is displayed } \\
\text { when there is really } \\
\text { another problem. }\end{array}$ & Correct software. \\
\hline Bearings & $\begin{array}{l}\text { There has been a } \\
\text { bearing and rod problem } \\
\text { with two Mark II engines } \\
\text { with less than 2,000 } \\
\text { operating hours. }\end{array}$ & $\begin{array}{l}\text { The problem was not investigated Could be that bearings } \\
\text { are too small or need to install motorized oil pump to } \\
\text { eliminate dry starts. }\end{array}$ \\
\hline Compressor & $\begin{array}{l}\text { Two compressors had to } \\
\text { be overhauled before } \\
1,000 \text { hours of } \\
\text { operation. }\end{array}$ & Not presently considered to be a problem. \\
\hline
\end{tabular}




\section{SYSTEM PERFORMANCE OF THE STIRLING DISH}

- Annual net energy efficiency of $22 \%$

- Levelized energy cost of less than 8 cents per kWh

- Major annual sources of energy losses are basic reflectivity and soiling of mirrors

The energy performance and operating performance from the test data are used in a computer simulation to estimate annual system performance in terms of annual energy output, dollars of generated revenue, and cost of O\&M. The architecture of the Stirling dish performance simulation is shown in Figure VIII-1. A description of the different models of this program are:

Solar Energy - The sun's irradiance energy for each day at the SCE Test Site was used to generate a probability distribution function for each month of the year. An example of the probability distribution function is shown in Figure VIII-2 for June and December. The daily energy is generated randomly using the monthly probability distribution function. The probability of rain is included as a function of the month of the year and daily sun-energy level. If the randomly generated daily sun energy is high for that time of the year, then the probability of rain occurring is low.

Wind Speed - The wind speed is generated randomly using the annual wind speed distribution for Barstow shown in Figure VIII-3 (Reference 12). The wind speed is used to estimate receiver energy spillage and determined if the system should go to a wind stow position. If the wind speed is above $35 \mathrm{mph}$, the system goes to a wind stow position. The time spent at the high wind stow position is randomly selected. This time includes the time at the wind stow position and the time to go to and from this position. At the present time, there is no correlation between wind speed and sun irradiance level.

Concentrator reflectivity - The mean reflectivity measurements for the Huntington Beach test site were used to determine the concentrator reflectivity as a function of the days since the last washing. There were not sufficient SCE Test Site data to define a model. Concentrator washing is performed when the reflectivity decreases to a minimum level. 


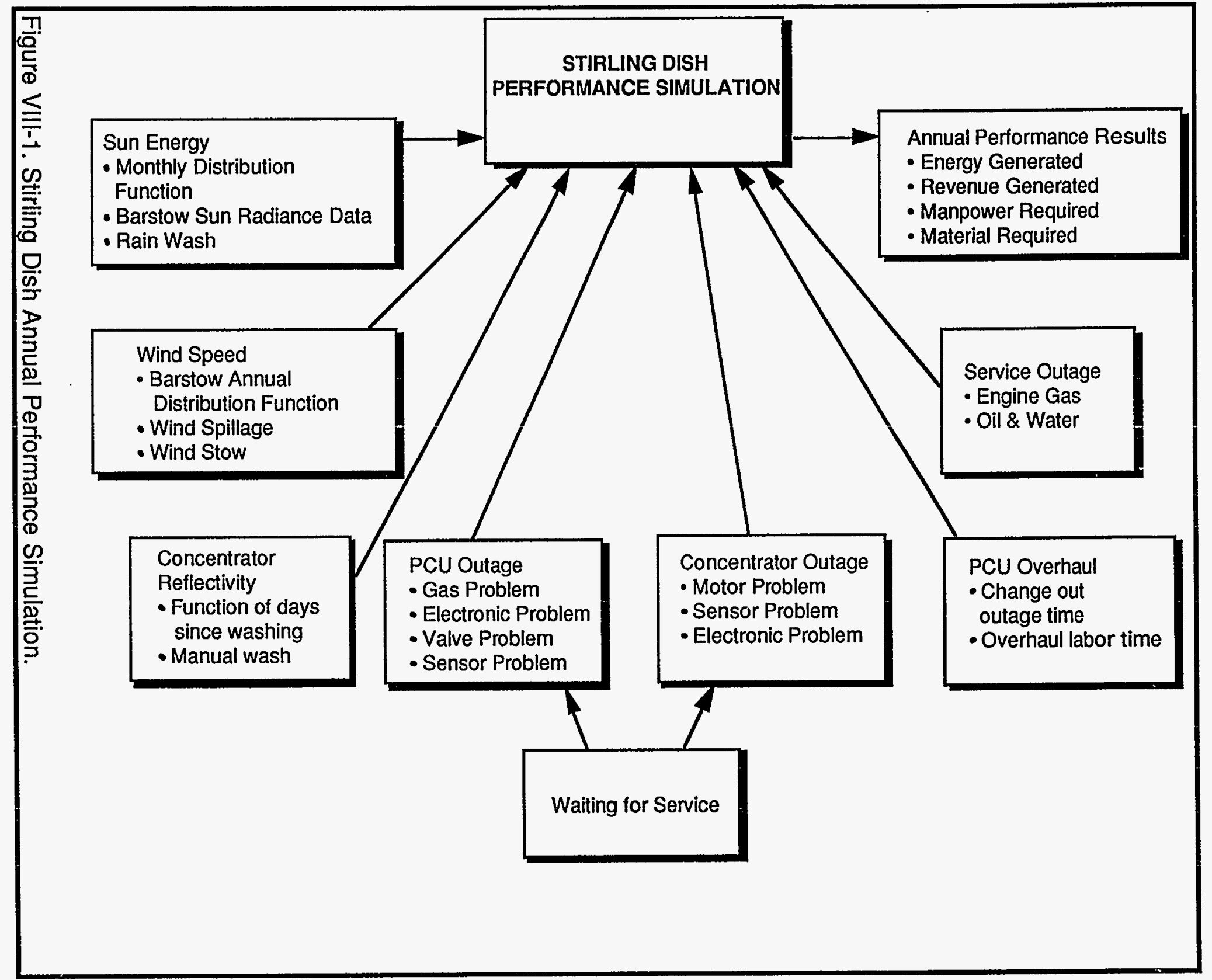



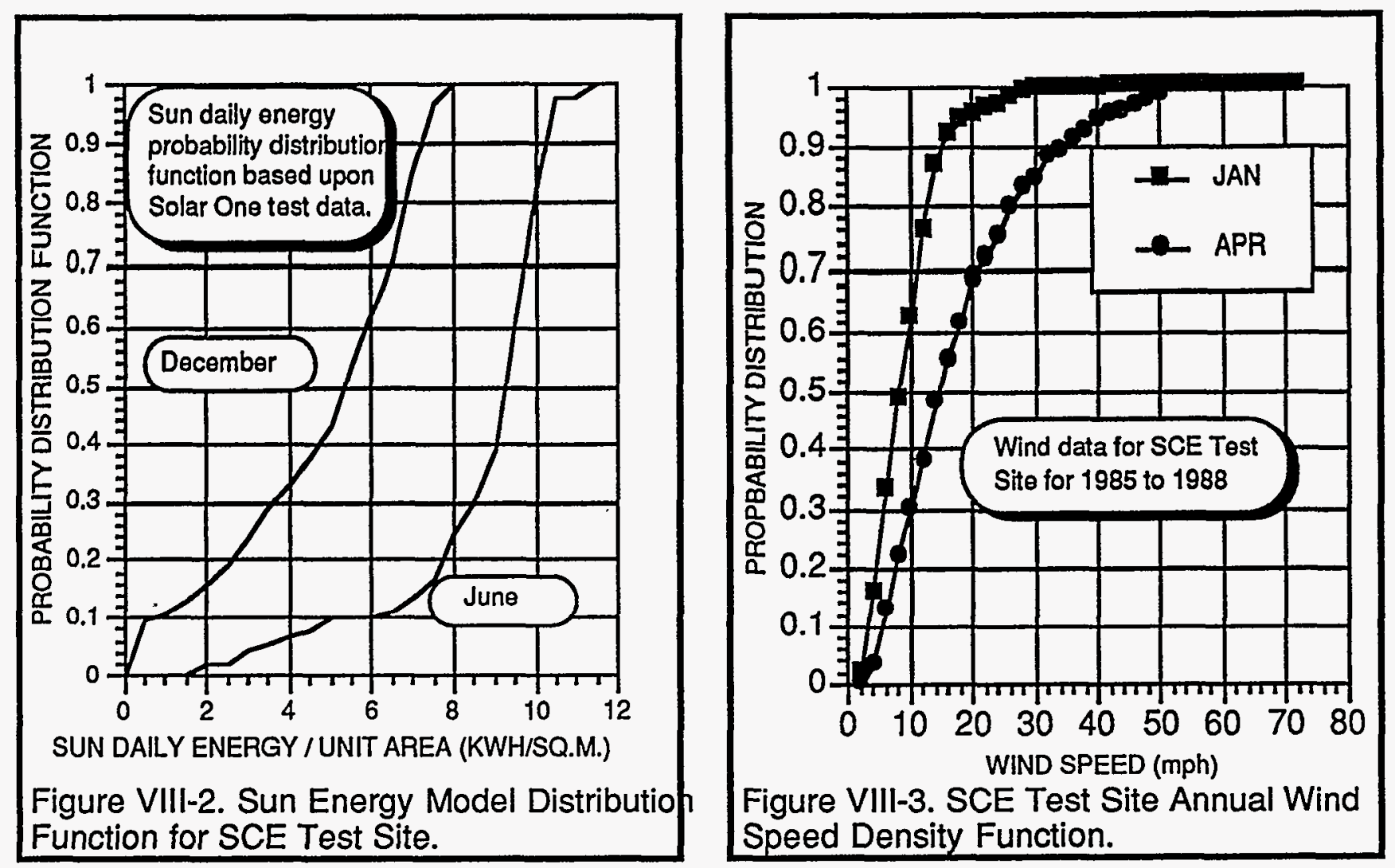

The reflectivity returns to the nominal level after washing. If it rained, the reflectivity also returns to the nominal value.

PCU problem outage - The mean time between failure is used to determine when a problem outage would occur as a result of a PCU gas valve, electronic, sensor, etc. Associated with the outage is the mean time to correct the problem and the time to put the system back in service. With each outage, there is an estimate of labor and material cost. There is also a non-outage labor and material cost included for repairing the problem with the replaced module, i.e., repair the electronic controller, valve, etc.

Concentrator problem outage - A mean time between failure is used to determine when an outage would occur as a result of an electronic, sensor, motor, etc. problem. Associated with the outage is the mean time to correct the problem and an estimate of labor and material cost. There is also a non-outage labor and material cost included for repairing the 
problem with the replaced module removed, i.e., repair the electronic controller, sensor, etc.

Waiting for service outage - Since maintenance personnel may not be available because they are working on another project at the time a PCU or concentrator problem occurs, there is a random wait period before the actual repair begins. A Chi-square probability distribution is used to define the waiting for service time.

PCU overhaul - A mean time between major overhauls is used to determine when the PCU should be removed and the rings, seals, etc. are replaced. An overhauled engine replaces the old engine so the system outage time is only the PCU change out time. The engine overhaul labor and material cost associated with each engine replacement is included in the simulation.

Service outage - The USAB 4-95 requires oil, water, and hydrogen gas servicing. The frequency of service time is based upon the number of operating hours on the engine. There is a different service time, labor time, and material cost associated with each of these service outages.

Although it is not the intent in this report to present a detailed discussion of the economic performance of the system, there are economic cost models included in the simulation as well (Reference $13 \& 14$ ). These include capital cost, operational and maintenance labor cost, management labor cost, plant overhead cost, inflation, taxes, interest on loan, tax base, etc. The management time and plant overhead cost are modeled as a function of the maintenance time, i.e. the less maintenance labor required to operate the plant, the less management is required. The lower the maintenance activity, the lower the plant overhead, i.e. less replacement material has to be ordered, less inventory, less storage area, less field vehicles to maintain, etc.

The simulation inputs and an example of data base values are shown in Table Vill-1. Two examples of the simulation's generated energy as a function of time for a two-year period using data base parameters based upon the SCE Test site are shown in Figure VIII-4. Also shown are the actual SCE Test Site data presented in Section IV. The long periods that the SCE system was off line waiting for service and spare parts has 


\begin{tabular}{|c|c|c|c|}
\hline \multicolumn{4}{|c|}{ Table VII-1. Example of Simulation Data Base. } \\
\hline Parameter & Value & Parameter & Value \\
\hline $\begin{array}{l}\text { PCU operating \& maintenance cost } \\
\text { Engine overhaul time } \\
\text { Mean change outage time } \\
\text { Overhaul time } \\
\text { Mean time between overhaul } \\
\text { Overhaul material cost } \\
\text { Hydrogen gas } \\
\text { Mean outage time } \\
\text { Gas bottle cost } \\
\text { Mean time between service } \\
\text { Oil \& water } \\
\text { Mean outage time } \\
\text { Mean time between service } \\
\text { Oil \& coolant material cost } \\
\text { PCU problem } \\
\text { Mean outage time } \\
\text { Mean time between failure } \\
\text { Repair time of unit } \\
\text { Repair cost of unit } \\
\text { Concentrator O\&M cost } \\
\text { Concentrator problem } \\
\text { Mean outage time } \\
\text { Mean time between failure } \\
\text { Repair time of unit } \\
\text { Repair cost of unit }\end{array}$ & $\begin{array}{l}2.00 \mathrm{~h} \\
5.50 \mathrm{~h} \\
6000.00 \mathrm{~h} \\
\$ 200.00 \\
1.00 \mathrm{~h} \\
\$ 38.00 \\
1500 \mathrm{~h} \\
\\
0.50 \mathrm{~h} \\
2200.00 \mathrm{~h} \\
5.00 \\
1.50 \mathrm{~h} \\
1,000.00 \mathrm{~h} \\
2.50 \mathrm{~h} \\
\$ 50.00 \\
\end{array}$ & $\begin{array}{l}\text { Washing cost } \\
\text { Mean outage time } \\
\text { Material cost per wash } \\
\text { System reflectivity } \\
\text { Cleaned mirror reflectivity } \\
\text { Soiling rate (\%/day) } \\
\text { Wash reflectivity level } \\
\text { Rain wash yearly mean } \\
\text { Wind stow level } \\
\text { General plant operation parameters } \\
\text { Field shadowing } \\
\text { Hourly labor rate } \\
\text { Inflation rate } \\
\text { Management cost } \\
\text { Labor rate } \\
\text { Percent required of manload } \\
\text { Plant overhead,percent of manload } \\
\text { Mean time before service } \\
\text { Interest rate } \\
\text { Length of loan } \\
\text { Hardware depreciation time } \\
\text { Tax base }\end{array}$ & $\begin{array}{l}0.75 \mathrm{~h} \\
\$ 4.00 \\
\\
0.920 \% \\
0.005 \\
0.750 \\
10.000 \\
35 \mathrm{mph} \\
\\
0.020 \\
\$ 15.00 \\
.04 \% \\
\$ 28.00 \\
10.00 \% \\
8.00 \% \\
3.00 \mathrm{~h} \\
5.0 \% \\
10 \mathrm{yr} \\
25 \mathrm{yr} \\
20 \%\end{array}$ \\
\hline
\end{tabular}

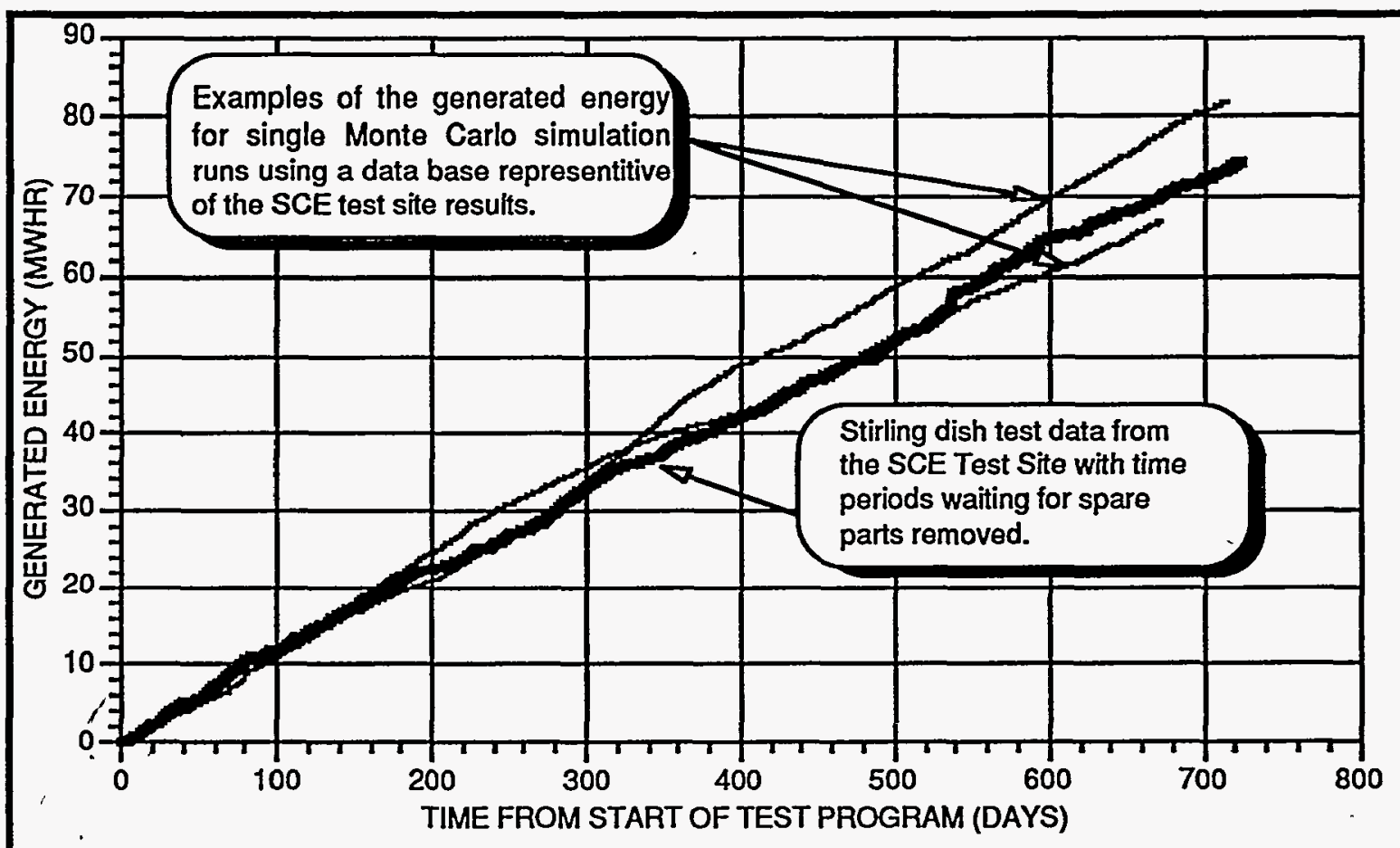

Figure VIII-4. Example of Simulation Accumulated Generated Energy. 
been removed from the test data. As shown, the amount of generated energy predicted by the simulation program is very similar to the actual generated electrical energy at the SCE test site. The daily energy normalized by the area for this same two year period is shown in Figure VIII-5. The distribution of data points from the performance line corresponds with the daily energy performance test data for the SCE Test Site shown in Section IV.

The average annual generated electrical energy of the Stirling dish is shown in Table VIII-2, which shows that the system has an average annual efficiency of $22 \%$. The data were generated by averaging the energy over a thirty-year period. A thirty-year period was used because the magnitude of the estimated mean time between failure of the different components precludes many failures in the first few years of operation and higher failure rates towards the end of the operating period as components are subjected to additional wear. For example, the estimated mean time between PCU overhaul is over two years, electronics is over five years and the estimated mean time between concentrator drive failure is over 30 years. The total annual energy that is incident on the aperture area of the concentrator is $217,878 \mathrm{kWhs}$ (Item 1). Of this amount, $154,737 \mathrm{kWhs}$ (Item 2) or $71 \%$ of the total incident energy are lost by the PCU

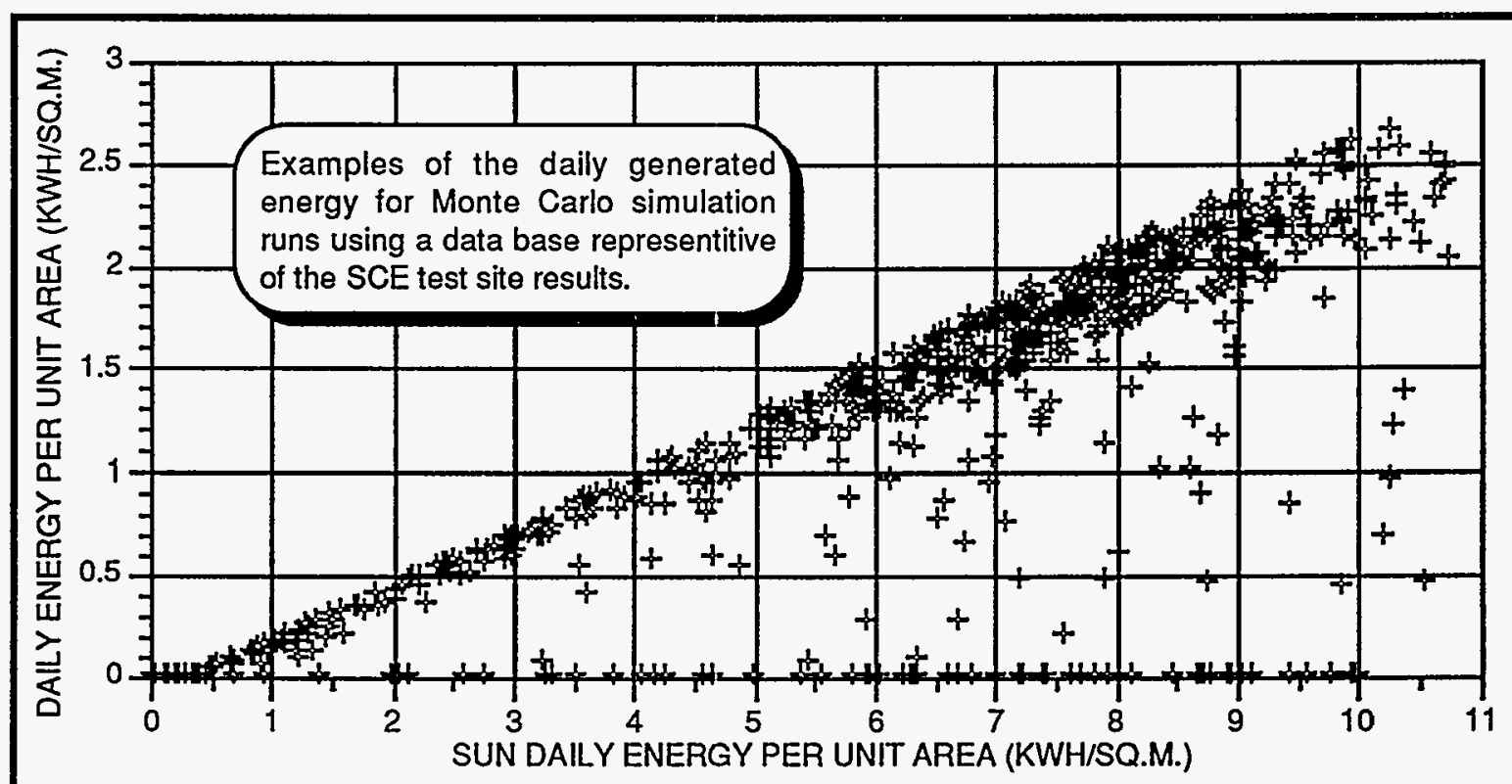

Figure VIII-5. Example of Simulation Daily Energy Performance. 
Table VIII-2. Annual Energy Performance.

\begin{tabular}{|c|c|c|c|c|}
\hline Item & Description & Energy & $\begin{array}{l}\text { As Percent of } \\
\text { Other Losses } \\
\text { (excludes PCU) }\end{array}$ & $\begin{array}{l}\text { Percent of Total } \\
\text { Aperture } \\
\text { Energy }\end{array}$ \\
\hline $\begin{array}{l}1 \\
2\end{array}$ & $\begin{array}{l}\text { Total aperture energy } \\
\text { PCU losses } \\
\text { Other system losses }\end{array}$ & $\begin{array}{l}217,878 \mathrm{kWh} \\
154,737 \mathrm{kWh}\end{array}$ & & $71.02 \%$ \\
\hline $\begin{array}{l}3 \\
4 \\
5 \\
6 \\
7 \\
8 \\
9 \\
10 \\
11 \\
12 \\
13 \\
14\end{array}$ & $\begin{array}{l}\text { Field shadowing energy loss } \\
\text { Base reflective energy loss } \\
\text { Mirror soiling energy loss } \\
\text { Wind spillage energy loss } \\
\text { Wind stow energy loss } \\
\text { Washing outage energy loss } \\
\text { Engine gas outage energy loss } \\
\text { Oil \& water outage loss } \\
\text { PCU overhaul outage loss } \\
\text { PCU problem outage loss } \\
\text { Conc. problem outage loss } \\
\text { Waiting for service outage loss }\end{array}$ & $\begin{array}{r}1154 \mathrm{kWh} \\
5,292 \mathrm{kWh} \\
5,636 \mathrm{kWh} \\
1,924 \mathrm{kWh} \\
215 \mathrm{kWh} \\
130 \mathrm{kWh} \\
22 \mathrm{kWh} \\
10 \mathrm{kWh} \\
19 \mathrm{kWh} \\
30 \mathrm{kWh} \\
12 \mathrm{kWh} \\
823 \mathrm{kWh}\end{array}$ & $\begin{array}{l}7.6 \% \\
34.7 \% \\
36.9 \% \\
12.6 \% \\
1.4 \% \\
0.9 \% \\
0.1 \% \\
0.1 \% \\
0.1 \% \\
0.2 \% \\
0.1 \% \\
5.4 \% \\
\end{array}$ & $\begin{array}{l}0.50 \% \\
2.50 \% \\
2.60 \% \\
0.90 \% \\
0.10 \% \\
0.05 \% \\
0.01 \% \\
0.01 \% \\
0.01 \% \\
0.02 \% \\
0.01 \% \\
0.37 \%\end{array}$ \\
\hline & Average annual grid energy $=$ & $50122 \mathrm{kWh}$ & & $22 \%$ \\
\hline
\end{tabular}

due to system efficiency and to the PCU's inability to utilize low solar irradiance, i.e., levels of less than $250-300 \mathrm{~W} / \mathrm{m}^{2}$. This leaves a maximum of $63,141 \mathrm{kWhs}$ for other system operating losses (Item 3 to 14) and net power generation.

Other System Losses - Each of the other system losses are shown as a percent of total other system losses in the fourth column and total incident energy in the fifth column of Table VIII-2. The largest of these losses is from the reflectivity of the mirror facets. The average annual loss of electrical energy from the ideal reflectivity (Item 4) and mirror soiling (Item 5) is over 10,000 kWhs which is $70 \%$ of the other system losses or over $5 \%$ of total aperture energy. The simulation assumes the mirrors are washed when the reflectivity drops to $0.75 \%$. Based upon the environmental model, there was an average of 10.7 concentrator washings per year and an average number of rain washings of 10.6 per year. The rain washing mainly occurred in the months from December through February which is common for Southern California. The soiling rate in the simulation was based upon the MDAC Test Site data because sufficient data were not available for the SCE Test Site. The soiling rate will vary from site to site, but it is expected to contribute a significant portion of the other system losses. The amount of soiling loss is a function of many site characteristics and operation such as the terrain cover, manual wash frequency, rain frequency, wind 
frequency, etc. Although soiling loss is a controllable variable, it would require a trade off between increased maintenance cost and improved performance.

The annual wind induced energy loss is a result of spillage out of the receiver due to motion of the concentrator caused by winds and loss out of the receiver from wind currents (Item 6). This loss is in addition to the receiver radiation and convection loss considered in the energy loss diagram presented in Table IV-6. A second windrelated energy loss result from high winds requiring the concentrator to go to a wind stow position (Item 7). The concentrator wind stow limit was set at $35 \mathrm{mph}$ for this analysis (Table VIII-1). The energy loss for maintenance (Item 8 to 13) accounts for less than $2 \%$ of the other system losses. This low loss is a result of the maintenance policy of module replacement. Therefore, the system is out of service a very short period of time. The energy lost while waiting for a service person to repair the unit (Item 14) represents over $5 \%$ of the other system losses. The waiting for service loss can be decreased by increasing the maintenance manload but the trade-off of this revenue loss verses maintenance cost must be made to find the optimum.

The installed cost of the Stirling dish system is shown in Figure VIII-6 as a function of the manufacturing rate for minimum, best and maximum cost variations. The upper three curves include a $30 \%$ profit margin, and the lower curve is the minimum cost variation with no profit margin. This cost is based upon a 1985 production

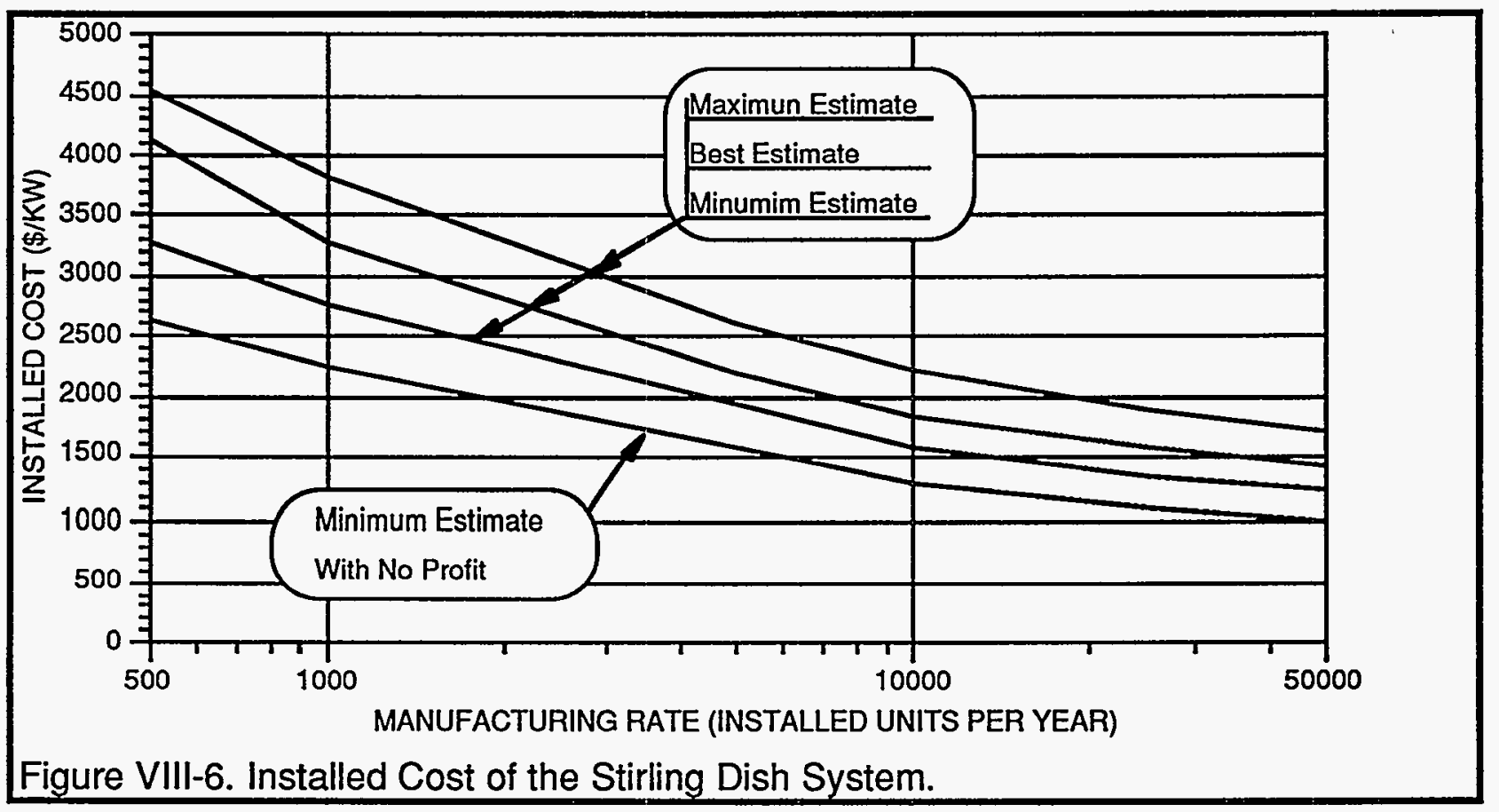


study conducted by MDAC (Reference $15 \& 16$ ) and updated to 1992 using a 4\% inflation rate. In addition, updated cost numbers were obtained for major components such as the drive, mirror assembly and mirror support structure from Peerless Winsmith, Naugatuck Glass, Mactac, General Electric, EWI, Rohn, Binkely, etc. Using this cost information, an estimate of the levelized energy cost over a $\mathbf{3 0}$ year period is shown in Figure VIII-7 as a function of concentrator MTBF. Since the PCU is more complicated that the concentrator (more ICs, more sensors, valves, etc.), the PCU MTBF was assumed to be 0.5 that of the concentrator. The levelized energy cost is the 30-year system cost (installation, manufacturing, O\&M, taxes, loan, etc.) divided by the total electrical energy generated over this 30 year period. The data show that a levelized energy cost of less than $\$ 0.08$ per $\mathrm{kWh}$ can be obtained with a concentrator MTBF of 2000 hours and PCU MTBF of 1000 hours. A levelized energy cost of $\$ 0.65$ per kWh can be obtained with a further increase in the MTBF. Even lower levelized energy cost can be obtained by increasing the PCU mean time between major overhauls or higher manufacturing rates. An estimate of the O\&M cost per kWh as a function of concentrator MTBF is shown in Figure VIII-8. This data show that depending upon the concentrator and PCU MTBF, the O\&M costs could be less than 2 cent per $\mathrm{kWh}$. The labor and material cost for a system with a concentrator MTBF of 4000 hours and PCU MTBF of 2000 hours is shown in Table VIII-3. The man loading requirements are shown in Table VIII-4. The major O\&M costsresult from the PCU overhaul and other PCU-related problems.

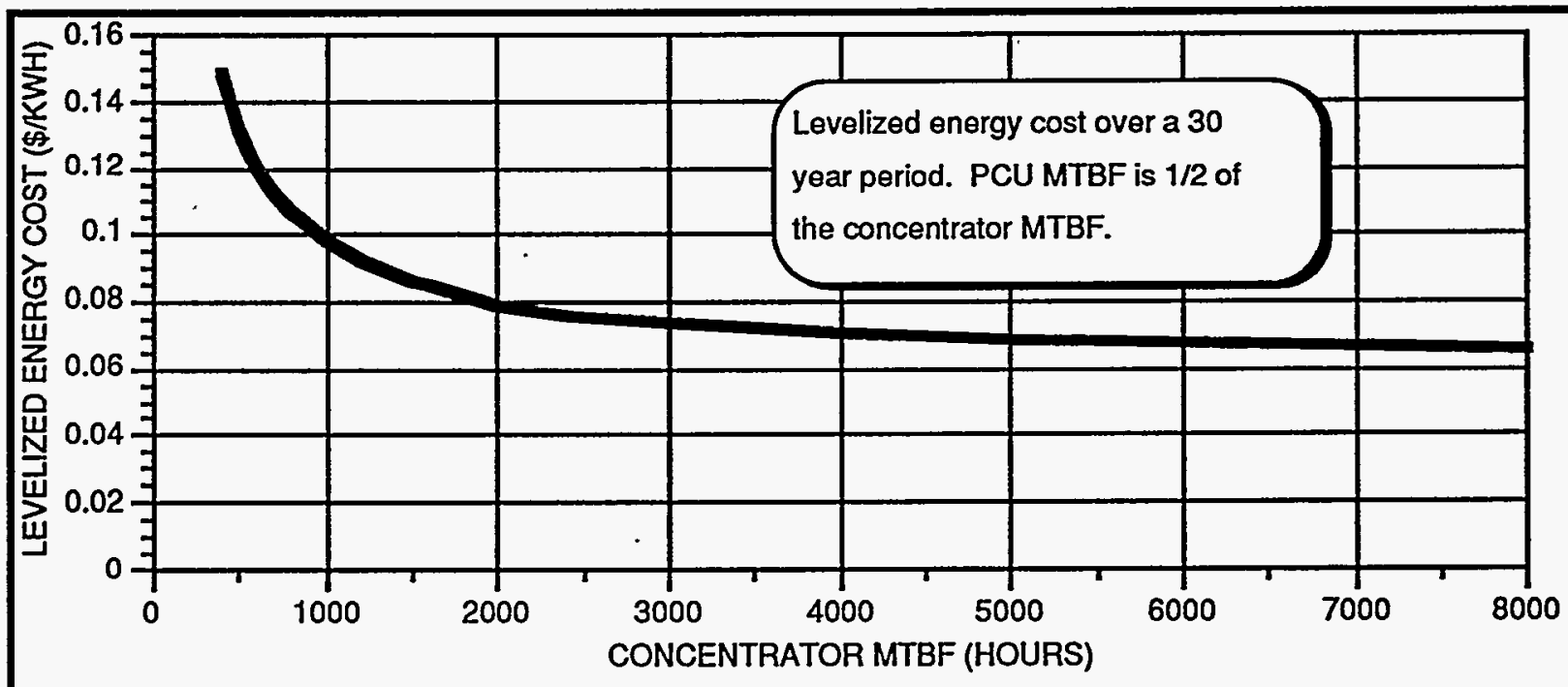

Figure VIII-7. Estimate of Levelized Energy Cost. 


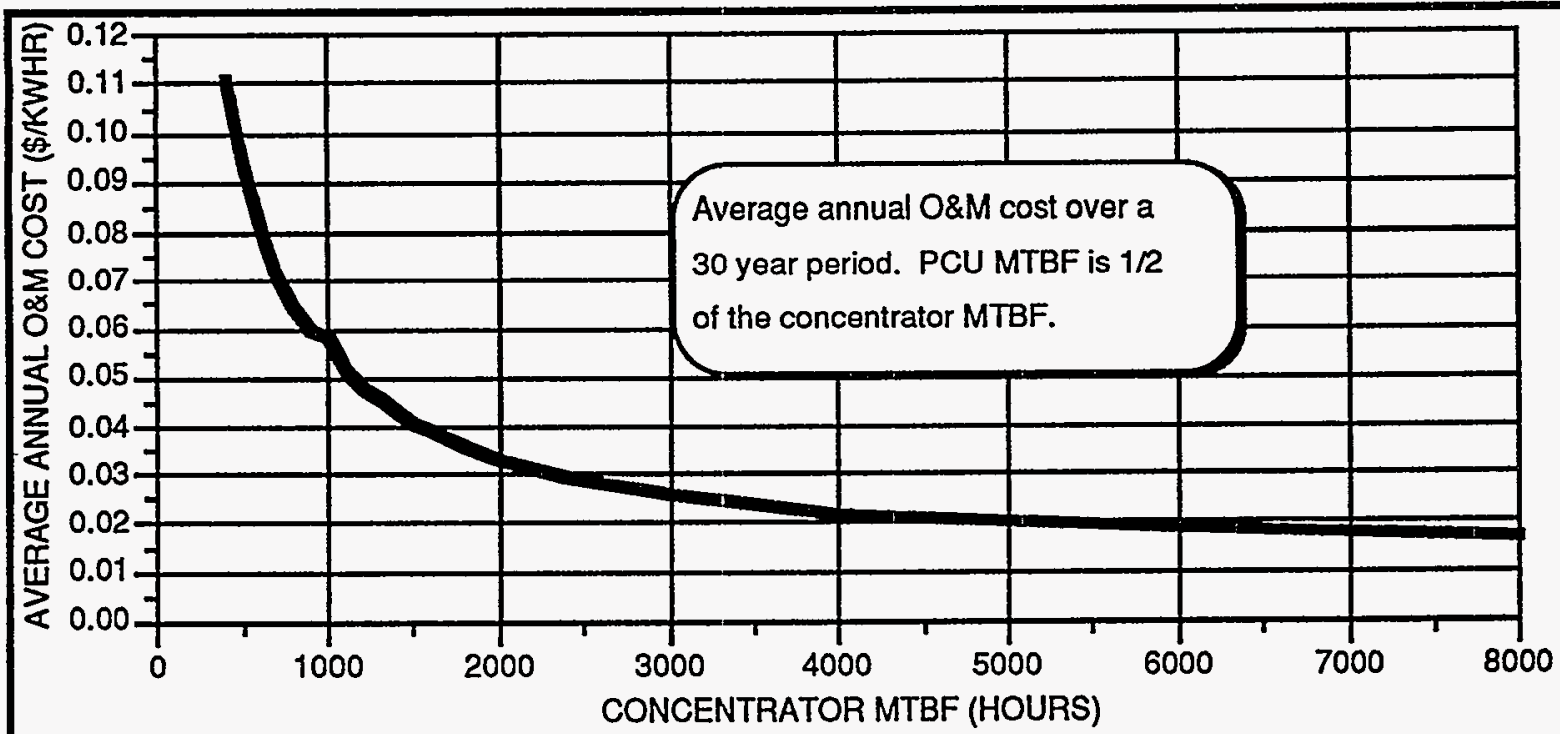

Figure VIII-8. Estimate of System O\&M Cost.

Table VIII-3. Estimate of Average Annual Cost Per Concentrator Over a 30 Year Period

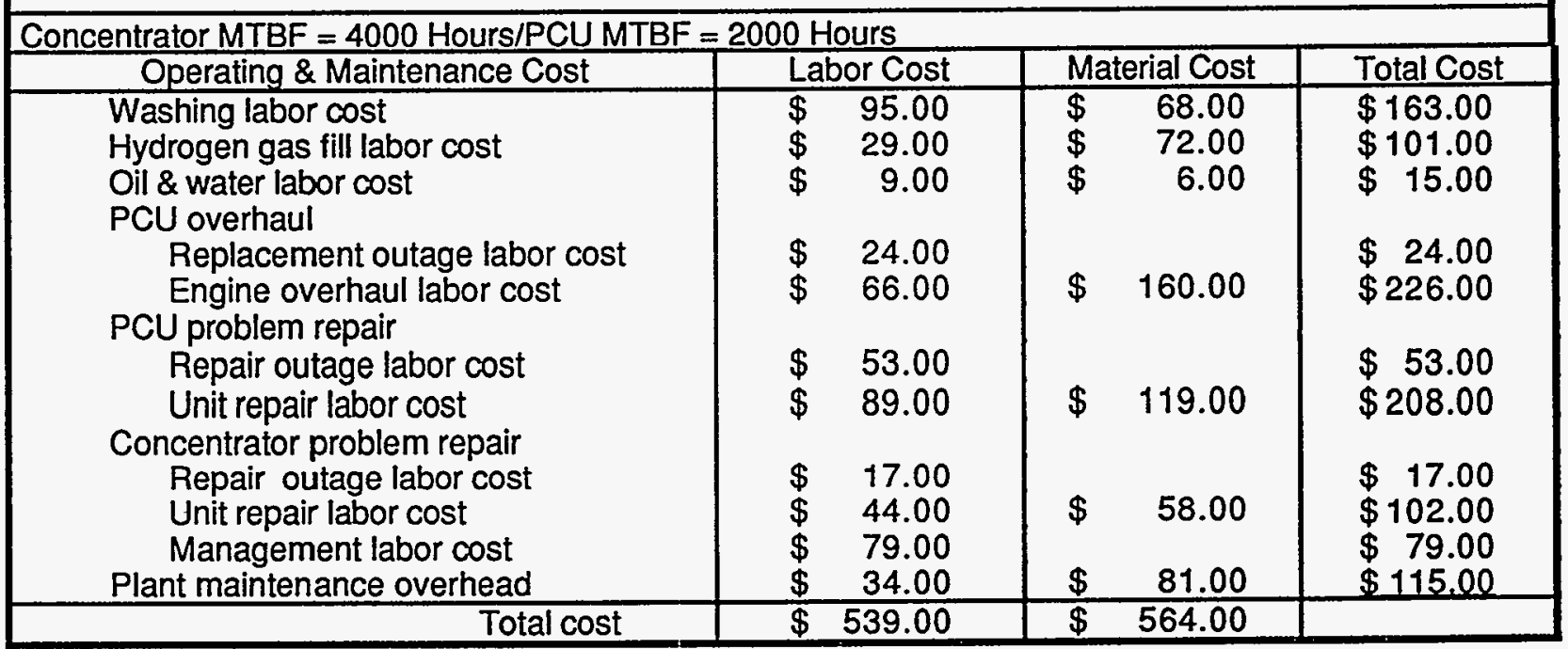


Table VIII-4. Estimate of Required Manload Per Concentrator Per Year.

Concentrator MTBF $=4000$ Hours $/$ PCU MTBF $=2000$ Hours

\begin{tabular}{|l|c|c|}
\hline \multicolumn{1}{|c|}{ Manpower Load Requirement for } & Manload & Percent of \\
\hline & Total \\
\hline Washing manload & 0.0021 man & $21.9 \%$ \\
Gas service manload & 0.0010 man & $11.0 \%$ \\
Oil and water service manload & 0.0004 man & $3.7 \%$ \\
Engine replacement manload & 0.0005 man & $5.4 \%$ \\
Engine overhaul manload per Year & 0.0014 man & $14.9 \%$ \\
PCU problem outage manload & 0.0006 man & $6.5 \%$ \\
PCU hardware repair manload & 0.0010 man & $10.9 \%$ \\
Concentrator problem outage manload & 0.0003 man & $3.3 \%$ \\
Concentrator hardware repair manload & 0.0008 man & $8.1 \%$ \\
Management manload & 0.0008 man & $7.9 \%$ \\
Plant overhead manload & 0.0006 man & $6.3 \%$ \\
\hline \multicolumn{2}{|c|}{ Total manpower requirement } & 0.0095 man \\
\hline
\end{tabular}




\section{LESSONS LEARNED AND RECOMMENDATIONS FOR A CONTINUING TEST PROGRAM}

Many important lessons were learned during the five year duration of the MDAC/USAB/SCE Stirling dish demonstration program. This section discusses the lessons whose consideration may be beneficial to future programs in accomplishing their program objectives. This program demonstrated once again that Stirling dish systems have the highest solar-to-electric conversion efficiency of systems under development and should be considered as a viable commercial electrical power generation resource. Since considerable amount of field testing is required prior to mass production of a system and the MDAC/USAB/SCE Stirling dish system has a substantial amount of the required test time, it is conceivable that an organization will continue development of the MDAC/USAB/SCE Stirling dish system. Therefore, recommendations for modifications to the MDAC/USAB/SCE components are discussed at the end of this section for future reference by that organization.

\section{LESSONS LEARNED}

The program clearly demonstrated the importance of early interface with the potential customers during the development of system requirements. As was shown in Section VIII, operating and maintenance cost is a major part of the overall system life-cycle cost. MDAC'S early contact with the potential customers enabled the customer to influence the basic design philosophy which resulted in adoption of customer preferred design features which lowered O\&M costs, e.g., the concentrator slot which allowed the PCU to be serviceable from ground level to facilitate maintenance and use of modular components to allow repair by replacement to minimize outage time that would otherwise be required to diagnose and correct maintenance problems in place. Modular components also allow for the repair of the components in a controlled environment with the proper test equipment.

Early customer involvement in the test program is very beneficial and the lessons learned during the testing could save considerable developer expense in finalizing the system design prior to start of mass production. Some of the lessons learned during this test period include: 
- The designers are of a different skill level and are more familiar with the technical operation of the system than the customer operating personnel and fail to fully appreciate the difficulty that will be encountered by the customer operating personnel. What is a very simple operation and easily understood by the designer whose focus may be on the single operation, may not be easily understood by the customer operating personnel.

- The developer must be aware that the customer will not normally employ operating personnel with the same skill level as the designer to operate the system and the designer needs to recognize the skill level of the potential customer's operating personnel. The higher the required skill level, the higher the customer cost for the customer to operate the system.

- The customer is faced with losing trained operating personnel for various reasons and must constantly train new people to operate the system. The more procedures involved in operating the system, the more training time and expense that the customer must endure.

- The operating personnel tend to forget certain aspects of the operation when a system operates daily or weekly with out requiring their involvement. This resulted in more system downtime for the test program and led to confusion in the diagnosis and correction of operating and maintenance problems. The current experience indicates that demonstration programs or commercial plants consisting of a small number of units should provide for the routine training of O\&M personnel.

The lessons learned validated the need to keep the system simple, eliminating all operating procedures, command, display, mechanical and electrical hardware, test equipment, etc. that can be eliminated to simplify operation and maintenance and in so doing will improve overall system availability. This will lower the O\&M personnel skill level requirement, initial and follow up training cost, inventory cost, etc. On the other hand, there must be sufficient information not only to operate the system but to easily diagnose problems in a timely manner. Customer involvement with testing before commercial production commences, enables the achievement of the delicate 
balance between complexity and simplicity for the most cost effective system for the customer.

The importance of field testing and field testing at different site locations. The USAB 4-95 PCU had thousands of hours of bench testing during the development of the engine and during checkout of each PCU before shipment to the test site. This allowed for the cost effective detection and solution of many problems. In spite of all of the bench testing, the field testing resulted in identification of additional problems. Interaction of the system with the environment, such as solar insolation, cloud passage, and wind transients, resulted in several modifications to the system design. The PCU rod bearing failures and the engine/generator oil leakage that may have been consequent to frequent daily system starts and stop cycles are examples of problems which occurred in field testing but never occurred during bench testing which had more cumulative hours of operation. In addition, a different set of problems were encountered at the different test site locations. For example, humidity and moisture was one of the main problems encountered at the Georgia Test Site but was not a problem at the SCE Site; dust/sand resulted in problems at the SCE Test Site but was not a problem at the Georgia Test Site.

The PCU bench test program was not adequate. Many of the PCU problems encountered in the field test could have been discovered during the bench testing if the bench testing had been more representative of the field operational conditions. Because field testing is expensive, it is advisable that future test programs consider expanding the bench testing to more closely model the actual real world operating environment. Where cost effective, consideration should be given to include the following operations as part of the PCU bench testing:

- As a result of cloud cover, the PCU may have many starts over the day and idle at low speeds for long periods of time. The high number of starts/stops and idling at low speeds for long periods of time should be included as part of the PCU bench testing.

- Since the concentrator operates at different elevation angles while tracking the sun over the day, the PCU should be operated at various attitude angles. This will ensure proper oil lubrication, water level sensor operation, etc. 
- Uneven flux levels over the PCU receiver as a result of gravity bending of the structure and wind movement of the reflective surface and PCU should be included in order to determine the long term life of the receiver.

- Operate the system in a hot and a cold environment.

- Vibration of the PCU resulted in electrical connectors becoming loose, insulation falling off and nuts coming off. The PCU should be mounted in such a way that the vibration will be similar to that encountered on the concentrator.

- Operate the system in a high and low ambient humidity. Simulation of blowing rain should be included.

Lightning is a major problem that must be taken into account in the design of the system. The level of lightning protection for the PCU electrical system and the data acquisition system were not adequate for the lightning environment encountered at both the SCE and Georgia test site. Lightning induced failures resulted in a lot of system downtime. Because of previous experience, the concentrator control electrical system was designed for a lightning environment and did not encounter lightning problems. The PCU, however, had frequent lightning induced problems. During the later part of the system testing at the SCE Test Site, modifications were made the to the PCU control and data acquisition components which reduced their sensitivity to lightning.

Serious consideration must be given to the maturity of the product when setting up a test program performed at potential customer test sites or the developer's remote test site. The MDAC commercialization program provided for early electric utility involvement in the test program. The intent of this program was for early involvement of the utilities in the program to provide first-hand information in the operation and performance of the Stirling dish and aid in further definition of utility specific needs with regards to the Stirling dish system. The development test period was less than one year which was driven by the MDAC/USAB desire to reach the marketplace in the shortest possible time. This Stirling dish system was being designed as an automatic or unattended low-maintenance system, a system with a 6000 hour MTBF, which is approximately 2 years of operation, and would not require significant utility personnel support for operations and maintenance. The 
demonstration program was therefore designed for a mature system with a high MTBF and did not provide for on-site spare parts, special test equipment, and provided only minimal personnel training. Spare parts, skilled personnel and special test equipment were located at the MDAC test site to service the MDAC and the remote utility test sites. The short development test period did not allow sufficient testing to develop the system maturity to the level that required for the designed test program. Therefore the test program design philosophy did not match the system maturity level and resulted in considerably more system down time than expected. Some of the lessons learned from this experience are:

- Personnel training must reflect the level of maturity of the product. The training covered the daily operation and general maintenance of the system but did not cover the basic principles of operation. Based on the lack of maturity of the system, the personnel were not sufficiently trained to the level required to diagnose and identify the source of the problems. Since the units were located across the US, the troubleshooting and analysis of many of the problems were conducted over the phone with the MDAC Test Site personnel. Often pertinent information was not observed, thought not to be important, or misinterpreted by the site personnel. This resulted in longer system outage time and much misdirected correction effort by MDAC and site personnel. The lack of local system knowledge led to frustration by the site personnel and vain attempts to correct the problems on their own. One such incident resulted in system damage when an operator performed the incorrect immediate action required due to the operator's inadequate system knowledge.

- Each utility test site must have at least one person who is dedicated and is responsible for the daily operation of the system. For example, at the SCE test site, there was a crew of operators and maintenance personnel whose secondary job was to operate and maintain the Stirling dish system. Because the system normally operated automatically without requiring routine $O \& M$ action and because the O\&M responsibility was rotated among the crew members, an individual would go a month or more without interacting with the system. When a problem arose, the individual assigned to correct the problem had forgotten much about the system and would thus have to re-familiarize himself prior to resolving the problem. Therefore, it is suggested that future similar demonstration programs designate 
one person at each site who is responsible for the day-to-day operation of the system.

- Adequate spare parts and special test equipment should be located at each test site. The lack of maturity of the system resulted in more hardware problems than anticipated. Since the spare parts and test equipment were not located at the test site, the time to diagnose the problem and ship the spare parts contributed to long downtimes.

In a future program where early customer site testing is desired before the system is very mature, program planning should include one multidiscipline person at each test site. That person must have a general technology background and comprehend the details of the software, controls system, electronics, electrical, thermal, mechanical, PCU fundamentals, etc. The customer (or the developer if within his budget) should identify this person to be responsible for servicing the system as required. One to three months before the delivery of the system to the customer, the customer designee should be assigned to the developer's test site for training in the fundamentals of the operation and to be involved in the development testing of the product. During this period of time, the assigned person should learn the details of the fundamentals of operation and be involved in the dayto-day operational tests performed on the systems. This would include the diagnosing of any problems, general maintenance, servicing, logging of daily activity, data recording, repair, overhauling components, and troubling shooting. In this way, the utility personnel will be familiar with the operation, problem history, and fault diagnosis through hands on experience.

\section{CONTINUATION OF THE MDAC/USAB/SCE PROGRAM}

The USAB 4-95 Stirling PCU has demonstrated the highest solar-to-electric conversion efficiency of any system in the world. Successful commercialization will be dependent upon achieving a competitive life-cycle cost in order to establish a market for Stirling dishes. Life-cycle cost include manufacture, installation, operation, and maintenance cost. The demonstration program did not provide the operating and maintenance cost data required for adequate estimates of a Stirling dish power plant operation because of the comparatively short test time. Therefore, the necessary information must be acquired through additional testing of the USAB Stirling 4-95 
Mark II PCUs. This system has accumulated more testing time than any other system and would require less testing time and thus a much lower cost to obtain the information with this system than any other present system. Even if newer technology would be later incorporated, much of the information obtained would still be applicable. Therefore there are good reasons for continuing with testing of this system. The test data would be valuable for the following purposes:

- Determination of the maintenance and material cost of the PCU and the mechanical life expectancy of the engine.

- Validation of performance improvements and cost reduction designs.

- Determination of design modifications necessary for low cost production units.

- Evaluation of modifications to extend the MTBF rate.

- Determination of performance improvements for future units.

- Generation of database for performance evaluation of alternate systems.

The Stirling dish components particularly the USAB Mark II PCU experienced problems that could have been corrected by application of relatively simple engineering solutions. At the time the problems were discovered, the program funding had been reduced to that essential for operation only. In the last two years of operation the authors, with the voluntary support of the Intersol Company, kept the SCE PCUs operating through their individual efforts and by cannibalizing parts from PCUs abandoned in Ann Arbor, Michigan. It is recommended that consideration be given to returning the original MDAC/USAB/SCE system to operational level to provide advancement of components as well as upgraded or improved components manufactured by others. Assuming the initial reuse of the original components, it is suggested that the recommendations below be given particular attention.

PCU - Failures such as the connecting rod crank shaft bearing experienced on the two Solar One USAB Mark II engines should be analyzed as to the cause of their failure and corrections made prior to their return to service. Each of the 495 engines should also be thoroughly checked out before returning them to service. The engines have been dormant since 1988 and were not subject to remedial preservation when the demonstration program was terminated.

Spare Parts - Obtain spare parts for the solar concentrators and the PCUs. Each test site should have available spare modules to minimize outage time 
and maximize the cost effectiveness of the demonstration program. In addition a parts storage and repair facility staffed by knowledgeable persons who can expedite problem resolution along with design specific support equipment should be available at each site.

Azimuth Gear Drive - The azimuth gear drives on all of the units should be replaced with the Sumitomo gear drive that was designed to overcome the mechanical weakness of the original drive assembly.

PCU Lightning Protection - This was a problem with the PCU electronics at all test sites. To ensure protection, a complete repackaging of the electronics will be required for a production unit. Modifications that were made at the MDAC Test Site and the SCE Test Site appeared to eliminate or at least greatly reduce the lightning-related problems. At a minimum, the grounding system of the PCU electronics should be modified; the wire shielding should be changed; a fiber optic link should replace the communications line between the PCU controller and the PCU monitor; a lightning-resistant diode should be added to the end of the line to discharge lightning-induced high potential to ground.

Fast Slew System - This emergency system was responsible for removing the concentrated solar energy from the receiver when the unit experienced either an interruption of its electrical grid connection or an emergency detrack condition. A new system needs to be designed to satisfy low-global latitude operation for the production design unit. The direct current motor did not have shaft bearings for radial loading. The belt connection with the main elevation drive motor resulted in a side load on the motor. This load would wear the bearing in a short time and render the motor inoperative. Also, the mechanical connection to the elevation gear drive was dependent on a compression-style coupling that proved to be unreliable. These problems can be easily resolved for future testing.

PCU Alarms/False Detracks - The PCU control system has a limited amount of information available to it for system diagnostics. The PCU control designer used this limited number of measurements to provide an extensive set of diagnostic alarms. These diagnostics were developed and tested in a controlled environment with a bench setup. The real solar environment is 
considerably different from this environment and as a result, detracks occurred even when there was no apparent problem. The detrack was cleared and the system was placed back in service without further incident. This type of problem occurred most frequently on cloudy days. It is recommended that a review be made of all alarms and that threshold settings be changed to reduce the problem.

PCU Electronics - The electronics should be upgraded to state-of-the-art technology and repackaged. Moisture caused a number of problems with the PCU electronics and related electrical connectors, particularly at the Georgia Power test site. Where possible, the number of connectors should be reduced and components that are not required for solar operation, should be removed.

Oil leakage - The two Mark II PCUs that operated at Barstow experienced oil leakage between the engine and generator. Although the SCE units oil leakage was minor, it needs to be resolved since it reduces concentrator efficiency and increases maintenance costs. The leaking oil collects on the concentrator's reflective surface during the time of day when the concentrator is at a high elevation angle. This oil cause increased soiling of the mirror surface from dust sticking to the oil. This reduced the total reflectivity of the system and resulted in an uneven receiver flux distribution which further reduced the system efficiency. Because the normal low cost washing technique would not remove the oil spot entirely, costly methods such as manual scrubbing had to be employed. 


\section{CONCLUSIONS}

The MDAC/USAB/SCE Stirling dish test program demonstrated the high performance of this solar-to-electric conversion technology and confirmed the performance results of previous DOE Stirling dish systems to include the systems tested in the JPL and Vanguard programs. The system reviewed in this report achieved a peak net power efficiency of $30 \%$ at $1000 \mathrm{~W} / \mathrm{m}^{2}$ solar insolation and a daily generated energy efficiency of $27 \%$ at daily sun energy levels of $10 \mathrm{kWh} / \mathrm{m}^{2}$. The system can start and operate at insolation levels as low as $250 \mathrm{~W} / \mathrm{m}^{2}$. Even on cloudy days the unit can produce net power at energy levels as low as $1 \mathrm{kWh} / \mathrm{m}^{2}$. The Solar One test site Stirling dish was able to produce up to one half of its normal daily net electrical output during days of frequent cloud passage, whereas, the adjacent Solar One and SEGS plants could not operate consequent to the cloud passage frequency. Over $118 \mathrm{MWh}$ of energy was generated and put onto the utility grid line during the test program. Nine USAB 4-95 Stirling PCUs were tested during the four-year program and accumulated over 13,852 hours of on-sun generating time. The first unit operated in late 1984, and PCUs operated on different units until late 1988. Several of the concentrators continue to operate up to the present time in various applications.

The Stirling dish system did not require a full-time operator because the control system had the capability of operating automatically. It would startup in the morning at sunrise and move to the sun position, track the sun all day, and then rotate back to a night stow position at sundown. If any problem occurred during the day, the system would detrack from the sun and return to a night stow position, where it would wait for the problem to be corrected. Following a grid power loss, the system would obtain a new reference position and then return to normal operation.

The power and energy performance of the USAB 4-95 engine was confirmed by this test program. No engine receiver problems were encountered during the test program. It was found during the test program that controlling the receiver quadrature temperature difference was not a.problem. It was generally maintained in the 60 to 70 $\operatorname{deg} C$ range and often was as low as 20 to $30 \mathrm{deg} C$. This validated that a uniform flux distribution over the receiver was achieved. The USAB Mark II engine heater heads that under went test operation on the Solar One Site engines did not evidence any degradation after each had $1700+$ hours of operation. The small heater head 
temperature differential that was demonstrated coupled with visual examination of the heater heads confirmed that silvered glass dishes can provide uniform flux distribution and thus operate without thermal buffers, e.g., reflux boilers and heat pipes between the solar irradiance and the working fluid heat exchanger. No hydrogen engine seals or piston ring problems were encountered during the test program. Consumption of hydrogen gas as a result of leakage was not found to be a major problem. Most of the problems experienced with the engine were of a minor nature and could be rectified merely by a repackaging of the electronics and modification of the control diagnostic.

The overall performance of the concentrator was good during the test program and has been improved since the end of the official test program in 1988. After eight years of operation at the different test sites, there has been no change in the structural performance that would indicate that the structure would not meet the 30-year design life. The mirrors in the desert environment withstood the environment without any apparent degradation in performance. After 8 years, the reflectivity was measured at $0.91+$, which is the same as the day the dish was manufactured. The surface waviness and radius of curvature were also measured and found to be the same as the day it was manufactured (within the limits of the instrument that is 0.2 mad and \pm 10 inches out of 700 inches). The surface of the mirror showed no signs of sand erosion. It was also found that the mirror withstood mishaps that might occur during plant operation without requiring their replacement. Because of their method of construction, mirror impact resulting from a falling wrench or other object will generally only break the local area glass and the balance of the reflective area is not affected. In addition, resulting cracks did not induce mirror silver corrosion thus minimal loss of reflectivity resulted from the incidents.

The tracking control system achieved a tracking accuracy of 0.2 mrad rms over the day. Achieving this accuracy did not result in costly control components, costly requirements on the structure and mechanical assembles, or costly installation requirements. This accuracy was achieved by developing a software error model that would adjust the tracking to compensate for these errors.

The alignment of the mirrors was maintained on all units throughout the test program. This included assembling and disassembling the concentrator and their shipment to Barstow, California, Nevada, Georgia, Japan and Switzerland. A mirror alignment method was developed during this program using an instrument called the Digital 
Image Radiometer (DIR). With the DIR, alignment of the mirrors to an accuracy of 0.2 mrad rms was achieved with a timely and cost-effective operation. Using the available equipment at the time, the 82 mirrors were aligned by one person in less than four hours. With current state-of-the-art equipment this would be greatly reduced.

The overall MDAC/USAB/SCE Stirling dish program results determined that the system is not faced with technical barriers that would preclude commercialization of this or similar Stirling dish systems. The significant component failures were the concentrator azimuth gear drive and Mark II PCU piston connecting rods bearings. A replacement gear drive was purchased, installed and underwent successful test. The failed bearings were a result of the conscious decision to optimize the performance of the PCU and accept the reduced reliability. Correction of the problem requires the use of larger bearings or the installation of a motor operated oil pump to lubricate the bearings in preparation for mechanically demanding start ups each day or following cloud passages.

A computer model of the energy performance of the Stirling dish system was created which uses actual MDAC/USAB/SCE Stirling dish program system cost, based on a 1985 cost reduction study and demonstrated performance data. The program using Barstow, California environment conditions, and mature system reliability data predicts a Stirling dish system annual energy performance efficiency of $23 \%$. The major sources of controllable energy loss are soiling of the mirrors. The major O\&M expenses are PCU overhaul and concentrator wash costs. The simulation model shows that system availability must be in the mid-90 percent range, under the above conditions, to achieve a competitive levelized energy cost. The 1985 cost data were updated in early 1993 in response to a U.S. Department of Energy request for proposal to commercialize distributed generation system. Using this new cost data, the Stirling dish simulation indicates that the system can be manufactured and installed in the $\$ 1,500$ to $\$ 2,000 / \mathrm{kW}$ range and produce power in the $\$ 0.08 / \mathrm{kWhr}$ range at production rates as low as 10,000 units per year. 


\section{REFERENCES}

1. United Stirling, Design Study of a Kinematic Stirling Engine for Dispersed Solar Electric Poser Systems, Final report, 1980, NASA Contract DEN 3-56, DOE/NASA/005679/2,NASA CR-159588.

2. Droher, J. J., Squier, S. E., Performance of the Vanguard Solar Dish-Stirling Engine Module, AP-6408, Research Project 2003-5, Prepared for: Energy Technology Engineering Center, Canoga Park, California and Electric Power Research Institute, Palo Alto, California, July 1986.

3. Hall, Larry, Worth Percival, Stan Holgerssen, Dana Sears, Keven Keogh, Vanguard I Solar Parabolic Dish-Stirling Engine Module, Final Report, September 30, 1984, DOE Cooperative Agreement DE-FC04-82AL16333, DOE-AL-16333-2

4. Blackmon, J.B., "Development and Performance of a Digital Image Radiometer for Heliostat Evaluation at Solar One," Journal of Solar Energy Engineering, Vol. 107/315, Nov. 1985.

5. Blackmon, J.B., Cross, C.R., Hennen, D.E., \& McFee, R.H., "Design and Performance of a Digital Image Radiometer for Dish Concentrator Evaluation," Solar Engineering, Vol. $1,1987$.

6. Stone, Kenneth W., "Automatic Heliostat Track Alignment Method," Patent No. 4,564,275, January 14, 1986.

7. King, D. L., Beam Quality and Tracking Accuracy Evaluation of Second-Generation and Barstow Production Heliostats, SAND82-0181, Sandia National Laboratories August 1982.

8. "Dish/Stirling Solar Electric Power System Development Test Project, McDonnell Douglas Monthly Test Report:

Test Site

Georgia Power

Georgia Power

Georgia Power

Georgia Power

Georgia Power

Georgia Power

Georgia Power

SCE

SCE

SCE

SCE

SCE

SCE

SCE Time Period

Oct. 85-Jan 86

Feb. 1986

Mar. 1986

Apr. 1986

May 1986

June 1986

July 1986

Oct. 85- Jan. 86

Feb. 1986

Mar. 1986

Apr. 1986

May 1986

June 1986

July 1986
Report Number

GPC-001

GPC-002

GPC-003

GPC-004

GPC-005

GPC-006

GPC-007

SCE-001

SCE-002

SCE-003

SCE-004

SCE-005

SCE-006

SCE-007 
9. Department of Energy, "Collector Field Optimization Report (RADL ITEM 2-25)", 10MWe Solar Thermal Central Receiver Pilot Plant, SAN/0499-22, MDCG8214, October 1979, Revised January 1981.

10. Kearney, D.W., Price, H.W.,"Overview of the SEGS Plants," Solar 87 Conference, American Solar Energy Society, Portland, Oregon, July 1987.

11. Kearney, D.W., "Solar Electric Generating Stations (SEGS)," IEEE Power Engineering Review, August 1989.

12. Dietrich, J. J., Knowles, R. K., Stone, K. W., Steinmeyer, D. A., Nourse, J. H., Optimization of the Second Generation Heliostat and Specification, SAND82-8181, Sandia National Laboratories, May 1982.

13. Fish, M.J.,Comparative Economics of Solar Thermal Central Receivers, SAND - 81-8236, Sandia National Laboratories, Albuquerque, New Mexico, August 1981.

14. Doane, J. W., O'Toole, R. P., Chamberlain, R. G., Bos, P. B., Maycock, P. D., "The Cost of Energy from Utility-owned Solar Electric Systems," JPL 5040-29, ERDA/JPL1012-76/3, EPRI, June 1976.

15. Dietrich, J. J., Radtke, C. W., "Production Planning and Cost Reduction of the Parabolic Dish Concentrator." Vol. 1, November 1985, MDC H2282.

16. Dietrich, J. J., Radtke, C. W., "Production Planning and Cost Reduction of the Parabolic Dish Concentrator." Vol. 2, November 1985, MDC H2282. 


\section{APPENDIX A}

This appendix contains a summary of the Stirling Dish testing from September 1984 to June 1986 at MDAC test site, Huntington Beach, California. 


\section{OPERATING SUMMARY FOR THE MDAC TEST SITE}

Date

1984

$12 / 3$

$12 / 4$

$12 / 5$

$12 / 6$

$12 / 7$

$12 / 10$

$12 / 12$

$12 / 13$

$12 / 18$

$12 / 19$

$12 / 20$

$12 / 21$

$12 / 24$

1985

$1 / 1$ to $1 / 4$

$1 / 7$ to $1 / 8$

$1 / 9$

$1 / 10$

$1 / 11$

$1 / 14$

$1 / 15$

$1 / 17$

$1 / 18$.

$1 / 22$

$1 / 24$

$1 / 28$

$1 / 29$

$1 / 30$

$1 / 31$

$2 / 1$

$2 / 4$

$2 / 5$

$2 / 8$

$2 / 11$

2/14

2/21

2/22

$2 / 25$ to $3 / 6$

$3 \pi$

$3 / 8$ to $3 / 15$

$3 / 19$

$3 / 20 / 3 / 31$

$4 / 1$ to $4 / 8$

$4 / 9$

$4 / 16$

$4 / 17$

$4 / 18$

$4 / 22$
Pad 2

Pad 2

Pad 2

Pad 2

Pad 2

Pad 2

Pad 2

Pad 2

Pad 2

Pad 2

Pad 2

Pad 2

Pad 2

Pad 2

Pad 2

Pad 2

Pad 2

Pad 2

Pad 2

Pad 2

Pad 2

Pad 2

Pad 2

Pad 2

Pad 2

Pad 2

Pad 2

Pad 2

Pad 2

Pad 2

Pad 2

Pad 2

$\mathrm{Pad} 2$

Pad 2

Pad 2

Pad 2

Pad 2

Pad 2

Pad 2

Pad 2

Pad 2

Pad 2

Pad

Pad 2

Pad 2

Pad 2

Pad 2
Description

First startup, had to adjust track system.

First full day operation, numerous clouds. No problems.

Dedication of Solar Dish.

No testing. Routing and tie down of concentrator wiring.

No testing, clouds.

Cloudy and rain. No testing. Intermittent problem with helicon sensor during reference update. PCU pressure transducer problem, damp connector.

Partly cloudy, no problem.

Structure deflection test.

Cloudy and rained all day, no testing.

Water in PXU electronic box caused system to be down

Changed cable routing and change Ptank to Pmin because of water connector problem

Many detracks in early morning because of clouds

- too many starts

- oil pressure but not running

System shut down over holidays.

Personnel on vacation.

No testing because of clouds.

Started operating at 10:39, no problems.

No problems.

Check gas leak, cone insolation fell off.

Put on flux mapper and camera.

Operated with no problem.

8:00 down - Rewire data wires for power meas. 900 track

Down 7:30 for DAS work, 9:07 track

Down for site work, started 11:56

Measure fan \& pump power.

Elevation motor ran into pedestal during night stow.

Replaced elevation motor.

Problem with elevation helicon sensor during reference update.

Operated in automatic, no problem.

Added oil to PCU.

Conducted tilt measurement in morning, tested in afternoon with no problem.

Detrack, found oil in gas system, removed PCU 101.

Replaced elevation gimbeland helicon sensor.

Replace PCU generated thermal shield. Rain in afternoon resulted in

insolation falling off.

Detrack-wrong start pressure.

Detrack, oil pressure but not running.

PCU water leak.

Remove PCU 102 and installed fluxmapper.

Install PCU 101 and checked out, check valve prob. replaced.

Operated with no problem.

System controller communication problem.

In automatic most of time, no problem.

No problem, did life cycling when cloudy

Software update.

Filled hydrogen tank, 11:50 in track

Took reflectivity measurements, 1:10 track.

Water pump fault, 8:30 track.

Took photos of system. 


\begin{tabular}{|c|c|c|}
\hline 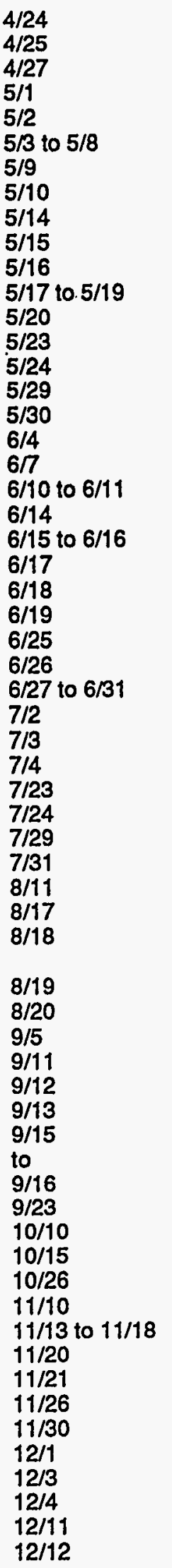 & 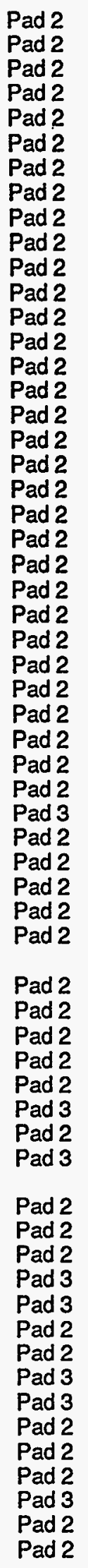 & 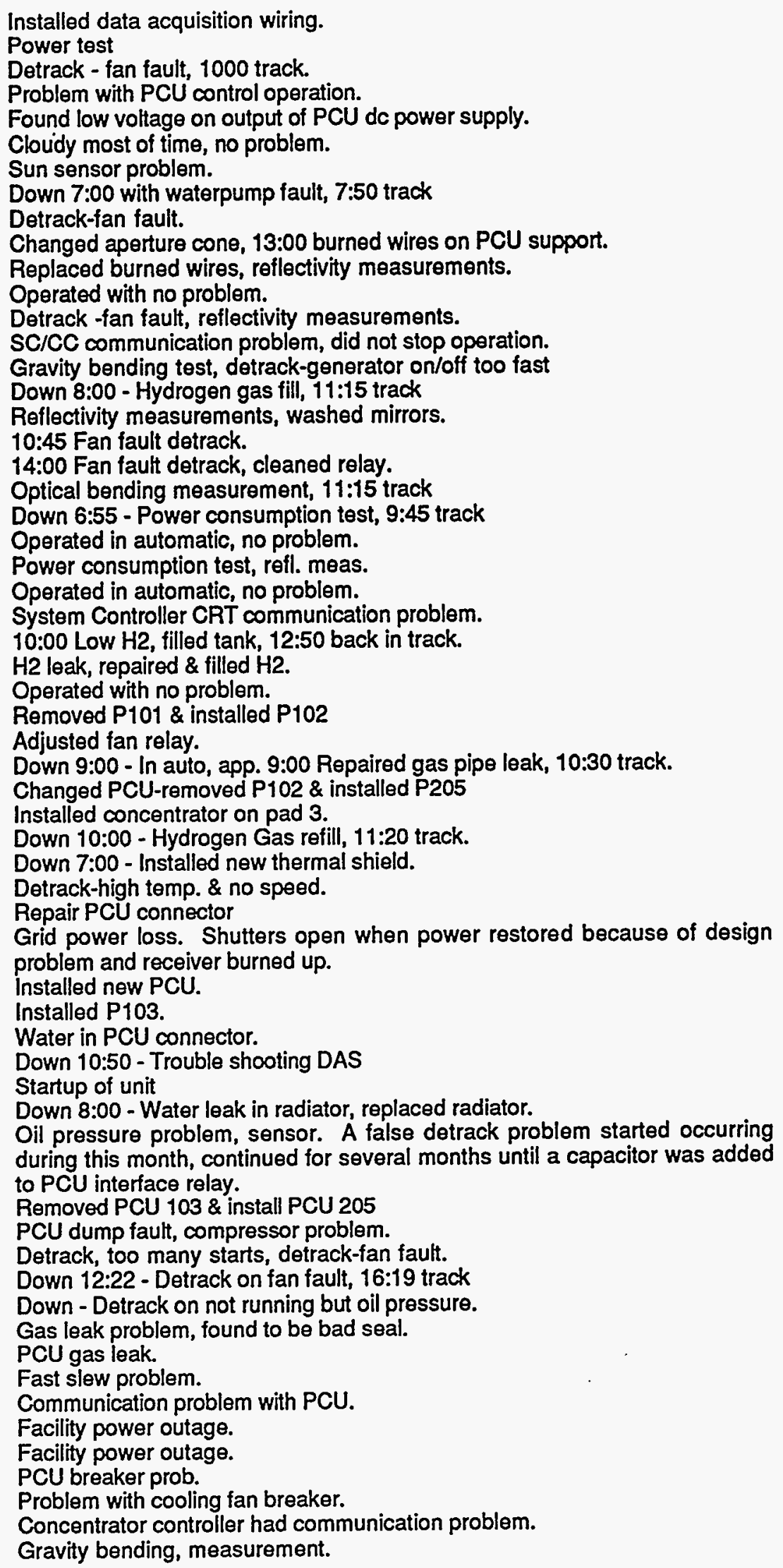 \\
\hline
\end{tabular}




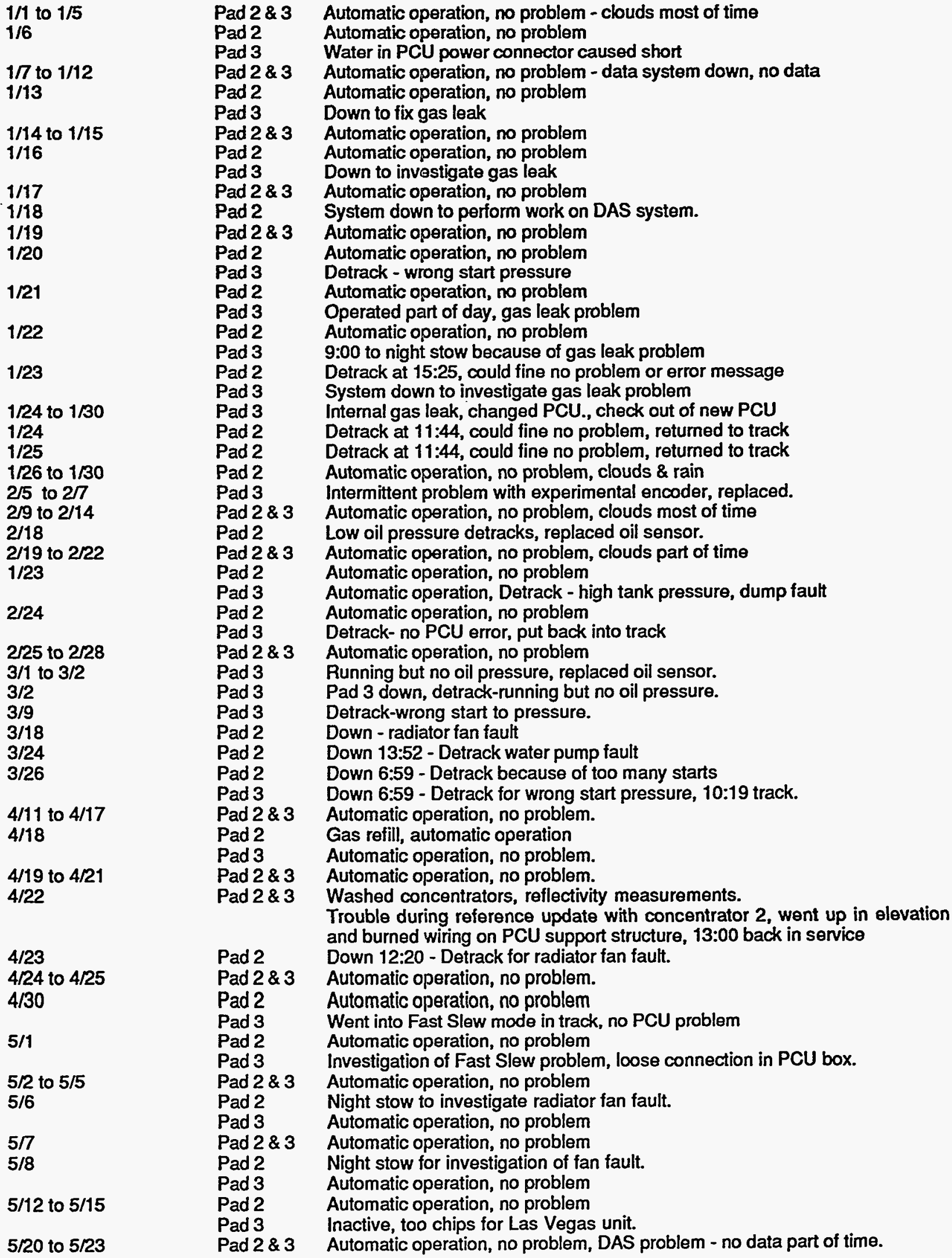

Pad 2\& 3 Automatic operation, no problem-clouds most of time

Pad 2 Automatic operation, no problem

Pad 3 Water in PCU power connector caused short

Pad 2 \& 3 Automatic operation, no problem - data system down, no data

Pad 2 Automatic operation, no problem

Pad 3 Down to fix gas leak

Pad 2 \& 3 Automatic operation, no problem

Pad 2 Automatic operation, no problem

Pad 3 Down to investigate gas leak

Pad 2\& 3 Automatic operation, no problem

Pad 2 System down to perform work on DAS system.

Pad 2 \& 3 Automatic operation, no problem

Pad 2 Automatic operation, no problem

Pad $3 \quad$ Detrack - wrong start pressure

Pad 2 Automatic operation, no problem

Pad 3 Operated part of day, gas leak problem

Pad 2 Automatic operation, no problem

Pad 3 9:00 to night stow because of gas leak problem

Pad 2 Detrack at 15:25, could fine no problem or error message

Pad 3 System down to investigate gas leak problem

Pad 3 Internal gas leak, changed PCU., check out of new PCU

Pad 2 Detrack at 11:44, could fine no problem, returned to track

Pad 2 Detrack at 11:44, could fine no problem, returned to track

Pad 2 Automatic operation, no problem, clouds \& rain

Pad 3 Intermittent problem with experimental encoder, replaced.

Pad 2 \& 3 Automatic operation, no problem, clouds most of time

Pad 2 Low oil pressure detracks, replaced oil sensor.

Pad 2 \& 3 Automatic operation, no problem, clouds part of time

Pad 2 Automatic operation, no problem

Pad 3 Automatic operation, Detrack - high tank pressure, dump fault

Pad 2 Automatic operation, no problem

Pad 3 Detrack- no PCU error, put back into track

Pad 2 \& 3 Automatic operation, no problem

Pad 3 Running but no oil pressure, replaced oil sensor.

Pad $3 \quad$ Pad 3 down, detrack-running but no oil pressure.

Pad 3 Detrack-wrong start to pressure.

Pad 2 Down - radiator fan fault

Pad 2 Down 13:52 - Detrack water pump fault

Pad 2 Down 6:59 - Detrack because of too many starts

Pad 3 Down 6:59 - Detrack for wrong start pressure, 10:19 track.

Pad 2 \& 3 Automatic operation, no problem.

Pad 2 Gas refill, automatic operation

Pad 3 Automatic operation, no problem.

Pad 2 \& 3 Automatic operation, no problem.

Pad 2 \& 3 Washed concentrators, reflectivity measurements.

Trouble during reference update with concentrator 2, went up in elevation and burned wiring on PCU support structure, 13:00 back in service

Pad 2 Down 12:20 - Detrack for radiator fan fault.

Pad 2\& 3 Automatic operation, no problem.

Pad 2 Automatic operation, no problem

Pad 3 Went into Fast Slew mode in track, no PCU problem

Pad 2 Automatic operation, no problem

Pad 3 Investigation of Fast Slew problem, loose connection in PCU box.

Pad 2 \& 3 Automatic operation, no problem

Pad $2 \quad$ Night stow to investigate radiator fan fault.

Pad 3 Automatic operation, no problem

Pad 2 \& 3 Automatic operation, no problem

Pad $2 \quad$ Night stow for investigation of fan fault.

Pad 3 Automatic operation, no problem

Pad 2 Automatic operation, no problem

Pad 3 Inactive, too chips for Las Vegas unit.

Pad 2 \& 3 Automatic operation, no problem, DAS problem - no data part of time. 
$6 / 3$ to $6 / 4$

$6 / 5$

$6 / 5$ to $6 / 9$

$6 / 5$ to end
Pad 2

Pad 3

$\mathrm{Pad} 2$

Pad 3

$\mathrm{Pad} 2$

Pad 3

Pad 2

Pad 3

Automatic operation, no problem

Detrack - wrong start pressure.

Automatic operation, no problem

Fast Slew problem

Checked mirror pattern in morning, 12:00 in track.

Checked mirror pattern in morning, inactive because of Fast Slew problem. Automatic operation, no problem

Fast slew problem, bad wire connections. 
DATA FOR MONTH 12 AND YEAR 1984 FOR PAD 2 AT HUNTINGTON BEACH

\begin{tabular}{|c|c|c|c|c|c|c|c|c|c|}
\hline$A T$ & $\begin{array}{l}\text { PEAK } \\
\text { POWER } \\
\text { KW }\end{array}$ & $\begin{array}{l}\text { PEAK } \\
\text { INSOL } \\
\mathrm{KW} / \mathrm{M} / \mathrm{M}\end{array}$ & $\begin{array}{l}\text { PEAK } \\
\text { POW EF } \\
\%\end{array}$ & $\begin{array}{l}\text { DAILY } \\
\text { ENERGY } \\
\text { KWHR }\end{array}$ & $\begin{array}{l}\text { SUN } \\
\text { ENERGY } \\
\text { KWHR }\end{array}$ & $\begin{array}{c}\text { AI LY } \\
\text { CFF IC. } \\
\%\end{array}$ & $\begin{array}{l}\text { TRACK } \\
\text { TIME } \\
\text { HR }\end{array}$ & $\begin{array}{l}\text { NIP> } \\
300 \text { WI } \\
\text { HR }\end{array}$ & $\begin{array}{l}\text { AX } \\
\text { ND } \\
\text { MPH }\end{array}$ \\
\hline $\begin{array}{r}1 \\
2 \\
3 \\
4 \\
5 \\
6 \\
7 \\
8 \\
9 \\
10 \\
11 \\
12 \\
13 \\
14 \\
15 \\
16 \\
17 \\
18 \\
19 \\
20 \\
21 \\
22 \\
23 \\
24 \\
25 \\
26 \\
27 \\
28 \\
29 \\
30 \\
31\end{array}$ & $\begin{array}{r}0.00 \\
0.00 \\
0.00 \\
0.00 \\
0.00 \\
0.00 \\
0.00 \\
0.00 \\
0.00 \\
0.00 \\
0.00 \\
15.40 \\
21.20 \\
21.20 \\
0.00 \\
0.00 \\
0.00 \\
0.00 \\
0.00 \\
15.50 \\
20.50 \\
0.00 \\
0.00 \\
0.00 \\
0.00 \\
0.00 \\
0.00 \\
0.00 \\
0.00 \\
0.00 \\
0.00\end{array}$ & $\begin{array}{r}0.0 \\
0.0 \\
0.0 \\
0.0 \\
0.0 \\
0.0 \\
0.0 \\
0.0 \\
0.0 \\
0.0 \\
0.0 \\
745.9 \\
927.7 \\
922.0 \\
0.0 \\
0.0 \\
0.0 \\
0.0 \\
0.0 \\
850.4 \\
864.9 \\
0.0 \\
0.0 \\
0.0 \\
0.0 \\
0.0 \\
0.0 \\
0.0 \\
0.0 \\
0.0 \\
0.0\end{array}$ & $\begin{array}{r}0.0 \\
0.0 \\
0.0 \\
0.0 \\
0.0 \\
0.0 \\
0.0 \\
0.0 \\
0.0 \\
0.0 \\
0.0 \\
23.5 \\
26.1 \\
26.2 \\
0.0 \\
0.0 \\
0.0 \\
0.0 \\
0.0 \\
20.8 \\
27.0 \\
0.0 \\
0.0 \\
0.0 \\
0.0 \\
0.0 \\
0.0 \\
0.0 \\
0.0 \\
0.0 \\
0.0\end{array}$ & $\begin{array}{r}0.0 \\
0.0 \\
0.0 \\
0.0 \\
0.0 \\
0.0 \\
0.0 \\
0.0 \\
0.0 \\
0.0 \\
-0.9 \\
17.3 \\
30.8 \\
132.5 \\
0.0 \\
0.0 \\
0.0 \\
0.0 \\
0.0 \\
9.8 \\
98.7 \\
0.0 \\
0.0 \\
0.0 \\
0.0 \\
0.0 \\
0.0 \\
0.0 \\
0.0 \\
0.0 \\
0.0\end{array}$ & $\begin{array}{l}0.000 \\
0.000 \\
0.000 \\
0.000 \\
0.000 \\
0.000 \\
0.000 \\
0.000 \\
0.000 \\
0.000 \\
0.115 \\
0.905 \\
4.174 \\
6.403 \\
0.000 \\
0.000 \\
0.000 \\
0.000 \\
0.000 \\
0.548 \\
5.340 \\
0.000 \\
0.000 \\
0.000 \\
0.000 \\
0.000 \\
0.000 \\
0.000 \\
0.000 \\
0.000 \\
0.000\end{array}$ & $\begin{array}{r}0.0 \\
0.0 \\
0.0 \\
0.0 \\
0.0 \\
0.0 \\
0.0 \\
0.0 \\
0.0 \\
0.0 \\
-9.0 \\
21.8 \\
22.1 \\
23.6 \\
0.0 \\
0.0 \\
0.0 \\
0.0 \\
0.0 \\
20.4 \\
21.1 \\
0.0 \\
0.0 \\
0.0 \\
0.0 \\
0.0 \\
0.0 \\
0.0 \\
0.0 \\
0.0 \\
0.0\end{array}$ & $\begin{array}{l}0.00 \\
0.00 \\
0.00 \\
0.00 \\
0.00 \\
0.00 \\
0.00 \\
0.00 \\
0.00 \\
0.00 \\
0.00 \\
0.00 \\
0.00 \\
0.00 \\
0.00 \\
0.00 \\
0.00 \\
0.00 \\
0.00 \\
0.00 \\
0.00 \\
0.00 \\
0.00 \\
0.00 \\
0.00 \\
0.00 \\
0.00 \\
0.00 \\
0.00 \\
0.00 \\
0.00\end{array}$ & $\begin{array}{l}0.00 \\
0.00 \\
0.00 \\
0.00 \\
0.00 \\
0.00 \\
0.00 \\
0.00 \\
0.00 \\
0.00 \\
0.00 \\
0.00 \\
0.00 \\
0.00 \\
0.00 \\
0.00 \\
0.00 \\
0.00 \\
0.00 \\
0.00 \\
0.00 \\
0.00 \\
0.00 \\
0.00 \\
0.00 \\
0.00 \\
0.00 \\
0.00 \\
0.00 \\
0.00 \\
0.00\end{array}$ & $\begin{array}{l}0.0 \\
0.0 \\
0.0 \\
0.0 \\
0.0 \\
0.0 \\
0.0 \\
0.0 \\
0.0 \\
0.0 \\
0.0 \\
0.0 \\
0.0 \\
0.0 \\
0.0 \\
0.0 \\
0.0 \\
0.0 \\
0.0 \\
0.0 \\
0.0 \\
0.0 \\
0.0 \\
0.0 \\
0.0 \\
0.0 \\
0.0 \\
0.0 \\
0.0 \\
0.0 \\
0.0\end{array}$ \\
\hline
\end{tabular}

TOTAL TRACK TIME FOR MONTH......... TIME THAT NIP WAS ABOVE 300 W/SQ.M.... TRACK TIME / TIME NIP > $300 \ldots \ldots \ldots$ MAXIMUM DAILY NET POWER ............. MAX. DAILY NET POWER EFFIC. FOR MONTH MAXIMUM DAILY NET ENERGY . . . . . . . . MAX. DAILY NET ENERGY EFFIC. FOR MONTH TOTAL NET POWER PRODUCED FOR MONTH. . . . TOTAL SUN ENERGY FOR THE MONTH. . . . . . SYSTEM NET EFFICIENCY FOR THE MONTH .

$\begin{array}{rl}0.00 & \text { HOURS } \\ 0.00 & \text { HOURS } \\ 0.0000 & \\ 21.20 & \mathrm{KW} \\ 27.0 & \% \\ 132.50 & \mathrm{KWHR} \\ 23.6 & \\ 3.9 & \mathrm{KWHR} / \mathrm{SQ.M} \\ 17.5 & \mathrm{KWHR} / \mathrm{SQ.M} \\ 22.1 \% & \end{array}$




\begin{tabular}{|c|c|c|c|c|c|c|c|c|c|}
\hline ATE & $\begin{array}{l}\text { PEAK } \\
\text { POWER } \\
\text { KW }\end{array}$ & $\begin{array}{l}\text { PEAK } \\
\text { INSOL } \\
\text { KW/M/M }\end{array}$ & $\begin{array}{l}\text { PEAK } \\
\text { POW EF } \\
\%\end{array}$ & $\begin{array}{l}\text { DAILY } \\
\text { ENERGY } \\
\text { KWHR }\end{array}$ & $\begin{array}{l}\text { SUN } \\
\text { ENERGY } \\
\text { KWHR }\end{array}$ & $\begin{array}{c}\text { DAILY } \\
\text { EFFIC. } \\
\%\end{array}$ & $\begin{array}{l}\text { TRACK } \\
\text { TIME } \\
\text { HR }\end{array}$ & $\begin{array}{l}\text { NIP> } \\
300 \text { W } \\
H R\end{array}$ & $\begin{array}{l}\text { MAX } \\
\text { IIND } \\
\text { MPH }\end{array}$ \\
\hline $\begin{array}{l}1 \\
2 \\
3 \\
4 \\
5 \\
6 \\
7 \\
8 \\
9 \\
10 \\
11 \\
12 \\
13 \\
14 \\
15 \\
16 \\
17 \\
18 \\
19 \\
20 \\
21 \\
22 \\
23 \\
24 \\
25 \\
26 \\
27 \\
28 \\
29 \\
30 \\
31\end{array}$ & $\begin{array}{r}0.00 \\
0.00 \\
0.00 \\
0.00 \\
0.00 \\
0.00 \\
0.00 \\
0.00 \\
17.00 \\
19.20 \\
21.50 \\
0.00 \\
0.00 \\
21.80 \\
19.90 \\
19.90 \\
19.60 \\
19.20 \\
0.00 \\
0.00 \\
0.00 \\
19.10 \\
12.20 \\
18.90 \\
13.80 \\
15.00 \\
0.00 \\
0.00 \\
0.00 \\
15.60 \\
21.20\end{array}$ & $\begin{array}{r}0.0 \\
0.0 \\
0.0 \\
0.0 \\
0.0 \\
0.0 \\
0.0 \\
0.0 \\
773.9 \\
833.4 \\
952.9 \\
0.0 \\
0.0 \\
935.3 \\
894.6 \\
865.0 \\
848.7 \\
853.3 \\
0.0 \\
0.0 \\
0.0 \\
880.5 \\
642.7 \\
858.0 \\
755.7 \\
735.6 \\
0.0 \\
0.0 \\
0.0 \\
754.3 \\
847.2\end{array}$ & $\begin{array}{r}0.0 \\
0.0 \\
0.0 \\
0.0 \\
0.0 \\
0.0 \\
0.0 \\
0.0 \\
25.1 \\
26.3 \\
25.7 \\
0.0 \\
0.0 \\
26.6 \\
25.4 \\
26.2 \\
26.3 \\
25.7 \\
0.0 \\
0.0 \\
0.0 \\
24.7 \\
21.7 \\
25.1 \\
20.8 \\
23.3 \\
0.0 \\
0.0 \\
0.0 \\
23.6 \\
28.5\end{array}$ & $\begin{array}{r}0.0 \\
0.0 \\
0.0 \\
0.0 \\
0.0 \\
0.0 \\
0.0 \\
0.0 \\
52.4 \\
40.8 \\
81.1 \\
0.0 \\
0.0 \\
90.0 \\
113.3 \\
98.5 \\
105.5 \\
109.0 \\
0.0 \\
0.0 \\
0.0 \\
45.8 \\
56.7 \\
76.2 \\
12.1 \\
23.6 \\
0.0 \\
0.0 \\
0.0 \\
36.1 \\
123.5\end{array}$ & $\begin{array}{l}0.000 \\
0.000 \\
0.000 \\
0.000 \\
0.000 \\
0.000 \\
0.000 \\
0.000 \\
2.929 \\
2.293 \\
4.151 \\
0.000 \\
0.000 \\
4.312 \\
5.590 \\
4.829 \\
4.722 \\
5.394 \\
0.000 \\
0.000 \\
0.000 \\
2.520 \\
3.615 \\
3.938 \\
0.907 \\
1.321 \\
0.000 \\
0.000 \\
0.000 \\
1.966 \\
5.669\end{array}$ & $\begin{array}{r}0.0 \\
0.0 \\
0.0 \\
0.0 \\
0.0 \\
0.0 \\
0.0 \\
0.0 \\
20.4 \\
20.3 \\
22.3 \\
0.0 \\
0.0 \\
23.8 \\
23.1 \\
23.3 \\
25.5 \\
23.0 \\
0.0 \\
0.0 \\
0.0 \\
20.7 \\
17.9 \\
22.1 \\
15.2 \\
20.4 \\
0.0 \\
0.0 \\
0.0 \\
20.9 \\
24.8\end{array}$ & $\begin{array}{l}0.00 \\
0.00 \\
0.00 \\
0.00 \\
0.00 \\
0.00 \\
0.00 \\
0.00 \\
6.30 \\
0.00 \\
0.00 \\
0.00 \\
6.60 \\
5.30 \\
0.00 \\
7.60 \\
7.90 \\
7.70 \\
0.00 \\
0.00 \\
0.00 \\
4.30 \\
7.80 \\
5.80 \\
5.40 \\
0.00 \\
0.00 \\
0.00 \\
0.00 \\
6.00 \\
8.60\end{array}$ & $\begin{array}{l}0.00 \\
0.00 \\
0.00 \\
0.00 \\
0.00 \\
0.00 \\
0.00 \\
0.00 \\
0.00 \\
0.00 \\
0.00 \\
0.00 \\
0.00 \\
0.00 \\
0.00 \\
0.00 \\
0.00 \\
0.00 \\
0.00 \\
0.00 \\
0.00 \\
0.00 \\
0.00 \\
0.00 \\
0.00 \\
0.00 \\
0.00 \\
0.00 \\
0.00 \\
0.00 \\
0.00\end{array}$ & $\begin{array}{l}0.0 \\
0.0 \\
0.0 \\
0.0 \\
0.0 \\
0.0 \\
0.0 \\
0.0 \\
0.0 \\
0.0 \\
0.0 \\
0.0 \\
0.0 \\
0.0 \\
0.0 \\
0.0 \\
0.0 \\
0.0 \\
0.0 \\
0.0 \\
0.0 \\
0.0 \\
0.0 \\
0.0 \\
0.0 \\
0.0 \\
0.0 \\
0.0 \\
0.0 \\
0.0 \\
0.0\end{array}$ \\
\hline
\end{tabular}

TOTAL TRACK TIME FOR MONTH.......... TIME THAT NIP WAS ABOUE 300 W/SQ.M.... TRACK TIME / TIME NIP > 300........ MAXIMUM DAILY NET POWER ............ MAX. DAILY NET POWER EFFIC. FOR MONTH MAXIMUM DAILY NET ENERGY ................ MAX. DAILY NET ENERGY EFFIC. FOR MONTH TOTAL NET POWER PRODUCED FOR MONTH.... TOTAL SUN ENERGY FOR THE MONTH....... SYSTEM NET EFFICIENCY FOR THE MONTH ..
79.30 HOURS

0.00 HOURS

0.0000

$21.80 \mathrm{KW}$

$28.5 \%$

$123.50 \mathrm{KWHR}$

$25.5 \%$

12.1 KWHR/ SQ.M

54.2 KWHR/ SQ.M

$22.4 \%$ 
DATA FOR MONTH 2 AND YEAR 1985 FOR PAD 2 AT HUNTINGTON BEACH

\begin{tabular}{|c|c|c|c|c|c|c|c|c|c|}
\hline $\mathrm{AT}$ & $\begin{array}{c}\text { PEAK } \\
\text { POWER } \\
\text { KW }\end{array}$ & $\begin{array}{l}\text { PEAK } \\
\text { INSOL } \\
\mathrm{KW} / \mathrm{M} / \mathrm{M}\end{array}$ & $\begin{array}{l}\text { 'EAK } \\
\text { OW EF } \\
\%\end{array}$ & $\begin{array}{l}\text { DAILY } \\
\text { ENERGY } \\
\text { KWHR }\end{array}$ & $\begin{array}{l}\text { SUN } \\
\text { DNERGY } \\
\text { KWHR }\end{array}$ & $\begin{array}{c}\text { DAILY } \\
\text { EFFIC. } \\
\%\end{array}$ & $\begin{array}{l}\text { TRACK } \\
\text { TIME } \\
\text { HR }\end{array}$ & $\begin{array}{l}\text { NIP> } \\
300 \mathrm{~W} \\
\text { HR }\end{array}$ & $\begin{array}{l}\text { MAX } \\
\text { JIND } \\
\text { MPH }\end{array}$ \\
\hline $\begin{array}{l}1 \\
2 \\
3 \\
4 \\
5 \\
6 \\
7 \\
8 \\
9 \\
10 \\
11 \\
12 \\
13 \\
14 \\
15 \\
16 \\
17 \\
18 \\
19 \\
20 \\
21 \\
22 \\
23 \\
24 \\
25 \\
26 \\
27 \\
28\end{array}$ & $\begin{array}{r}22.30 \\
0.00 \\
0.00 \\
0.00 \\
0.00 \\
0.00 \\
16.60 \\
0.00 \\
0.00 \\
0.00 \\
20.00 \\
18.80 \\
19.30 \\
21.80 \\
21.00 \\
19.80 \\
14.80 \\
0.00 \\
8.00 \\
10.50 \\
17.60 \\
19.00 \\
17.00 \\
19.00 \\
0.00 \\
0.00 \\
0.00 \\
0.00\end{array}$ & $\begin{array}{r}904.6 \\
0.0 \\
0.0 \\
0.0 \\
0.0 \\
0.0 \\
729.6 \\
0.0 \\
0.0 \\
0.0 \\
906.1 \\
884.1 \\
861.9 \\
965.6 \\
913.8 \\
879.4 \\
708.8 \\
0.0 \\
498.2 \\
529.5 \\
772.6 \\
825.7 \\
768.6 \\
850.7 \\
0.0 \\
0.0 \\
0.0 \\
0.0\end{array}$ & $\begin{array}{c}28.1 \\
0.0 \\
0.0 \\
0.0 \\
0.0 \\
0.0 \\
26.0 \\
0.0 \\
0.0 \\
0.0 \\
25.2 \\
24.3 \\
25.5 \\
25.8 \\
26.2 \\
25.7 \\
23.8 \\
0.0 \\
18.3 \\
22.6 \\
26.0 \\
26.2 \\
25.2 \\
25.5 \\
0.0 \\
0.0 \\
0.0 \\
0.0\end{array}$ & $\begin{array}{r}114.4 \\
0.0 \\
0.0 \\
0.0 \\
0.0 \\
0.0 \\
70.7 \\
0.0 \\
0.0 \\
0.0 \\
106.4 \\
97.2 \\
124.9 \\
168.6 \\
125.5 \\
141.4 \\
12.1 \\
0.0 \\
9.1 \\
25.4 \\
91.3 \\
95.0 \\
103.6 \\
122.0 \\
0.0 \\
0.0 \\
0.0 \\
0.0\end{array}$ & $\begin{array}{l}5.093 \\
0.000 \\
0.000 \\
0.000 \\
0.000 \\
0.000 \\
3.629 \\
0.000 \\
0.000 \\
0.000 \\
5.226 \\
4.671 \\
6.119 \\
7.847 \\
5.900 \\
6.685 \\
1.016 \\
0.000 \\
0.718 \\
1.502 \\
4.842 \\
5.145 \\
5.265 \\
6.140 \\
0.000 \\
0.000 \\
0.000 \\
0.000\end{array}$ & $\begin{array}{r}25.6 \\
0.0 \\
0.0 \\
0.0 \\
0.0 \\
0.0 \\
22.2 \\
0.0 \\
0.0 \\
0.0 \\
23.2 \\
23.7 \\
23.3 \\
24.5 \\
24.3 \\
24.1 \\
13.6 \\
0.0 \\
14.5 \\
19.3 \\
21.5 \\
21.1 \\
22.4 \\
22.7 \\
0.0 \\
0.0 \\
0.0 \\
0.0\end{array}$ & $\begin{array}{l}0.00 \\
0.00 \\
0.00 \\
0.00 \\
0.00 \\
0.00 \\
7.00 \\
0.00 \\
0.00 \\
0.00 \\
7.60 \\
8.70 \\
9.00 \\
9.50 \\
8.30 \\
9.20 \\
7.90 \\
0.00 \\
2.60 \\
4.10 \\
9.60 \\
8.80 \\
8.50 \\
9.10 \\
0.00 \\
0.00 \\
0.00 \\
0.00\end{array}$ & $\begin{array}{l}0.00 \\
0.00 \\
0.00 \\
0.00 \\
0.00 \\
0.00 \\
0.00 \\
0.00 \\
0.00 \\
0.00 \\
0.00 \\
0.00 \\
0.00 \\
0.00\end{array}$ & $\begin{array}{l}0.0 \\
0.0 \\
0.0 \\
0.0 \\
0.0 \\
0.0 \\
0.0 \\
0.0 \\
0.0 \\
0.0 \\
0.0 \\
0.0 \\
0.0 \\
0.0 \\
0.0 \\
0.0 \\
0.0 \\
0.0 \\
0.0 \\
0.0 \\
0.0 \\
0.0 \\
0.0 \\
0.0 \\
0.0 \\
0.0 \\
0.0 \\
0.0\end{array}$ \\
\hline
\end{tabular}

TOTAL TRACK TIME FOR MONTH...........

TIME THAT NIP WAS ABOVE 300 W/SQ.M...

TRACK TIME / TIME NIP > $300 \ldots . . . .$.

MAXIMUM DAILY NET POWER $\ldots \ldots \ldots \ldots \ldots$

MAX. DAILY NET POWER EFFIC. FOR MONTH

MAXIMLM DAILY NET ENERGY $\ldots \ldots \ldots \ldots \ldots$

MAX. DAILY NET ENERGY EFFIC. FOR MONTH

TOTAL NET POWER PRODUCED FOR MONTH....

TOTAL SUN ENERGY FOR THE MONTH........

SYSTEM NET EFFICIENCY FOR THE MONTH ..
109.90 HOURS

0.00 HOURS

0.0000

$22.30 \mathrm{KW}$

$28.1 \%$

$168.60 \mathrm{KWHR}$

$25.6 \%$

16.1 KWHR/ SQ.M

69.8 KWHR/ SQ.M

$23.0 \%$ 
DATA FOR MONTH

3 AND YEAR 1985 FOR PAD 2 AT HUNTINGTON BEACH

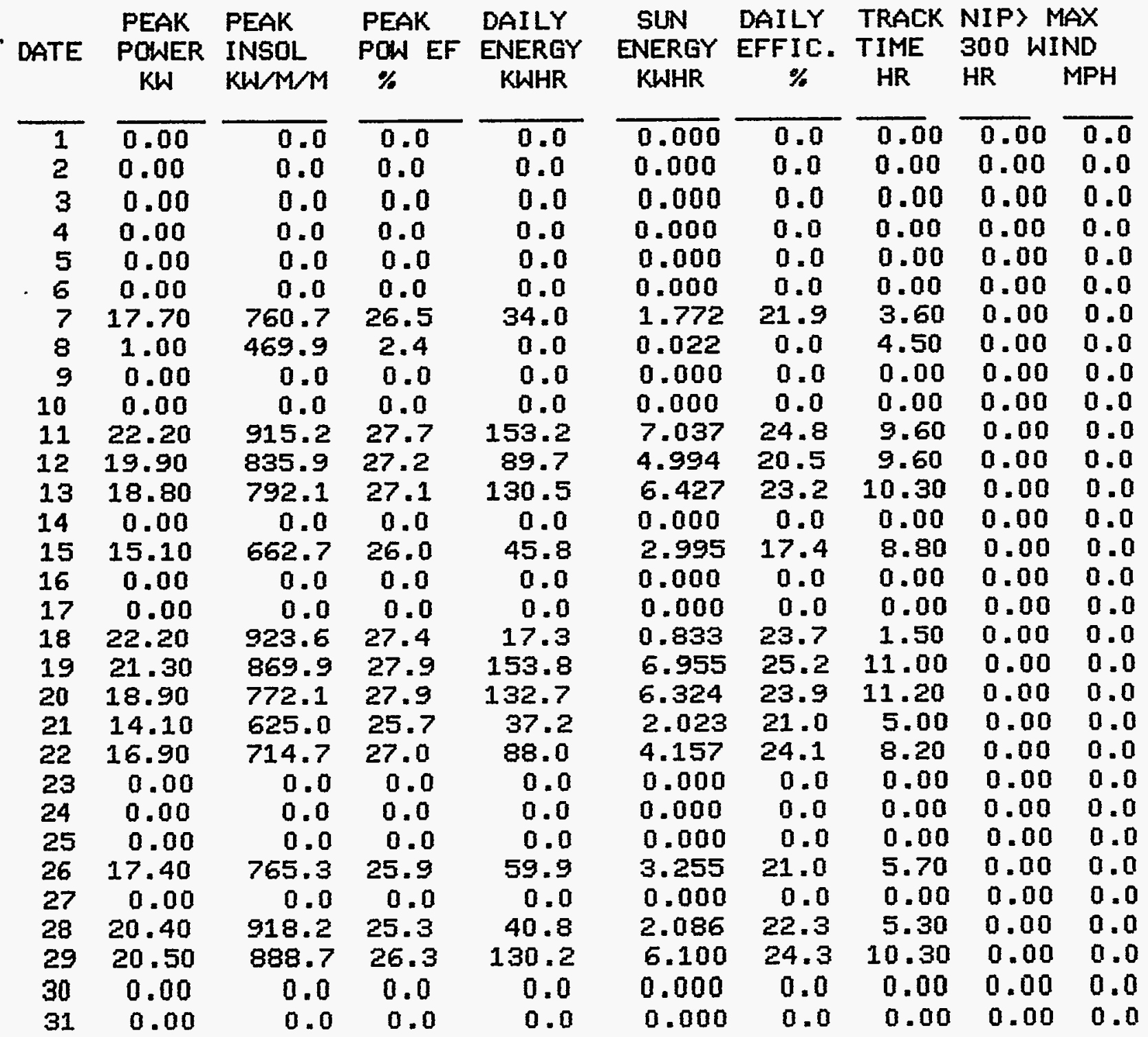

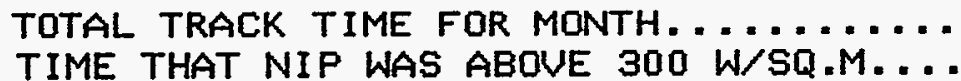
TRACK TIME / TIME NIP > 300......... MAXIMUM DAILY NET POWER ........... MAX. DAILY NET POWER EFFIC. FOR MONTH MAXIMUM DAILY NET ENERGY . . . . . . . . . . MAX. DAILY NET ENERGY EFFIC. FOR MONTH TOTAL NET POWER PRODUCED FOR MONTH. ... TOTAL SUN ENERGY FOR THE MONTH....... SYSTEM NET EFFICIENCY FOR THE MONTH ..

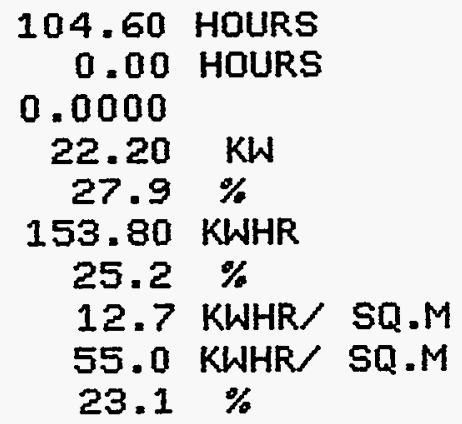


DATA FOR MONTH 4 AND YEAR 1985 FOR PAD 2 AT HUNTINGTON BEACH

\begin{tabular}{|c|c|c|c|c|c|c|c|c|c|}
\hline TTE & $\begin{array}{c}\text { PEAK } \\
\text { POWER } \\
\text { KW }\end{array}$ & $\begin{array}{l}\text { SAK } \\
\text { ISOL } \\
\mathrm{J} / \mathrm{M} / \mathrm{M}\end{array}$ & $\begin{array}{l}\text { EAK } \\
\text { OW EF } \\
\%\end{array}$ & $\begin{array}{c}\text { DAILY } \\
\text { ENERGY } \\
\text { KWHR }\end{array}$ & $\begin{array}{l}\text { SUN } \\
\text { ENERGY } \\
\text { KWHR }\end{array}$ & $\begin{array}{c}\text { DAILY } \\
\text { EFFIC. } \\
\%\end{array}$ & $\begin{array}{l}\text { RACK } \\
\text { IME } \\
\text { HR }\end{array}$ & $\begin{array}{l}\| I P>M \\
00 W \\
\text { IR WI }\end{array}$ & $\begin{array}{l}\text { MAX } \\
\text { IIND } \\
\text { MPH }\end{array}$ \\
\hline $\begin{array}{l}1 \\
2 \\
3 \\
4 \\
5 \\
6 \\
7 \\
8 \\
9 \\
10 \\
11 \\
12 \\
13 \\
14 \\
15 \\
16 \\
17 \\
18 \\
19 \\
20 \\
21 \\
22 \\
23 \\
24 \\
25 \\
26 \\
27 \\
28 \\
29 \\
30\end{array}$ & $\begin{array}{r}0.00 \\
21.10 \\
19.70 \\
17.60 \\
0.00 \\
0.00 \\
13.00 \\
12.60 \\
17.70 \\
19.80 \\
15.70 \\
19.40 \\
17.00 \\
0.00 \\
18.40 \\
18.70 \\
22.80 \\
20.90 \\
18.30 \\
0.00 \\
0.00 \\
15.80 \\
20.00 \\
19.80 \\
13.70 \\
20.00 \\
18.10 \\
0.00 \\
18.30 \\
18.50\end{array}$ & $\begin{array}{r}0.0 \\
928.0 \\
873.7 \\
778.8 \\
0.0 \\
0.0 \\
639.1 \\
635.5 \\
795.4 \\
874.2 \\
727.8 \\
871.6 \\
811.4 \\
0.0 \\
845.1 \\
885.4 \\
716.0 \\
854.6 \\
767.2 \\
0.0 \\
0.0 \\
828.5 \\
861.4 \\
866.8 \\
680.8 \\
908.3 \\
847.1 \\
0.0 \\
863.5 \\
864.7\end{array}$ & $\begin{array}{c}0.0 \\
25.9 \\
25.7 \\
25.8 \\
0.0 \\
0.0 \\
23.2 \\
22.6 \\
25.4 \\
25.8 \\
24.6 \\
25.4 \\
23.9 \\
0.0 \\
24.8 \\
24.1 \\
36.3 \\
27.9 \\
27.2 \\
0.0 \\
0.0 \\
21.8 \\
26.5 \\
26.1 \\
23.0 \\
25.1 \\
24.4 \\
0.0 \\
24.2 \\
24.4\end{array}$ & $\begin{array}{r}0.0 \\
171.3 \\
153.0 \\
24.5 \\
0.0 \\
0.0 \\
33.5 \\
20.7 \\
33.1 \\
122.2 \\
89.9 \\
113.8 \\
66.1 \\
0.0 \\
74.7 \\
54.7 \\
106.3 \\
126.8 \\
50.6 \\
0.0 \\
0.0 \\
29.1 \\
167.7 \\
107.6 \\
17.4 \\
172.4 \\
97.7 \\
0.0 \\
42.8 \\
75.0\end{array}$ & $\begin{array}{l}5.882 \\
2.513 \\
0.000 \\
0.000 \\
0.000 \\
7.990 \\
6.080 \\
3.380 \\
8.470 \\
0.000 \\
0.000 \\
2.530 \\
7.280\end{array}$ & $\begin{array}{r}0.0 \\
23.6 \\
22.6 \\
20.7 \\
0.0 \\
0.0 \\
21.0 \\
17.7 \\
20.3 \\
23.3 \\
21.7 \\
22.5 \\
21.4 \\
0.0 \\
20.6 \\
19.3 \\
25.5 \\
24.6 \\
23.0 \\
0.0 \\
0.0 \\
0.0 \\
23.9 \\
20.2 \\
5.9 \\
23.2 \\
0.0 \\
0.0 \\
19.3 \\
11.8\end{array}$ & $\begin{array}{r}0.00 \\
10.70 \\
11.30 \\
3.70 \\
0.00 \\
3.70 \\
3.70 \\
4.50 \\
3.40 \\
8.50 \\
8.00 \\
8.40 \\
7.30 \\
0.00 \\
7.40 \\
6.10 \\
6.70 \\
8.90 \\
5.40 \\
0.00 \\
0.00 \\
0.00 \\
11.40 \\
10.40 \\
12.10 \\
11.80 \\
8.20 \\
0.00 \\
4.50 \\
7.00\end{array}$ & $\begin{array}{l}0.00 \\
0.00 \\
0.00 \\
0.00 \\
0.00 \\
0.00 \\
0.00 \\
0.00 \\
0.00 \\
0.00 \\
0.00 \\
0.00 \\
0.00 \\
0.00 \\
0.00 \\
0.00 \\
0.00 \\
0.00\end{array}$ & $\begin{array}{l}0.0 \\
0.0 \\
0.0 \\
0.0 \\
0.0 \\
0.0 \\
0.0 \\
0.0 \\
0.0 \\
0.0 \\
0.0 \\
0.0 \\
0.0 \\
0.0 \\
0.0 \\
0.0 \\
0.0 \\
0.0 \\
0.0 \\
0.0 \\
0.0 \\
0.0 \\
0.0 \\
0.0 \\
0.0 \\
0.0 \\
0.0 \\
0.0 \\
0.0 \\
0.0\end{array}$ \\
\hline
\end{tabular}

TOTAL TRACK TIME FOR MONTH. . . . . . . . . TIME THAT NIP WAS ABOUE 300 W/SQ.M.... TRACK TIME / TIME NIP > $300 \ldots \ldots . . .$. MAXIMUM DAILY NET POWER . . . . . . . . MAX. DAILY NET POWER EFFIC. FOR MONTH MAXIMUM DAILY NET ENERGY $\ldots \ldots \ldots \ldots \ldots$ MAX. DAILY NET ENERGY EFFIC. FOR MONTH TOTAL NET POWER PRODUCED FOR MONTH.... TOTAL SUN ENERGY FOR THE MONTH........ SYSTEM NET EFFICIENCY FOR THE MONTH ..
173.10 HOURS

0.00 HOURS

0.0000

$\begin{array}{rl}22.80 & \mathrm{KW} \\ 36.3 & \% \\ 172.40 & \mathrm{KWHR} \\ 25.5 \% & \\ 20.8 \mathrm{KWHR} / & \text { SQ.M } \\ 98.6 \mathrm{KWHR} / & \text { SQ.M } \\ 21.1 \% & \end{array}$


DATA FOR MONTH 5 AND YEAR 1985 FOR PAD 2 AT HUNTINGTON BEACH

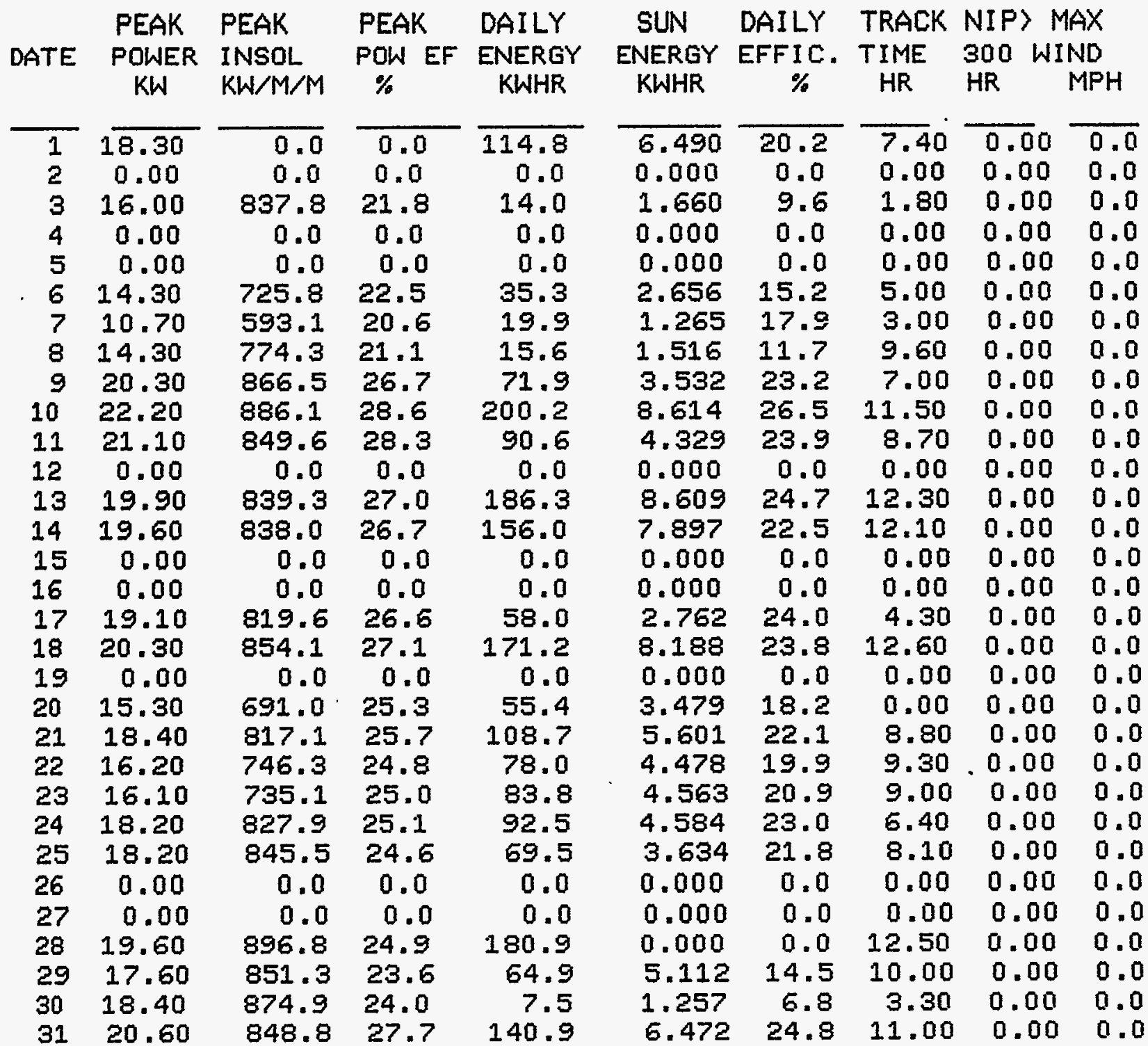

TOTAL TRACK TIME FOR MONTH......... 173.70 HOURS

TIME THAT NIP WAS ABOVE 300 W/SQ.M.... 0.00 HOURS

TRACK TIME / TIME NIP > $300 \ldots \ldots \ldots \ldots .0 .0000$

MAXIMUM DAILY NET POWER ........... $22.20 \mathrm{KW}$

MAX. DAILY NET POWER EFFIC. FOR MONTH $28.6 \%$

MAXIMUM DAILY NET ENERGY .......... 200.20 KWHR

MAX. DAILY NET ENERGY EFFIC. FOR MONTH $26.5 \%$

TOTAL NET POWER PRODUCED FOR MONTH.... $20.9 \mathrm{KWHR/}$ SQ.M

TOTAL SUN ENERGY FOR THE MONTH....... 96.7 KWHR/ SQ.M

SYSTEM NET EFFICIENCY FOR THE MONTH .. $21.6 \%$ 
DATA FOR MONTH 6 AND YEAR 1985 FOR PAD 2 AT HUNTINGTON BEACH

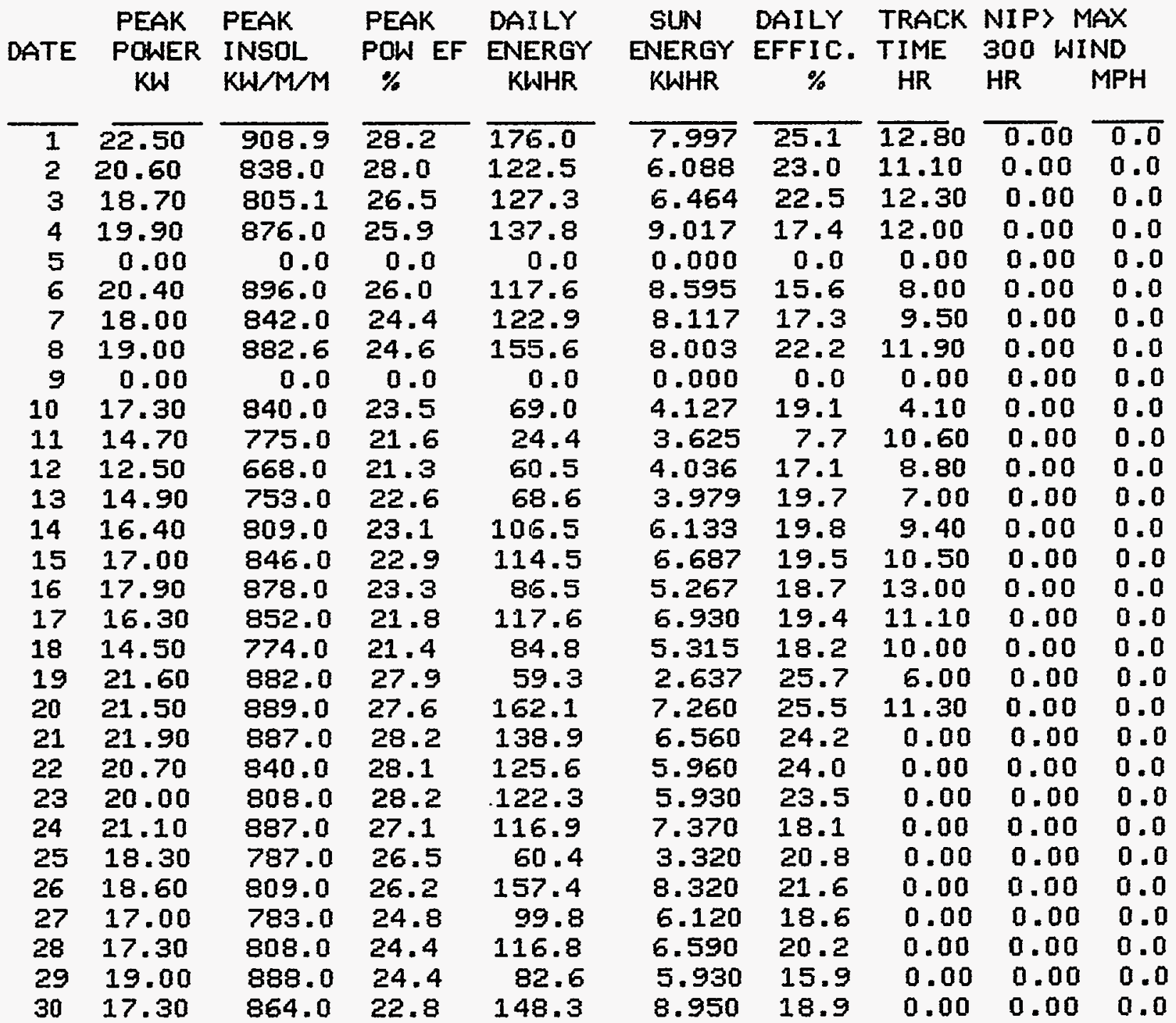

TOTAL TRACK TIME FOR MONTH. . . . . . . . . TIME THAT NIP WAS ABOVE 300 W/SQ.M.... TRACK TIME / TIME NIP > $300 \ldots . . . \ldots$ MAXIMUM DAILY NET POWER ............... MAX. DAILY NET POWER EFFIC. FOR MONTH MAXIMUM DAILY NET ENERGY ............. MAX. DAILY NET ENERGY EFFIC. FOR MONTH TOTAL NET POWER PRODUCED FOR MONTH.... TOTAL SUN ENERGY FOR THE MONTH........ SYSTEM NET EFFICIENCY FOR THE MONTH ..
179.40 HOURS 0.00 HOURS

0.0000

$\begin{array}{rl}22.50 & \mathrm{KW} \\ 28.2 & \% \\ 176.00 & \mathrm{KWHR} \\ 25.7 & \% \\ 35.2 & \mathrm{KWHR} / \mathrm{SQ.M} \\ 175.3 & \mathrm{KWHR} / \mathrm{SQ.M} \\ 20.1 \% & \end{array}$


DATA FOR MONTH 7 AND YEAR 1985 FOR PAD 2 AT HUNTINGTON BEACH

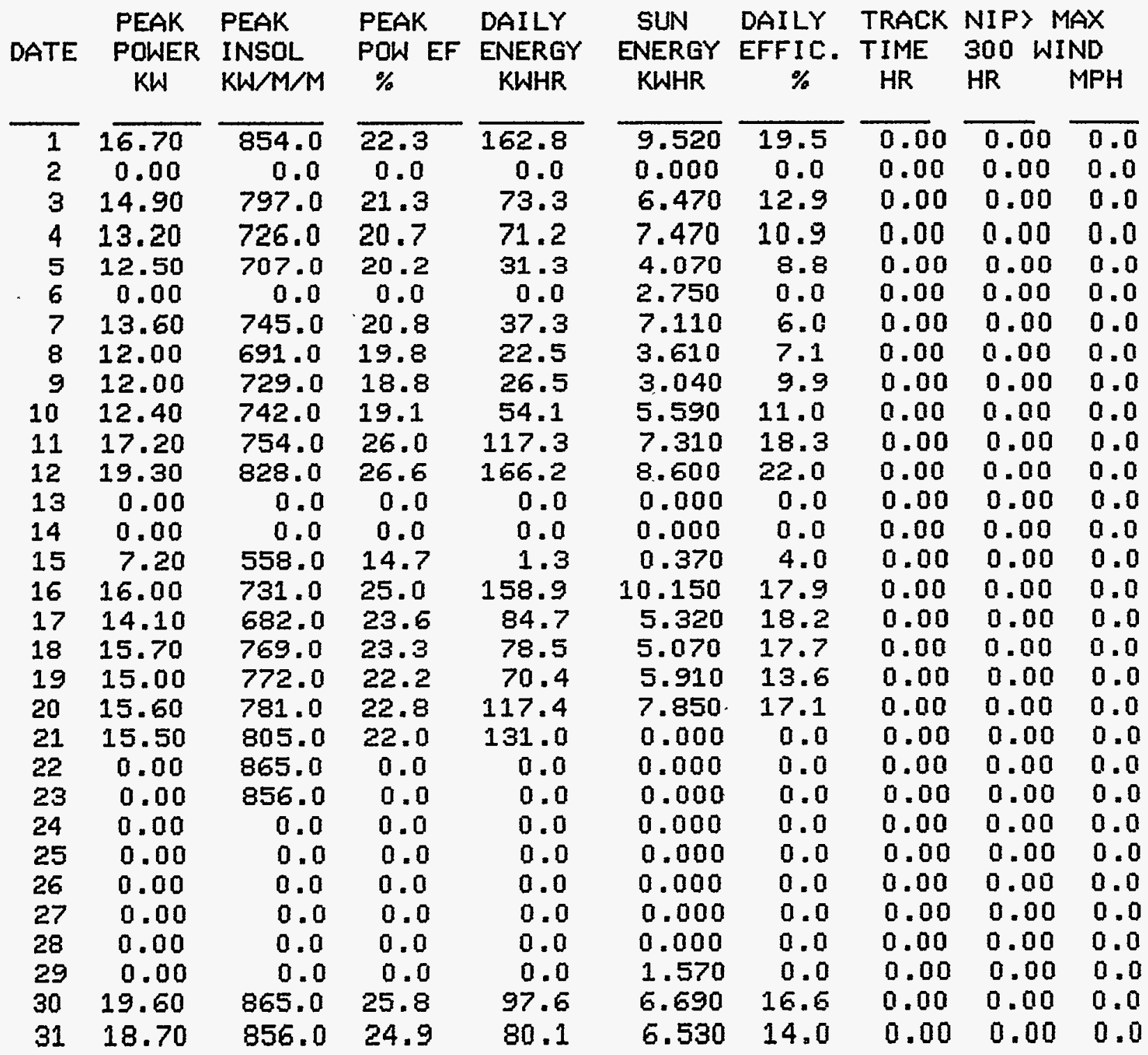

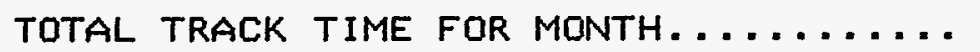

TIME THAT NIP WAS ABOVE $300 \mathrm{~W} / \mathrm{SQ} . \mathrm{M} . .$.

TRACK TIME / TIME NIP > $300 \ldots . . \ldots \ldots$

$\begin{aligned} & 0.00 \text { HOURS } \\ & 0.00 \text { HOURS } \\ & 0.0000 \\ & 19.60 \mathrm{KW} \\ & 26.6 \% \\ & 166.20 \mathrm{KWHR} \\ & 22.0 \% \\ & 16.6 \mathrm{KWHR} / \mathrm{SQ.M} \\ & 115.0 \mathrm{KWHR} / \mathrm{SQ.M} \\ & 14.4 \%\end{aligned}$

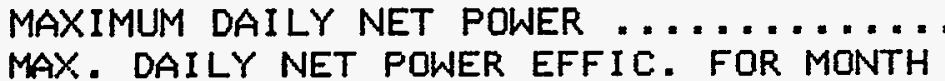

MAXIMUM DAILY NET ENERGY $\ldots \ldots \ldots \ldots . . . . .$.

MAX. DAILY NET ENERGY EFFIC. FOR MONTH

TOTAL NET POWER PRODUCED FOR MONTH....

TOTAL SUN ENERGY FOR THE MONTH.......

SYSTEM NET EFFICIENCY FOR THE MONTH ..

$14.4 \%$ 
DATA FOR MONTH 8 AND YEAR 1985 FOR PAD 2 AT HUNTINGTON BEACH

\begin{tabular}{|c|c|c|c|c|c|c|c|c|c|}
\hline DATE & $\begin{array}{l}\text { PEAK } \\
\text { POWER } \\
\text { KW }\end{array}$ & $\begin{array}{l}\text { PEAK } \\
\text { INSOL } \\
\mathrm{KW} / \mathrm{M} / \mathrm{M}\end{array}$ & $\begin{array}{l}\text { PEAK } \\
\text { POW EF } \\
\%\end{array}$ & $\begin{array}{c}\text { DAILY } \\
\text { ENERGY } \\
\text { KWHR }\end{array}$ & $\begin{array}{l}\text { SUN } \\
\text { ENERGY } \\
\text { KWHR }\end{array}$ & $\begin{array}{c}\text { DAILY } \\
\text { EFFIC. } \\
\%\end{array}$ & $\begin{array}{l}\text { TRACK } \\
\text { TIME } \\
\text { HR }\end{array}$ & $\begin{array}{l}\text { NIP> } \\
300 W \\
H R\end{array}$ & $\begin{array}{l}1 A X \\
\text { MD } \\
\text { MPH }\end{array}$ \\
\hline $\begin{array}{l}1 \\
2 \\
3 \\
4 \\
5 \\
6 \\
7 \\
8 \\
9 \\
10 \\
11 \\
12 \\
13 \\
14 \\
15 \\
16 \\
17 \\
18 \\
19 \\
20 \\
21 \\
22 \\
23 \\
24 \\
25 \\
26 \\
27 \\
28 \\
29 \\
30 \\
31\end{array}$ & $\begin{array}{r}20.00 \\
19.90 \\
17.80 \\
19.00 \\
0.00 \\
16.70 \\
17.00 \\
16.40 \\
20.40 \\
19.40 \\
17.30 \\
19.30 \\
17.60 \\
19.60 \\
19.20 \\
20.50 \\
16.40 \\
0.00 \\
0.00 \\
0.00 \\
0.00 \\
0.00 \\
0.00 \\
0.00 \\
0.00 \\
0.00 \\
0.00 \\
0.00 \\
0.00 \\
0.00 \\
0.00\end{array}$ & $\begin{array}{r}910.0 \\
924.0 \\
886.0 \\
903.0 \\
0.0 \\
863.0 \\
902.0 \\
856.0 \\
899.0 \\
869.0 \\
880.0 \\
882.0 \\
825.0 \\
911.0 \\
903.0 \\
844.0 \\
795.0 \\
0.0 \\
0.0 \\
0.0 \\
0.0 \\
0.0 \\
0.0 \\
0.0 \\
0.0 \\
0.0 \\
0.0 \\
0.0 \\
0.0 \\
0.0 \\
0.0\end{array}$ & $\begin{array}{r}25.1 \\
24.6 \\
22.9 \\
24.0 \\
0.0 \\
22.1 \\
21.5 \\
21.9 \\
25.9 \\
25.5 \\
22.4 \\
25.0 \\
24.3 \\
24.5 \\
24.3 \\
27.7 \\
23.5 \\
0.0 \\
0.0 \\
0.0 \\
0.0 \\
0.0 \\
0.0 \\
0.0 \\
0.0 \\
0.0 \\
0.0 \\
0.0 \\
0.0 \\
0.0 \\
0.0\end{array}$ & $\begin{array}{r}133.8 \\
139.3 \\
106.9 \\
132.4 \\
0.0 \\
150.4 \\
97.6 \\
106.9 \\
143.6 \\
124.6 \\
39.9 \\
111.7 \\
89.6 \\
108.2 \\
61.5 \\
54.2 \\
45.3 \\
0.0 \\
0.0 \\
0.0 \\
0.0 \\
0.0 \\
0.0 \\
0.0 \\
0.0 \\
0.0 \\
0.0 \\
0.0 \\
0.0 \\
0.0 \\
0.0\end{array}$ & $\begin{array}{l}6.760 \\
7.410 \\
7.940 \\
0.000 \\
0.000 \\
0.000 \\
6.850 \\
6.710 \\
9.160 \\
6.370 \\
6.040 \\
0.000 \\
4.920 \\
9.220 \\
8.620 \\
3.220 \\
3.080 \\
0.000 \\
0.000 \\
0.000 \\
0.000 \\
0.000 \\
0.000 \\
0.000 \\
0.000 \\
0.000 \\
0.000 \\
0.000 \\
0.000 \\
0.000 \\
0.000\end{array}$ & $\begin{array}{r}22.5 \\
21.4 \\
15.4 \\
0.0 \\
0.0 \\
0.0 \\
16.3 \\
18.2 \\
17.9 \\
22.3 \\
7.5 \\
0.0 \\
20.8 \\
13.4 \\
8.1 \\
19.2 \\
16.8 \\
0.0 \\
0.0 \\
0.0 \\
0.0 \\
0.0 \\
0.0 \\
0.0 \\
0.0 \\
0.0 \\
0.0 \\
0.0 \\
0.0 \\
0.0 \\
0.0\end{array}$ & $\begin{array}{l}0.00 \\
0.00 \\
0.00 \\
0.00 \\
0.00 \\
0.00 \\
0.00 \\
0.00 \\
0.00 \\
0.00 \\
0.00 \\
0.00 \\
0.00 \\
0.00 \\
0.00 \\
0.00 \\
0.00 \\
0.00 \\
0.00 \\
0.00 \\
0.00 \\
0.00 \\
0.00 \\
0.00 \\
0.00 \\
0.00 \\
0.00 \\
0.00 \\
0.00 \\
0.00 \\
0.00\end{array}$ & $\begin{array}{l}0.00 \\
0.00 \\
0.00 \\
0.00 \\
0.00 \\
0.00 \\
0.00 \\
0.00 \\
0.00 \\
0.00 \\
0.00 \\
0.00 \\
0.00 \\
0.00 \\
0.00 \\
0.00 \\
0.00 \\
0.00 \\
0.00 \\
0.00 \\
0.00 \\
0.00 \\
0.00 \\
0.00 \\
0.00 \\
0.00 \\
0.00 \\
0.00 \\
0.00 \\
0.00 \\
0.00\end{array}$ & $\begin{array}{l}0.0 \\
0.0 \\
0.0 \\
0.0 \\
0.0 \\
0.0 \\
0.0 \\
0.0 \\
0.0 \\
0.0 \\
0.0 \\
0.0 \\
0.0 \\
0.0 \\
0.0 \\
0.0 \\
0.0 \\
0.0 \\
0.0 \\
0.0 \\
0.0 \\
0.0 \\
0.0 \\
0.0 \\
0.0 \\
0.0 \\
0.0 \\
0.0 \\
0.0 \\
0.0 \\
0.0\end{array}$ \\
\hline
\end{tabular}

TOTAL TRACK TIME FOR MONTH.......... TIME THAT NIP WAS ABOVE $300 \mathrm{~W} / \mathrm{SQ} . \mathrm{M} . .$. TRACK TIME / TIME NIP > $300 \ldots \ldots \ldots \ldots$ MAXIMUM DAILY NET POWER . . . . . . . MAX. DAILY NET POWER EFFIC. FOR MONTH MAXIMUM DAILY NET ENERGY ........... MAX. DAILY NET ENERGY EFFIC. FOR MONTH TOTAL NET POWER PRODUCED FOR MONTH.... TOTAL SUN ENERGY FOR THE MONTH........ SYSTEM NET EFFICIENCY FOR THE MONTH ..

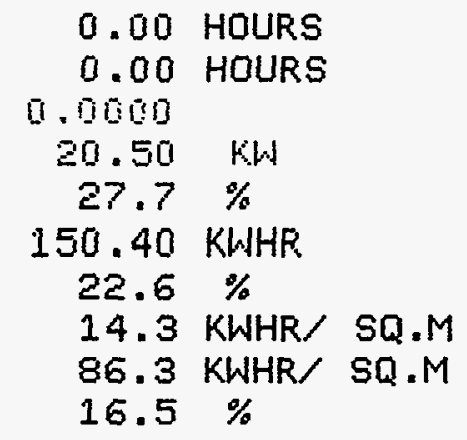


DATA FOR MONTH 9 AND YEAR 1985 FOR PAD 2 AT HUNTINGTON BEACH

\begin{tabular}{|c|c|c|c|c|c|c|c|c|c|}
\hline $\overrightarrow{A T}$ & $\begin{array}{l}\text { PEAK } \\
\text { POWER } \\
\text { KW }\end{array}$ & $\begin{array}{l}\text { PEAK } \\
\text { INSOL } \\
\text { KW } / M / M\end{array}$ & $\begin{array}{l}\text { PEAK } \\
\text { POW EF } \\
\%\end{array}$ & $\begin{array}{l}\text { OAILY } \\
\text { ENERGY } \\
\text { KWHR }\end{array}$ & $\begin{array}{l}\text { SUN } \\
\text { ENERGY } \\
\text { KWHR }\end{array}$ & $\begin{array}{c}\text { AILY } \\
\text { FFIC. } \\
\%\end{array}$ & $\begin{array}{l}\text { TRACK } \\
\text { TIME } \\
\text { HR }\end{array}$ & $\begin{array}{l}\text { NIP> } \\
300 W I \\
\text { HR }\end{array}$ & $\begin{array}{l}\text { AX } \\
\text { ND } \\
\text { MPH }\end{array}$ \\
\hline $\begin{array}{r}1 \\
2 \\
3 \\
4 \\
5 \\
6 \\
7 \\
8 \\
9 \\
10 \\
11 \\
12 \\
13 \\
14 \\
15 \\
16 \\
17 \\
18 \\
19 \\
20 \\
21 \\
22 \\
23 \\
24 \\
25 \\
26 \\
27 \\
28 \\
29 \\
30\end{array}$ & $\begin{array}{r}0.00 \\
0.00 \\
0.00 \\
0.00 \\
0.00 \\
14.20 \\
0.00 \\
0.00 \\
19.80 \\
0.00 \\
18.60 \\
23.40 \\
0.00 \\
20.10 \\
18.40 \\
17.60 \\
18.30 \\
0.00 \\
0.00 \\
0.00 \\
0.00 \\
0.00 \\
0.00 \\
0.00 \\
0.00 \\
0.00 \\
0.00 \\
0.00 \\
0.00 \\
0.00\end{array}$ & $\begin{array}{r}0.0 \\
0.0 \\
0.0 \\
0.0 \\
0.0 \\
674.0 \\
771.0 \\
821.0 \\
878.0 \\
0.0 \\
868.0 \\
889.0 \\
0.0 \\
705.0 \\
839.0 \\
808.0 \\
811.0 \\
832.0 \\
890.0 \\
0.0 \\
0.0 \\
0.0 \\
797.0 \\
878.0 \\
0.0 \\
0.0 \\
0.0 \\
0.0 \\
0.0 \\
0.0\end{array}$ & $\begin{array}{r}0.0 \\
0.0 \\
0.0 \\
0.0 \\
0.0 \\
24.0 \\
0.0 \\
0.0 \\
25.7 \\
0.0 \\
24.4 \\
30.0 \\
0.0 \\
32.5 \\
25.0 \\
24.8 \\
25.7 \\
0.0 \\
0.0 \\
0.0 \\
0.0 \\
0.0 \\
0.0 \\
0.0 \\
0.0 \\
0.0 \\
0.0 \\
0.0 \\
0.0 \\
0.0\end{array}$ & $\begin{array}{r}0.0 \\
0.0 \\
0.0 \\
0.0 \\
0.0 \\
0.0 \\
0.0 \\
0.0 \\
41.9 \\
0.0 \\
52.2 \\
119.6 \\
0.0 \\
154.5 \\
120.3 \\
66.8 \\
48.1 \\
89.7 \\
155.0 \\
0.0 \\
0.0 \\
0.0 \\
0.0 \\
69.0 \\
0.0 \\
0.0 \\
0.0 \\
0.0 \\
0.0 \\
0.0\end{array}$ & $\begin{array}{l}0.000 \\
0.000 \\
0.000 \\
0.000 \\
0.000 \\
1.150 \\
0.000 \\
0.000 \\
6.610 \\
0.000 \\
7.390 \\
5.660 \\
0.000 \\
0.000 \\
7.820 \\
4.210 \\
4.810 \\
0.000 \\
3.650 \\
8.060 \\
7.490 \\
8.110 \\
6.210 \\
7.230 \\
0.000 \\
0.000 \\
0.000 \\
0.000 \\
0.000 \\
0.000\end{array}$ & $\begin{array}{r}0.0 \\
0.0 \\
0.0 \\
0.0 \\
0.0 \\
0.0 \\
0.0 \\
0.0 \\
7.2 \\
0.0 \\
8.1 \\
24.1 \\
0.0 \\
0.0 \\
17.5 \\
18.1 \\
11.4 \\
0.0 \\
48.4 \\
0.0 \\
0.0 \\
0.0 \\
0.0 \\
10.9 \\
0.0 \\
0.0 \\
0.0 \\
0.0 \\
0.0 \\
0.0\end{array}$ & $\begin{array}{l}0.00 \\
0.00 \\
0.00 \\
0.00 \\
0.00 \\
0.00 \\
0.00 \\
0.00 \\
0.00 \\
0.00 \\
0.00 \\
0.00 \\
0.00 \\
0.00 \\
0.00 \\
0.00 \\
0.00 \\
0.00 \\
0.00 \\
0.00 \\
0.00 \\
0.00\end{array}$ & $\begin{array}{l}0.00 \\
0.00 \\
0.00 \\
0.00 \\
0.00 \\
0.00 \\
0.00 \\
0.00 \\
0.00 \\
0.00 \\
0.00 \\
0.00 \\
0.00 \\
0.00 \\
0.00 \\
0.00 \\
0.00 \\
0.00 \\
0.00 \\
0.00 \\
0.00 \\
0.00 \\
0.00 \\
0.00 \\
0.00 \\
0.00 \\
0.00 \\
0.00 \\
0.00 \\
0.00\end{array}$ & $\begin{array}{l}0.0 \\
0.0 \\
0.0 \\
0.0 \\
0.0 \\
0.0 \\
0.0 \\
0.0 \\
0.0 \\
0.0 \\
0.0 \\
0.0 \\
0.0 \\
0.0 \\
0.0 \\
0.0 \\
0.0 \\
0.0 \\
0.0 \\
0.0 \\
0.0 \\
0.0 \\
0.0 \\
0.0 \\
0.0 \\
0.0 \\
0.0 \\
0.0 \\
0.0 \\
0.0\end{array}$ \\
\hline
\end{tabular}

TOTAL TRACK TIME FOR MONTH.......... TIME THAT NIP WAS ABOVE 300 W/SQ.M.... TRACK TIME / TIME NIP > $300 \ldots . . . \ldots$ MAXIMUM DAILY NET POWER ................ MAX. DAILY NET POWER EFFIC. FOR MONTH MAXIMUM DAILY NET ENERGY ............. MAX. DAILY NET ENERGY EFF.IC. FOR MONTH
TOTAL NET POWER PRODUCED FOR MONTH.... TOTAL SUN ENERGY FOR THE MONTH........ SYSTEM NET EFFICIENCY FOR THE MONTH ..

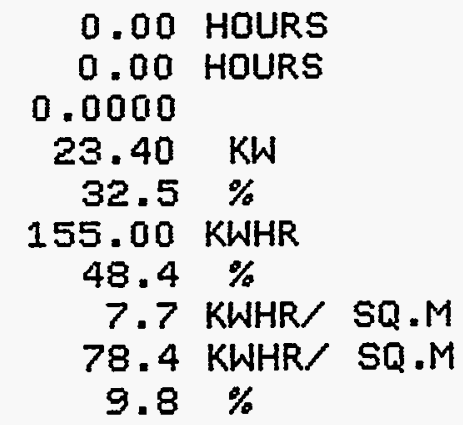


DATA FOR MONTH 10 AND YEAR 1985 FOR PAD 2 AT HUNTINGTON BEACH

\begin{tabular}{|c|c|c|c|c|c|c|c|c|c|}
\hline ATE & $\begin{array}{l}\text { PEAK } \\
\text { OWWR } \\
\text { KW }\end{array}$ & $\begin{array}{l}\text { PEAK } \\
\text { INSOL } \\
\mathrm{KW} / \mathrm{M} / \mathrm{M}\end{array}$ & $\begin{array}{l}\text { PEAK } \\
\text { OW EF } \\
\%\end{array}$ & $\begin{array}{c}\text { DAILY } \\
\text { ENERGY } \\
\text { KWHR }\end{array}$ & $\begin{array}{l}\text { SUN } \\
\text { ENERGY } \\
\text { KWHR }\end{array}$ & $\begin{array}{c}\text { DAILY } \\
\text { EFFIC. } \\
\%\end{array}$ & $\begin{array}{l}\text { TRACK } \\
\text { TIME } \\
\text { HR }\end{array}$ & $\begin{array}{l}\text { NIP> } \\
300 \text { WI } \\
\text { HR }\end{array}$ & $\begin{array}{l}\text { IAX } \\
\text { ND } \\
\text { MPH }\end{array}$ \\
\hline $\begin{array}{r}1 \\
2 \\
3 \\
4 \\
5 \\
6 \\
7 \\
8 \\
9 \\
10 \\
11 \\
12 \\
13 \\
14 \\
15 \\
16 \\
17 \\
18 \\
19 \\
20 \\
21 \\
22 \\
23 \\
24 \\
25 \\
26 \\
27 \\
28 \\
29 \\
30 \\
31\end{array}$ & $\begin{array}{l}0.00 \\
0.00 \\
0.00 \\
0.00 \\
0.00 \\
0.00 \\
0.00 \\
0.00 \\
0.00 \\
0.00 \\
0.00 \\
0.00 \\
0.00 \\
0.00 \\
0.00 \\
0.00 \\
0.00 \\
0.00 \\
0.00 \\
0.00 \\
0.00 \\
0.00 \\
0.00 \\
0.00 \\
0.00 \\
0.00 \\
0.00 \\
0.00 \\
0.00 \\
0.00 \\
0.00\end{array}$ & $\begin{array}{r}754.0 \\
829.0 \\
0.0 \\
794.0 \\
784.0 \\
0.0 \\
0.0 \\
775.0 \\
847.0 \\
892.0 \\
0.0 \\
0.0 \\
0.0 \\
911.0 \\
926.0 \\
843.0 \\
0.0 \\
0.0 \\
0.0 \\
0.0 \\
0.0 \\
0.0 \\
0.0 \\
0.0 \\
0.0 \\
0.0 \\
0.0 \\
0.0 \\
0.0 \\
0.0 \\
0.0\end{array}$ & $\begin{array}{l}0.0 \\
0.0 \\
0.0 \\
0.0 \\
0.0 \\
0.0 \\
0.0 \\
0.0 \\
0.0 \\
0.0 \\
0.0 \\
0.0 \\
0.0 \\
0.0 \\
0.0 \\
0.0 \\
0.0 \\
0.0 \\
0.0 \\
0.0 \\
0.0 \\
0.0 \\
0.0 \\
0.0 \\
0.0 \\
0.0 \\
0.0 \\
0.0 \\
0.0 \\
0.0 \\
0.0\end{array}$ & $\begin{array}{r}109.0 \\
125.0 \\
0.0 \\
0.0 \\
55.0 \\
0.0 \\
0.0 \\
45.0 \\
48.0 \\
0.0 \\
0.0 \\
0.0 \\
0.0 \\
91.0 \\
132.0 \\
30.0 \\
77.5 \\
56.4 \\
169.0 \\
0.0 \\
0.0 \\
0.0 \\
0.0 \\
140.5 \\
134.3 \\
43.2 \\
0.0 \\
0.0 \\
58.8 \\
0.0 \\
15.0\end{array}$ & $\begin{array}{l}3.820 \\
0.000 \\
0.000 \\
1.020 \\
3.370 \\
0.000 \\
0.000 \\
2.790 \\
3.230 \\
7.330 \\
0.000 \\
0.000 \\
0.000 \\
7.200 \\
8.200 \\
1.970 \\
3.690 \\
3.860 \\
0.000 \\
0.000 \\
0.000 \\
0.000 \\
5.270 \\
5.190 \\
5.490 \\
3.010 \\
1.270 \\
0.000 \\
2.400 \\
0.560 \\
4.690\end{array}$ & $\begin{array}{r}32.5 \\
0.0 \\
0.0 \\
0.0 \\
18.6 \\
0.0 \\
0.0 \\
18.4 \\
17.0 \\
0.0 \\
0.0 \\
0.0 \\
0.0 \\
14.4 \\
18.4 \\
17.4 \\
24.0 \\
16.7 \\
0.0 \\
0.0 \\
0.0 \\
0.0 \\
0.0 \\
30.9 \\
27.9 \\
16.4 \\
0.0 \\
0.0 \\
27.9 \\
0.0 \\
3.6\end{array}$ & $\begin{array}{l}0.00 \\
0.00 \\
0.00 \\
0.00 \\
0.00 \\
0.00 \\
0.00 \\
0.00 \\
0.00 \\
0.00 \\
0.00 \\
0.00 \\
0.00 \\
0.00 \\
0.00 \\
0.00 \\
0.00 \\
0.00 \\
0.00 \\
0.00 \\
0.00 \\
0.00 \\
0.00 \\
0.00 \\
0.00 \\
0.00 \\
0.00 \\
0.00 \\
0.00 \\
0.00 \\
0.00\end{array}$ & $\begin{array}{l}0.00 \\
0.00 \\
0.00 \\
0.00 \\
0.00 \\
0.00 \\
0.00 \\
0.00 \\
0.00 \\
0.00 \\
0.00 \\
0.00 \\
0.00 \\
0.00 \\
0.00 \\
0.00 \\
0.00 \\
0.00 \\
0.00 \\
0.00 \\
0.00 \\
0.00 \\
0.00 \\
0.00 \\
0.00 \\
0.00 \\
0.00 \\
0.00 \\
0.00 \\
0.00 \\
0.00\end{array}$ & $\begin{array}{l}\text { U.0 } \\
0.0 \\
0.0 \\
0.0 \\
0.0 \\
0.0 \\
0.0 \\
0.0 \\
0.0 \\
0.0 \\
0.0 \\
0.0 \\
0.0 \\
0.0 \\
0.0 \\
0.0 \\
0.0 \\
0.0 \\
0.0 \\
0.0 \\
0.0 \\
0.0 \\
0.0 \\
0.0 \\
0.0 \\
0.0 \\
0.0 \\
0.0 \\
0.0 \\
0.0 \\
0.0\end{array}$ \\
\hline
\end{tabular}

TOTAL TRACK TIME FOR MONTH........... TIME THAT NIP WAS ABOVE 300 W/SQ.M.... TRACK TIME / TIME NIP > $300, \ldots \ldots \ldots$. MAXIMUM DAILY NET POWER $\ldots \ldots \ldots \ldots$ MAX. DAILY NET POWER EFFIC. FOR MONTH MAXIMUM DAILY NET ENERGY $\ldots \ldots \ldots \ldots \ldots$ MAX. DAILY NET ENERGY EFFIC. FOR MONTH TOTAL NET POWER PRODUCED FOR MONTH.... TOTAL SUN ENERGY FOR THE MONTH....... SYSTEM NET EFFICIENCY FOR THE MONTH ..

\author{
0.00 HOURS \\ 0.00 HOURS \\ 0.0000 \\ $0.00 \mathrm{KW}$ \\ $0.0 \%$ \\ $169.00 \mathrm{KWHR}$ \\ $32.5 \%$ \\ 11.8 KWHR/ SQ.M \\ 74.4 KWHR/ SQ.M \\ $15.9 \%$
}


DATA FOR MONTH 11 AND YEAR 1985 FOR PAD 2 AT HUNTINGTON BEACH

\begin{tabular}{|c|c|c|c|c|c|c|c|c|c|}
\hline ATE & $\begin{array}{l}\text { PEAK } \\
\text { POWER } \\
\text { KW }\end{array}$ & $\begin{array}{l}\text { PEAK } \\
\text { INSOL } \\
\mathrm{KW} / \mathrm{M} / \mathrm{M}\end{array}$ & $\begin{array}{l}\text { PEAK } \\
\text { POW EF } \\
\%\end{array}$ & $\begin{array}{c}\text { DAILY } \\
\text { ENERGY } \\
\text { KWHR }\end{array}$ & $\begin{array}{l}\text { SUN } \\
\text { ENERGY } \\
\text { KWHR }\end{array}$ & $\begin{array}{c}\text { DAILY } \\
\text { EFFIC. } \\
\frac{\%}{4}\end{array}$ & $\begin{array}{l}\text { TRACK } \\
\text { TIME } \\
\text { HR }\end{array}$ & $\begin{array}{l}\text { NIP> } \\
300 \text { W } \\
H R\end{array}$ & $\begin{array}{c}\text { MAX } \\
\text { NIND } \\
\text { MPH }\end{array}$ \\
\hline $\begin{array}{l}1 \\
2 \\
3 \\
4 \\
5 \\
6 \\
7 \\
8 \\
9 \\
10 \\
11 \\
12 \\
13 \\
14 \\
15 \\
16 \\
17 \\
18 \\
19 \\
20 \\
21 \\
22 \\
23 \\
24 \\
25 \\
26 \\
27 \\
28 \\
29 \\
30\end{array}$ & $\begin{array}{l}0.00 \\
0.00 \\
0.00 \\
0.00 \\
0.00 \\
0.00 \\
0.00 \\
0.00 \\
0.00 \\
0.00 \\
0.00 \\
0.00 \\
0.00 \\
0.00 \\
0.00 \\
0.00 \\
0.00 \\
0.00 \\
0.00 \\
0.00 \\
0.00 \\
0.00 \\
0.00 \\
0.00 \\
0.00 \\
0.00 \\
0.00 \\
0.00 \\
0.00 \\
0.00\end{array}$ & $\begin{array}{l}0.0 \\
0.0 \\
0.0 \\
0.0 \\
0.0 \\
0.0 \\
0.0 \\
0.0 \\
0.0 \\
0.0 \\
0.0 \\
0.0 \\
0.0 \\
0.0 \\
0.0 \\
0.0 \\
0.0 \\
0.0 \\
0.0 \\
0.0 \\
0.0 \\
0.0 \\
0.0 \\
0.0 \\
0.0 \\
0.0 \\
0.0 \\
0.0 \\
0.0 \\
0.0\end{array}$ & $\begin{array}{l}0.0 \\
0.0 \\
0.0 \\
0.0 \\
0.0 \\
0.0 \\
0.0 \\
0.0 \\
0.0 \\
0.0 \\
0.0 \\
0.0 \\
0.0 \\
0.0 \\
0.0 \\
0.0 \\
0.0 \\
0.0 \\
0.0 \\
0.0 \\
0.0 \\
0.0 \\
0.0 \\
0.0 \\
0.0 \\
0.0 \\
0.0 \\
0.0 \\
0.0 \\
0.0\end{array}$ & $\begin{array}{r}54.5 \\
191.6 \\
0.0 \\
0.0 \\
84.4 \\
110.6 \\
24.3 \\
0.0 \\
56.0 \\
0.0 \\
0.0 \\
0.0 \\
11.5 \\
0.0 \\
0.0 \\
0.0 \\
0.0 \\
0.0 \\
85.0 \\
92.4 \\
120.2 \\
358.8 \\
0.0 \\
0.0 \\
0.0 \\
40.6 \\
40.1 \\
18.0 \\
0.0 \\
0.0\end{array}$ & $\begin{array}{l}0.000 \\
0.000 \\
0.000 \\
0.000 \\
3.750 \\
0.000 \\
0.000 \\
0.000 \\
0.000 \\
0.000 \\
0.000 \\
0.000 \\
6.800 \\
6.620 \\
7.070 \\
4.460 \\
5.310 \\
0.000 \\
5.620 \\
5.400 \\
0.000 \\
0.000 \\
0.000 \\
0.000 \\
0.000 \\
2.360 \\
1.900 \\
1.930 \\
0.810 \\
0.000\end{array}$ & $\begin{array}{r}0.0 \\
0.0 \\
0.0 \\
0.0 \\
25.7 \\
0.0 \\
0.0 \\
0.0 \\
0.0 \\
0.0 \\
0.0 \\
0.0 \\
1.9 \\
0.0 \\
0.0 \\
0.0 \\
0.0 \\
0.0 \\
17.3 \\
19.5 \\
0.0 \\
0.0 \\
0.0 \\
0.0 \\
0.0 \\
19.6 \\
24.1 \\
10.6 \\
0.0 \\
0.0\end{array}$ & $\begin{array}{l}0.00 \\
0.00 \\
0.00 \\
0.00 \\
0.00 \\
0.00 \\
0.00 \\
0.00 \\
0.00 \\
0.00 \\
0.00 \\
0.00 \\
0.00 \\
0.00 \\
0.00 \\
0.00 \\
0.00 \\
0.00 \\
0.00 \\
0.00 \\
0.00 \\
0.00 \\
0.00 \\
0.00 \\
0.00 \\
0.00 \\
0.00 \\
0.00 \\
0.00 \\
0.00\end{array}$ & $\begin{array}{l}0.00 \\
0.00 \\
0.00 \\
0.00 \\
0.00 \\
0.00 \\
0.00 \\
0.00 \\
0.00 \\
0.00 \\
0.00 \\
0.00 \\
0.00 \\
0.00 \\
0.00 \\
0.00 \\
0.00 \\
0.00 \\
0.00 \\
0.00 \\
0.00 \\
0.00 \\
0.00 \\
0.00 \\
0.00 \\
0.00 \\
0.00 \\
0.00 \\
0.00 \\
0.00\end{array}$ & $\begin{array}{l}0.0 \\
0.0 \\
0.0 \\
0.0 \\
0.0 \\
0.0 \\
0.0 \\
0.0 \\
0.0 \\
0.0 \\
0.0 \\
0.0 \\
0.0 \\
0.0 \\
0.0 \\
0.0 \\
0.0 \\
0.0 \\
0.0 \\
0.0 \\
0.0 \\
0.0 \\
0.0 \\
0.0 \\
0.0 \\
0.0 \\
0.0 \\
0.0 \\
0.0 \\
0.0\end{array}$ \\
\hline
\end{tabular}

\footnotetext{
TOTAL TRACK TIME FOR MONTH.......... 0.00 HOURS

TIME THAT NIP WAS ABQUE 300 W/SQ.M.... 0.00 HOURS

TRACK TIME / TIME NIP > 300........ 0.0000

MAXIMUM DAILY NET POWER .......... $0.00 \mathrm{KW}$

MAX. DAILY NET POWER EFFIC. FOR MONTH $0.0 \%$

MAXIMUM DAILY NET ENERGY .......... $358.80 \mathrm{KWHR}$

MAX. DAILY NET ENERGY EFFIC. FOR MONTH $25.7 \%$

TOTAL NET POWER PRODUCED FOR MONTH.... 4.2 KWHR/ SQ.M

TOTAL SUN ENERGY FOR THE MONTH....... 52.0 KWHR/ SQ.M

SYSTEM NET EFFICIENCY FOR THE MONTH .. $8.2 \%$
} 
DATA FOR MONTH 12 AND YEAR 1985 FOR PAD 2 AT HUNTINGTON BEACH

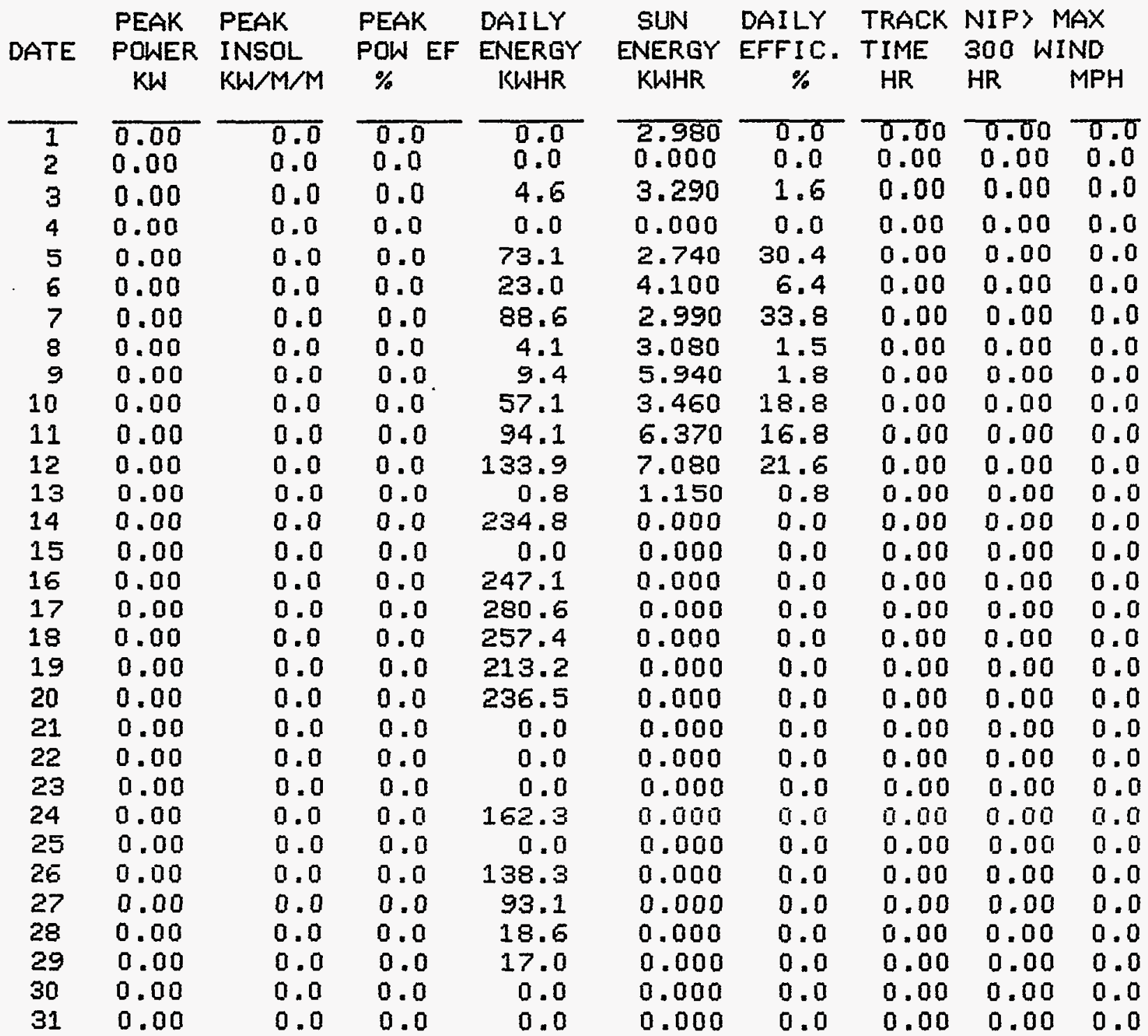

TOTAL TRACK TIME FOR MONTH.......... TIME THAT NIP WAS ABOVE 300 W/SQ.M.... TRACK TIME / TIME NIP > $300 \ldots \ldots \ldots \ldots$

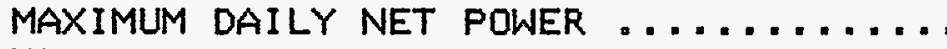
MAX. DAILY NET POWER EFFIC. FOR MONTH MAXIMUM DAILY NET ENERGY ............ MAX. DAILY NET ENERGY EFFIC. FOR MONTH TOTAL NET POWER PRODUCED FOR MONTH.... TOTAL SUN ENERGY FOR THE MONTH........ SYSTEM NET EFFICIENCY FOR THE MONTH :.

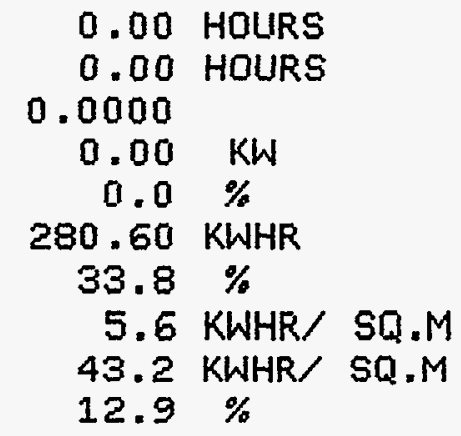




\begin{tabular}{|c|c|c|c|c|c|c|c|c|c|}
\hline & FOR $N$ & H & ND $Y$ & 6 & JR PAD & 2 & IT TNGT & $N$ & $H$ \\
\hline TTE & $\begin{array}{l}\text { PEAK } \\
\text { POWER } \\
K W\end{array}$ & $\begin{array}{l}\text { PEAK } \\
\text { INSOL } \\
\mathrm{KW} / \mathrm{M} / \mathrm{M}\end{array}$ & $\begin{array}{l}\text { PEAK } \\
\text { POW EF } \\
\%\end{array}$ & $\begin{array}{c}\text { DAILY } \\
\text { ENERGY } \\
\text { KWHR }\end{array}$ & $\begin{array}{l}\text { SUN } \\
\text { ENERGY } \\
\text { KWHR }\end{array}$ & $\begin{array}{c}\text { DAILY } \\
\text { EFFIC. } \\
\%\end{array}$ & $\begin{array}{c}\text { TRACK } \\
\text { TIME } \\
\text { HR }\end{array}$ & $\begin{array}{l}\text { NIP> M } \\
300 \text { WI } \\
H R\end{array}$ & $\begin{array}{l}\text { MAX } \\
\text { IND } \\
\text { MPH }\end{array}$ \\
\hline $\begin{array}{l}1 \\
2 \\
3 \\
4 \\
5 \\
6 \\
7 \\
8 \\
9 \\
10 \\
11 \\
12 \\
13 \\
14 \\
15 \\
16 \\
17 \\
18 \\
19 \\
20 \\
21 \\
22 \\
23 \\
24 \\
25 \\
26 \\
27 \\
28 \\
29 \\
30 \\
31\end{array}$ & $\begin{array}{r}16.50 \\
20.80 \\
0.00 \\
0.00 \\
19.30 \\
16.90 \\
18.40 \\
17.70 \\
0.00 \\
0.00 \\
0.00 \\
16.00 \\
14.30 \\
0.00 \\
0.00 \\
0.00 \\
0.00 \\
0.00 \\
15.90 \\
14.20 \\
12.30 \\
7.20 \\
0.00 \\
0.00 \\
13.50 \\
9.50 \\
13.10 \\
0.00 \\
0.00 \\
0.00 \\
0.00\end{array}$ & $\begin{array}{r}738.5 \\
872.3 \\
0.0 \\
0.0 \\
906.2 \\
864.1 \\
908.7 \\
876.3 \\
0.0 \\
0.0 \\
0.0 \\
834.1 \\
765.9 \\
0.0 \\
0.0 \\
0.0 \\
0.0 \\
0.0 \\
872.1 \\
826.7 \\
755.8 \\
547.1 \\
0.0 \\
0.0 \\
788.6 \\
631.8 \\
789.1 \\
0.0 \\
0.0 \\
0.0 \\
0.0\end{array}$ & $\begin{array}{r}25.5 \\
27.2 \\
0.0 \\
0.0 \\
24.3 \\
22.3 \\
23.1 \\
23.0 \\
0.0 \\
0.0 \\
0.0 \\
21.9 \\
21.3 \\
0.0 \\
0.0 \\
0.0 \\
0.0 \\
0.0 \\
20.8 \\
19.6 \\
18.6 \\
15.0 \\
0.0 \\
0.0 \\
19.5 \\
17.2 \\
18.9 \\
0.0 \\
0.0 \\
0.0 \\
0.0\end{array}$ & $\begin{array}{r}50.2 \\
195.7 \\
0.0 \\
0.0 \\
137.9 \\
68.5 \\
102.6 \\
151.9 \\
0.0 \\
0.0 \\
0.0 \\
131.2 \\
72.7 \\
0.0 \\
0.0 \\
0.0 \\
0.0 \\
0.0 \\
106.9 \\
93.4 \\
21.9 \\
34.3 \\
0.0 \\
0.0 \\
107.1 \\
17.0 \\
98.2 \\
0.0 \\
0.0 \\
0.0 \\
0.0\end{array}$ & $\begin{array}{l}4.150 \\
9.160 \\
0.000 \\
0.000 \\
7.110 \\
6.790 \\
9.280 \\
8.730 \\
9.210 \\
0.000 \\
0.000 \\
7.470 \\
4.620 \\
2.000 \\
0.000 \\
4.480 \\
7.740 \\
7.750 \\
6.367 \\
6.170 \\
2.320 \\
3.765 \\
0.000 \\
0.000 \\
7.220 \\
1.360 \\
6.630 \\
6.420 \\
2.990 \\
2.361 \\
4.965\end{array}$ & $\begin{array}{r}13.8 \\
24.4 \\
0.0 \\
0.0 \\
22.1 \\
11.5 \\
12.0 \\
19.8 \\
0.0 \\
0.0 \\
0.0 \\
20.0 \\
17.9 \\
0.0 \\
0.0 \\
0.0 \\
0.0 \\
0.0 \\
19.2 \\
17.3 \\
10.8 \\
10.4 \\
0.0 \\
0.0 \\
16.9 \\
14.3 \\
16.9 \\
0.0 \\
0.0 \\
0.0 \\
0.0\end{array}$ & $\begin{array}{l}0.00 \\
0.00 \\
0.00 \\
0.00 \\
0.00 \\
0.00 \\
0.00 \\
0.00 \\
0.00 \\
0.00 \\
0.00 \\
0.00 \\
0.00 \\
0.00 \\
0.00 \\
0.00 \\
0.00 \\
0.00 \\
0.00 \\
0.00 \\
0.00 \\
0.00 \\
0.00 \\
0.00 \\
0.00 \\
0.00 \\
0.00 \\
0.00 \\
0.00 \\
0.00 \\
0.00\end{array}$ & $\begin{array}{l}0.00 \\
0.00 \\
0.00 \\
0.00 \\
0.00 \\
0.00 \\
0.00 \\
0.00 \\
0.00 \\
0.00 \\
0.00 \\
0.00 \\
0.00 \\
0.00 \\
0.00 \\
0.00 \\
0.00 \\
0.00\end{array}$ & $\begin{array}{l}0.0 \\
0.0 \\
0.0 \\
0.0 \\
0.0 \\
0.0 \\
0.0 \\
0.0 \\
0.0 \\
0.0 \\
0.0 \\
0.0 \\
0.0 \\
0.0 \\
0.0 \\
0.0 \\
0.0 \\
0.0 \\
0.0 \\
0.0 \\
0.0 \\
0.0 \\
0.0 \\
0.0 \\
0.0 \\
0.0 \\
0.0 \\
0.0 \\
0.0 \\
0.0 \\
0.0\end{array}$ \\
\hline
\end{tabular}

TOTAL TRACK TIME FOR MONTH.......... TIME THAT NIP WAS ABOVE 300 W/SQ.M.... TRACK TIME / TIME NIP $>300 \ldots \ldots . . .$. MAXIMUM DAILY NET POWER ... . . . . . MAX. DAILY NET POWER EFFIC. FOR MONTH MAXIMUM DAILY NET ENERGY ............. MAX. DAILY NET ENERGY EFFIC. FOR MONTH TOTAL NET POWER PRODUCED FOR MONTH.... TOTAL SUN ENERGY FOR THE MONTH......... SYSTEM NET EFFICIENCY FOR THE MONTH ..

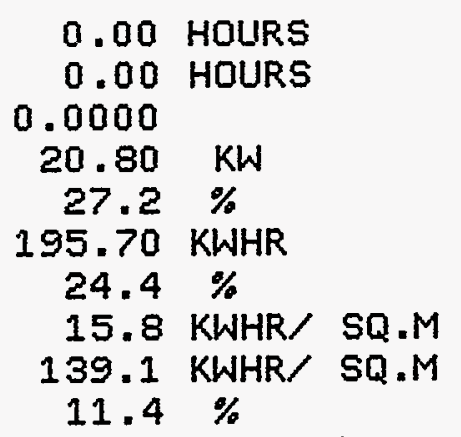


DATA FOR MONTH 4 AND YEAR 1986 FOR PAD 2 AT HUNTINGTON BEACH

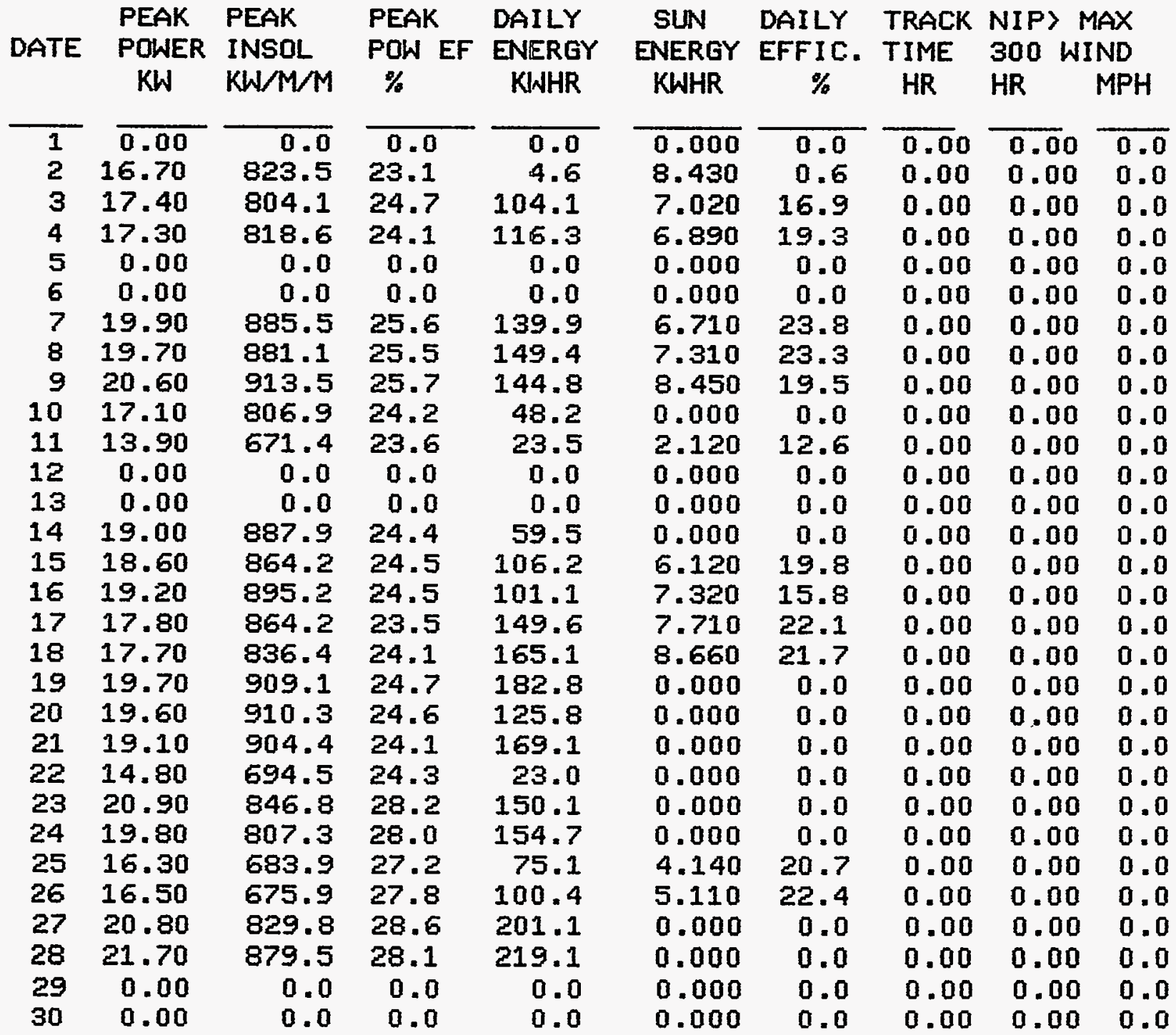

TOTAL TRACK TIME FOR MONTH. .......... TIME THAT NIP WAS ABOUE 300 W/SQ.M.... TRACK TIME / TIME NIP > 300........ MAXIMUM DAILY NET POWER ............ MAX. DAILY NET POWER EFFIC. FOR MONTH MAXIMLM DAILY NET ENERGY .......... MAX. DAILY NET ENERGY EFFIC. FOR MONTH TOTAL NET POWER PRODUCED FOR MONTH.... TOTAL SUN ENERGY FOR THE MONTH........ SYSTEM NET EFFICIENCY FOR THE MONTH ..

$\begin{array}{rl}0.00 & \text { HOURS } \\ 0.00 & \text { HOURS } \\ 0.0000 & \\ 21.70 & \mathrm{KW} \\ 28.6 & \% \\ 219.10 & \mathrm{KWHR} \\ 23.8 \% & \\ 15.7 \mathrm{KWHR} & \text { SQ.M } \\ 86.0 \mathrm{KWHR} & \text { SQ.M } \\ 18.3 \% & \end{array}$




\begin{tabular}{|c|c|c|c|c|c|c|c|c|c|}
\hline ATE & $\begin{array}{l}\text { PEAK } \\
\text { POWER } \\
\text { KW }\end{array}$ & $\begin{array}{l}\text { PEAK } \\
\text { INSOL } \\
\mathrm{KW} / \mathrm{M} / \mathrm{M}\end{array}$ & $\begin{array}{l}\text { PEAK } \\
\text { POW EF } \\
\%\end{array}$ & $\begin{array}{l}\text { DAILY } \\
\text { ENERGY } \\
\text { KWHR }\end{array}$ & $\begin{array}{l}\text { SUN } \\
\text { ENERGY } \\
\text { KWHR }\end{array}$ & $\begin{array}{c}\text { DAILY } \\
\text { EFFIC } \\
\%\end{array}$ & $\begin{array}{l}\text { TRACK } \\
\text { TIME } \\
\text { HR }\end{array}$ & $\begin{array}{l}\text { NIP> } \\
300 \text { WI } \\
\text { HR }\end{array}$ & $\begin{array}{l}\text { MAX } \\
\text { IIND } \\
\text { MPH }\end{array}$ \\
\hline $\begin{array}{l}1 \\
2 \\
3 \\
4 \\
5 \\
6 \\
7 \\
8 \\
9 \\
10 \\
11 \\
12 \\
13 \\
14 \\
15 \\
16 \\
17 \\
18 \\
19 \\
20 \\
21 \\
22 \\
23 \\
24 \\
25 \\
26 \\
27 \\
28 \\
29 \\
30 \\
31\end{array}$ & $\begin{array}{r}0.00 \\
0.00 \\
16.40 \\
0.00 \\
0.00 \\
0.00 \\
0.00 \\
0.00 \\
0.00 \\
0.00 \\
0.00 \\
0.00 \\
0.00 \\
15.30 \\
21.20 \\
0.00 \\
22.00 \\
24.00 \\
20.70 \\
0.00 \\
22.10 \\
20.60 \\
0.00 \\
16.30 \\
17.20 \\
15.50 \\
19.00 \\
0.00 \\
0.00 \\
0.00 \\
17.30\end{array}$ & $\begin{array}{r}0.0 \\
0.0 \\
736.7 \\
0.0 \\
0.0 \\
0.0 \\
0.0 \\
0.0 \\
0.0 \\
0.0 \\
0.0 \\
0.0 \\
0.0 \\
671.9 \\
741.0 \\
0.0 \\
896.4 \\
970.1 \\
867.3 \\
0.0 \\
906.5 \\
855.0 \\
0.0 \\
700.0 \\
747.0 \\
714.5 \\
825.1 \\
0.0 \\
0.0 \\
0.0 \\
777.5\end{array}$ & $\begin{array}{r}0.0 \\
0.0 \\
25.4 \\
0.0 \\
0.0 \\
0.0 \\
0.0 \\
0.0 \\
0.0 \\
0.0 \\
0.0 \\
0.0 \\
0.0 \\
26.0 \\
32.6 \\
0.0 \\
28.0 \\
28.2 \\
27.2 \\
0.0 \\
27.8 \\
27.5 \\
0.0 \\
26.6 \\
26.3 \\
24.7 \\
26.3 \\
0.0 \\
0.0 \\
0.0 \\
25.4\end{array}$ & $\begin{array}{r}0.0 \\
0.0 \\
71.0 \\
39.0 \\
13.0 \\
-6.0 \\
-6.0 \\
-6.0 \\
94.0 \\
-7.0 \\
-6.0 \\
107.0 \\
107.0 \\
17.7 \\
63.7 \\
0.0 \\
161.7 \\
169.4 \\
168.5 \\
178.7 \\
39.2 \\
165.2 \\
0.0 \\
111.7 \\
107.2 \\
40.6 \\
66.7 \\
54.6 \\
0.0 \\
0.0 \\
0.0\end{array}$ & $\begin{array}{l}0.000 \\
0.000 \\
3.770 \\
1.290 \\
1.060 \\
0.000 \\
0.000 \\
0.000 \\
0.000 \\
0.000 \\
0.000 \\
0.000 \\
0.000 \\
0.000 \\
1.840 \\
0.000 \\
7.450 \\
8.120 \\
7.910 \\
0.000 \\
8.210 \\
8.010 \\
0.000 \\
6.130 \\
0.000 \\
4.920 \\
5.620 \\
0.000 \\
0.000 \\
0.000 \\
2.910\end{array}$ & $\begin{array}{r}0.0 \\
0.0 \\
21.5 \\
34.5 \\
14.0 \\
0.0 \\
0.0 \\
0.0 \\
0.0 \\
0.0 \\
0.0 \\
0.0 \\
0.0 \\
0.0 \\
39.5 \\
0.0 \\
24.8 \\
23.8 \\
24.3 \\
0.0 \\
5.4 \\
23.5 \\
0.0 \\
20.8 \\
0.0 \\
9.4 \\
13.5 \\
0.0 \\
0.0 \\
0.0 \\
0.0\end{array}$ & $\begin{array}{l}0.00 \\
0.00 \\
0.00 \\
0.00 \\
0.00 \\
0.00 \\
0.00 \\
0.00 \\
0.00 \\
0.00 \\
0.00 \\
0.00 \\
0.00 \\
0.00 \\
0.00 \\
0.00 \\
0.00 \\
0.00 \\
0.00 \\
0.00 \\
0.00 \\
0.00 \\
0.00 \\
0.00 \\
0.00 \\
0.00 \\
0.00 \\
0.00 \\
0.00 \\
0.00 \\
0.00\end{array}$ & $\begin{array}{l}0.00 \\
0.00 \\
0.00 \\
0.00 \\
0.00 \\
0.00 \\
0.00 \\
0.00 \\
0.00 \\
0.00 \\
0.00 \\
0.00 \\
0.00 \\
0.00 \\
0.00 \\
0.00 \\
0.00 \\
0.00 \\
0.00 \\
0.00 \\
0.00 \\
0.00 \\
0.00 \\
0.00 \\
0.00 \\
0.00 \\
0.00 \\
0.00 \\
0.00 \\
0.00 \\
0.00\end{array}$ & $\begin{array}{l}0.0 \\
0.0 \\
0.0 \\
0.0 \\
0.0 \\
0.0 \\
0.0 \\
0.0 \\
0.0 \\
0.0 \\
0.0 \\
0.0 \\
0.0 \\
0.0 \\
0.0 \\
0.0 \\
0.0 \\
0.0 \\
0.0 \\
0.0 \\
0.0 \\
0.0 \\
0.0 \\
0.0 \\
0.0 \\
0.0 \\
0.0 \\
0.0 \\
0.0 \\
0.0 \\
0.0\end{array}$ \\
\hline
\end{tabular}

TOTAL TRACK TIME FOR MONTH........... TIME THAT NIP WAS ABOVE 300 W/SQ.M.... TRACK TIME / TIME NIP > 300......... MAXIMUM DAILY NET POWER ............ MAX. DAILY NET POWER EFFIC. FOR MONTH

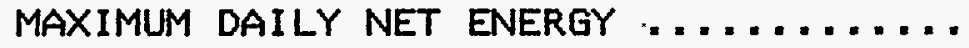
MAX. DAILY NET ENERGY EFFIC. FOR MONTH TOTAL NET POWER PRODUCED FOR MONTH.... TOTAL SUN ENERGY FOR THE MONTH........ SYSTEM NET EFFICIENCY FOR THE MONTH ..

\author{
0.00 HOURS \\ 0.00 HOURS \\ 0.0000 \\ $24.00 \mathrm{KW}$ \\ $32.6 \%$ \\ $178.70 \mathrm{KWHR}$ \\ $39.5 \%$ \\ 12.7 KWHR/SQ.M \\ 67.2 KWHR SQ.M \\ $18.8 \%$
}


DATA FOR MONTH 2 AND YEAR 1986 FOR PAD 2 AT HUNTINGTON BEACH

\begin{tabular}{|c|c|c|c|c|c|c|c|c|c|}
\hline DATE & $\begin{array}{l}\text { PEAK } \\
\text { POWER } \\
\text { KW }\end{array}$ & $\begin{array}{l}\text { PEAK } \\
\text { INSOL } \\
\text { KW/M/M }\end{array}$ & $\begin{array}{l}\text { PEAK } \\
\text { POW EF } \\
\%\end{array}$ & $\begin{array}{l}\text { DAILY } \\
\text { ENERGY } \\
\text { KWHR }\end{array}$ & $\begin{array}{l}\text { SUN } \\
\text { ENERGY } \\
\text { KWHR }\end{array}$ & $\begin{array}{c}\text { DAILY } \\
\text { EFFIC. } \\
\%\end{array}$ & $\begin{array}{c}\text { TRACK } \\
\text { TIME } \\
\text { HR }\end{array}$ & $\begin{array}{l}\text { NIP> M } \\
300 \text { WI } \\
\text { HR }\end{array}$ & $\begin{array}{l}\text { MAX } \\
\text { IND } \\
\text { MPH }\end{array}$ \\
\hline $\begin{array}{l}1 \\
2 \\
3 \\
4 \\
5 \\
6 \\
7 \\
8 \\
9 \\
10 \\
11 \\
12 \\
13 \\
14 \\
15 \\
16 \\
17 \\
18 \\
19 \\
20 \\
21 \\
22 \\
23 \\
24 \\
25 \\
26 \\
27 \\
28\end{array}$ & $\begin{array}{l}0.00 \\
0.00 \\
0.00 \\
0.00 \\
0.00 \\
0.00 \\
0.00 \\
0.00 \\
0.00 \\
0.00 \\
0.00 \\
0.00 \\
0.00 \\
0.00 \\
0.00 \\
0.00 \\
0.00 \\
0.00 \\
0.00 \\
0.00 \\
0.00 \\
0.00 \\
0.00 \\
0.00 \\
0.00 \\
0.00 \\
0.00 \\
0.00\end{array}$ & $\begin{array}{l}0.0 \\
0.0 \\
0.0 \\
0.0 \\
0.0 \\
0.0 \\
0.0 \\
0.0 \\
0.0 \\
0.0 \\
0.0 \\
0.0 \\
0.0 \\
0.0 \\
0.0 \\
0.0 \\
0.0 \\
0.0 \\
0.0 \\
0.0 \\
0.0 \\
0.0 \\
0.0 \\
0.0 \\
0.0 \\
0.0 \\
0.0 \\
0.0\end{array}$ & $\begin{array}{l}0.0 \\
0.0 \\
0.0 \\
0.0 \\
0.0 \\
0.0 \\
0.0 \\
0.0 \\
0.0 \\
0.0 \\
0.0 \\
0.0 \\
0.0 \\
0.0 \\
0.0 \\
0.0 \\
0.0 \\
0.0 \\
0.0 \\
0.0 \\
0.0 \\
0.0 \\
0.0 \\
0.0 \\
0.0 \\
0.0 \\
0.0 \\
0.0\end{array}$ & $\begin{array}{r}0.0 \\
0.0 \\
0.0 \\
45.1 \\
1.9 \\
24.0 \\
24.0 \\
-6.0 \\
-6.0 \\
-6.0 \\
-6.0 \\
-6.0 \\
-6.0 \\
-6.0 \\
-6.0 \\
-6.0 \\
-6.0 \\
-6.0 \\
47.0 \\
63.0 \\
104.0 \\
104.0 \\
104.0 \\
119.0 \\
146.0 \\
90.0 \\
-2.0 \\
0.0\end{array}$ & $\begin{array}{l}1.642 \\
1.383 \\
4.978 \\
6.989 \\
5.781 \\
3.850 \\
1.077 \\
0.000 \\
6.016 \\
0.143 \\
6.445 \\
0.263 \\
0.000 \\
0.000 \\
0.000 \\
0.000 \\
0.000 \\
0.000 \\
0.000 \\
0.000 \\
0.000 \\
0.000 \\
0.000 \\
0.000 \\
0.000 \\
0.000 \\
0.000 \\
0.000\end{array}$ & $\begin{array}{r}0.0 \\
0.0 \\
0.0 \\
7.4 \\
0.4 \\
7.1 \\
25.4 \\
0.0 \\
-1.1 \\
-47.9 \\
-1.1 \\
-26.0 \\
0.0 \\
0.0 \\
0.0 \\
0.0 \\
0.0 \\
0.0 \\
0.0 \\
0.0 \\
0.0 \\
0.0 \\
0.0 \\
0.0 \\
0.0 \\
0.0 \\
0.0 \\
0.0\end{array}$ & $\begin{array}{l}0.00 \\
0.00 \\
0.00 \\
0.00 \\
0.00 \\
0.00 \\
0.00 \\
0.00 \\
0.00 \\
0.00 \\
0.00 \\
0.00 \\
0.00 \\
0.00 \\
0.00 \\
0.00 \\
0.00 \\
0.00 \\
0.00 \\
0.00 \\
0.00 \\
0.00 \\
0.00 \\
0.00 \\
0.00 \\
0.00 \\
0.00 \\
0.00\end{array}$ & $\begin{array}{l}0.00 \\
0.00 \\
0.00 \\
0.00 \\
0.00 \\
0.00 \\
0.00 \\
0.00 \\
0.00 \\
0.00 \\
0.00 \\
0.00 \\
0.00 \\
0.00 \\
0.00 \\
0.00 \\
0.00 \\
0.00 \\
0.00 \\
0.00 \\
0.00 \\
0.00 \\
0.00 \\
0.00 \\
0.00 \\
0.00 \\
0.00 \\
0.00\end{array}$ & $\begin{array}{l}0.0 \\
0.0 \\
0.0 \\
0.0 \\
0.0 \\
0.0 \\
0.0 \\
0.0 \\
0.0 \\
0.0 \\
0.0 \\
0.0 \\
0.0 \\
0.0 \\
0.0 \\
0.0 \\
0.0 \\
0.0 \\
0.0 \\
0.0 \\
0.0 \\
0.0 \\
0.0 \\
0.0 \\
0.0 \\
0.0 \\
0.0 \\
0.0\end{array}$ \\
\hline
\end{tabular}

TOTAL TRACK TIME FOR MONTH. . . . . .....

TIME THAT NIP WAS ABOVE $300 \mathrm{~W} / \mathrm{SQ} . \mathrm{M} \ldots$

TRACK TIME / TIME NIP > $300 \ldots . . . .$.

MAXIMUM DAILY NET POWER ...........

MAX. DAILY NET POWER EFFIC. FOR MONTH

MAXIMUM DAILY NET ENERGY ...........

MAX. DAILY NET ENERGY EFFIC. FOR MONTH

TOTAL NET POWER PRODUCED FOR MONTH....

TOTAL SUN ENERGY FOR THE MONTH....... SYSTEM NET EFFICIENCY FOR THE MONTH ..

\author{
0.00 HOURS \\ 0.00 HOURS \\ 0.0000 \\ $0.00 \mathrm{KW}$ \\ $0.0 \%$ \\ $146.00 \mathrm{KWHR}$ \\ $25.4 \%$ \\ 0.8 KWHR/SQ.M \\ 38.6 KWHR/SQ.M \\ $2.1 \%$
}


DATA FOR MONTH 1 AND YEAR 1986 FOR PAD 2 AT HUNTINGTON BEACH

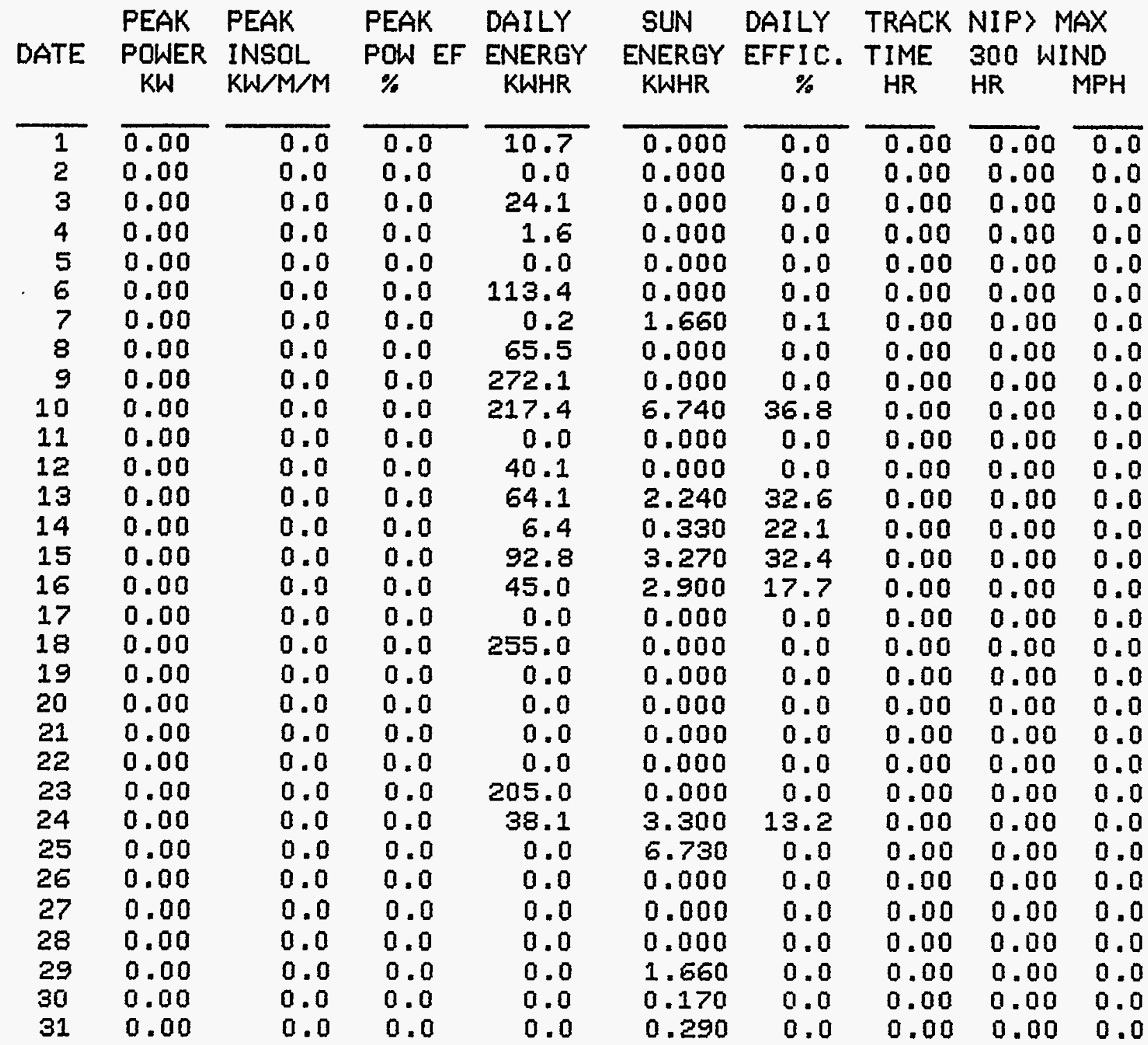

TOTAL TRACK TIME FOR MONTH........... TIME THAT NIP WAS ABOUE $300 \mathrm{~W} / \mathrm{SQ} . \mathrm{M} . .$. TRACK TIME / TIME NIP > $300 \ldots \ldots \ldots \ldots$ MAXIMUM DAILY NET POWER . . . . . . . . MAX. DAILY NET POWER EFFIC. FOR MONTH MAXIMUM DAILY NET ENERGY ........... MAX. DAILY NET ENERGY EFFIC. FOR MONTH TOTAL NET POWER PRODUCED FOR MONTH.... TOTAL SUN ENERGY FOR THE MONTH........ SYSTEM NET EFFICIENCY FOR THE MONTH ..

\author{
0.00 HOURS \\ 0.00 HOURS \\ 0.0000 \\ $0.00 \mathrm{~kW}$ \\ $0.0 \%$ \\ $272.10 \mathrm{KWHR}$ \\ $36.8 \%$ \\ 5.3 KWHR/SQ.M \\ 29.3 KWHR/ SQ.M \\ $18.1 \%$
}


DATA FOR MONTH 1 AND YEAR 1986 FOR PAD 3 AT HUNTINGTON BEACH

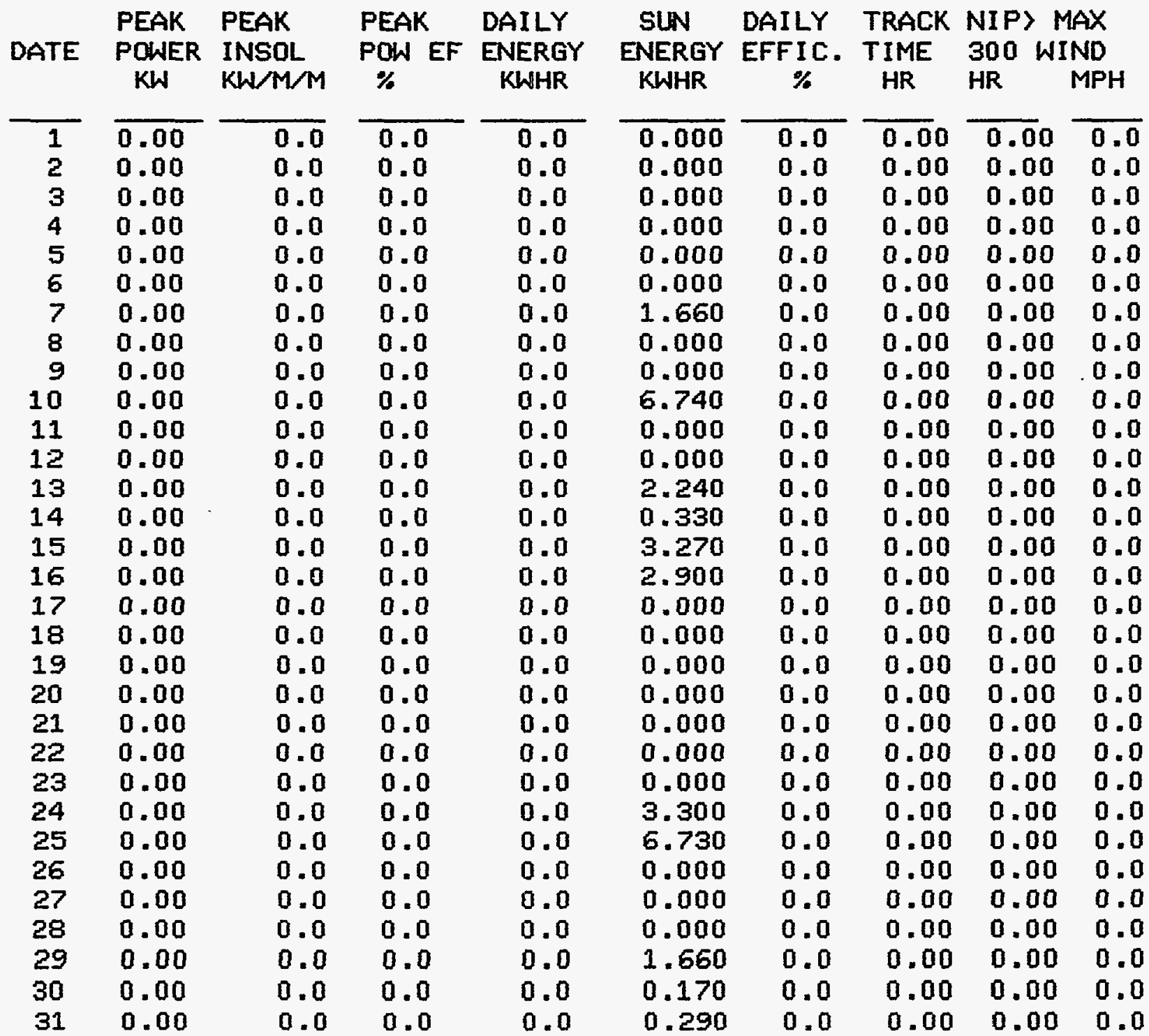

\footnotetext{
TOTAL TRACK TIME FOR MONTH.......... 0.00 HOURS

TIME THAT NIP WAS ABOVE $300 \mathrm{~W} / S Q . M \ldots . . .0 .00$ HOURS

TRACK TIME / TIME NIP > $300 \ldots \ldots . . . .0 .0000$

MAXIMUM DAILY NET POWER ............. $0.00 \mathrm{KW}$

MAX. DAILY NET POWER EFFIC. FOR MONTH $0.0 \%$

MAXIMUM DAILY NET ENERGY .......... $0.00 \mathrm{KWHR}$

MAX. DAILY NET ENERGY EFFIC. FOR MONTH $0.0 \%$

TOTAL NET POWER PRODUCED FOR MONTH.... $0.0 \mathrm{KWHR/SQ.M}$

TOTAL SUN ENERGY FOR THE MONTH....... 29.3 KWHR/ SQ.M

SYSTEM NET EFFICIENCY FOR THE MONTH .. $0.0 \%$
} 


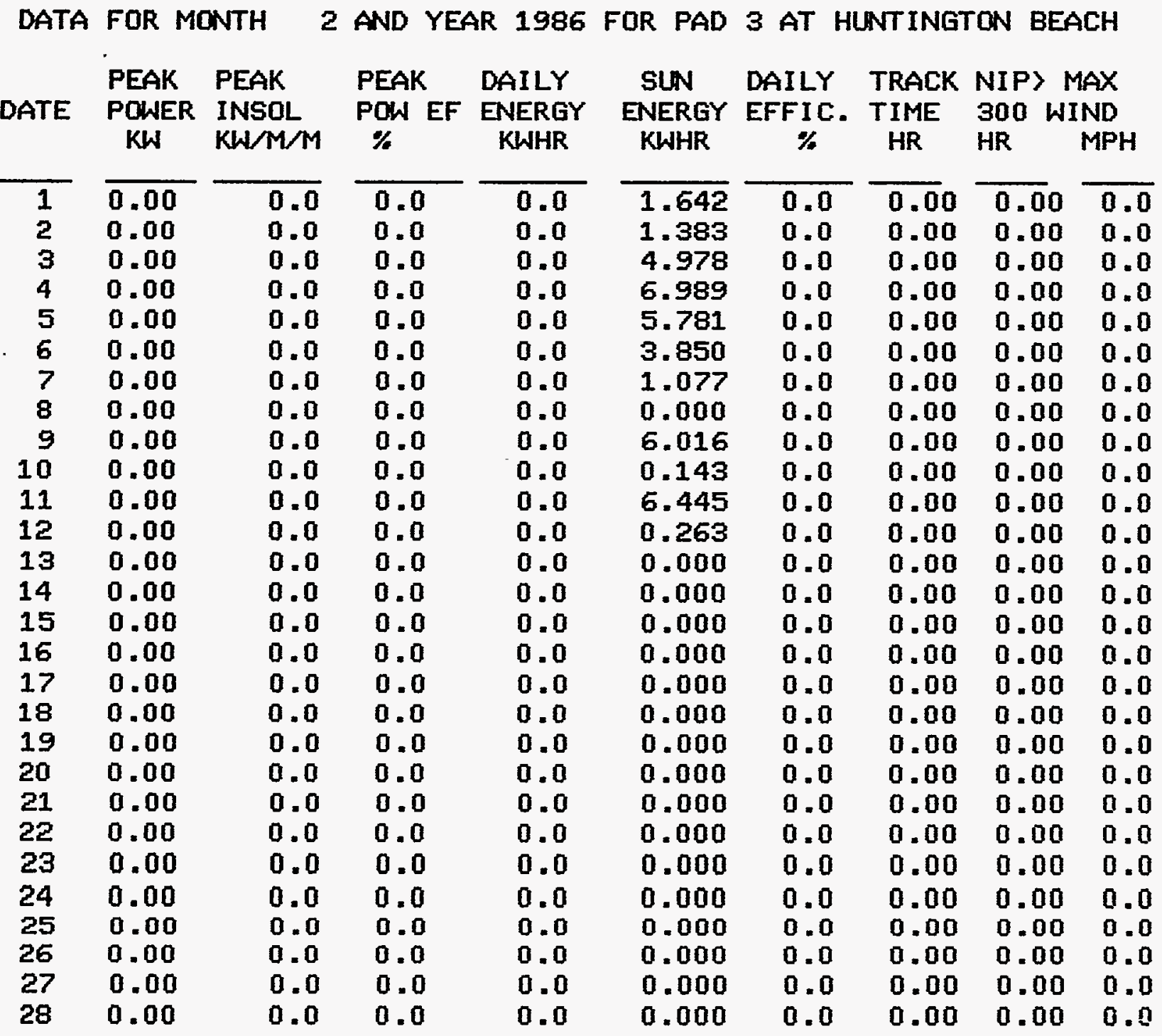

TOTAL TRACK TIME FOR MONTH. .......... TIME THAT NIP WAS ABOUE 300 W/SQ.M.... TRACK TIME / TIME NIP > $300 . . . . . .$. MAXIMUM DAILY NET POWER ............. MAX. DAILY NET POWER EFFIC. FOR MONTH MAXIMUM DAILY NET ENERGY ........... MAX. DAILY NET ENERGY EFFIC. FOR MONTH TOTAL NET POWER PRODUCED FOR MONTH.... TUTAL SUN ENERGY FOR THE MONTH........ SYSTEM NET EFFICIENCY FOR THE MONTH :.

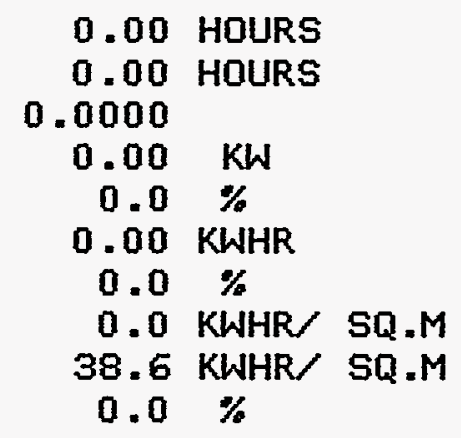


DATA FOR MONTH 3 AND YEAR 1986 FOR PAD 3 AT HUNTINGTON BEACH

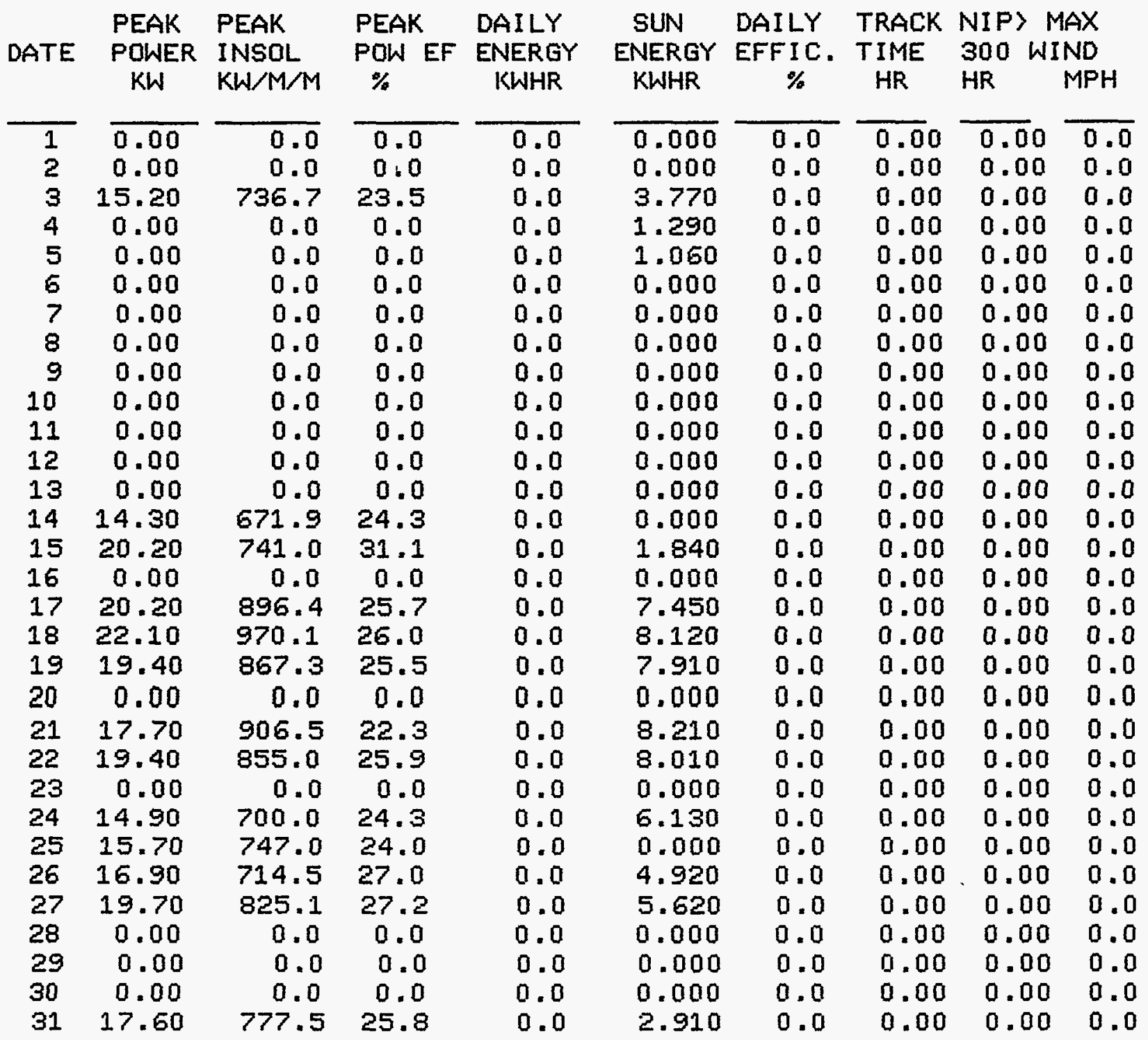

TOTAL TRACK TIME FOR MONTH. . . . . . . .

TIME THAT NIP WAS ABOVE 300 W/SQ.M....

TRACK TIME / TIME NIP > $300 \ldots \ldots \ldots$

MAX. DAILY NET POWER EFFIC. FOR MONTH

MAXIMUM DAILY NET ENERGY .............

MAX. DAILY NET ENERGY EFFIC. FOR MONTH

TOTAL NET POWER PRODUCED FOR MONTH....

TOTAL SUN ENERGY FOR THE MONTH........

SYSTEM NET EFFICIENCY FOR THE MONTH ..

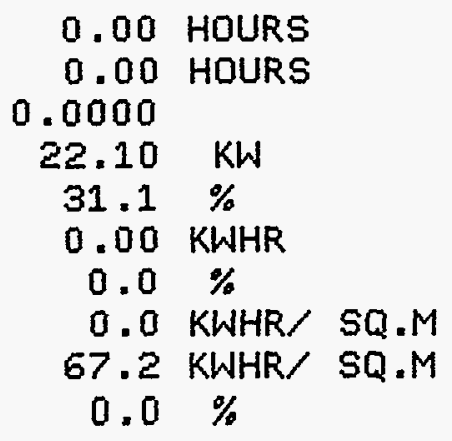
$22.10 \mathrm{KW}$
$31.1 \%$
$0.00 \mathrm{KWHR}$
$0.0 \%$
67.2 KWHR/ SQ.M
$.0 \%$




\begin{tabular}{|c|c|c|c|c|c|c|c|c|c|}
\hline$T$ & $\begin{array}{l}\text { PEAK } \\
\text { POWER } \\
\text { KW }\end{array}$ & $\begin{array}{l}\text { PEAK } \\
\text { INSOL } \\
\text { KW/M/M }\end{array}$ & $\begin{array}{l}\text { PEAK } \\
\text { SOW EF } \\
\%\end{array}$ & $\begin{array}{l}\text { AILY } \\
\text { NERGY } \\
\text { KWHR }\end{array}$ & $\begin{array}{l}\text { SUN } \\
\text { ENERGY } \\
\text { KWHR }\end{array}$ & $\begin{array}{c}\text { DAILY } \\
\text { EFFIC. } \\
\quad \%\end{array}$ & $\begin{array}{l}\text { TRACK } \\
\text { TIME } \\
\text { HR }\end{array}$ & $\begin{array}{l}\text { NIP> } \\
300 \quad W \\
H R\end{array}$ & $\begin{array}{l}\text { MAX } \\
\text { IIND } \\
\text { MPH }\end{array}$ \\
\hline $\begin{array}{c}1 \\
2 \\
3 \\
4 \\
5 \\
6 \\
7 \\
8 \\
9 \\
10 \\
11 \\
12 \\
13 \\
14 \\
15 \\
16 \\
17 \\
18 \\
19 \\
20 \\
21 \\
22 \\
23 \\
24 \\
25 \\
26 \\
27 \\
28 \\
29 \\
30\end{array}$ & $\begin{array}{r}0.00 \\
17.40 \\
17.10 \\
16.90 \\
0.00 \\
0.00 \\
19.60 \\
19.60 \\
20.40 \\
19.20 \\
13.70 \\
0.00 \\
0.00 \\
19.00 \\
18.60 \\
18.60 \\
17.60 \\
17.30 \\
19.50 \\
19.30 \\
18.80 \\
16.00 \\
21.50 \\
20.50 \\
16.90 \\
17.00 \\
21.30 \\
22.40 \\
0.00 \\
0.00\end{array}$ & $\begin{array}{r}0.0 \\
823.5 \\
804.1 \\
818.6 \\
0.0 \\
0.0 \\
885.5 \\
881.1 \\
913.5 \\
806.9 \\
671.4 \\
0.0 \\
0.0 \\
887.9 \\
864.2 \\
895.2 \\
864.2 \\
836.4 \\
909.1 \\
910.3 \\
904.4 \\
694.5 \\
846.8 \\
807.3 \\
683.9 \\
675.9 \\
829.8 \\
879.5 \\
0.0 \\
0.0\end{array}$ & $\begin{array}{r}0.0 \\
24.1 \\
24.3 \\
23.5 \\
0.0 \\
0.0 \\
25.2 \\
25.4 \\
25.5 \\
27.1 \\
23.3 \\
0.0 \\
0.0 \\
24.4 \\
24.5 \\
23.7 \\
23.2 \\
23.6 \\
24.5 \\
24.2 \\
23.7 \\
26.3 \\
29.0 \\
29.0 \\
28.2 \\
28.7 \\
29.3 \\
29.1 \\
0.0 \\
0.0\end{array}$ & $\begin{array}{r}0.0 \\
25.6 \\
25.7 \\
80.3 \\
0.0 \\
0.0 \\
141.8 \\
149.0 \\
167.9 \\
33.2 \\
29.0 \\
0.0 \\
0.0 \\
60.6 \\
107.4 \\
103.6 \\
146.2 \\
114.0 \\
182.5 \\
125.5 \\
170.0 \\
17.1 \\
115.0 \\
144.1 \\
73.7 \\
98.1 \\
195.8 \\
195.0 \\
0.0 \\
0.0\end{array}$ & $\begin{array}{l}0.000 \\
8.430 \\
7.020 \\
6.890 \\
0.000 \\
0.000 \\
6.710 \\
7.310 \\
8.450 \\
0.000 \\
2.120 \\
0.000 \\
0.000 \\
0.000 \\
6.120 \\
7.320 \\
7.710 \\
8.660 \\
0.000 \\
0.000 \\
0.000 \\
0.000 \\
0.000 \\
0.000 \\
4.140 \\
5.110 \\
0.000 \\
0.000 \\
0.000 \\
0.000\end{array}$ & $\begin{array}{r}0.0 \\
3.5 \\
4.3 \\
13.3 \\
0.0 \\
0.0 \\
24.1 \\
23.2 \\
22.7 \\
0.0 \\
15.5 \\
0.0 \\
0.0 \\
0.0 \\
20.0 \\
16.1 \\
21.6 \\
15.0 \\
0.0 \\
0.0 \\
0.0 \\
0.0 \\
0.0 \\
0.0 \\
20.3 \\
21.9 \\
0.0 \\
0.0 \\
0.0 \\
0.0\end{array}$ & $\begin{array}{l}0.00 \\
0.00 \\
0.00 \\
0.00 \\
0.00 \\
0.00 \\
0.00 \\
0.00 \\
0.00 \\
0.00 \\
0.00 \\
0.00 \\
0.00 \\
0.00 \\
0.00 \\
0.00 \\
0.00 \\
0.00 \\
0.00 \\
0.00 \\
0.00 \\
0.00 \\
0.00 \\
0.00 \\
0.00 \\
0.00 \\
0.00 \\
0.00 \\
0.00 \\
0.00\end{array}$ & $\begin{array}{l}0.00 \\
0.00 \\
0.00 \\
0.00 \\
0.00 \\
0.00 \\
0.00 \\
0.00 \\
0.00 \\
0.00 \\
0.00 \\
0.00 \\
0.00 \\
0.00 \\
0.00 \\
0.00 \\
0.00 \\
0.00 \\
0.00 \\
0.00 \\
0.00 \\
0.00 \\
0.00 \\
0.00 \\
0.00\end{array}$ & $\begin{array}{l}0.0 \\
0.0 \\
0.0 \\
0.0 \\
0.0 \\
0.0 \\
0.0 \\
0.0 \\
0.0 \\
0.0 \\
0.0 \\
0.0 \\
0.0 \\
0.0 \\
0.0 \\
0.0\end{array}$ \\
\hline
\end{tabular}

TOTAL TRACK TIME FOR MONTH........... TIME THAT NIP WAS ABOVE 300 W/SQ.M.... TRACK TIME / TIME NIP > $300 \ldots \ldots . . .$. MAXIMUM DAILY NET POWER ............ MAX. DAILY NET POWER EFFIC. FOR MONTH MAXIMUM DAILY NET ENERGY ........... MAX. DAILY NET ENERGY EFF.IC. FOR MONTH TOTAL NET POWER PRODUCED FOR MONTH. ... TOTAL SUN ENERGY FOR THE MONTH........ SYSTEM NET EFFICIENCY FOR THE MONTH ..

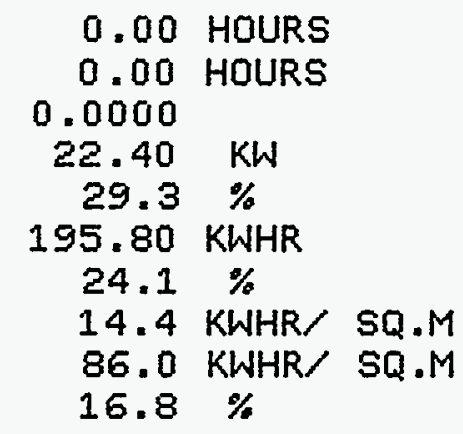


DATA FOR MONTH 5 AND YEAR 1986 FOR PAD 3 AT HLNTINGTON BEACH

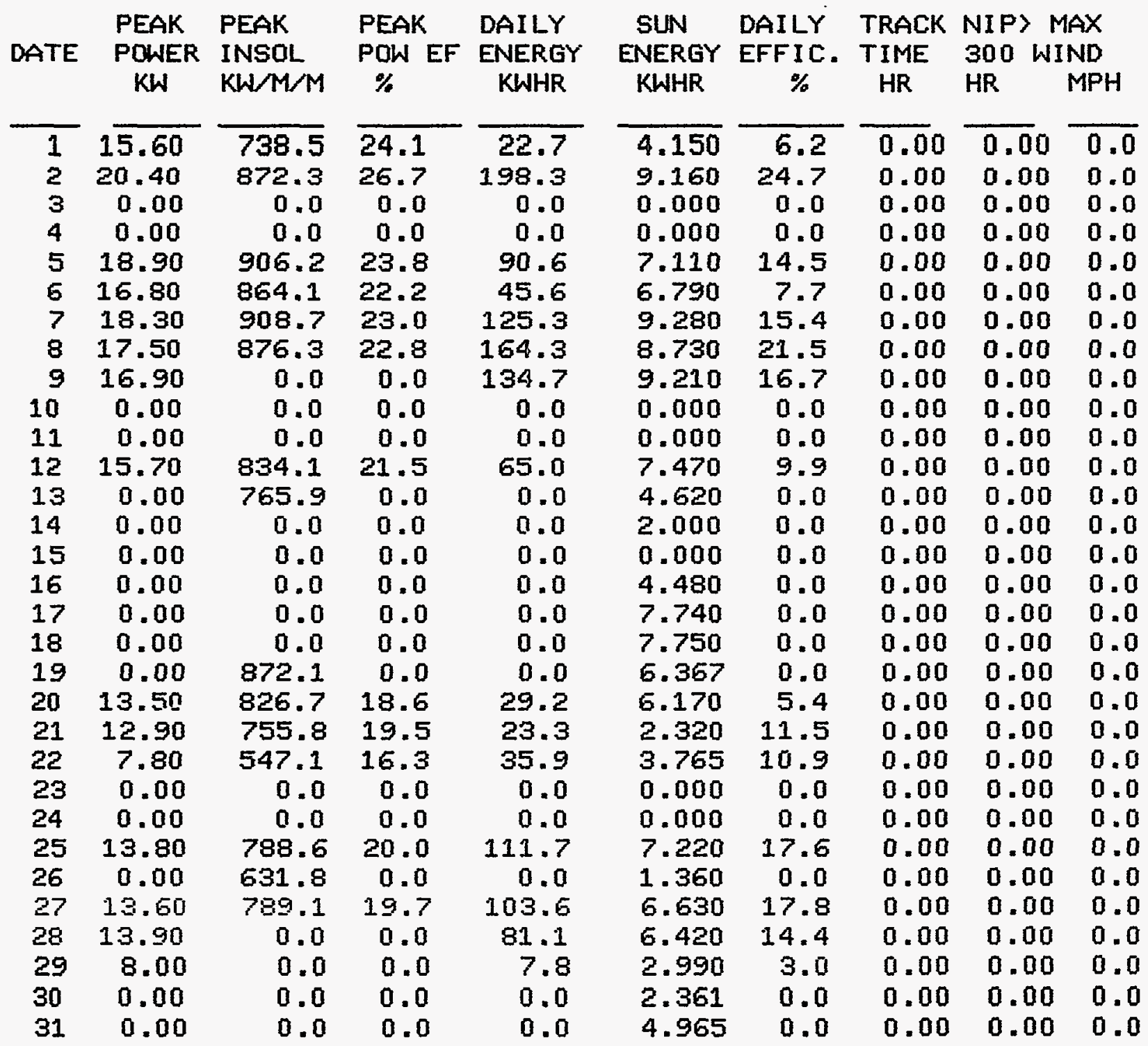

TOTAL TRACK TIME FOR MONTH...........

TIME THAT NIP WAS ABDUE 300 W/SQ.M....

TRACK TIME $/$ TIME NIP > $300 \ldots \ldots \ldots \ldots$

MAXIMUM DAILY NET POWER .............

MAX. DAILY NET POWER EFFIC. FOR MONTH

MAXIMUM DAILY NET ENERGY ..........

MAX. DAILY NET ENERGY EFFIC. FOR MONTH

TOTAL NET POWER PRODUCED FOR MONTH....

TOTAL SUN ENERGY FOR THE MONTH. .......

SYSTEM NET EFFICIENCY FOR THE MONTH ..

\author{
0.00 HOURS \\ 0.00 HOURS \\ 0.0000 \\ $20.40 \mathrm{KW}$ \\ $26.7 \%$ \\ $198.30 \mathrm{KWHR}$ \\ $24.7 \%$ \\ 14.1 KWHR/ SQ.M \\ 139.1 KWHR SQ.M \\ $10.2 \%$
}




\section{APPENDIX B}

This appendix contains a summary of the

Stirling Dish testing from November 1985 to June 1986 at the Georgia Power, Shenandoah, Georgia. 


\section{OPERATING SUMMARY FOR THE GEORGIA POWER TEST SITE}

Date Description

1985

$10 / 7$

$10 / 8$

$10 / 9$

$10 / 12$

$10 / 15$

$10 / 25$

$10 / 26$

$10 / 27$

$11 / 5$

$11 / 11$

$11 / 12$

$11 / 23$

$12 / 2$

$12 / 5$

$12 / 8$

$12 / 11$

$12 / 16$

$12 / 17$

$12 / 18$

$12 / 19$

$12 / 26$

1986

$1 / 2$

$1 / 18$

$1 / 19$

$1 / 27$

$1 / 28$

$1 / 29$

$2 / 5$

$2 / 6$

$2 / 7$

$2 / 9$

$2 / 12$

$3 / 1$

$3 / 5$

$3 / 6$

$3 / 7$

$3 / 14$ to

$3 / 17$

$3 / 24$

Concentrator \#5 was delivered to Georgia Power.

Concentrator was unloaded.

Crane late in showing up to install unit. Installation started at 12:30 pm and erection

completed by $4: 30 \mathrm{pm}$. PCU \#103 was installed.

Concentrator reference helicon magnet shattered, design problem.

Dead fast slew battery because charger not hooked up.

First positive power from unit occurred at 11:32 am.

Water pump logic chip failure.

Moisture in PCU control plug caused PCU control problem.

Loose wire and broken diode on PCU bypass valve, back in service by 10:30.

CRT screen blank, reboot DEC.

Problem with DEC controller time drifting.

Noise spike on wind data line, caused unit to go to wind stow position during night.

Only happened at night so no power production was lost.

Anomalies with data acquistion system began appearing during the month.

Protective aperture insulation fell out.

Ceramic tiles installed in placed of cone insulation.

New fast slew motor.

Installed new DC power supply in DEC to correct time drift problem that had estra fitters on line to reduce line noise.

Water pump failure and control relay failure.

Replaced new contactor \& protection relay

Found burned wiring

Replaced water pump and relay

Detrack because of engine stiffness caused by cold morning.

Continued anomalies with the data acquisition system throughout the month.

STEP grid out while in track.

Lightning strike, blown communication ICs.in PCU monitor \& several in PCU controller.

DEC AD board blown from previous lightning, did not stop operation of unit.

Detrack, high engine pressure caused by a valve problem.

Site power shutdown to install equipment.

Dish reference/inc. encoder problem.

Continued anomalies with the data acquisition system throughout the month.

Thunderstorm and lightning

Overpressurized engine/DEC A/D lighting problem from lightning on 2/5.

Water pump failed, foun that water pump had been installed wrong on 12/15.

System repaired and back in service.

Oil sensor problem.

Solenoid hydrogen valve failed and overpressurized engine on $3 / 1$ and $3 / 2$.

System out because of site work

Replaced solonoid H2 supply valve.

DEC monitor failed, unit was replaced. Probable result of lightning.

Lightning strike damaged the PCU interface board. Moisture in a connector caused a monitor keyswitch problem. DEC AVD failed but did not limit operation. Had to wait for USAB personnel to fix PCU problems.

Startup, oil transducer problem.

Minor problems left over from the lightning on the 13th caused delays throughout the month.

Wash mirrors to remove pollen from trees. 
$4 / 3$

$4 / 4$

$4 / 11$

$4 / 21$

$4 / 23$

$4 / 29$

$5 / 19$

$5 / 20$ to $5 / 28$

$6 / 1$

$6 / 10$ to

$6 / 14$

$6 / 15$ to $6 / 23$

$6 / 24$

$6 / 25$

$6 / 26$

$7 / 2$

$7 / 8$

$7 / 20$

$7 / 23$

$7 / 25$
9:20 site grid loss, 10:45 back in service, 16:00 out of service for software update. Disconnected sun sensor because of problems, not required for operation. 10:30 site grid loss, $12: 30$ back in service.

7:30 Receiver center cone fell out, 17:15 back in service.

Produced $223 \mathrm{kWh}$ of gross power.

14:50 receiver center cone fell out, bracket bad, 16:20 back in service. Cone hit and cracked a mirror.

Many detracks, no oil pressure.

Oil pressure sensor replaced. Later a detrack set the fast slew and because of a design problem in the fast slew, it would not deactivate and was cycling. In an attempt to stop the system, the power was cycled, a manual controller was used and a motor wire was broken while changing which resulted in the elevation motor burning up. The unit was left at an elevation angle that resulted in the reflecting beam burning the PCU wiring. All repairs were made by the end of the month.

A Mark II engine was mounted and checked out. The large reserve hydrogen bottle was added to the PCU 208 support structure. Design changes were made to the fast slew system.

Checkout continued, most of day PCU monitor problem. Gravity bending measurement taken, PCU monitor false alarm buzzer. Tested Fast Slew track checkout. Trouble shoot ref. update problem.

Down waiting for parts and service personnel.

Checkout continued on ref. update problem.

Modified Fast Slew system, system put back in automatic service.

Operation started.

Detrack caused by water in connectors, cleaned and dried

Detrack cause by loose thermocouple wire on terminal strip.

Lightning damage to PCU monitor and AVD DEC board.

Repaired PCU monitor IC damaged by lightning. DEC AVD board bad but did not stop operation.

Repaired DEC A/D board damaged by lightning. 
DATA FOR MONTH 11 AND YEAR 1985

\begin{tabular}{|c|c|c|c|c|c|c|c|c|c|}
\hline ATE & $\begin{array}{l}\text { PEAK } \\
\text { POWER } \\
K W\end{array}$ & $\begin{array}{l}\text { PEAK } \\
\text { INSOL } \\
\mathrm{KW} / \mathrm{M} / \mathrm{M}\end{array}$ & $\begin{array}{l}\text { EAK } \\
\% \\
\text { OW EF }\end{array}$ & $\begin{array}{l}\text { DAILY } \\
\text { ENERGY } \\
\text { KWHR }\end{array}$ & $\begin{array}{c}\text { SUN } \\
\text { ENERGY } \\
\text { KWHR }\end{array}$ & $\begin{array}{l}\text { AILY } \\
\text { FFIC. } \\
\%\end{array}$ & $\begin{array}{l}\text { TRACK } \\
\text { TIME } \\
\text { HR }\end{array}$ & $\begin{array}{l}\text { NIP> M } \\
300 \text { WI } \\
\text { HR }\end{array}$ & $\begin{array}{l}X \\
D \\
\text { PH }\end{array}$ \\
\hline $\begin{array}{l}1 \\
2 \\
3 \\
4 \\
5 \\
6 \\
7 \\
8 \\
9 \\
10 \\
11 \\
12 \\
13 \\
14 \\
15 \\
16 \\
17 \\
18 \\
19 \\
20 \\
21 \\
22 \\
23 \\
24 \\
25 \\
26 \\
27 \\
28 \\
29 \\
30\end{array}$ & $\begin{array}{r}0.00 \\
0.00 \\
0.00 \\
0.00 \\
0.00 \\
0.00 \\
18.70 \\
0.00 \\
22.30 \\
0.00 \\
0.00 \\
0.00 \\
0.00 \\
0.00 \\
0.00 \\
0.00 \\
19.10 \\
0.00 \\
0.00 \\
0.00 \\
0.00 \\
0.00 \\
0.00 \\
0.00 \\
0.00 \\
0.00 \\
0.00 \\
0.00 \\
0.00 \\
0.00\end{array}$ & $\begin{array}{r}0.0 \\
23.8 \\
23.9 \\
571.7 \\
0.0 \\
0.0 \\
851.5 \\
0.0 \\
971.5 \\
0.0 \\
0.0 \\
0.0 \\
0.0 \\
0.0 \\
0.0 \\
0.0 \\
865.5 \\
0.0 \\
768.1 \\
61.5 \\
0.0 \\
0.0 \\
0.0 \\
0.0 \\
0.0 \\
0.0 \\
249.5 \\
261.5 \\
20.6 \\
158.0\end{array}$ & $\begin{array}{r}0.0 \\
0.0 \\
0.0 \\
0.0 \\
0.0 \\
0.0 \\
25.0 \\
0.0 \\
26.2 \\
0.0 \\
0.0 \\
0.0 \\
0.0 \\
0.0 \\
0.0 \\
0.0 \\
25.2 \\
0.0 \\
0.0 \\
0.0 \\
0.0 \\
0.0 \\
0.0 \\
0.0 \\
0.0 \\
0.0 \\
0.0 \\
0.0 \\
0.0 \\
0.0\end{array}$ & $\begin{array}{l}0.0 \\
0.0 \\
0.0 \\
0.0 \\
0.0 \\
0.0 \\
0.0 \\
0.0 \\
0.0 \\
0.0 \\
0.0 \\
0.0 \\
0.0 \\
0.0 \\
0.0 \\
0.0 \\
0.0 \\
0.0 \\
0.0 \\
0.0 \\
0.0 \\
0.0 \\
0.0 \\
0.0 \\
0.0 \\
0.0 \\
0.0 \\
0.0 \\
0.0 \\
0.0\end{array}$ & $\begin{array}{l}0.000 \\
0.518 \\
0.511 \\
0.831 \\
0.000 \\
0.000 \\
0.000 \\
0.000 \\
0.000 \\
0.000 \\
0.000 \\
0.000 \\
0.000 \\
0.000 \\
0.000 \\
0.000 \\
0.000 \\
0.000 \\
1.660 \\
0.496 \\
0.000 \\
0.000 \\
0.000 \\
0.000 \\
0.000 \\
0.000 \\
0.613 \\
0.590 \\
0.461 \\
0.509\end{array}$ & $\begin{array}{l}0.0 \\
0.0 \\
0.0 \\
0.0 \\
0.0 \\
0.0 \\
0.0 \\
0.0 \\
0.0 \\
0.0 \\
0.0 \\
0.0 \\
0.0 \\
0.0 \\
0.0 \\
0.0 \\
0.0 \\
0.0 \\
0.0 \\
0.0 \\
0.0 \\
0.0 \\
0.0 \\
0.0 \\
0.0 \\
0.0 \\
0.0 \\
0.0 \\
0.0 \\
0.0\end{array}$ & $\begin{array}{l}0.00 \\
0.00 \\
0.00 \\
0.00 \\
0.00 \\
0.00 \\
0.00 \\
0.00 \\
0.00 \\
0.00 \\
0.00 \\
0.00 \\
0.00 \\
0.00 \\
0.00 \\
0.00 \\
0.00 \\
0.00 \\
0.00 \\
0.00 \\
0.00 \\
0.00 \\
0.00 \\
0.00 \\
0.00 \\
0.00 \\
0.00 \\
0.00 \\
0.00 \\
0.00\end{array}$ & $\begin{array}{l}0.00 \\
0.00 \\
0.00 \\
0.00 \\
0.00 \\
0.00 \\
0.00 \\
0.00 \\
0.00 \\
0.00 \\
0.00 \\
0.00 \\
0.00 \\
0.00 \\
0.00 \\
0.00 \\
0.00 \\
0.00 \\
0.00 \\
0.00 \\
0.00 \\
0.00 \\
0.00 \\
0.00 \\
0.00 \\
0.00 \\
0.00 \\
0.00 \\
0.00 \\
0.00\end{array}$ & $\begin{array}{l}0.0 \\
0.0 \\
0.0 \\
0.0 \\
0.0 \\
0.0 \\
0.0 \\
0.0 \\
0.0 \\
0.0 \\
0.0 \\
0.0 \\
0.0 \\
0.0 \\
0.0 \\
0.0 \\
0.0 \\
0.0 \\
0.0 \\
0.0 \\
0.0 \\
0.0 \\
0.0 \\
0.0 \\
0.0 \\
0.0 \\
0.0 \\
0.0 \\
0.0 \\
0.0\end{array}$ \\
\hline
\end{tabular}

TOTAL TRACK TIME FOR MONTH..........

TIME THAT NIP WAS ABOVE 300 W/SQ.M....

TRACK TIME $/$ TIME NIP > 300........

MAXIMUM DAILY POWER.............

MAX. DAILY POWER EFFIC. FOR MONTH. ....

MAXIMUM DAILY NET ENERGY . .........

MAX. DAILY ENERGY EFFIC. FOR MONTH ...

TOTAL POWER PRODUCED FOR MONTH.......

TOTAL SUN ENERGY FOR THE MONTH.......

SYSTEM EFFICIENCY FOR THE MONTH.......

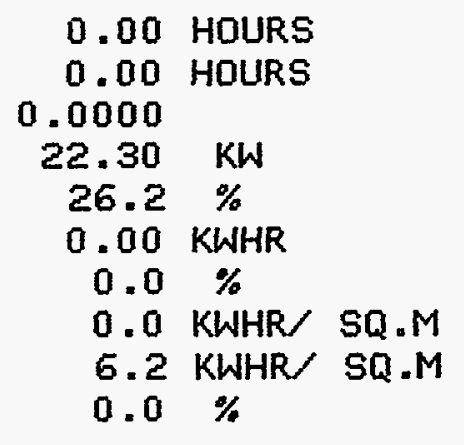


DATA FOR MONTH 12 AND YEAR 1985

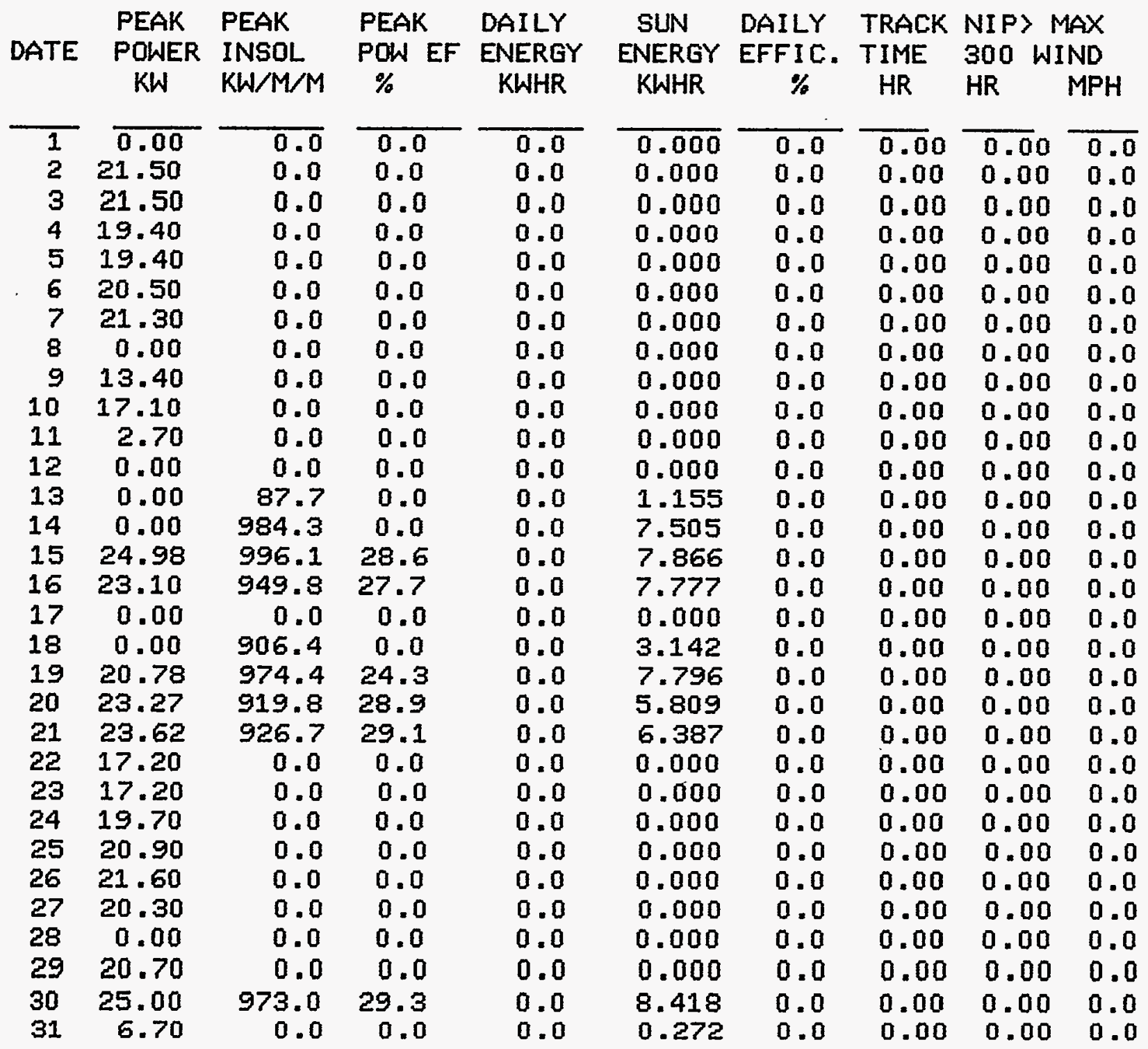

TOTAL TRACK TIME FOR MONTH......... 0.00 HOURS

TIME THAT NIP WAS ABOVE $300 \mathrm{~W} / \mathrm{SQ} . \mathrm{M} \ldots . .000$ HOURS

TRACK TIME / TIME NIP > $300 \ldots \ldots \ldots . .0 .0000$

MAXIMUM DAILY POWER............... 25.00 KW

MAX. DAILY POWER EFFIC. FOR MONTH..... $29.3 \%$

MAXIMUM DAILY NET ENERGY.......... $0.00 \mathrm{KWHR}$

MAX. DAILY ENERGY EFFIC. FOR MONTH ... $0.0 \%$

TOTAL POWER PRODUCED FOR MONTH....... $0.0 \mathrm{KWHR/ \text {SQ.M }}$

TOTAL SUN ENERGY FOR THE MONTH...... 56.1 KWHR/ SQ.M

SYSTEM EFFICIENCY FOR THE MONTH...... $0.0 \%$ 
DATA FOR MONTH 1 AND YEAR 1986

\begin{tabular}{|c|c|c|c|c|c|c|c|c|c|}
\hline ATE & $\begin{array}{c}\text { PEAK } \\
\text { POWER } \\
\text { KW }\end{array}$ & $\begin{array}{l}\text { PEAK } \\
\text { INSOL } \\
\mathrm{KW} / \mathrm{M} / \mathrm{M}\end{array}$ & $\begin{array}{l}\text { PEAK } \\
\text { POW EF } \\
\%\end{array}$ & $\begin{array}{c}\text { DAILY } \\
\text { ENERGY } \\
\text { KWHR }\end{array}$ & $\begin{array}{l}\text { SUN } \\
\text { ENERGY } \\
\text { KWHR }\end{array}$ & $\begin{array}{c}\text { DAILY } \\
\text { EFFIC. } \\
\%\end{array}$ & $\begin{array}{l}\text { TRACK } \\
\text { TIME } \\
\text { HR }\end{array}$ & $\begin{array}{l}\text { NIP> } \\
300 \text { WI } \\
\text { HR }\end{array}$ & $\begin{array}{l}\text { MAX } \\
\text { IND } \\
\text { MPH }\end{array}$ \\
\hline $\begin{array}{r}1 \\
2 \\
3 \\
4 \\
5 \\
6 \\
7 \\
8 \\
9 \\
10 \\
11 \\
12 \\
13 \\
14 \\
15 \\
16 \\
17 \\
18 \\
19 \\
20 \\
21 \\
22 \\
23 \\
24 \\
25 \\
26 \\
27 \\
28 \\
29 \\
30 \\
31\end{array}$ & $\begin{array}{r}21.90 \\
17.50 \\
12.50 \\
0.00 \\
21.60 \\
19.40 \\
19.50 \\
23.96 \\
18.72 \\
0.20 \\
23.79 \\
23.37 \\
20.80 \\
20.20 \\
20.50 \\
19.60 \\
2.90 \\
0.00 \\
0.00 \\
0.00 \\
0.00 \\
0.00 \\
0.00 \\
23.73 \\
0.00 \\
7.50 \\
0.00 \\
18.50 \\
0.00 \\
25.40 \\
21.20\end{array}$ & $\begin{array}{r}0.0 \\
0.0 \\
0.0 \\
0.0 \\
0.0 \\
0.0 \\
0.0 \\
937.8 \\
794.4 \\
72.6 \\
934.0 \\
919.3 \\
0.0 \\
0.0 \\
0.0 \\
0.0 \\
0.0 \\
517.6 \\
0.0 \\
1029.4 \\
998.8 \\
206.4 \\
0.0 \\
922.6 \\
172.8 \\
0.0 \\
0.0 \\
0.0 \\
0.0 \\
990.0 \\
0.0\end{array}$ & $\begin{array}{r}0.0 \\
0.0 \\
0.0 \\
0.0 \\
0.0 \\
0.0 \\
0.0 \\
29.1 \\
26.9 \\
3.1 \\
29.1 \\
29.0 \\
0.0 \\
0.0 \\
0.0 \\
0.0 \\
0.0 \\
0.0 \\
0.0 \\
0.0 \\
0.0 \\
0.0 \\
0.0 \\
29.3 \\
0.0 \\
0.0 \\
0.0 \\
0.0 \\
0.0 \\
29.3 \\
0.0\end{array}$ & $\begin{array}{r}117.0 \\
56.0 \\
32.0 \\
-4.0 \\
150.0 \\
74.0 \\
87.0 \\
104.0 \\
25.0 \\
-4.0 \\
150.0 \\
151.0 \\
116.0 \\
139.0 \\
145.0 \\
87.0 \\
-5.0 \\
-4.0 \\
-7.0 \\
-8.0 \\
-8.0 \\
-5.0 \\
4.0 \\
155.0 \\
-5.0 \\
20.0 \\
-7.0 \\
61.0 \\
-11.0 \\
159.0 \\
159.0\end{array}$ & $\begin{array}{r}7.071 \\
3.990 \\
5.534 \\
0.230 \\
8.215 \\
5.170 \\
4.830 \\
5.995 \\
2.467 \\
1.077 \\
7.988 \\
8.812 \\
7.068 \\
8.267 \\
7.213 \\
5.551 \\
0.000 \\
2.747 \\
3.002 \\
10.032 \\
8.541 \\
0.591 \\
7.392 \\
8.806 \\
6.970 \\
1.762 \\
4.416 \\
4.341 \\
0.072 \\
8.697 \\
8.412\end{array}$ & $\begin{array}{r}18.9 \\
16.0 \\
6.6 \\
-19.8 \\
20.8 \\
16.3 \\
20.5 \\
19.8 \\
11.6 \\
-4.2 \\
21.4 \\
19.5 \\
18.7 \\
19.2 \\
22.9 \\
17.9 \\
0.0 \\
-1.7 \\
-2.7 \\
-0.9 \\
-1.1 \\
-9.7 \\
0.6 \\
20.1 \\
-0.8 \\
12.9 \\
-1.8 \\
16.0 \\
-174.3 \\
20.9 \\
21.6\end{array}$ & $\begin{array}{l}0.00 \\
0.00 \\
0.00 \\
0.00 \\
0.00 \\
0.00 \\
0.00 \\
0.00 \\
0.00 \\
0.00 \\
0.00 \\
0.00 \\
0.00 \\
0.00 \\
0.00 \\
0.00 \\
0.00 \\
0.00 \\
0.00 \\
0.00 \\
0.00 \\
0.00 \\
0.00 \\
0.00 \\
0.00 \\
0.00 \\
0.00 \\
0.00 \\
0.00 \\
0.00 \\
0.00\end{array}$ & $\begin{array}{l}0.00 \\
0.00 \\
0.00 \\
0.00 \\
0.00 \\
0.00 \\
0.00 \\
0.00 \\
0.00 \\
0.00 \\
0.00 \\
0.00 \\
0.00 \\
0.00 \\
0.00 \\
0.00 \\
0.00 \\
0.00 \\
0.00 \\
0.00 \\
0.00 \\
0.00 \\
0.00 \\
0.00 \\
0.00 \\
0.00 \\
0.00 \\
0.00 \\
0.00 \\
0.00 \\
0.00\end{array}$ & $\begin{array}{l}0.0 \\
0.0 \\
0.0 \\
0.0 \\
0.0 \\
0.0 \\
0.0 \\
0.0 \\
0.0 \\
0.0 \\
0.0 \\
0.0 \\
0.0 \\
0.0 \\
0.0 \\
0.0 \\
0.0 \\
0.0 \\
0.0 \\
0.0 \\
0.0 \\
0.0 \\
0.0 \\
0.0 \\
0.0 \\
0.0 \\
0.0 \\
0.0 \\
0.0 \\
0.0 \\
0.0\end{array}$ \\
\hline
\end{tabular}

TOTAL TRACK TIME FOR MONTH. . . . . . . . . TIME THAT NIP WAS ABOVE 300 W/SQ.M.... TRACK TIME / TIME NIP > 300......... MAXIMUM DAILY POWER............... MAX. DAILY POWER EFFIC. FOR MONTH. .... MAXIMUM DAILY NET ENERGY............ MAX. DAILY ENERGY EFFIC. FOR MONTH ... TOTAL POWER PRODUCED FOR MONTH....... TOTAL SUN ENERGY FOR THE MONTH....... SYSTEM EFFICIENCY FOR THE MONTH.

\author{
0.00 HOURS \\ 0.00 HOURS \\ 0.0000 \\ $25.40 \mathrm{KW}$ \\ $29.3 \%$ \\ $159.00 \mathrm{KWHR}$ \\ $22.9 \%$ \\ 22.0 KWHR SQ.M \\ 165.3 KWHR SQ.M \\ $13.3 \%$
}


DATA FOR MONTH 2 AND YEAR 1986

\begin{tabular}{|c|c|c|c|c|c|c|c|c|c|}
\hline ATE & $\begin{array}{l}\text { PEAK } \\
\text { POWER } \\
\text { KW }\end{array}$ & $\begin{array}{l}\text { PEAK } \\
\text { INSOL } \\
K W / M / M\end{array}$ & $\begin{array}{l}\text { PEAK } \\
\text { POW EF } \\
\%\end{array}$ & $\begin{array}{c}\text { DAILY } \\
\text { ENERGY } \\
\text { KWHR }\end{array}$ & $\begin{array}{l}\text { SUN } \\
\text { ENERGY } \\
\text { KWHR }\end{array}$ & $\begin{array}{c}\text { DAILY } \\
\text { EFFIC. } \\
\%\end{array}$ & $\begin{array}{l}\text { TRACK } \\
\text { TIME } \\
\text { HR }\end{array}$ & $\begin{array}{l}N I P>N \\
300 W \\
H R\end{array}$ & $\begin{array}{l}\text { MAX } \\
\text { JIND } \\
\text { MPH }\end{array}$ \\
\hline $\begin{array}{r}1 \\
2 \\
3 \\
4 \\
5 \\
6 \\
7 \\
8 \\
9 \\
10 \\
11 \\
12 \\
13 \\
14 \\
15 \\
16 \\
17 \\
18 \\
19 \\
20 \\
21 \\
22 \\
23 \\
24 \\
25 \\
26 \\
27 \\
28\end{array}$ & $\begin{array}{r}19.00 \\
17.60 \\
18.50 \\
0.00 \\
0.00 \\
2.20 \\
0.00 \\
0.00 \\
16.30 \\
0.00 \\
0.00 \\
22.40 \\
26.30 \\
0.00 \\
21.30 \\
22.00 \\
14.00 \\
18.00 \\
7.80 \\
20.60 \\
0.00 \\
0.00 \\
22.60 \\
17.30 \\
21.80 \\
17.50 \\
10.70 \\
1.80\end{array}$ & $\begin{array}{l}0.0 \\
0.0 \\
0.0 \\
0.0 \\
0.0 \\
0.0 \\
0.0 \\
0.0 \\
0.0 \\
0.0 \\
0.0 \\
0.0 \\
0.0 \\
0.0 \\
0.0 \\
0.0 \\
0.0 \\
0.0 \\
0.0 \\
0.0 \\
0.0 \\
0.0 \\
0.0 \\
0.0 \\
0.0 \\
0.0 \\
0.0 \\
0.0\end{array}$ & $\begin{array}{l}0.0 \\
0.0 \\
0.0 \\
0.0 \\
0.0 \\
0.0 \\
0.0 \\
0.0 \\
0.0 \\
0.0 \\
0.0 \\
0.0 \\
0.0 \\
0.0 \\
0.0 \\
0.0 \\
0.0 \\
0.0 \\
0.0 \\
0.0 \\
0.0 \\
0.0 \\
0.0 \\
0.0 \\
0.0 \\
0.0 \\
0.0 \\
0.0\end{array}$ & $\begin{array}{r}77.0 \\
95.0 \\
97.0 \\
-7.0 \\
-8.0 \\
-8.0 \\
-2.0 \\
-4.0 \\
29.0 \\
-11.0 \\
-7.0 \\
159.0 \\
189.0 \\
-9.0 \\
132.0 \\
157.0 \\
13.0 \\
79.0 \\
-2.0 \\
111.0 \\
-8.0 \\
-8.0 \\
186.0 \\
36.0 \\
177.0 \\
65.0 \\
22.0 \\
-2.0\end{array}$ & $\begin{array}{l}0.000 \\
0.000 \\
0.000 \\
0.000 \\
0.000 \\
0.000 \\
0.000 \\
0.000 \\
0.000 \\
0.000 \\
0.000 \\
0.000 \\
0.000 \\
0.000 \\
0.000 \\
0.000 \\
0.000 \\
0.000 \\
0.000 \\
0.000 \\
0.000 \\
0.000 \\
0.000 \\
0.000 \\
0.000 \\
0.000 \\
0.000 \\
0.000\end{array}$ & $\begin{array}{l}0.0 \\
0.0 \\
0.0 \\
0.0 \\
0.0 \\
0.0 \\
0.0 \\
0.0 \\
0.0 \\
0.0 \\
0.0 \\
0.0 \\
0.0 \\
0.0 \\
0.0 \\
0.0 \\
0.0 \\
0.0 \\
0.0 \\
0.0 \\
0.0 \\
0.0 \\
0.0 \\
0.0 \\
0.0 \\
0.0 \\
0.0 \\
0.0\end{array}$ & $\begin{array}{l}0.00 \\
0.00 \\
0.00 \\
0.00 \\
0.00 \\
0.00 \\
0.00 \\
0.00 \\
0.00 \\
0.00 \\
0.00 \\
0.00 \\
0.00 \\
0.00 \\
0.00 \\
0.00 \\
0.00 \\
0.00 \\
0.00 \\
0.00 \\
0.00 \\
0.00 \\
0.00 \\
0.00 \\
0.00 \\
0.00 \\
0.00 \\
0.00\end{array}$ & $\begin{array}{l}0.00 \\
0.00 \\
0.00 \\
0.00 \\
0.00 \\
0.00 \\
0.00 \\
0.00 \\
0.00 \\
0.00 \\
0.00 \\
0.00 \\
0.00 \\
0.00 \\
0.00 \\
0.00 \\
0.00 \\
0.00 \\
0.00 \\
0.00 \\
0.00 \\
0.00 \\
0.00 \\
0.00 \\
0.00 \\
0.00 \\
0.00 \\
0.00\end{array}$ & $\begin{array}{l}0.0 \\
0.0 \\
0.0 \\
0.0 \\
0.0 \\
0.0 \\
0.0 \\
0.0 \\
0.0 \\
0.0 \\
0.0 \\
0.0 \\
0.0 \\
0.0 \\
0.0 \\
0.0 \\
0.0 \\
0.0 \\
0.0 \\
0.0 \\
0.0 \\
0.0 \\
0.0 \\
0.0 \\
0.0 \\
0.0 \\
0.0 \\
0.0\end{array}$ \\
\hline
\end{tabular}

TOTAL TRACK TIME FOR MONTH......... 0.00 HOURS

TIME THAT NIP WAS ABOUE $300 \mathrm{~W} / \mathrm{SQ} . \mathrm{M} . . . .000$ HOLRS

TRACK TIME / TIME NIP > 300........ 0.0000

MAXIMUM DAILY POWER.............. $26.30 \mathrm{KW}$

MAX. DAILY POWER EFFIC. FOR MONTH.... $0.0 \%$

MAXIMUM DAILY NET ENERGY........... 189.00 KWHR

MAX. DAILY ENERGY EFFIC. FOR MONTH ... $0.0 \%$

TOTAL POWER PRODUCED FOR MONTH....... 0.0 KWHR SQ.M

TOTAL SUN ENERGY FOR THE MONTH....... $0.0 \mathrm{KWHR/SQ.M}$

SYSTEM EFFICIENCY FOR THE MONTH...... $0.0 \%$ 
DATA FOR MONTH 3 AND YEAR 1986

\begin{tabular}{|c|c|c|c|c|c|c|c|c|c|}
\hline$A T$ & $\begin{array}{l}\text { PEAK } \\
\text { POWER } \\
\text { KW }\end{array}$ & $\begin{array}{l}\text { PEAK } \\
\text { INSOL } \\
\text { KW/M/M }\end{array}$ & $\begin{array}{l}\text { PEAK } \\
\text { POW EF } \\
\%\end{array}$ & $\begin{array}{c}\text { DAILY } \\
\text { ENERGY } \\
\text { KNHR }\end{array}$ & $\begin{array}{l}\text { SUN } \\
\text { ENERGY } \\
\text { KWHR }\end{array}$ & $\begin{array}{c}\text { DAILY } \\
\text { EFFIC. } \\
\%\end{array}$ & $\begin{array}{l}\text { TRACK } \\
\text { TIME } \\
\text { HR }\end{array}$ & $\begin{array}{l}\text { NIP> } \\
300 \text { WI } \\
\text { HR }\end{array}$ & $\begin{array}{l}\text { MAX } \\
\text { JIND } \\
\text { MPH }\end{array}$ \\
\hline $\begin{array}{l}1 \\
2 \\
3 \\
4 \\
5 \\
6 \\
7 \\
8 \\
9 \\
10 \\
11 \\
12 \\
13 \\
14 \\
15 \\
16 \\
17 \\
18 \\
19 \\
20 \\
21 \\
22 \\
23 \\
24 \\
25 \\
26 \\
27 \\
28 \\
29 \\
30 \\
31\end{array}$ & $\begin{array}{r}24.97 \\
24.89 \\
23.28 \\
21.58 \\
22.68 \\
0.00 \\
16.30 \\
21.04 \\
20.70 \\
10.69 \\
11.49 \\
20.43 \\
0.00 \\
0.00 \\
0.00 \\
0.00 \\
0.00 \\
0.00 \\
0.00 \\
0.00 \\
0.00 \\
0.00 \\
0.00 \\
0.00 \\
20.65 \\
17.07 \\
19.74 \\
21.21 \\
20.92 \\
18.98 \\
17.90\end{array}$ & $\begin{array}{r}915.6 \\
906.0 \\
818.0 \\
807.0 \\
859.0 \\
1132.0 \\
1050.0 \\
824.0 \\
856.0 \\
773.0 \\
562.0 \\
852.0 \\
83.0 \\
73.4 \\
431.6 \\
0.0 \\
1021.0 \\
860.0 \\
56.4 \\
621.9 \\
981.7 \\
952.1 \\
951.0 \\
883.0 \\
886.0 \\
777.5 \\
892.4 \\
994.8 \\
959.5 \\
868.0 \\
808.0\end{array}$ & $\begin{array}{r}31.1 \\
31.3 \\
32.5 \\
30.5 \\
30.1 \\
0.0 \\
17.7 \\
29.1 \\
27.6 \\
15.8 \\
23.3 \\
27.4 \\
0.0 \\
0.0 \\
0.0 \\
0.0 \\
0.0 \\
0.0 \\
0.0 \\
0.0 \\
0.0 \\
0.0 \\
0.0 \\
0.0 \\
26.6 \\
25.0 \\
25.2 \\
24.3 \\
24.9 \\
24.9 \\
25.3\end{array}$ & $\begin{array}{r}174.8 \\
167.0 \\
98.2 \\
68.2 \\
48.0 \\
0.0 \\
23.0 \\
122.9 \\
40.3 \\
4.8 \\
8.6 \\
11.5 \\
-2.9 \\
0.0 \\
0.0 \\
0.0 \\
0.0 \\
-5.3 \\
-7.7 \\
-7.7 \\
-5.8 \\
-4.8 \\
-4.8 \\
-3.8 \\
109.4 \\
42.2 \\
146.9 \\
180.5 \\
167.1 \\
119.0 \\
124.7\end{array}$ & $\begin{array}{l}8.353 \\
8.252 \\
5.599 \\
4.924 \\
8.140 \\
10.012 \\
8.622 \\
7.276 \\
3.704 \\
2.676 \\
1.819 \\
2.470 \\
0.576 \\
0.000 \\
0.000 \\
0.000 \\
4.878 \\
6.861 \\
1.043 \\
1.431 \\
9.901 \\
9.472 \\
9.594 \\
7.364 \\
8.290 \\
4.125 \\
8.875 \\
9.987 \\
9.246 \\
7.729 \\
7.129\end{array}$ & $\begin{array}{r}23.9 \\
23.1 \\
20.0 \\
15.8 \\
6.7 \\
0.0 \\
3.0 \\
19.3 \\
12.4 \\
2.0 \\
5.4 \\
5.3 \\
-5.7 \\
0.0 \\
0.0 \\
0.0 \\
0.0 \\
-0.9 \\
-8.4 \\
-6.1 \\
-0.7 \\
-0.6 \\
-0.6 \\
-0.6 \\
15.1 \\
11.7 \\
18.9 \\
20.6 \\
20.6 \\
17.6 \\
19.9\end{array}$ & $\begin{array}{l}0.00 \\
0.00 \\
0.00 \\
0.00 \\
0.00 \\
0.00 \\
0.00 \\
0.00 \\
0.00 \\
0.00 \\
0.00 \\
0.00 \\
0.00 \\
0.00 \\
0.00 \\
0.00 \\
0.00 \\
0.00 \\
0.00 \\
0.00 \\
0.00 \\
0.00 \\
0.00 \\
0.00 \\
0.00 \\
0.00 \\
0.00 \\
0.00 \\
0.00 \\
0.00 \\
0.00\end{array}$ & $\begin{array}{l}0.00 \\
0.00 \\
0.00 \\
0.00 \\
0.00 \\
0.00 \\
0.00 \\
0.00 \\
0.00 \\
0.00 \\
0.00 \\
0.00 \\
0.00 \\
0.00 \\
0.00 \\
0.00 \\
0.00 \\
0.00 \\
0.00 \\
0.00 \\
0.00 \\
0.00 \\
0.00 \\
0.00 \\
0.00 \\
0.00 \\
0.00 \\
0.00 \\
0.00 \\
0.00 \\
0.00\end{array}$ & $\begin{array}{l}0.0 \\
0.0 \\
0.0 \\
0.0 \\
0.0 \\
0.0 \\
0.0 \\
0.0 \\
0.0 \\
0.0 \\
0.0 \\
0.0 \\
0.0 \\
0.0 \\
0.0 \\
0.0 \\
0.0 \\
0.0 \\
0.0 \\
0.0 \\
0.0 \\
0.0 \\
0.0 \\
0.0 \\
0.0 \\
0.0 \\
0.0 \\
0.0 \\
0.0 \\
0.0 \\
0.0\end{array}$ \\
\hline
\end{tabular}

TOTAL TRACK TIME FOR MONTH.......... TIME THAT NIP WAS ABOVE $300 \mathrm{~W} / \mathrm{SQ} . \mathrm{M} . .$. TRACK TIME / TIME NIP > 300........ MAXIMUM DAILY POWER............... MAX. DAILY POWER EFFIC. FOR MONTH. ....

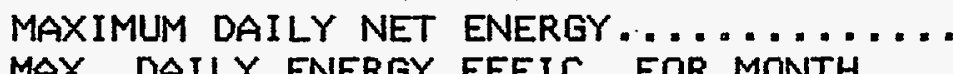
MAX. DAILY ENERGY EFFIC. FOR MONTH ... TOTAL POWER PRODUCED FOR MONTH........ TOTAL SUN ENERGY FOR THE MONTH........ SYSTEM EFFICIENCY FOR THE MONTH.......

\author{
0.00 HOURS \\ 0.00 HOURS \\ 0.0000 \\ $24.97 \mathrm{KW}$ \\ $32.5 \%$ \\ 180.48 KWHR \\ $23.9 \%$ \\ 18.4 KWHR/SQ.M \\ 178.3 KWHR SQ.M \\ $10.3 \%$
}


DATA FOR MONTH 4 AND YEAR 1986.

\begin{tabular}{|c|c|c|c|c|c|c|c|c|c|}
\hline ATE & $\begin{array}{c}\text { PEAK } \\
\text { POWER } \\
\text { KW }\end{array}$ & $\begin{array}{l}\text { PEAK } \\
\text { INSOL } \\
\mathrm{KW} / \mathrm{M} / \mathrm{M}\end{array}$ & $\begin{array}{l}\text { PEAK } \\
\text { POW EF } \\
\%\end{array}$ & $\begin{array}{c}\text { DAILY } \\
\text { ENERGY } \\
\text { KWHR }\end{array}$ & $\begin{array}{l}\text { SUN } \\
\text { ENERGY } \\
\text { KWHR }\end{array}$ & $\begin{array}{c}\text { DAILY } \\
\text { EFFIC. } \\
\%\end{array}$ & $\begin{array}{l}\text { rRACK } \\
\text { IME } \\
\text { HR }\end{array}$ & $\begin{array}{l}\text { NIP> } \\
300 \\
\text { HR }\end{array}$ & $\begin{array}{c}\text { MAX } \\
\text { WIND } \\
\text { MPH }\end{array}$ \\
\hline $\begin{array}{r}1 \\
2 \\
3 \\
4 \\
5 \\
6 \\
7 \\
8 \\
9 \\
10 \\
11 \\
12 \\
13 \\
14 \\
15 \\
16\end{array}$ & $\begin{array}{r}16.97 \\
21.29 \\
18.05 \\
14.64 \\
12.73 \\
18.12 \\
14.93 \\
0.00 \\
23.88 \\
24.22 \\
24.08 \\
0.00 \\
22.56 \\
20.78 \\
24.56 \\
23.41\end{array}$ & $\begin{array}{r}0.0 \\
835.2 \\
734.5 \\
745.2 \\
725.1 \\
831.4 \\
755.1 \\
194.5 \\
995.5 \\
953.7 \\
985.7 \\
109.1 \\
951.8 \\
892.3 \\
1000.5 \\
935.9\end{array}$ & $\begin{array}{r}0.0 \\
29.1 \\
28.0 \\
22.4 \\
20.0 \\
24.9 \\
22.6 \\
0.0 \\
27.4 \\
29.0 \\
27.9 \\
0.0 \\
27.0 \\
26.6 \\
28.0 \\
28.5\end{array}$ & $\begin{array}{r}78.7 \\
128.6 \\
36.5 \\
30.7 \\
40.3 \\
80.6 \\
18.2 \\
-8.6 \\
195.8 \\
162.0 \\
143.0 \\
-11.5 \\
164.2 \\
79.7 \\
131.5 \\
129.6\end{array}$ & $\begin{array}{r}8.036 \\
4.788 \\
5.085 \\
5.883 \\
7.074 \\
4.810 \\
1.670 \\
10.719 \\
0.000 \\
9.527 \\
1.449 \\
9.950 \\
7.005 \\
8.464 \\
8.004 \\
7.166\end{array}$ & $\begin{array}{r}11.2 \\
30.6 \\
8.2 \\
6.0 \\
6.5 \\
19.1 \\
12.5 \\
-0.9 \\
0.0 \\
19.4 \\
112.6 \\
-1.3 \\
26.7 \\
10.7 \\
18.7 \\
20.6\end{array}$ & $\begin{array}{l}0.00 \\
0.00 \\
0.00 \\
0.00 \\
0.00 \\
0.00 \\
0.00 \\
0.00 \\
0.00 \\
0.00 \\
0.00 \\
0.00 \\
0.00 \\
0.00 \\
0.00 \\
0.00\end{array}$ & $\begin{array}{l}0.00 \\
0.00 \\
0.00 \\
0.00 \\
0.00 \\
0.00 \\
0.00 \\
0.00 \\
0.00 \\
0.00 \\
0.00 \\
0.00 \\
0.00 \\
0.00 \\
0.00 \\
0.00\end{array}$ & $\begin{array}{l}0.0 \\
0.0 \\
0.0 \\
0.0 \\
0.0\end{array}$ \\
\hline $\begin{array}{l}17 \\
18 \\
19 \\
20 \\
21 \\
22 \\
23 \\
24 \\
25 \\
26 \\
27 \\
28 \\
29 \\
30\end{array}$ & $\begin{array}{r}22.28 \\
22.88 \\
21.90 \\
0.00 \\
0.00 \\
0.00 \\
0.00 \\
0.00 \\
0.00 \\
0.00 \\
0.00 \\
0.00 \\
24.36 \\
19.75\end{array}$ & $\begin{array}{r}894.2 \\
929.4 \\
917.9 \\
0.0 \\
0.0 \\
0.0 \\
0.0 \\
0.0 \\
0.0 \\
0.0 \\
0.0 \\
0.0 \\
976.0 \\
984.2\end{array}$ & $\begin{array}{r}28.4 \\
28.1 \\
27.2 \\
0.0 \\
0.0 \\
0.0 \\
0.0 \\
0.0 \\
0.0 \\
0.0 \\
0.0 \\
0.0 \\
28.5 \\
22.9\end{array}$ & $\begin{array}{r}97.0 \\
185.7 \\
153.6 \\
0.0 \\
21.0 \\
154.0 \\
219.0 \\
208.0 \\
166.0 \\
166.0 \\
166.0 \\
39.0 \\
122.9 \\
32.6\end{array}$ & $\begin{array}{r}9.934 \\
9.206 \\
0.000 \\
0.000 \\
0.000 \\
0.000 \\
0.000 \\
0.000 \\
0.000 \\
0.000 \\
0.000 \\
0.000 \\
10.100 \\
10.942\end{array}$ & $\begin{array}{r}11.1 \\
23.0 \\
0.0 \\
0.0 \\
0.0 \\
0.0 \\
0.0 \\
0.0 \\
0.0 \\
0.0 \\
0.0 \\
0.0 \\
13.9 \\
3.4\end{array}$ & $\begin{array}{l}0.00 \\
0.00 \\
0.00 \\
0.00 \\
0.00 \\
0.00 \\
0.00 \\
0.00 \\
0.00 \\
0.00 \\
0.00 \\
0.00 \\
0.00 \\
0.00\end{array}$ & $\begin{array}{l}0.00 \\
0.00 \\
0.00 \\
0.00 \\
0.00 \\
0.00 \\
0.00 \\
0.00 \\
0.00 \\
0.00 \\
0.00 \\
0.00 \\
0.00 \\
0.00\end{array}$ & $\begin{array}{l}0.0 \\
0.0 \\
0.0 \\
0.0 \\
0.0 \\
0.0 \\
0.0 \\
0.0 \\
0.0 \\
0.0 \\
0.0\end{array}$ \\
\hline
\end{tabular}

\footnotetext{
TOTAL TRACK TIME FOR MONTH.......... 0.00 HQURS TIME THAT NIP WAS ABOVE $300 \mathrm{~W} / \mathrm{SQ} . \mathrm{M} . \ldots .0 .00$ HOURS TRACK TIME / TIME NIP > 300........ 0.0000 MAXIMUM DAILY POWER.............. $24.56 \mathrm{~kW}$ MAX. DAILY POWER EFFIC. FOR MONTH..... $29.1 \%$ MAXIMUM DAILY NET ENERGY........... $219.00 \mathrm{KWHR}$ MAX. DAILY ENERGY EFFIC. FOR MONTH ... $112.6 \%$ TOTAL POWER PRODUCED FOR MONTH....... 18.7 KWHR/ SQ.M TOTAL SUN ENERGY FOR THE MONTH....... 139.8 KWHR/ SQ.M SYSTEM EFFICIENCY FOR THE MONTH....... $13.4 \%$
} 


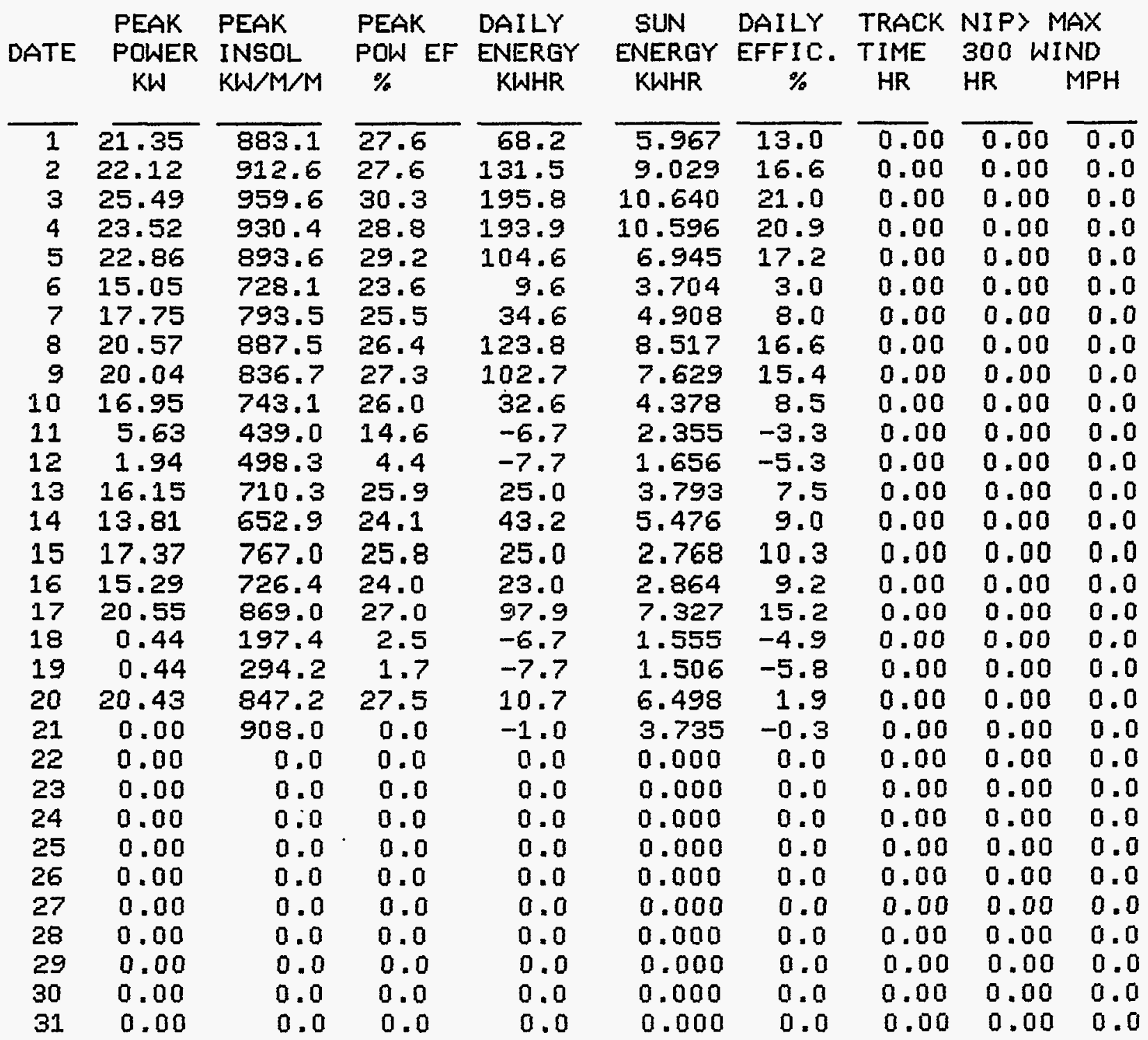

TOTAL TRACK TIME FOR MONTH.......... TIME THAT NIP WAS ABOUE 300 W/SQ.M... TRACK TIME / TIME NIP > $300 \ldots . \ldots \ldots .$.

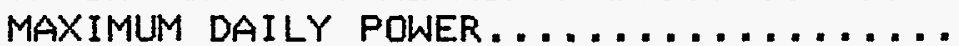
MAX. DAILY POWER EFFIC. FOR MONTH. .... MAXIMUM DAILY NET ENERGY ............ MAX. DAILY ENERGY EFFIC. FOR MONTH ... TOTAL POWER PRODUCED FOR MONTH........ TOTAL SUN ENERGY FOR THE MONTH....... SYSTEM EFFICIENCY FOR THE MONTH.

\author{
0.00 HOURS \\ 0.00 HOURS \\ 0.0000 \\ $25.49 \mathrm{KW}$ \\ $30.3 \%$ \\ $195.84 \mathrm{KWHR}$ \\ $21.0 \%$ \\ 13.6 KWHR/ SQ.M \\ 111.8 KWHR/ SQ.M \\ $12.2 \%$
}


DATA FOR MONTH 6 AND YEAR 1986

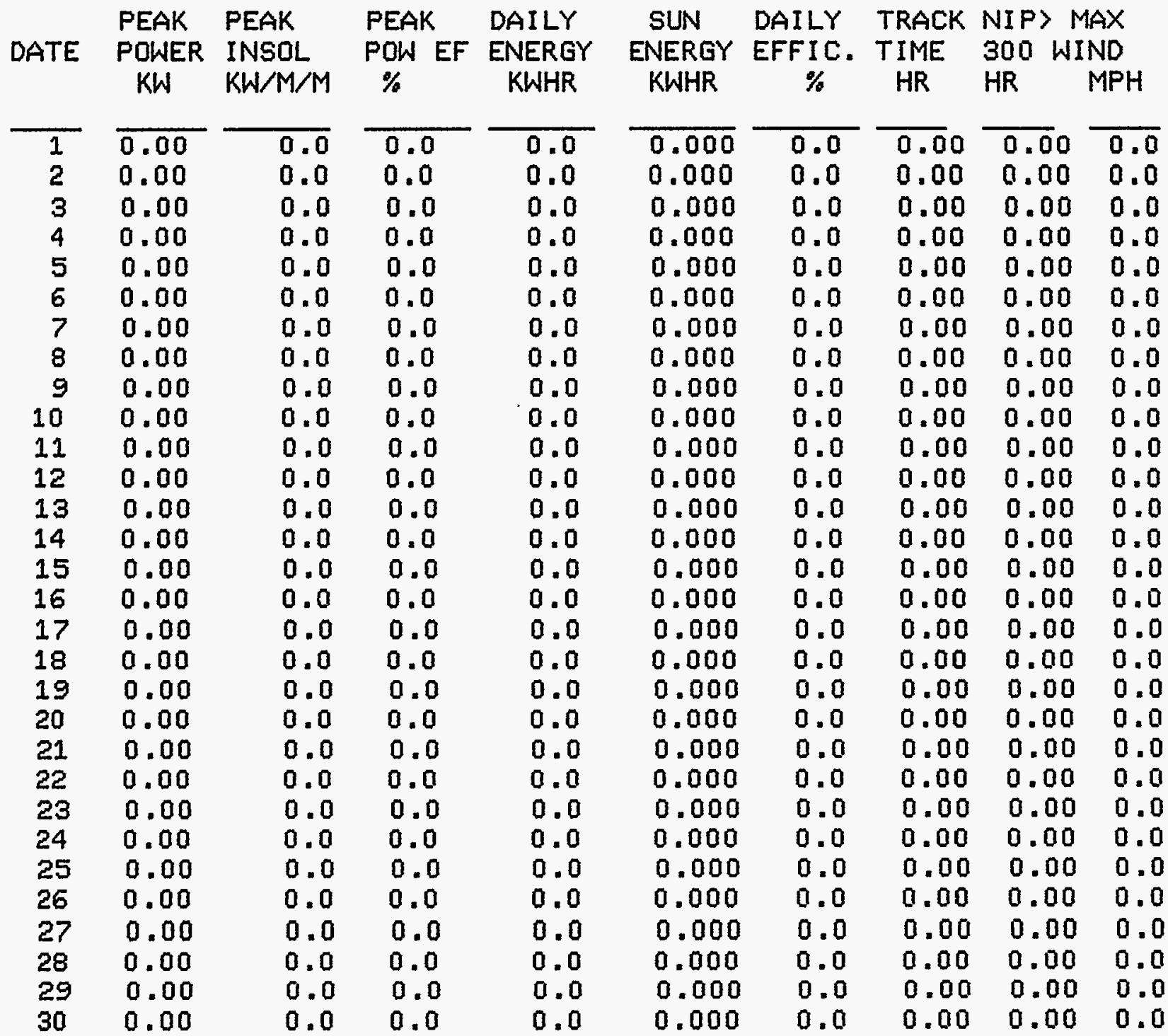

TOTAL TRACK TIME FOR MONTH........... TIME THAT NIP WAS ABQVE 300 W/SQ.M... TRACK TIME / TIME NIP > $300 \ldots . . . .$. MAXIMUM DAILY POWER............. MAX. DAILY POWER EFFIC. FOR MONTH..... MAXIMUM DAILY NET ENERGY.......... MAX. DAILY ENERGY EFFIC. FOR MONTH ... TOTAL POWER PRODUCED FOR MONTH. ....... TOTAL SUN ENERGY FOR THE MONTH........ SYSTEM EFFICIENCY FOR THE MONTH.......

\author{
0.00 HOURS \\ 0.00 HOURS \\ 0.0000 \\ $0.00 \mathrm{KW}$ \\ $0.0 \%$ \\ $0.00 \mathrm{KWHR}$ \\ $0.0 \%$ \\ 0.0 KWHR SQ.M \\ 0.0 KWHR/SQ.M \\ $0.0 \%$
}


DATA FOR MONTH 7 AND YEAR 1986

\begin{tabular}{|c|c|c|c|c|c|c|c|c|c|}
\hline$T$ & $\begin{array}{l}\text { PEAK } \\
\text { POWER } \\
\text { KW }\end{array}$ & $\begin{array}{l}E A K \\
J S O L \\
J / M / M\end{array}$ & $\begin{array}{l}\text { PEAK } \\
\text { POW EF } \\
\%\end{array}$ & $\begin{array}{l}\text { AILY } \\
\text { NERGY } \\
\text { KWHR }\end{array}$ & $\begin{array}{l}\text { SUN } \\
\text { ENERGY } \\
\text { KWHR }\end{array}$ & $\begin{array}{l}\text { ILY } \\
\text { FIC. } \\
\%\end{array}$ & $\begin{array}{l}\text { TRACK } \\
\text { TIME } \\
\text { HR }\end{array}$ & $\begin{array}{l}\text { NIP> } \\
300 W \\
H R\end{array}$ & $\begin{array}{l}x \\
D \\
\text { PH }\end{array}$ \\
\hline $\begin{array}{l}1 \\
2 \\
3 \\
4 \\
5 \\
6 \\
7 \\
8 \\
9 \\
10 \\
11 \\
12 \\
13 \\
14 \\
15 \\
16 \\
17 \\
18 \\
19 \\
20 \\
21 \\
22 \\
23 \\
24 \\
25 \\
26 \\
27 \\
28 \\
29 \\
30 \\
31\end{array}$ & $\begin{array}{r}0.00 \\
1.22 \\
21.61 \\
18.76 \\
16.66 \\
19.35 \\
18.02 \\
18.39 \\
17.01 \\
16.94 \\
21.12 \\
18.21 \\
20.77 \\
19.55 \\
19.34 \\
21.17 \\
16.47 \\
17.69 \\
13.32 \\
0.00 \\
0.00 \\
0.00 \\
0.00 \\
0.00 \\
0.00 \\
0.00 \\
0.00 \\
16.17 \\
18.70 \\
21.06 \\
19.55\end{array}$ & $\begin{array}{r}0.0 \\
0.0 \\
0.0 \\
0.0 \\
0.0 \\
0.0 \\
0.0 \\
0.0 \\
0.0 \\
0.0 \\
0.0 \\
0.0 \\
0.0 \\
706.9 \\
711.9 \\
756.9 \\
615.9 \\
620.0 \\
497.4 \\
0.0 \\
0.0 \\
0.0 \\
0.0 \\
0.0 \\
0.0 \\
0.0 \\
0.0 \\
616.0 \\
694.4 \\
765.5 \\
702.2\end{array}$ & $\begin{array}{l}0.0 \\
0.0 \\
0.0 \\
0.0 \\
0.0 \\
0.0 \\
0.0 \\
0.0 \\
0.0 \\
0.0 \\
0.0 \\
0.0 \\
0.0 \\
31.5 \\
31.0 \\
31.9 \\
30.5 \\
32.5 \\
30.5 \\
0.0 \\
0.0 \\
0.0 \\
0.0 \\
0.0 \\
0.0 \\
0.0 \\
0.0 \\
29.9 \\
30.7 \\
31.4 \\
31.8\end{array}$ & $\begin{array}{r}0.0 \\
-7.7 \\
148.8 \\
101.8 \\
62.4 \\
38.4 \\
53.8 \\
69.1 \\
27.8 \\
79.7 \\
78.7 \\
36.5 \\
72.0 \\
79.7 \\
25.9 \\
126.7 \\
62.4 \\
76.8 \\
23.0 \\
0.0 \\
0.0 \\
0.0 \\
0.0 \\
0.0 \\
0.0 \\
0.0 \\
0.0 \\
41.3 \\
104.6 \\
146.9 \\
90.2\end{array}$ & $\begin{array}{l}0.000 \\
6.688 \\
5.125 \\
3.419 \\
3.542 \\
2.228 \\
4.169 \\
3.819 \\
6.642 \\
4.558 \\
5.219 \\
4.627 \\
4.489 \\
2.393 \\
6.122 \\
3.617 \\
4.724 \\
1.557 \\
0.000 \\
0.000 \\
0.000 \\
0.000 \\
0.000 \\
0.000 \\
0.000 \\
0.000 \\
0.000 \\
5.315 \\
5.324 \\
7.167 \\
4.552\end{array}$ & $\begin{array}{r}20.6 \\
4.8 \\
19.9 \\
17.2 \\
9.0 \\
18.3 \\
38.0 \\
4.8 \\
40.0 \\
15.1 \\
56.3 \\
0.0 \\
0.0 \\
0.0 \\
0.0 \\
0.0 \\
0.0 \\
0.0 \\
0.0 \\
0.0 \\
8.9 \\
22.4 \\
23.4 \\
22.6\end{array}$ & $\begin{array}{l}0.00 \\
0.00 \\
0.00 \\
0.00 \\
0.00 \\
0.00 \\
0.00 \\
0.00 \\
0.00 \\
0.00 \\
0.00 \\
0.00 \\
0.00 \\
0.00 \\
0.00 \\
0.00 \\
0.00 \\
0.00 \\
0.00 \\
0.00 \\
0.00 \\
0.00 \\
0.00 \\
0.00 \\
0.00 \\
0.00 \\
0.00 \\
0.00 \\
0.00 \\
0.00 \\
0.00\end{array}$ & $\begin{array}{l}0.00 \\
0.00 \\
0.00 \\
0.00 \\
0.00 \\
0.00 \\
0.00 \\
0.00 \\
0.00 \\
0.00 \\
0.00 \\
0.00 \\
0.00 \\
0.00 \\
0.00 \\
0.00 \\
0.00 \\
0.00 \\
0.00 \\
0.00 \\
0.00 \\
0.00 \\
0.00 \\
0.00 \\
0.00 \\
0.00 \\
0.00 \\
0.00 \\
0.00 \\
0.00 \\
0.00\end{array}$ & $\begin{array}{l}0.0 \\
0.0 \\
0.0 \\
0.0 \\
0.0 \\
0.0 \\
0.0 \\
0.0 \\
0.0 \\
0.0 \\
0.0 \\
0.0 \\
0.0 \\
0.0 \\
0.0 \\
0.0 \\
0.0 \\
0.0 \\
0.0 \\
0.0 \\
0.0 \\
0.0 \\
0.0 \\
0.0 \\
0.0 \\
0.0 \\
0.0 \\
0.0 \\
0.0 \\
0.0 \\
0.0\end{array}$ \\
\hline
\end{tabular}

TOTAL TRACK TIME FOR MONTH. . . . . . . .

TIME THAT NIP WAS ABOVE 300 W/SQ.M....

TRACK TIME / TIME NIP > 300.........

MAXIMUM DAILY POWER. ...............

MAX. DAILY POWER EFFIC. FOR MONTH......

MAXIMUM DAILY NET ENERGY . . .........

MAX. DAILY ENERGY EFFIC. FOR MONTH $\ldots$

TOTAL POWER PRODUCED FOR MONTH. .......

TOTAL SUN ENERGY FOR THE MONTH. . . . . . .

SYSTEM EFFICIENCY FOR THE MONTH.

\author{
0.00 HOURS \\ 0.00 HOURS \\ 0.0000 \\ $21.61 \mathrm{KW}$ \\ $32.5 \%$ \\ $148.80 \mathrm{KWHR}$ \\ $56.3 \%$ \\ 17.3 KWHR/SQ.M \\ 95.3 KWHR SQ.M \\ $18.1 \%$
}




\section{APPENDIX C}

This appendix contains a summary of the Stirling Dish testing from August 1985 to Sept. 1988 at SCE test site, Barstow, California. 


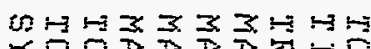

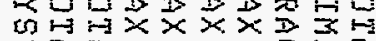

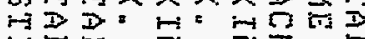

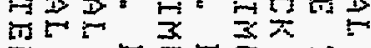
而

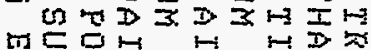

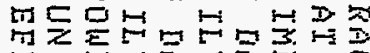

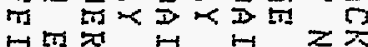

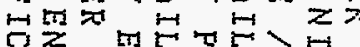

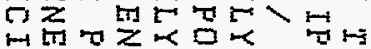

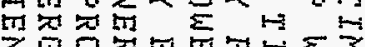

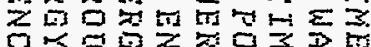

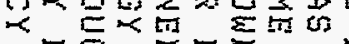

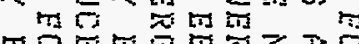

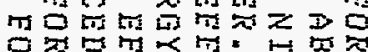
页

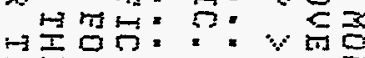
至葫: : 而的: 주의:0:00T 3응뭉:

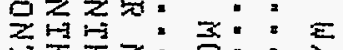

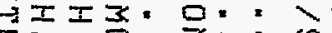

: : : : :

$\because=$ H: $I=:$ :

$\therefore: 10: \div$

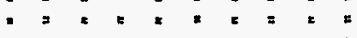

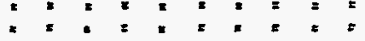

is 0

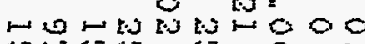
(T) J का

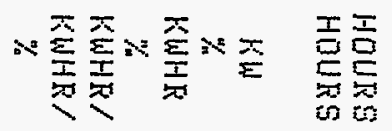

0

:

3

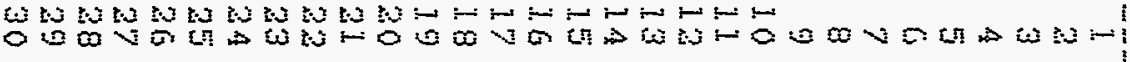

0000001000000000000000000000001

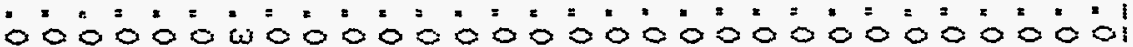

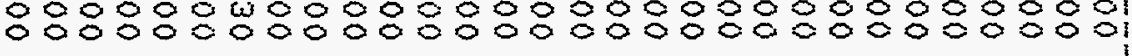

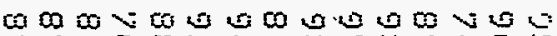

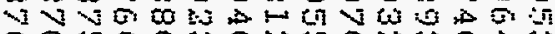

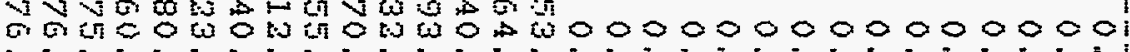

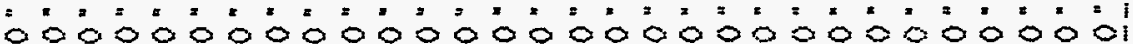

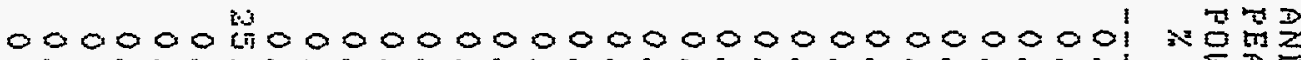

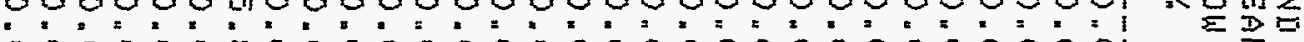
00000000000000000000000000000

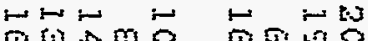

W

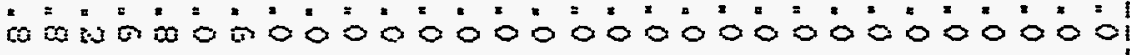

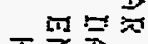

穴西

E 究象象

जolim

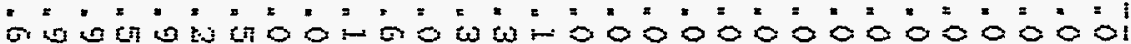

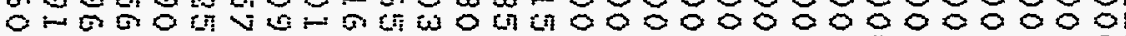
ow 0 जu

$=\sum_{i}^{\pi}$

$\underset{i}{i} \frac{2}{2}$

芴焉

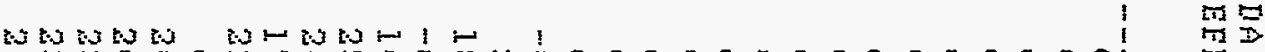
$\rightarrow$ wo 00 W. wis

0000000000000000000000000000001

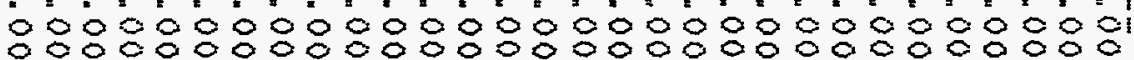
0000000000000000000000000000001

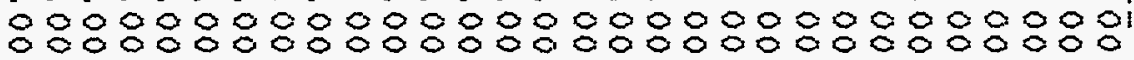

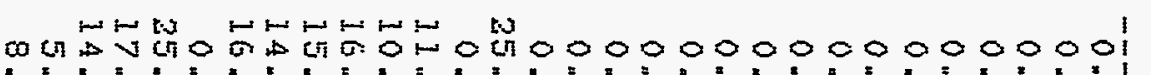

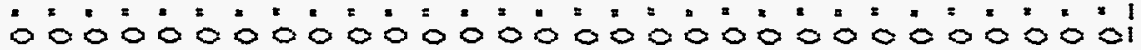

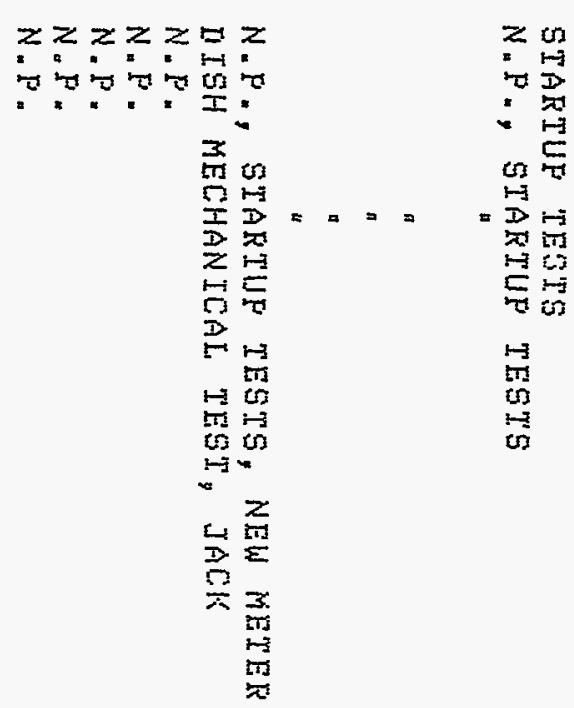

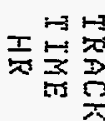

I $w z$

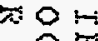
$\underset{i}{\Sigma} \underset{D}{\Sigma}$

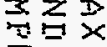

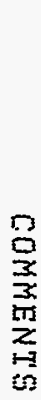




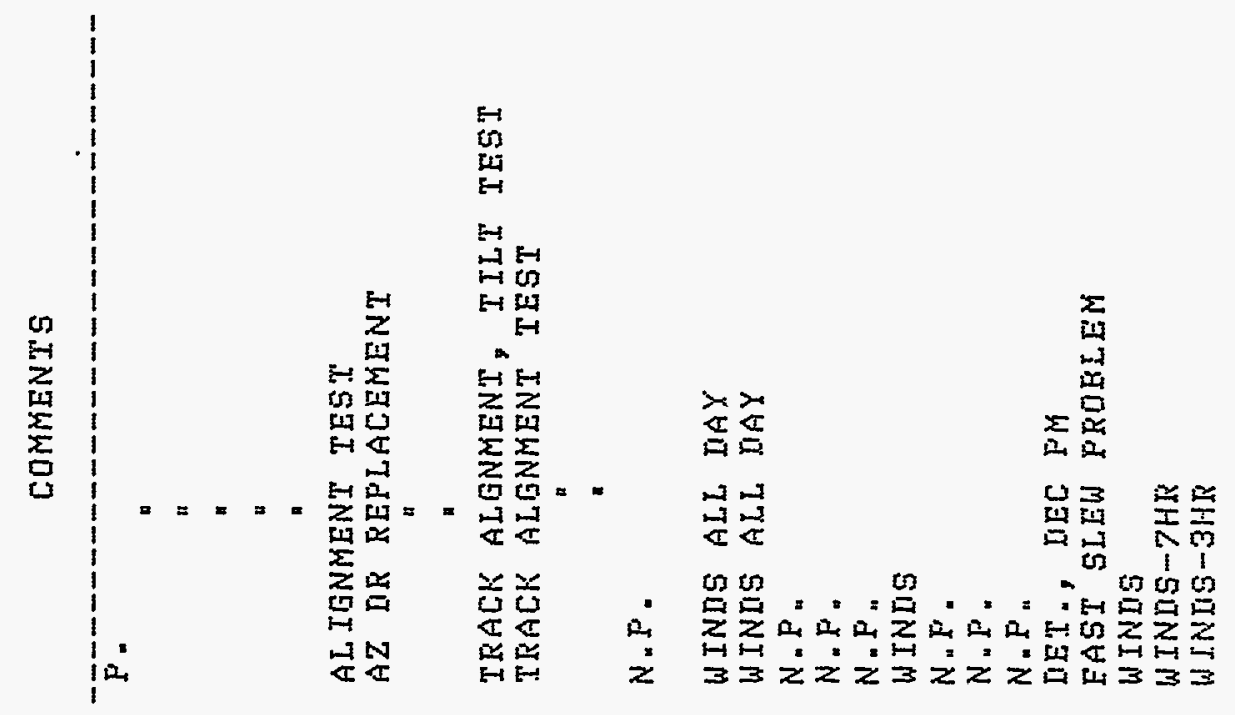

I 1000000000000000000000000000000 萑空 $\Sigma$ $=$ $\therefore$

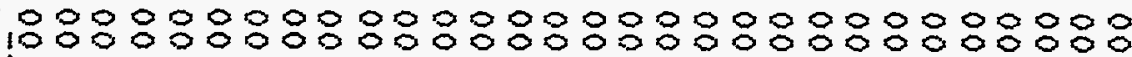

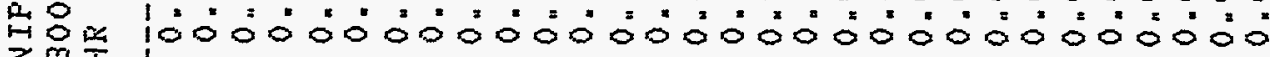
- 00000000000000000000000000000 는 证仼 यू

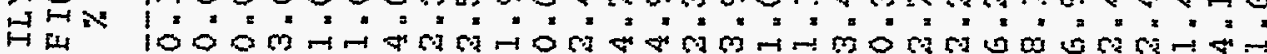
II (1)

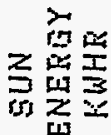
11

$$
i
$$$$
11
$$

$100000 \%$

$$
1
$$$$
\text { is }
$$

(0mp 10ल0m

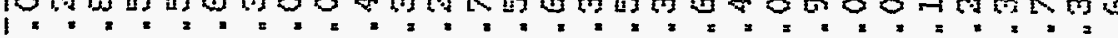

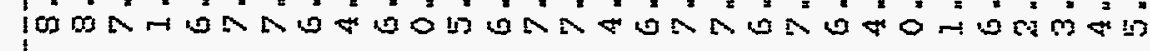

$\lim _{\infty} \rightarrow$

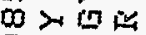

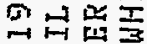

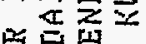
近 (5)

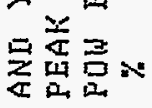
1000000000000000000700000000000 1 .

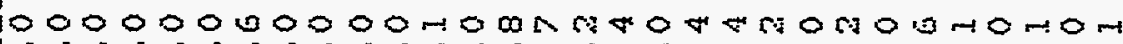

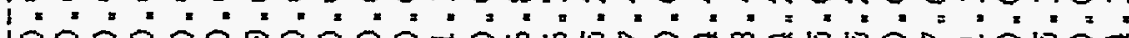

$m$

I运它

$\sum_{2}^{2}$ $\sum_{i=1} \sum_{i=1}$ $\sum$ 电 空些 농 足实品

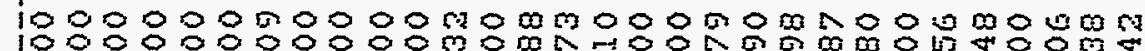

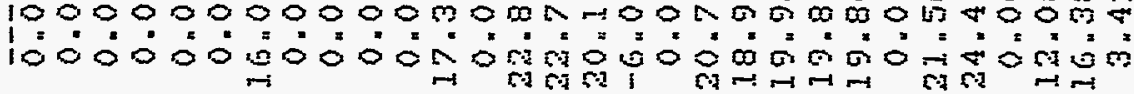

兵

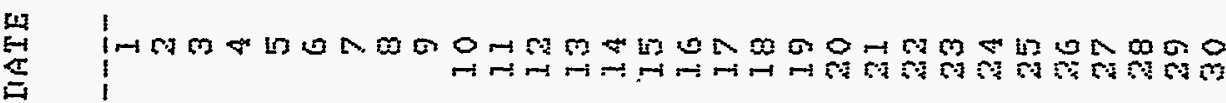

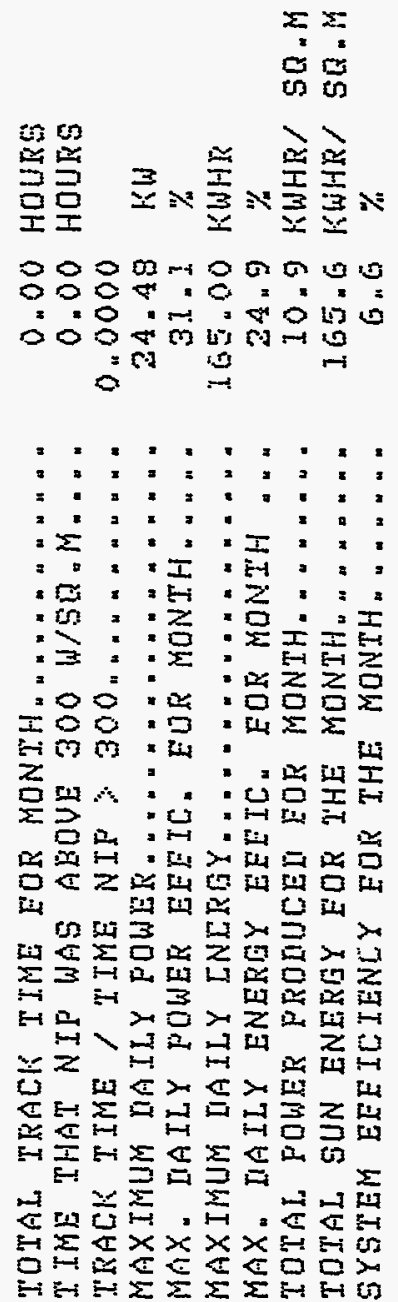

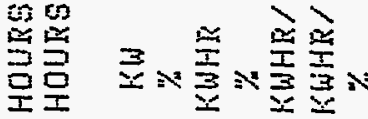
$0000 \mathrm{mon} 0 \mathrm{0}$ $000 \%: 0=$ : $=6 \pi$ 


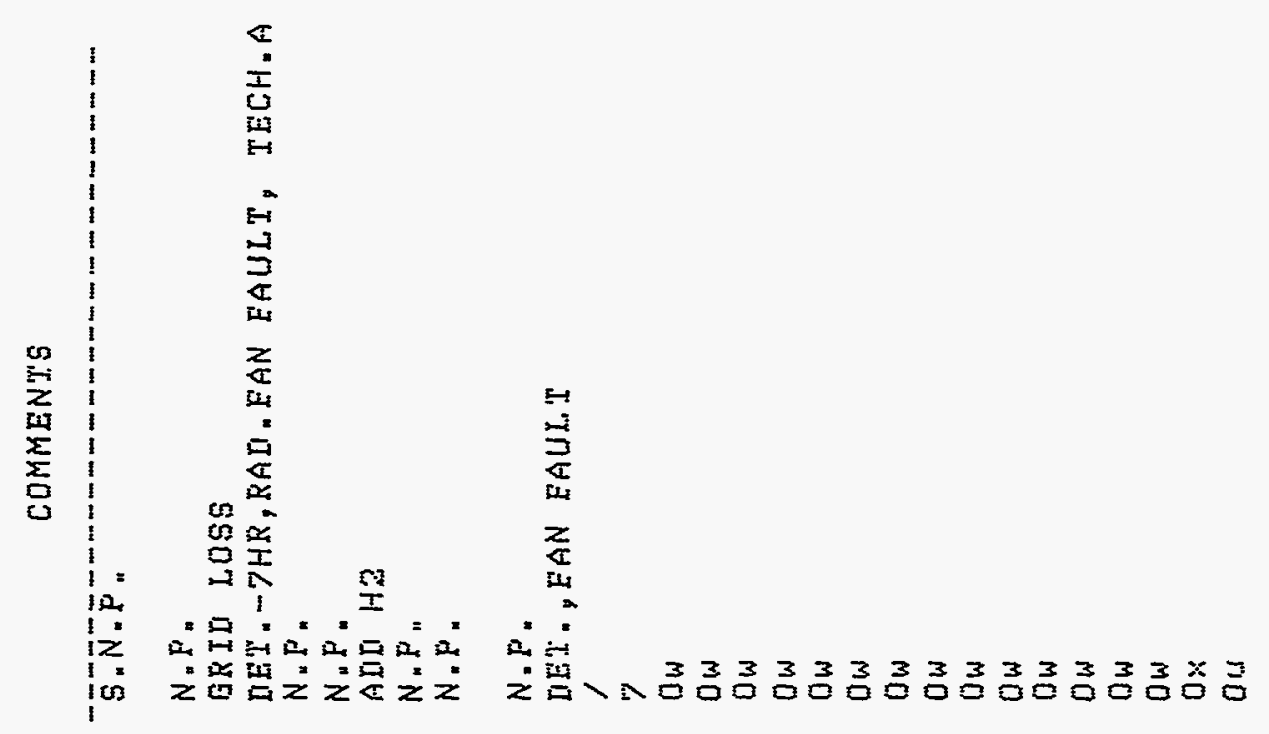

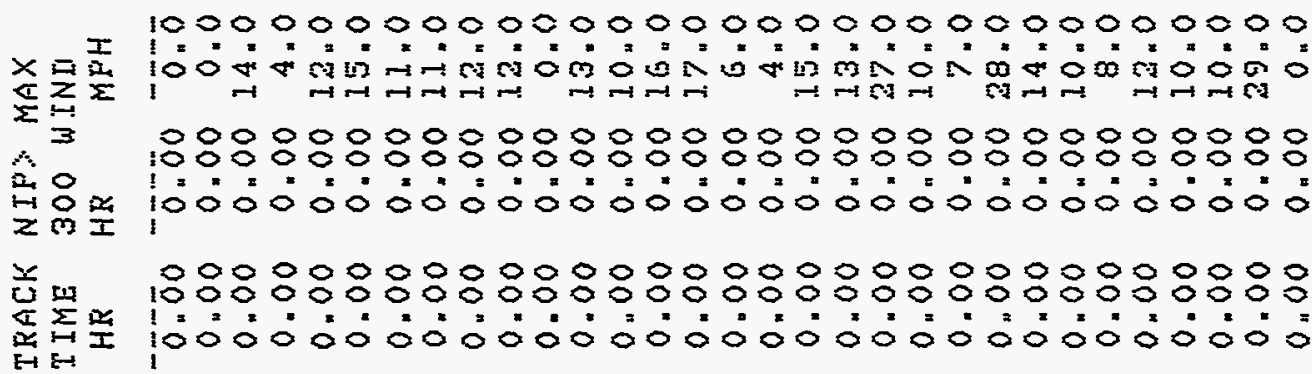

$>\sum_{i=1}^{\infty}$

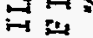

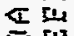

แแ

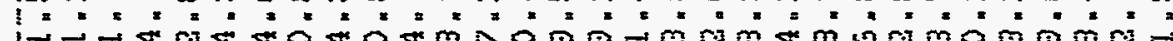

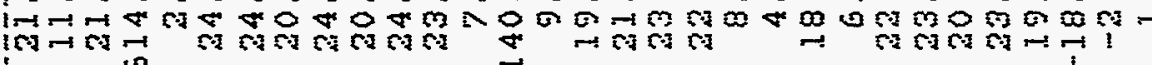

- IRNA

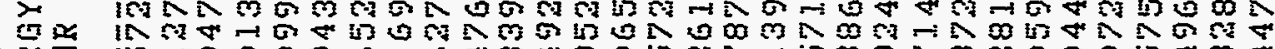

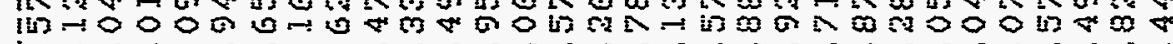

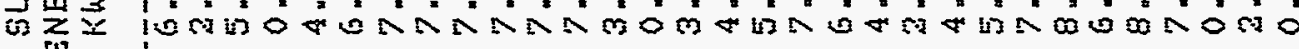

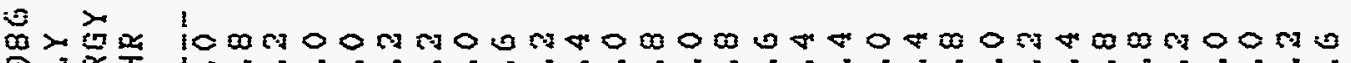
国些资 $\rightarrow+\frac{11}{2}$

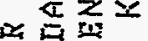

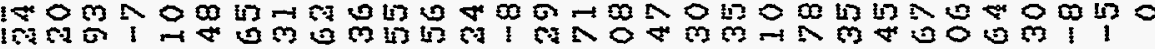
(1) $=\frac{1}{2}$

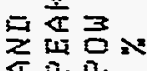

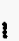
$\rightarrow \rightarrow \rightarrow \rightarrow \rightarrow \rightarrow \rightarrow$ $\rightarrow \rightarrow r$ $\rightarrow \rightarrow \rightarrow \rightarrow$

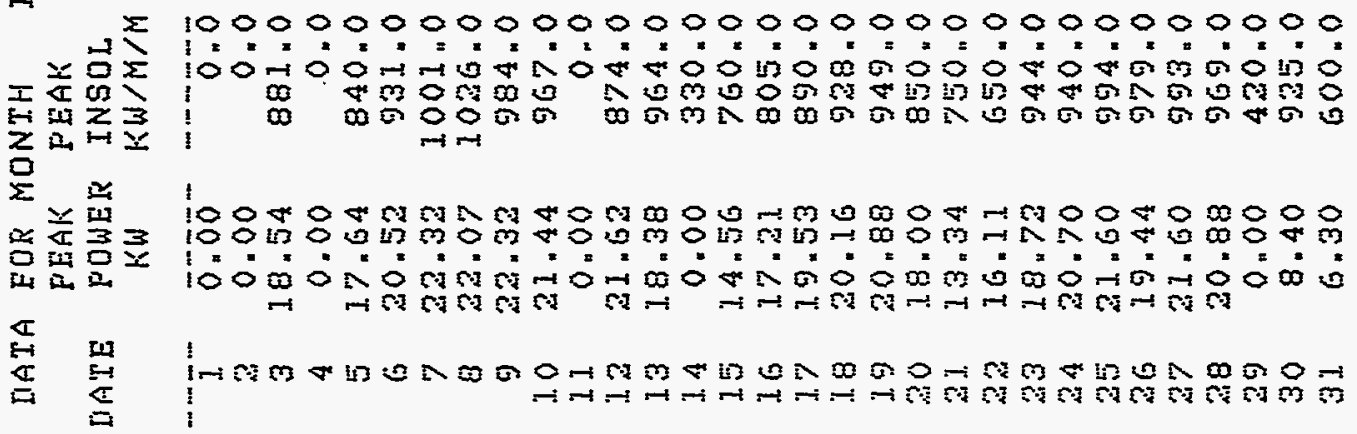

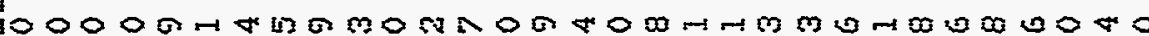
$10^{2}=0^{2} 0^{2}$ 100

10000000000000000000000000000000

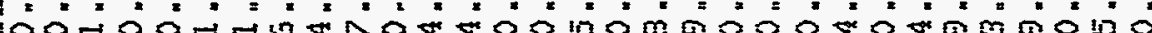
c 


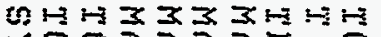

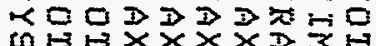
HDD

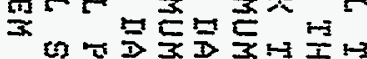

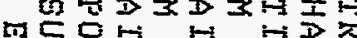

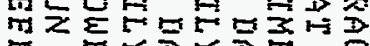

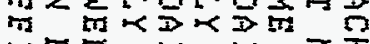

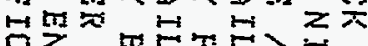

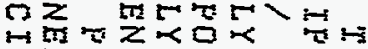

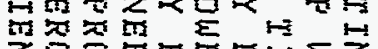

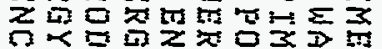

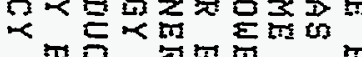

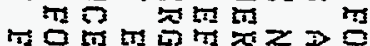

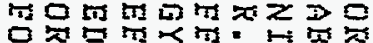

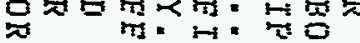

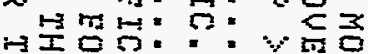

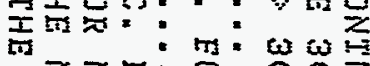

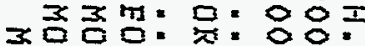
응충: :

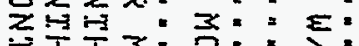
定:士 : : 之:

: : :

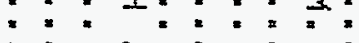

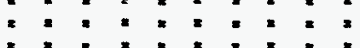

$\rightarrow \quad \sin =$

in

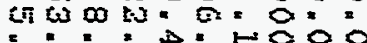

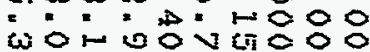

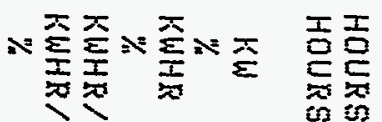

00

$=2$

33

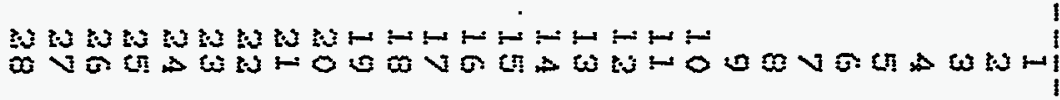

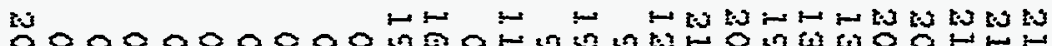

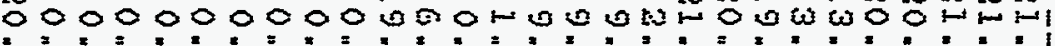
w0ㅇㅇㅇㅇㅇㅇㅇㅇㅇㅇㅔ

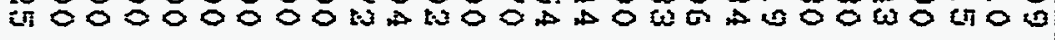

T.

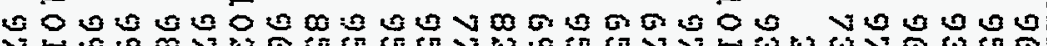
k0

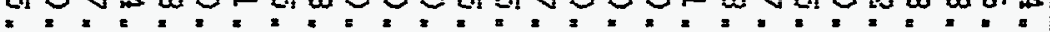

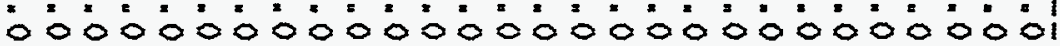
is or 5. w00000000010006

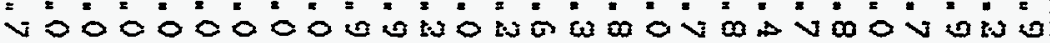

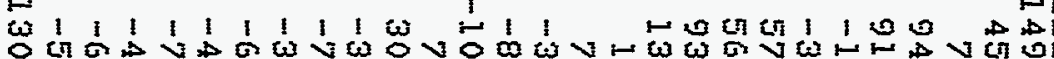

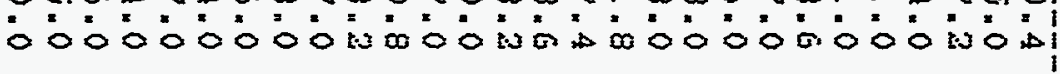

$\stackrel{9}{D} \frac{9}{D}$

西宁 슬을 $\min$

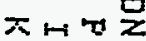

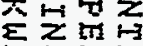
$\sum_{0 \rightarrow} \frac{\pi}{D}$

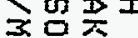
$\geq 5$

s.

a

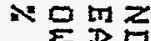

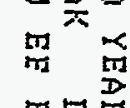
不型量

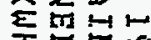
它

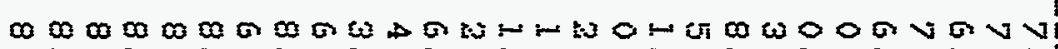

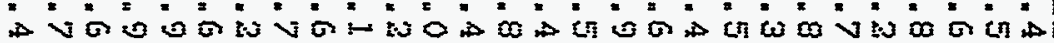
औ.

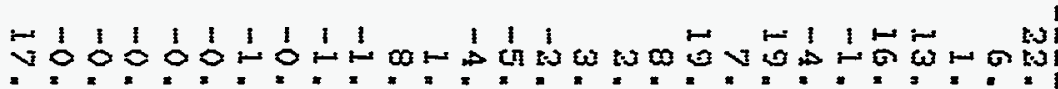

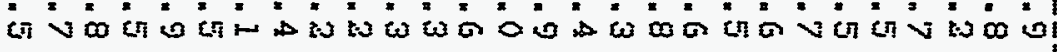
00000000000000000000000000001

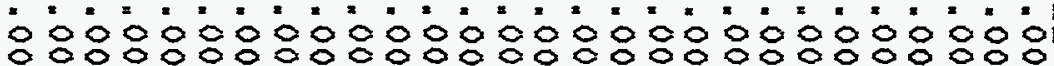

00000000000000000000000000001

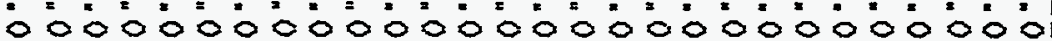

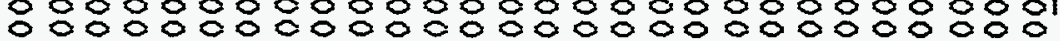

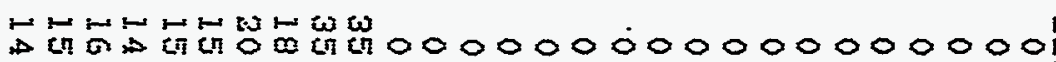

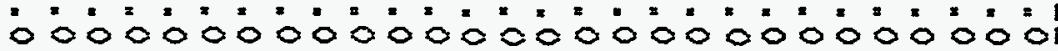

碓罚的 帘密

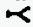

$\operatorname{mos}$ 而 $\therefore \rightarrow$ H 전 药

$I \omega z$ 응봉 $\checkmark$ $E$ 至至 I

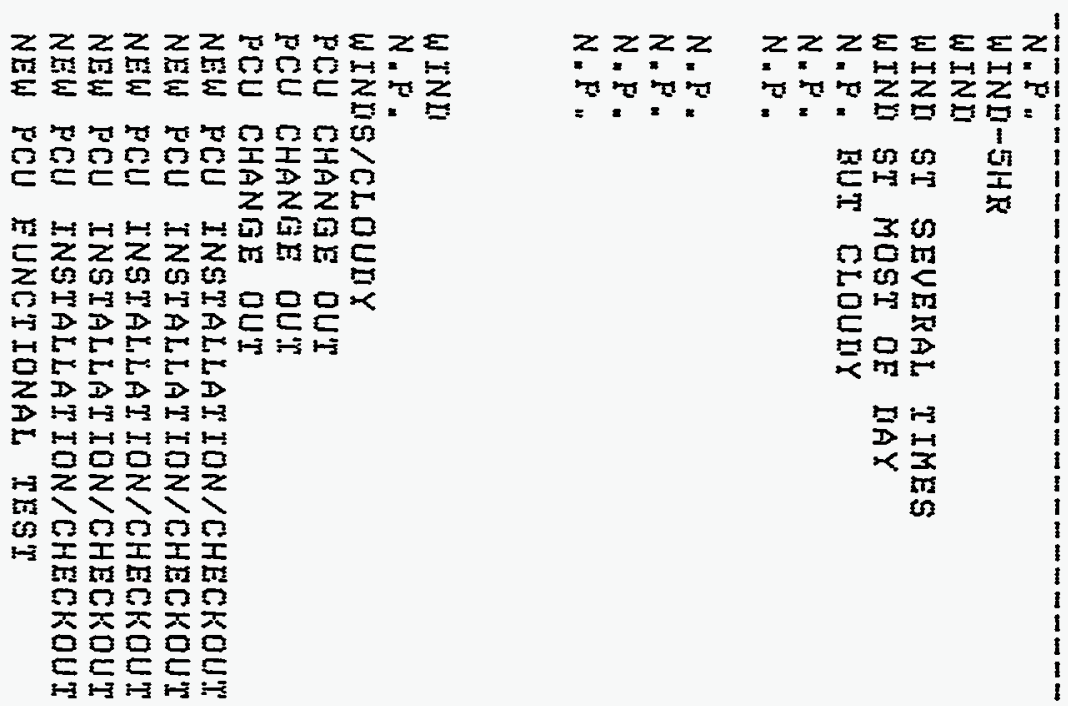




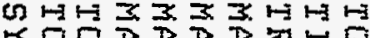

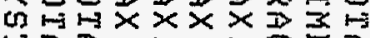

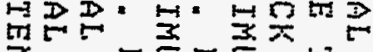

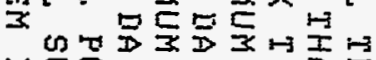

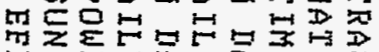

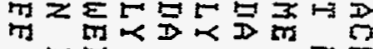

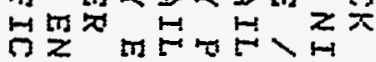

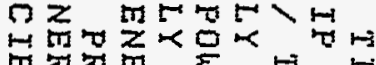

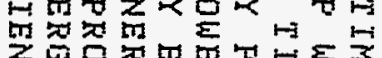

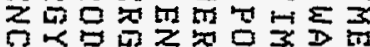

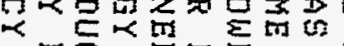

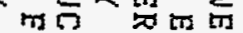

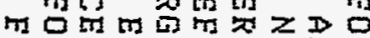

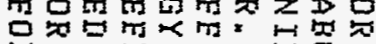

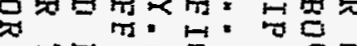

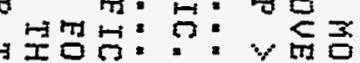

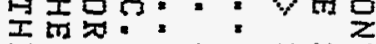

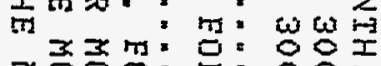

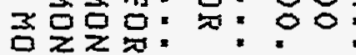

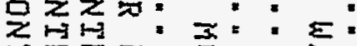

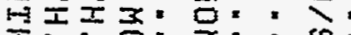

I:: 官: $z_{i=1:}^{0}: 0:$

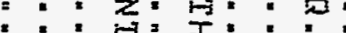

$:: I=I:: 3:$

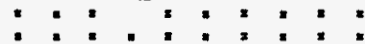

$::: \vdots: !: !: !$

- $\omega$ w

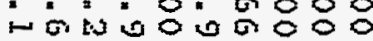

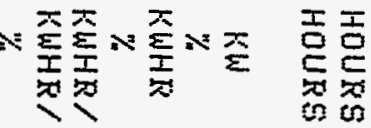

$\cong$

3

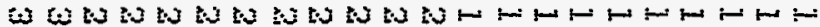

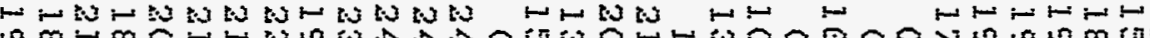
a

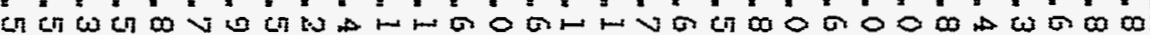
क.

ง

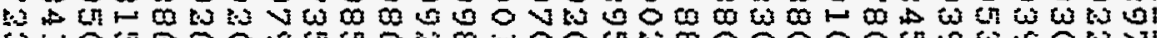
w.

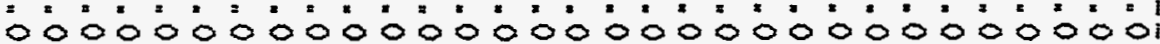

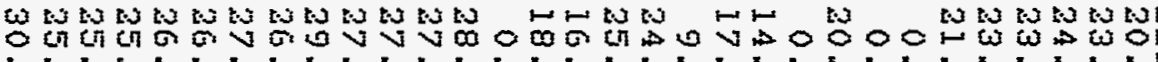
ம.

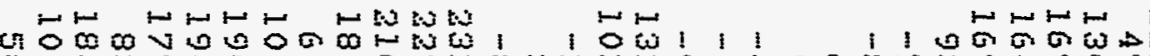

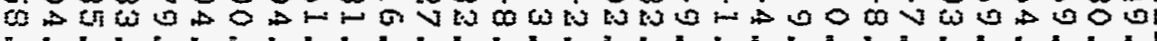
क

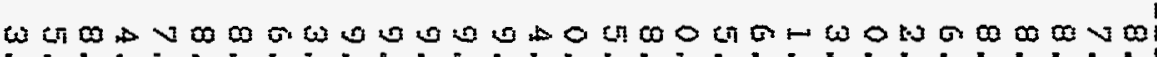
$\Rightarrow$ in t 내의 von 0 in

00000000000000000000000000000001

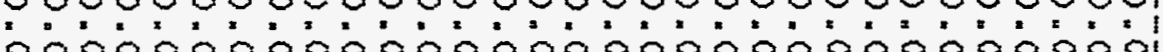

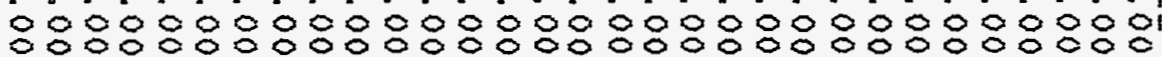

00000000000000000000000000000001

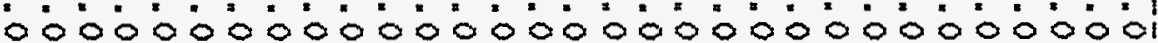
0000080000000000000000000000000

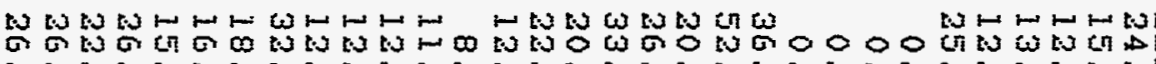
ज小 -

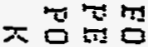
E in 제 is $D I$ $30 \pi$ 3

$w$

$=\stackrel{0}{0}$ (1) 전 m $D$ 不 드내

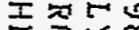
至

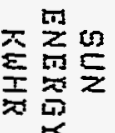
족

$\therefore \mapsto 5$ $B<$

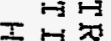

亲兵 西

I 0 $\sum \underset{3}{*}$ tis

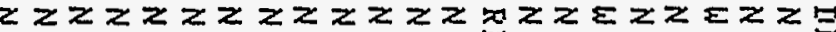

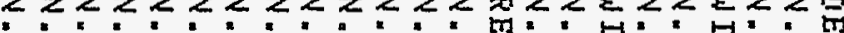

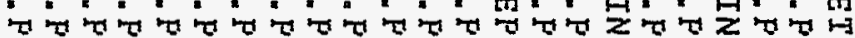

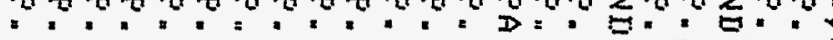

D

:

$\sum \prod_{0 \rightarrow-3}$

$\underset{2}{\mathbb{Z}} \mathrm{E}$

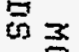

no 0

矛口

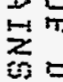

量

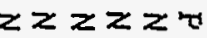

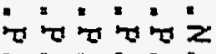
* $=$. "ता 

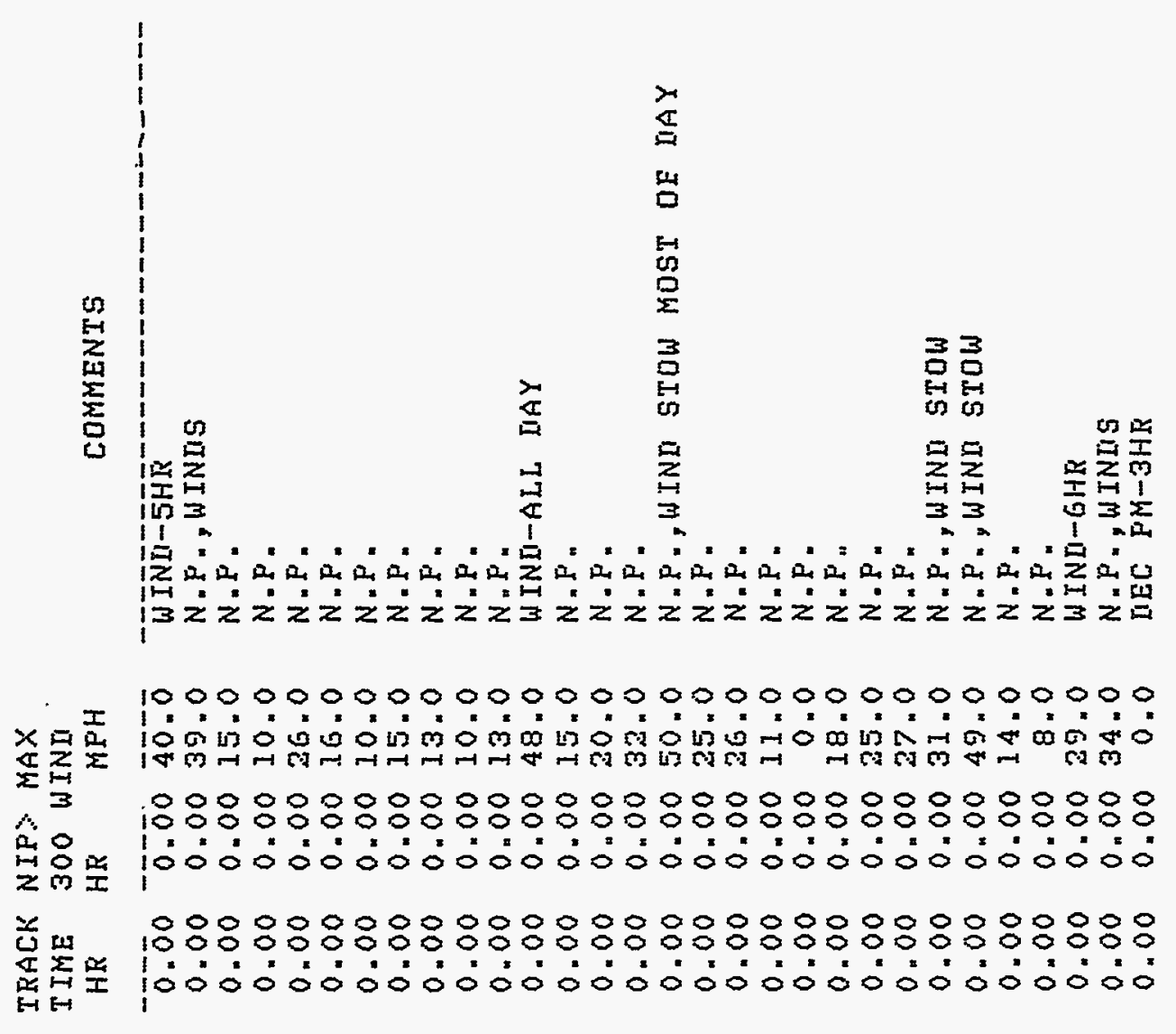

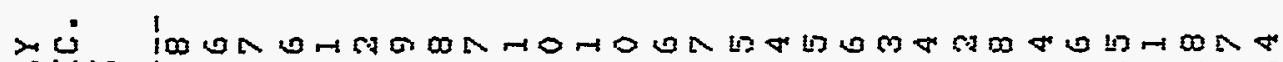

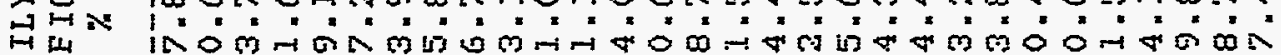

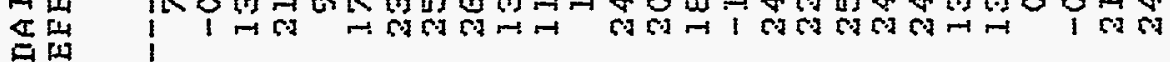

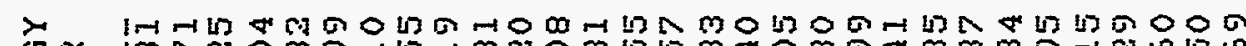
乙远粕 $\Rightarrow$ 北 14 की is $\underset{\text { ing }}{ }$

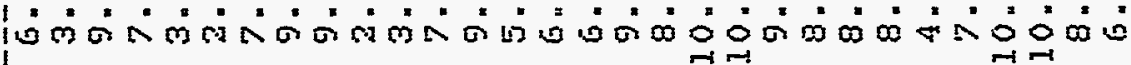

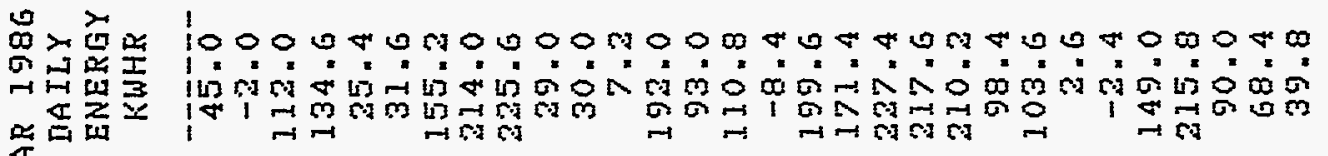
站出 $=\frac{1}{4}=$

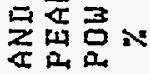
1

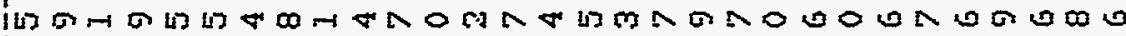
"." m"

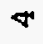

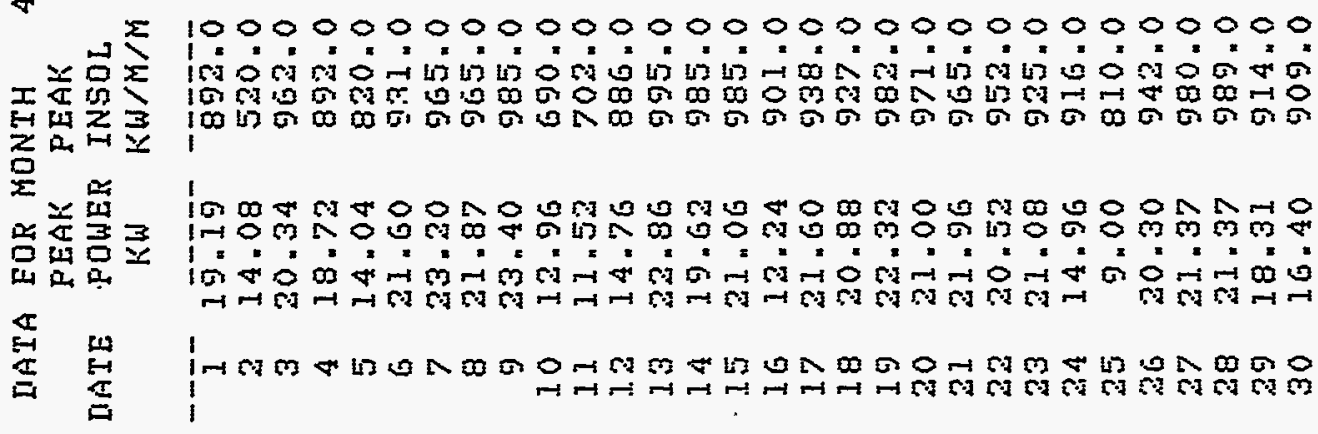




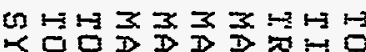

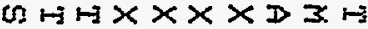

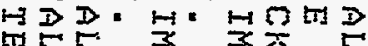

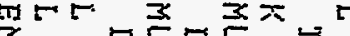

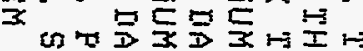

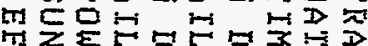

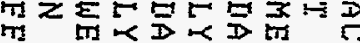

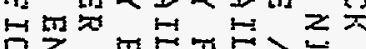

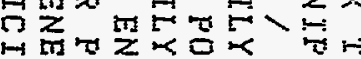

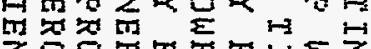

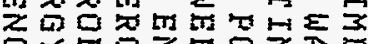

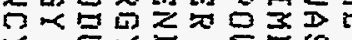

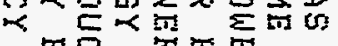

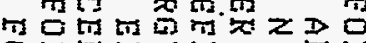

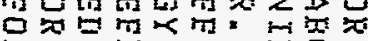

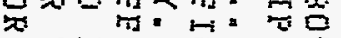

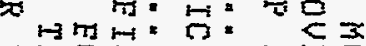

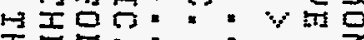

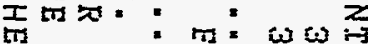
33m:

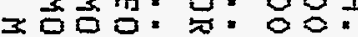

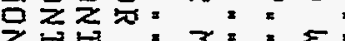

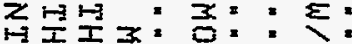
곤종: : : Z: 住: : - $:$ I: : : : I: : : : :

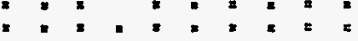

: : : : : : : : : :

$\operatorname{tin} \omega \infty$

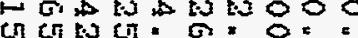
Thing on: ising

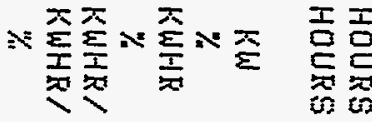

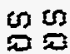

$3: 3$

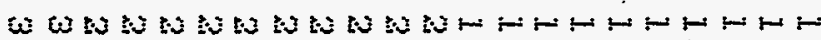

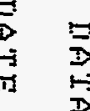

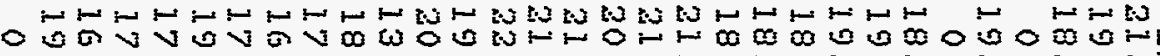
- ${ }^{2}$

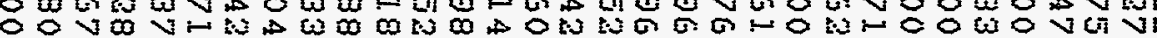

0000000 V00000000000000000000000

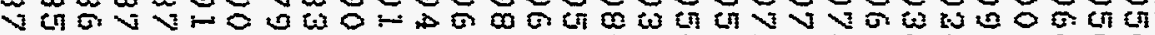
H o 0 kn 00000000000000000000000000000001

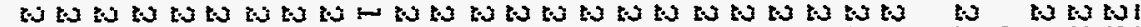

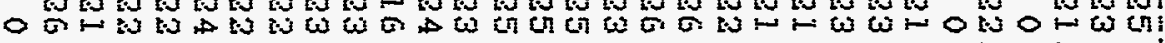

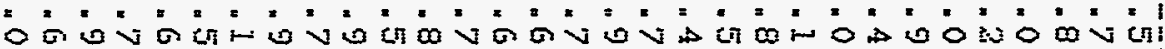
西

1 1

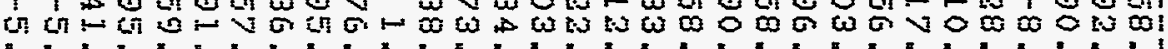

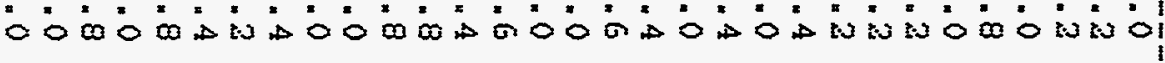

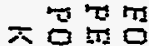

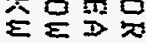
露

不的定

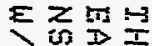
$30 \div$ $\frac{2}{3}$

도를 $E D$ $m^{x}$ 줄

爸希D

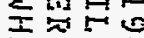
㐮飞政

ง

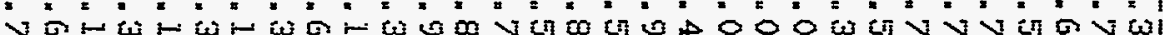

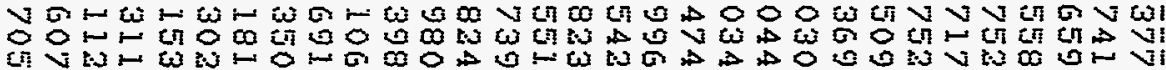

15

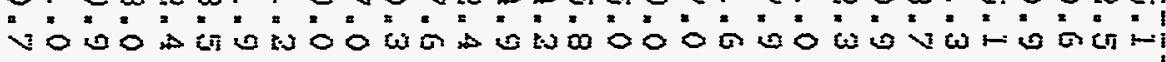

00000000000000000000000000000001

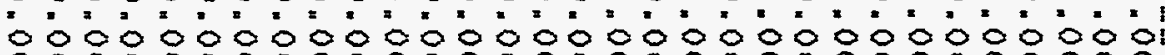

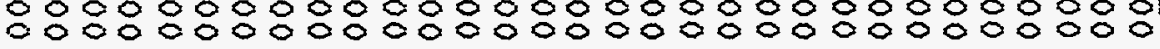

00000000000000000000000000000001

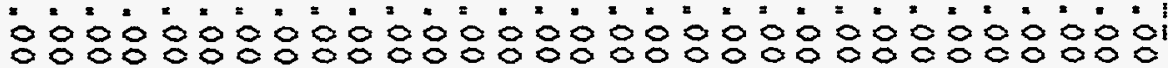
00000000000000000000000000000001

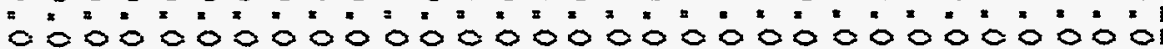
西思的

需索

$\min _{\rightarrow \rightarrow}$

$\rightarrow \leftrightarrow$

I年资

空

的突

I $\omega x$

응봉

$\Sigma$

$3 \stackrel{\frac{\pi}{2}}{2}$

고 


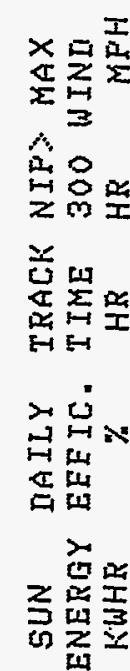

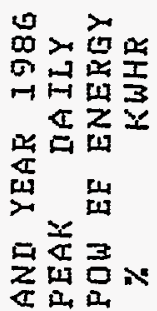

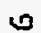

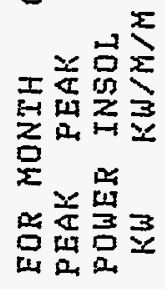

岳

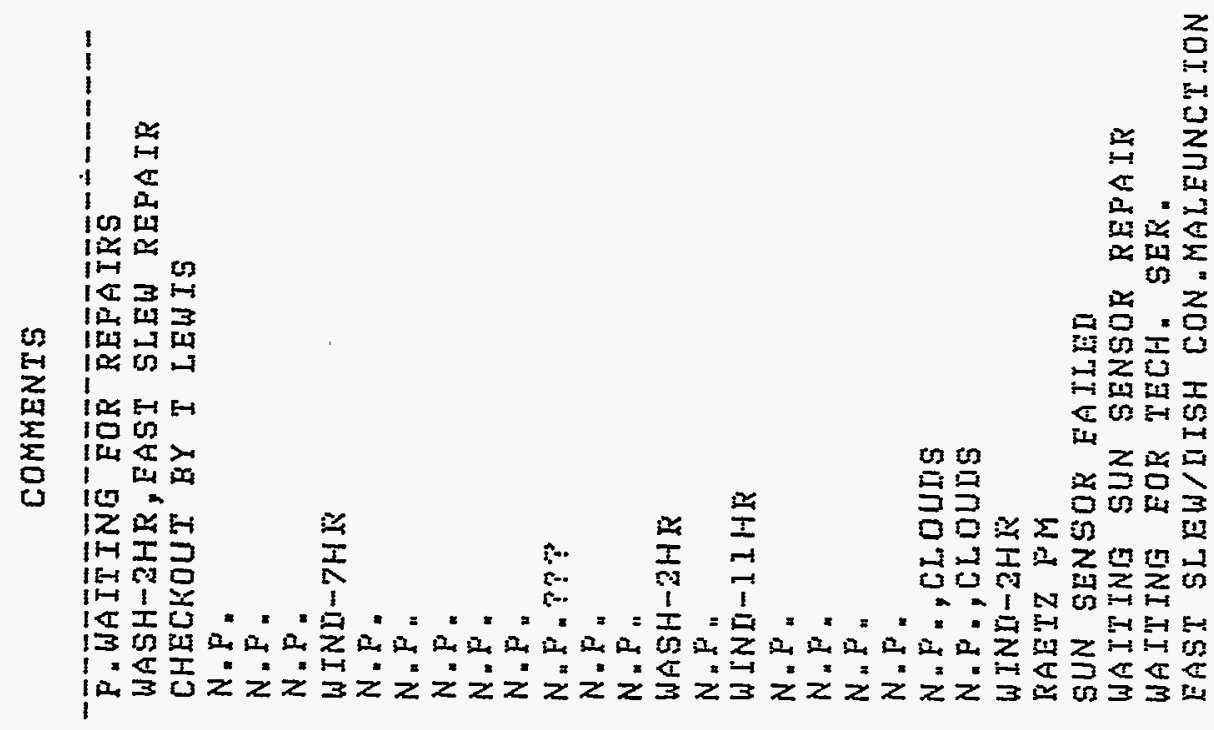

1000000000000000000000000000000

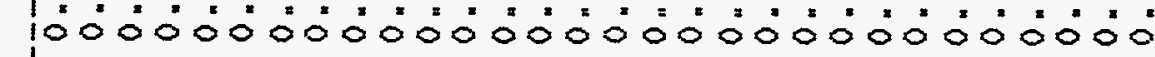
000000000000000000000000000000 1080808808808088808080808088080

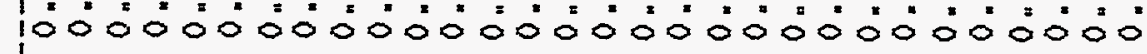

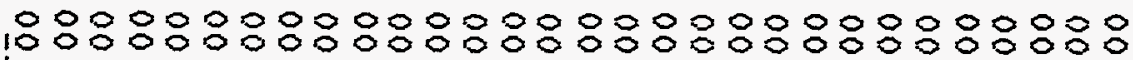
lóó:

lon 10́0" 1

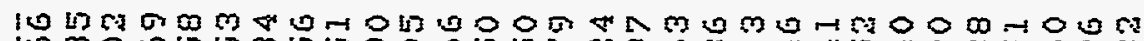

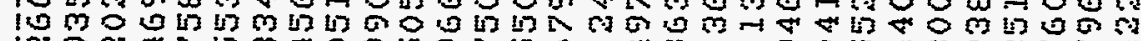

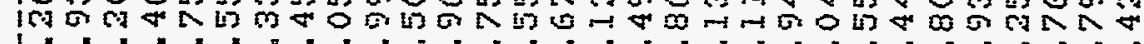

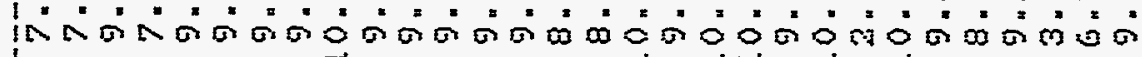

10 " $100 \mathrm{n}$ की

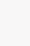

lom

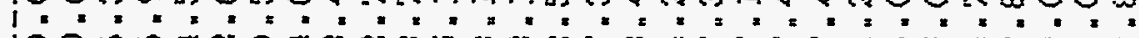

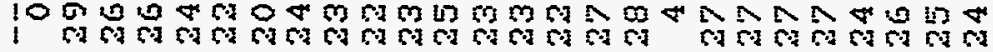

1000000000000000000000000000000

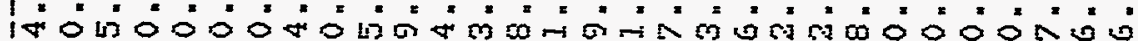
1

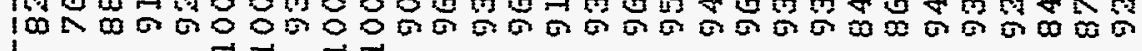

lom moo 10\%

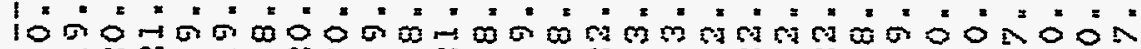

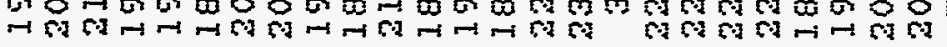

1,

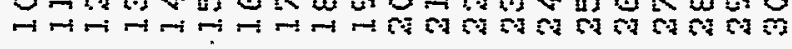

\title{
.
}

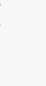




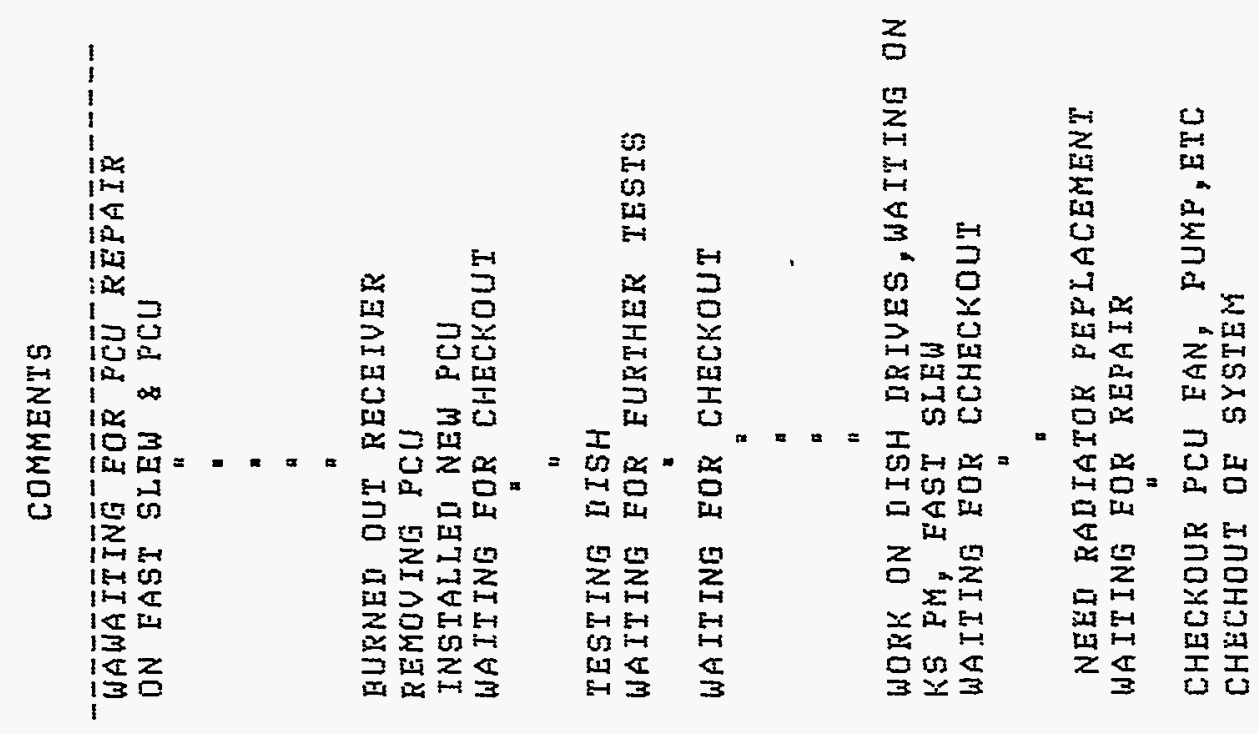

10000000000000000000000000000000

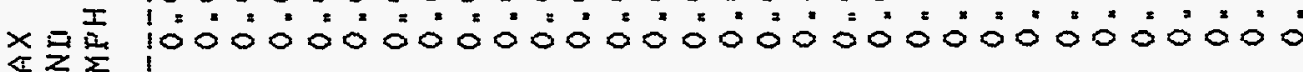
我

3

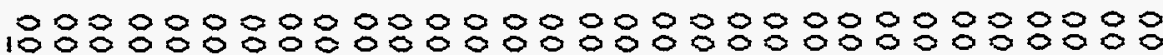

$\lim _{i \rightarrow 0} 0$

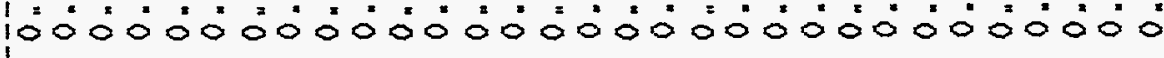

占品

穵电

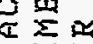

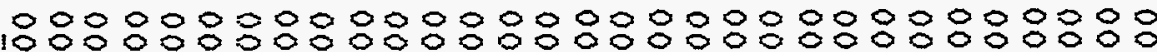

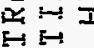

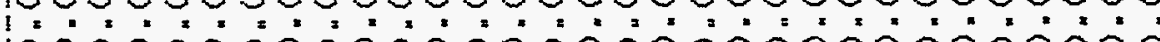

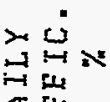

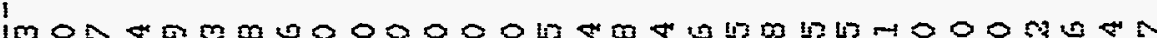

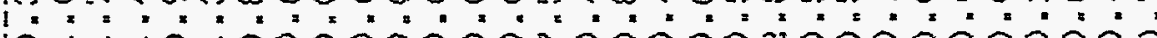

正进

$\rightarrow$ 10नसम0-100000000

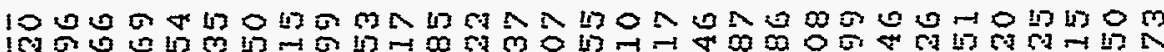

西

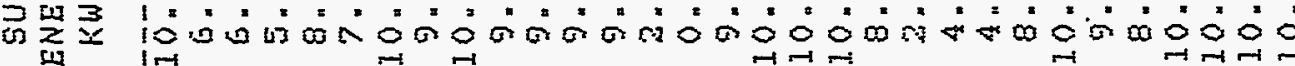

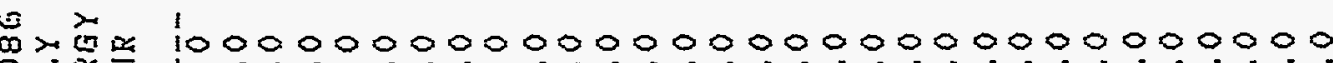

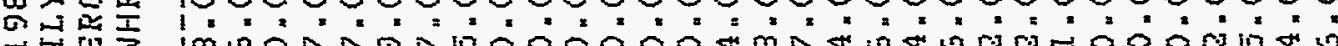
$\rightarrow H$ 出 近要运

兵㟶

$x$

$=\frac{1}{\pi}=$

昰品

10000000000000000000000000000000

N

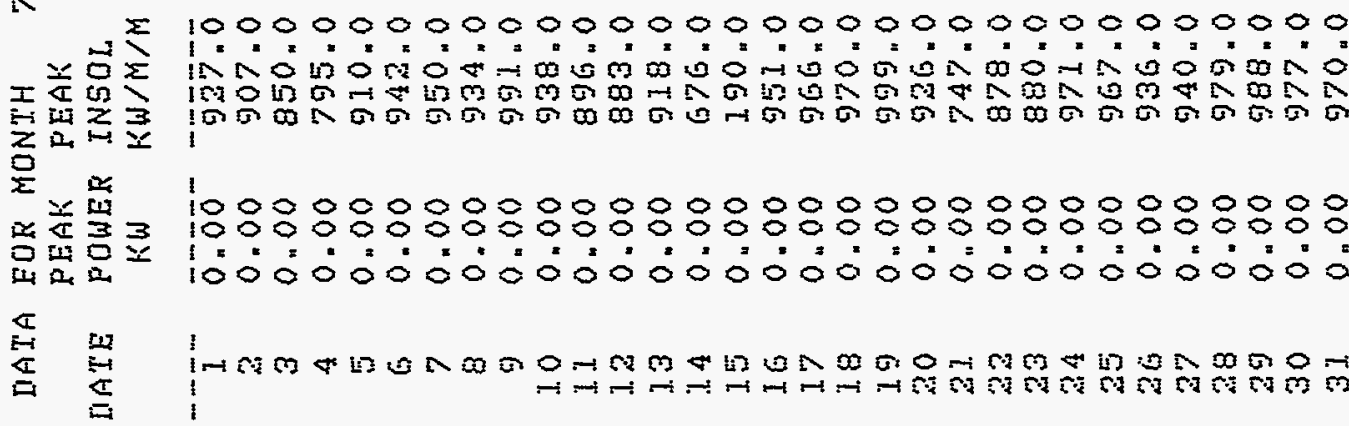


IATA EOR MONTH PEAK PEAK

$\mathrm{KW} \mathrm{KW} / \mathrm{M} / \mathrm{M}$

P

\section{IIAILY}

I98G

IIATE

$\overline{0.00}-\overline{9} \overline{1} . \overline{0}$

$0.00 \quad 927.0$

$0.00 \quad 878.0$

$0.00 \quad 868.0$

$0.00 \quad 832.0$

$0.00 \quad 889.0$

$0.00 \quad 878.0$

$0.00 \quad 857.0$

0.00826 .0

$0.00 \quad 822.0$

$0.00 \quad 860.0$

$0.00 \quad 860.0$

$0.00 \quad 865.0$

$0.00 \quad 930.0$

$0.00 \quad 953.0$

0.00968 .0

956.0

$0.00 \quad 870.0$

0.00

860.0

16.92

18.63

0.00

828.0

858.0

930.0

918.0

875.0

850.0

836.0

983.0

985.0

0.00

2.0
0.0

19.44

0.00

900.0

$\%$ KWHR

SUN

IIAILY TRACK NIFY MAX

NERGY EEEIC. TIME 300 WINI

$-\frac{-5}{0 .--5.0}-$

$0.0-5.0$

$0.0-6.0$

$0.0 \quad-4.0$

0.0

$-7.0$

0.8

$.4-4.0$

0.0

$-5.0$

$.0 \quad-5.0$

$0.0 \quad-4.0$

$0.0 \quad-5.0$

$0.0 \quad-6.0$

$0.0 \quad-5.0$

$0.0 \quad-6.0$

$0.0 \quad-4.0$

$0.0-6.0$

$0.0-2.2$

0.0

$-5.0$

$0.0 \quad-5.0$

$23.3 \quad 102.2$

$24.8 \quad 145.2$

$0.0 \quad-9.0$

$0.0-1.0$

$0.0-10.0$

$0.0-11.0$

$0.0-8.0$

$0.0 \quad-5.0$

0.0

$-5.0$

$0.0 \quad 37.0$

$0.0-11.0$

$-5.5 \overline{8}-5-\overline{1}-\overline{0}-\overline{0}$

$\begin{array}{lll}\% & H R & H R\end{array}$

8.326
7.954

6.967

7.929

7.469

8.213

8.213
7.150

4.075

$0.727-0.7$

$7.355-0.8$

$8.060-0.8$

$8.298-0.7$

9.153

9.855

$1.740-3.3$

$7.228-0.8$

$5.899 \quad 19.8$

$7.162 \quad 23.1$

$8.648-1.2$

9.132

8. 142

7.951

3.071

6.028

7.450

8. 336

8.498

7.893

$0.0 \quad-9.0$ $-\overline{0.00} \quad-0.000-\overline{0.0}$

$\begin{array}{llll}0.00 & 0.00 & 0.0\end{array}$

$0.00 \quad 0.00 \quad 0.0$

$\begin{array}{llll}0.00 & 0.00 & 0.0\end{array}$

$0.00 \quad 0.000 .0$

$\begin{array}{llll}0.00 & 0.00 & 0.0\end{array}$

$0.00 \quad 0.00 \quad 0.0$

$\begin{array}{llll}0.00 & 0.00 & 0.0\end{array}$

$0.00 \quad 0.00 \quad 0.0$

$0.00 \quad 0.00 \quad 0.0$

$0.00 \quad 0.00 \quad 0.0$

$0.00 \quad 0.00 \quad 0.0$

$0.00 \quad 0.00 \quad 0.0$

$0.00 \quad 0.00 \quad 0.0$

$\begin{array}{lll}0.00 & 0.00 & 0.0\end{array}$

$0.00 \quad 0.00 \quad 0.0$

$0.00 \quad 0.00 \quad 0.0$

$0.00 \quad 0.00 \quad 0.0$

$0.00 \quad 0.00 \quad 0.0$

$0.00 \quad 0.00 \quad 0.0$

$0.00 \quad 0.00 \quad 0.0$

$\begin{array}{llll}-1.4 & 0.00 & 0.00 & 0.0\end{array}$

$\begin{array}{llllll}-1.4 & 0.00 & 0.00 & 0.0\end{array}$

$\begin{array}{lllll}-1.6 & 0.00 & 0.00 & 0.0\end{array}$

$\begin{array}{llll}-3.0 & 0.00 & 0.000 & 0.0\end{array}$

$\begin{array}{llll}-0.9 & 0.00 & 0.00 & 0.0\end{array}$

$\begin{array}{llll}-0.8 & 0.00 & 0.00 & 0.00\end{array}$

$\begin{array}{rrrr}5.1 & 0.00 & 0.00 & 0.0 \\ -1.5 & 0.00 & 0.00 & 0.0\end{array}$

$\begin{array}{llll}-1.3 & 0.00 & 0.00 & 0.0\end{array}$
TOTAL TKACK TIME EOR MONTH........... 0... 0.00 HOURS

TIME THAT NIF WAS AEOUE 300 W/SQ.M.... 0.00 HOURS

TRACK TIME, TIME NIP $300 \ldots \ldots \ldots \ldots . . . . .0000$

MAXIMUM IIAILY POWER...................

MAX. DAILY POWER EEEIC. EOR MONTH .... $34.8 \%$

MAXIMUM IIATLY ENERGY................ 145.20 KWHR

MAX. IIAILY ENERGY EEEIC. EOR MONTH...

TOTAL POWER PROIUCEI FOK MONTH.........

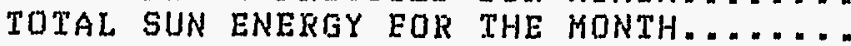

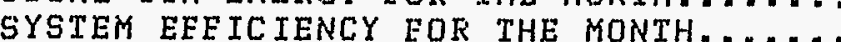

$23.1 \%$

1.3 KWHR/ $5 \mathrm{~K}$. M

233.2 KWHR/ SQ.M

$0.6 \%$
COMMENTS

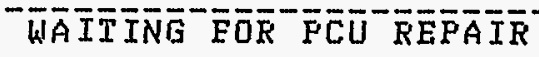

KS PM

PCU BURN IN FROB, KS PM

SOLENOIII FROB, NO SFARE

WAITING EOR REFAIR

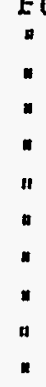

KS PM, REPLACE VALUE

KS FM

REC. BURN IN CONTINUEI

WAITINS EOR NEW PCU

WAITING FOR FAST SLEW MONS.

KS FM 


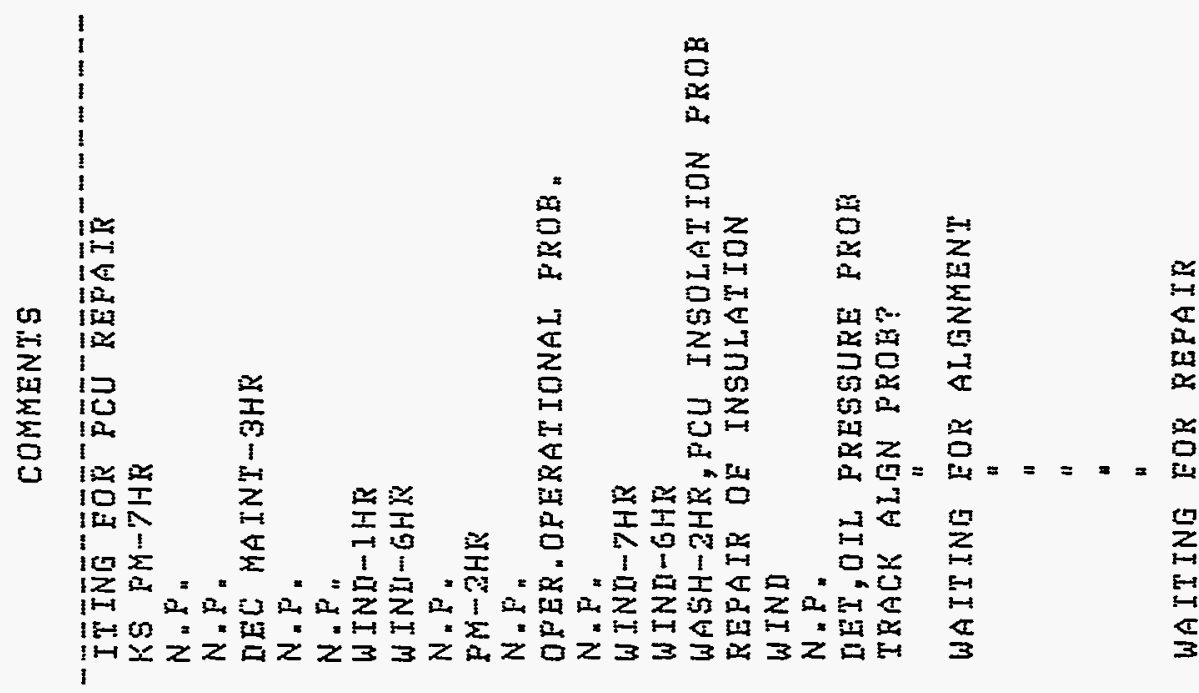

肴至竞

$\therefore=$

$i_{0} 0$

工m

产

돈 하

팜ㅍ

$\rightarrow[1$

20
$\Rightarrow \pm 1$

叫

en

$x$ 뚝

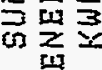

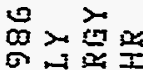

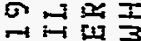

$\pi z$

주

I0 出

$=\frac{2}{4}=$

近品

D.

\section{$x a$ \\ I

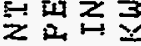 \\ z \\ $\Sigma \times$ 要 \\ 눈 $\frac{5}{3}=$ \\ 0 证 \\ I4 空}

$\pm$

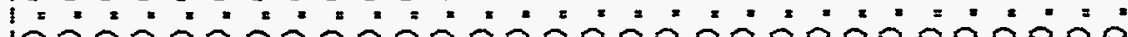
1000000000000000000000000000000

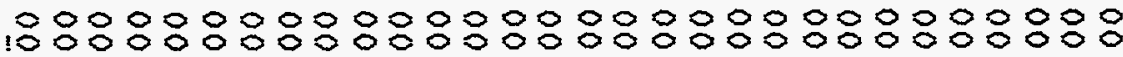
$100000000 \%$ 1000000000000000000000000000000

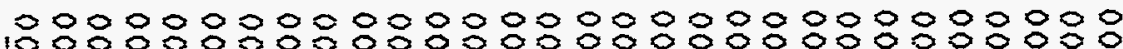
$10000000000000000000000000000 \%$

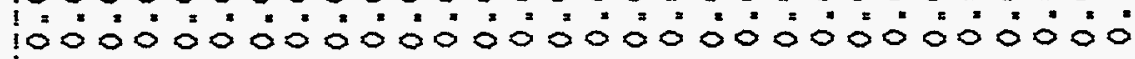

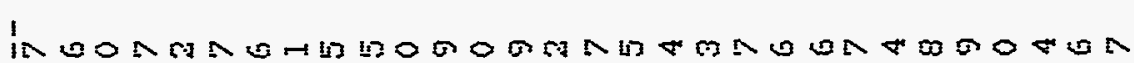

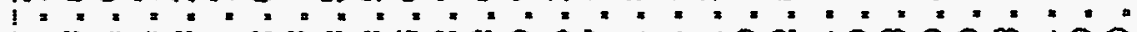

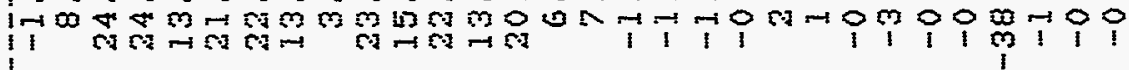

IN

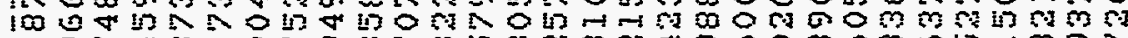

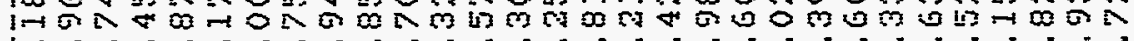
IN

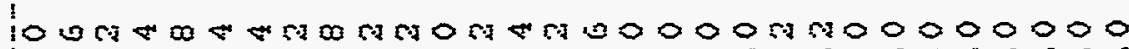

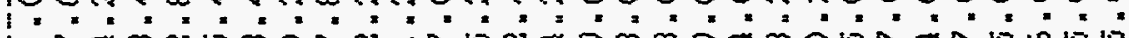

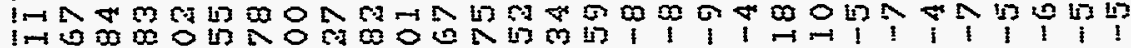

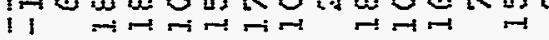

10

10 10mm

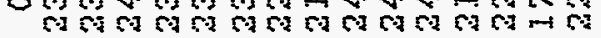
讨

1000000000000000000000000000000

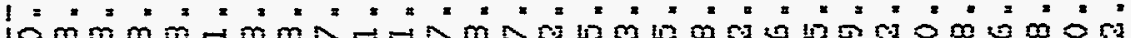

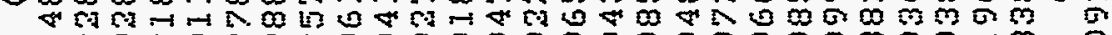

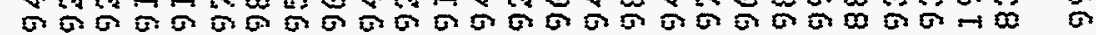

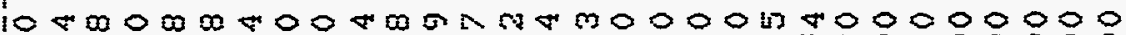
10 F⿻口卄.

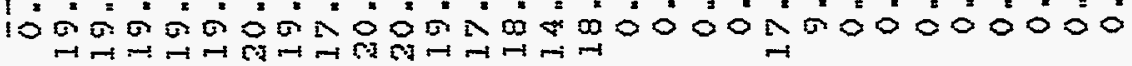

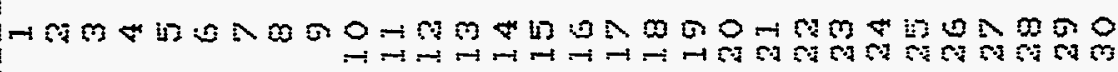

1000000000000000000000000000000

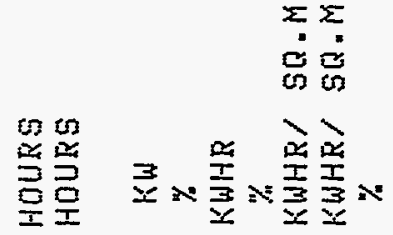

000 แ

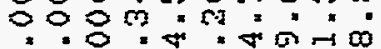
0000 में $0_{0}^{0} \stackrel{0}{\pi}$

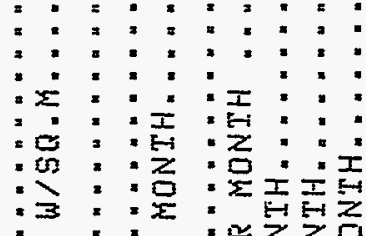

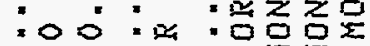

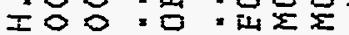

至品:

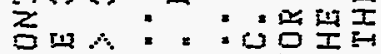

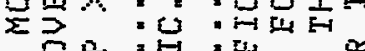

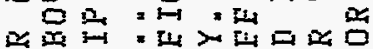

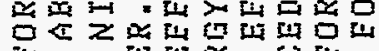

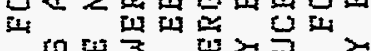

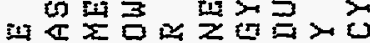

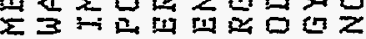

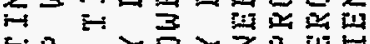

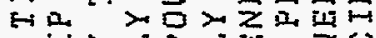

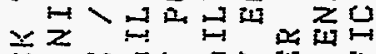

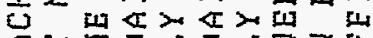

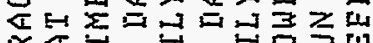

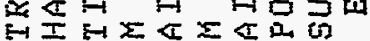

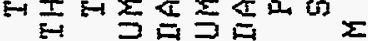

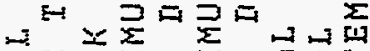

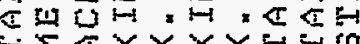

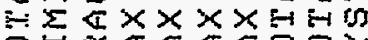

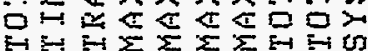




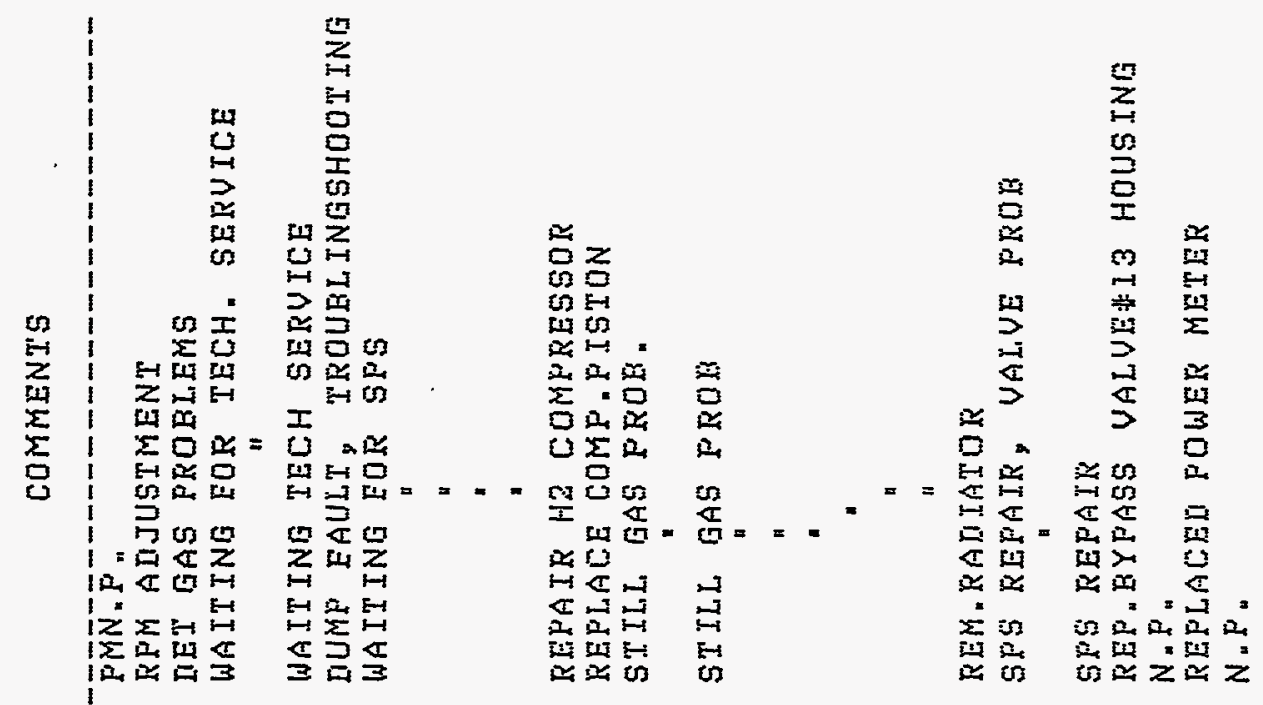

I 10000000000000000000000000000000 壬贸 10000000000000000000000000000000

3

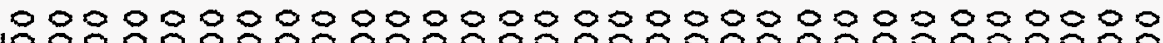

10000000000000000000000000000000 虹总监

ㄴ 近造 帒等

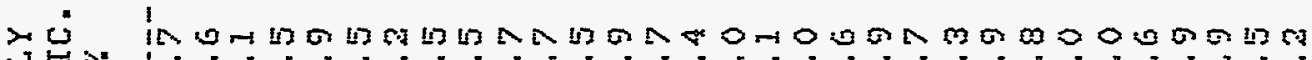
出出 I.

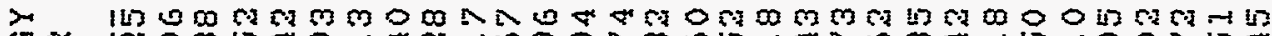

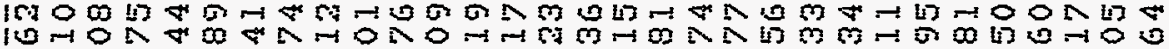

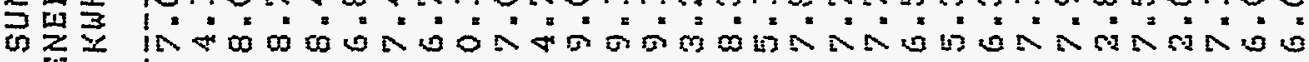

品空。

E

密出

토는

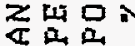

$\stackrel{0}{\rightarrow-1}$

물

号主

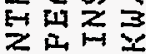

官

$\Sigma$ 学

品范

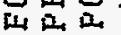

焉
$10000000000000+00000000000000000$ "10 $\mid$ |lm

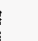

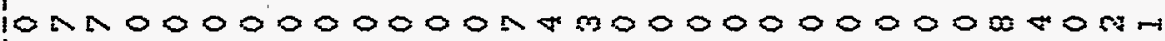

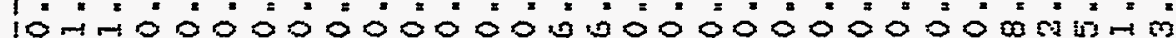

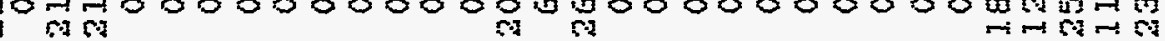

\section{0}

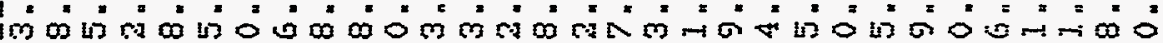
1450त

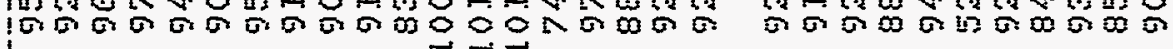
$\rightarrow \rightarrow-1$

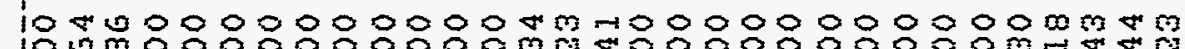

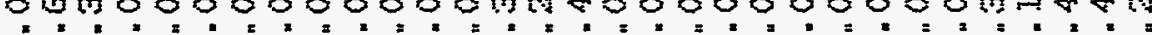

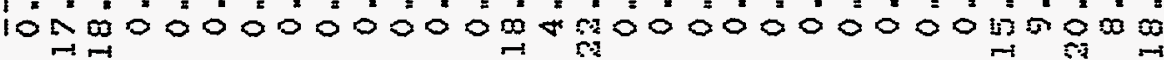
|

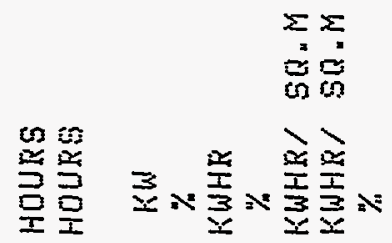

$888 \Rightarrow m 00 \pi n$ $=8=0=0 \mathrm{~mm}$ $000 \sin 0$ 0 :

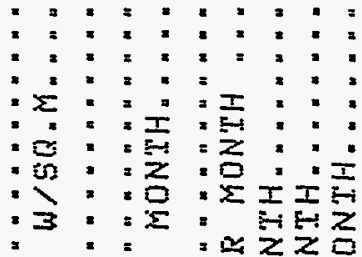
$: 00: \approx=0$ :

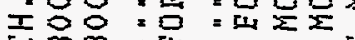

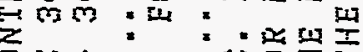

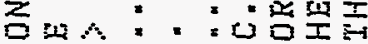
空党: :

目: : : :

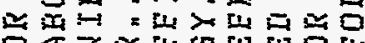
$0<z \cong$ 边山出

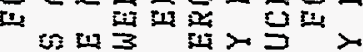

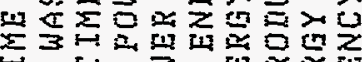

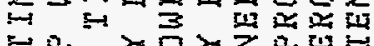

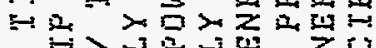

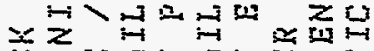

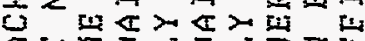

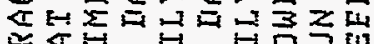

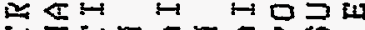

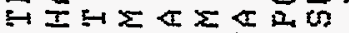

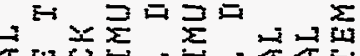

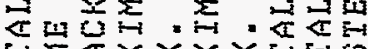
$5 \sum_{i} \times \times \times \times=0$

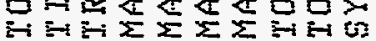




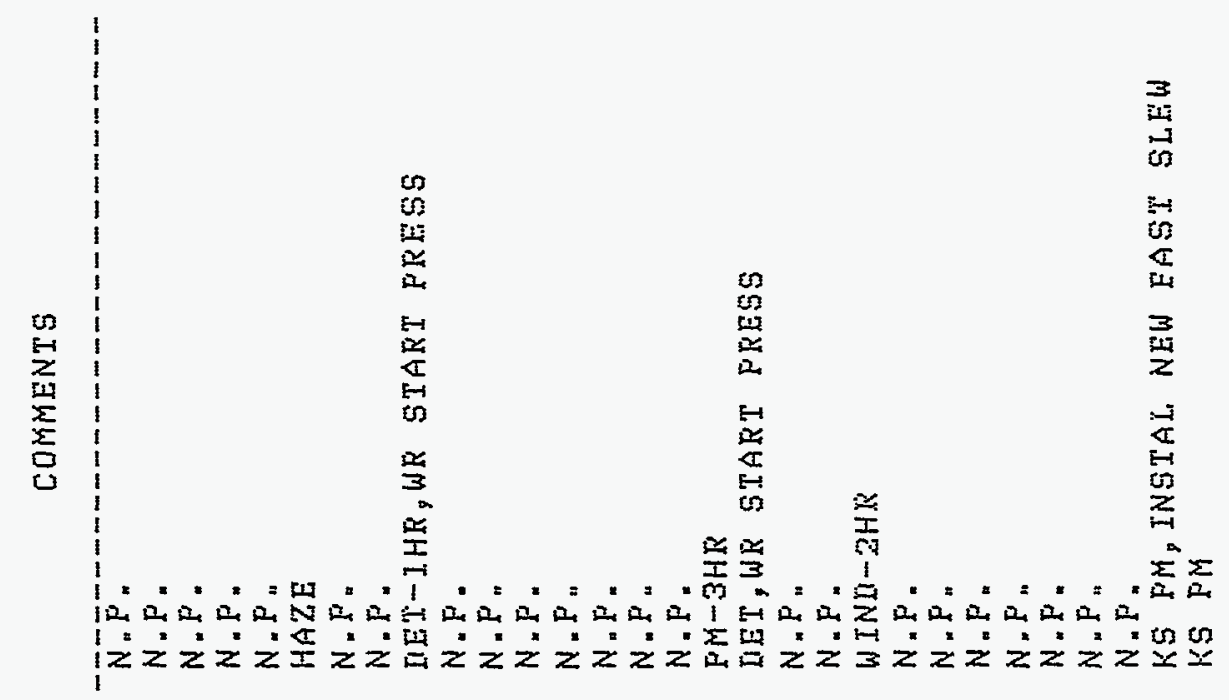

I 1000000000000000000000000000000000

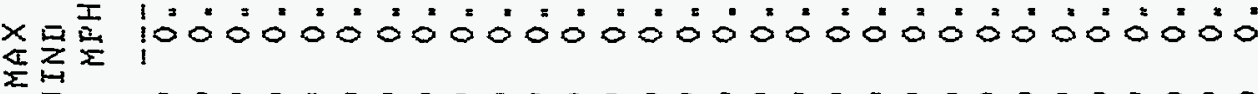

$\therefore$

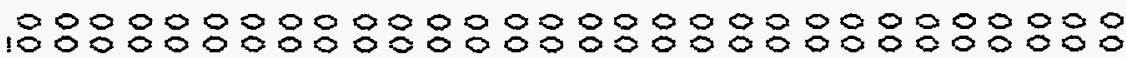
L

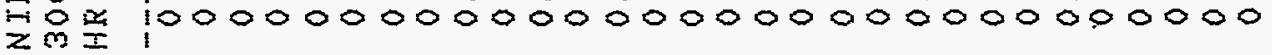

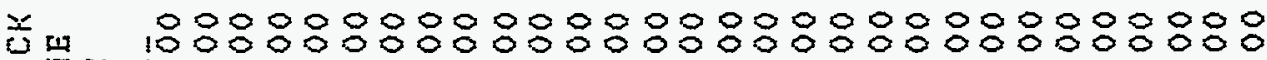

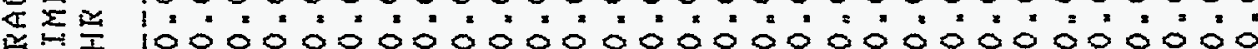
Ex

$>\underbrace{\infty}_{i=1}$

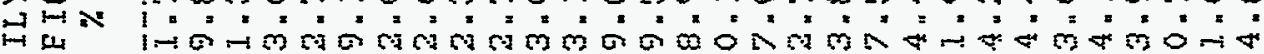

IN

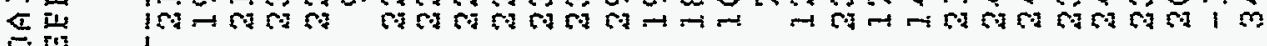

ज小

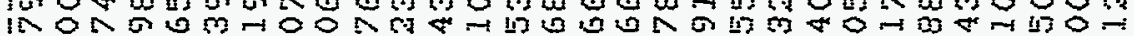

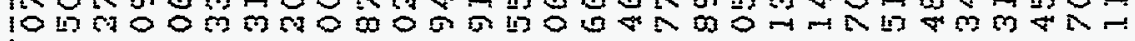
แ艹

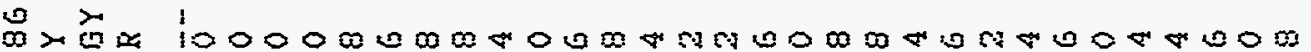
ज! -

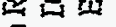

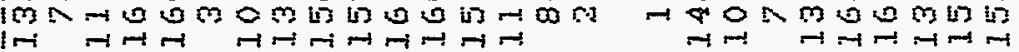

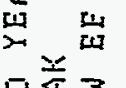

在 3

更远

ismo $\rightarrow$ $+\frac{0}{\pi}$ $0_{0}^{2} \sum^{2}$ 넌 $\geq \geq$ $z$ is $\rightarrow x$

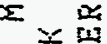

$\therefore \div \frac{1}{3}$

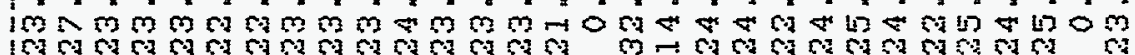

0

1000000000000000000000000000000

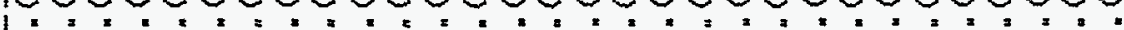

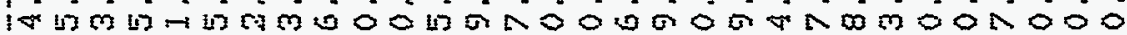

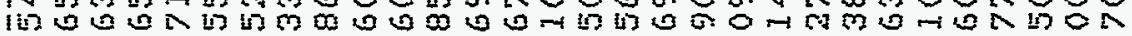
in $\mathrm{A}$ ब

I4.

! INmOMNA í

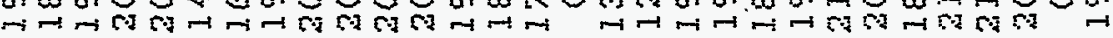

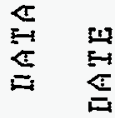

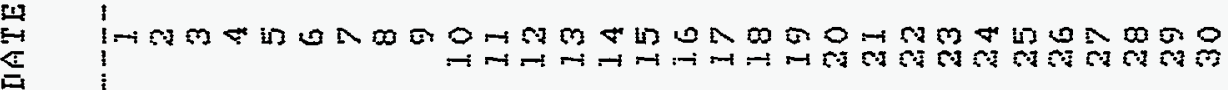

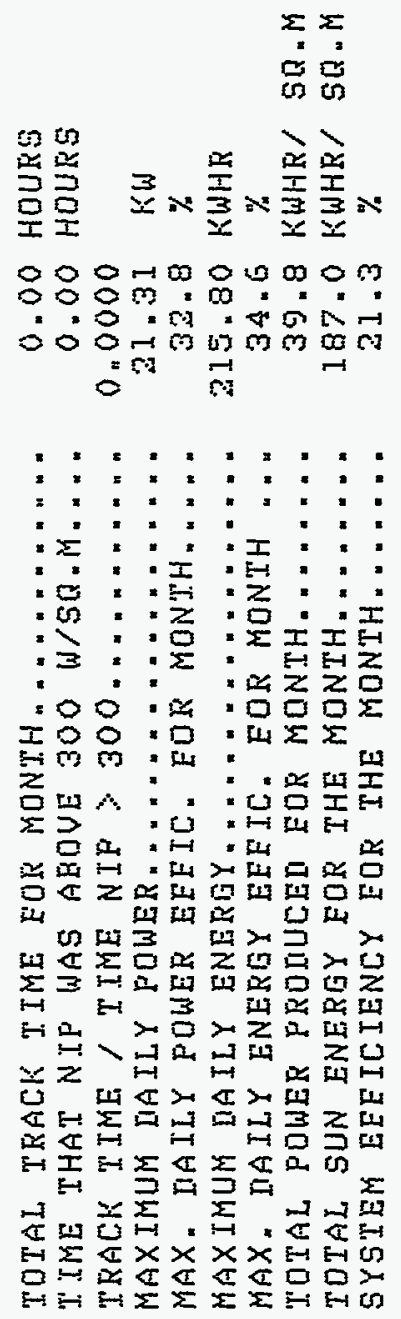




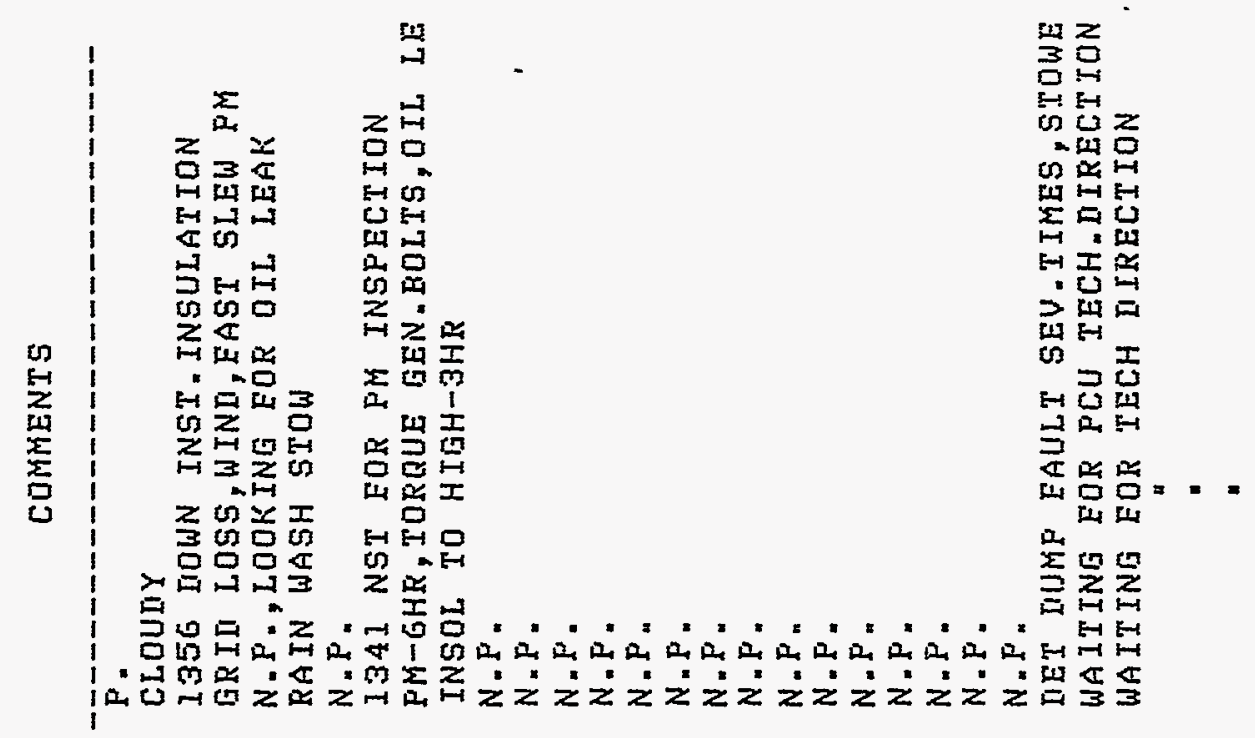

$\times$ :

10000000000000000000000000000000 蛋 3

$\therefore$

0000000000000000000000000000000 10000000000000000000000000000000 出品

这出

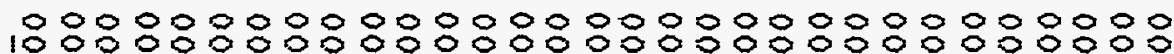

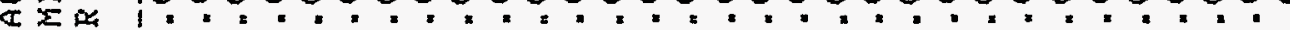
丝出 10000000000000000000000000000000

出 16月0, 至出

点

$z \underset{1}{2}$

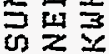

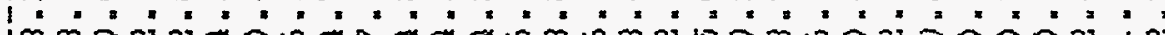
mpand $\rightarrow \rightarrow$ in

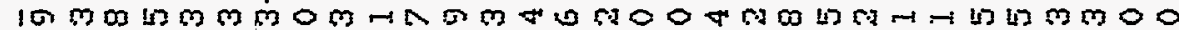
10.0

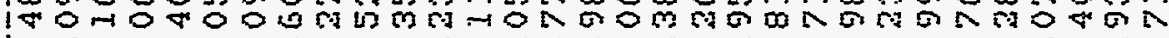

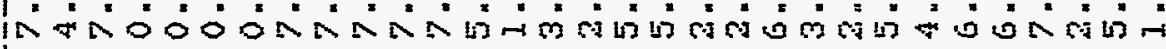

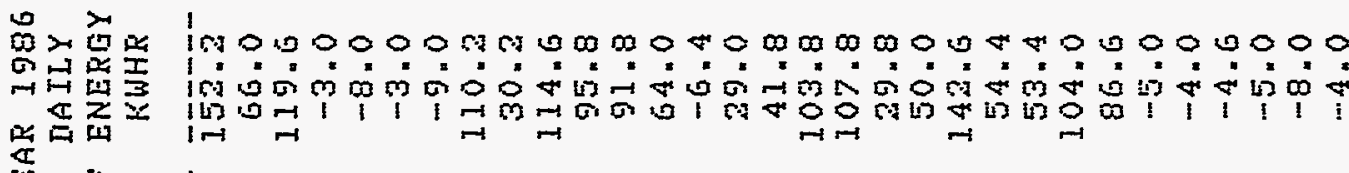
$\sum_{>\rightarrow 1}^{4}$

E

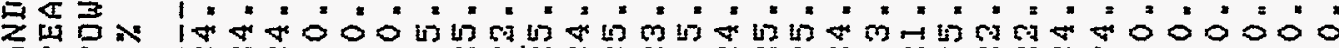

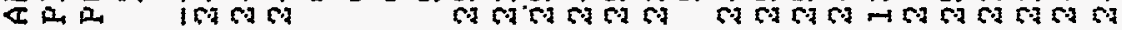

is

工它昆空

踏落

它

工些

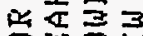

品证吕

10000000000000000000000000000000

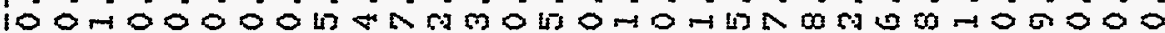

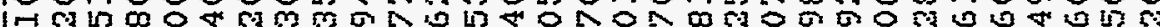

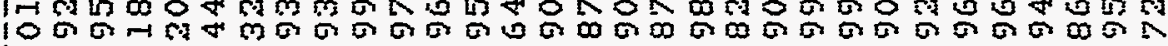

Tr

息出

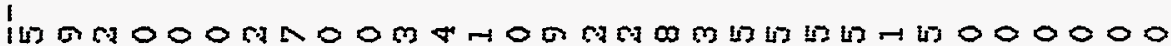

m世

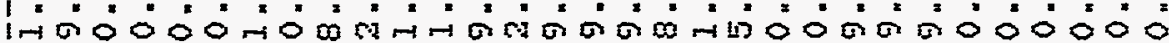
$\rightarrow \rightarrow$ की ming

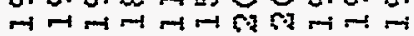

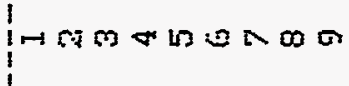

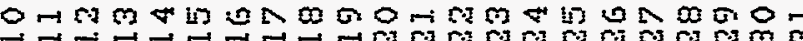

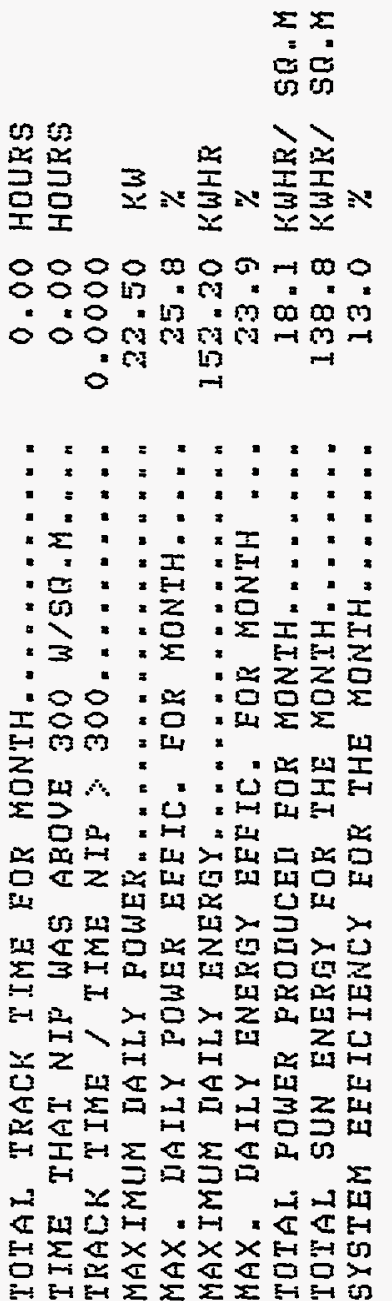

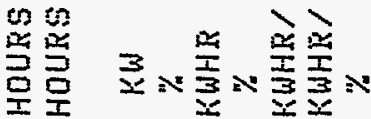
$\circ 800000000$ 4.

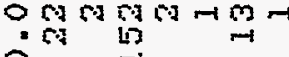




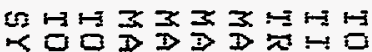

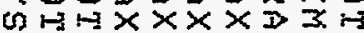

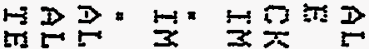

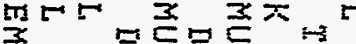

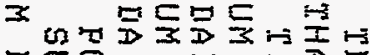

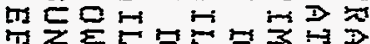

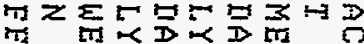

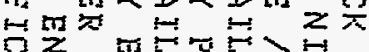

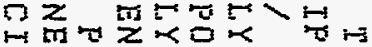

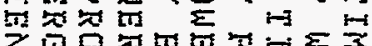

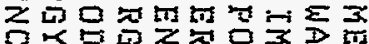

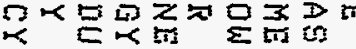

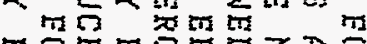

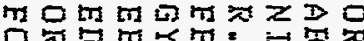

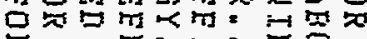
事明:

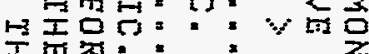

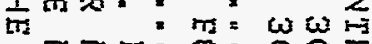

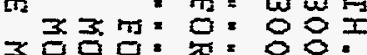

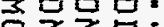

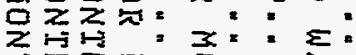

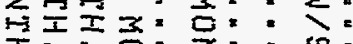

$I: * 0: Z:=0$

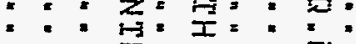

$: I::=: 3$

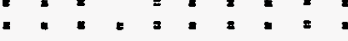

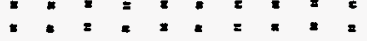

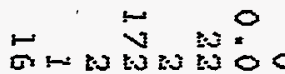
ant कW

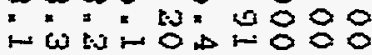

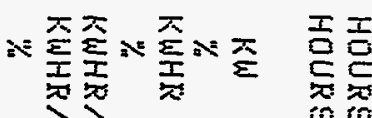

on 13

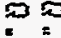

33

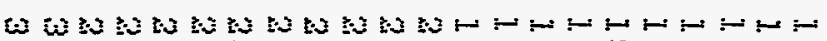

$\stackrel{9}{3}$

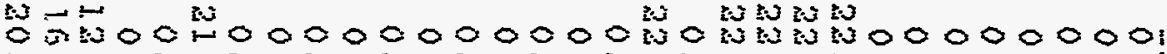

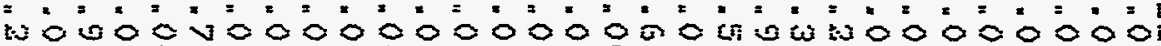

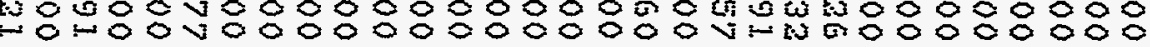

0ล0010000

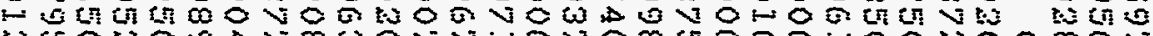
W

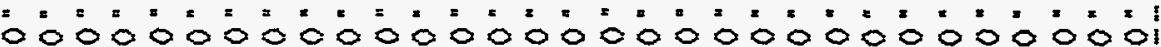

W

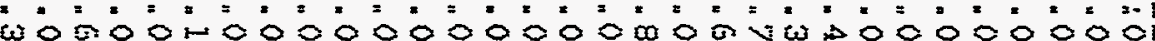

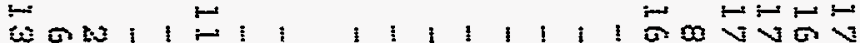

Оow

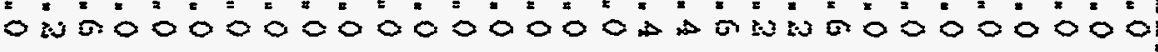

논

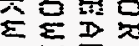
西

주음

$\sum z \ln$ 红正 $30 ;$ \rangle$^{2}$

$2 \pi$ $E \frac{D}{X}$

$\operatorname{ma}$

중

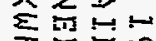
$\frac{1000}{200}$ $\overrightarrow{2}<\stackrel{0}{i}$

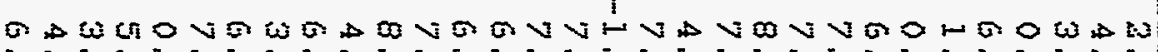

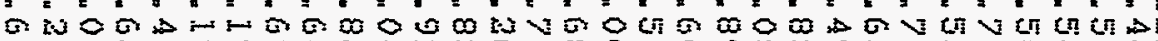

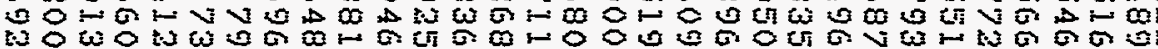

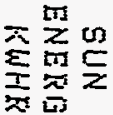

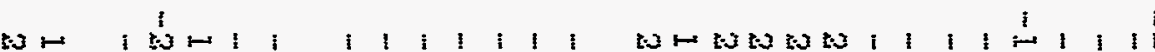

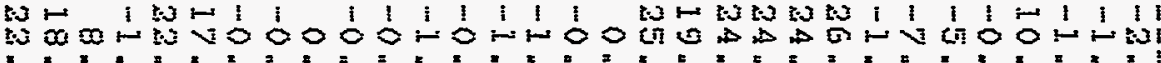

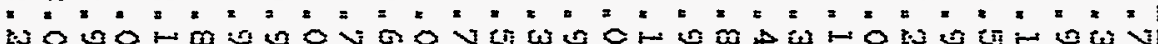

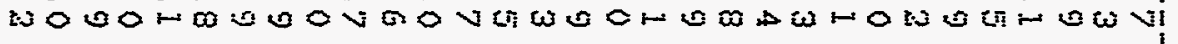
00000000000000000000000000000001

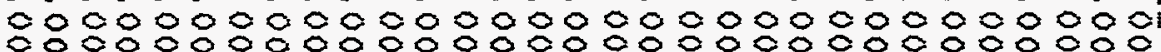
:0000000000000000000000000000001

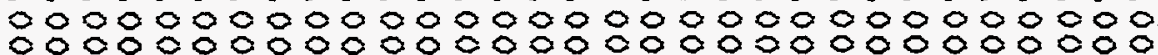
00000000000000000000000000000001

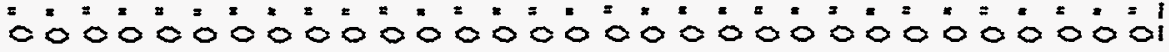

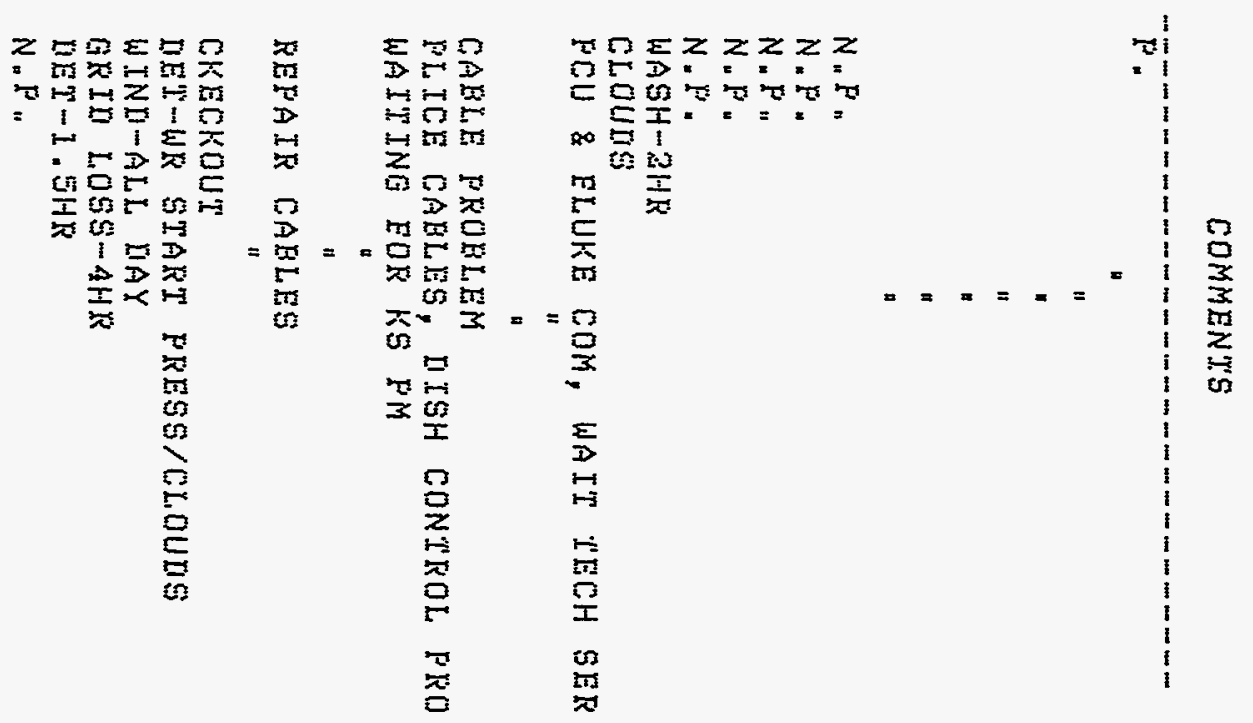

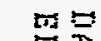
mi $\therefore \rightarrow$

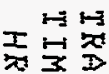
$\pi \frac{\pi}{x}$

I $w z$ 8 $\Sigma$ $3 \stackrel{i}{2} \frac{3}{D}$ $x=x$ $\frac{2}{3}$ 


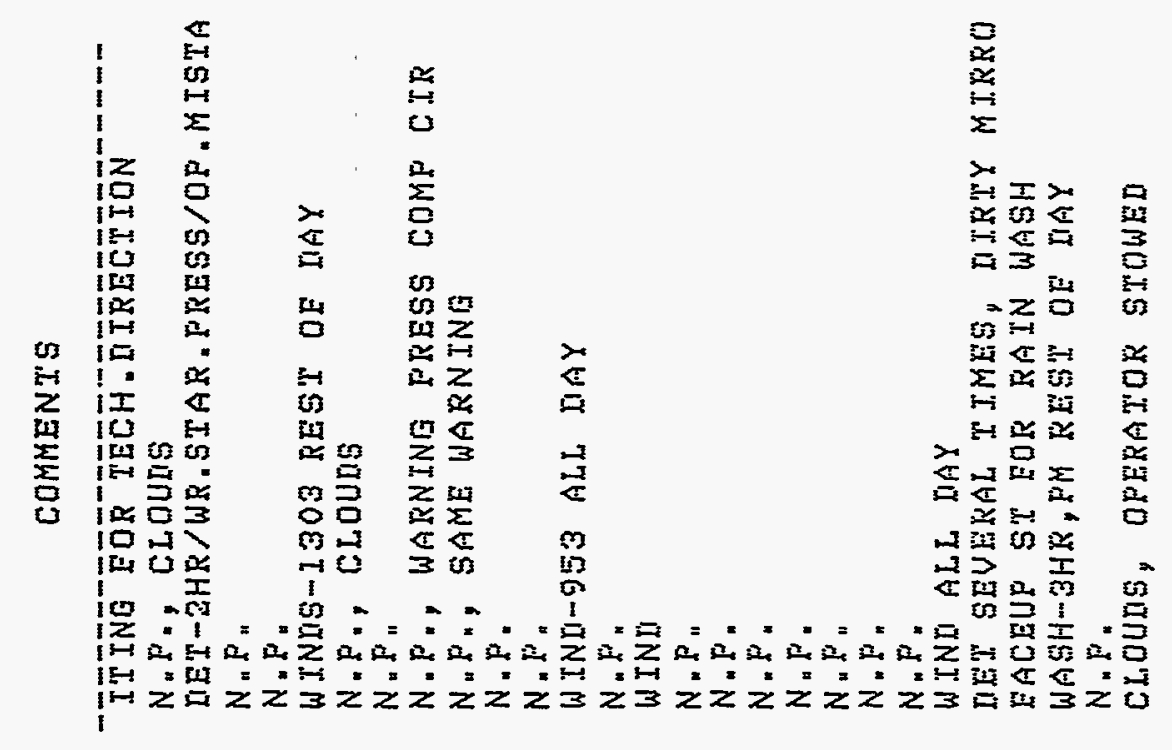

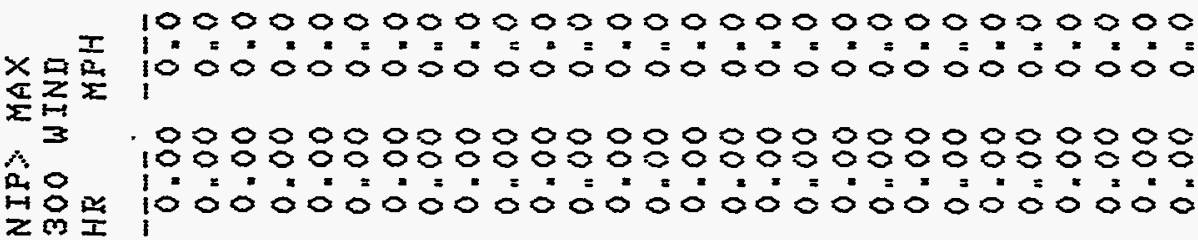

× 0000000000000000000000000000

U

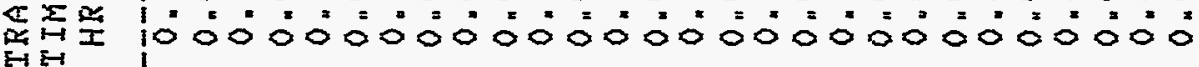

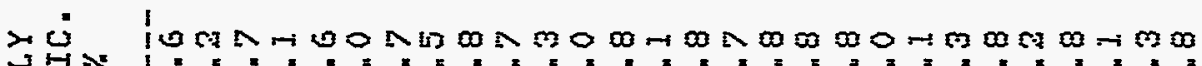

且出 (4

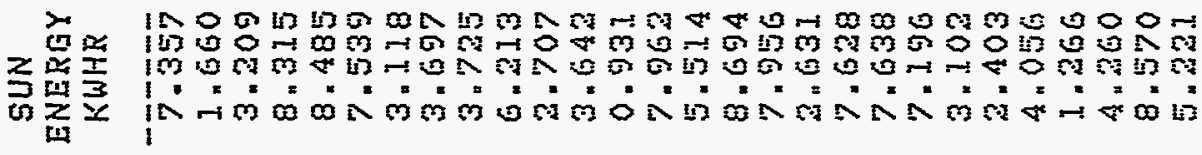

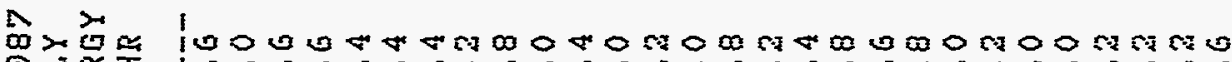
,

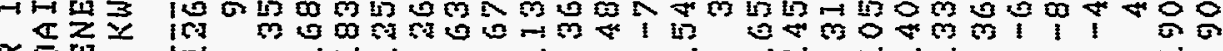

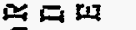

空

突

要要 近西

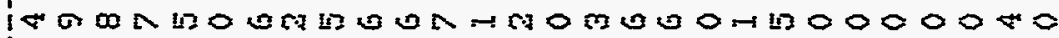
ce

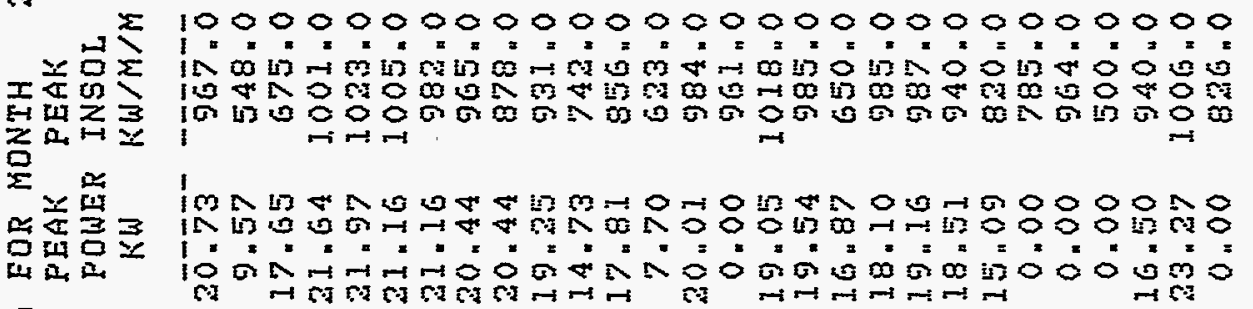

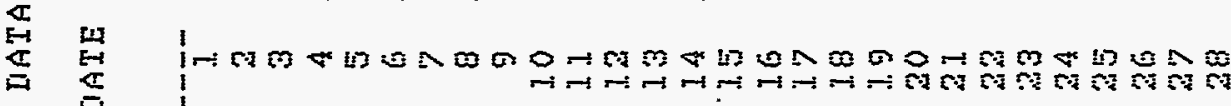

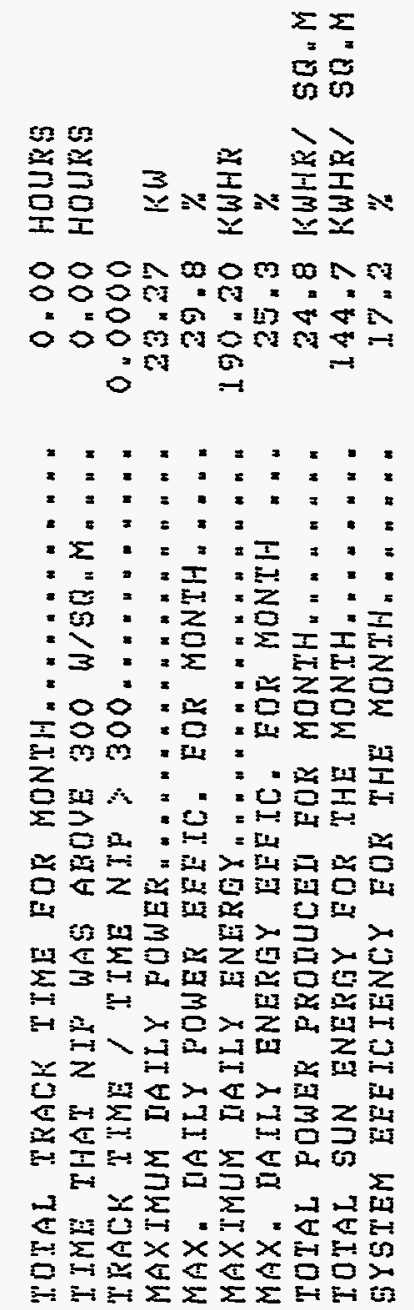




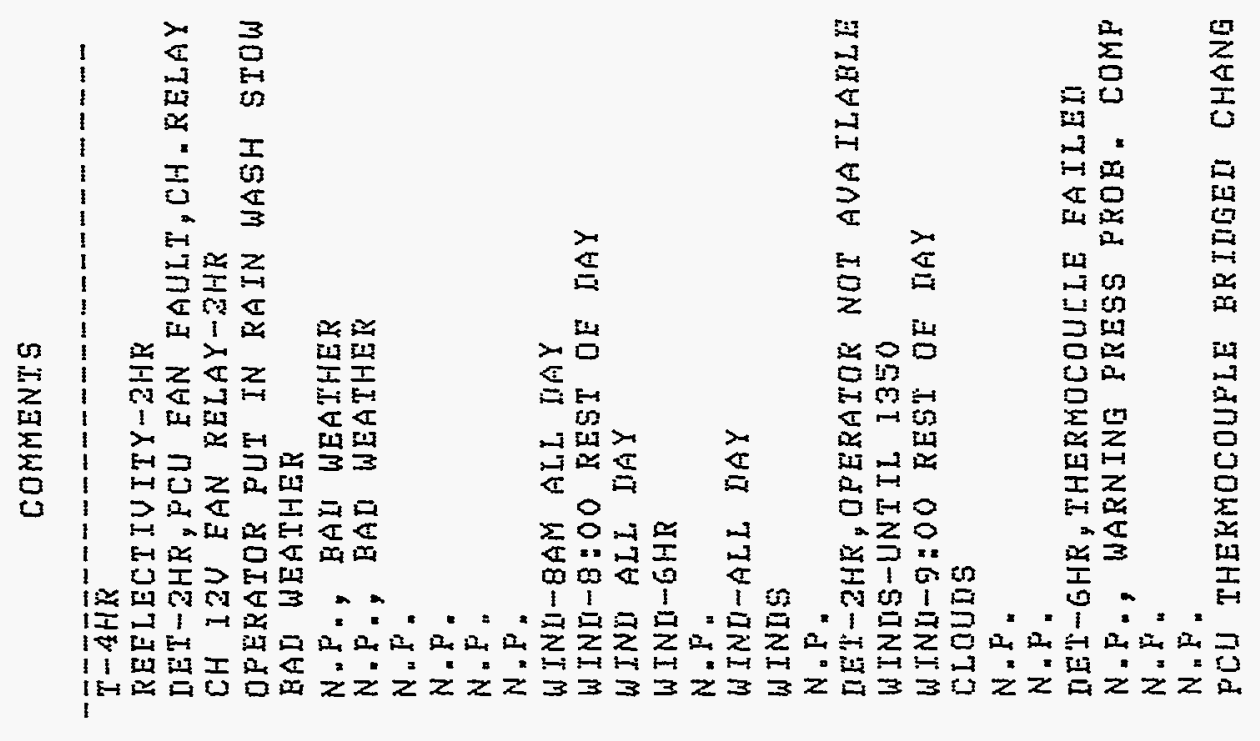

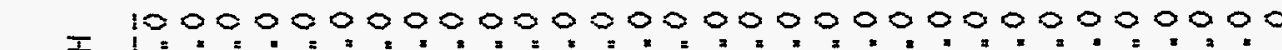
KIㄴ 10000000000000000000000000000000000 $\sum_{i=1}^{\infty}$

$\therefore 0$

$-0$ $z m I$

它 넥

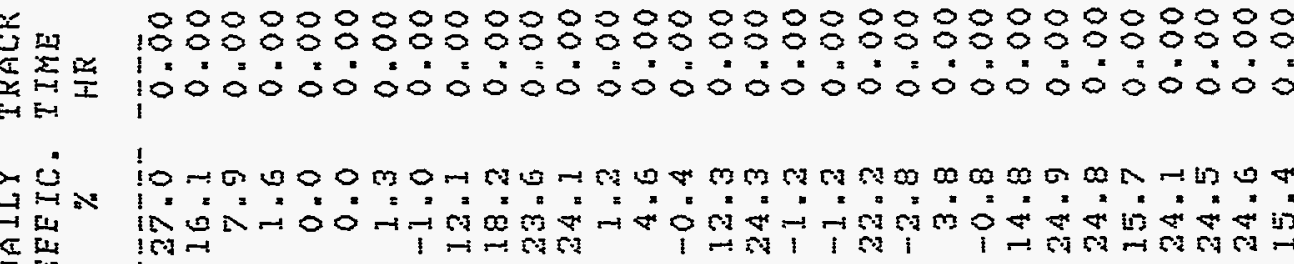

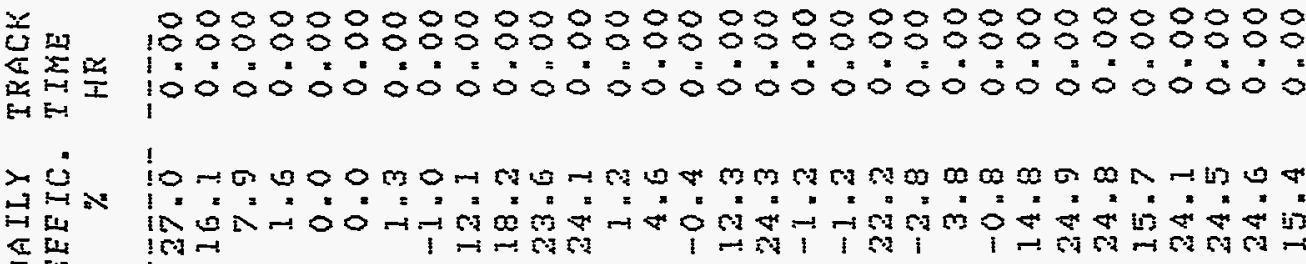

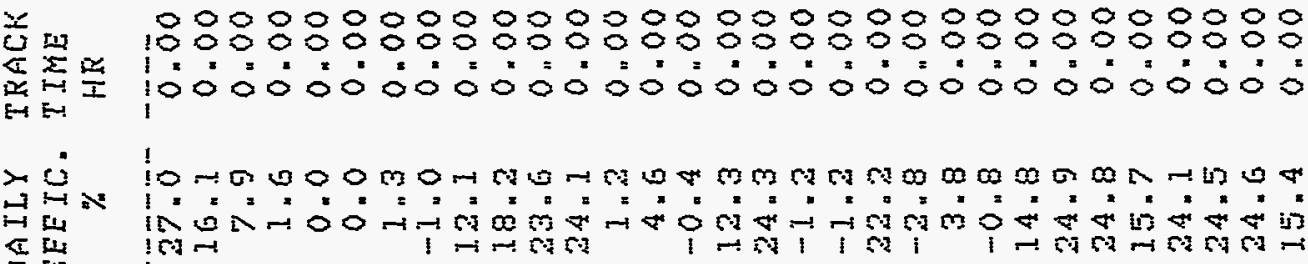
$\pi$ =11

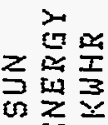

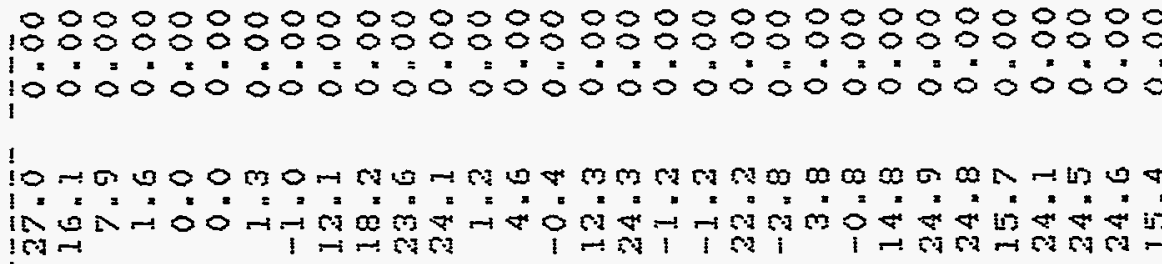

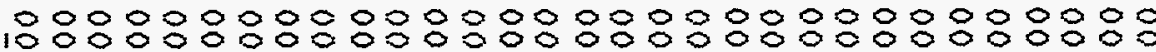

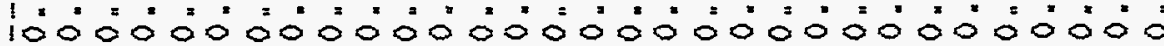

10m0000Nam imnma 00 फल

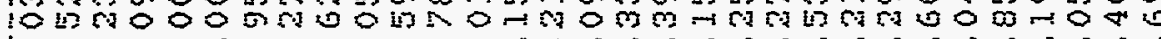
Z

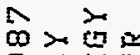
0,2

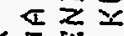
听

$\stackrel{1}{20}$

妾

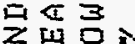
는

$m$

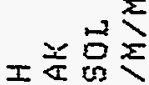

E-1 in 3

5 举 $\approx \frac{1}{3} 3$ 눈문 $\stackrel{1}{\Xi}$

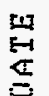

lark

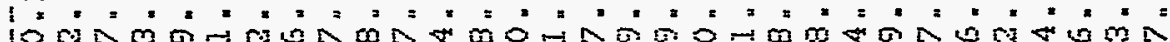

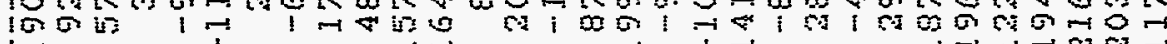
$1 m$

$!$

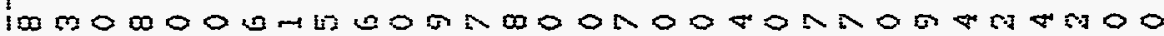

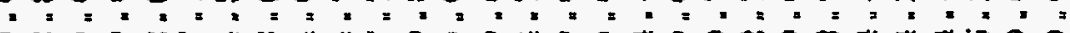

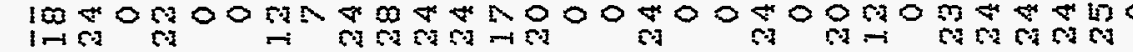

10000000000000000000000000000000

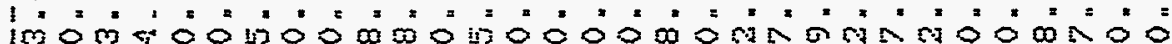

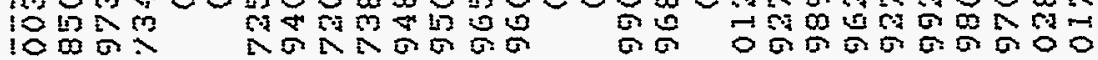

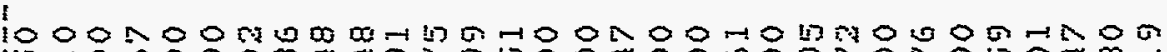

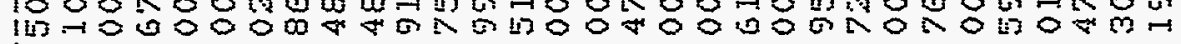
is

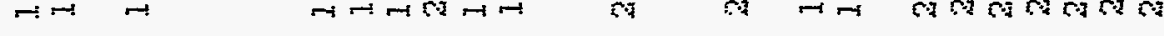
".

(1)
造骂 000 \&

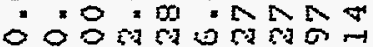
0

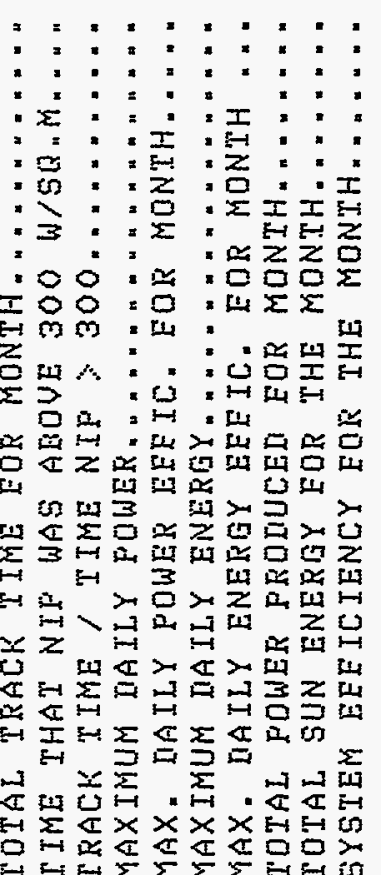




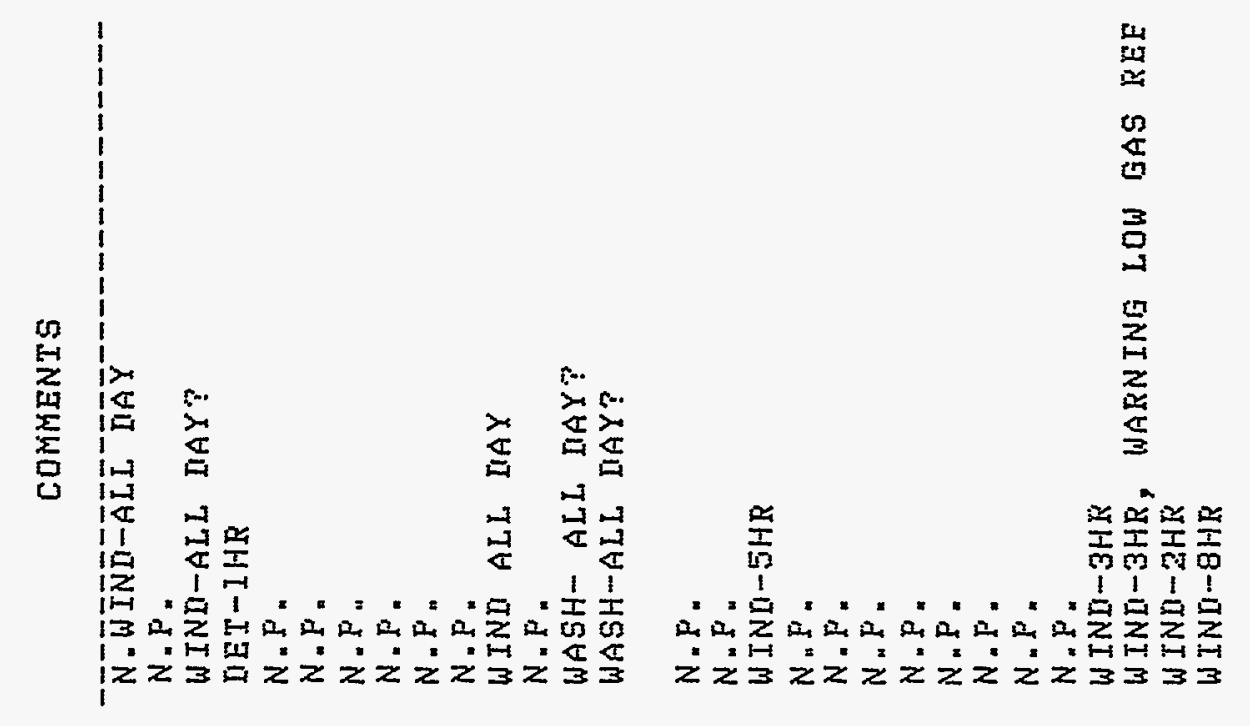

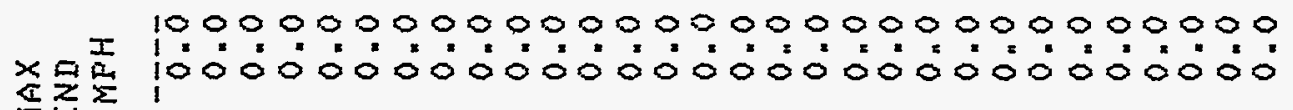
$\sum_{\substack{1 \\ 3}}^{\sum_{i=1}}$

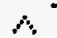

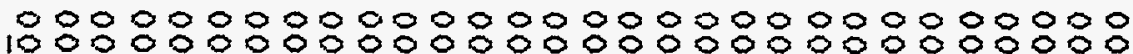
A

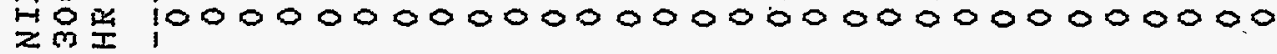

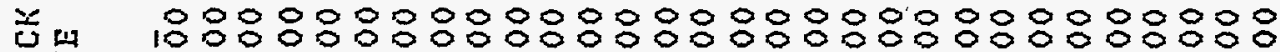
兲出 我里 1000000000000000000000000000000

- : I I 然出 世崖

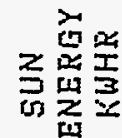

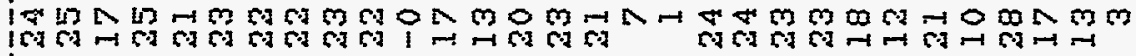

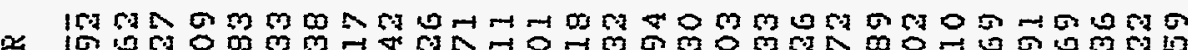
10

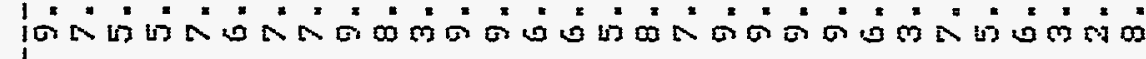

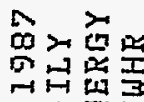

正至主

器要

एᄂ

둔

希出品

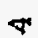

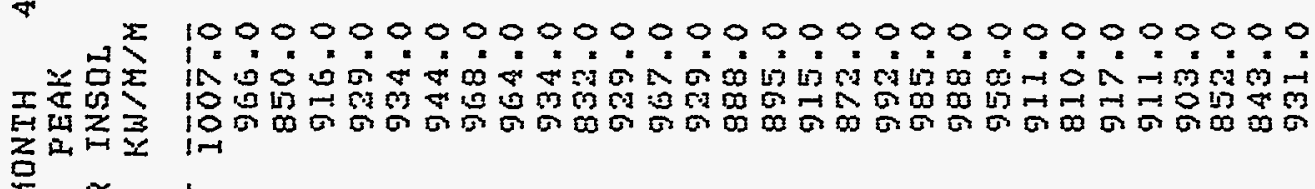
Q

×出

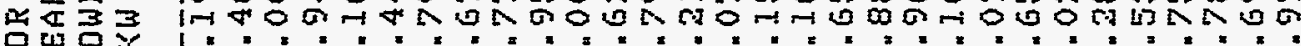

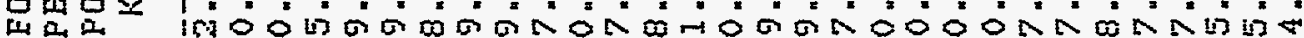

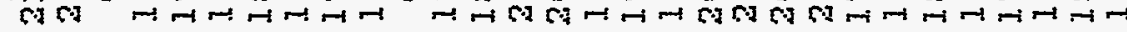

采

I in

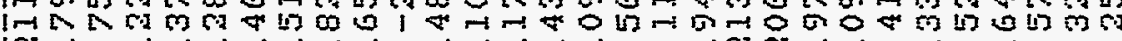
1

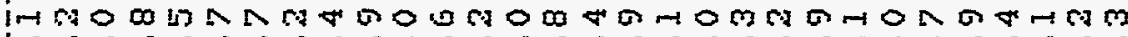

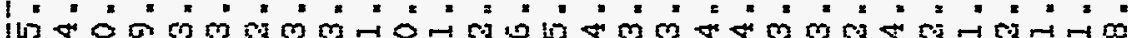

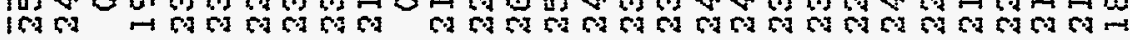

焉

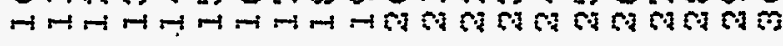

$\Sigma \Sigma$

동

骂号 8용요 $0087.0 \times 1$. 15 60ㅇำ

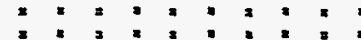

с:!:!:!: : :

: : : : : : : :

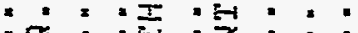

-

-

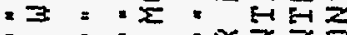

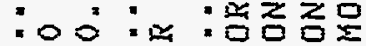

ㅇㅇㅇ:告:记是是

F以n:

艺的

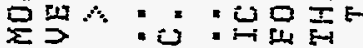

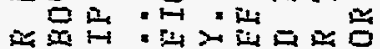

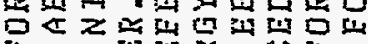

แ

क⿺ 世

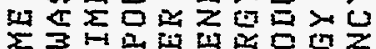

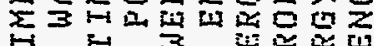
매 ${ }^{5}>3$

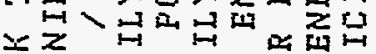

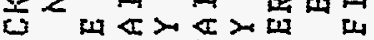

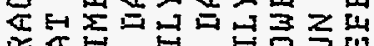

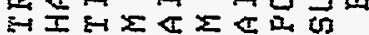
놉

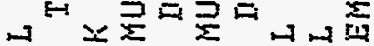

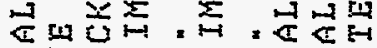
$\sum \sum \times x \times \times \sum_{1}=0$

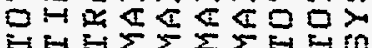




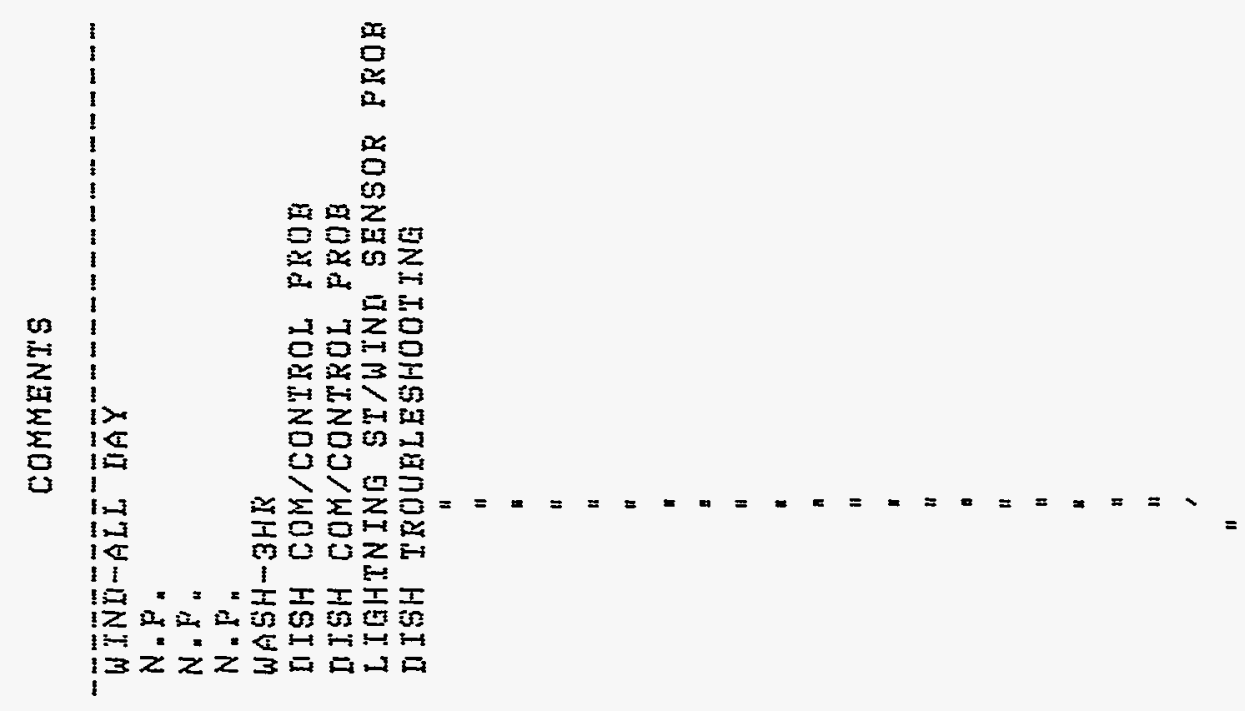

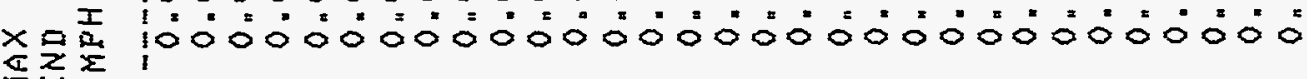
$\sum_{i=1}$

$\therefore$ :0009000000000000000000000000000000000

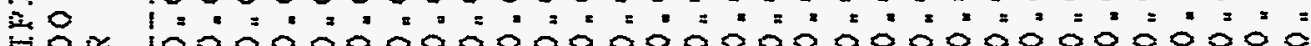

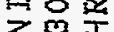

I 19

$\leftarrow x$

0 I 1

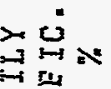

$\rightarrow$ II

EI II

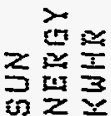
!

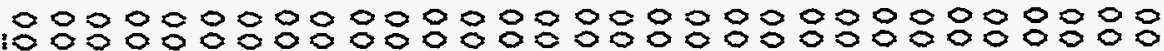

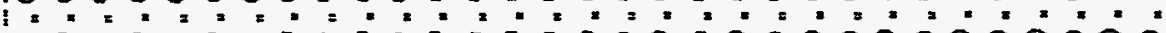
10000000000000000000000000000000

10000 10 m

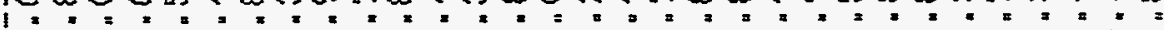

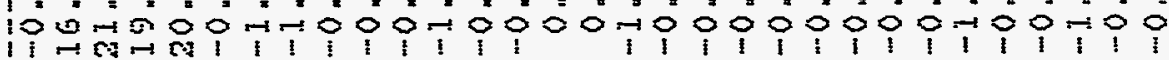
1 i

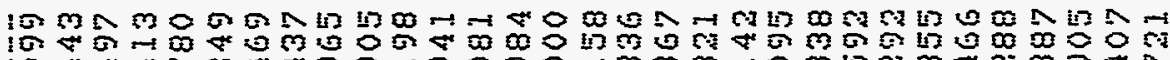

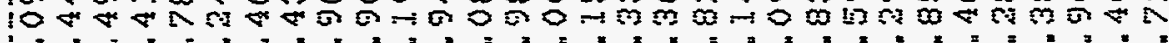

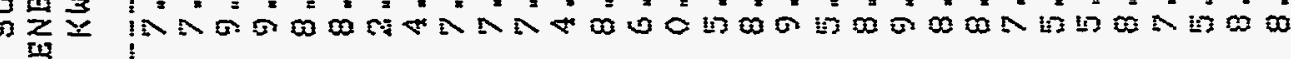

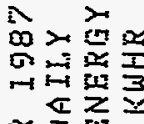
or

栏

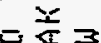
要运

$10+10000000000000000000000000000$

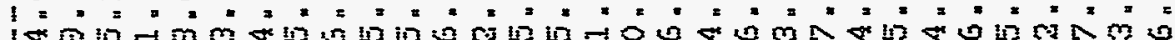

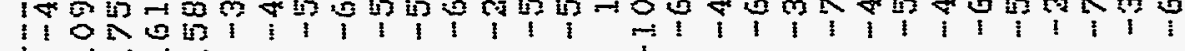
$\rightarrow \rightarrow \rightarrow \rightarrow$

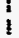

$10 \mathrm{~mm}=00000000000000000000000000$

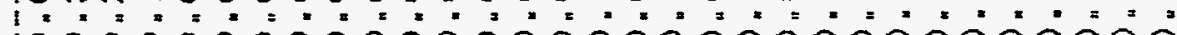

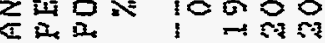

it)

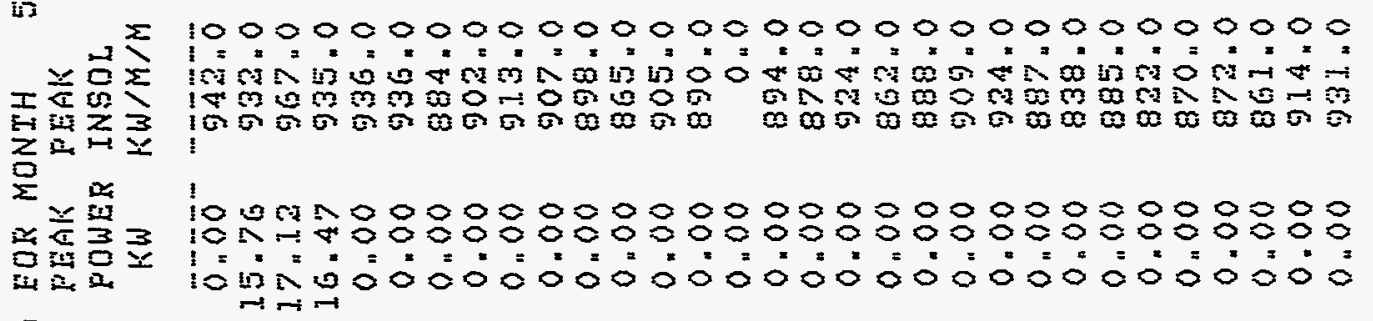

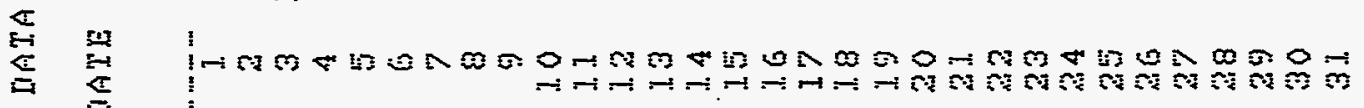

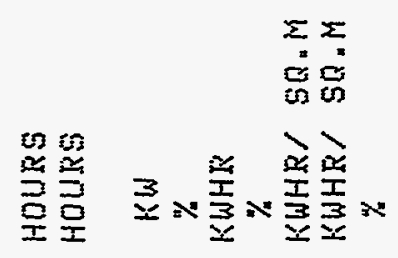

000 moln

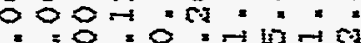

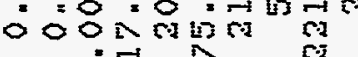
$\therefore \rightarrow$

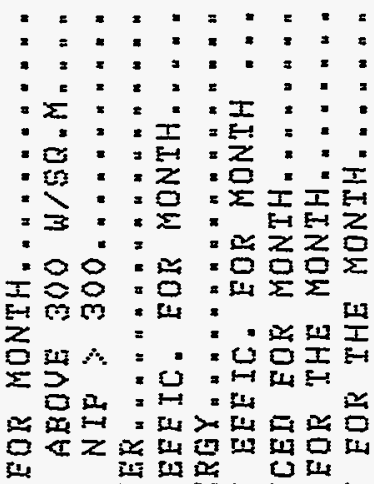
in

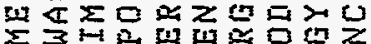

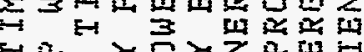

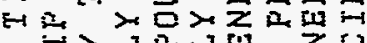

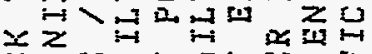

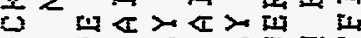

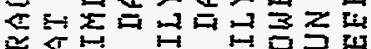

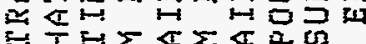

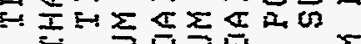

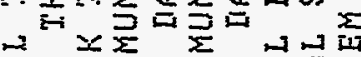

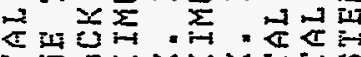
$5 x<\times \times \times E$ E

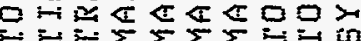




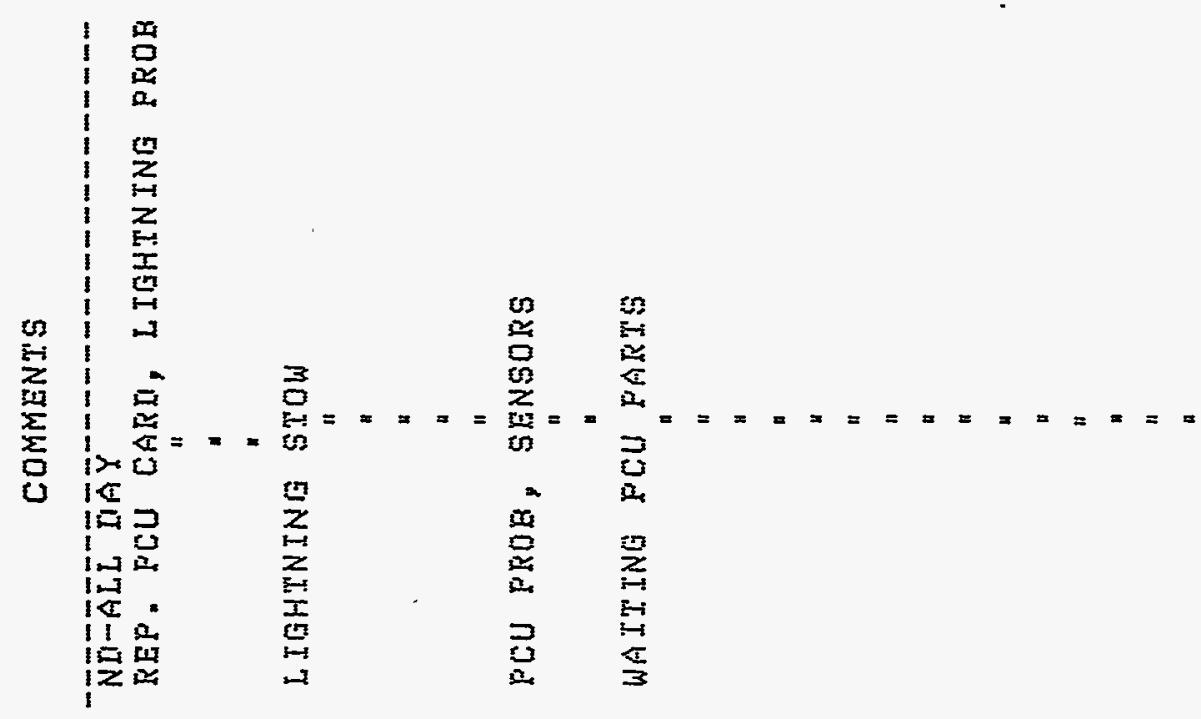

1000000000000000000000000000000

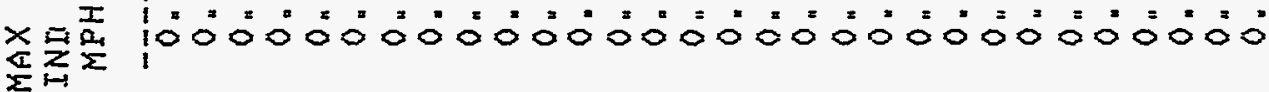
$\sum_{3}$

A.

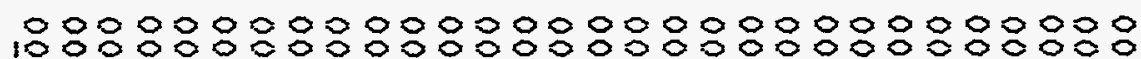

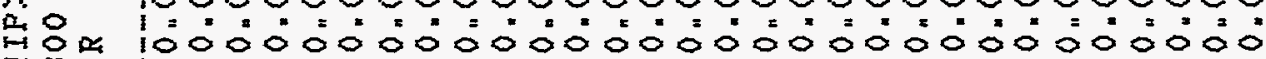
乙心空

落

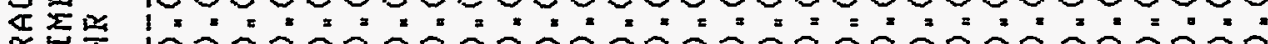

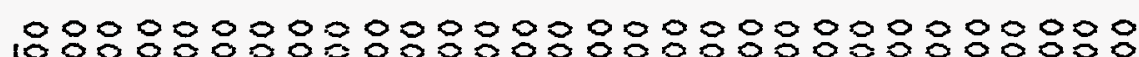
$\lim _{\mathrm{L} \rightarrow \mathrm{i}}$

20

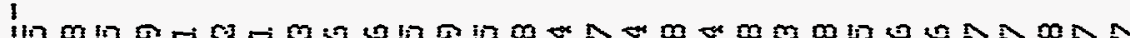
$\stackrel{1}{\rightarrow+1}$ $<$ is 至些

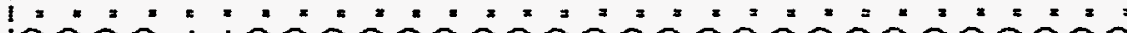

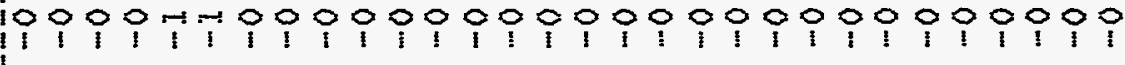

10-0

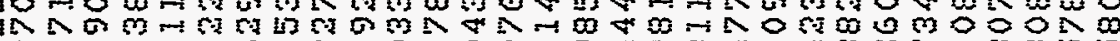

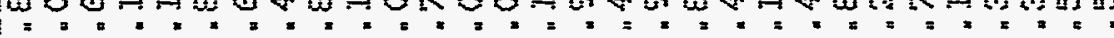
100

全>

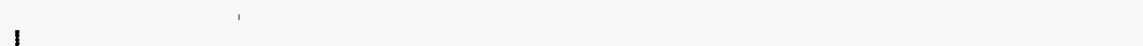

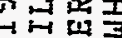
$\leftarrow \frac{2}{x}$ II 崖出 度弯 1000000000000000000000000000000

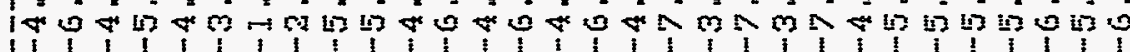
娄要品

$\omega$

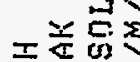

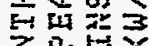

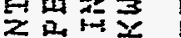
压嵒 吅运崖 运采要 品出足 壱 崖

\section{0}

1000000000000000000000000000000

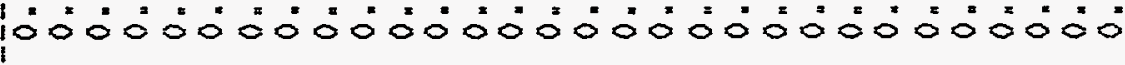

1000000000000000000000000000000

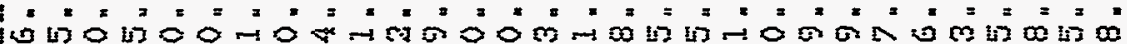

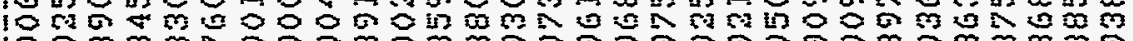

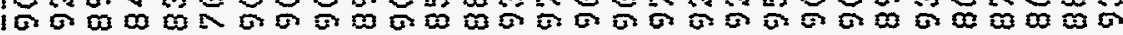

1000000000000000000000000000000

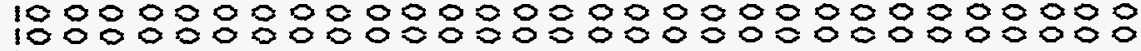
10́0்

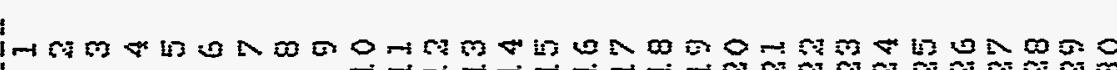

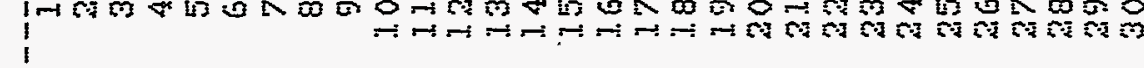

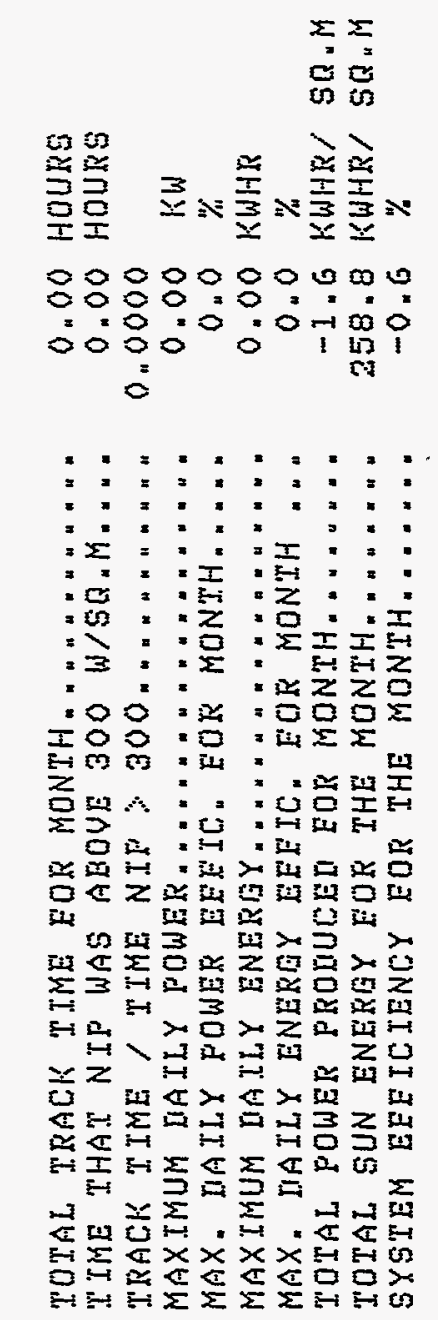

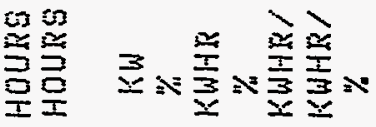

0000000000 $0000=0=1$. $000=0: 07$ in

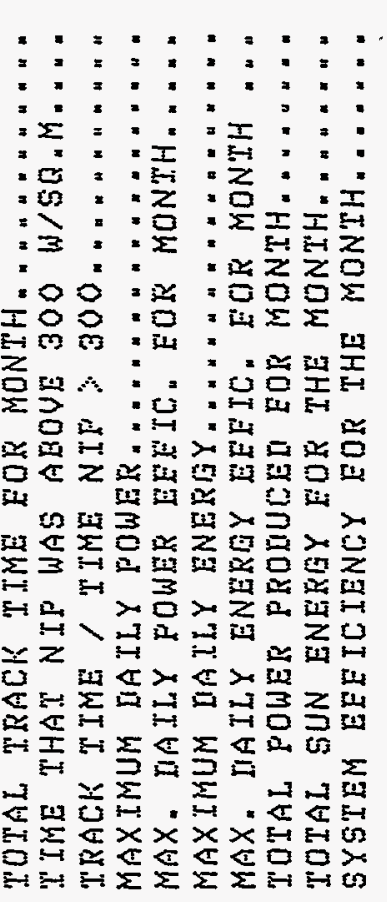




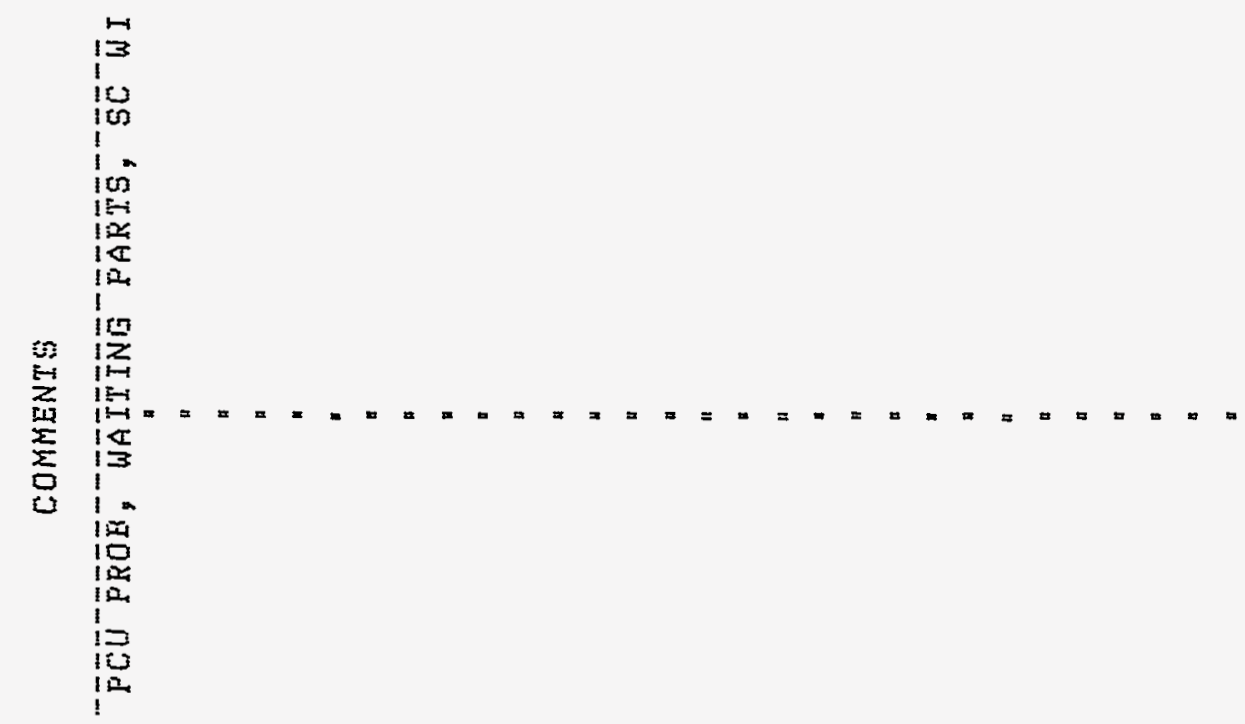

T 10000000000000000000000000000000

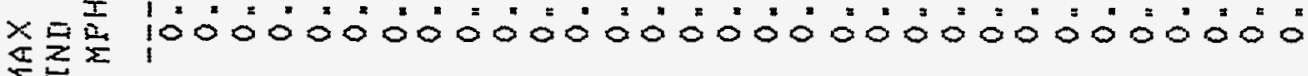
$\Sigma$ i.

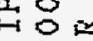
工

兰出

$\underset{2}{2}$ $\underset{1}{I}$

$\rightarrow \dot{0}$

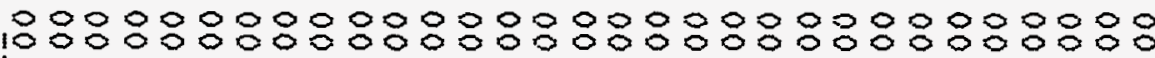

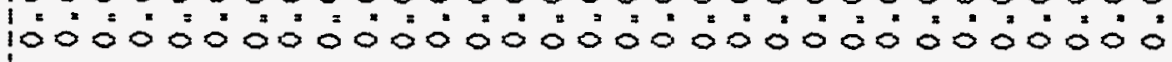

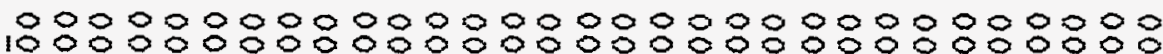

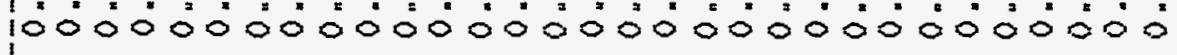

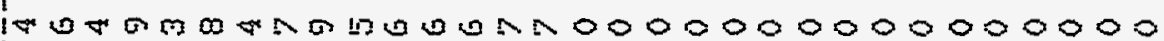

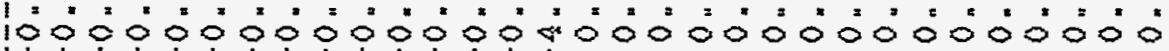
1

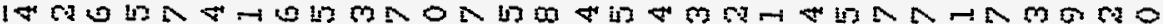

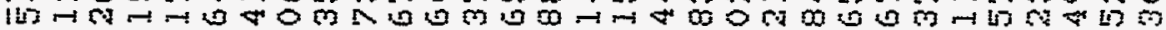

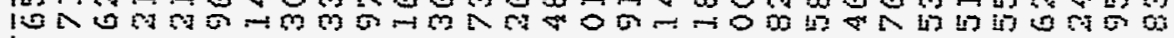
ㄴ.

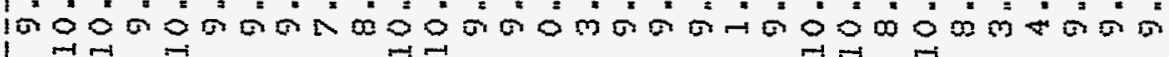

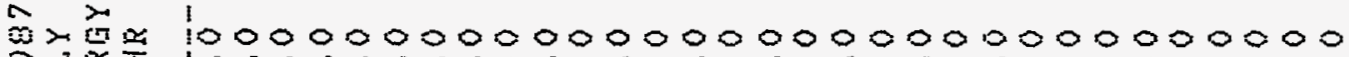

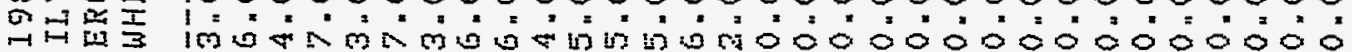
$4 \geq$

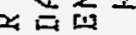
๘ 竞㟧

$=\frac{1}{\varepsilon}$

要要》

近证

10000000000000000000000000000000

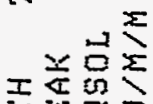

12

10000000000000000000000000000000

I

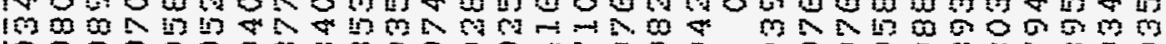
石足约 $\underline{\Sigma}$ $\Sigma$ 米 $\therefore \frac{1}{3}$ 0 1

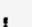

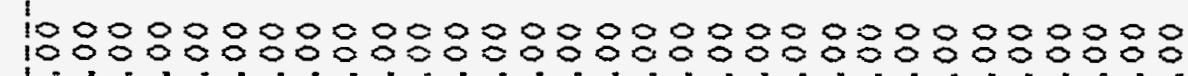
10000000000000000000000000000000

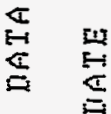
1,

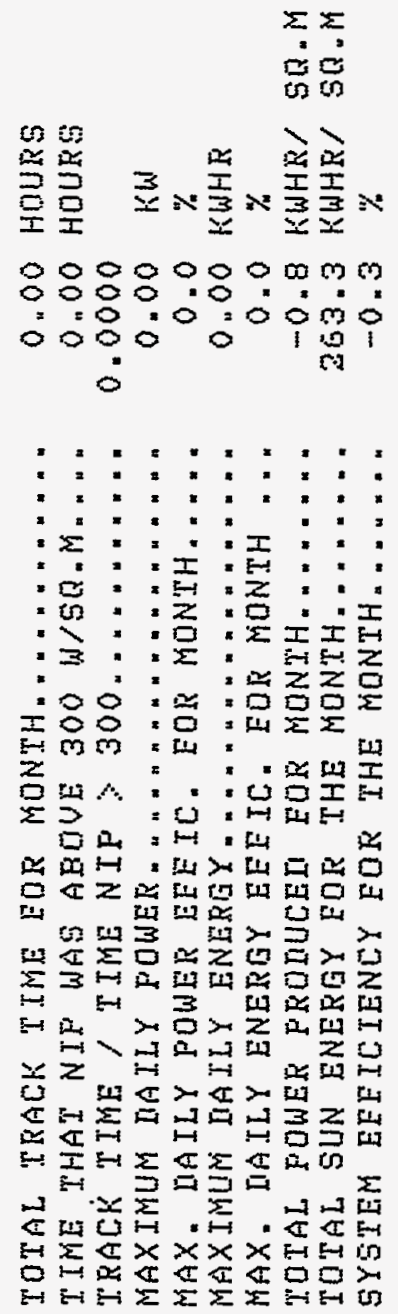

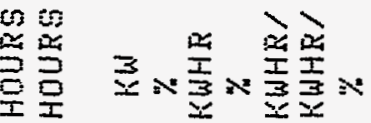
$00000000 \mathrm{~mm}$ $0000: 0: 1.1$. $=0: 0=00 \% 0$ 


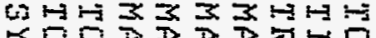
of

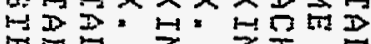

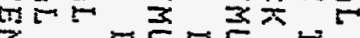

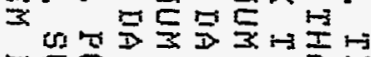

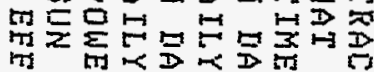

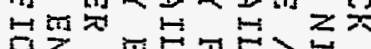

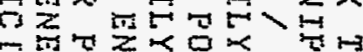

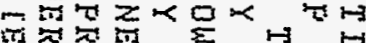

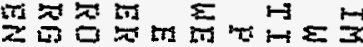

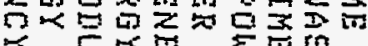

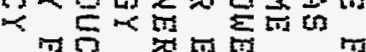

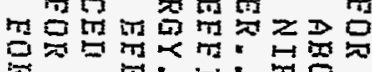

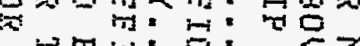
봉응: :

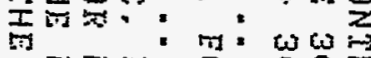

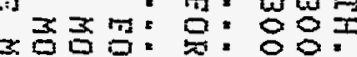
远远: 事: $\sum_{i=1}: x^{2}: 5$

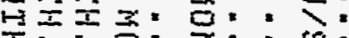
I: :

: :

: I: : $: 3$

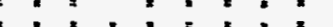

$\div: 1: 2: 5: 5$

20000

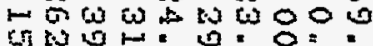
ㄴ. as $\Rightarrow 50800$

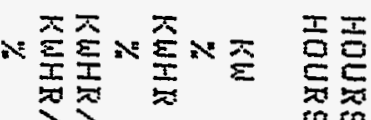
$\cos$ $\infty 0$

33

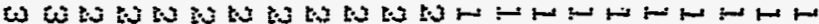
$\stackrel{9}{5}$

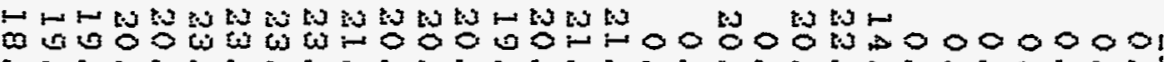

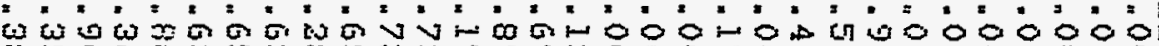

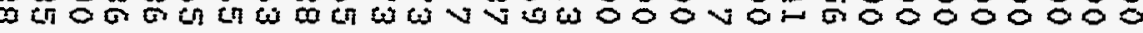

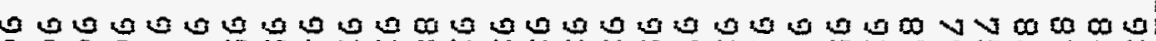
○유.

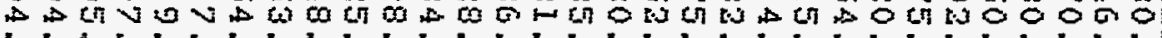

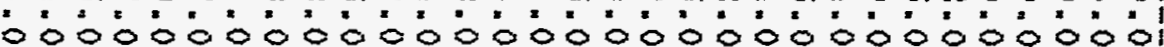

W

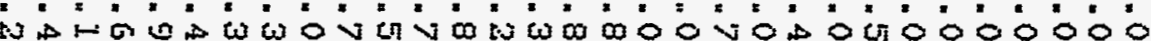

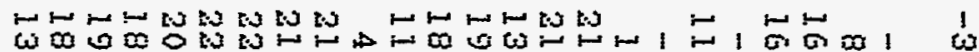
4

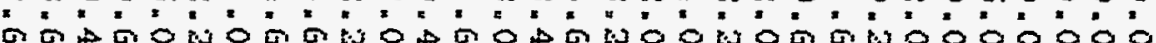

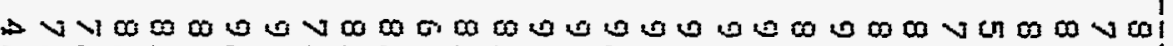

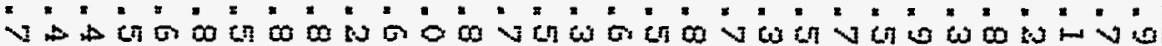

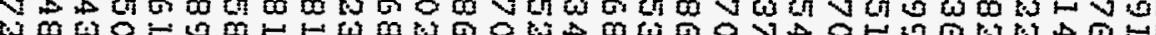

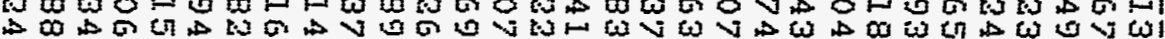

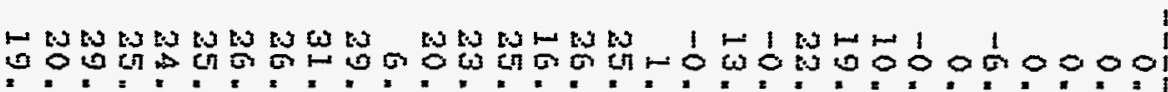

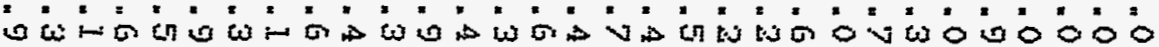

000000000000 W W

* :

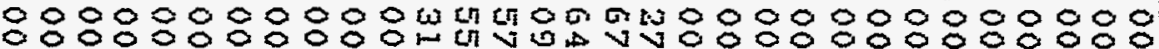

00000000000000000000000000000001 ó0000000000000000000000000000

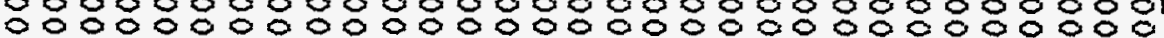
00000000000 W

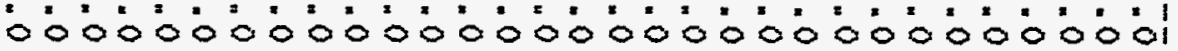

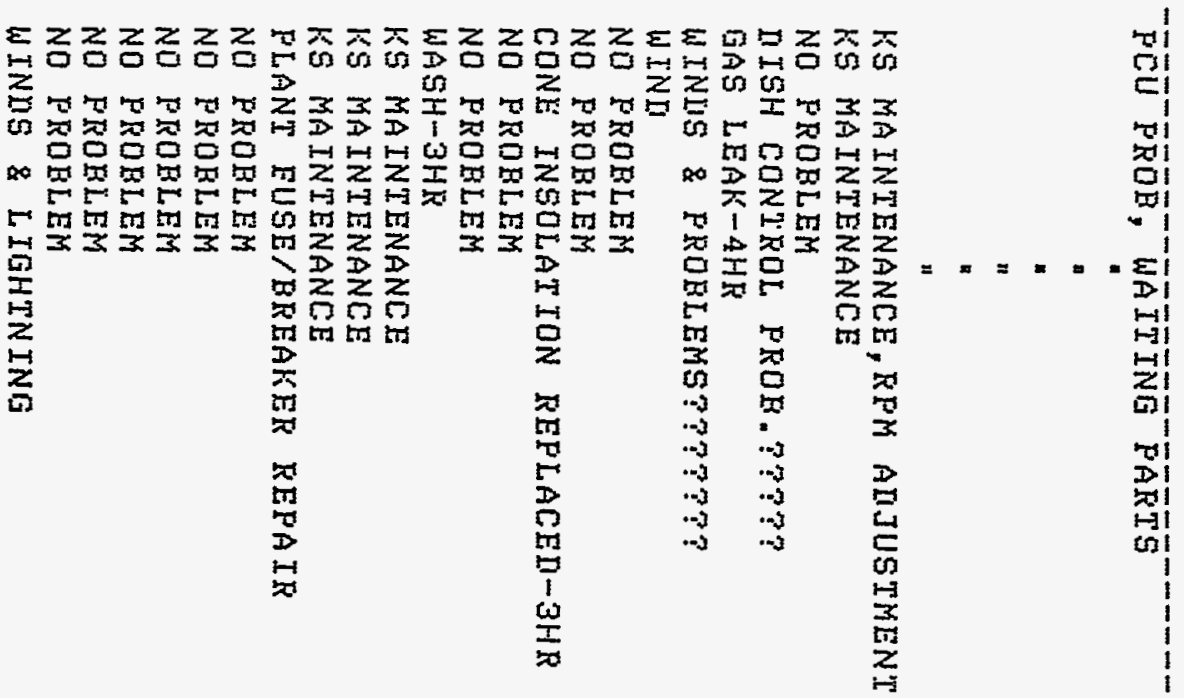

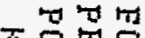

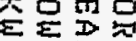
줒

不畹 $\sum \sum_{0=1} \sum_{D}$ 3뭊

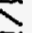

$\infty$

'万d

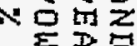

E

$\min _{2}$

正而至

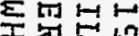
牙岕心恖

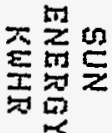

而

in

रम

Dx

H겅

究望忽

的是

I $w z$

영

$=$

3. 暂 


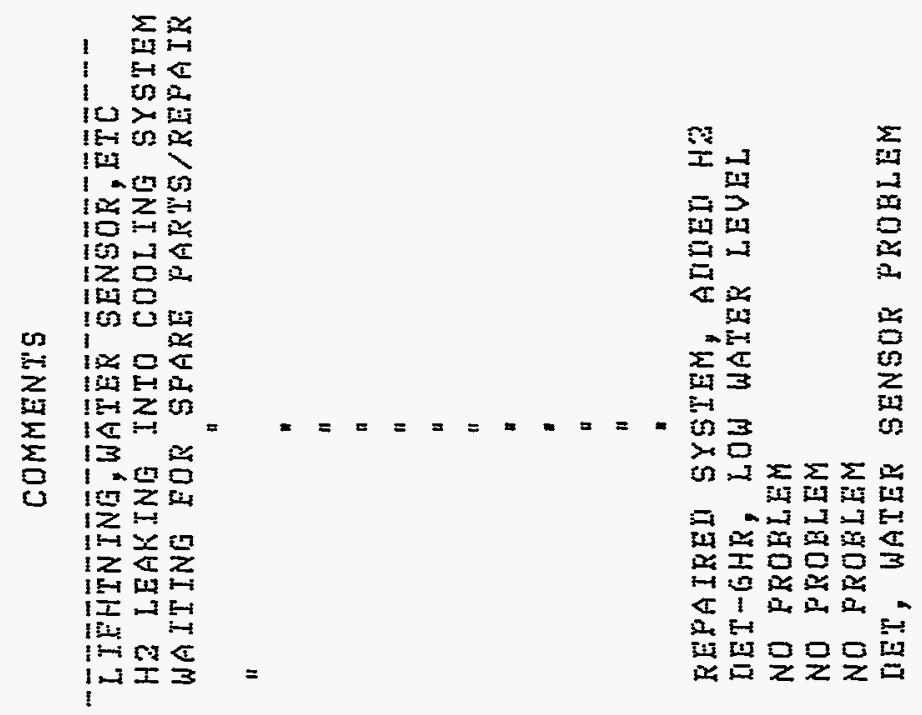

$x \equiv \frac{\overline{3}}{2}$

$\Sigma z$

$\Sigma$

$\therefore$

is

zल

产

柆는

品

$>0$

$\rightarrow$

$\leftarrow$ 世

红

年

Z 논

en 2

[I]

今心

메

正 $\underset{1}{2} \cong$

문

In

$=$

品步

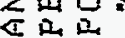

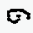

I 1000000000000000000000000000000 $T<\frac{0}{0}$

I $\rightarrow 2 \geq$ $x$ 단

$\underset{2}{2} \approx$

$\simeq \frac{11}{3}$

중

in 20

$\stackrel{\square}{=}$

1 I: $\rightarrow-i \rightarrow-i$

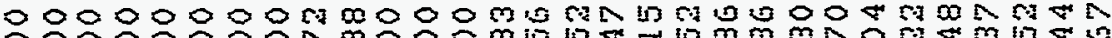
$100000000 \mathrm{NOO}$. 100000000000000 a

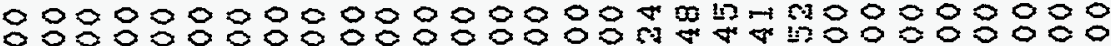

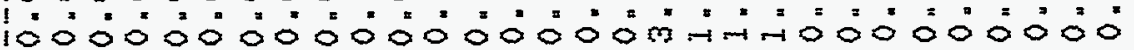

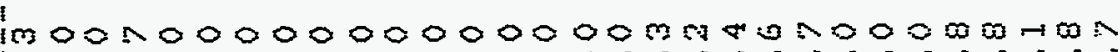
in 1

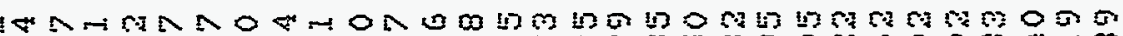
ब 1. 10 HN

10000000000000000000000004000

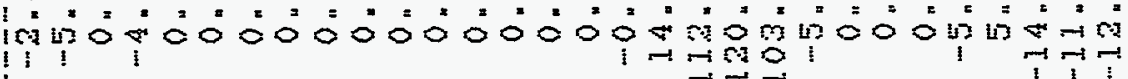
1

$1 \% 0000000000000000$ m 1000000000000 in:

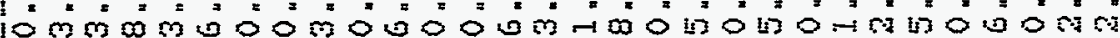

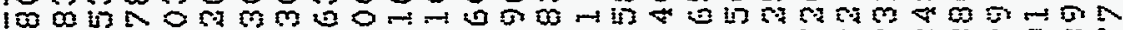

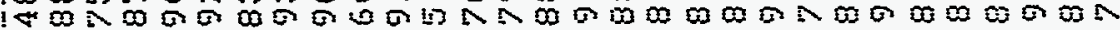

\section{(1)}

100000000000000000000000000000000 $10000000000000000000000 m$ m. 


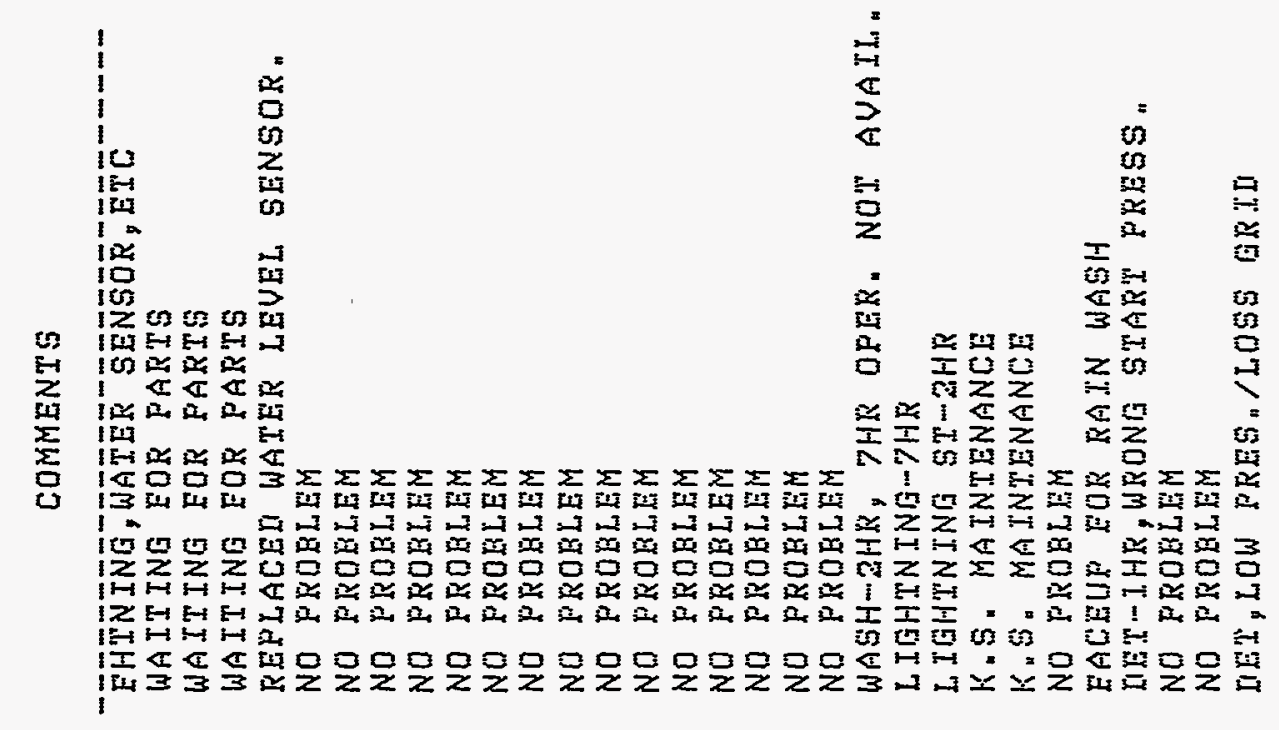

10000000000000000000000000000000

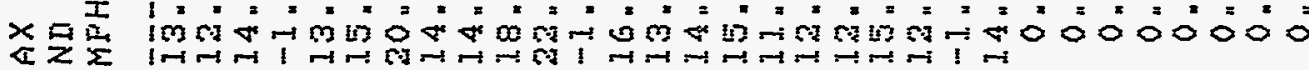

ב

$\therefore 0$

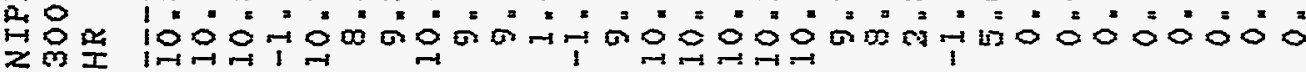

M०

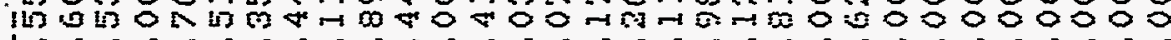

sw

㱐

点正工

Fi

20

$\rightarrow$

$\rightarrow$

五

肾望要

$00000 \mathrm{~mm}$ mo

1.

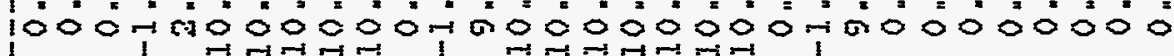

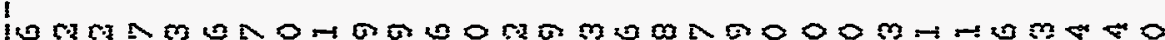

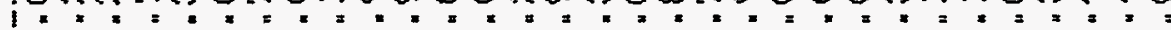

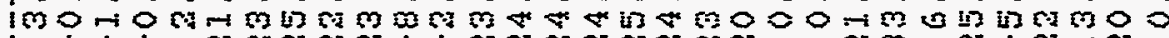

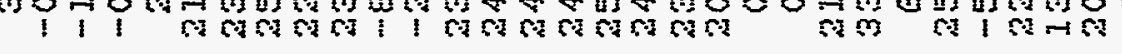

109002

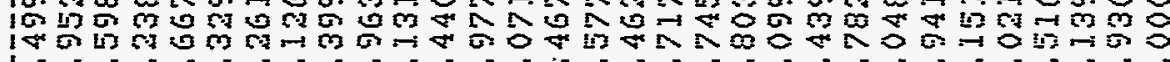

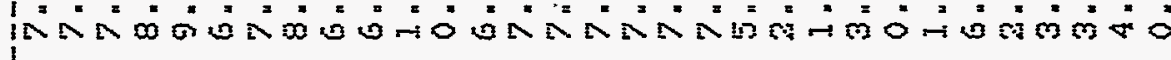

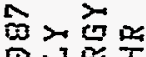
a) $\rightarrow$ 의 $I$ $<\geq$ or

空

$>$

표 $\frac{1}{0}$ 近a

0

잉

I $\frac{1}{2}$ en

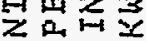

可

둔

运它

H 15

$\underset{⿱ ㇒}{\mathbb{I}}$ is

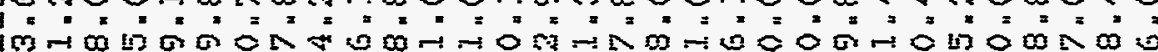

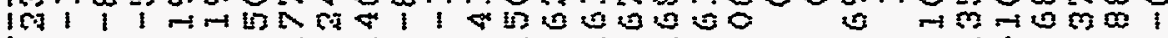

1

10000 H $10^{\circ} 0^{\circ} 0^{\prime 2}$ :

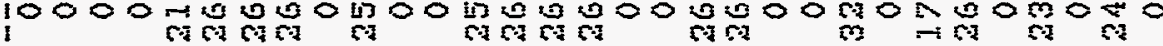

10000000000000000000000000000000 100 "

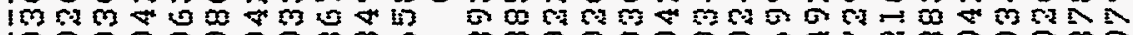
100\%

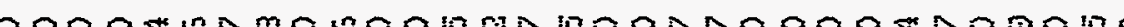

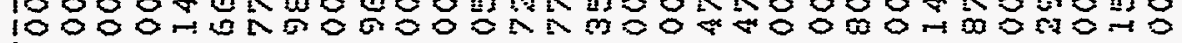

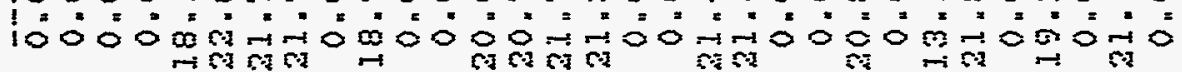
1,0
1

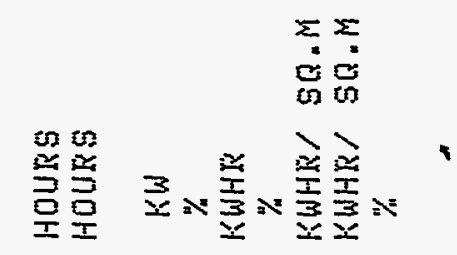

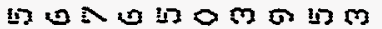
m $\mathrm{n}=\mathrm{a}=\mathrm{m}, \mathrm{m}$ $=m=m=m \infty i$ l) 겅

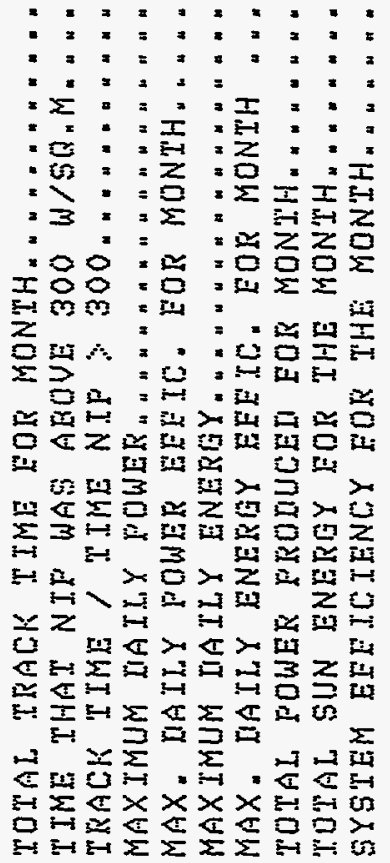




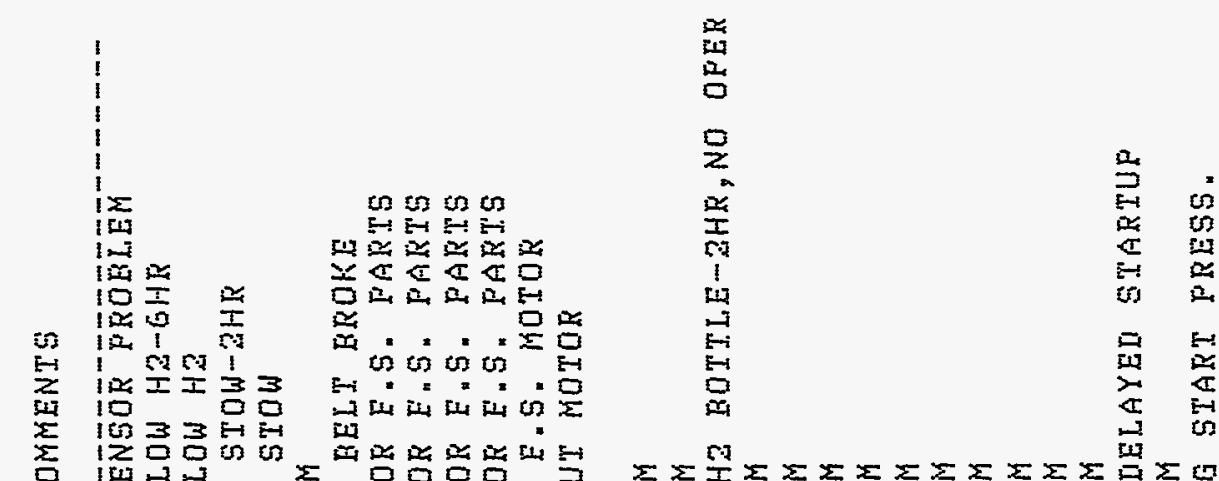

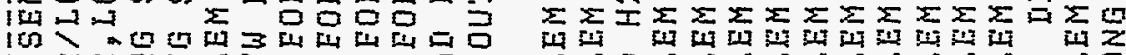

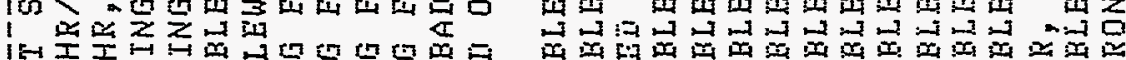

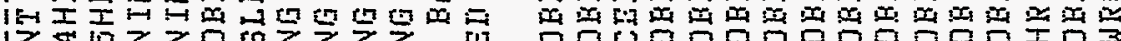

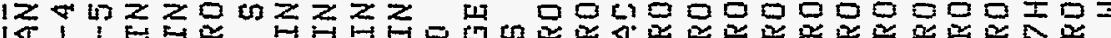

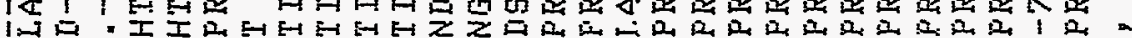

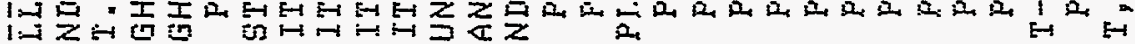

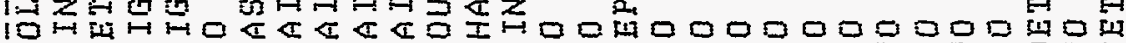

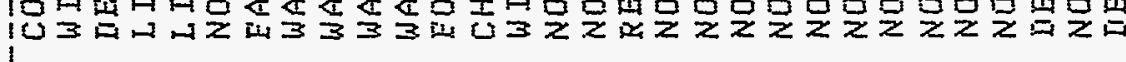

1000000000000000000000000000000

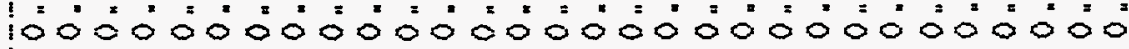
3

is

눈응

$\because$

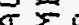

$\sum_{i=1}^{\infty}$ $\sum_{i=1}$

$\rightarrow:$

Hit

$\rightarrow$

吉迤

2

乙 튼 족

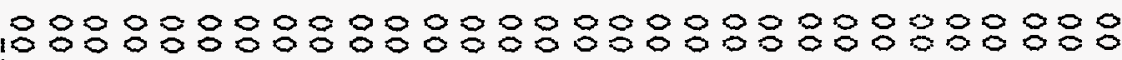

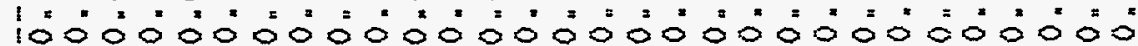

$\operatorname{lig}_{0} \frac{10}{3}$

$\hat{\infty}>$ 苗 Es: $\Xi z$

는

एᄂ

$>\frac{1}{5}$

要迹 $\sum_{x \rightarrow 0}$

$\rightarrow$

$=\stackrel{0}{-1}$

000009000000009009090909090900

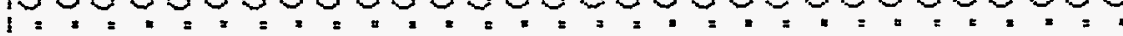
1000000000000000000000000000000

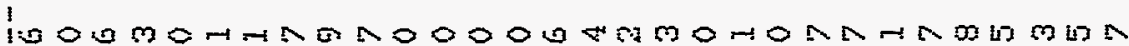

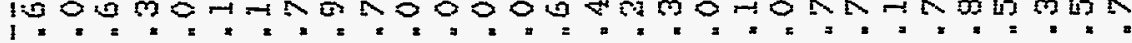

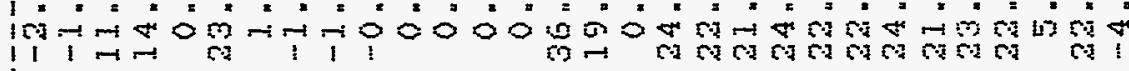

loth 17م iNmm心 $\rightarrow$ स 1M

$\frac{1}{10}$

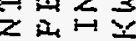

$x$

$\simeq \frac{1}{3}$

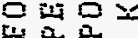

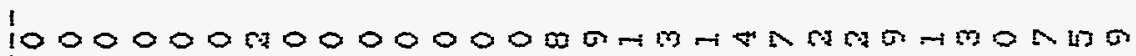

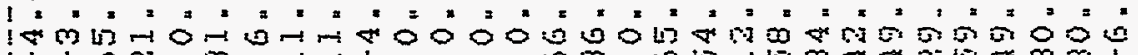
11 1 की 空

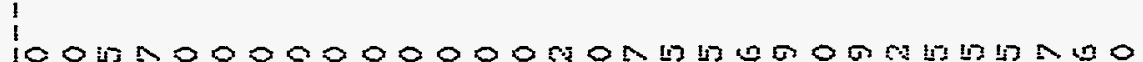

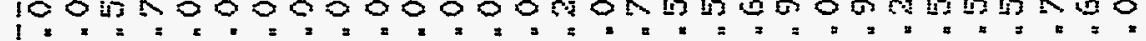
$10^{\prime}$ 100 की

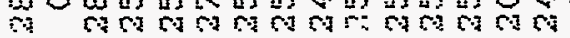

1000000000000000000000000000000 1 10 in $0 \mathrm{~m}$ -

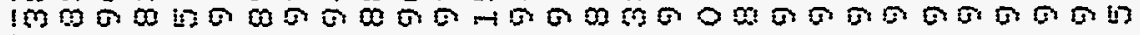

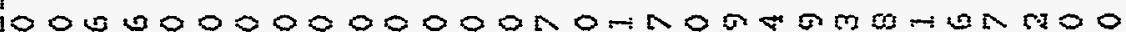

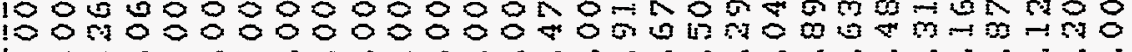
1000 !

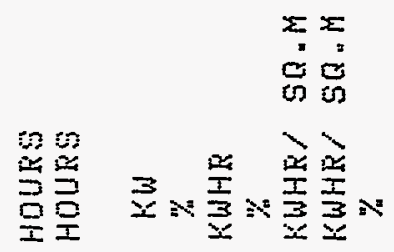

OONONOD $00 \pi$ in $=0.0 .0$ -

$$
00 \text { a }
$$

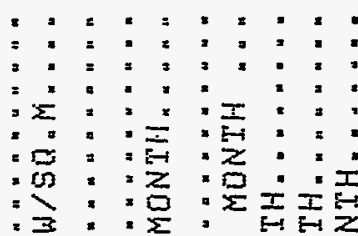

$=0: 2$ :

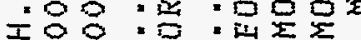

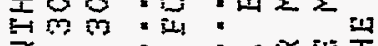

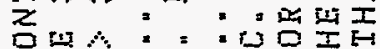

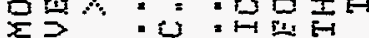
古进: : : :

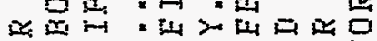

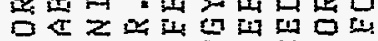

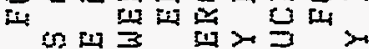

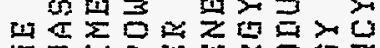

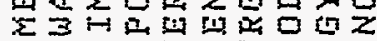
$\sum_{i=1}{ }_{1}$

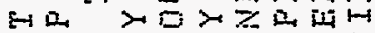

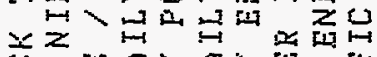

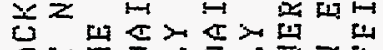

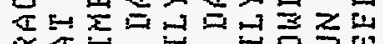

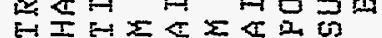

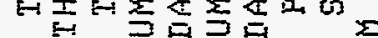

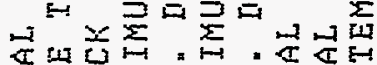

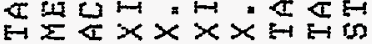

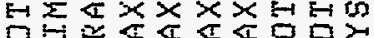

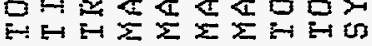




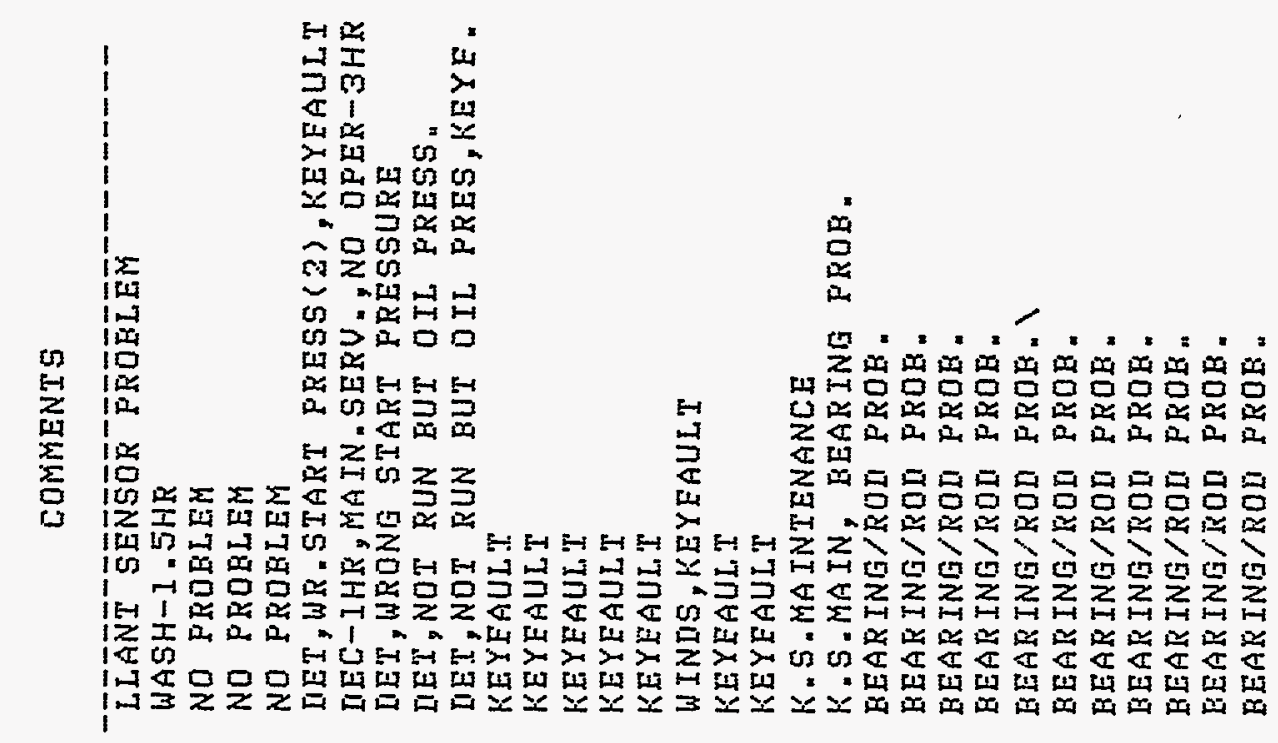

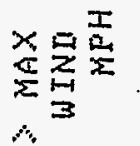

100000000000000000000000000000000 100000000000000000000000 ".

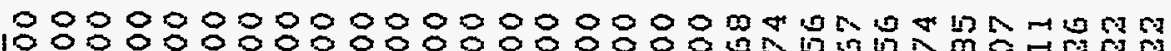

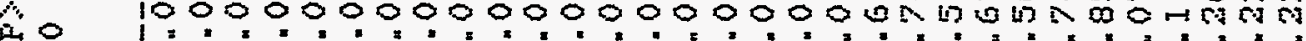
崖品

.

$\frac{11}{1}$ $\sum_{i=1}^{I} \sum_{I}^{\underline{I}}$

30

$\rightarrow=$

(1)

要

空

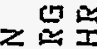

㟧岸

18888088888880888808880808888888

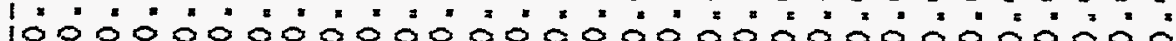

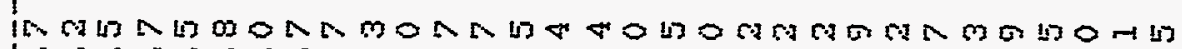

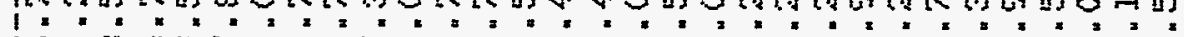

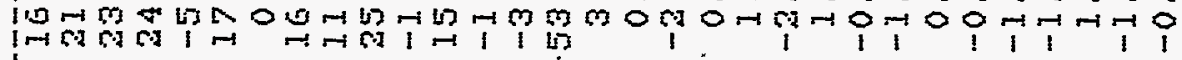

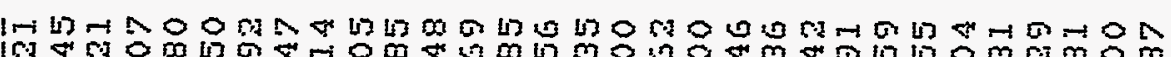

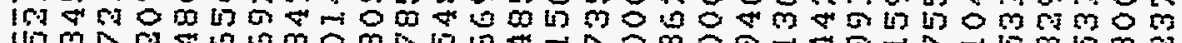

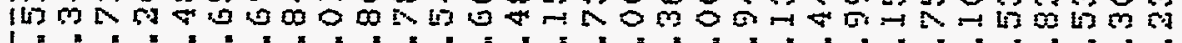
im

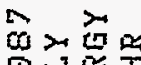

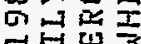

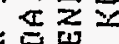

空㟧

至

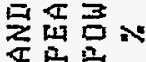

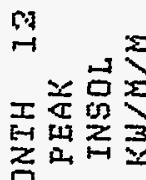

出出空

品

$2 \frac{\pi}{3} 3$

要宫妾

$\leftarrow$

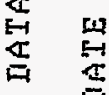

in 1.:.

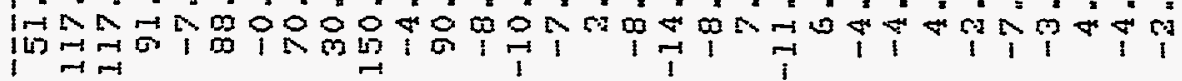

1

inna0000000m00000000\$00000000000

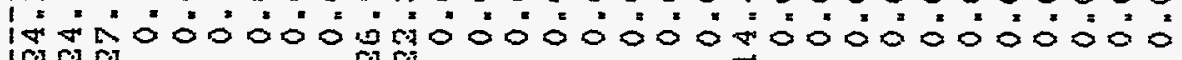
ind

$$
\text { o. }
$$

10000000000000000000000000000000

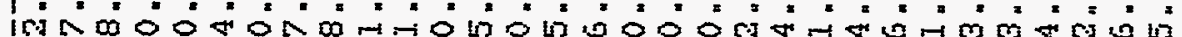
mO-G 100

10

10 1. in !
$\Sigma \Sigma$

$\underbrace{}_{0}$

骂骂

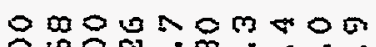
$060 \mathrm{~m}=00$. o. व.

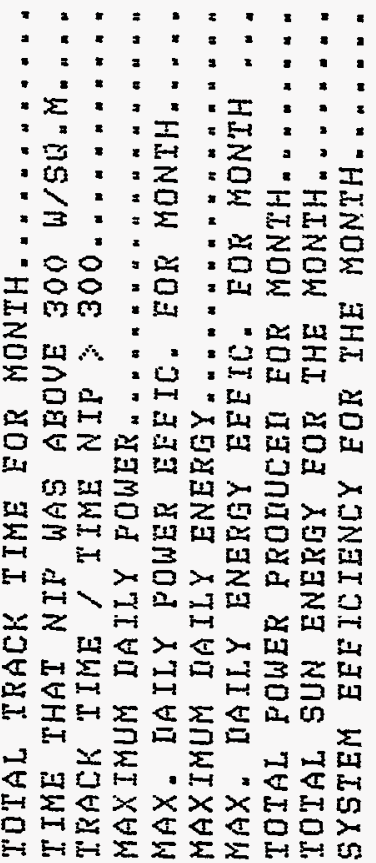




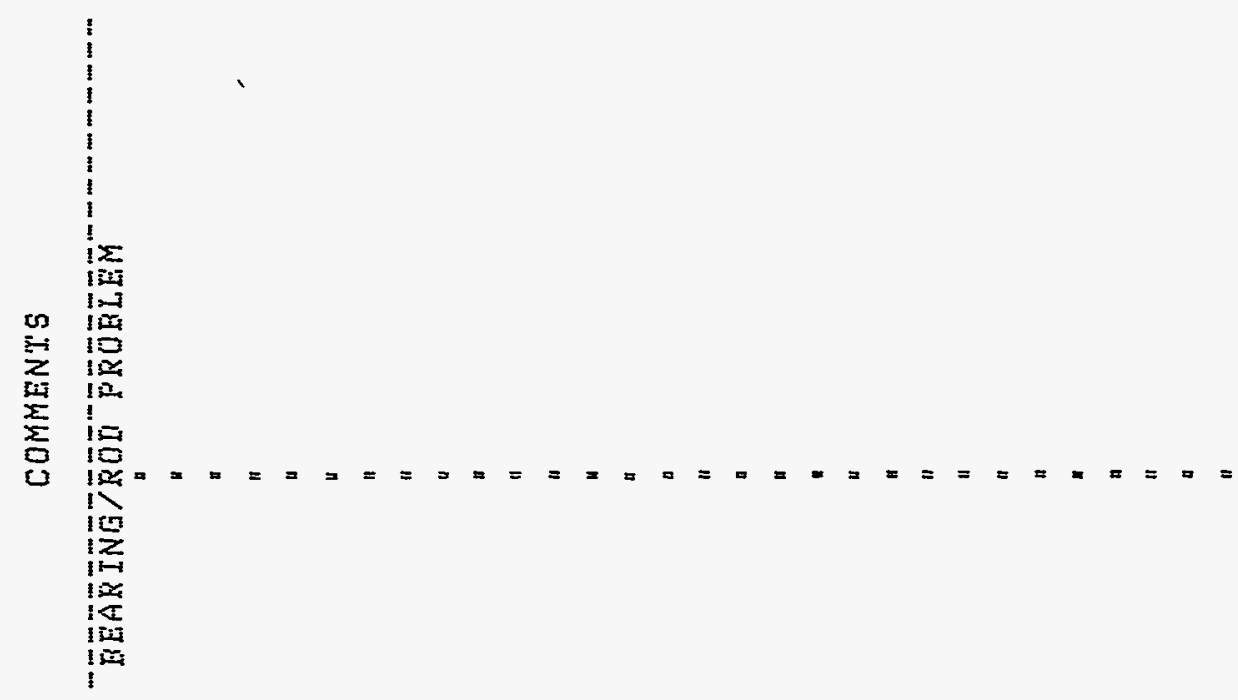

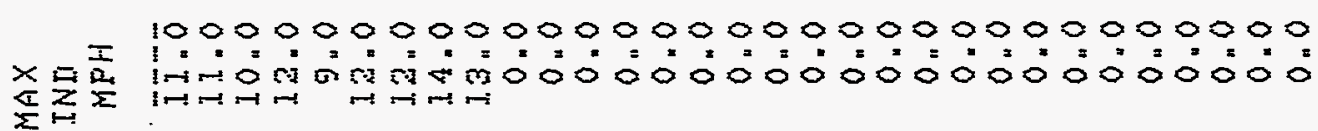

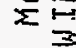

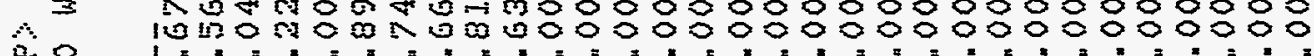

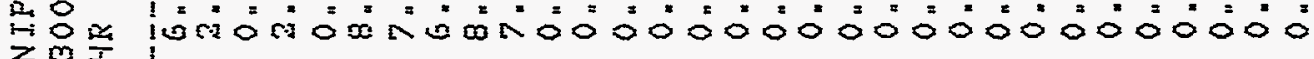

产

震空空

$\sum_{i=1}$

$>0$

至

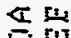

$>$

乙足空

$2 \frac{5}{2} \frac{3}{x}$

$m>$

的里里

$\rightarrow:-3$

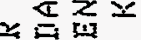

近

渠 留

둔

空运

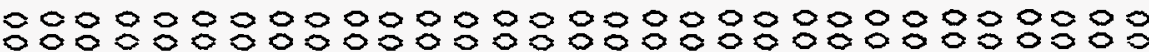

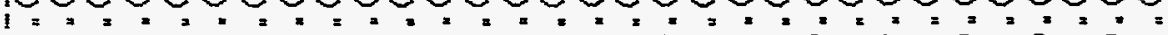
10000000000000000000000000000000

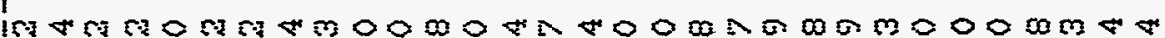

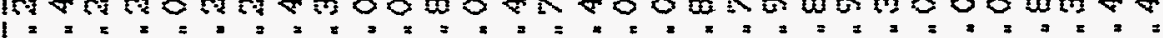
1000

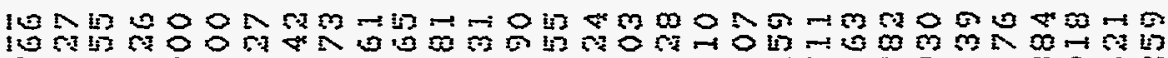

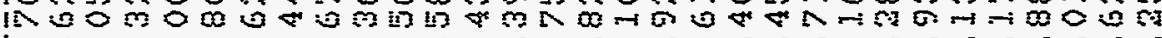

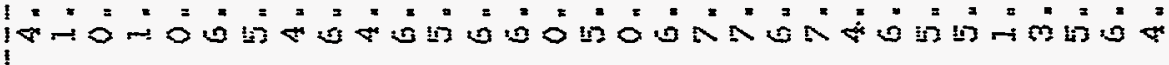

$r$

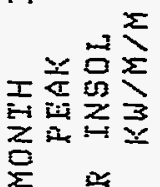

$\sum^{2}$

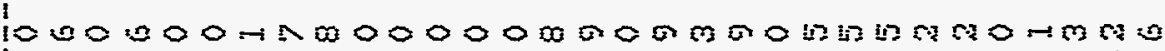
1ि0m 1

10000000000000000000000000000000

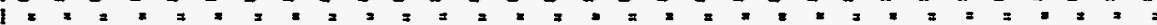
10000000000000000000000000000000

10000000000000000000000000000000

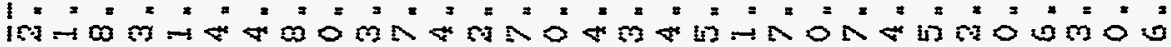

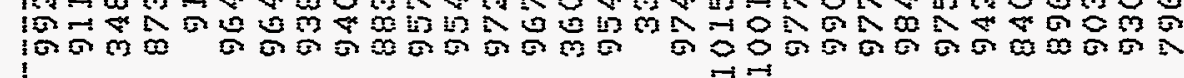

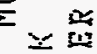

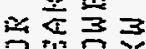

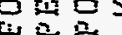

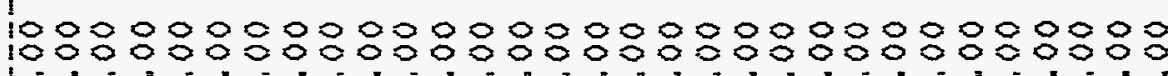

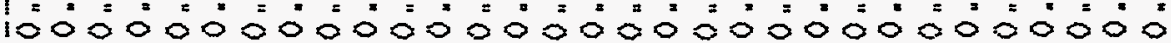

E

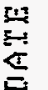

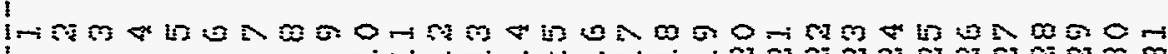

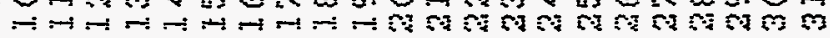

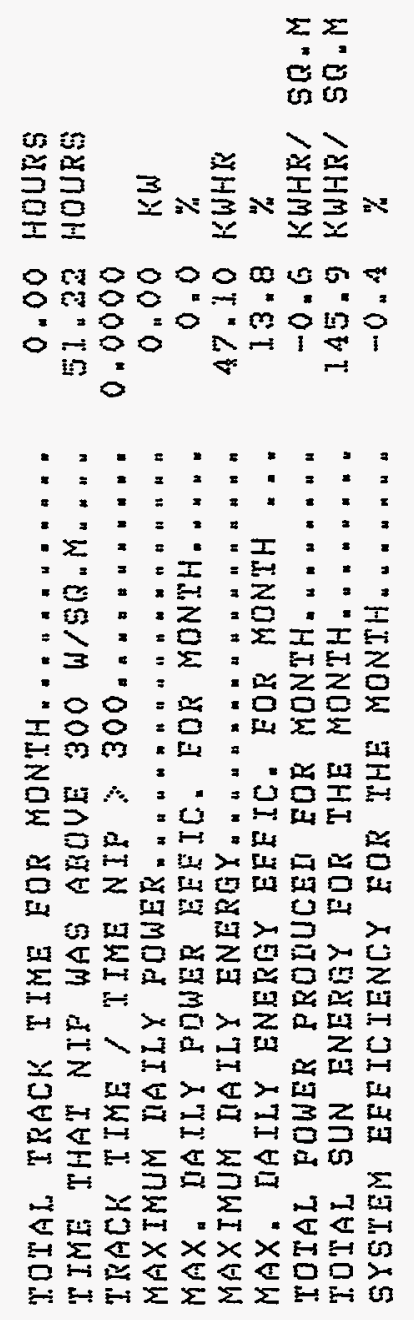

$x$ $\sin ^{2}$

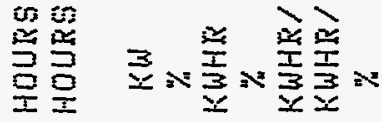
0 m000000

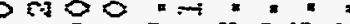
$=0=0=m 0$ in a 


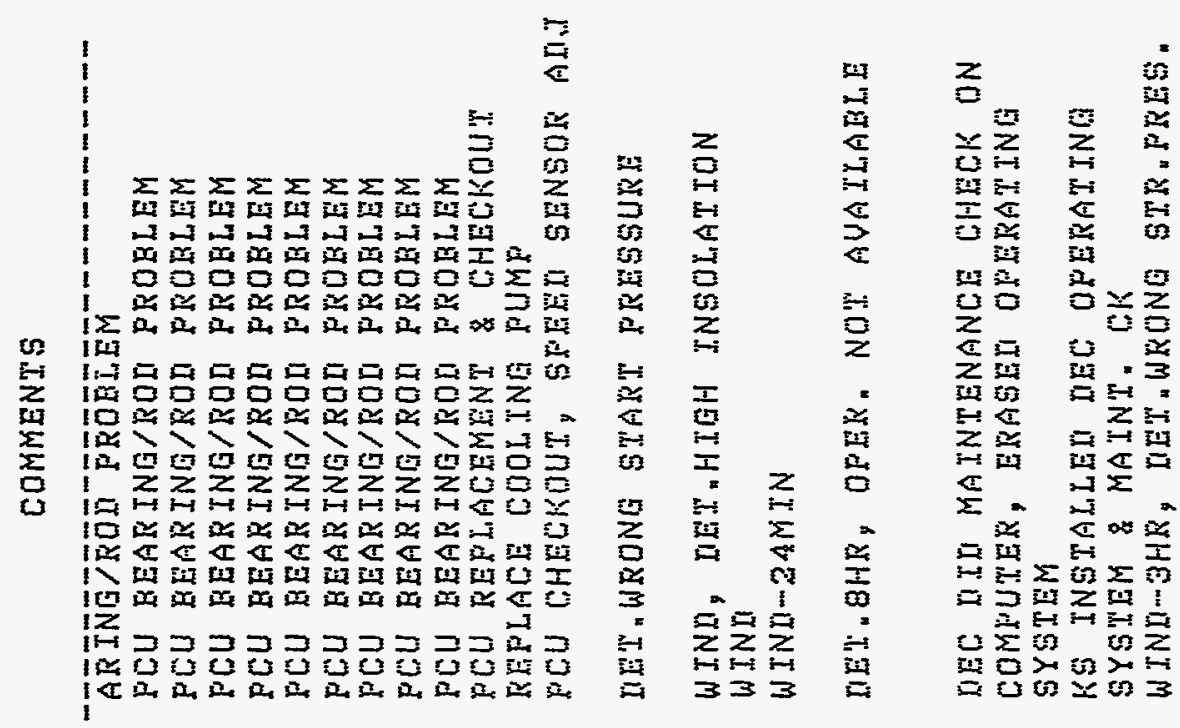

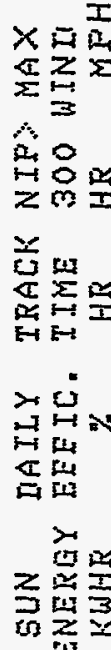

100000000000000000000000000000

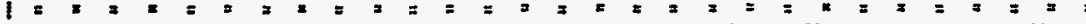

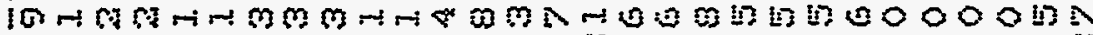

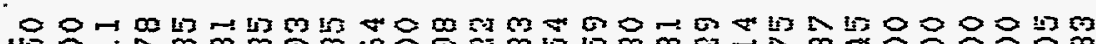

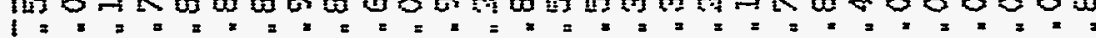

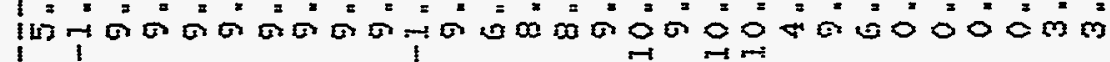

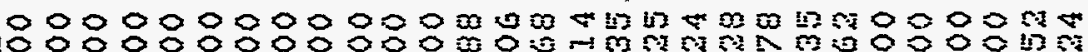

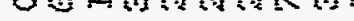

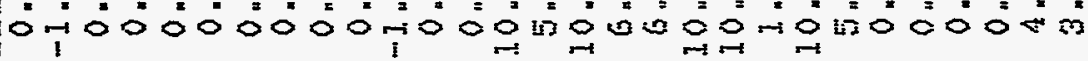
lä

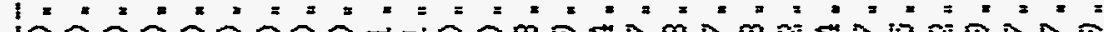

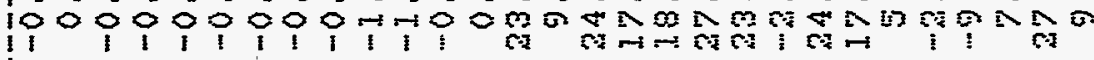

1000 in

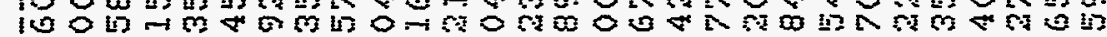

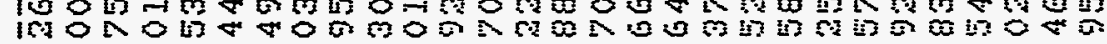

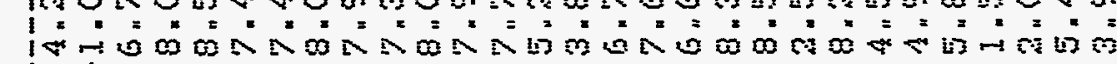

品子然。 ond $\rightarrow$ 品 唈灷 空 背齿 둗 준훙 (1) 중 c.3 $I \ll$

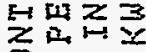

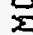
米骂

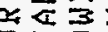

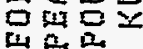
站 兽 lim 0 m

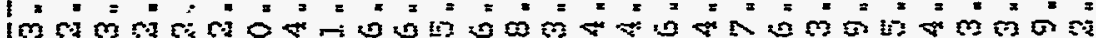
11 $10000000000000000+1000101200001$

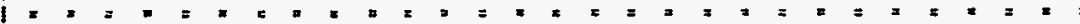

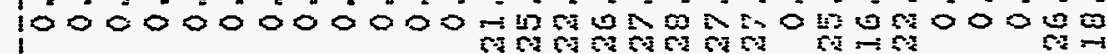

100000000000000000000000000000

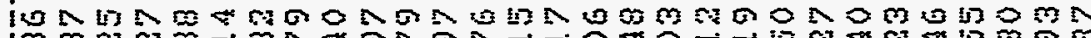

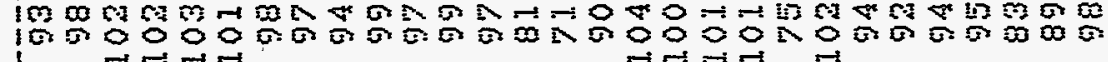

1000000000000m 100000000000040 a

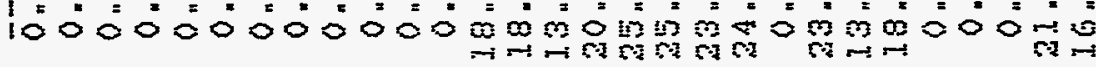

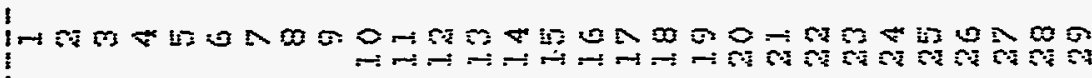

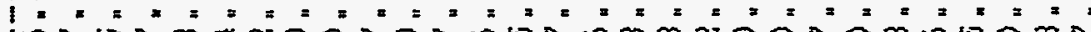

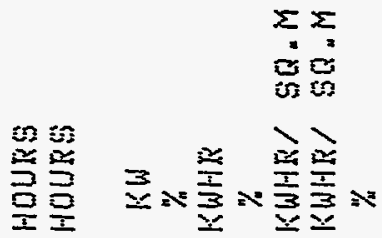

G纟内 $m \neq m=m=$ $m=m=\infty$ $\infty 0=0.0$

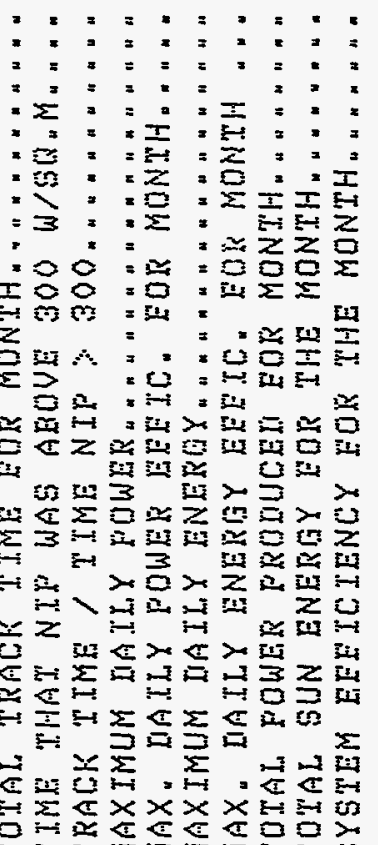
$\sum_{i=1} x \times x \times 0$

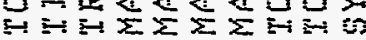




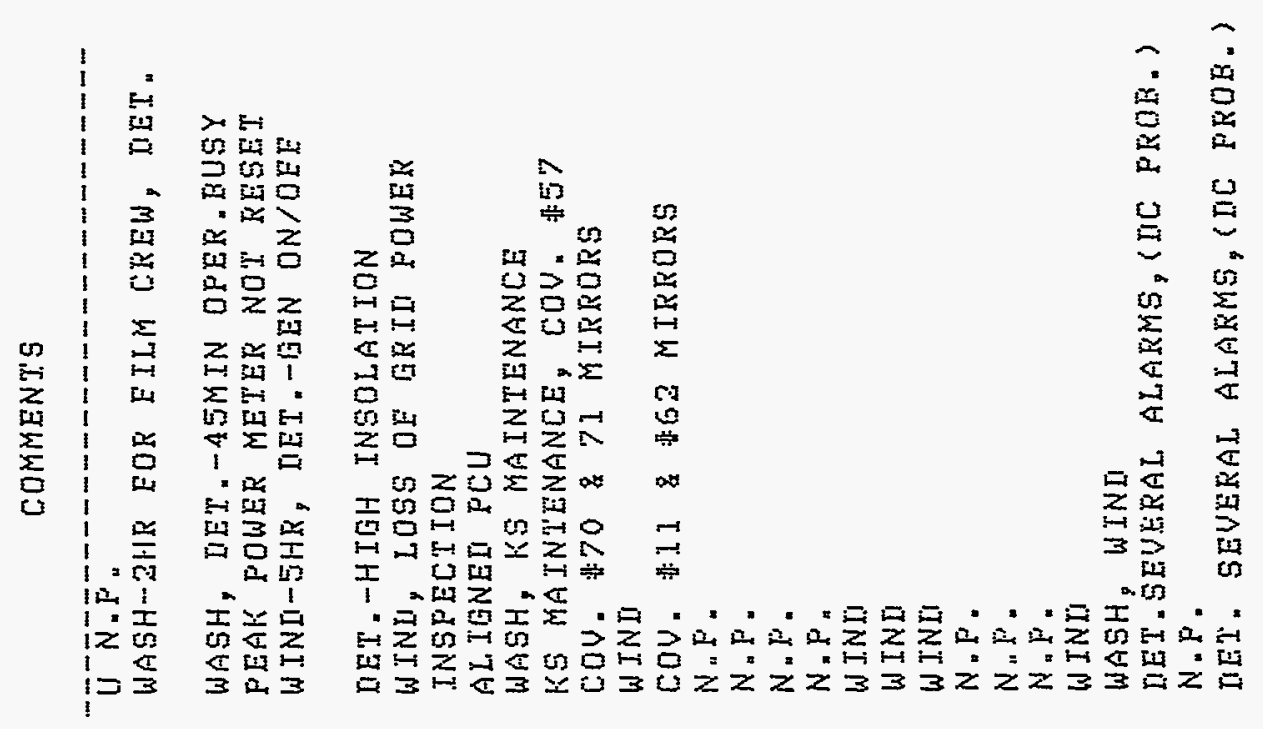

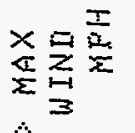

10000000000000000000000000000000

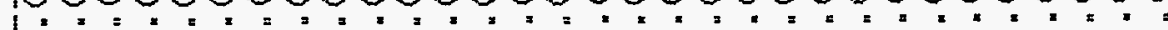

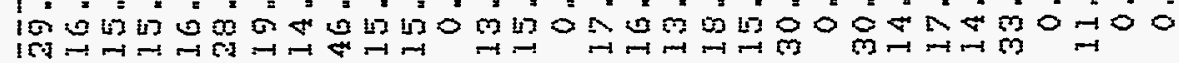

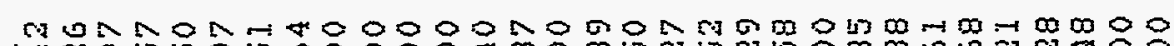
1 密昆崖 ㄸ 造造

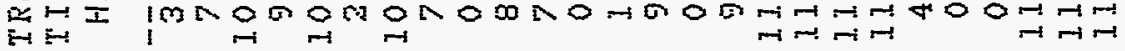

$>0$

$\rightarrow=$

$\because$

$\Xi$ 㟧

不

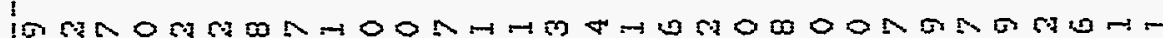

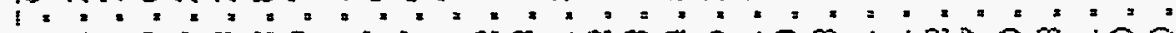
10

1 $\mathrm{mm}$ m

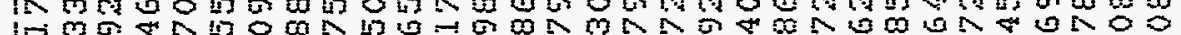

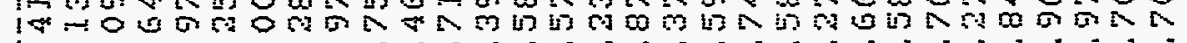

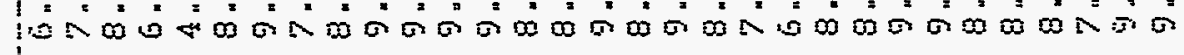

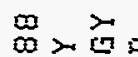

oiti

$\rightarrow$ ti

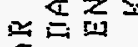

被

学新

产

zin

m

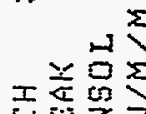

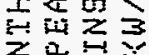

空 里

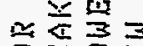

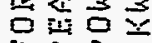

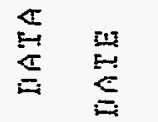

InNonm 10ं

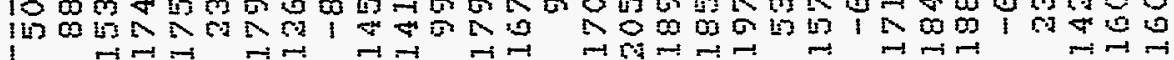
1

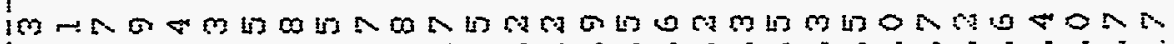

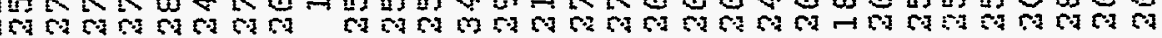

10000000000000000000000000000000

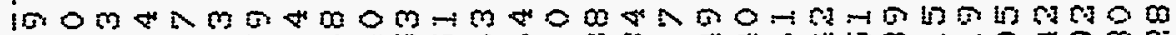
100

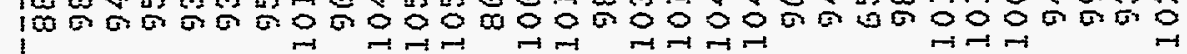

1 क

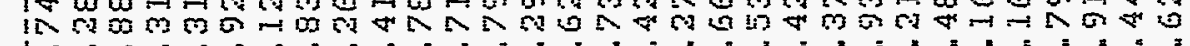
10ं

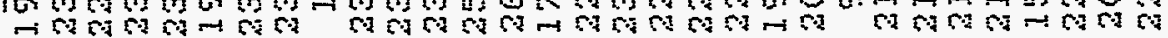

Mnm |

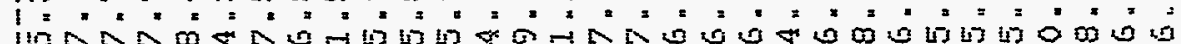

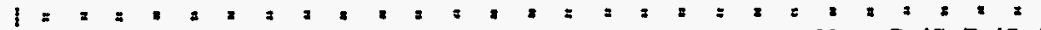

\section{$\Sigma \Sigma$ \\ $\cos$

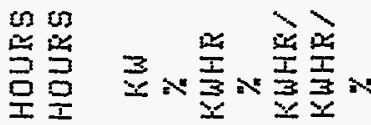

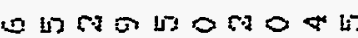

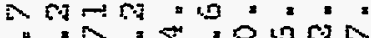

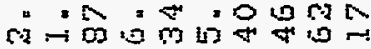
ब.

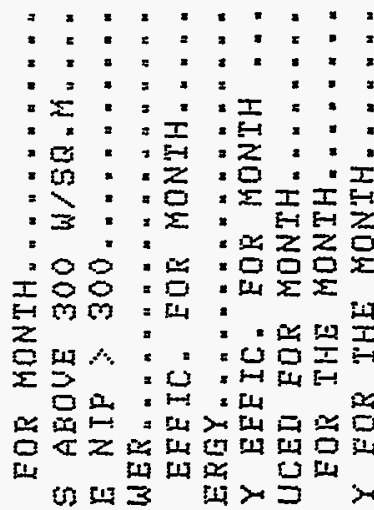

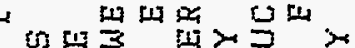

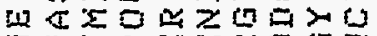

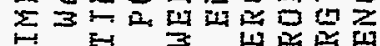

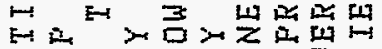

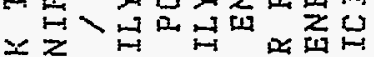
U w

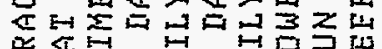

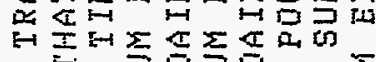

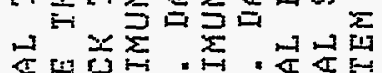
$\Leftrightarrow \sum \approx x \times x=10$

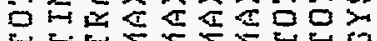



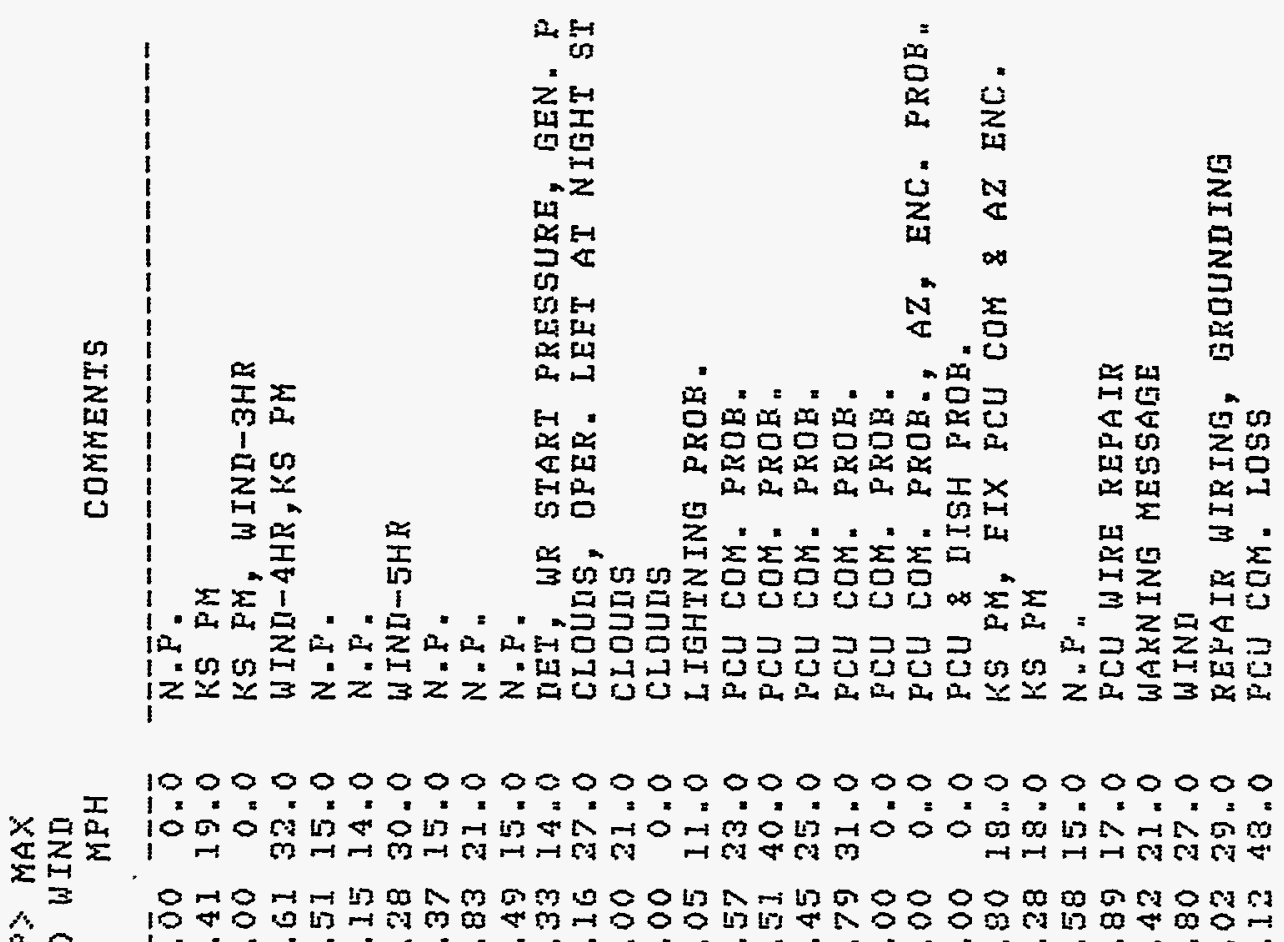

10000000000000000000000000000000 $10^{2}$

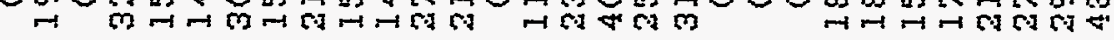

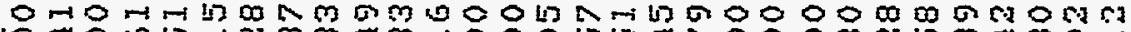

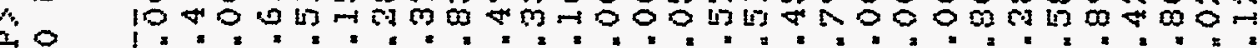
인

$\frac{1}{10}$

$\sum_{1} \frac{12}{2}$ $\mathbb{H}_{\mathrm{L}-1}^{+1}$

$>0$

$\rightarrow H N$

단

(1)

ron

즌 똔

os 2

品舟员

DI I I I

-4 1 का

0 近证

至

$=\frac{x}{1}=$

豆出寻

좀ㄷ․

P

 $+2$

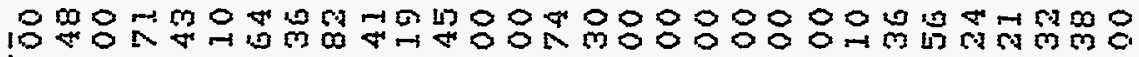
1000 iन ITHस

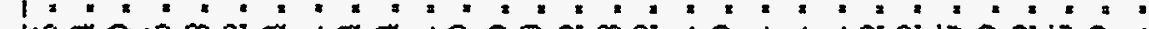

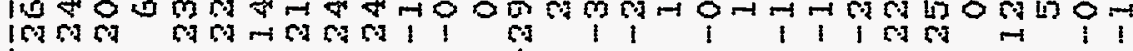
10

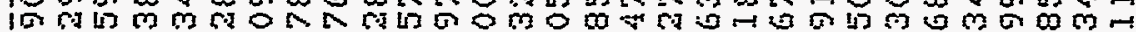
10m स

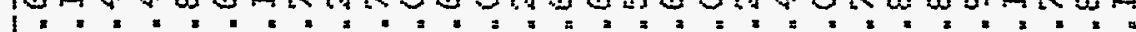
íم"

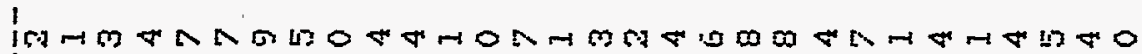
$10^{\prime 2}$ im, 每 1

10 M M M M

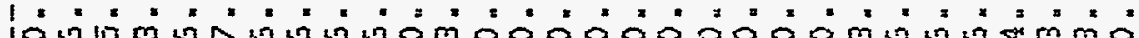

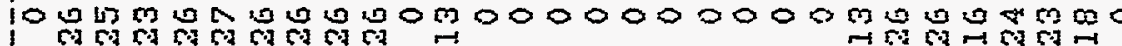

$I \leq 0 \mathrm{CO}$

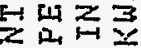

$\approx$

$x \geq \frac{11}{3}$

$\sum_{11}=3$

0 in

$\stackrel{\square}{\square}$
1000000000000000000000000000000

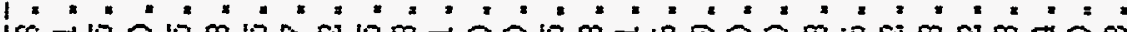
"r.

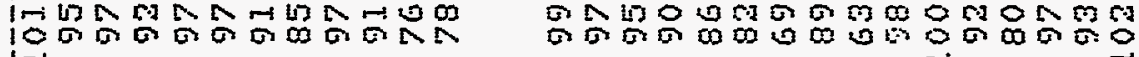

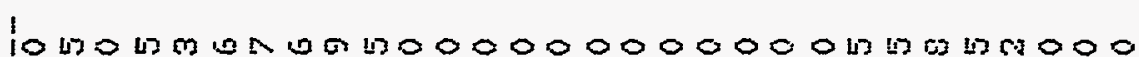

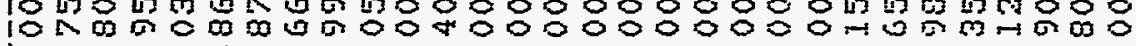

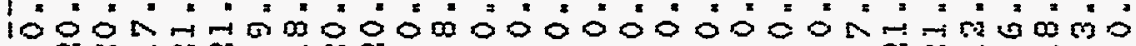

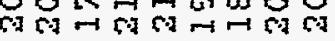

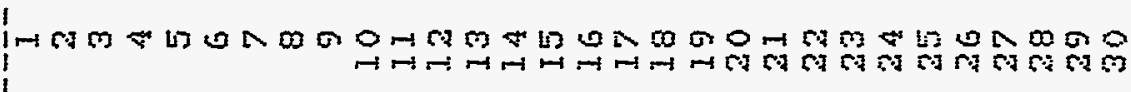

C.

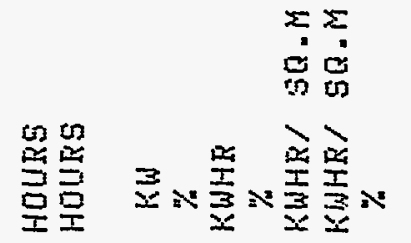

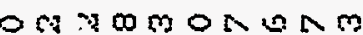

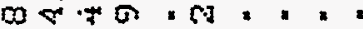

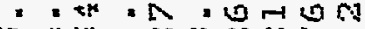
is $>\pi 0^{\infty}$ का

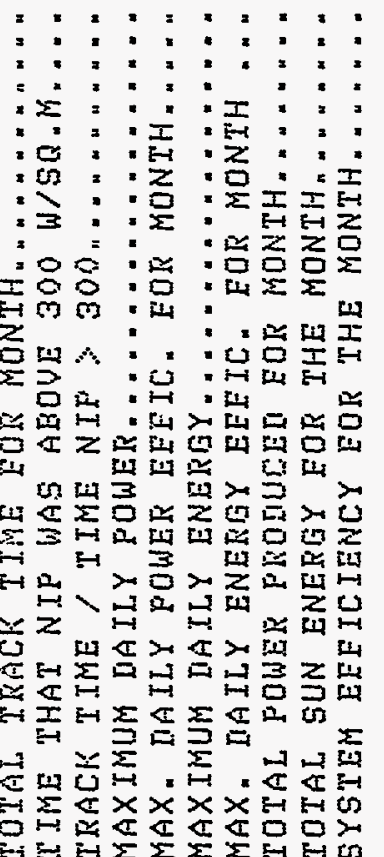




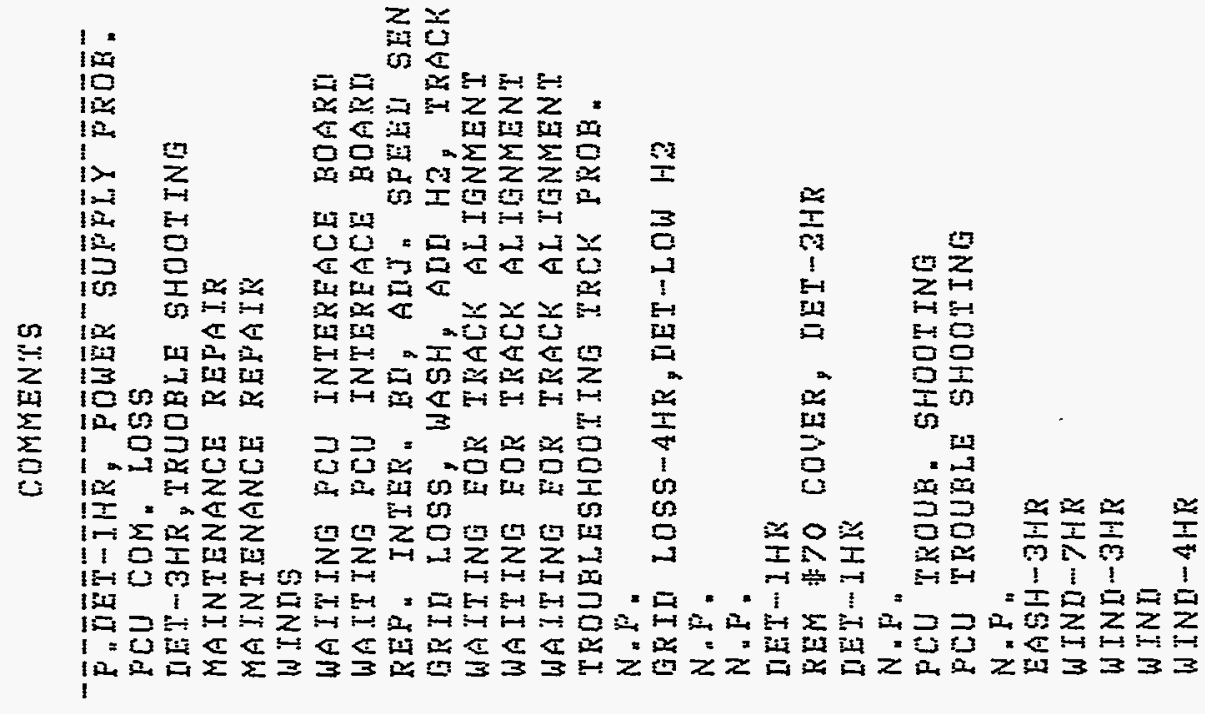

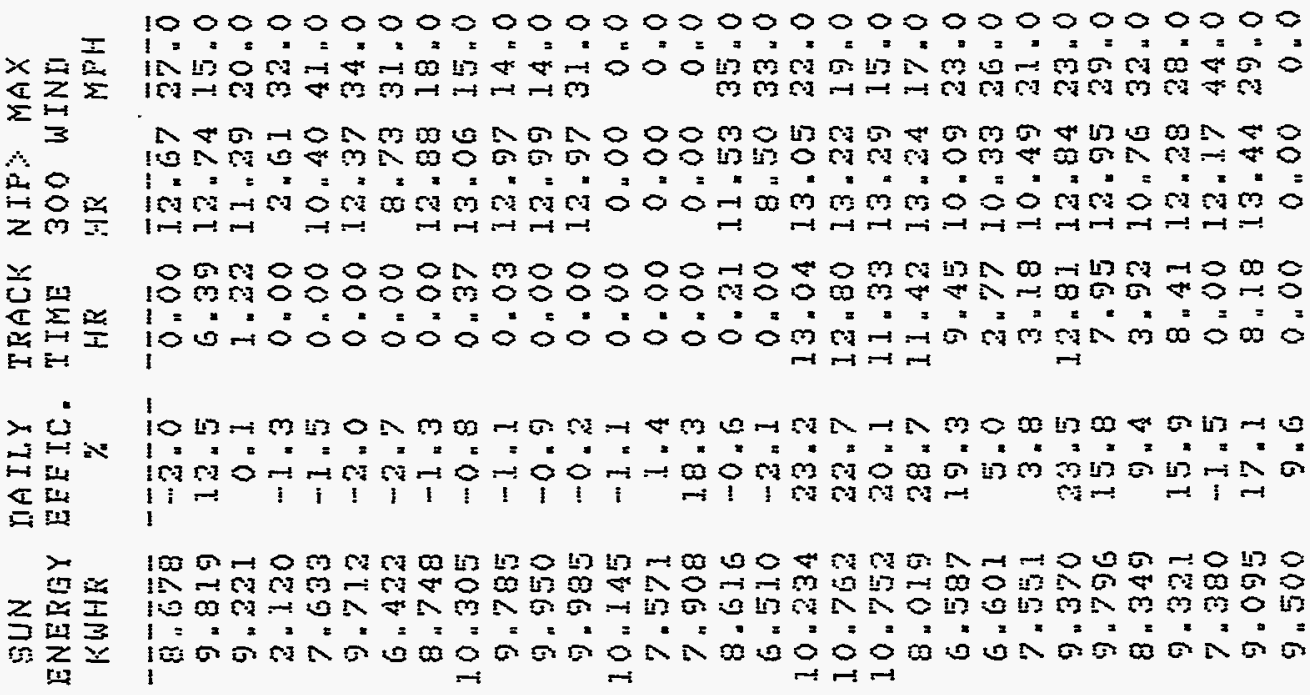

$\infty>0$

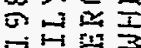

$\approx \sum_{i=1}$

는

2 些

运存

$\sum_{1}$

แบ

I

为望

运落

运证要

I 10n1 स०

1

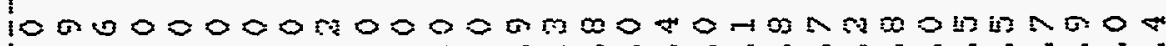

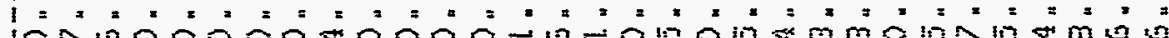
की

10000000000000000000000000000000

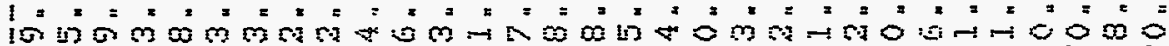

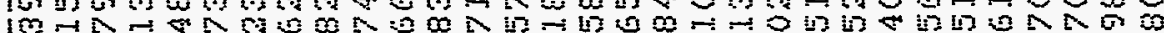

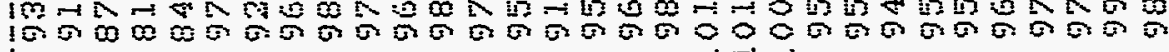

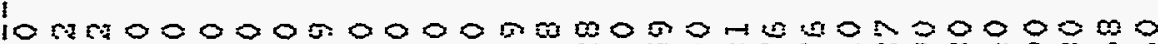

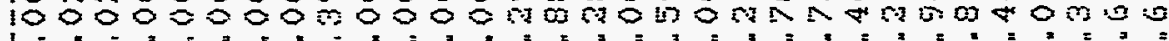
10. !
$\Sigma \Sigma$

$\cos ^{2} \cos$

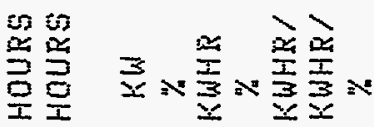
$\infty 000000 \%$ - $0=R=00$ a

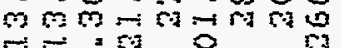
$=m_{0}$

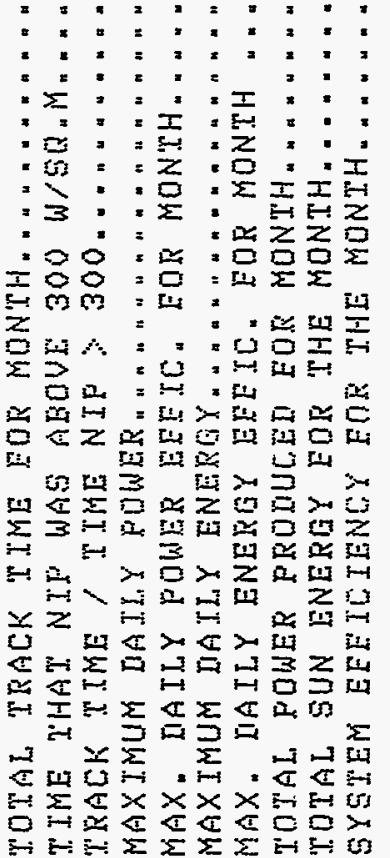




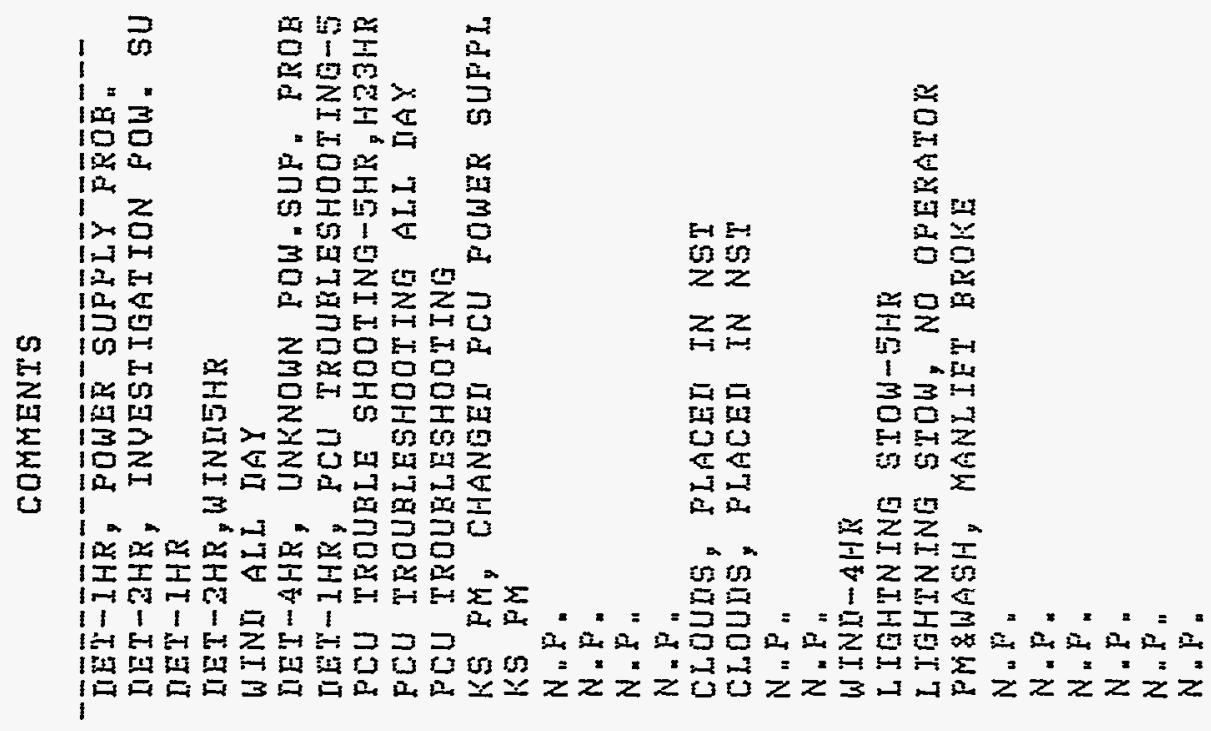

兵焉焉

is

品吕告

空

更包

단다

20

品

$\rightarrow$ 出

点㟧

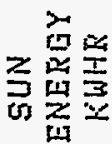

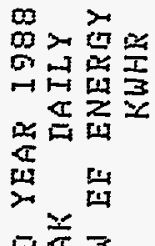

巨穴

先出吕

0

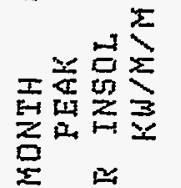

$\pm \simeq$

단 $\frac{1}{2} 3$

近些官

I
1000000000000000000000000000000

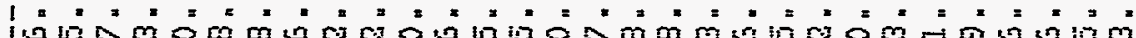

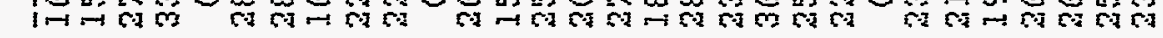

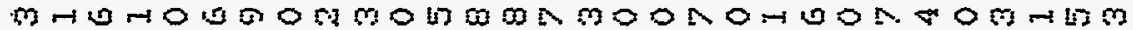
ism, 10m m

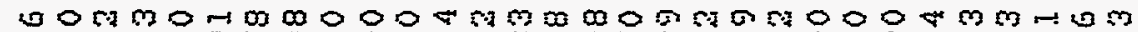

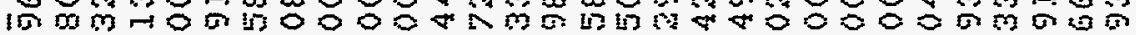

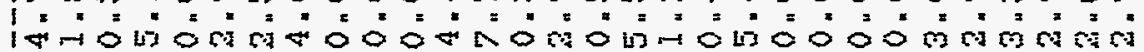

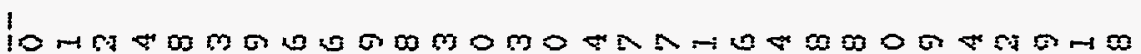
150

14 mमm INmम

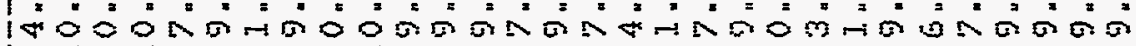
$\rightarrow \rightarrow-1$ in

स

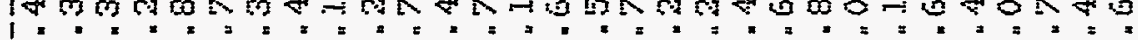

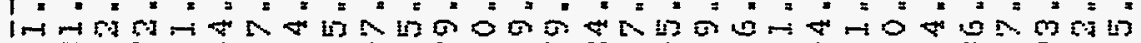
mon

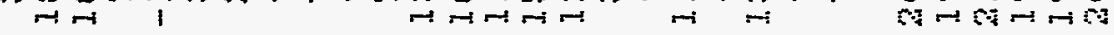
10

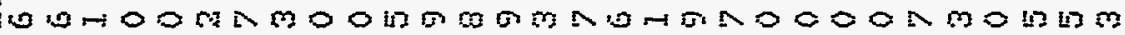

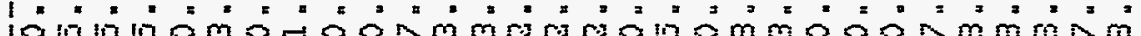
man

1000000000000000000000000000000

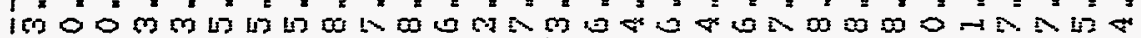

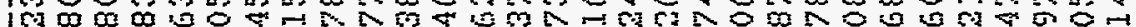
10

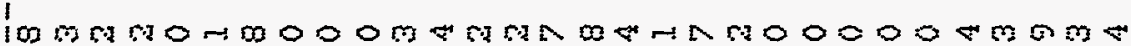

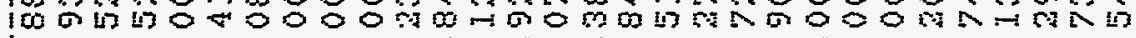
|W $\rightarrow$ मी !

\section{$\sum_{i} \Sigma_{0}$

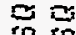 \\ 焉侸}

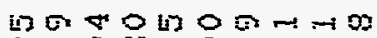

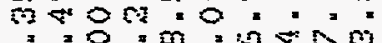

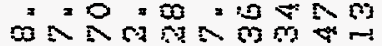
0000 की

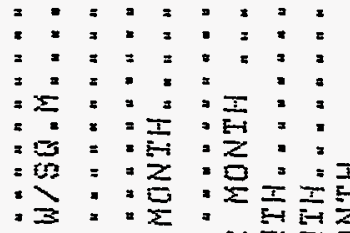
: : : : : :

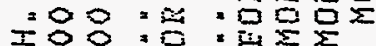

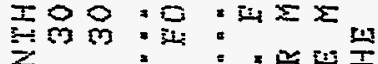

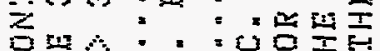

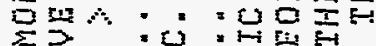
运:

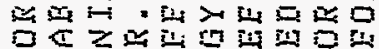

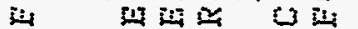

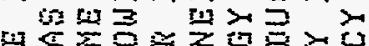

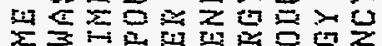

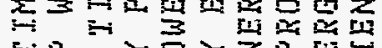

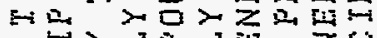

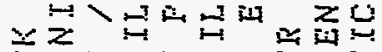

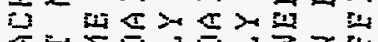

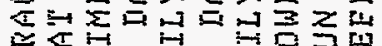

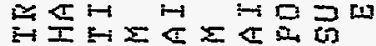

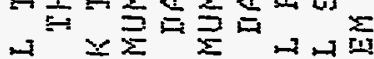

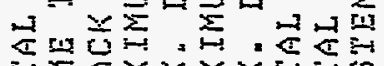

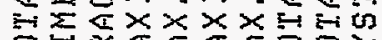
: 


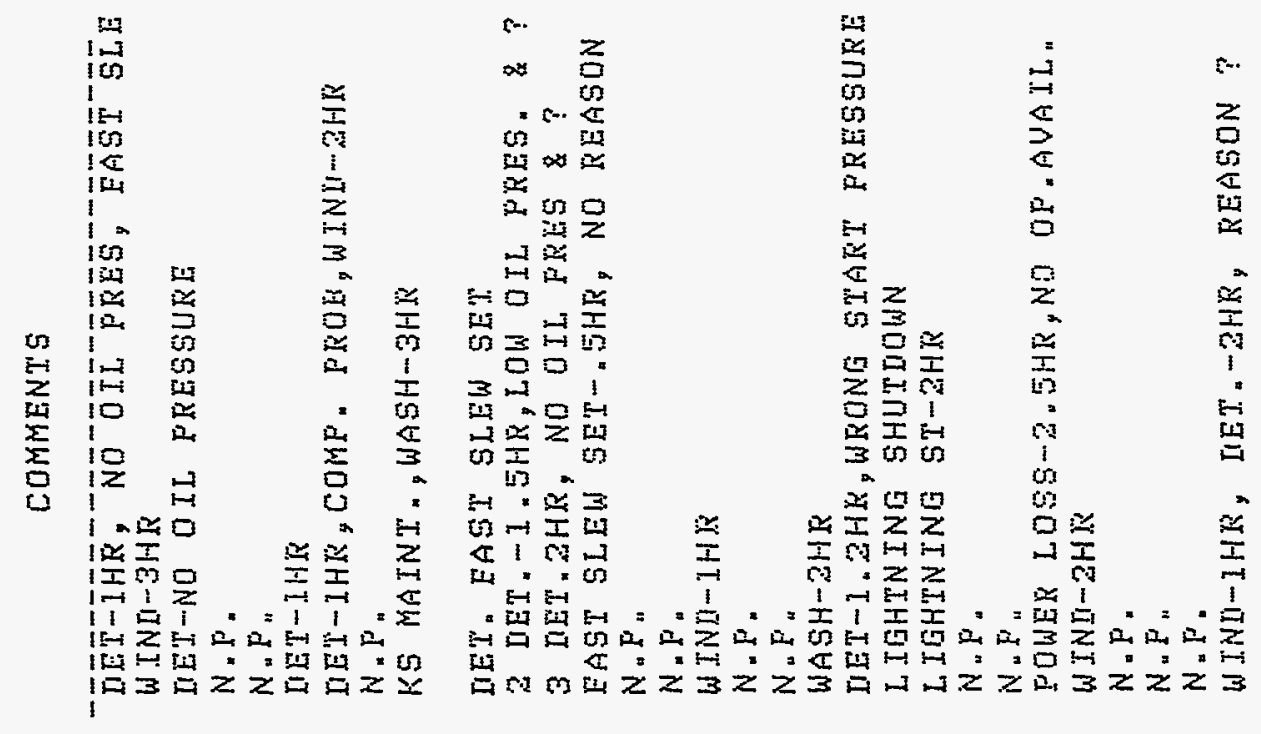

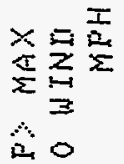

요모

Y

运足

난도

245

-

¿ Ix

宛

논

os $\frac{21}{2}=$

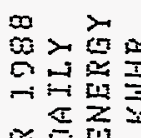

$\leftarrow$

II

告留

한

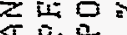

N

I $\frac{0}{2}$

$\lim _{\substack{x \\ 2}}^{x}$

2 正等

$\Sigma$ 든

눈

$0 \leq \overline{0}$

is 다 D.

$\pm$
10000000000000000000000000000000

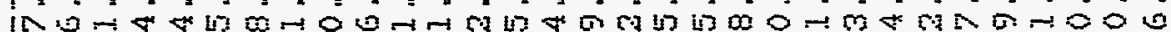

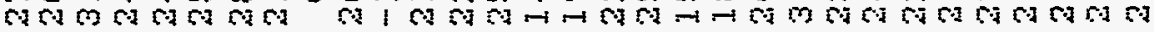
mmm a m N 10 कालm m in 0س 0 4

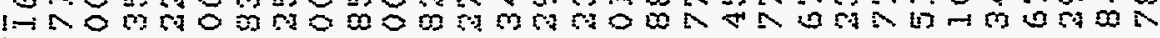

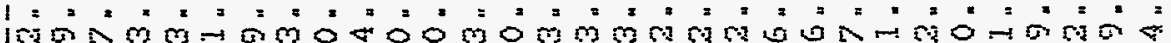

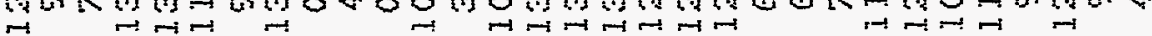
$10 N$ H.

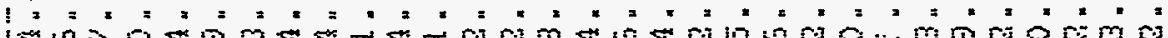

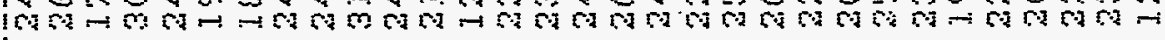

I3

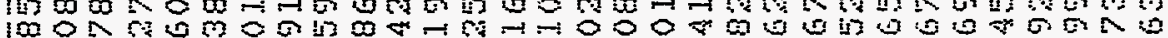

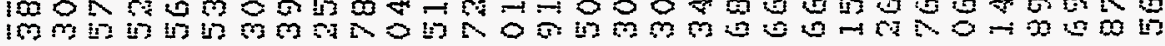
:

1000+4 m $1=0$ :

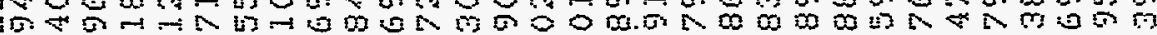

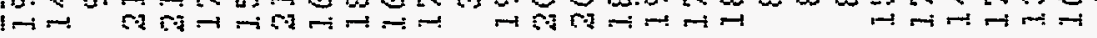$$
1
$$

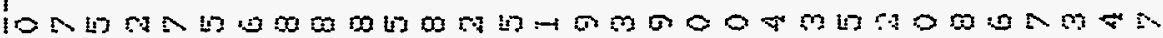

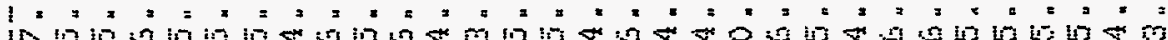

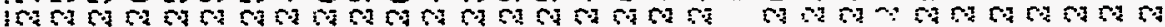

10000000000000000000000000000000 1:i.

1ิน

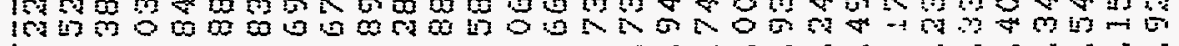

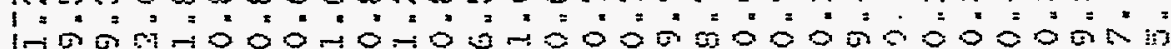

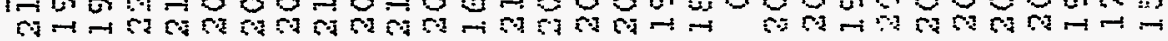

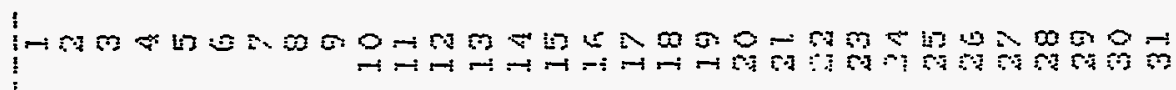

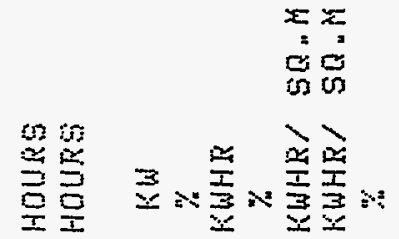

$04 \mathrm{ism} 000 \mathrm{mN}$ \& 650 :

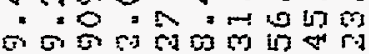

की

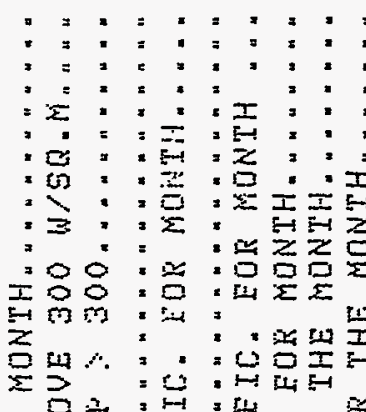

近: :

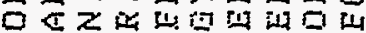

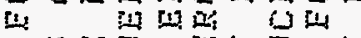
n

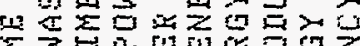

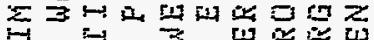

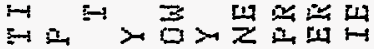

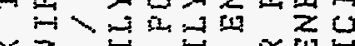

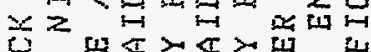

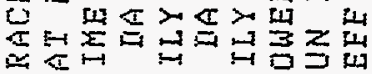

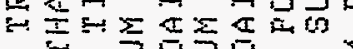

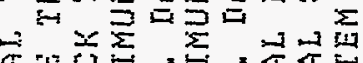

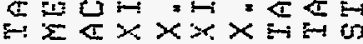

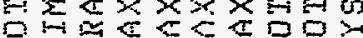
EN 

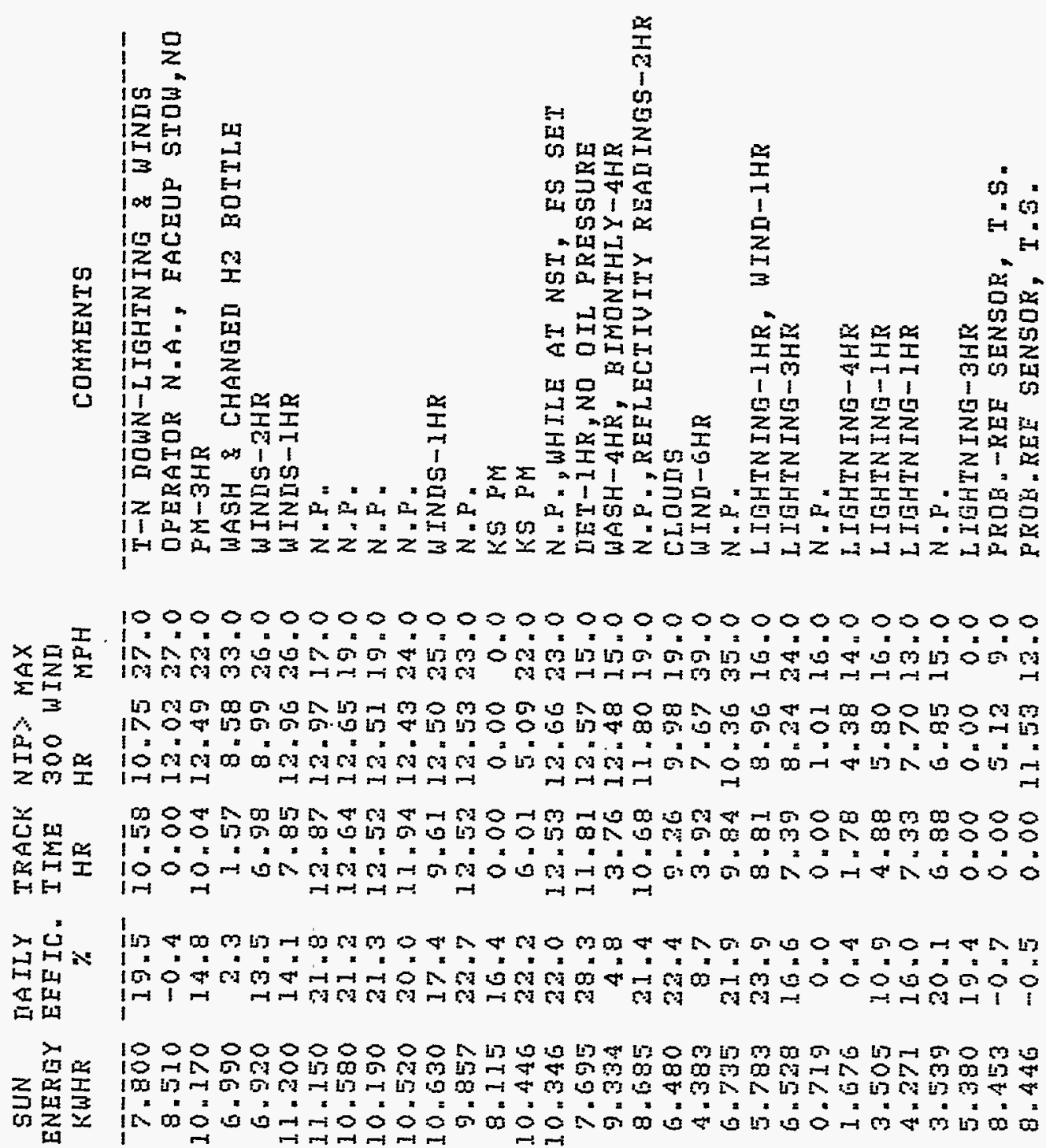

10000000000000000000000000000000 in

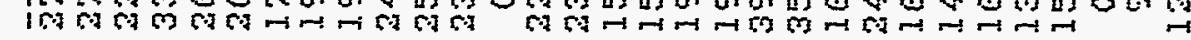
un

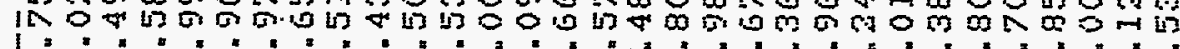
(6) <

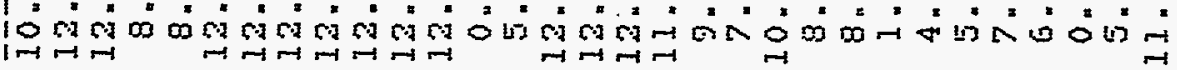
$\frac{10}{x}$

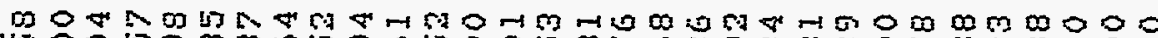
1500 1000

1 $\rightarrow \rightarrow \rightarrow$

車里

13

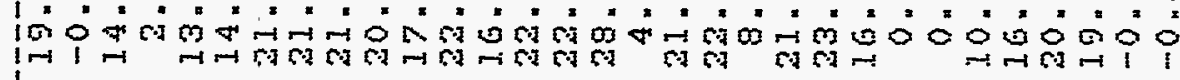

in

100000000000N is a 10नR

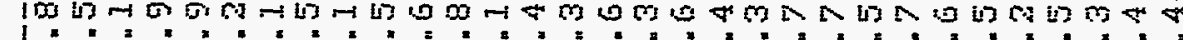
1000

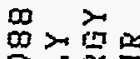
대몰

10

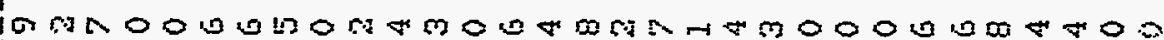
1 19

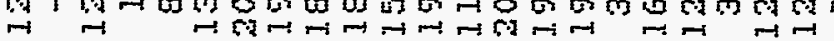

1

$\infty$

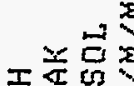
战范要 $\Sigma$ 든

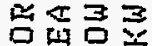
世口回

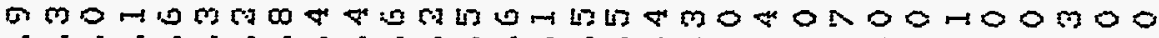
1

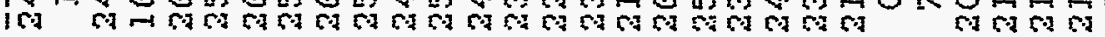

10000000000000000000000000000000 $10 \mathrm{~s}$ " in 10

ing

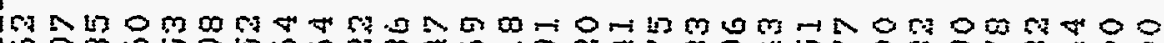
$10050401300 \mathrm{~m}$. in on

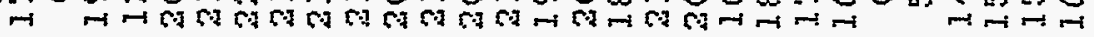

$\stackrel{I}{\stackrel{I}{I}} \stackrel{\square}{E-1}$

!

$\Sigma \Sigma$ cis in

嵒骂 品 800000000

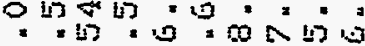

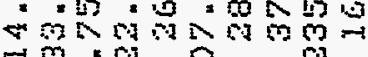
aino

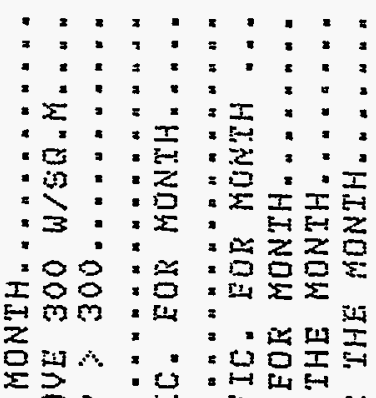

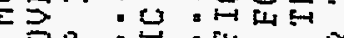

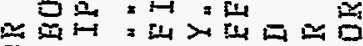

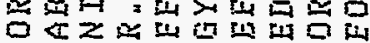
भ

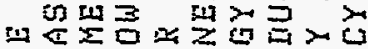

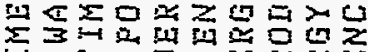

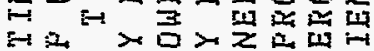

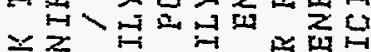

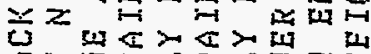

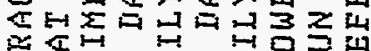

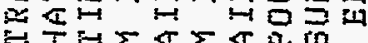

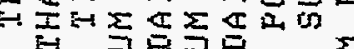

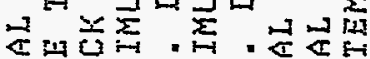

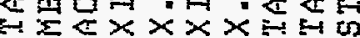
0

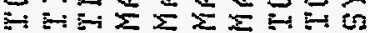




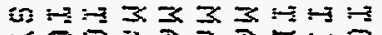

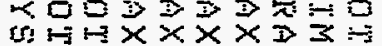
$43 D \times m \times 10$

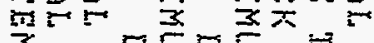
了

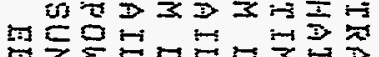

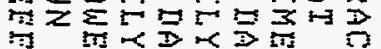

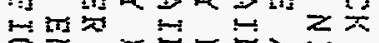

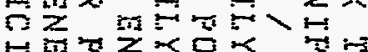

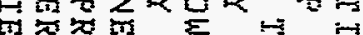

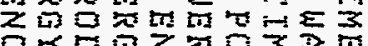

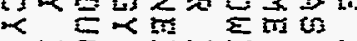

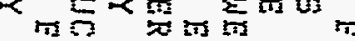

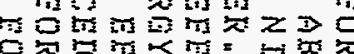

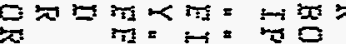

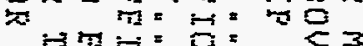

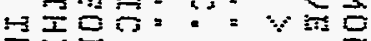

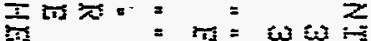
хзи:

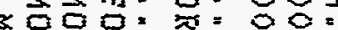
$\overrightarrow{0} \geq 20$

乙:

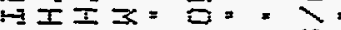

$I=: \underline{z}=0$

$\because z=2=0$

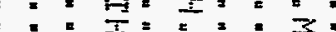

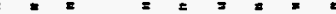

$z=z: z=z=z$

$=E=E=$ L $=$

$\infty$

- $\quad 0 \omega=$

00000001. 0000808040

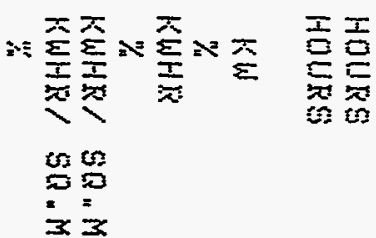

5

00000000000000000001

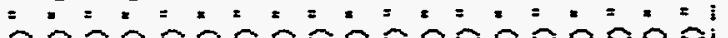
$00000000000000000000 \%$

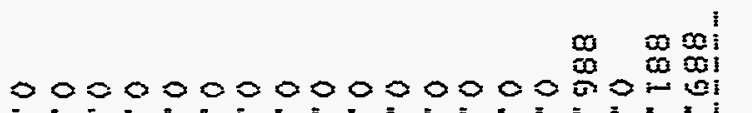

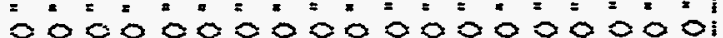

0000000000000000000

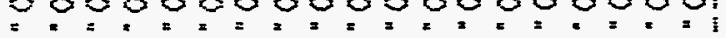
O.

00000000000000000001

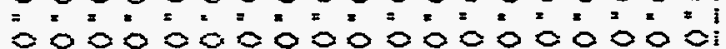$$
\text { E }
$$

2000000000000000000

0000000000000000000001 :

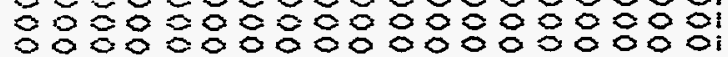

$2 \sum^{\pi}$

Em 잔

\section{$m$ \\ $\therefore \rightarrow$}

00000000000000000000

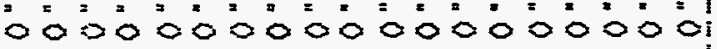

00000000000000000001

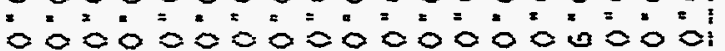

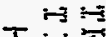

$\pm \div$

$\frac{3}{2 \pi}$

I $w$

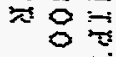

$000000000000000 \% 0:$ m

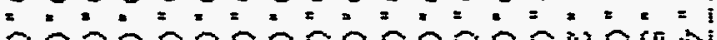

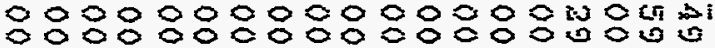

$000000000000000 \mathrm{ij0i:1}$ $=2=:=2=1=1$

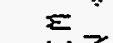
$3 \stackrel{i}{2} \frac{3}{2}$ ? 00000000000000000001

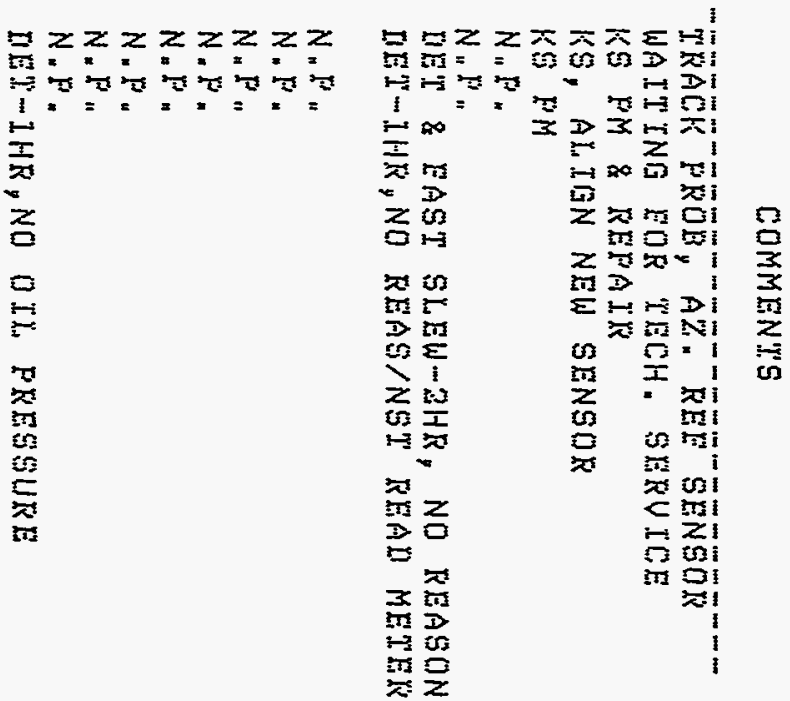


U.S. Department of Energy (5)

Forrestal Building

Code EE-132

1000 Independence Avenue, SW

Washington, DC 20585

Attn: G. Burch

S. Gronich

U.S. Department of Energy (2)

Forrestal Building

Code EE-13

1000 Independence Avenue, SW

Washington, DC 20585

Attn: R. Annan

U.S. Department of Energy (2)

Albuquerque Operations Office

P.O. Box 5400

Albuquerque, NM 87115

Attn: G. Tennyson

N. Lackey

U.S. Department of Energy

San Francisco Operations Office

1333 Broadway

Oakland, CA 94612

Attn: R. Hughey

Arizona Dept. of Commerce

3800 N. Central, Suite 1200

Phoenix, AZ 85012

Attn: F. Mancini

Battelle Pacific Northwest Laboratory

P.O. Box 999

Richland, WA 99352

Attn: D. Brown

California Polytechnic University

Dept. of Mechanical Engineering

3801 West Temple Avenue

Pomona, CA 91768

Attn: Dr. Wm. B. Stine (10)

Central and Southwest Services

Mail Stop 7RES

1616 Woodall Rogers Freeway

Dallas, TX 75202

Attn: Edward L. Gastineau
Clever Fellows

Innovation Consortium, Inc.

R.D. 1, Box 410, River Road

Melrose, NY 12121

Attn: J. A. Corey, P.E.

Cummins Power Generation (2)

MC 60125

P. O. Box 3005

Columbus, IN 47202-3005

Attn: R. Kubo

Cummins Power Generation South

150 Tannehill Drive

Abilene, TX 79602

Attn: M. McGlaun

Dynatherm Corporation

1 Beaver Court

P.O. Box 398

Cockeysville, MD 21030

Attn: David Wolf

Electric Power Research Institute

P.O. Box 10412

Palo Alto, CA 94303

Attn: J. Schaeffer

Energy Technology Engr. Center (2)

Rockwell International Corp.

P. O. Box 1449

Canoga Park, CA 91304

Attn: W. Bigelow

R. LeChevalier

Karl Thomas Feldman, Jr. Ph.D., P.E. Mechanical Engineering Consultant 1704 Stanford Dr. NE

Albuquerque, NM 87106

Florida Solar Energy Center

300 State Road, Suite 401

Cape Canaveral, FL 32920

Attn: Library

Georgia Power

7 Solar Circle

Shenandoah, GA 30265

Attn: W. King 
Hydrogen Engineering Associates

4738 East Rancho Drive

Phoenix, AZ 85018

Attn: H. Braun

Institute of Gas Technology

34245 State Street

Chicago, IL 60616

Attn: Library

Jet Propulsion Laboratory

4800 Oak Grove Drive

Pasadena, CA 91109

Attn: M. Alper

Lawrence Berkeley Laboratory

MS 90-2024

One Cyclotron Road

Berkeley, CA 94720

Attn: A. Hunt

Los Alamos National Laboratory

MS-E13

Los Alamos, NM 87545

Attn: M. Merrigan

McDonnell-Douglas Astronautics Company (20)

5301 Bolsa Avenue

Huntington Beach, CA 92647

Attn: K. Stone

Mechanical Technology, Inc. (2)

968 Albany Shaker Road

Latham, NY 12110

Attn: G. Dochat

J. Wagner

NASA Lewis Research Center (4)

21000 Brook Park Road

Cleveland, $\mathrm{OH} 44135$

Attn: R. Shaltens

J. Schrieber

National Renewable Energy Laboratory (6)

1617 Cole Boulevard

Golden, CO 80401

Attn: T. Williams

L. M. Murphy

G. Jorgensen

T. Wendelin

A. Lewandowski

M. Bohn
Northern Research and Engineering Corp.

39 Olympia Avenue

Woburn, MA 01801-2073

Attn: J. Kesseli

Power Kinetics, Inc.

415 River Street

Troy, NY 12180-2822

Attn: W. E. Rogers

Research International

18706 142nd Avenue NE

Woodinville, WA 98072

Attn: E. Saaski

Science Applications International Corporation 15000 W. 6th Avenue, Suite 202

Golden, CO 80401

Attn: Kelly Beninga

Science Applications International Corporation Mail Stop 32

10260 Campus Point Court

San Diego, CA 92121

Attn: B. Butler

Solar Energy Industries Assoc. (2)

777 North Capitol St. NE

Suite 805

Washington, D.C. 20002

Attn: S. Sklar

K. Sheinkopf

Solar Kinetics, Inc. (2)

P.O. Box 540636

Dallas, TX 75354-0636

Attn: J. A. Hutchison

P. Schertz

Southern California Edison (15)

Bldg. 601, Room 455

2244 Walnut Grove Ave.

Rosemead, CA 91770

Attn: C. Lopez

Stirling Technology Company (3)

2952 George Washington Way

Richland, WA 99352

Attn: Maurice A. White

Stirling Thermal Motors (2)

275 Metty Drive

Ann Arbor, MI 48103

Attn: Lennart Johansson 
Stirling Machine World

1823 Hummingbird Court

West Richland, WA $99352-9542$

Attn: Brad Ross

Sunpower, Inc.

6 Byard Street

Athens, OH 45701

Attn: W. Beale

Tech Reps, Inc. (2)

5000 Marble NE, Suite 222

Albuquerque, NM 87110

Attn: J. Stikar

Thermacore, Inc. (2)

780 Eden Road

Lancaster, PA 17601

Attn: Donald Ernst

University of Houston

Solar Energy Laboratory

4800 Calhoun

Houston, TX 77704

Attn: J. Richardson

University of Minnesota

Dept. of Mechanical Engineering

111 Church St., SE

Minneapolis, MN 55455

Attn: E. A. Fletcher

Australian National University

Department of Engineering

Physics.

P. O. Box 4

Canberra ACT 2600 AUSTRALIA

Attn: S. Kaneff

DLR

Pfaffenwaldring 38-40

D 7000 Stuttgart 80

GERMANY

Attn: R. Buck

Energy Research Centre

R. S. Phy. Sc.

Australian National University

Canberra ACT 2601 AUSTRALIA

Attn: K. Inall

Dr. David Hagen

134 Kitchener St.

Garran, ACT 2605

AUSTRALIA

Pacific Power

Park and Elizabeth Streets

GPO Box 5257, Sydney

New South Wales 2001, Australia

Attn: Peter Lynch

Schlaich, Bergermann \& Partner

Hohenzollernstr. 1

D -7000 Stuttgart 1 GERMANY

Attn: W. Schiel

1513

1513

1513

1513

1561

1561

1833

2756

4313

6000

6115

6200

6201

6213

6215

6215

6215

6216

6216

6216

6216

6216

6216

6216

6216

6216

7141

7151

7613-2

8523-2
D. R. Adkins

R. E. Hogan

V. J. Romero

R. D. Skocypec

E. L. Hoffman

C. M. Stone

J. A. VanDenAvyle

G. S. Phipps

J. F. Muir

D. L. Hartley

W. C. Ginn

D. E. Arvizu

P. C. Klimas

A. R. Mahoney

C. P. Cameron

K. S. Rawlinson

Library (15)

C. E. Tyner

C. E. Andraka

R. B. Diver

D. R. Gallup

T. R. Mancini

D. F. Menicucci

J. B. Moreno

T. A. Moss

Library (5)

Technical Library (5)

Technical Publications

Document Processing for DOE/OSTI (10)

Central Technical Files 